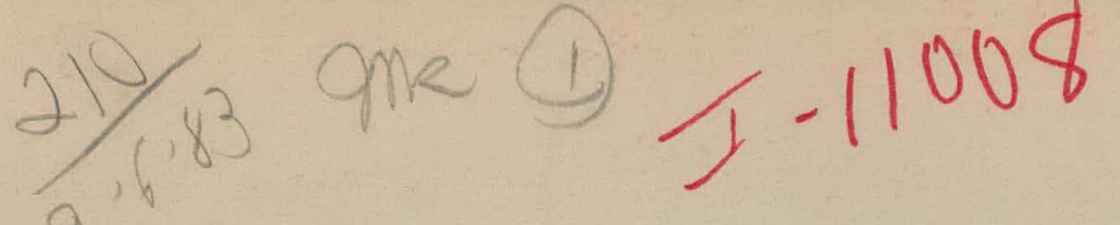

Dr.1726-4 GEND

034

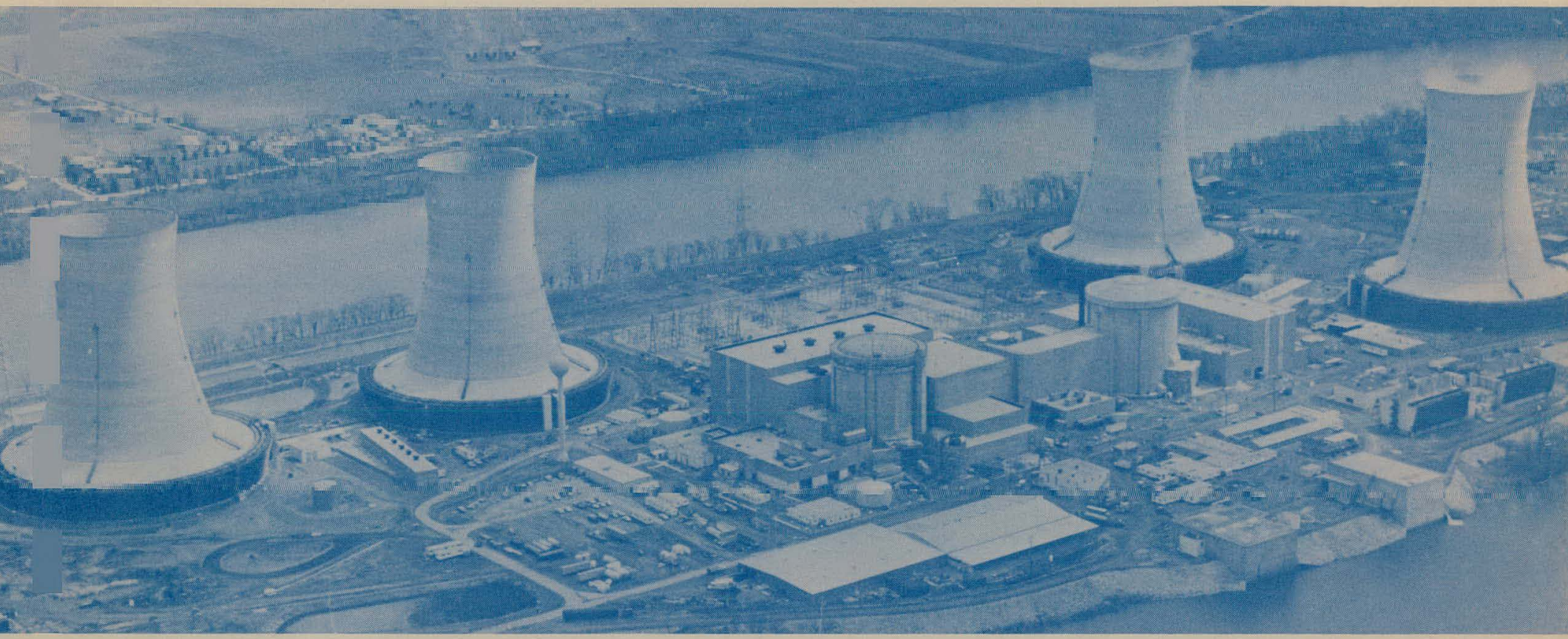

\title{
GEND
}

General Public Utilities - Electric Power Research Institute • U.S. Nuclear Regulatory Commission • U.S. Department of EnergY

\section{Gross Decontamination Experiment Report}
R. Mason
K. Kinney
J. Dettorre
V. Gilbert

July 1983

Prepared for the

U.S. Department of Energy

Three Mile Island Operations Office

Under DOE Contract No. DE-AC07-76ID01570

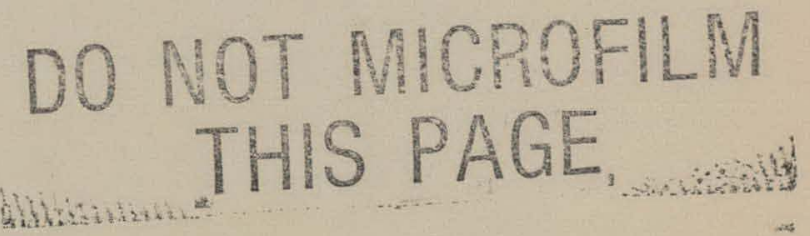

MSTES

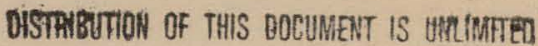




\section{DISCLAIMER}

This report was prepared as an account of work sponsored by an agency of the United States Government. Neither the United States Government nor any agency Thereof, nor any of their employees, makes any warranty, express or implied, or assumes any legal liability or responsibility for the accuracy, completeness, or usefulness of any information, apparatus, product, or process disclosed, or represents that its use would not infringe privately owned rights. Reference herein to any specific commercial product, process, or service by trade name, trademark, manufacturer, or otherwise does not necessarily constitute or imply its endorsement, recommendation, or favoring by the United States Government or any agency thereof. The views and opinions of authors expressed herein do not necessarily state or reflect those of the United States Government or any agency thereof. 


\section{DISCLAIMER}

Portions of this document may be illegible in electronic image products. Images are produced from the best available original document. 
Printed in the United States of America

Available from

National Technical Information Service

U.S. Department of Commerce

5285 Port Royal Road

Springfield, VA 22161

NTIS Price Codes: Printed Copy A99

Microfiche A01

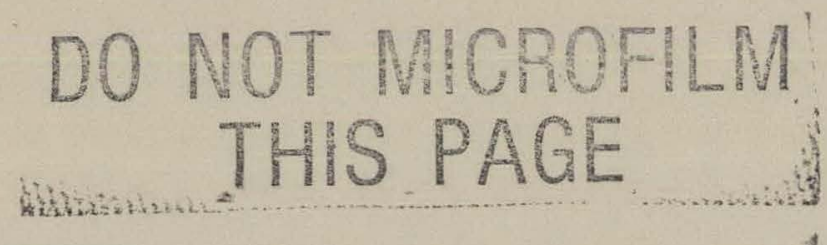

1

\section{DISCLAIMER}

This book was prepared as an account of work sponsored by an agency of the United States Government. Neither the United States finvernment nnr any agenny therenf, nor any of their employees, makes any warranty, express or implied, or assumes any legal liability or responsibility for the accuracy, completeness, or usefulness of any information, apparatus, product or process disclosed, or represents that its use would not infringe privately owned rights. References herein to any specific commercial product, process, or service by trade name, trademark, manufacturer, or otherwise, does not necessarily constitute or imply its endorsement, recommendation, or favoring by the United States Government or any agency thereof. The views and opinions of authors expressed herein do not necessarily state or reflect those of the United States Government or any agency thereof. 
This report was prepared as an account of work sponsored by an agency of the United States Government. Neither the United States Government nor any agency thereof, nor any of their employees, makes any warranty, express or implied, or assumes any legal liability or responsibility for the accuracy, completeness, or usefulness of any information, apparatus, product, or process disclosed, or represents that its use would not infringe privately owned rights. Reference herein to any specific commercial product, process, or service by trade name, trademark, manufacturer, or otherwise does not necessarily constitute or imply its endorsement, recommendation, or favoring by the United States Government or any agency thereof. The views and opinions of authors expressed herein do not necessarily state or reflect those of the United States Government or any agency thereof.

\title{
GROSS DECONTAMINATION EXPERIMENT REPORT
}

\author{
R. Mason \\ K. Kinney \\ J. Dettorre \\ V. Gilbert
}

Published July 1983

\author{
Bechtel National, Inc. \\ Oak Ridge, Tennessee
}

\section{NOTHCE}

PORTIONS OF THIS REPOBT ARE ULLGIBLE.

It has been reproduced from the best available copy to permit the broadest possible availability.

Prepared for EG\&G Idaho, Inc. and the U.S. Department of Energy Three Mile Island Operations Office Under DOE Contract No. DE-AC07-78ID01570

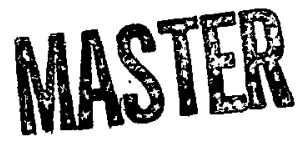




\section{ABSTRACT}

A Gross Decontamination Experiment was conducted on various levels and surfaces of the l'M1 - Unit 2 reactor building in March 1982. The polar crane, D-rings, missile shields, refueling canals, refueling

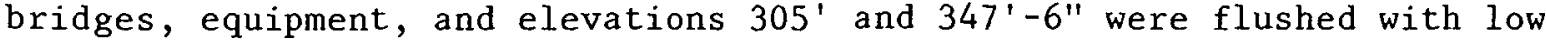
pressure water. Additionally, floor surfaces on elevation $305^{\prime}$ and floor surfaces and major pieces of equipment on elevation $347^{\prime}-6^{\prime \prime}$ were sprayed with high pressure water. Selective surfaces were decontaminated with a mechanical scrubber and chemicals. Strippable coating was tested and evaluated on equipment and floor surfaces.

The objectives of the experiment were to evaluate several decontamination techniques and to decontaminate the reactor building surfaces. Both objectives were only partially successful since the objectives were not compatible. The effectiveness, efficiency, and satety of several decontamination techniques were established for the large, complex decontamination effort. Various decontamination equipment was evaluated and its effectiveness was documented. Decontamination training and procedures were documented and evaluated, as were the support systems and organization for the experiment. Information was obtained to facilitate generic decontamination planning, in addition to planning for TMI - Unit 2 . Optimum techniques were selected on the basis of the tests for various types of surfaces.

The results of the experiment showed that the gross decontamination of the reactor building, with the proper techniques and water, could obtain the smearable contamination goal. Other techniques with strippable coating or with the mechanical scrubber and chemicals would result in smearable contamination levels well below the goal. Radiation dose rates in the best test areas were successfully reduced below the target for practical work area, and for head lift and defueling. Recontamination, other sources, storage, trash, and ineffective tests kept area dose rates in some areas from being reduced by the amount that had been forecasted. The surface deposition boring resulls indicate that the activity is generally limited to the paint. Airborne particulate activity-was reduced during the experiment to the point where the results showed that additional decontamination would reduce the requirement for respirators. Further decontamination activity would reduce the area dose rates if the storage, trash, and waste are removed from the reactor building.

'l'he major recommendations are to continue the decontamination effort in preparation for head lift and defueling, and to make improvements that will increase the effectiveness and efficiency of the decontamination effort. 


\subsection{INTRODUCTION}

Purpose

$1-1$

Objectives

$1-2$

Scope of the Experiment $1-2$

Experimental Design 1-6

Limitations

$1-12$

Data Analysis Approach

$1-14$

2.0 SUMMARY OF RESULTS

Low Pressure Activity 2-1

General Summary of Low Pressure Flush of Elevation 305'

General Summary of Low Pressure Flush of the Polar Crane

General Summary of Low Pressure Flush of the D-Rings, Missile Shields, Canals, Reactor Head Service Structure, and Refueling Bridges

General Summary of Low Pressure Flush of Elevation $347^{\prime}-6^{\prime \prime}$

High Pressure Flush Activity

General Summary of High Pressure Flush of Elevation 347'-6"

General Summary of High Pressure Flush of Elevation 305'

Reflushing of Elevation 305'

General Summary of Reflushing of Elevation $305^{\prime}$

Strippable Coating l'est

General Summary of Results

Mechanical Scrubber Test 
CONTENTS (Continued)

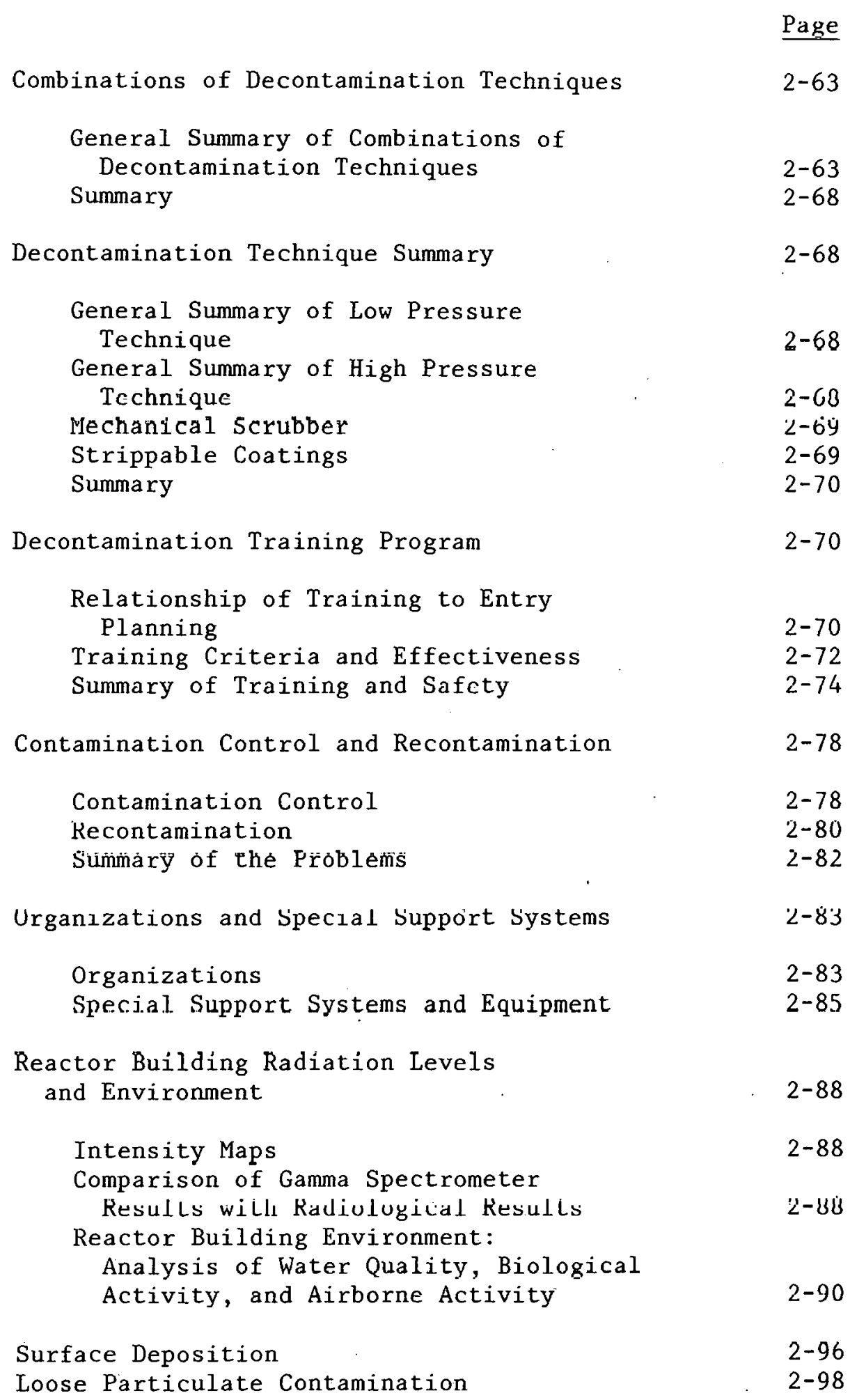


3.0 CONCLUSIONS

Decontamination Experiment Effectiveness 3-1

Decontamination Effectiveness 3-2

Decontamination Techniques 3-5

Decontamination Control and Surveillance 3-6

Support Systems and Organization 3-8

Decontamination Training 3-11

Decontamination Criteria 3-13

Gross Decontamination Goals and Criteria 3-13

Conclusion Summary 3-17

4.0 RECOMMENDATIONS

Additional Testing 4-1

Decontamination Techniques 4-2

Other Recommendations 4-2

Additional Decontamination 4-2

5.0 REFERENCES 5-1

APPENDICES

$\begin{array}{ll}\text { A } & \text { SURFACE DEPOSITION } \\ \text { B } & \text { EQUIPMENT } \\ \text { C } & \text { RAW DATA } \\ \text { D } & \text { TRAINING AND SAFETY } \\ \text { E } & \text { ORGANIZATION AND SUPPORT } \\ \text { F } & \text { PHOTOGRAPHS AND VIDEOTAPE RECORDINGS OF THE } \\ & \text { DECONTAMINATION EXPERIMENT } \\ \text { G } & \text { VIDEOTAPE AND WORK PACKAGE LISTING } \\ \text { H } & \text { EXPERIMENTAL DESIGN AND METHODOLOGY } \\ \text { I } & \text { GAMMA SPECTROMETER RESULTS }\end{array}$

TABLES

2-1 Elcvation 305' Low Prcasurc Fluch - Summary of Worker Radiation Exposure

2=2 Summary of Results of Low Pressure Flush of Elevation $305^{\prime}$

2-3 Elevation 305' Low Pressure Flush 
TABLES (Continued)

\begin{tabular}{|c|c|}
\hline $2-4$ & $\begin{array}{l}\text { Polar Crane Low Pressure Flush - Summary of } \\
\text { Worker Exposure }\end{array}$ \\
\hline $2-5$ & Summary of Low Pressure Flushing of Polar Crane \\
\hline & later Use for Polar Crane and Dome \\
\hline-7 & $\begin{array}{l}\text { Contamination Levels of D-Rings, Refueling Canal, } \\
\text { and Fuel Handling Bridge }\end{array}$ \\
\hline $2-8$ & $\begin{array}{l}\text { D-Rings, Refueling Canal, Missile Shields, and } \\
\text { Fuel Handling Bridge Water Rates }\end{array}$ \\
\hline $2-9$ & $\begin{array}{l}\text { D-Rings, Missile Shields, and Refueling Equipment } \\
\text { Summary of Worker Exposure }\end{array}$ \\
\hline $2-10$ & $\begin{array}{l}\text { Summary of Results of D-Ring Walls, Canals, and } \\
\text { Fuel Handling Bridge }\end{array}$ \\
\hline $2-11$ & $\begin{array}{l}\text { Median Contact Radiation Reduction (differences in } \\
\text { pre-test and post-test values) }\end{array}$ \\
\hline $2-12$ & $\begin{array}{l}\text { Elevaliun 347'-6" Luw Fiessure Fluslı - Summary } \\
\text { of Worker Exposure }\end{array}$ \\
\hline $2-13$ & Elevation $34^{\prime}-6^{\prime \prime}$ Low Pressure Flush \\
\hline $2-14$ & Contamination Levels of Elevation $34^{\prime}-6^{\prime \prime}$ \\
\hline$\angle-15$ & Elevation $347^{\prime}-6^{\prime \prime}$ High Pressure Flush Water Use \\
\hline $2-16$ & $\begin{array}{l}\text { Elevation } 347^{\prime}-6^{\prime \prime} \text { Equipment High Pressure Flush } \\
\text { Water Use }\end{array}$ \\
\hline $2-17$ & $\begin{array}{l}\text { Elevation } 347^{\prime}-6^{\prime \prime} \text { High Pressure Flush - Summary } \\
\text { of Worker Exposure }\end{array}$ \\
\hline $2-18$ & $\begin{array}{l}\text { Summary of Results of Elevation } 347^{\prime}-6^{\prime \prime} \text { Floor } \\
\text { High Pressure Flush }\end{array}$ \\
\hline $2-19$ & $\begin{array}{l}\text { Summary of Results of Elevation } 347^{\prime}-6^{\prime \prime} \text { Equipment } \\
\text { High Pressure Flush }\end{array}$ \\
\hline-20 & Elevation $305^{\prime}$ High Pressure Flush Water Use \\
\hline $2-21$ & $\begin{array}{l}\text { Summary of Results of Elevation } 305^{\prime} \text { High Pressure } \\
\text { Fluslı }\end{array}$ \\
\hline $2-22$ & $\begin{array}{l}\text { Summary of Reflushing Radiation and Contamination } \\
\text { Data of Elevation } 305 \text {, }\end{array}$ \\
\hline $2-23$ & $\begin{array}{l}\text { Strippable Coating 'lest - Elevation } 305^{\prime} \text { Floor } \\
\text { and Elevation } 347^{\circ}-6^{\prime \prime} \text { Head Storage Stand }\end{array}$ \\
\hline $2-24$ & $\begin{array}{l}\text { Elevation } 305^{\prime} \text { Area ISC and Elevation } 347^{\prime}-6^{\prime \prime} \\
\text { Equipment - Strippable Coating Test Parameters }\end{array}$ \\
\hline-25 & Summary of Results of Elevation '3úb' Area ISL \\
\hline 26 & Mechanical Scrubber Test - Elevation 347'-6 \\
\hline $2-27$ & Summary of Results of Mechanical Scrubber Test \\
\hline $2-28$ & $\begin{array}{l}\text { Summary of Results - Elevation 305' Low Pressure, } \\
\text { High Pressure, and Strip Coating Tests }\end{array}$ \\
\hline $2-29$ & $\begin{array}{l}\text { Summary of Results - Tlevation } 347^{\prime}-6^{\prime \prime} \text { Low } \\
\text { and High Pressure Flush of Concrete Floors } \\
\text { and Diamond Plate }\end{array}$ \\
\hline $2-30$ & $\begin{array}{l}\text { Summary of Results - Elevation } 347^{\prime}-6^{\prime \prime} \text { Low } \\
\text { and High Pressure Flush on Concrete Floors }\end{array}$ \\
\hline
\end{tabular}


TABLES (Continued)

$\begin{array}{ll}2-31 & \text { Summary of Various Test Results } \\ 2-32 & \text { Man-Hour and Material Costs for Support } \\ 2-33 & \text { Gross Decontamination Test Water Quality } \\ 2-34 & \text { Radinnurlide Connentrations in Decontamination } \\ & \text { Water } \\ \text { 2-35 } & \text { Airborne Data Summary }\end{array}$

\section{FIGURES}

1-1 Data Acquisition Program for. Gross Decontamination Experiment

1-2 Gross Decontamination Data Acquisition Tasks

1-3 Gross Decontamination Experiment Summary

2-1 Elevation 305' Low Pressure Flush - Planned

2-2 Elevation 305' Low Pressure Flush - Actual

2-3 Data Acquisition Survey Locations - Elevation 305'

Low Pressure, High Pressure, and Strippable Coating Tests

2-4 Low Pressure Flush of Polar Crane

2-5 Diagram of Dome Area/Polar Crane - Data Acquisition Locations

2-6 Diagram of Polar Crane - Data Acquisition Locations

2-7 Data Acquisition Locations - Elevation 347'-6"

D-Rings and Missile Shield Areas

2-8 Data Acquisition Locations - Refueling Canal and Service Structure

2-9 Data Acquisition Locations - Fuel Handling Bridge

2-10 Elevation 347'-6" Low Pressure Flush - Planned

2-11 Elevation 347'-6" Low Pressure Flush - Actual

2-12 Elevation 347'-6" Planned Data Acquisition

Locations - Low Pressure and High Pressure Flush

2-13 Elevation 347'-6" High Pressure Flush - Planned

2-14 Elevation 347'-6" High Pressure Flush - Actual

2-15 Elevation 305' High Pressure Flush - Planned

2-16 Elevation 305' High Pressure Flush - Actual

2-17 Mechanical Floor Scrubber Area - Elevation $347^{\prime}-6^{\prime \prime}$

2-18 Plot of Total Man-Hours per Hour in Containment Versus Time

2-19 Plot of Man-Hours Expended Versus Time

2-20 Elevation 305' Radiation Intensity Map

2-21 Elevation 347'-6" Radiation Intensity Map

3-1 Plot of Decontamination Factor (based on contact

measurements) Versus Water Rate

3-2 Decontamination Logic Diagram 

DO NOT MOROFLIL
THS PAEE 
GROSS DECON'IAMINA'I'TON EXPERIMENT REPORT

\subsection{INTRODUCTION}

The Department of Energy. (DOE) proposed in July 1981 that a Gross Decontamination Experiment should be performed within the reactor building of TMI - Unit 2. The proposed scope of work was modified over the next several months, and an agreement was reached with General Public Utilities (GPU) on the content of the experiment in October 1981, with a proposed start date in November 1981.

Nuclear Regulatory Commission (NRC) approval of the experiment, which was expected in November, was delayed while GPU prepared responses to questions posed by the NRC. Also, engineering and installation of support equipment needed for the experiment were not completed within the scheduled NovemberDecember time frame. As a result, the experiment was rescheduled in late January 1982, with low pressure flushing of the reactor building to begin in early March 1982 .

Although some minor deviations were encountered early in the course of the experiment, it was successfully completed in March 1982.

\section{$\underline{\text { Purpose }}$}

The purpose of the Gross Decontamination Experiment was to provide the nuclear industry with the fullest possible access to applicable engineering and operational experience that can be gained from decontamination of the reactor building of TMI - Unit 2, and to document the following activities:

- Gross decontamination effectiveness

- Decontamination criteria 
- Decontamination training and procedures

- Radiation monitoring and mapping

- Support systems and organization.

\section{Objectives}

The objectives of the Gross Decontamination Experiment were to:

- Evaluate the safety, etfectiveness, and efficiency of various methods and equipment for performing gross decontamination of large, complex, contaminated surfaces within the reactor building. Support systems and organization for such a large decontamination effort were also to be evaluated.

- Reduce the contamination present on selected surfaces within the reactor building in a manner consistent with ALARA (as low as is reasonably achievable) principles for personnel radiation exposure management.

During the course of the experiment, a later objective-increased the importance of the derontamination aepect. However, during final prcparation for and actual conduct of the experiment, decontamination became the focus of the work.

\section{Scope of the Experiment}

The scope of the Gross Decontamination Experiment changed several times during the planning and execution phases. During the planning phase, some decontamination test areas were deleted from the scope due to budgetary and 
time constraints. After the experiment was begun, several of the deleted test areas were reinstated, and some data acquisitions tasks were deleted.

In the final planning phase, the scope of work included testing various decontamination techniques on major equipment, stairs, floor surfaces on

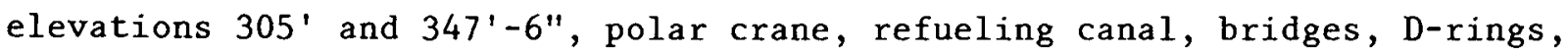
and missile shields. The sample (data acquisition) and work packages were structured to provide data on decontamination techniques, and to provide information necessary to evaluate the systems and organizational aspects of the effort.

Other work performed in support of the experiment included:

- Installation of a polar crane access system ("Spider shafter" system) on elevation $305^{\prime}$ with provisions to off-load personnel and equipment at elevation $347^{\prime}-6^{\prime \prime}$.

- Installation of additional services: decontamination water (rated at $10,000 \mathrm{psig}$ ) and $480 \mathrm{~V}$ ac power ( $100 \mathrm{psi}$ service air is currently available through $R$ 561).

- Acquisition of data associated with the experiment - radiological surveys, including use of a gamma spectrometer, pictures, videotapes, etc.

- Decontamination of the enclosed stairwell, using low pressure and high pressure water, if access to elevation 347'-6" via the Spider shafter is not accomplished.

- Use of strippable coatings on the elevation $305^{\prime}$ floor and equipment on elevation 347'-6", regardless of Spider status. The test area is approximately 700 square feet. 
The relationship between the Gross Decontamination Experiment and the Gross Decontamination Technical Plan (TPO/TMI-007) is that the experiment encompassed the first 13 steps of the plan, with the exception of:

- Installing the enclosure from personnel air lock No. 2 to enclosed stairwell No. 2

- Installing an enclusure area around the slairwell No. 2 door and elevation $347^{\prime}-6^{\prime \prime}$

- Sealing off elevation $347^{\prime}-6^{\prime \prime}$

a Srat ing afr forvation 305 ,

Figure 1-1 shows the planned and actual sequence of steps for the experiment. The steps deleted from the Gross Decontamination Technical Plan were not performed because they were judged to be man-hour and man-rem intensive and because they would not contribute to general area dose reduction. No attempts, other than sequencing considerations and operational precautions, were made to prevent recontamination during the experiment. In addition, chemicals were used in small areas where they could be controlled and removed as separate waste. This prevented any impact of the chemicals on the submerged demineralizer system (SDS), which processes the water out of elevation 282'-6".

Prior to the experiment, various necessary equipment and items were installed in the reactor building. Processed water with a flow rate of up to 25 gallons per minute (gpm) and up to $180 \mathrm{~F}$ was provided to the building. Electrical power was provided for the spider and for elevation 305', because most of the circuits for that level were on elevation 282'-6", which had been under water.

A Spider lift access platform was installed on elevation $347^{\prime}-6^{\prime \prime}$ and on the polar crane; to provide access to the crane. A new radio system was 
installed with new antennas, a duplex base station, throat microphones, and stethoscope-type earphones.

The equipment that was brought into the containment consisted of:

- High reach platform - Model S15E

o Forklift

- Lifting device to move heavy items between elevations $305^{\prime}$ and $347^{\prime}-6^{\prime \prime}$.

Decontamination techniques used during the Decontamination Experiment were demonstrated in either the auxiliary building or the reactor building, with the exception of the high pressure water floor scrubber. The basic technique was a water flush at pressures varying from $60 \mathrm{psig}$ to $6000 \mathrm{psig}$, and at temperatures ranging from ambient to $140 \mathrm{~F}$ at the output of the penetration. The floor rates varied from 5 to $25 \mathrm{gpm}$. The major techniques tested were:

- High pressure (HP) flush - Water lances directed manually were used to apply water at pressures between 2000 and 6000 psig. The actual pressure was the maximum that can be used without destroying the integrity of protective coatings. The water temperature did vary; however, the maximum at the pump was based on the design of the pump seals. The temperature was expected to be a maximum of $140 \mathrm{~F}$. The actual application temperature did vary with heat losses through hoses.

- Low pressure (LP) flush - Water lances directed manually were to be used to apply water at temperatures between ambient and $140 \mathrm{~F}$ at the inlet to the pump, at flow rates of approximately $25 \mathrm{gpm}$. Actual temperatures and pressures were to be dependent on line losses from the pump to the nozzle. 
- Spin jet - High pressure water was to be applied through a series of rotating nozzles. Application consists of pushing this device across the floor, which had the advantages of consistent application and a faster decontamination rate. The water floor scrubber required $230 \mathrm{~V}$ ac power. Pressures from 2000 to 6000 psig and flow rates from 5 to $25 \mathrm{gpm}$ were to be used.

- Strippable coatings - Strippable coatings were to bc used to decontaminate the exposed concrete surfaces in the enclosed stairwell. The test area was to be approximately 350 square feet.

- A mechanical scrubbing device was to be used on a small test area (150 square feet).

- Wet vacuums were to be used to reduce squeegee operations and problems.

- Evaluation of other equipment will continue throughout the test, and some substitution of equipment may occur.

\section{Experimental Design}

In planning for the execution of this experiment, a systematic approach was taken to selection of sampling locations, data collection standards, and test sequences. Details of the experimental design are contained in Appendix $H$.

Sampling locations were selected to provide a minimally representative data base for evaluation of the results produced by various decontamination techniques. Additionally, sufficient redundancy was included to permit evaluation of data precision, biases, reproducibility, etc. 
Data collection standards were established to provide consistency in instrument usage or swipe (smears) collection. In all cases, sample points were permanently marked to ensure accurate relocation of data acquisition poinls.

The data collection and work sequence (see Figure 1-2) was established to provide an orderly and systematic approach to obtaining comprehensive results without recontamination or loss of data. The sequence was:

u Task Nu. 1 - Elevaliun $305^{\circ}$

Initial data collection and misting

Low pressure flush of overheads

Low pressure flush of major equipment

Low pressure flush of wall and floor surfaces

o Task No. 2

Stairwell shielding

Flush stairwell No. 2 concrete block wall

- Task No. 3 - Polar Crane

Data collection and misting

Low pressure flush of polar crane and dome area

High pressure spray of polar crane and dome area 
- Task No. 4

Initial data collection

Mist and flush top of D-rings, missile shields, and open stairwell

Initial data collection - elevation $347^{\prime}-6^{\prime \prime}$

Mist elevation $3 / 7^{\prime}-6^{\prime \prime}$

Low pressure flush of elevation $34^{\prime}-6^{\prime \prime}$ major equipment

Low pressure flush of elevation $347^{\prime}-6^{\prime \prime}$ wall and floor surfaces

High pressure spray of elévatiun $347^{\prime}=6^{\prime \prime}$ major equipment

High pressure spray of elevation $347^{\prime}-6^{\prime \prime}$ major surfaces

Strippable coating test on reactor vessel head storage stand

Mechanical floor scrubber test on elevation $347^{\prime}-6^{\prime \prime}$

Wet abrasive spray on wall and floor surfaces on elevation $347^{\prime}-6^{\prime \prime}$

o Task No. 5

Initial data collection and mist of refueling canal area and equipment

Low pressure flush of major equipment over refueling canal and reactor head service structure

Low pressure flush of refueling canal wall and floor surfaces 
- Task No. 6

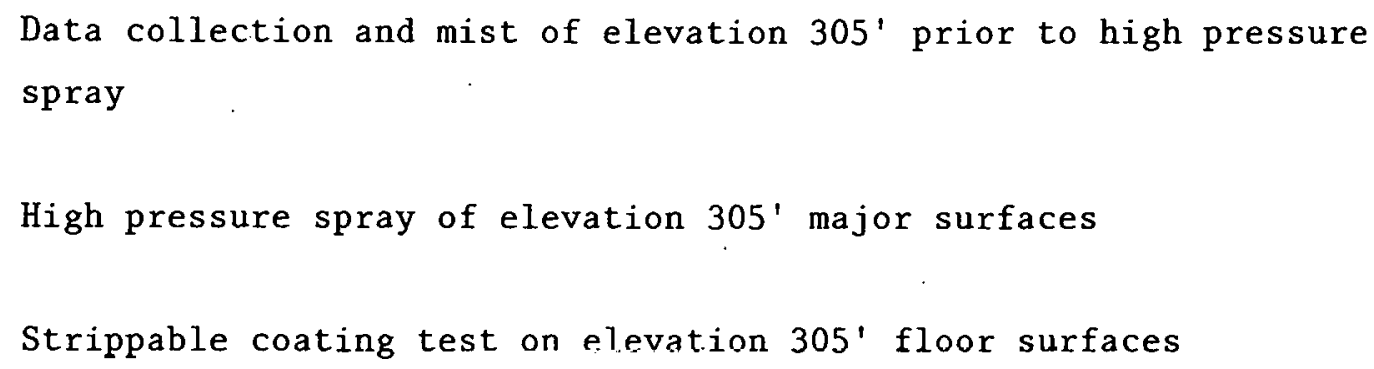

The initial changes to the scope of the experiment deleted the following items :

o Task No. 1 - Flush of walls, overheads, and major equipment

o Task No. 2 - Entire task

- Task No. 3 - Low pressure spray of dome; hïgh pressure spray of polar crane and dome

- Task No. 4 - Low pressure flush of elevation 347'-6" wall surfaces; wet abrasive spray of wall and floor surfaces.

- Task No. 5 - No change

- Task No. 6 - High pressure spray of elevation $305^{\prime}$ walls and equipment surfaces 
Based on the approved scope of work, work packages were developed to implement the tasks and data acquisition packages contained within the tasks. This resulted in the following breakdown and sequence of tasks and work packages for the experiment:

- Work Package $47^{\mathrm{a}}$ (Task 1)

All initial data acquisition for Work Packages $47,53,49$, and -50

Mist elevation $305^{\prime}$

Low pressure flush of elevation $305^{\prime}$

Poet-low prescure fluch data acquioition

- Work Package 53 (Task 3)

Mist of polar crane

Low pressure flush of polar crane

Post-low pressure flush data acquisition

Data acquisition on elevation $347^{\prime}-6^{\prime \prime}$ D-rings, missile shields, refucling canal; and reactor scrvice ocruccure

o Work Package 49 (Tasks 4 and 5)

Low pressure mist and fllush missile shields, D-rings, reactor head service structure, refueling bridges, and refueling canal

Post-low pressure flush data acquisition

a. The work package numbers do not have a numerical sequence significance but are representative of the task, i.e., Work Package 50 - low pressure flush of elevation $347^{\prime}-6^{\prime \prime}$. 
- Work Package 50 (Task 4)

Low pressure mist and flush of elevation $347^{\prime}-6^{\prime \prime}$

Post-low pressure flush data acquisition

- Work Package 51 (Task 4)

High pressure flush of elcvation $34^{\prime}-6^{\prime \prime}$ major equipment and floor

Post-high pressure flush data acquisition

- Work Package 52 (Task 6)

High pressure mist and flush of elevation 305'

Post-high pressure flush data acquisition

o Work Package 54 (Task 4)

Strippable cuating test on elevation $347^{\prime}-6^{\prime \prime}$

o Work Package 81 (Task 6)

Strippable coating test on elevation 305'

- Work Package 80 (Task 4)

Mechanical scrubber test on elevation $347^{\prime}-6^{\prime \prime}$ 
After the experiment was in progress, the following items previously deleted from the scope of work were reinstated:

- Overheads, walls, and major equipment on elevation $305^{\prime}$

- Mechaniral scrubber toat i chemicals

- Low pressure flush of the dome

l'he following items were delcted:

- Post-low pressure data acquisition of the polar crane flush on elevatinn $347^{\prime}=6^{\prime \prime}$, mo3ile slinelds, canaj.s, and bridges

- Post-low pressure flush data acquisition on elevation $347^{\prime}-6^{\prime \prime}$

- Proper sequence of low pressure flush on elevation 305'

Figure 1-3 reflects the sequence and work package accomplishment for the experiment.

\section{Limitations}

The deletion of the interim data bases, which had been established to provide separate data on low and high pressure flushing, limited the ability to determine the effectiveness of some of the low, high, and combination pressure flush tests.

After the initial radiation readings and samples were collected on the lower elevations, canals, missile shields, and refueling bridges, additional debris and contamination were deposited from the polar crane flushing on these areas. The low pressure test of these areas, then, did not have valid pre-test data. 
On elevation 305', the floor was flushed first, post-test data were taken, and then the overheads, walls, and floor were flushed. The change in sequence did not provide a good baseline for determining elevation 305' high pressure spraying effectiveness. However, based on data acquisition from other test areas on elevalion $305^{\prime}$, some estimates of technique effectiveness can be made.

Video recordings of the experiment allowed examination of the data acquisition techniques and the low pressure, high pressure, and combination tests. As a result, the recordings allowed the tests to be reviewed and a determination to be made on the success, failure, recontamination, and problems that did affect the results of the experiment.

Where operational circumstances invalidated some test data readings, the invalid data were removed prior to the evaluation of the various decontamination techniques.

The low pressure flushing of the enclosed stairwell was designed to provide information on:

- Changes in airborne activity due to flushing operations

- Effectiveness of decontaminating concrete block wall surfaces

- Contamination control resulting from application of a coating to the open concrete block

- The effectiveness in dose reduction and ease of installation of several different coatings.

This task was deleted from the scope of work. As a result, information was not provided during the experiment or in other tasks on decontamination of concrete block wall surfaces, contamination control with several different coatings, and water bladder shielding. 


\section{Data Analysis Approach}

Analysis of the data acquired from the Gross Decontamination Experiment could be performed only by employing a "valid data" selection process. This approach employed a careful evaluation of the impact of operational parameters upon the validity of the data. As an example, a study of the videotapes of operations revealed that water control operators directed water over areas already decontaminated, or a worker walked through loose debris and tracked it t. $n$ areas already cleaned. Sample points affected by such events were not used in results, since their validity was lost or questionable. Clearly, this reduced the data availablc for analysis, but served to eliminate many of the inconsistencies produced by inclusion of all data acquired.

After removal of invalid data, the analyses were done for each planned area within the reactor building and technique used (either singly or in combination). Pre- and post-test results were evaluated for each valid sampling point in a pair-wise fashion. The net result of this approach was a significant reduction in sample variances within groups, which provides the opportunity for more straightforward analyses of the data sets.

To analyze the data, the following scheme was employed:

- Area gamma dose rate reductions were calculated by obtaining the difference between pre-test and post-test gamma radiation measuremenls.

- Decontamination factors were calculated from contact gamma and beta results. To do this, the difference between pre-test and post-test contact gamma values was obtained. This was connected to microcuries $/ \mathrm{cm}^{2}\left(\mu \mathrm{Ci} / \mathrm{cm}^{2}\right)$ by using the rationale contained in Reference 2 .

Similarly, post-test betca values were converted to $\mu \mathrm{Ci} / \mathrm{cm}^{2}$ by the rationale contained in Reference 2. This provided an estimate of the areal density of the contaminants remaining on the surface after 
treatment. The decontamination factor (DF) was then calculated from the following equation:

$\mathrm{DF}=\frac{\mathrm{Ci}(\mathrm{P})+\mathrm{Ci}(\mathrm{F})}{\mathrm{Ci}(\mathrm{F})}$

where $C i(P)=\mu C i / \mathrm{cm}^{2}$ calculated from pre-test contact gamma measurement

$\mathrm{Ci}(\mathrm{F})=\| \mathrm{H} \mathrm{i} / \mathrm{cm}^{2}$ calculatcd frum pusl=Lest contact beta values.

This method was used to analyze data obtained from the Large-Scale Decontamination l'est conducted in 1981 (Reference 3). Although valid issues can be raised regarding this calculational method, it does provide a basis for comparison of results. It does not, however, provide absolute values for areal concentrations of contaminants. Gamma spectroscopy, deposition sample analyses, and the experiment data permit an evaluation of the relationship between areal concentrations, as used here, and the actual number of $\mu \mathrm{Ci} / \mathrm{cm}^{2}$ as determined by quantitative analyses. In addition, the decontamination factors may be compared between the different technique analyses.

- To determine decontamination factors from swipe data merely requires a calculation of the ratio of pre-test to post-test swipe results. In these analyses, total cesium ratios were used. Thus:

$\mathrm{DF}=\frac{\text { Pre-test } \mathrm{dpm} / 100 \mathrm{~cm}^{2}(\mathrm{Cs})}{\text { Post-test } \mathrm{dpm} / 100 \mathrm{~cm}^{2}(\mathrm{Cs})}$

- To establish other parameters, e.g., gallons/square feet, square feet/min, etc., required a careful analysis of the videotapes to establish times for specific operations and areas involved. Derived parameters were then obtained from observed variables such as water flow rate (gpm), total water usage, and pump power cycles, in appropriate combination with data obtained from videotapes. 


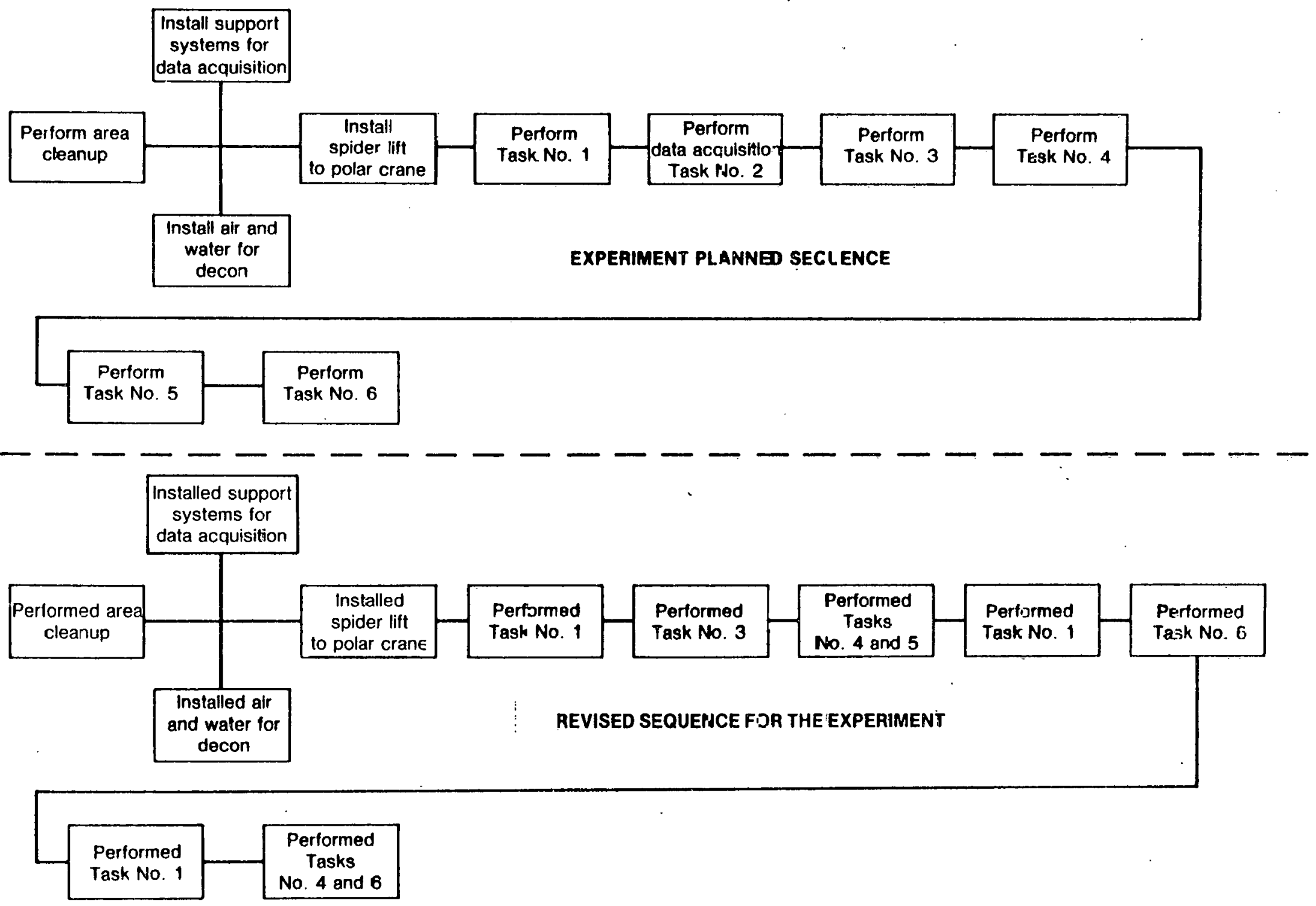

Figure 1-1. Dafa acquisition program for gross deccntamination experiment: 
Task No. 1

\begin{tabular}{|c|c|c|c|}
\hline \multirow{2}{*}{$\begin{array}{l}1.1 \text { Determine airt.orne activity } \\
\text { level changes as } \varepsilon \text { result of mist- } \\
\text { ing the } 305^{\prime} \cdot 0^{\prime \prime} \text { elevation. }\end{array}$} & \multirow{3}{*}{$\begin{array}{l}\text { 1.2 Perform a test to determine } \\
\text { effectiveness of LP flush of } \\
\text { overhead surfaces. Test cable } \\
\text { trays, piping surfaces, and plat- } \\
\text { forms. LP spray temp should be } \\
\text { tested at ambient and } 140 \mathrm{~F} \text {. } \\
\text { The filow rates should vary from } \\
15 \text { and } 25 \mathrm{gpm} \text {. The test should } \\
\text { be conducted from both the } 305 \\
\text { floor level }\end{array}$} & \multirow{4}{*}{$\begin{array}{l}\text { 1.3 Perform a test of the decon- } \\
\text { tamination effectiveness of } L P \\
\text { flush of major equipment surfaces } \\
\text { on the } 305 \text { ' elevation. The sur- } \\
\text { faces should include the air } \\
\text { cooler, core ftood tank } B \text {, core } \\
\text { flood tank } A \text {, and open stairwell } \\
\text { "1. The LP spray temp should be } \\
\text { tested at ambient and } 140 \mathrm{~F} \text {. } \\
\text { The flow rates should vary from } \\
15 \text { and } 25 \text { gpm. The test should } \\
\text { be conducted from both } 305^{\circ} \\
\text { floor }\end{array}$} & \multirow{3}{*}{$\begin{array}{l}1.4 \text { Perforn a test of the decon- } \\
\text { tamination of the } \Xi 05 \text { ' floor with } \\
\text { LP water. The water temperature } \\
\text { should vary from ambient and } \\
140 \mathrm{~F} \text {. the llow rates should vary } \\
\text { from } 15 \text { and } 25 \mathrm{grm} \text {. The } \\
\text { second pass of the area in front } \\
\text { of air lock } \# 2 \text { should be } \\
\text { evaluated. The walls up } 10 \mathrm{ft} \text {. } \\
\text { should also be flushed. Various } \\
\text { surfaces wil be evaluated. }\end{array}$} \\
\hline & & & \\
\hline \multirow[t]{3}{*}{ 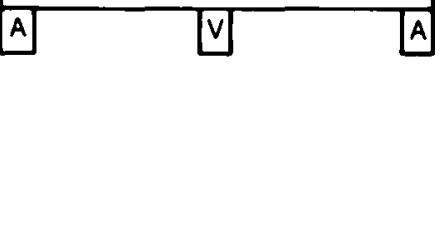 } & & & \\
\hline & 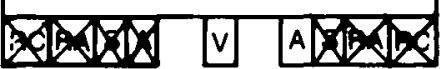 & & \begin{tabular}{|l|l|l|l|l|l|l|l|l|}
$R C$ & $R A$ & $S$ & $A$ & & $V$ & A & $S$ & $R A$ \\
\end{tabular} \\
\hline & 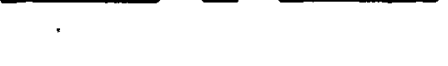 & EBA $v \mid A$ & \\
\hline
\end{tabular}

Data Collected
A Airbcine aclivity monitoring RC Radiation surveys (contact)
RA Radiation surveys (area)
$S$ Swipe sampes
G Gamma spectrometer survey
$P$ Photographs
$\checkmark$ Videctape
$X$ Not azcompl shed

Figure 1-2. Gross decontamination data acquisition tasks. 
Task No. 2

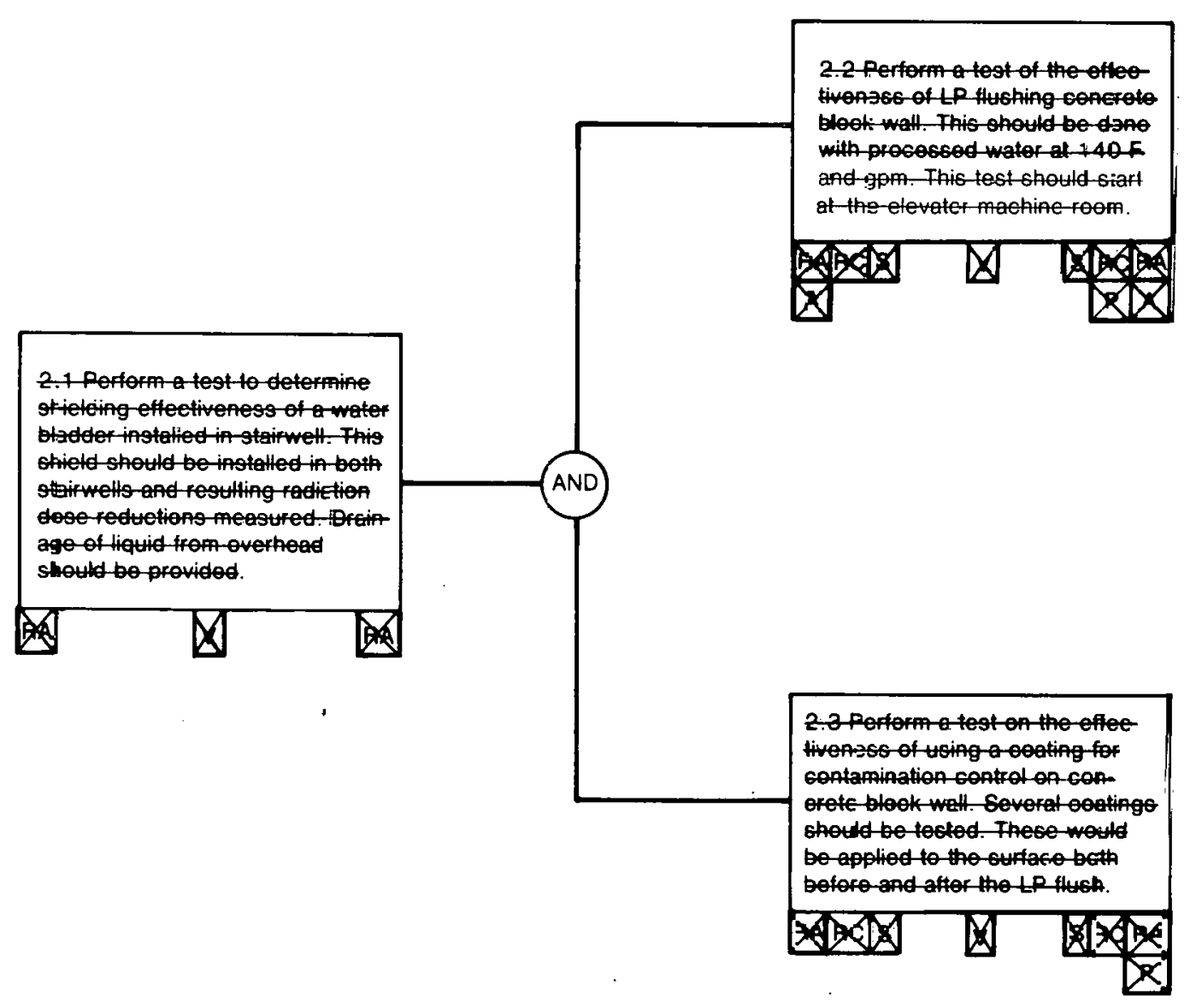

Figare 1-2. (Continued) 
Task No. 3

\begin{tabular}{|l|l|l|l|}
\hline $\begin{array}{l}\text { 3.1 Determine airborne activity level } \\
\text { changes as a result of misting the polar } \\
\text { crane. This includes misting of the dome } \\
\text { area above the LOCA ducts and all horizon. } \\
\text { tal surfaces of the crane. }\end{array}$ \\
\hline$A$ & D
\end{tabular}

Figure 1-2. (Continued) 
Task No. 4

(Contingency)

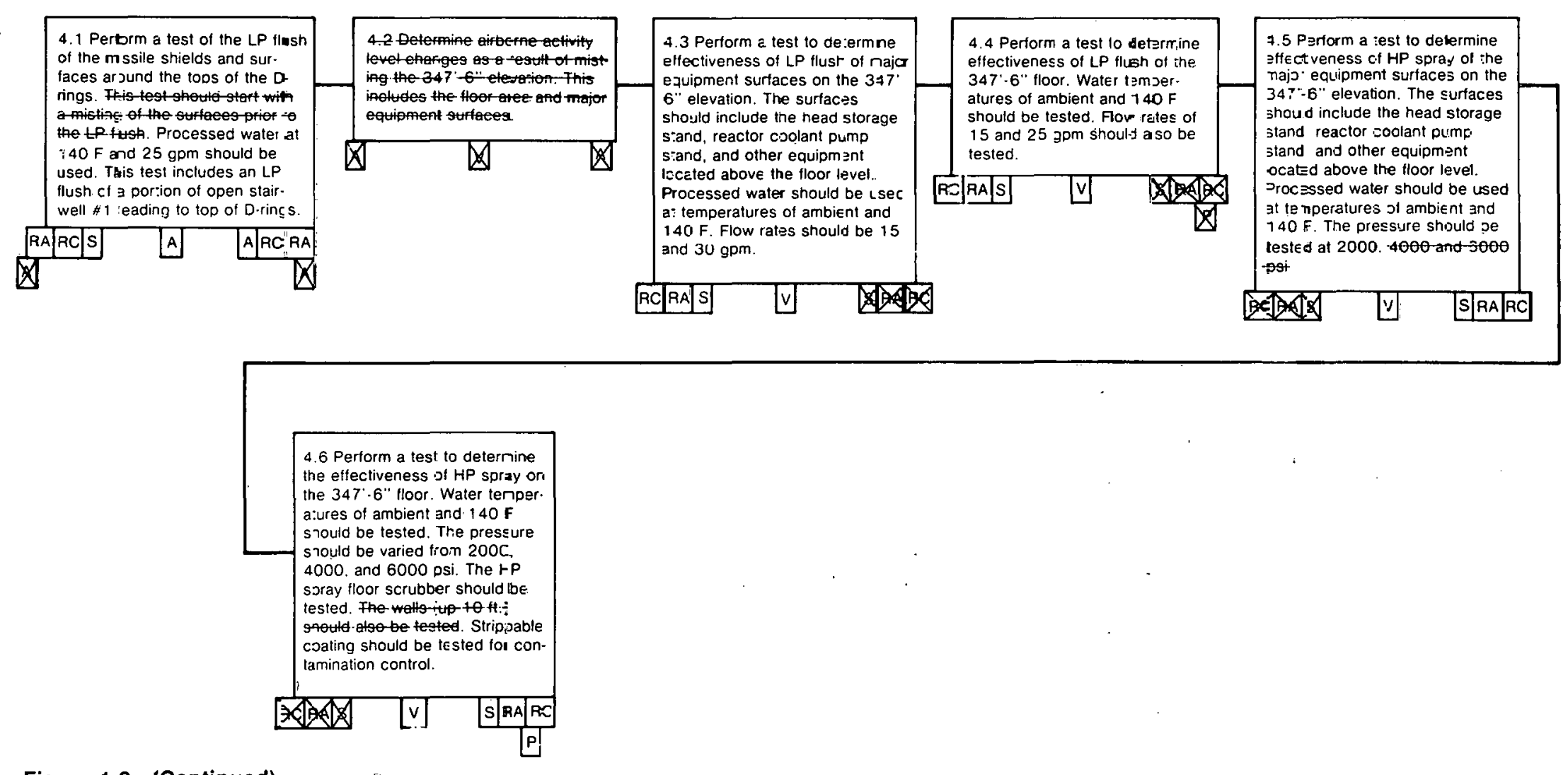

Figure 1-2. (Continued) 
Task No. 5

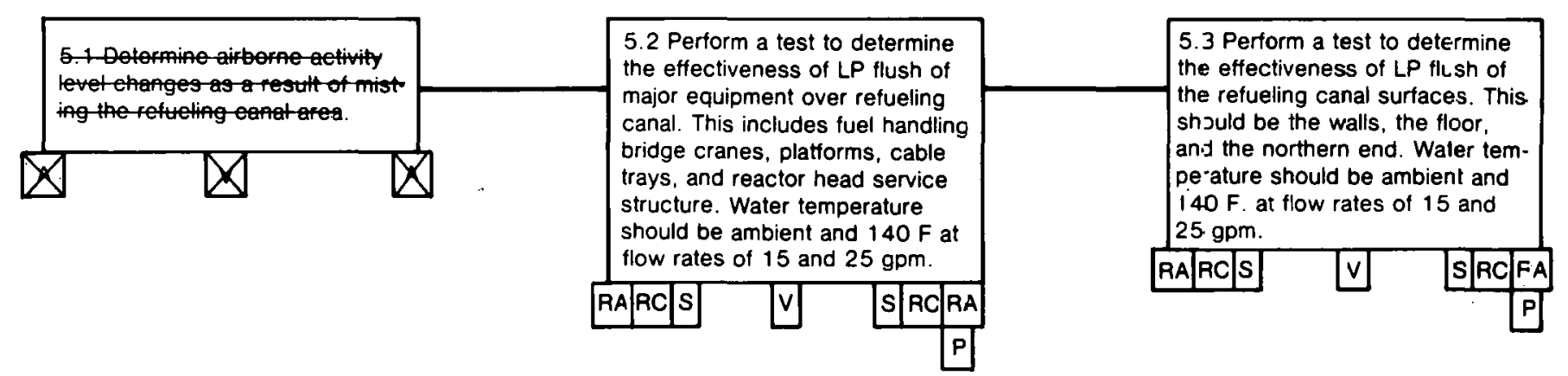

Figure 1-2. (Continued) 
Task No. 6

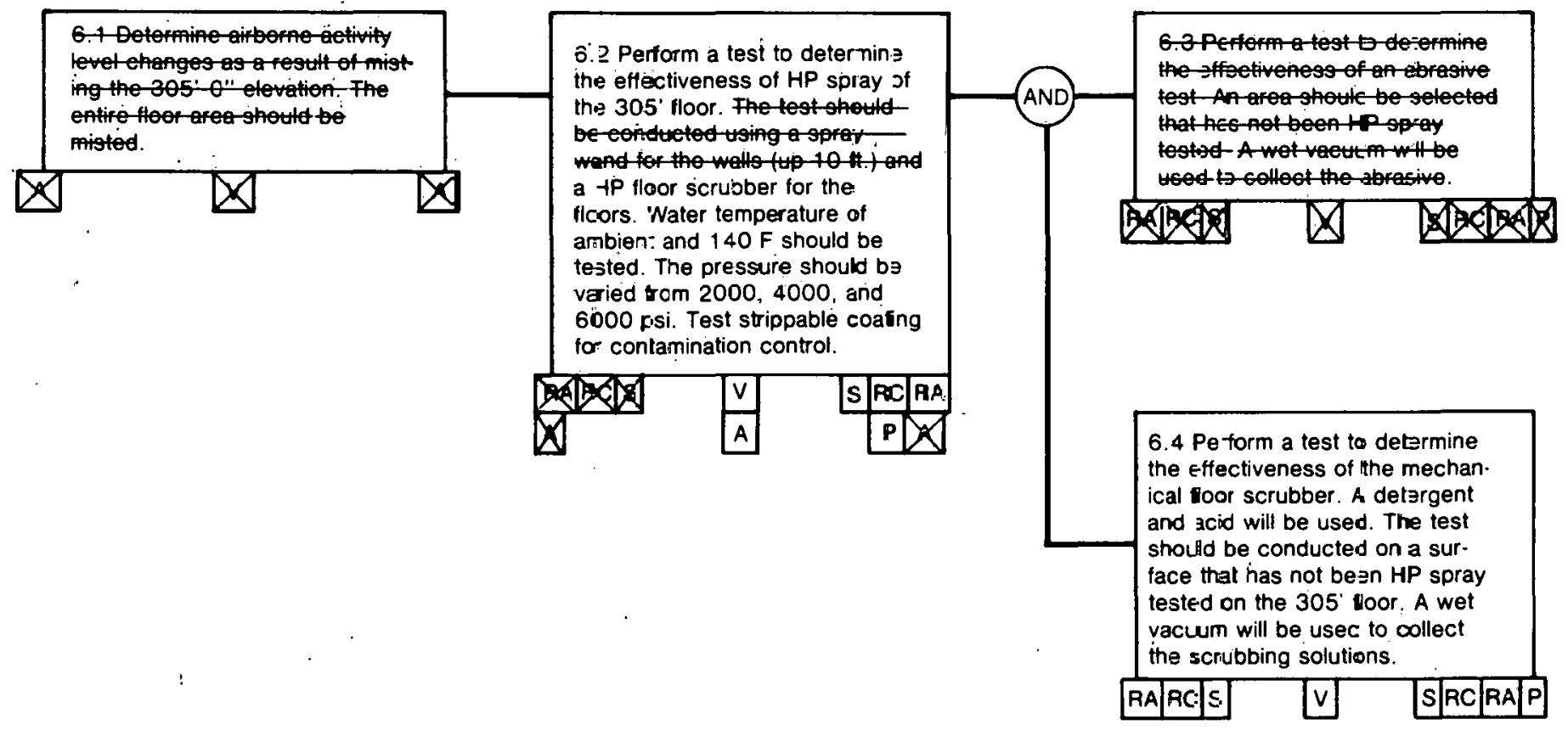

Figure 1-2. (Contiñued) 


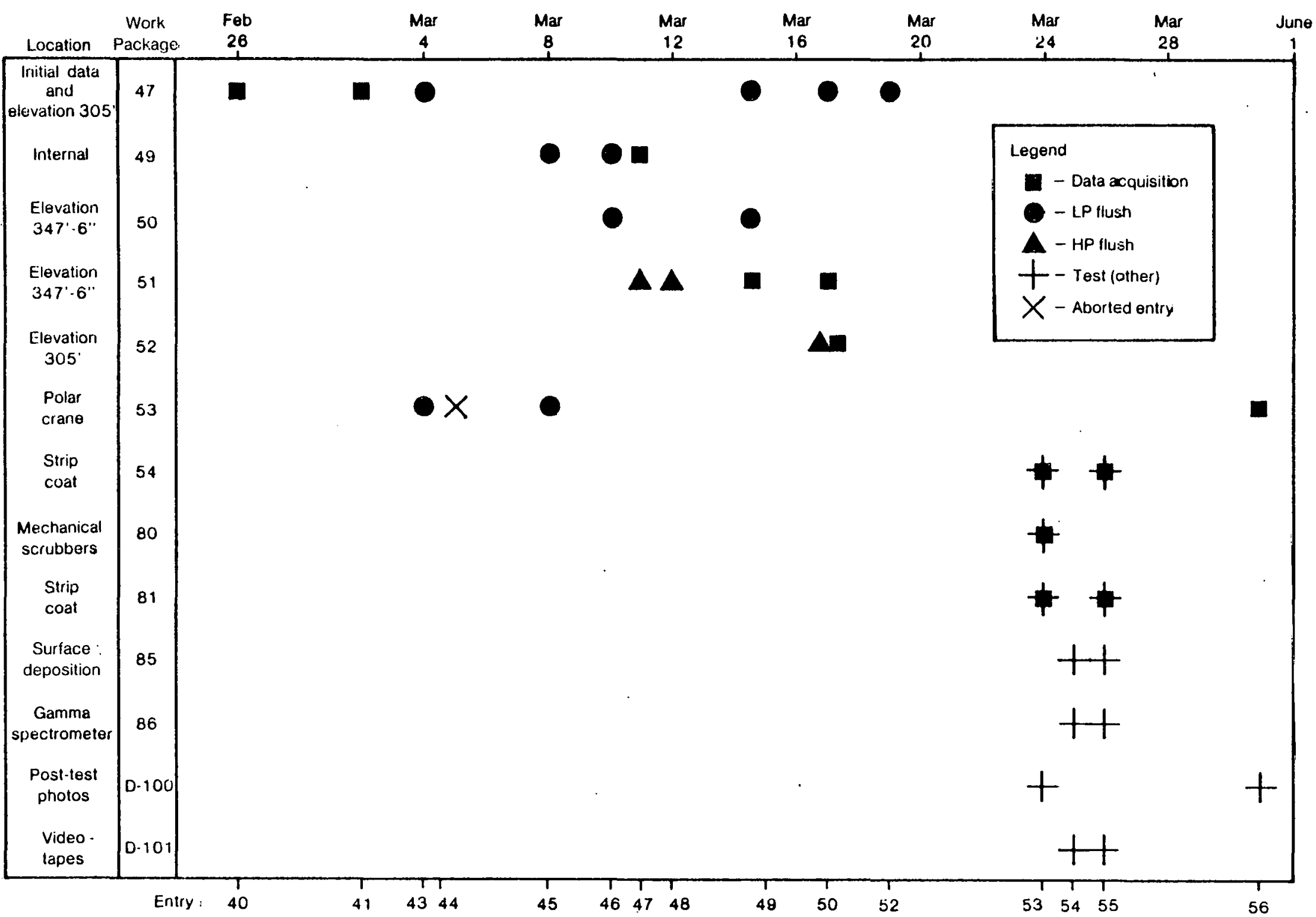

Figure 1-3. Gross decontamination experiment summary. 


\section{DO NOT MICROFILM \\ THIS PAGE,}




\subsection{SUMMARY OF RESULTS}

\section{Low Pressure Activity}

General Summary of Low Pressure Flush of Elevation 305'

Technique Description. The low pressure flush of elevation $305^{\prime}$ was designed to:

- Conduct a second decontamination test on the surfaces that were previously decontaminated during the large-scale decontamination test.

o Determine the effectiveness of decontaminating overhead surfaces, the equipment required for overhead decontamination, and flushing at different angles.

- Determine the airborne activity created by this type of flushing and determine worker clothing requirements.

- Determine the effectiveness of hot water flushing using various application techniques.

- Decontaminate various types of surfaces found within the building, i.e., floors, walls, piping, cables, cable trays, and platforms.

- Determine the advantage of misting surfaces prior to flushing.

- Evaluate the sequence of operations, i.e., mist, flush overheads, flush major equipment, flush wall.s, and flush floors. 
The low pressure flush was conducted in stages on elevation $305^{\prime}$ because the scope of work was changed during the experiment. As a result, the work sequence was:

o Mist

o Floor

o Overheads

- Major equipment

- Walls

o Floor

o Reflush floor.

Smearable Contamination Levels. The amount of contamination at the beginning of the low pressure flush of elevation $305^{\prime}$ ranged from mid-106 $\mathrm{dpm} /$ $100 \mathrm{~cm}^{2}$ to mid-107 $\mathrm{dpm} / 100 \mathrm{~cm}^{2}$ of $\mathrm{Cs}-137$. The pre-test average was $1.1 \times 10^{7}$ $\mathrm{dpm} / 1 \dot{0} \mathrm{~cm}^{3}$ of $\mathrm{is}-131$. Atter the experiment, the readings ranged from $10^{3} \mathrm{dpm} /$ $100 \mathrm{~cm}^{2}$ to $10^{6} \mathrm{dpm} / 100 \mathrm{~cm}^{2}$, and averaged $4.1 \times 10^{6} \mathrm{dpm} / 100 \mathrm{~cm}^{2}$ of $\mathrm{Cs}-137$. The average reduction in smearable contamination was 63 percent. The $\mathrm{Cs}-137$ to Sr-90 ratio remained constant during the test.

Degree of Uncertainty - Decontamination Effectiveness. Before and after misting and the first flush of the floor, data were acquired on floor and piping surfaces. Data were not taken on overheads or vertical surfaces, so no determination of technique effectiveness could be made for these areas. Visual observation of the experiment indicated that a signiticant amount of dirt and debris was flushed from the overheads and major equipment surfaces. 
Hot water was tested during some flush operations on elevation $305^{\prime}$ although the intended temperature was not reached because of problems with the heater. For a short time, a high temperature of $155 \mathrm{~F}$ was recorded, but throughout most of the experiment the water temperature averaged $112 \mathrm{~F}$.

Decontaminating the overheads, equipment, and wall surfaces created some recontamination during the experiment because water and debris dripped onto the clean floor surfaces.

Waste Volume. The volume of waste generated during the test was less than had been expected because the worker rate was higher than projected and the water rate was lower. The total volume of water used for the experiment was 3300 gallons.

Results - Expected Versus Actual. The low pressure flushing results for areas of higher contamination were as expected or exceeded expectations. It appeared that area gamma radiation could be reduced by 50 percent, and the decontamination factor (DF) was greater than 10 for smearable contamination. For areas with lower radiation and contamination, a different technique than was used in the experiment may be appropriate because these areas were not as affected by the low pressure flush.

Equipment and Techniques. New techniques and equipment were developed for the test. In general, equipment provided by the manufacturer was not as rugged, reliable, or effective as desired for the harsh environment of the experiment. See Appendix B for equipment problems.

Worker Radiation Exposure. The worker exposure during the low pressure flush test, including data acquisition, misting, and flushing, was 9.813 manrem. Table 2-1 shows the worker exposure for each task. 
TABLE 2-1. ELEVATION 305: LOW PRESSURE FLUSH - SUMMARY OF WORKER RADIATION EXPOSURE

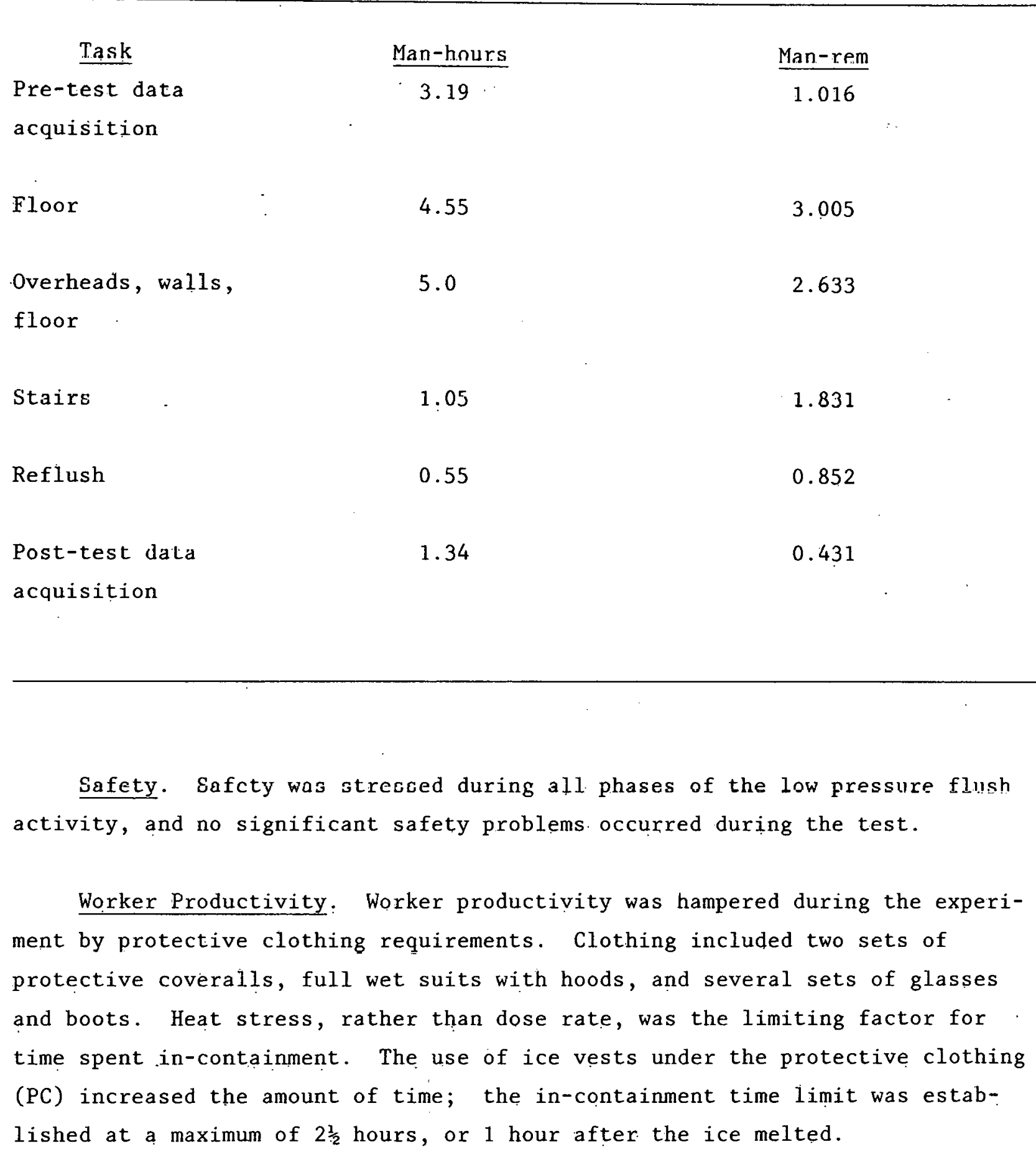


During training, each individual was tested to determine how long he could correctly operate the lance used for flushing at various pressures. Because of limited physical endurance exhibited by many of the workers, the time that they could flush was short. As a result, an optimum time limit was established for each crew that would not excessively tire the workers.

Summary of Specific Results. In general, the results of the low pressure flush test showed that contamination was reduced in all areas.

Low Pressure Flush Parameters--The results of the low pressure flush test on elevation $305^{\prime}$ are shown in Table 2-2. Three crews of three members each misted and flushed for a total of 91 minutes ( 11 minutes misting, 80 minutes flushing). Approximately 1100 gallons of water were used during the test; . 4405 square feet were covered per hour. The planned and actual test parameters and the data sample points are shown in Figures 2-1, 2-2, and 2.3.

Visual Results--The visual observations of the low pressure flush on elevation 305' showed that a great amount of dirt and debris was moved with the water. Flush crews reported that hot water produced better visual results; however, the data did not indicate more contamination reduction. The flush nozzle produced striping on the floor and diamond plate in heavy dirt (see Photograph 1). 'The low pressure flush did not move this "semi-fixed" debris observed on the diamond plate and other sections of the floor. Photograph 2 illustrates the high effectiveness of the flushing activities for removing dirt and debris from the stainless steel surfaces.

Radiation Changes--The low pressure flush produced area dose reductions ranging from 14 percent to 37 percent, as shown in Table 2-2.

Relative decontamination factors (RDFs) based on contact readings varied from 6.9 to 75.6 for floors, and to 124 for stainless steel. Area radiation readings showed dose reductions. However, Area II LP appeared to have some other sources (air coolers, core flood tank piping, stairwells) contributing to the area dose rate, since the contamination reduction should have produced a larger dose rate reduction. 
TABLE 2-2. SUMMARY OF RESULTS OF LOW PRESSURE FLUSH OF ELEVATION 305

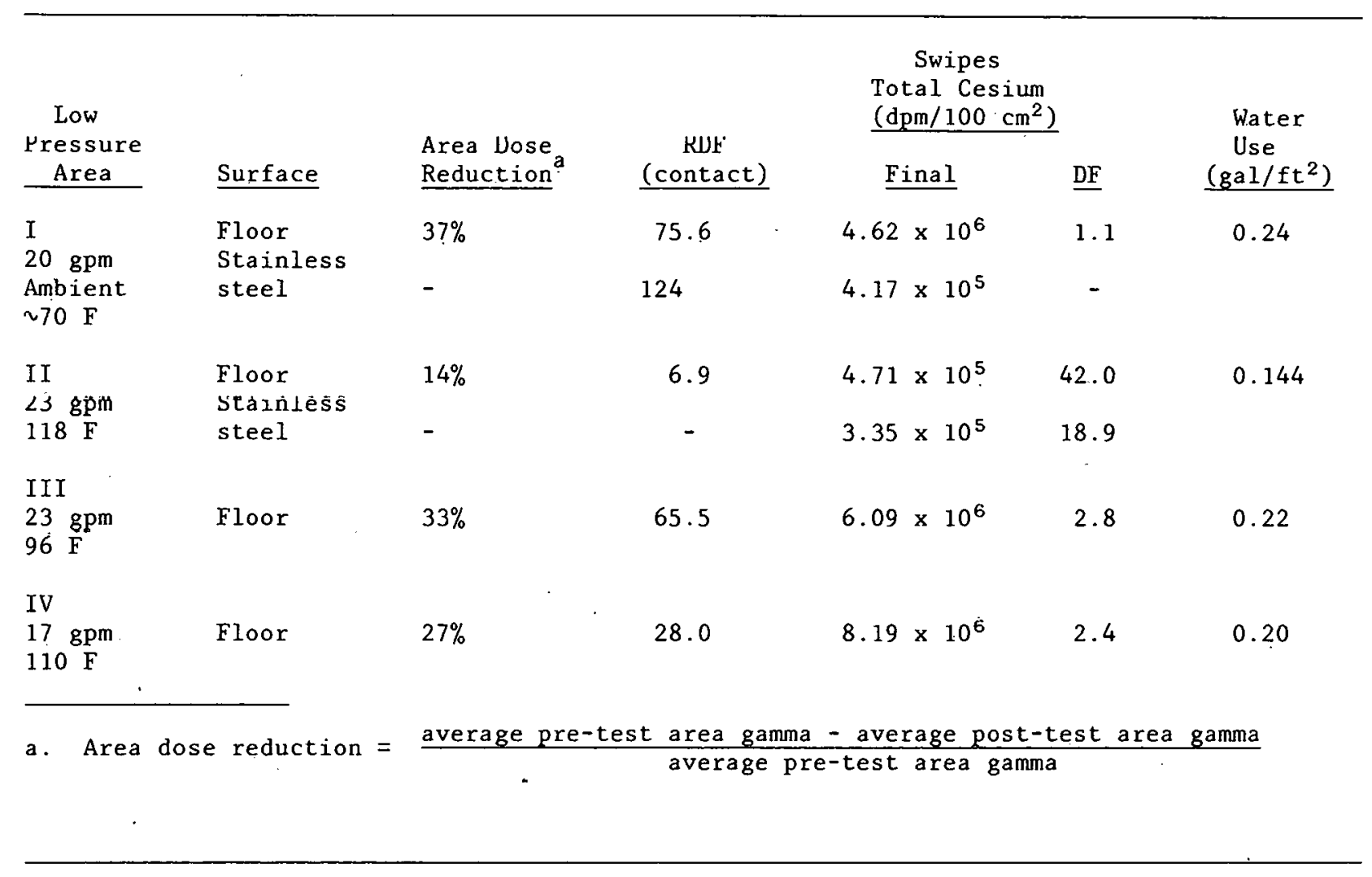


Contamination and Recontamination--The contamination on the various test areas on elevation $305^{\prime}$ was reduced and results varied in swipe DFs from 1.1 to 42 for floor surfaces. The best results recorded in total cesium were in Area II LP, with $4.7 \times 10^{5} \mathrm{dpm} / 100 \mathrm{~cm}^{2}$. Recontamination of sample point 23 occurred when crews walked over the spot continuously during entering and leaving the air lock to change air samples and shifts. Recontamination was also observed during the flushing effort when the lance water stream splattered from spraying angle iron support braces and equipment stands at close range.

Effectiveness of the Different Low Pressure Flush Techniques---The effectiveness between 17 and $22 \mathrm{gpm}$ did not appear to change during the test. If the water volume was too large for wet vacuum, the lower end of the flow rate range would be satisfactory.

Efficiency of the Low Pressure Techniques--The largest water use per square foot produced the highest contact DFs in the test areas. See Tables 2-2 and 2-3 for the specific results.

TABLE 2-3. ELEVATION 305: LOW PRESSURE FLUSH

\begin{tabular}{|c|c|c|c|}
\hline $\begin{array}{l}\text { Test } \\
\text { Area } \\
\end{array}$ & $\begin{array}{l}\text { Area } \\
\left(\mathrm{ft} \mathrm{t}^{2}\right) \\
\end{array}$ & $\begin{array}{c}\text { Water Used } \\
\text { (gal) } \\
\end{array}$ & $\begin{array}{r}\text { Water Use } \\
\left(\mathrm{gal} / \mathrm{ft}^{2}\right. \\
\end{array}$ \\
\hline $\mathrm{I}$ & 944 & 229 & 0.24 \\
\hline II & 4427 & 652 & 0.14 \\
\hline III & 532 & 120 & 0.23 \\
\hline IV & 469 & 96 & 0.20 \\
\hline Overheads & 23,174 & 1442 & 0.06 \\
\hline
\end{tabular}


General Summary of Low Pressure Flush of the Polar Crane

Technique Description. The low pressure flush of the polar crane was designed to:

- Determine airborne activity level changes as a result "of misting the polar crane, dome area, LOCA ducts, and horizontal crane surfaces.

- Determine the decontamination effectiveness of low pressure flushing on crane equipment and surfaces with various pressures and water tcmperatures.

- Decontaminate the polar crane, dome area, crane rails, girrers, surfaçe, and equipment.

o Determine the efficiency of the polar crane decontamination tests.

The polar crane low pressure flush was conducted during several entries. Not all of the pre-test data were acquired during the specified entry due to entry operational problems, and another entry had to be rescheduled. During the second entry, about 80 percent of the data collection requirements were completed. Flushing and misting of the crane were accomplished during two entries. The first entry occurred late in the day after the elevation $305^{\prime}$ low pressure flush. As a result, misting of the crane and some flushing of the dome were accomplished before the end of the workday. During the second entry the crane was flushed, completing the low pressure test. The post-test data acquisition task was attempted during three entries that started approximately 3 weeks after the crane tlush. 'l'he post-test data acquisition requirements were not completed, and recontamination of several of the crane surfaces occurred during crane recovery tasks before partial ( $~ .50$ percent.) post-test data acquisition was accomplished. See Figures 2-4, 2-5, and 2-6 for diagrams of the polar crane and dome area test parameters and data acquisition locations. 
Smearable Contamination Levels. The degree of smearable contamination at the beginning of the task varied from $1.1 \times 10^{7} \mathrm{dpm} / 100 \mathrm{~cm}^{2}$ to $2.9 \times 10^{4} \mathrm{dpm} /$ $100 \mathrm{~cm}^{2}$ of $\mathrm{Cs}-137$ on horizontal surfaces, and from $6.2 \times 10^{6} \mathrm{dpm} / 100 \mathrm{~cm}^{2}$ to $2.7 \times 10^{4} \mathrm{dpm} / 100 \mathrm{~cm}^{2}$ of $\mathrm{Cs}-137$ on vertical surfaces. Post-test results, where available, showed decontamination on vertical surfaces but recontamination on horizontal surfaces. Post-test horizontal surface contamination was in the same range as the pre-test data, and post-test vertical surfaces indicated swipe DFs from 2.55 to 1.72. See Appendix C for the raw data.

Degree of Uncertainty - Decontamination Effectiveness. Assessment of the decontamination effectiveness is uncertain for two reasons: (a) the data acquisition was insufficient and not timely to accurately record the results; (b) the crane surfaces were recontaminated by personnel traffic on the surfaces and by operational problems during the decontamination effort.

Waste Volume. Several problems with the rate of application and pressure for flushing activity on the crane reduced the amount of waste expected. The flush teams had problems with footing, flush pressure, and items to secure to; thereby reducing flush time from the total time available for the task.

Results - Expected Versus Actual. The test did not achieve the test objectives. The main reasons the task was not successfully completed were as foll. lows :

- Tlie Lask did not have sufficient reserve manpower qualified for crane work.

- The task was hurried to try to accomplish the test within a time frame that was imposed by remote reporter work schedules at TMI.

- Decunlamination and other tasks were given priority over data acquisition and test parameters. 
The crew members that attempted the task were the best trained of all the decontamination crews. However, they were not allowed to funclion to their capacity due to safety restrictions on their stay time on the crane (i.e., heat stress and safety line hookup rules).

Equipment and Techniques. The polar crane was decontaminated by standard low pressure flushing with a hydrolance. No new techniques were used or developed for the task.

Worker Kadiation Exposure. The wüiker exposurc for the low pressurc flushing of the crane was high compared to the surface arca and task performed. Multiple entries to accomplish this task resulted in higher exposures. The breakdown for the task is shown in Table 2-4. The actual man-rem associated with misting and flushing time averaged 310 mrem per individual.

TABLE 2-4. POLAR CRANE LOW PRESSURE FIUSH - SUMMARY OF WORKER EXPOSURE

\begin{tabular}{ccc}
\hline$\underline{\text { Task }}$ & $\underline{\text { Man-hours }}$ & Man-rem \\
Pre-test data & 11.56 & 1.350 \\
Misting - flushing & 16.69 & 2.027 \\
Post-test data & 10.37 & $\underline{1.202}$ \\
Total & 38.62 & 4.179 \\
\hline
\end{tabular}

Safety. Safety considerations were a major reason that this task required a much longer time than expected from training. Conservatism in safety rules applied to the crane task limited the time available for the work, and added 
personnel requirements and equipment. The task was accomplished safely; however, the results were impacted where the safety requirements increased the work time beyond that which was available for the task. There did not appear to be a method to moderate the safety versus risk assessment of the task until a later time in the experiment.

Worker Productivity. Three more entries were required for this task than had been planned. The worker productivity for this task was limited by the concern for heat stress, which had occurred during previous crane tasks. This limited individuals' total work time. Equipment problems and insufficient reserve manpower for the task did not allow efficient rotation of personnel throughout the task. During planning for data acquisition, the total task time required for pre- and post-test data acquisition was underestimated. Data acquisition needs contributed to the need for additional entries as much as personnel factors. GPU linemen, rad-con technicians, and contractor electricians were used for this task. The GPU linemen were the best trained and appeared to be in the best physical condition of all the personnel in the experiment. However, other GPU commitments did not allow them to return for additional entries. Since GPU personnel could not be teamed with contractor personnel due to union rules, the task was limited to available personnel.

Summary of Specific Results. The decontamination results of the low pressure flushing task of the polar crane were disappointing and not indicative of what can be accomplished by low pressure flushing on equipment and surfaces. However, the results were also revealing concerning safe, effective, and efficient decontamination of a large, complex reactor building.

Low Pressure Flush Parameters--The results of the polar crane task are shown in Tables $2-5$ and 2-6. Two crews of four (three flush crew members and a rad-con technician) were used in the misting and flushing operations. 
TABLE 2-5. SUMMARY OF LOW PRESSURE FLUSHING OF POLAR CRANE

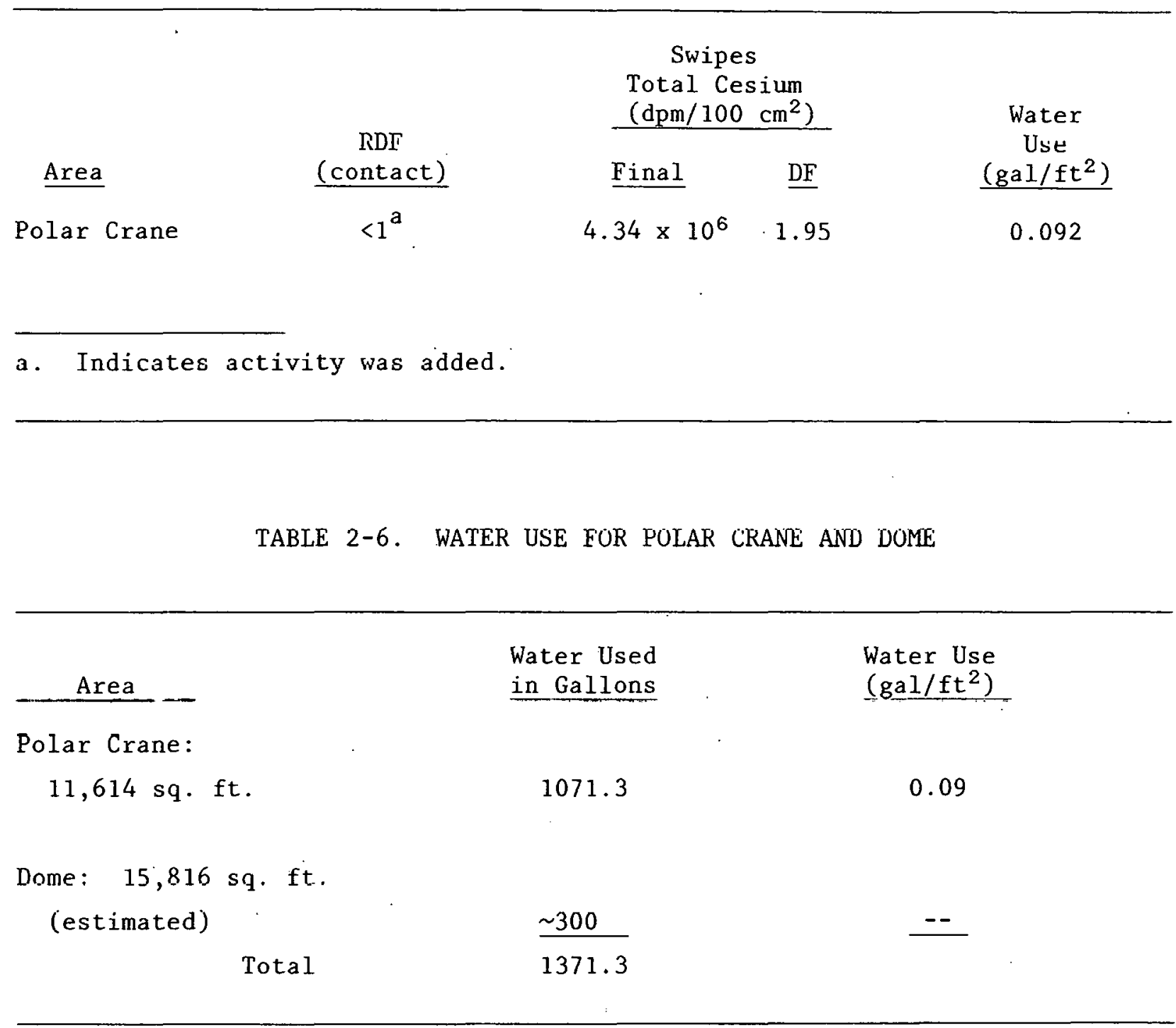

During the 1 hour and 27 minutes required for the task, 1375 gallons of water were used to mist and flush the dome and polar crane. The dome and crane area was approximately 27,000 square feet; for comparison, the elevation $305^{\prime}$ area is approximately 25 percent of that area. Similarly, the amount of water and time per square foot was vastly different between the elevation $305^{\prime}$ and crane areas, as the results indicate. 
Visual Results--Visual results observed by the flush crews were that the flushing did a good job of removing dirt and debris from the crane and dome areas. Observation from the closed circuit televisions (CCTV) revealed considerable dirt, debris, and paint chips from the dome falling to the lower levels. However, actual flushing operations could not be observed because of the location of the TV cameras. Photographs 3 through 7 show the pre-test conditions of the crane and the work areas for the crews. Post-test photographs were not taken, as these were part of the deleted data acquisition tasks.

\section{Radiation Changes--Area pre- and post-test radiation measurements} were not made at the same locations, so area dose rate reductions could not be calculated. Post-test area measurements along the walkways and girder A indicated approximately 100 mrem gamma. At the top of the rails, the measurement was 150 mrem. Where conlact gamma was reduced, it was reduced by 300 mrem (median). Contact beta reductions varied from 103 to $6700 \mathrm{mrem}$. Several locations indicated that both contact gamma and beta radiation readings increased.

Contamination and Recontamination--It appeared from CCTV results that the polar crane was recontaminated prior to the post-test measurements.

Several crew members crossed contaminated areas to the polar crane and then went across most of the walkways, girders, etc., before the post-test data acquisition was conducted. During debriefing, crew members indicated that there were a few surfacca of the crane that had not been flushed since the crew could not "see" or reach them with the lance.

Effectiveness of the Technique--The results of the crane low pressure flush are not indicative of the efficiency of low pressure flushing. There was not as much dirt and rubble on the surface of the polar crane as on the elevation $305^{\prime}$ or 3/17'-6" floors. There was oil, grease, and considerable corrosion and the crane does have a large percentage of vertical and angled surfaces. Debriefing results, visual observations, and radiation results indicate that a different technique should be used to decontaminate the polar 
crane. Appropriate spray nozzles, pressures, and flow rates should be selected to remove the oil, grease, and dirt on the various surfaces of the dome and crane. A variety of nozzles and pressures would be required because of the large variance in distances and surfaces present in the crane area.

\section{Efficiency of the Low Pressure Flush Technique--The water rate per} square foot for this task was extremely low for the total area. Insufficient water was placed on the dome and crane to remove the contamination.

General Summary of Low Pressure Flush of the D-Rings, Missile Shields, Canals, Reactor Head Service Sliulluie, and Rcfucling Britges

Technique Description. The low pressure flush of these areas was designed to accomplish the following:

- Determine the effectiveness of decontaminating the refueling equipment, canals, and service structures, with low pressure flushing at various temperatures.

- Decontaminate various surfaces and matcriale, including walkways, stairs, ladders, bicidges, and walls.

- Determine the advantages of misting the surfaces prior to flushing.

o Determine the radiation reduction as a result of the flushing opcration.

The low pressure flush of this area was conducted over a 2-day period, starting late in lhe atternoon aftur the low proscure flush of the polar crane. The pre-test data were taken before the low pressure flush of the polar crane. During the polar crane flush, debris was deposited on the surfaces of the missile shields, D-rings, and refueling canals, and had to be removed along with the debris and contamination already in place. The first flush effort for this task was on the top of the D-ring, and the rest of the task was completed 2 days later. The D-rings were flushed on top and down into the interior from 
elevation $367^{\prime}$. The refueling bridge, reactor head service structure (RHSS), and the shallow and deep refueling canals, were flushed from elevation 347' $-6^{\prime \prime}$ and the walkways along the refueling bridge. No flushing was accomplished physically down in the canals. Post-test decontamination data were taken the day after the completion of this task and the low pressure flush of elevation 347'-6". Deleted from the task in the scope change were the data points on the elevation 347'-6" floor associated with the D-ring task to determine recontamination, overspray, and deposited debris from the crane. Photographs 8, 9, 10, and 11 show the refueling bridge and walkways, the underside of the missile shields and D-ring walkway, the shallow end of the refueling canal, and the deep end of the refueling canal and RHSS, respectively. Figures 2-7, 2-8, and 2-9 show the data acquisition locations for the D-rings, missile shields, refueling canals, RHSS, and refueling bridges.

Smearable Contanination Levels. The levels of smearable contaminants associated with the task are shown in Table 2-7. The D-rings had contamination reductions of 68 percent in $\mathrm{Cs}-137$ and 96 percent in Sr-90. In the refueling canals, the deep end contained more contamination both before and after flushing than the shallow end. There was no reduction in Cs-137 in the deep end, and a 70 percent reduction in $\mathrm{Cs}-137$ and a 57 percent reduction in $\mathrm{Sr}-90$ in the shallow end of the canal. The fuel handling bridge had an increase of 23 percent in Cs-137 during the flushing operation.

Degree of Uncertaj.nty - Decontamination Effectiveness. The decontamination effcctiveness of this lask is uncertain because of the contamination and water deposited on the surfaces after the polar crane flush and the timing of the pre-test data acquisition task. The equipment provided "shadows" on some of the surfaces which required angle changes to obtain flushing of the entire surfaces. It is apparent that some areas were not flushed effectively because of equipment obstructions. 
TABLE 2-7. CONTAMINATION LEVELS OF D-RINGS, REFUELING CANAL, AND FUEL HANTJLING BRIDGE.

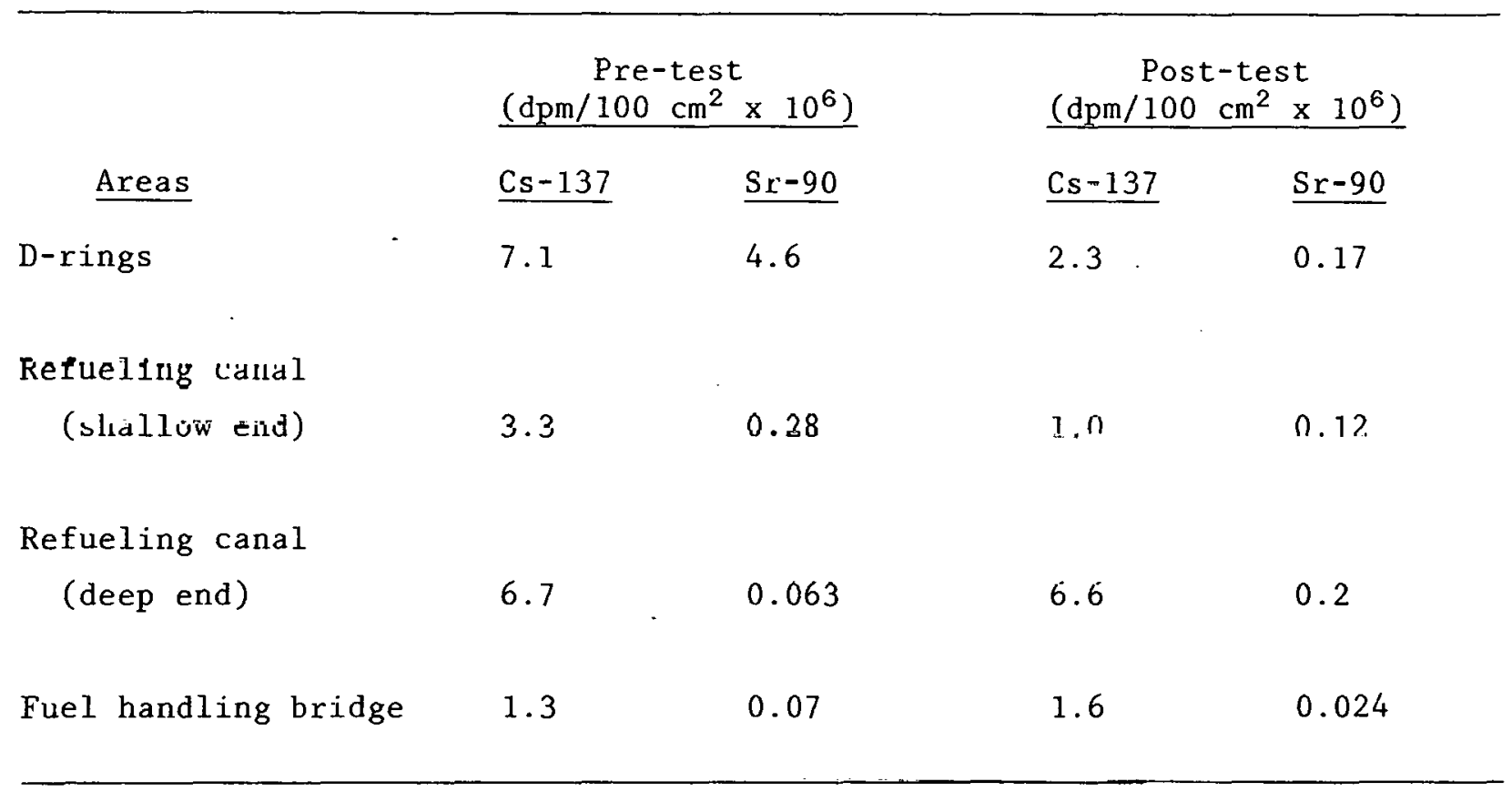

Wasle Vulume. Waste volume for thio tack was low compared to the tintal square footage of the area. Since this area contained a large percentage of vertical surfaces and run-down from spraying occurred, helping the deconlamination, it is understandable why the DFs were obtained with a low amount of water. Table 2-8 shows the results. 
TABLE 2-8. D-RINGS, REFUELING CANAL, MISSILE SHIELDS, AND FUEL HANDLING BRIDGE WATER RATES

\begin{tabular}{lccc}
\hline $\begin{array}{l}\text { Test } \\
\text { Area }\end{array}$ & $\begin{array}{c}\text { Area } \\
\left(\mathrm{ft}^{2}\right)\end{array}$ & $\begin{array}{c}\text { Water Used } \\
(\mathrm{gal})\end{array}$ & $\begin{array}{c}\text { Water Use } \\
\left(\mathrm{gal}_{\mathrm{ft}}{ }^{2}\right)\end{array}$ \\
Top of D-rings & 1169 & 294 & 0.25 \\
$\begin{array}{l}\text { D-ring walls } \\
\text { Refueling canal } \\
\text { (shallow end) }\end{array}$ & 13,100 & 316 & 0.024 \\
Refueling canal \\
$\begin{array}{l}\text { (deep end) } \\
\text { Fuel handling bridge }\end{array}$
\end{tabular}

Results - Expected Versus Actual. The results of the refueling canal produced the expected 50 percent reduction in dose rate in those areas where it was believed that the major source term was from the contamination. On top of the D-rings and areas associated with the top part of the RHSS, the reduction in dose rate was not as large because of other source terms. Contamination result.ts were expected to have a higher amount removed and a lower amount remaining on the surface than was achieved. The amount remaining would have been lower if the water and debris had been picked up with a vacuum or if the flushing had occurred at the refueling canal. floor level, which would have allowed the debris to be flushed into the drain rather than dry on the floor. Because debris was loosened from the surface but not effectively moved to the drain, higher floor contamination levels remained. 
Equipment and Techniques. The basic low pressure flush technique was used for the lask.

Worker Radiation Exposure. The man-hours associated with the entire task are given in Table 2-9.

TABLE 2-9. D-RINGS, MISSILE SHIELDS, AND REFUELING EQUIPMENT - SUMMARY OF WORKER EXPOSURE

\begin{tabular}{|c|c|c|}
\hline & Man-hours & Man-rem \\
\hline Pre-test data acquisition & 4.75 & 0.919 \\
\hline Post-test data acquisition & 4.91 & 0.980 \\
\hline Experiment operations & 15.56 & 2.353 \\
\hline
\end{tabular}

Safety. Safety planning for the task had several areas of concern. Special centerline lock harnesses were used by data acquisition personnel to climb in and out of the canals on the vertical ladders over 20 feet high. Keeping track of contaminated harnesses in the reactor building and their limited number caused some delay when equipment had to bè swapped inslde. Lhe reactor building. Heat stress, associated with the climbing and data taking task, aborted two tasks before the crews completed their assigmunts. Additional personnel and task time was spent completing the data requirements. Physical condition was important in the task, and the personnel were rotated to avoid similar incidents in the post-test data taking activities. The top of the walkways was slippery when wet, and when coupled with hydrolance operations, care had to be exercised on the operating pressure of the lance. A safety harness should be worn by flush operators working on the walkways where they can connect the harness to the railing. 
Worker Productivity. The flushing of the task area was conducted from the walkways, the top of the D-rings, and elevation 347'-6". Minimal climbing was required except for data acquisition, which required descents into the refueling canals. Worker rates for the canals, RHSS, and D-rings were as projected. The clothing requirements were the same as all other low pressure flushing tasks. This task could not be simulated or a mock-up built because of the variety and complexity of the equipment and areas; therefore, photographs and cutaways of the reactor building had been used for planning. Covering the area properly with water was a problem, and adjustments had to be made repeatedly from the command center. The task used remote reporters and a rad-con technician. The capabilities of these people were acceptable although the lack of physical endurance of some of the personnel caused some task delay.

Summary of Specific Results. The task demonstrated that the refueling canals, equipment, and surface areas could be successfully flushed to produce acceptable results. It showed vividly what large RDFs could be obtained from surfaces that had not been walked on and had debris ground into them. The task shows the different source terms, dose rate reductions, and type of surfaces that impact on decontamination results.

Low Pressure Flush Parameters--The results of the low pressure flush test on the D-rings, refueling canals, RHSS, and refueling bridges are shown in Table 2-10. The flushing task was conducted during two entries. The first part of the task was conducted late in the day and consisted of approximately 35 minutes of actual flushing of the top of the D-rings. The task was completed during the second entry, for a total of 2 hours and 12 minutes of flushing with 1378 gallons of water. The actual amount of man-rem for flushing was 2.125 . 
TABLE 2-10. SUMMARY OF RESULTS OF D-RING WALLS, CANALS, AND FUEL HANDLING BRIDGE

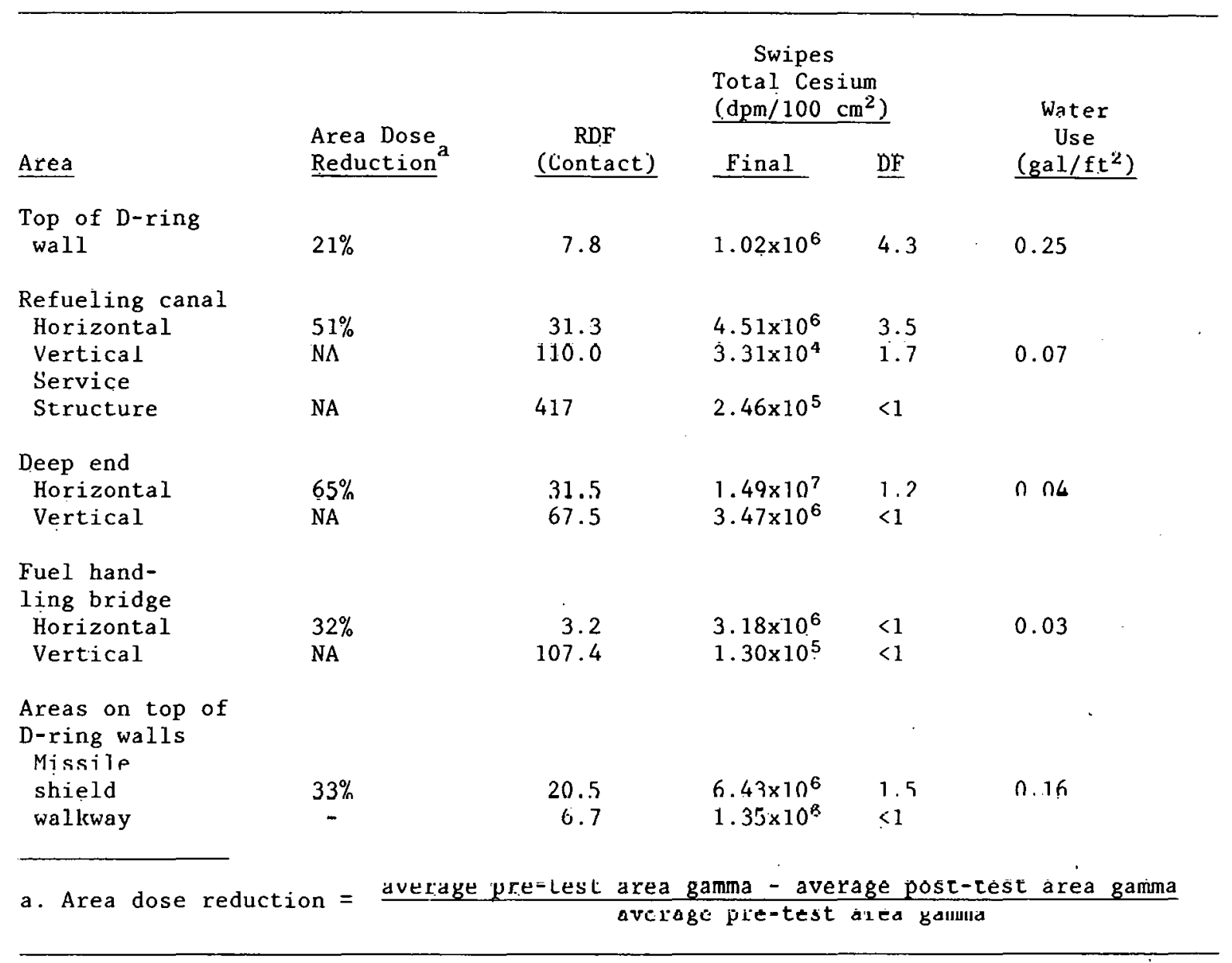


Visual Results--Visual results were limited by the CCTV location; only the walkways and top of the D-rings could be observed. The walkways, missile shields, top of the D-rings, and bridge were not as dirty as the elevation 347'-6" floor, but they did have surface debris from the crane task. Visual. observations by the flush crews indicated that dirt and debris were not visible on the walls or canal floor, except for crud piles and some dirt near the drains.

Radiation Changes--The low pressure flushing produced radiation changes in area dose rates; the largest reduction was in the deep end of the refueling canal, at 65 percent. The lowest area reduction was on top of the D-rings at 21 percent. This was anticipated because other sources, such as the $B D$-ring, had internal readings varying from 5 to 30 rem gamma, and the $A$ D-ring had lower readings. The median reductions are given in Table 2-11. Follow-on tasks in the refueling canal areas showed approximately a 50 percent or larger reduction in man-rem for comparable tasks and time. Had the refuelling canals been flushed from the floor, the area dose rate reduction would have been much greater.

TABLE 2-11. MEDIAN CONTACT RADIATION REDUCTION (differences in pre-test and post-test values)

\begin{tabular}{|c|c|c|}
\hline Area & Contact Gamma (mrem) & Contact Beta (mrem) \\
\hline D-ring & 70 & 2250 \\
\hline \multicolumn{3}{|l|}{ Refueling canal } \\
\hline (shallow end) & 110 & 1774 \\
\hline \multicolumn{3}{|l|}{ Refueling canal } \\
\hline (deep end) & 58 & 1054 \\
\hline Fuel handling bridge & 35 & 724 \\
\hline
\end{tabular}


Contamination. and Recontamination--The post-test contamination revealed low DFs for swipe samples. It appeared that the contamination was moved from the large vertical surfaces to the horizontal surfaces; however, the flushing was not as successful in moving the debris to the drains because of the long distance from the floor to the flush teams. Thus, the contamination was left on the floor and between equipment sections. Had the crews flushed from the lower sections and the floor, the debris would have been moved to the drains.

Fiffertiveness of the Terhniques--The low pressure flushing of stainless steel will produce excellent KUls for contact readings on vertical surtaces and substantial area dose reduction. For low pressure flushing on horizontal surfaces, it is possible to obtain the same contamination levels $\left(10^{4} \mathrm{dpm} / 100\right.$ $\mathrm{cm}^{2}$ of $\mathrm{Cs}-137$ ) as the vertical surfaces when the flush is properly executed and the floors are flushed to move contamination and dirt to the drains. If the surfaces can be flushed before traffic is allowed on the surface, the decontamination of surfaces should be effective and easily obtained. Flush pressure of 500 to $1000 \mathrm{psi}$ at 20 to $25 \mathrm{gpm}$ appears to be optimum from the analysis and visual results.

Efficiency of the Techniques--The low pressure flush of the refueling equipment used both hot and ambient water at $22 \mathrm{gpm}$, except for a few brief periods of reduced flow and pressure on the deep end of the canal. Some flush crew members were not large enough in stature to control the lance adequately at the pressure and flow rates required. As a result of this and the observed lack of physical endurance of the crew members, the pressure and flow rates were reduced. As a result, excessive rotation of the flush operator position took place, which increased the flush time and reduced the effectiveness of the task. In addition, when crew members switched to the lance operator position, they lost track of what had been flushed, what had to be reflushed, and what remained to be cleaned. Warmer water appeared to produce better visual and data results in the shallow end of the canal. 
Technique Description. The low pressure flushing of elevation 347'-6" was designed to:

- Determine the effectiveness of various combinations of flow rates and temperatures on floor, walls, equipment, and other surfaces

- Determine the efficiencies of the low pressure flush combinations

- Determine airborne activity changes due to flushing activity

- Determine the quantity of waste generated

- Determine the radiation reductions as a result of the flushing operation

- Decontaminate the elevation $347^{\prime}-6^{\prime \prime}$ area

- Evaluate the sequence of decontamination for the vertical, horizontal, and overhead surfaces

The low pressure flushing of the elevation 347'-6" floor and equipment took place in conjunction with and continued after the low pressure flushing of the $D=$ rings, missile shields, refueling canal, RHSS, and refueling bridge.

Figures 2-10 and 2-11 show the planned and actual test areas and parameters for the low pressure flushing of the elevation floor and equipment. The flushing removed a great deal of construction dirt and debris, and some of this dirt had to be shoveled into bags for waste removal. Spraying vertical surfaces, such as the liner and outside D-ring walls, 10 feet above the floor was removed from the scope of work and was not accomplished. 
Smearable Contamination Levels. The pre-test contamination levels averaged $7.1 \times 10^{6} \mathrm{dpm} / 100 \mathrm{~cm}^{2}$ of $\mathrm{Cs}-137$. No post-test low-pressure flushing smearable contamination levels were measured except in the area of the mechanical scrubber test, where one $8 \times 20$ foot area was not high pressure sprayed. The average smearable contamination reading was $1.5 \times 10^{5} \mathrm{dpm} / 100 \mathrm{~cm}^{2}$ in that area. The RHSS was also low pressure flushed only because the strippable coating was to be applied to its surface instead of its being high pressure sprayed. The average smearable contamination on the RHSS after low pressure flushing was $7.1 \times 10^{4} \mathrm{dpm} / 100 \mathrm{~cm}^{2}$ for Cs-137. However, after the high pressure spray on the elevation $347^{\prime}-6^{\prime \prime}$ floor but before the application of the strippable coating, the readings were $2.44 \times 10^{\mathrm{G}} \mathrm{dpm} / 100 \mathrm{~cm}^{2}$. I'his indicates a high level of recontamination from high pressure activities on the floor near the equipment.

Degree of Uncertainty - Decontamination Effectiveness. The data acquisition for the low pressure flushing of elevation 347'-6" was made during entry 43, along with the data acquisition task for the rest of the elevations. The polar crane had been flushed with the dome, and contamination, water, and debris were deposited on elevation 347'-6" after the initial elevation 347'-6" pre-test data were taken for low pressure flushing. Both the part of the post-test data acquisition task for the polar crane which had sample points on the elevation 347'-6" surface, and the post-test data acquisition for the low pressure flushing, were deleted from the scope of work so more decontamination tasks could be accomplished. As a result, the amount of contamination deposited on the elevation 347'-6" floor from the crane could not be determined, and only some isolated points in one test area were available for analysis of low pressure flushing.

Waste Volume. The low pressure tlushing Lask used 14/3 gallons of water during its sequences. Besides flushing liquid waste, crews had to shovel dirt and debris into bags and bring them out as solid waste. In confined spaces, the water was unable to move the dirt to the drains. As a result, the low pressure flushing had to be suspended while large dirt piles were removed and 


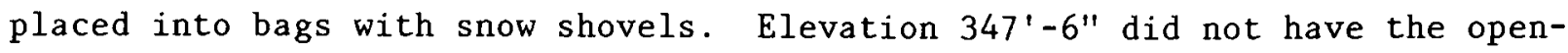
ings, floor penetrations, or other areas to dispose of the debris into the sump or basement level as were common on elevation $305^{\prime}$. The amount of water used was within 5 percent of what had been estimated for the task in the waste management plan.

Results - Expected versus Actual. The low pressure results were not measured after the task was completed. Some reduction in man-rem for later tasks was observed on elevation $347^{\prime}-6^{\prime \prime}$.

Equipment and Techniques. The standard low pressure flushing techniques were used for the task. New equipment included:

- Plastic snow shovels

- Plastic children's sand shovels

- Denim laundry bags and holders

- Stainless steel meter sticks for 1-meter measurements.

The laundry bags were filled with dirt and debris and placed over drains. Water was sprayed into the bags to bring the dose rate down below a requirement of a 2-rem contact reading for each bag.

Worker Radiation Exposure. The worker exposure during the low pressure flushing test was 1.764 man-rem. Table 2-12 shows the exposure for each part of the task. 
TABLE 2-12. ELEVATION 347'-6" LOW PRESSURE FLUSH - SUMMARY OF WORKF:R FXPOSIIRF.

\begin{tabular}{lcc}
\hline \multicolumn{1}{c}{ Task } & $\frac{\text { Man-hours }}{4.47}$ & $\frac{\text { Man-rem }}{2}$ \\
Pre-test data acquisition & 4.813 \\
Low pressure flushing & & \\
of elevation $347^{\prime}-6^{\prime \prime}$ & 6.15 & 0.951 \\
\hline
\end{tabular}

Safety. There were no specific comments on safety-related items for this task.

Worker Productivity. Worker productivity was hampered by the protective clothing requirements for the task. Heat stress and fatigue were the major limiting task length factors, rather than dose rate, on elevation 347'-6". The long hydrolance used was designed to prevent an operator from "shooting" himself with it. Safety, however, required foot and shin guards for operators using the hydrolance. It appeared at times that these guards were more of a tripping hazard than a protection. The rate of application of the low pressure flushing was not uniform during the task. It was evident in the videotapes that some lance operators did an outstanding job in the flushing task but others did not. The problem appeared to be a deficiency in the training for the operators. In one case, however, an attempt was made to hurry the crews to finish the task and leave the reactor building. Apprehension was very noticeable during data acquisition for elevation 347'-6". Some of the samples had to be retaken because of worker fear of high radiation exposure, which caused inattention to readings and procedures. Remote reporters and rad-con technicians were both used for this task. 
Summary of Specific Results.

Low Pressure Flush Parameters--The low pressure flushing test on elevation 347'-6" used 1475 gallons of water in 2 hours and 3 minutes of flushing. Three crews of three men each were used for the flushing task. A total of 19 man-hours and 3.197 man-rem was charged to this task. The data acquisition sample points are shown in Figure 2-12.

Visual Results--The visual results of elevation 347'-6" showed that dirt and debris were moved by the water. There was some striping of the floor by the low pressure.water, but it was minimal compared to the striping of elevation 305'. The storage, equipment areas, and floors were washed and the water ran out from under the storage onto the floors after the teams had flushed them.

Radiation Changes--A post-test data survey was not conducted after. the low pressure flushing. The only indications of radiation changes were the periodic digital dosimeter readings for the crew members during subsequent tasks on elevation 347'-6". From these readings, dose rates appeared to have decreased since the flushing operations.

Contamination and Recontamination--The contamination control for this task consisted of controlling the sequence and direction of the flushing. Problems were caused as the rad-con technicians were going from the air lock to and from the flushing areas to change the air sampler during the task. They walked from highly contaminated areas through the decontamination operations area to "cleaned" areas to obtain air samples and then returned over the same route. As a result, contamination control was ineffective. Recontamination was evident in this tracking of people, both on videotape and when evaluating the areas where there had been traffic. 
Effectiveness of the Different Low Pressure Flushing Techniques--Data were not taken to evaluate the differences among the techniques used during the low pressure flushing on elevation $347^{\prime}-6^{\prime \prime}$.

Efficiency of the Low Pressure Flush Techniques--There was a difference in the efficiency of the personnel who flushed elevation $347^{\prime}-6^{\prime \prime}$, but the efficiency among the techniques could not be evaluated. Table 2-13 shows the flush rate in gallons per square foot. In the experiment, it was apparent that a water rate below 0.10 gallon per square foot was ineffertive in decontamination except for vcrtical surfaces,

TABLE 2-13. ELEVATION $347^{\prime}-6^{\prime \prime}$ LOW PRESSURE. FTUSSH

\begin{tabular}{lccc}
\hline $\begin{array}{c}\text { Test } \\
\text { Area }\end{array}$ & $\begin{array}{c}\text { Area } \\
\left(\mathrm{ft}^{2}\right)\end{array}$ & $\begin{array}{c}\text { Water Ised } \\
(\mathrm{gal})\end{array}$ & $\begin{array}{c}\text { Water Use } \\
\left(\mathrm{gal} / \mathrm{ft}^{2}\right)\end{array}$ \\
$\mathrm{V}$ & 1282 & 208 & 0.16 \\
$\mathrm{IV}$ & 5507 & 77 & 0.14 \\
VII & 464 & 221 & 0.48 \\
VIII & 1143 &. & 0.24 \\
\hline
\end{tabular}


High Pressure Flush Activity

General Summary of High Pressure Flush of Elevation $347^{\prime}-6^{\prime \prime}$

Technique Description. The high pressure flush of elevation 347'-6" was designed to:

- Determine the effectiveness and efficiency of high pressure water spraying of major equipment of different types, material composition, and coatings.

- Determine the effectiveness of various high pressures, temperatures, and flow rates on horizontal and vertical surfaces as well as on all types of equipment.

o Decontaminate the elevation $347^{\prime}-6^{\prime \prime}$ floor and major equipment.

- Determine the airborne concentrations associated with high pressure spraying.

o Determine the radiation reductions from high pressure spraying.

- Determine recontamination resulting from further decontamination operations.

The high pressure flushing on elevation $347^{\prime}-6^{\prime \prime}$ started during entry 47 with high pressure spraying of the equipment. The following day, during entry 48, high pressure spin jet cleaning of the floor was completed. Post-test data acquisition for the flushing activity occurred 3 days later during entry 49. Some adjustments were made in the test areas due to operational considerations. 
High pressure spray consisted of spraying with a hydrolance at approximately 2600 to $3200 \mathrm{psi}$ and at $7.5 \mathrm{gpm}$ on the following equipment:

o Stairwell No. 1

- Seal ring

- Reactor coolant pump motor stand

- Reactor coolant pump motor alignment stand

- Internals indexing fixlure

- East and west LOCA ducts

o Cable tray rack in Area I HP.

The high pressure water scrub of the floor on elevation 347'-6" consisted of operating the water scrubber at various pressures, temperatures, and flow rates on concrete floors, diamond plate, and grating. This was followed by a low pressure flush to move into the drain system the debris loosened from the floor by the water scrubber. The wall areas 2 to 4 feet above the floors were flushed to remove splatter by the scrubher. See Figures 2-13 and 2-14 for the planned and actual test areas and parameters. Figure 2-12 shows data acquisition sample points.

Smearable Contamination Levels. The average levels of contamination . $\left(\mathrm{dpm} / 100 \mathrm{~cm}^{2}\right.$ of $\left.\mathrm{Cs}-137\right)$ for elevation $347^{\prime}-6^{\prime \prime}$ are shown in Table $2-14$. 
TABLE 2-14. CONTAMINATION LEVELS OF ELEVATION $347^{\prime}-6^{\prime \prime}$

\begin{tabular}{|c|c|c|c|}
\hline Surface & $\begin{array}{l}\text { Pre-test } \mathrm{Cs}-137 \\
\left(\mathrm{dpm} / 100 \mathrm{~cm}^{2}\right)\end{array}$ & $\begin{array}{l}\text { Post-test Cs-137 } \\
\quad\left(\mathrm{dpm} / 100 \mathrm{~cm}^{2}\right) \\
\end{array}$ & Tests $^{\mathrm{a}}$ \\
\hline Concrete floor & $7.1 \times 10^{6}$ & $4.2 \times 10^{5}$ & $\mathrm{LP} / \mathrm{HP}$ \\
\hline Diamond plate & $3.85 \times 10^{6}$ & $3.21 \times 10^{5}$ & $\mathrm{LP} / \mathrm{HP}$ \\
\hline \multicolumn{4}{|l|}{ Equipment } \\
\hline Index fixturc & $1.57 \times 10^{5}$ & $2.44 \times 10^{4}$ & $\mathrm{LP} / \mathrm{HP}$ \\
\hline LOCA ducts & $3.09 \times 10^{5}$ & $9.2 \times 10^{4}$ & $\mathrm{LP} / \mathrm{HP}$ \\
\hline Cable trays & $1.73 \times 10^{7}$ & $2.39 \times 10^{4}$ & $\mathrm{LP} / \mathrm{HP}$ \\
\hline RC pump motor stand & $6.61 \times 10^{6}$ & $5.02 \times 10^{5}$ & $\mathrm{LP} / \mathrm{HP}$ \\
\hline RC pump alignment stand & $6.34 \times 10^{6}$ & $6.32 \times 10^{6}$ & $\mathrm{LP} / \mathrm{HP}$ \\
\hline RHSS & $1.11 \times 10^{5}$ & $8.08 \times 10^{4}$ & LP only \\
\hline RHSS & $1.25 \times 10^{6}$ & $2.36 \times 10^{4}$ & LP and strip coat \\
\hline
\end{tabular}

a. LP = Low pressure flushing, $H P=$ High pressure flushing.

During the low pressure/high pressure effort on elevation $34^{\prime}-6^{\prime \prime}$, Cs-137 was reduced 94 percent and Sr-90 was reduced 92 percent. Data representing all test points and areas show no discernable differences. in the cesium/strontium ratios before and after the test.

Degree of Uncertainty - Decontamination Effectiveness. It was concluded from an examination of the videotapes, photographs, and data taken before the low pressure test and after the high pressure test that high pressure flushing alone of the surfaces on elevation 347'-6" would have produced the post-test high pressure readings. Surfaces of special test areas that were high pressured sprayed only produced test results equal to or greater than the low pressure flush. After examining the videotapes and debriefings and determining that the high pressure spraying had marked visual results on the floor surface, 
it was reaffirmed that the high pressure flushing alone on the surfaces would produce the results attained by both the low and high pressure spray. Sample points were removed from the analysis of the high pressure test in various areas where the water scrubber could not be operated. (Area IX HP was the exception since only the lance was used for that area. See Photograph 12 for Area IX.) As a result, the $4000 \mathrm{psi}, 15 \mathrm{gpm}$ test results in Area IX.for the water floor scrubber were not determined, even though they were considered critical to the test data. Visual observations of the test noted recontamination of sample points by personnel traffic; this was taken into consideration in the results of individual tests.

Waste Volume. Tables 2-15 and 2-16 rcflcct the specifics for the amount of liquid waste generated during the high pressure spray of the equipment and the water floor scrubber cleaning of the floor surfaces. The 2157.1 gallons were within a small percentage of what had been estimated for the task.

Results - Expected Versus Actual. The results of the high pressure spraying on the equipment on elevation 347'-6" showed which tests were effective and which tests were not appropriate or would cause problems. Initially, some of the high pressure cest results were disappointing; however, with dn understanding of what really took place (recontamination, contributing radiation sources, ineffective procedures, or inappropriate techniques), the lest results indicate which high pressure techniques were effective. The best technique produced the expected decontamination results; recontamination by technique and personnel traffic was not expected to be as large as it was in total $\mathrm{dpm} / 100 \mathrm{~cm}^{2}$ for some of the tests.

Equipment and Techniques. The equipment used during the tests included:

o The water floor:scrubber with four rotating nozzles and equipped with three sets of various flushing nozzles. (0-, 15-, and

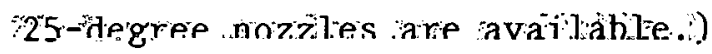


TABLE 2-15. ELEVATION 347'-6" HIGH PRESSURE FLUSH WATER USE

\begin{tabular}{lccc}
\hline $\begin{array}{l}\text { Test } \\
\text { Area }\end{array}$ & $\begin{array}{c}\text { Area } \\
\left(\mathrm{ft}^{2}\right)\end{array}$ & $\begin{array}{c}\text { Water Used } \\
(\mathrm{gal})\end{array}$ & $\begin{array}{c}\text { Water Use } \\
\left(\mathrm{gal} / \mathrm{ft}^{2}\right)\end{array}$ \\
I & 646 & 182.3 & 0.28 \\
II & 337 & 104.1 & 0.31 \\
III & 299 & 164.3 & 0.55 \\
IV & 1167 & 121.3 & 0.10 \\
V & 2251 & 519.2 & 0.23 \\
VI & 839 & 355.1 & 0.42 \\
VII & 465 & 121.3 & 0.26 \\
VIII & 296 & 190.6 & 0.64 \\
IX & 618 & 130.5 & 0.21
\end{tabular}

TABLE 2-16. ELEVATION 347'-6" EQUIPMENT HIGH PRESSURE FLUSH WATER USE

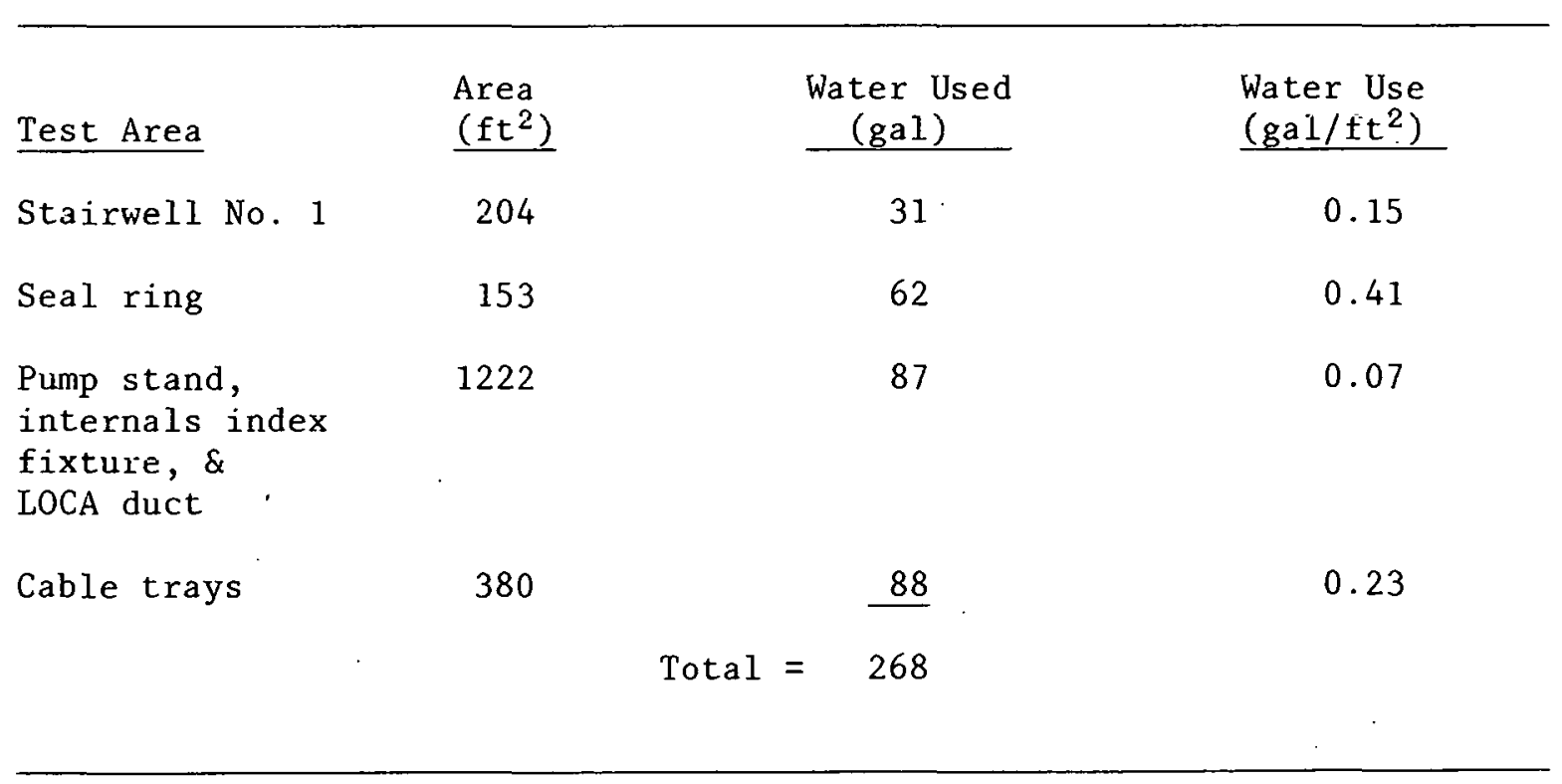


- The hydrolance with a high pressure spray tip for. cleaning the debris removed by the spin jet.

The standard technique was used for high pressure spraying. The water floor scrubber had adapters placed on the nozzle holders to facilitate removal, and the lance was modified to allow quick changing of the various nozzles used during the tests. The test results showed that the 25-degree nozzle was not optimum for the scrubber and was removed from further testing because it produced more overspray and did not cut into the paint as well as the 15-degree nozzle. The 0-degree nozzle at $6000 \mathrm{psi}$ would remove the paint from the concrete; theretore, it was not used in the reactor bullding. (line 15 -degree nozzle was substituted for the 25-degree nozzle during the elevation 305' high pressure test.) The procedure for flushing after the water scrubber operation was inadequate for some of the test areas because of insufficient test pressure and application techniques. As a result, material loosened from the floor surface by the water floor scrubber was not moved by the flush water into the drains, but remained in small crud piles or as a film on the test area.

Worker Radiation Exposure. The worker exposure for the high pressure spray of elevation $347^{\prime}-6^{\prime \prime}$ is shown in Table $2-17$.

TABLE 2-17. ELEVATION 347'-6" HIGH PRESSURE FLUSH - SIMMARY OF WORKER EXPOSURE

\begin{tabular}{ccc}
\hline Task & Man-hours & Man-rem. \\
Pre-test data: acquisition & 12.96 & 2.318 \\
High' pressure spray & 30.16 & 4.413. \\
Poste-test? dàta: acquisition & $6: 19:$ & 0.898 \\
\hline
\end{tabular}


Safety. A safety "hold" occurred during the entry for high pressure spraying. A procedural problem on personnel restraints near the open grating had not been discussed prior to the entry, and several man-hours were lost during the entry to resolve the issue. This inflated the total hours for the experiment.

Worker Productivity. The worker productivity varied from 600 square feet per hour, for a surface with a lot of equipment and floor obstructions, to over 1600 square feet per hour. It was concluded that approximately 1000 square feet per hour should be used for planning purposes for successful high pressure spin jet operations. Productivity improved as water floor scrubber experience was gained in the reactor building. Personnel who were small in stature and those not physically fit had problems with maneuvering the 250-pound water floor scrubber and tired quickly.

\section{Summary of Specific Results.}

High Pressure Flush Parameters--High pressure flush of the equipment on elevation $347^{\prime}-6^{\prime \prime}$ used 268 gallons of water in 43 minutes of actual flushing. It had been planned that several pressures, temperatures, and flow rates were to be used on the hydrolance operations. The temperature was varied, but the flush crews could not control the hydrolance at pressures higher than 3000 psi. When the pressure was reduced, it was not effective because the distance was too far from the nozzle tip to the equipment surface. The pressure was increased slightly during the test on the equipment, but the 4000 and 6000 psi tests with the hydrolance were not accomplished. The test could have been completed and all parameters could have been tested had sufficient personnel been available to allow persons of large stature ( $>250$ pounds) to be selected for the task. In addition to low pressures, the horizontal and vertical surfaces above head height were not satisfactorily sprayed because necessary high reach equipment was unavailabile. Post-test data samples were taken on horizontal surfaces that had not been adequately sprayed (see Photograph 13). Because the drain by the east LOCA duct plugged, the test on that duct was discontinued, and the duct was not effectively sprayed. The cable trays and 
vertical surfaces, which were exceptions to the equipment spray task, were sprayed effectively with 3000 to 3200 psi.(see Photograph 14 for vertical surfaces).. The water floor scrubber task used 1889 gallons in 3 hours and 37 minutes. Pressures of 2000,4000 , and $6000 \mathrm{psi}$ were used at 5, 15, and $25 \mathrm{gpm}$ at ambient and hot water (101 $\mathrm{F}$ average). Approximately 50 percent of the task was not observed on the CCTV because of camera problems. The crews failed to notify the command center when they finished the Area IV HP, and did not change the nozzles on the water scrubber to obtain $25 \mathrm{gpm}$ for Area $V$. As a result, Area $V$ scrubbing had to be repeated. Several sample points were not considered during analysis because the water scrubber would not tit in the area or was not used on the surface. Photographs 15 and 16 show highly congested areas where the scrubber could not be used. The floor area that was decontaminated the most effectively. had the most gallons used per square foot of surface area. (See Tables 2-15 and 2-18).

Visual: Results--Visual results of the color changes of the floor surfaces indicated that the water floor scrubber was more effective at higher pressures than lower pressures (see Photograph 17). At high pressures and high flow rates, a vapor cloud was observed around the machine. It was also noticed during the operation that flushing atter the scrubber did not spray high enough on the walls and equipment to effectively remove the debris and contamination from the floor cleaning operations. Recontamination of the equipment on elevation 347'-6" was evident during the operation. Poor flushing techniques and test pressures too low for flushing the debris loosened from the floor by the scrubber were observed in some of the locations on elevation. 347'-6". The smearable results went below $1.0^{5} \mathrm{dpm} / 100 \mathrm{~cm}^{2}$ of cesium only where concentrated effort was made to clean and prevent recontamination after the water floor ocrubber operation. 
TABLE 2-18. SUMMARY OF RESULTS OF ELEVATION 347'-6" FLOOR HIGH PRESSURE FLUSH

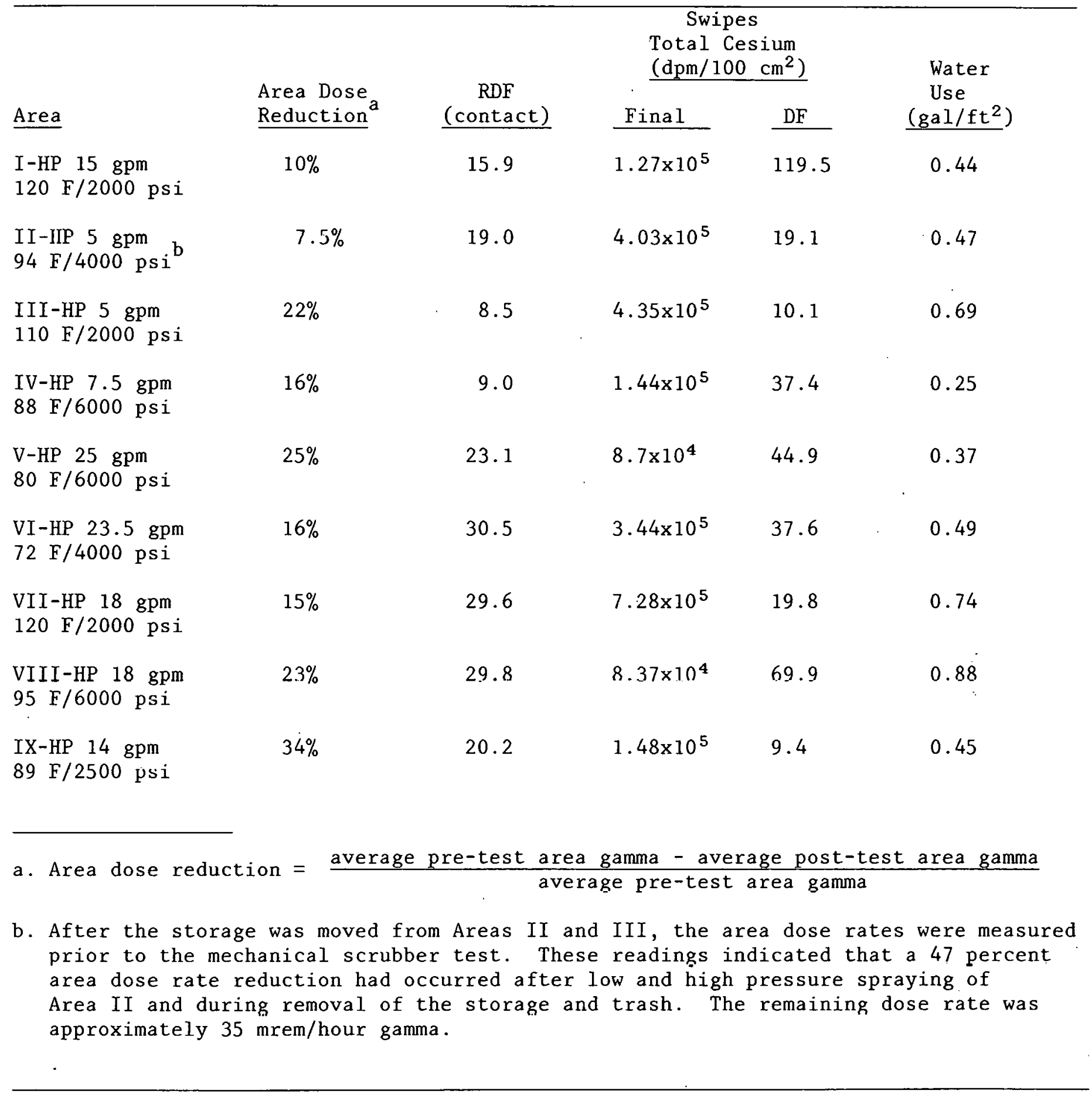


Radiation Changes--The radiation changes in the area where the technique was judged most effective and optimum were:

$\begin{array}{lr}\text { Area gamma } & 20 \mathrm{mrem} \quad \text { (an average of } 50 \mathrm{mrem} \text { remaining) } \\ \text { Contact gamma } & 130 \mathrm{mrem} \\ \text { Contact beta } & 2086.5 \mathrm{mrem}\end{array}$

The cable trays had the largest changes in contact readings for the equipment decontamination. See Table 2-19 for the results.

Contamination and Recontamination--Contamination wac evident in the high pressure and high flow rate tests. The established flush procedures did not do the job in minimizing the recontamination. There was insufficient detail in the procedures for the crews to recognize recontamination and inadequate guidance to increase the flush area where necessary. Contamination. was not removed in several locations because the test pressure, water rate, or application rate was insufficient to be effective. In addition, personnel changing air samples traveled to the test areas several times through highly contaminated areas during the cleaning post-test data acquisition operations.

Effectivenec of the Tcchniquec--In the combination of low preceure and high pressure flush, where it was assumed that the high pressure was the major technique, $6000 \mathrm{psi}$ at $18 \mathrm{gpm}$ gave the best results (see Table 2-18).

Efficiency of the Techniques--The higher pressure with the optimum flow rate of $18 \mathrm{gpm}$ appeared to give the best DF with the least amount of waste and recontamination. The operation was most efficient when the pressure could be increased, the flow rate reduced, and the application rate decreased. 
TABLE 2-19. SUMMARY OF RESULTS OF ELEVATION 347'-6" EQUIPMENT HIGH PRESSURE FLUSH

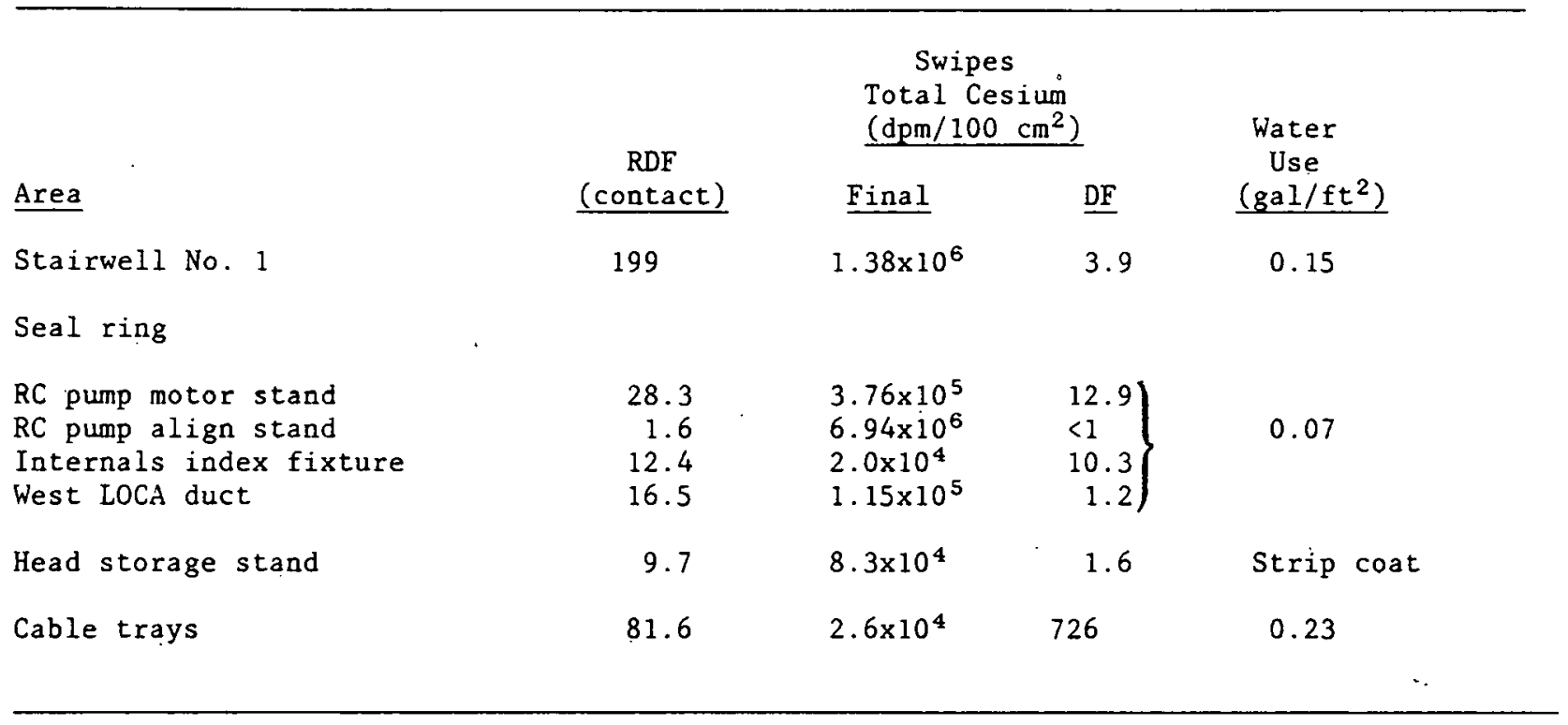


General Summary of High Pressure Flush of Elevation 305'

Technique Description. The high pressure flush of elevation $305^{\prime}$ was designed to:

- Determine the effectiveness of high pressure spin jet opcrations at various pressures, flow rates, and temperatures on the elevation $305^{\prime}$ floor and wall surfaces

- Determine the effectiveness of the various decontamination techniques

- Determine the airborne activity changes as a result of operations

- Determine the effectiveness of high pressure spraying on surfaces previously decontaminated during the large-scale decontamination test conducted in 1981

- Determine man-rem, productivity of workers, safety of operations, and waste generated during the test.

The high pressure spraying on elevation $305^{\prime}$ occurred during entry 50 . During this entry, a storage area on elevation $347^{\prime}-6^{\prime \prime}$, the open stairwell connecting elevation $347^{\prime}-6^{\prime \prime}$ with elevation $305^{\prime}$, and elevation $305^{\prime}$ ' were decontaminated.

l'he Low pressure flushing of the stairwell, which had caken place a few minutes before the high pressure water floor scrubber operations on elevation 305', dumped the water, contamination, and debris from the stairwell onto elevation 305' Areas XII and ISC. The operations plan on elevation $305^{\prime}$ was to spray Areas X, XI, and XII, in that order. However, since the hoses were already in Area XII, the operational decision was made to start in Area XII and flush counterclockwise. Figures 2-15 and 2-16 show the planned and actual test parameters. Refer to Figure 2-3 for data acquisition sample points. 
Smearable Contamination Levels. The average levels of smearable contamination $\left(\mathrm{dpm} / 100 \mathrm{~cm}^{2}\right.$ of $\left.\mathrm{Cs}-137\right)$ for the elevation $305^{\prime}$ floor were $9.7 \times 10^{6}$ (pre-test) and $6.1 \times 10^{5}$ (post-test). The reductions in smearable contamination were 83 percent for $\mathrm{Cs}-137$ and 90 percent for $\mathrm{Sr}-90$ from the low pressure flush.

Degree of Uncertainty - Decontamination Effectiveness. The level of contamination on the floor after the low pressure flush is known, but the level of floor contamination at the start of the high pressure test is not known. After the post-test data acquisition had been conducted for the low pressure elevation 305' flushing, the flushing of the elevation 305' walls and overheads, elevation $347^{\prime}-6^{\prime \prime}$ floor (debris came down through the floor grating), and the open stairwell deposited debris on the elevation $305^{\prime}$ floor. As a result, after the high pressure test, radiation readings and contamination of some areas exceeded the values from the post-test low pressure flushing. The flushing to move the debris, loosened from the floor, by the water floor scrubber was unsatisfactory because the wrong nozzle and flow rate for the test were used. Thus, the test was not considered representative of the technique.

Waste Volumes. Table 2-20 shows the waste volume for the high pressure test on elevation $305^{\prime}$.

TABLE 2-20. ELEVATION 305' HIGH PRESSURE FLUSH WATER USE

\begin{tabular}{lrcc}
\hline $\begin{array}{l}\text { High Pres } \\
\text { sure Area }\end{array}$ & $\begin{array}{c}\text { Area } \\
(\mathrm{ft})\end{array}$ & $\begin{array}{c}\text { Water Used } \\
(\mathrm{gal})\end{array}$ & $\begin{array}{c}\text { Water Use } \\
\left(\mathrm{gal} / \mathrm{ft}^{2}\right)\end{array}$ \\
\cline { 1 - 2 } $\mathrm{X}$ & 547 & 216.2 & 0.39 \\
XI & 552 & 132.5 & 0.24 \\
XII & 3468 & 1197.7 & 0.35
\end{tabular}


Rcsults - Expected Versus Aclual. The results of the high pressure spraying operation illustrated the impact of recontamination due to debris deposited on the surfaces from above and, in some cases, due to ineffective operational procedures. As a result, the high pressure spray did not produce the expected results. The tests, however, did show the techniques and the necessary procedures to produce the effectiveness desired. Area radiation results, which are dependent on the source term, proper contamination control techniques, and good decontamination procedures, did not reach the desired reductions on this elevation. It had heen experted that contamination levelc could be reduced below $10^{5} \mathrm{dpm} / 100 \mathrm{~cm}^{2}$ of $\mathrm{Cs}-137$ for elevation $305^{\prime}$. It was apparent that the watcr floor scrubber loosened the semi-fixed debris from the surface of the floor, but the debris did not remain in solution and was not transported down the drains. As a result, much of the debris that was loosened from the surface dried on the floor or other surfaces.

Equipment and Techniques. The equipment used during the tests included the spin jet with four 15-degree nozzles, and the hydrolance with a 0050 nozzle for flushing. The equipment was the same as in the Equipment and Techniques section for the high pressure flushing of elevation $347^{\prime}-6^{\prime \prime}$, with the exception of the flush nozzle. The techniques used involved water floor scrubbing the floor surface and then flushing the debris down the drain. A squeegee was used to control excess water and keep it in the floor contours to the drain system.

Worker Radiation Exposure. Worker radiation exposure for the high pres sure test on elevation $305^{\prime}$ was 5.75 man-hours and 2.525 man-rem. It mist be noted that the elevation 305' high pressure spray task did not include Area ISC, which was only low pressure flushed (strippable coating was placed on Area ISC for testing after it had been low pressure flushed). The high pressure exposure was less than the low pressure exposure because the low pressure tests consisted of three separate activities (low pressure test on walls, overheads, and floor, and on the elevation 305' floor, and low pressure reflush).

Safety. The task did not have any problems during high pressure spraying, except that a crew member entered the reactor building with only one shin guard and was prohibited from assuming the lance operator position during the task. 
Worker Productivity. The worker productivity varied from 1500 to 4600 square feet per hour. The rate of application was hurried in an attempt to complete the task in one entry, and the coverage of the area was incomplete. In the areas where there are considerable equipment and protrusions from the wall and floor surfaces, an estimate of the application rate cannot be projected. The water scrubber operators were told several times to slow their rate of application and movement with the machine. In the Area X HP, which had a pressure of 2000 psi and the lowest square foot per hour of application rate, considerable debris was left on the floor. See Photograph 18 for the debris, wheel marks, and flush marks on the floor. The results of high pressure water floor scrubber operations support the conclusion that 1000 square feet per hour at the proper pressure and flow rate will produce acceptable results.

\section{Summary of Specific Results.}

High Pressure Flush Parameters--High pressure flushing of the elevation 305' floor used 1546 gallons of water for 1 hour and 47 minutes of actual flushing time. Pressures of 2000 and 6000 psi were used at 24, 20.5, and 14 gallons per minute. Both ambient and hot water $(120 \mathrm{~F})$ were used at $2000 \mathrm{psi}$, and ambient was used at $6000 \mathrm{psi}$. Only the floor surfaces were high pressure sprayed. The flush after the water floor scrubber operation covered the floor and edge of the wall surface near the floor. Results of the high pressure flush are summarized in Table 2-21. During the task it was apparent that:

- The $6000 \mathrm{psi}$ and $25 \mathrm{gpm}$ water floor scrubber operation used too much water and resulted in a large vapor cloud during and following the operation.

- The wrong flush nozzle was used for Area XII, and the debris loosened from the floor by the scrubber was not moved effectively into the drains. 
TABLE 2-21. SUMMARY OF RESULTS OF ELEVATION 305' HIGH PRESSURE FLUSH

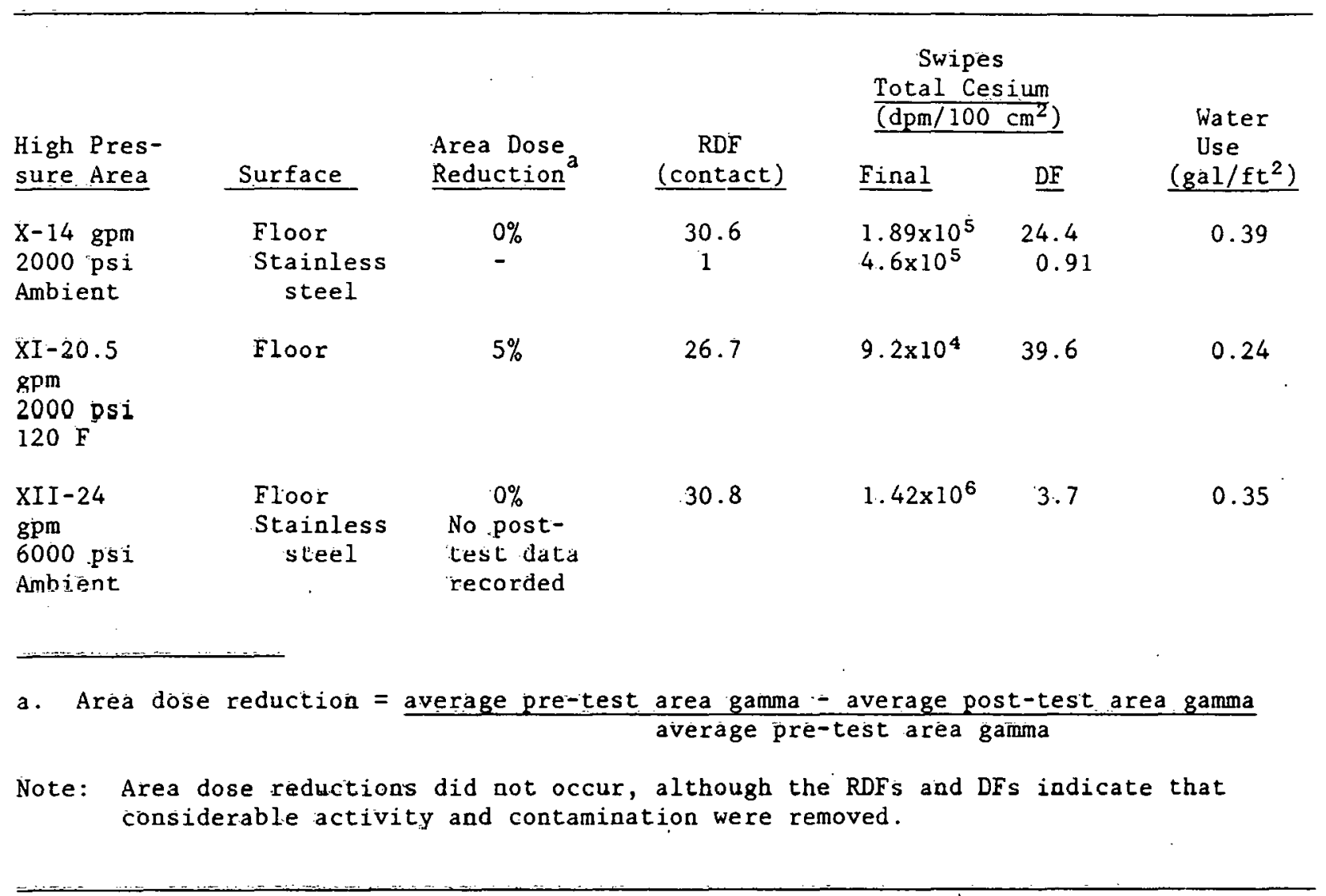


Debris was squeegeed back onto clean surfaces in Areas X and XII.

- The application rate by the water scrubber operator was greater than used in training, and was too rapid to clean the amount of debris on the floor surface in Areas $X$ and XII.

o Post-test water scrubber flush operations with the lance did not cover the walls high enough to remove contamination caused by the machine operations at $6000 \mathrm{psi}$ and $25 \mathrm{gpm}$.

- The 15-degree nozzle on the water floor scrubber at $6000 \mathrm{psi}$ and $25 \mathrm{gpm}$ removed the dirt and some paint. This is shown in Photograph 19 and can be compared to results of $2000 \mathrm{psi}$ at $14 \mathrm{gpm}$ in Photograph 18. Water rates were not sufficient to produce good results at $14 \mathrm{gpm}$.

Visual Results--Visual results are shown in the photographs of Areas $X, X I$, and XII. Area XII had significant results at 6000 psi (Photograph 19) compared to 2000 psi (Photograph 18). The floor surface in Photograph 20 looked like that in Photograph 18 (wheel marks, etc.). The rate of application was so fast, even with the high pressure, that the surface was not being cleaned. After the crew repeated the task in Area VII, better results were achieved and are shown in Photograph 20, although some of the wheel marks are still visible on the floor surface. The diamond plate is visible in the top right area of Photograph 20. Photograph 21 shows the cleaned floor at 6000 psi and shows where a bucket had been on the floor surface during the accident and was later removed. Photograph 22 illustrates a surface cleaned at 6000 psi compared to a 2000 psi water floor scrubbed area in Photograph 23. In Photograph 24, the wheel marks of the machine are visible in the debris on the floor. The 2000 psi test and flush did not move the debris off the floor and down the drains, but the wheels of the machine did pick up contamination as did rubber boots worn by the decontamination crews, who tracked debris over the cleaned floor surfaces--a major source of recontamination. 
Radiation Changes--The radiation changes in the area dose rate for Areas X HP and XII HP were actual increases over the pre-decontamination experiment values. Initially, low pressure flushing reductions were achieved, but recontamination and the inability of the post-test high pressure water floor scrubber flush to move the debris down the drains left the area with a 200 percent increașe over the low pressure pre-test values. Failure to wash the wall surfaces and the floor effectively (and other sources) contributed to the high area radiation readings. The only area that showed a reduction in radiation readings was Area XI HP where a 13 percent reduction was achieved over low pressure flushing results. Contact radiation readings were reduced in all areas with the highest RDF of 30.6 .

Contamination and Recontamination--Contamination of the other surfaces was evident in the videotapes of tests in which the high flow rates and high pressures were used (6000 psi and $24 \mathrm{gpm})$. Recontamination was evident as personnel changed air samples, moved wastewater with squeegees, and performed cleanup tasks. Swipe samples had DFs in the 20 to 25 range for 2000 psi and a $\mathrm{DF}$ of 3 for $6000 \mathrm{psi}$. The smearable contamination level averaged 10. dpm/:100 $\mathrm{cm}^{2}$ for cesium. During the flush of the stairwell prinr th the high pressure spraying of elevation $305^{\prime}$, a large quantity of dirt and contamination was deposited on the elevation $305^{\prime}$ floor in Area XII HP.

Effectiveness of the Different High Pressure Techniques--The effectiveness of the techniques used during this test showed that 2000 psi was an insufficient pressure to use at any flow rate with the water floor scrubber to remove contamination. The recontamination of other surfaces and the inability to flush the loosened debris into the drains demonstrated that 6000 psi at 24 gpm was too much water to control at high pressure.

\section{Efficiency of the High Pressure Techniques--The test showed that}

these techniques were not efficient. In addition, the task was not completed, required additional effort to remove contamination, and in some instances led to recontamination of clean surfaces. This series of tests showed the parameters where the techniques did not remove enough debris and where the removal of a lot of debris was inefficient and recontamination occurred. 
Reflushing of Elevation 305'

General Summary of Reflushing of Elevation $305^{\prime}$

Technique Description. At the completion of the high pressure flushing, data acquisition and a review of the task indicated that large amounts of contamination and high dose rates remained in Area XII HP. Since this area provided major access to higher elevations and to the polar crane, an attempt was made to reflush this area before debris was Lracked throughout the building. Unfortunately, the reflush was not scheduled until the second entry following the high pressure spraying of elevation 305'. Therefore, some contamination had been tracked to other levels and areas. The task was established to conduct a low pressure flushing from the area around the open stairwell through high pressure Area XII into Area XI to the entrance of the No. 2 air lock. During the last portion of the flushing operations, the air lock door developed a problem. As a result, most of the flushing continued unsupervised while the command center developed a procedure to enable personnel to exit the reactor building. As a result, the flushing task was not completed as planned.

Smearable Contamination Levels. Table 2-22 shows the pre- and post-test smearable contamination levels for this reflushing operation. The contamination levels were not effectively reduced during the reflush of the area because not all the recontaminated areas were flushed and the crew failed to move the debris down the drains.

Degrec of Uncertainty - Decontamination Effectiveness. The data acquisition of the reflushing of elevation 305' was accomplished during a later entry. Some personnel traffic did occur in the area prior to the measurements.

Waste Volume. The liquid waste generated during the 32 minutes of flushing was 781.3 gallons of water, which was directed down the drains and the open stairwell to elevation $282^{\prime}-6^{\prime \prime}$. 
TAEIE 2-22. SUMARY OE REFLINHING RADIATION AND CONTAMINATION JATA OF ELEVATION 305'

\begin{tabular}{|c|c|c|c|c|c|c|c|c|c|c|c|c|c|c|c|c|c|c|}
\hline $\begin{array}{l}\text { LP } \\
\text { Area }\end{array}$ & Location & Surface & $\begin{array}{l}\text { Pre-Test } \\
\text { Gamma } \\
\end{array}$ & $\begin{array}{l}\text { Pest-Te:t } \\
\text { Fitst LE' } \\
\text { Gz:mma } \\
\end{array}$ & $\begin{array}{l}\text { Post-Test } \\
\text { HE: } \\
\text { Gamma }\end{array}$ & $\begin{array}{l}\text { Post-Test } \\
\text { Reflush } \\
\text { Gamma } \\
\end{array}$ & $\begin{array}{l}\text { Pre-Test } \\
\text { Contact } \\
\text { Gamma } \\
\end{array}$ & $\begin{array}{l}\text { Pos1-Tes: } \\
\text { LP } \\
\text { Gamna } \\
\end{array}$ & $\begin{array}{l}\text { Post-Test } \\
\text { HP } \\
\text { Gamma } \\
\end{array}$ & $\begin{array}{l}\text { Post-Test } \\
\text { Reflush LP } \\
\text { Gamma } \\
\end{array}$ & $\begin{array}{l}\text { Pre-Test } \\
\text { Beta } \\
\end{array}$ & $\begin{array}{l}\text { Post-Tesa } \\
\text { LP } \\
\text { Beta }\end{array}$ & $\begin{array}{l}\text { Post-Test } \\
\text { HP } \\
\text { Beta } \\
\end{array}$ & $\begin{array}{l}\text { Post-Test } \\
\text { Reflush } \\
\text { LP } \\
\text { Beta } \\
\end{array}$ & $\begin{array}{l}\text { Pre-Test } \\
\text { Cs-137 }\end{array}$ & $\begin{array}{l}\text { Post-Test } \\
\text { LP } \\
\text { Cs-137 } \\
\end{array}$ & $\begin{array}{l}\text { Post-Test } \\
\text { HP } \\
\text { Cs-137 } \\
\end{array}$ & $\begin{array}{l}\text { Post-Test } \\
\text { Reflush } \\
\text { LP } \\
\text { Cs-137 } \\
\end{array}$ \\
\hline & $53-1$ & Floor & & & $130 \mathrm{C}$ & 1200 & & & & 3800 & & & 9360 & 12,800 & & & & \\
\hline & $53-2$ & Floor & & & $1: 0 C$ & 1300 & & & & 1800 & & & 1170 & 2000 & & & & \\
\hline \multirow[t]{4}{*}{ III } & $53-3$ & Floor & 800 & $\equiv 0.0$ & 1200 & 1300 & 1000 & 90.0 & 1800 & 1900 & 4560 & 2660 & 780 & 1200 & $4.8 \times 10^{6}$ & $1.7 \times 10^{6}$ & $7.5 \times 10^{6}$ & $6.2 \times 10^{5}$ \\
\hline & $53-4$ & Floor & & & 1100 & 900 & & & & 1600 & & & 3900 & 800 & & & & \\
\hline & $53-5$ & Floor & & & 900 & 900 & & & & 1200 & & & 780 & 6400 & & & & \\
\hline & 61 & Floor & 1000 & 500 & & 400 & 3400 & 1000 & 900 & 1000 & 17,480 & 8360 & 8190 & 10,000 & & $9.3 \times 10^{6}$ & & $9.5 \times 10^{6}$ \\
\hline
\end{tabular}


Results - Expected Versus Actual. The results of the reflush demonstrated that:

o The area must be flushed properly, including the walls and recontaminated surfaces, to reduce area readings

- Contamination levels achievable with water spraying are limited without some assistance of mechnical or chemical agents to remove the debris or keep debris suspended until it is flushed down the drains

- Squeegee operations must keep the debris moving ahead of the lance operator

- Contamination control and decontamination sequencing must be used together in order to minimize rccontamination.

The results were expected to exceed the decontamination factors achieved as a result of low pressure reflushing.

\section{Strippable Coating Test}

\section{General Summary of Results}

Technique Description. The strippable coating test was designed to provide information to:

o Determine the effectiveness, safety, and efficiency of the strippable coating as a means of decontaminating major equipment items on elevation 347'-6' and floor surfaces on elevation 305'.

o Determine the man-rem, man-hours, solid waste generated, worker productivity, and radiation changes during the test.

o Determine the effectiveness of using cheesecloth beneath the coating to add strength on irregular surfaces, 
o Delermine the allount of activity removed by the coating and its effectiveness on surfaces of complex geometry.

The strippable coating was tested on equipment on elevation $347^{\prime}-6^{\prime \prime}$ and on the elevation 305' floor surface. Water in the bottom of the center tank on the reactor head storage stand prevented it from being coated. As a result, the outer support flange horizontal and vertical surfaces on the storage stand were stripcoated with Imperial ALARA DECON 1146 and 1148 (self-strippable coating). Photograph 25 shows the support flange.

The clcvation 305' floor Area ISC wac coated with ALARA DECON 11/6. All the coatings were allowed to dry for at least 24 hours before being removed. The material was cut with a carpet knife into strips several feet long and placed in plastic bags as compactable trash. The bags were loaded to less than $2 \mathrm{R}$ gamma (contact) and were tied with long cords so the bags could be dragged. The coating on the elevation 305' floor is shown in Photographs 26 and 27.

Smearable Contamination Levels. The smearable contamination levels for Area ISC were $10^{6}$ to $10^{7} \mathrm{dpm} / 100 \mathrm{~cm}^{2}$ of $\mathrm{Cs}-137$ at the start of the test and were $10^{4} \mathrm{dpm} / 100 \mathrm{~cm}^{2}$ of $\mathrm{Cs}-137$ after the material was removed from the floor. On elevation $347^{\prime}-6^{\prime \prime}$, the vertical surfaces were $10^{4} \mathrm{dpm} / 100 \mathrm{~cm}^{2}$ and the horizontal surfaces were $10^{6} \mathrm{dpm} / 100 \mathrm{~cm}^{2}$ of $\mathrm{Cs}-137$ at the start of the test. Post-test results showed $10^{4} \mathrm{dpm} / 100 \mathrm{~cm}^{2}$ of $\mathrm{Cs}-137$ on horizontal equipment surfaces and floors. Vertical surfaces had post-test smearable results in the $10^{3} \mathrm{dpm} / 100 \mathrm{~cm}^{2}$ range for $\mathrm{Cs}-137$. Table $2-23$ presents the contamination results. 
TABLE 2-23. STRIPPABLE COATING TEST - ELEVATION 305' FLOOR AND ELEVATION 347'-6" HEAD STORAGE STAND

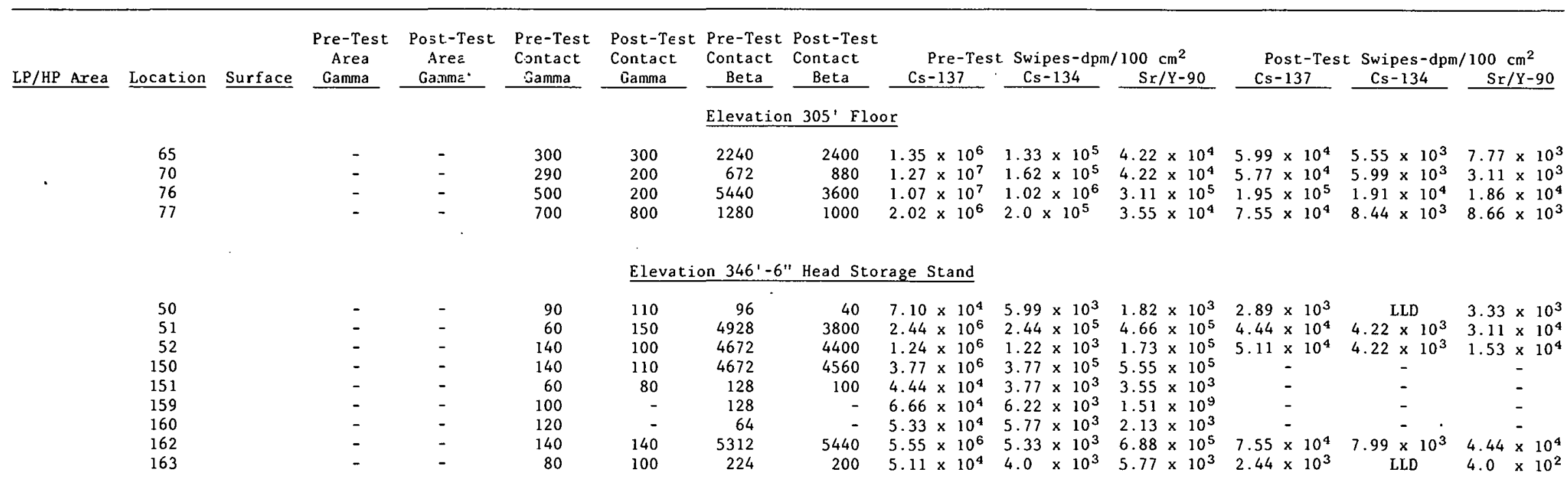

Intermediace Readings with Strip Coating on Elevation 305'

\section{Contact Gamma Contact Beta}

$\begin{array}{rr}300 & 800 \\ 280 & 400 \\ 600 & 2000 \\ 600 & 800\end{array}$

$7.55 \times 10^{4} 1.86 \times 10^{4} 1.31 \times 10^{4}$ $4.0 \times 10^{4} 4.22 \times 10^{3} 2.44 \times 10^{3}$ $2.22 \times 10^{5} 2.22 \times 10^{4} 6.44 \times 10^{3}$

400

800

Head Storage Stand

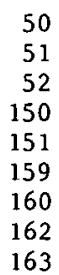

$\begin{array}{rr}120 & \text { NDB } \\ 150 & 3000 \\ 150 & 3000 \\ 120 & 2920 \\ 80 & 120 \\ - & - \\ - & - \\ 125 & 4300 \\ 110 & 40\end{array}$

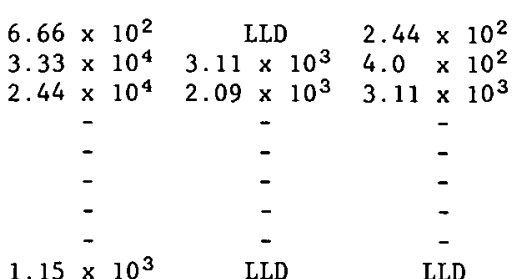

A $750 \mathrm{mg}$ sample of self-strippable coating after removal contained:

$9.32 \times 10^{6} 9.10 \times 10^{5} 2.18 \times 10^{5}$ 
Intermediate-level samples were taken while the coating was on the surfaces and indicated levels of activity comparable with the post-test contamination levels after the coating was removed. There appeared to be some crosscontamination of the samples-and surface recontamination during data acquisition.

The self-strippable coating sample analyzed after removal from the reactor building showed $9.3 \times 10^{6} \mathrm{dpm} / 100 \mathrm{~cm}^{2}$. This analysis and the photographs of the coating removals (Photographs 28 and 29) show that the coating removed considerable debris from the floor surface.

Degree of Uncertainty - Decontamination Effectiveness. Dala were acquired on two occasions before the floor and equipment were strip-coated. Post-test data taken for two separate tasks confirmed the levels and readings. Area radiation readings were not taken, however, while the coating was on the floor; therefore, it was not possible to determine the coating's ettectiveness in area radiation reduction.

Waste Volume. Both solid and compactable waste were generated by removal of the strippabie coating. Ihe trash consisted of the containers tor the strippable coating and the coating after it was removed from the floor. The trash was placed in plastic bags and removed from the reactor building. Ihe total volume of waste was 4.5 cubic feet (which should be compactable to approximately 3 cubic feet). Preliminary calculations indicate that a 55gallon drum filled with the used ALARA 1146 strippable coating from an area of comparable contamination levels will show contact gamma readings of less than 5 rem. One drum will hold the refuse from 2000 to 2500 square feet of coated surface.

Results - Expected Versus Actual. The strippable coating test showed better decontamination effectiveness than expected. More debris was removed using the coating as a decontamination medium after low pressure flushing than had been demonstrated during any previous test in containment. Previous tests, using another manufacturer's product, had shown that the coating might be 
difficult to remove from the floor. The Imperial ALARA DECON 1146 product was easy to apply and easy to remove. However, the self-strippable coating (1148) was not easy to remove and it is not recommended for use in the reactor building.

A section was also tested with cheesecloth as a base to evaluate the removal qualities with and without cheesecloth. The results showed that the cheesecloth was unnecessary and that the coating could be removed easily without it. However, if positive removal of the organir coating is required to ensure quality control criteria, consideration should be given to using the cheesecloth as a base for the coating.

Equipment and Techniques. The strippable coating was sprayed on the equipment and floor surfaces with an airless pump sprayer. The pump was set in a 5-gallon can of the coating and had a standard service air inlet of 90 psi and an outlet line of 2200 psi to the spray gun. A "mil stick" was used to periodically check the depth of the coating thickness and keep the coverage depth at 30 to 50 mils,

Worker Radiation Exposure. The worker exposure for the total task was 2.603 man-rem. The man-hours associated with the task were 10.65. Table 2-24 shows the individual man-rem and times for spraying and removing the coatings:

Safety. There were no safety problems with the strippable coating task, and normal precautions for any spraying of coatings were observed.

Worker Productivity. The test demonstrated that a floor surface could be. strip coated at the rate of approximately 1000 square feet per hour. Removal of the floor coating was slightly less, at 750 to 800 square feet per hour.

The equipment test had an 800 square foot per hour rate of coverage, and included some surfaces with complex geometry. The removal rate was approximately half of the coverage rate for equipment. The crew consisted of three 
TARIE 2-24. FLEVATION 305' AREA ISC AND ELEVATION 347'-6" EQUIPMEUT - STRIFPABLE COATING TEST PARAMETIRS

\begin{tabular}{|c|c|c|c|c|c|c|c|c|c|c|c|c|}
\hline \multirow[b]{2}{*}{ Test $\Lambda$ rea } & \multicolumn{2}{|c|}{ Test } & \multirow{2}{*}{$\begin{array}{l}\text { Area } \\
\left(\mathrm{ft} \mathrm{t}^{2}\right) \\
\end{array}$} & \multicolumn{5}{|c|}{ Dosimeter - Worker } & \multirow[b]{2}{*}{ Activi=y } & \multirow{2}{*}{$\begin{array}{c}\text { Rate- } \\
\text { Coverage/ } \\
\text { Rencoval } \\
\end{array}$} & \multirow{2}{*}{$\begin{array}{l}\text { T'ime } \\
\text { (min) }\end{array}$} & \multirow[b]{2}{*}{ Remarks } \\
\hline & Start & $\underline{S t c p}$ & & & No. 1 & Nio.2 & $\mathrm{Nc} \cdot 3$ & No. 4 & & & & \\
\hline$\underset{\text { ISC }}{\text { E1. } 305^{\circ}}$ & $\begin{array}{r}1540 \\
.\end{array}$ & 1613 & 533 & $\begin{array}{l}\text { Start } \\
\text { Stop } \\
\text { Eose }\end{array}$ & $\begin{array}{l}260 \\
587 \\
327\end{array}$ & $\begin{array}{l}195 \\
511 \\
\frac{316}{316}\end{array}$ & $\begin{array}{l}197 \\
417 \\
220\end{array}$ & . & $\begin{array}{l}\text { Spraying } \\
\text { strip coat }\end{array}$ & $\begin{array}{l}969 \mathrm{ft} / \\
\mathrm{hr}\end{array}$ & 33 & $\begin{array}{l}\text { One worker rotaled } \\
\text { in and out of air } \\
\text { lork to reduce man- } \\
\text { ren. }\end{array}$ \\
\hline${ }_{\text {ISC }}^{305^{\circ}}$ & 1507 & 1549 & & $\begin{array}{l}\text { Start } \\
\text { Stop } \\
\text { Irose }\end{array}$ & $\begin{array}{l}107 \\
\frac{323}{216}\end{array}$ & $\begin{array}{r}97 \\
261 \\
-64\end{array}$ & $\begin{array}{r}59 \\
257 \\
158\end{array}$ & $\begin{array}{r}99 \\
268 \\
169\end{array}$ & $\begin{array}{l}\text { Strip csat } \\
\text { removal }\end{array}$ & $\begin{array}{l}761 \mathrm{ft} / \\
\mathrm{hr}\end{array}$ & 42 & \\
\hline $\begin{array}{l}\text { Ei. } 347^{\prime}-6^{\prime \prime} \\
\text { Equipment }\end{array}$ & 1507 & 1520 & 174 & $\begin{array}{l}\text { Start } \\
\text { Stop } \\
\text { lose }\end{array}$ & $\begin{array}{l}123 \\
\frac{197}{74}\end{array}$ & $\begin{array}{l}124 \\
195 \\
71\end{array}$ & $\begin{array}{r}119 \\
192 \\
73\end{array}$ & & $\begin{array}{l}\text { Spraying } \\
\text { strip cכat }\end{array}$ & $\begin{array}{l}790 \mathrm{ft} / \\
\mathrm{hr}\end{array}$ & 13 & $\begin{array}{l}\text { Only flange of head } \\
\text { storage stand was } \\
\text { strip coated. }\end{array}$ \\
\hline $\begin{array}{l}\text { E.1. } 347^{\prime}-6^{\prime \prime} \\
\text { Equipment }\end{array}$ & 1431 & 1456 & & Dose & 83 & 73 & 75 & 75 & $\begin{array}{l}\text { Strip coat } \\
\text { removai }\end{array}$ & $\begin{array}{l}414 \mathrm{ft} / \\
\mathrm{hr}\end{array}$ & 25 & . \\
\hline
\end{tabular}


people. However, one individual was rotated in and out of the air lock to assist as required, thereby keeping the dose rate lower for the crew.

Three people were required for setup; two people for spraying, and three people for cleanup and removal of the material.

Summary of Specific Results. The results of the strippable coating test on elevation $305^{\prime}$ are shown in Table 2-25. The results are presented as a separate test and as a combination test after low pressure flushing. The final smearable contamination levels and the DFs for the strippable coating test indicate that it produced $10^{4} \mathrm{dpm} / 100 \mathrm{~cm}^{2}$ of cesium, with DFs in the hundreds for floor surfaces. The rate of application is comparable to that of high pressure flushing with vacuuming to pick up water. The application/removal time for the strippable coating is also comparable to the high pressure flush with vacuuming. Exposure reduction factors (ERFs) for area dose rate reductions are not available because no measurements were taken. The low pressure flushing plus strip coating did produce substantial reductions and DFs in area readings, contact readings, and smearable contamination results.

The test on the equipment showed that both vertical and horizontal surfaces could be reduced by a DF of approximately 50 for comparable surfaces and levels of smearable contamination. It appeared that $10^{4} \mathrm{dpm} / 100 \mathrm{~cm}^{2}$ of cesium was the best result that could be achieved on equipment. From the photographs of the equipment horizontal surfaces, it is apparent that more aggressive techniques are required to remove corrosion and reduce smearable contamination to obtain $10^{3} \mathrm{dpm} / 100 \mathrm{~cm}^{2}$ for total cesium.

The values in Table $2-23$ show that the coating will reduce surface contamination. The coating is waterproof except under direct, high pressure spraying conditions, and is fairly durable. It should not be used in areas where the temperature will approach $120 \mathrm{~F}$. 
TABLE 2-25. SUMMARY OF RESULTS OF ELEVATION 305' AREA ISC

\begin{tabular}{lccc}
\hline Test Area & $\begin{array}{c}\text { Contact } \\
\text { RDF }\end{array}$ & $\begin{array}{c}\text { Swipe } \\
\text { DF }\end{array}$ & $\begin{array}{c}\text { Final Swipe } \\
\text { Total Cesium } \\
\left(\text { dpm/100 } \mathrm{cm}^{2}\right)\end{array}$ \\
$\begin{array}{l}\text { Elevation 305, } \\
\text { ISC }\end{array}$ & 8.8 & 111.1 & $6.45 \times 10^{4}$ \\
$\begin{array}{l}\text { Elevation 305, } \\
\text { Area IV LF/ISt }\end{array}$ & 35.9 & 302.3 & $6.45 \times 10^{4}$ \\
\hline
\end{tabular}

The self-stripping coating could not be removed easily and is not recommended for use in TMI at the present time. It appeared that too much effort would be spent removing the coating. The strippable coating is easy to remove and would be suitable.

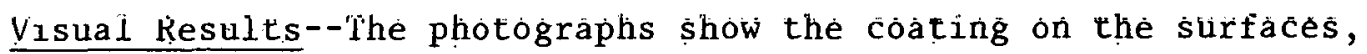
removal of the coating, and the surfaces after the coating has been removed (see Photographs 30 and 31 ). The debris captured by the coating can be observed on the underside of the coating.

Radiation Levels--The coating reduced the beta radiation levels: as expected, however, the contact gamma radiation levels did not change. The residual contact gamma radiation indicates that the source level was fairly constant throughout the test.

Contamination and Recontamination-- The intermediate readings on the strippable coating, shown in Table 2-23, show essentially the same level of contamination on top of the coating as under the surface after the coating was removed. This appears to be the result of cross-contamination by personnel walking on the area prior to sample collection. 
Technique Effectiveness:-The technique results showed that the use of strippable coatings is an effective technique to reduce smearable contamination to approximately $10^{4} \mathrm{dpm} / 100 \mathrm{~cm}^{2}$ of cesium for the contamination levels observed on elevation 305'. If used following a water spray, the technique would "fix" loose debris to the coating for removal. The coating protects against recontamination while it is on the surface. The removal rate of the technique is approximately 800 square feet per hour. If a heavy traffic area is to be decontaminated using a strippable coating, consideration should be given to using a chcesecloth base and plastic "egg crate" support walkway on top.

Technique Efficiency--The results produced were the most effective on elevation $305^{\prime}$. On elevation 305' the task used approximately 100 mrem per 100 square feet of coverage and approximately the same for removal. The volume of wastc was less from this technique than from the water spray. When working larger surface areas, the efficienty will improve since the mobilization and set-up time would be less of a consideration.

\section{Mechanical Scrubber Test}

\section{General Summary of the Task}

Technical Description. A mechanical scrubber test was conducted on elevation $347^{\prime}-6^{\prime \prime}$. The purpose of this test was to:

- Determine the effectiveness of decontaminating with an acid and with a detergent solution

- Determine the decontamination rates for the chemical solutions and the

- Quantity of waste generated

- Productivity of the workers

- Radiation level reduction

- Man-hours and man-rem assnciated with the test 
- Determine the safety and the efficiency of the chemical solutions and the test.

The test was conducted in a different area from the one originally selected. The size of the actual test area was so small that an additional area further to the north also had to be designated as part of the new test area. Figure 2-17 shows the areas actually used for the mechanical scrubber test.

The original plan had an area set aside in the mechanical scrubber test area that would not be tested with the high pressure water floor scrubber. This would allow testing of both solutions on an area that had been filushed with low pressure, as well as a combination of low and high pressure. When the test area was moved, a portion of each test was conducted over low pressure flushed areas and both low and high pressure flushed areas. However, these sections were not well defined.

During the cleanup operation, prior to the start of the experiment, trash and waste were consolidated in a few locations on elevation $347^{\prime}-6^{\prime \prime}$ and elevation 305'. The trash/waste storage area was located in one-half of the mechanical scrubber area. After the high pressure flushing was completed and prior to the mechanical scrubber test, the storage area and trash were relocated away from the test area. During the scrubber test, the soluiluns wert dispemsed un the floor, scrubbed, rinsed with a small amount of water, and wet vacuumed into a 55-gallon waste drum. Data acquisition was accomplished prior to and after the test.

Smearable Contamination Levels. The pre- and post-test smearable contamination levels are shown in l'able 2-26. 'l'he average prè-tést smearable level ur Cs-137 was $2 \times 10^{5} \mathrm{dpm} / 100 \mathrm{~cm}^{2}$. Post-test results averaged $5 \times 10^{3} \mathrm{dpm} / 100 \mathrm{~cm}^{2}$.

Recontamination of the test area occurred after the high pressure test. The squeegee operator was observed moving debris and water batk into the area after it had been high pressure flushed. When the trash was moved, the area under the storage and trash that had not previously been decontaminated was 
TABLE 2-26. HECHANICAL SCRUBBER TEST - ELEVATION 347'6"

\begin{tabular}{|c|c|c|c|c|c|c|c|c|c|c|c|c|c|c|}
\hline $\mathrm{LP} / \mathrm{H}$ ? Area & Location & Surface & $\begin{array}{c}\text { Pre-Test } \\
\text { Area } \\
\text { Gamma } \\
\end{array}$ & $\begin{array}{c}\text { Post-Tes.t } \\
\text { Area } \\
\text { Gamma } \\
\end{array}$ & $\begin{array}{l}\text { Pre-Test } \\
\text { Contact } \\
\text { Gamma } \\
\end{array}$ & $\begin{array}{l}\text { Post-Test } \\
\text { Contact } \\
\text { Gamma } \\
\end{array}$ & $\begin{array}{l}\text { Pre-Test } \\
\text { Contact } \\
\text { Beta } \\
\end{array}$ & $\begin{array}{l}\text { Post-Test } \\
\text { Contact } \\
\text { Beta } \\
\end{array}$ & $\begin{array}{l}\begin{array}{l}\text { Pre-Test } \\
\text { Cs-137 }\end{array} \\
\end{array}$ & $\begin{array}{l}\text { Swipes-dpm/ } \\
\mathrm{Cs}-134\end{array}$ & $\begin{array}{l}/ 100 \mathrm{~cm}^{2} \\
\quad \mathrm{Sr} / \mathrm{Y}-90 \\
\end{array}$ & $\begin{array}{l}\text { Post-Test } \\
\text { Cs-137 }\end{array}$ & $\begin{array}{l}\text { Swipes-dpm } \\
\mathrm{Cs}_{\mathrm{s}} 134\end{array}$ & $\begin{array}{c}100 \mathrm{~cm}^{2} \\
\mathrm{SR} / \mathrm{Y}-90 \\
\end{array}$ \\
\hline $\begin{array}{l}\text { AREA II MS } \\
\text { (acid) }\end{array}$ & $\begin{array}{r}153 \\
156 \\
93 \\
96 \\
157 \\
152\end{array}$ & $\begin{array}{c}\text { Concrete } \\
\text { Floor } \\
\mid\end{array}$ & $\begin{array}{r}- \\
- \\
38 \\
39 \\
- \\
60\end{array}$ & $\begin{array}{r}- \\
- \\
39 \\
40 \\
- \\
60\end{array}$ & $\begin{array}{r}110 \\
50 \\
60 \\
80 \\
60 \\
50\end{array}$ & $\begin{array}{r}120 \\
50 \\
60 \\
80 \\
49 \\
46\end{array}$ & $\begin{array}{l}160 \\
320 \\
320 \\
256 \\
288 \\
160\end{array}$ & $\begin{array}{r}64 \\
224 \\
256 \\
288 \\
227 \\
109\end{array}$ & $\begin{array}{l}2.89 \times 10^{5} \\
1.29 \times 10^{5} \\
1.07 \times 10^{5} \\
1.42 \times 10^{5} \\
1.22 \times 10^{5} \\
1.6 \times 10^{5}\end{array}$ & $\begin{array}{l}2.89 \times 10^{4} \\
1.31 \times 10^{4} \\
1.07 \times 10^{4} \\
1.22 \times 10^{4} \\
1.11 \times 10^{4} \\
1.44 \times 10^{4}\end{array}$ & $\begin{array}{l}1.44 \times 10^{4} \\
7.1 \times 10^{3} \\
9.1 \times 10^{3} \\
1.13 \times 10^{4} \\
8.21 \times 10^{3} \\
1.44 \times 10^{4}\end{array}$ & $\begin{array}{l}2.22 \times 10^{3} \\
3.11 \times 10^{4} \\
3.33 \times 10^{3} \\
2.66 \times 10^{3} \\
2.66 \times 10^{3} \\
1.78 \times 10^{3}\end{array}$ & $\begin{array}{c}\text { LLD } \\
3.55 \times 10^{3} \\
\text { LLD } \\
\text { LLD } \\
\text { LLD } \\
\text { LLD }\end{array}$ & $\begin{array}{c}\text { LLD } \\
1.22 \times 10^{3} \\
\text { LLD } \\
\text { LLD } \\
\text { LLD } \\
\text { LLD }\end{array}$ \\
\hline $\begin{array}{l}\text { AREA I MS } \\
\text { (detergent) }\end{array}$ & $\begin{array}{r}99 \\
155 \\
112 \\
110 \\
154 \\
98\end{array}$ & $\begin{array}{l}\text { Concrete } \\
\text { Floor }\end{array}$ & $\begin{array}{r}35 \\
- \\
- \\
31 \\
36\end{array}$ & $\begin{array}{r}34 \\
- \\
- \\
30 \\
- \\
36\end{array}$ & $\begin{array}{l}34 \\
32 \\
50 \\
38 \\
60 \\
60\end{array}$ & $\begin{array}{l}30 \\
29 \\
44 \\
34 \\
60 \\
60\end{array}$ & $\begin{array}{l}131 \\
154 \\
224 \\
262 \\
352 \\
320\end{array}$ & $\begin{array}{r}96 \\
99 \\
51 \\
147 \\
256 \\
224\end{array}$ & $\begin{array}{l}7.10 \times 10^{4} \\
7.77 \times 10^{4} \\
5.77 \times 10^{5} \\
3.11 \times 10^{5} \\
1.98 \times 10^{5} \\
2.22 \times 10^{5}\end{array}$ & $\begin{array}{l}7.10 \times 10^{3} \\
7.55 \times 10^{3} \\
5.55 \times 10^{4} \\
3.11 \times 10^{4} \\
1.93 \times 10^{4} \\
2.06 \times 10^{4}\end{array}$ & $\begin{array}{l}6.44 \times 10^{3} \\
8.88 \times 10^{3} \\
3.11 \times 10^{4} \\
2.02 \times 10^{4} \\
1.18 \times 10^{4} \\
1.35 \times 10^{4}\end{array}$ & $\begin{array}{l}3.11 \times 10^{3} \\
2.44 \times 10^{3} \\
4.22 \times 10^{3} \\
3.77 \times 10^{3} \\
2.2 \times 10^{3} \\
3.11 \times 10^{3}\end{array}$ & $\begin{array}{l}\text { LLD } \\
\text { LLD } \\
\text { LLD } \\
\text { LLD } \\
\text { LLD } \\
\text { LLD }\end{array}$ & $\begin{array}{c}\text { LLD } \\
\text { LLD } \\
1.33 \times 10^{2} \\
1.55 \times 10^{2} \\
2.64 \times 10^{4} \\
3.55 \times 10^{2}\end{array}$ \\
\hline
\end{tabular}


flushed with low pressure. As a result, the average post-test contamination. for low/high pressure testing prior to the mechanical scrubber test was higher than the pre-test contamination levels for the mechanical scrubber test in the same area.

Degree of Uncertainty - Decontamination Effectiveness. Data acquisition was conducted before and after the test. Swipe samples were damp during post-test data acquisition; therefore, the results may not be totally comparable. The exact location of the boundary where low pressure tlushing stopped and high pressure flushing began is not known. However, examination of the data negates the importance of knowing the exact boundary point because the final results are the same for the entire area in terms of contamination levels.

Waste Volume. The volume of waste generated during the test was governed partially by local requirements. Because the waste drum could contain only 35 gallons total prior to transfer to the radwaste section, only. 33 gallons of water could be used during the test in both test areas.

One gallon of acid was used for test Area II MS and one gallon of detergent solution was used in Area I MS. To prevent excessive detergent foaming, the vacuum was spiked with a defoamer prior to the entry. The waste drum was also spiked with a neutralizer prior to the entry to ensure that the waste would be in an acceptable form when removed. Approximately 0.2 gallon of water per square foot of test area was used to rinse the chemicals from the floor surface to the vacuum.

Kesults - Expected Versus. Accual. The results of the chemicals used ill the mechanical scrubber were as expected. However, the DF was sufficiently large that it is questionable whether water used with the scrubber would have produced the same result as chemicals. The acid test produced the best visual and decontamination results. 
The area dose rate was expected to decrease below the post-high pressure - test results of 61 mrem gamma for Area II HP and 76 mrem gamma for Area III HP. When the pre-test mechanical scrubber test area readings were examined, however, they were approximately 35 to 40 mrem gamma, well below the previous survey. Because the trash and waste had been moved between the tests, it was concluded that the trash and waste storage area was a factor in the area reading source terms. The area readings for the post-mechanical scrubber test were the lowest observed on elevation $347^{\prime}-6^{\prime \prime}$ and only slightly higher than those in the deep end of the refueling canal.

Equipment and Techniques. The mechanical scrubber test was conducted with a 20-inch Clark industrial scrubber with an automatic liquids dispenser. The detergent and acid solutions were premixed and used on the surface with a medium coarse buffer pad (no abrasives). The residue was flushed with $<100$ psi. and vacuumed into a waste container. The pad was not changed between tests, although requirements dictated that it should have been changed (the spare pads were misplaced in the reactor building during the staging task). The residence time for the acid was significantly less than was recommended by the manufacturer.

Worker Radiation Exposure. The work exposure for the task was 5.45 man-hours and 0.424 man-rem. This was the lowest exposure rate for any of the elevation $347^{\prime}-6^{\prime \prime}$ tasks. To accomplish the task, workers had to travel through elevation 305' and the open stairwell to reach elevation 347'-6". Even with travel through these high dose rate areas, the per hour dose rate for the task was 78 mrem gamma.

Safety. There were no safety problems associated with this task. The phosphoric acid was neutralized in the waste container, and no waste entered the drains as they were sealed and covered.

Worker Productivity. The rate of application with the mechanical scrubber was approximately 600 square feet per hour. This included cleaning and vacuuming the waste. Three crew members were required to operate the scrubber, lanre, and varmm. All equipment romld opitate simulaneously. 
Summary of Specific Results. The results of the mechanical scrubber test are shown in Table 2-27. The results of the acid test reflect higher DFs in area, contact, and swipe data. The contamination was reduced to $10^{3} \mathrm{dpm} / 1.00$ $\mathrm{cm}^{2}$ of cesium. Area readings in the range of 30 to $40 \mathrm{mrem}$ gamma could be obtained if trash and waste storage is removed and the areas properly cleaned.

TABLE 2-27. SUMMARY OF RESULTS OF MECHANICAI SCRUBBER TEST

\begin{tabular}{|c|c|c|c|c|}
\hline \multirow[b]{2}{*}{ Area } & \multirow{2}{*}{$\begin{array}{l}\text { Area Dose } \\
\text { Reduction }\end{array}$} & \multirow{2}{*}{$\begin{array}{c}\mathrm{RDF} \\
\text { (contact) }\end{array}$} & \multicolumn{2}{|c|}{$\begin{array}{l}\text { 3wipes } \\
\text { Total Cesium } \\
\left(\mathrm{dpm} / 100 \mathrm{~cm}^{2}\right)\end{array}$} \\
\hline & & & Final & $\underline{\mathrm{DF}}$ \\
\hline I MS & $0 \%$ & $2 . .2$ & $7.9 \times 10^{3}$ & 21.9 \\
\hline II MS & $2 \%$ & 6.5 & $3.1 \times 10^{3}$ & 84.8 \\
\hline
\end{tabular}

Visual Results--Photograph 32 shows the visual difference between the acid and the detergent solutions tests. Photograph 33 shows the difference between areas that were not scrubbed (Areas I MS and II MS). Photograph 34 shows the differences between Area II HP and II MS.

\section{Contamination and Recontamination--Specific instructions were given} and followed to keep recontamination to a minimum. I'he flloor was not walked on prior to the post-data acquisition, and decontamination was sequenced to leave a clean floor that would not be recontaminated from an area of higher contamination.

Technique Effectiveness--It was established that the mechanical scrubber would produce $10^{3} \mathrm{dpm} / 100 \mathrm{~cm}^{2}$ after low pressure or high pressure. flushing. What effect the detergent, acid, mechanical scrubber, and vacuum had on the overall effectiveness could not be computed or estimated. 
Technique Efficiency--The technique efficiency would be improved if the same results could be produced without chemicals. The waste volume can be controlled using this technique so the total liquid waste volume is less than that of either low or high pressure flushing of surface areas.

\section{Combinations of Decontamination Techniques}

\section{General Summary of Combinations of Decontamination Techniques}

The Decontamination Experiment was designed to test various decontamination techniques and to test multiple techniques in sequence on different types of surfaces. The test sequence was designed to increase in severity as the techniques were applied. For example, low pressure flush with water was the first test conducted, and phosphoric acid applied with a mechanical scrubber was the final test in the sequence. The results were as expected; the more aggressive the technique, the higher the decontamination factor.

\section{Specific Results.}

Elevation 305'--Table 2-28 shows the results of the low and high pressure water flushing and strip coating on the horizontal surfaces. Each of the low and high pressure tests had various parameters of flow rate, pressure, and temperature. The strip coating was applied after low pressure flushing. The strip coating test in Area IV LP had the lowest smearable contamination measurements at $6.45 \times 10^{1} \mathrm{dpm} / 100 \mathrm{~cm}^{2}$ of cesium. The less than optimum results for the tests of the high pressure flush of elevation $305^{\prime}$ and other radiation sources distort the area reductions shown in the table. 


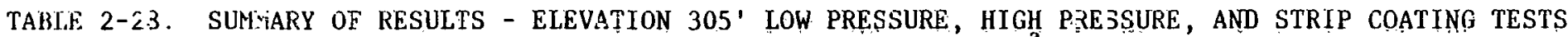
(Based on representative data points ${ }^{\mathrm{a}}$ )

\begin{tabular}{|c|c|c|c|c|c|c|c|c|}
\hline \multicolumn{2}{|c|}{ Arrea } & \multirow{2}{*}{$\begin{array}{c}\text { Pressure } \\
\frac{(p s i=\text { est. })}{\sim 500}\end{array}$} & \multirow{2}{*}{$\frac{\begin{array}{c}\text { Temperature } \\
(F)\end{array}}{\text { Anjient }}$} & \multirow{2}{*}{$\frac{\begin{array}{c}8 p m \\
\text { (actual } 1 / \text { planned) }\end{array}}{20 / 15}$} & \multirow{2}{*}{$\begin{array}{l}\text { Area Exposure } \\
\text { Reduction Factor/ } \\
\% \text { of reduction } \\
1.58 / 37\end{array}$} & \multirow{2}{*}{$\frac{\begin{array}{c}\text { Contact } \\
\text { RDF }\end{array}}{75.6}$} & \multirow{2}{*}{$\frac{\substack{\text { Swipe } \\
\text { DF }}}{1.1}$} & \multirow{2}{*}{$\begin{array}{l}\begin{array}{l}\text { Final Swipe } \\
\text { (total cesium } \\
\left.\text { dpm } 100 \mathrm{~cm}^{2}\right)\end{array} \\
4.62 \times 10^{6}\end{array}$} \\
\hline $\mathrm{I}$ & LP & & & & & & & \\
\hline IV & LP & $\sim 400$ & 110 & $17 / 15$ & $1.37 / 27$ & 28.0 & 2.4 & $8.19 \times 10^{6}$ \\
\hline II & LP & $\sim 900$ & 118 & $23 / 25$ & $1.16 / 14$ & 6.9 & 42.0 & $4.71 \times 10^{5}$ \\
\hline $\operatorname{III}$ & $\mathrm{LP}$ & 2900 & 96 & $23 / 25$ & $1.33 / 25$ & 65.5 & 2.8 & $6.09 \times 10^{6}$ \\
\hline$X$ & HP & $20 \div 0$ & Ambient & $14 / 15$ & $0.89 / 0^{\mathrm{b}}$ & 30.6 & 24.4 & $1.89 \times 10^{5}$ \\
\hline$X I$ & HP & $20 \therefore 0$ & 120 & $20.5 / 25$ & $1.05 / 5^{b}$ & 26.7 & 39.6 & $9.2 \times 10^{4}$ \\
\hline$X \Pi I$ & $\mathrm{HP}$ & $60 \div 0$ & Ambient & $24 / 25$ & $0.85 / 0^{b}$ & 30.8 & 3.7 & $1.42 \times 10^{6}$ \\
\hline XIT & $\amalg P$ & $60 \div 0$ & Hot & $24 / 25$ & $1.05 / 5^{b}$ & $10.8^{\mathrm{C}}$ & 15.9 & $8.25 \times 10^{5}$ \\
\hline Strip & Coant & - & - & - & $\mathrm{N} / \mathrm{A}$ & 8.8 & 111.1 & $6.45 \times 10^{4}$ \\
\hline I & LP:X & & & & $1.42 / 29$ & 238.9 & 26.9 & $1.89 \times 10^{5}$ \\
\hline II & $\begin{array}{l}\text { LP:XI } \\
\text { (Ambi }\end{array}$ & & & & $1.05 / 5$ & 40.2 & 18.9 & $1.42 \times 10^{6}$ \\
\hline II & LP? & & & & $1.0 / 0$ & 40.1 & 33.7 & $1.67 \times 10^{5}$ \\
\hline IV & LPSSt & & & & $\begin{array}{c}1.37 / 27 \\
\text { (from LP only) }\end{array}$ & 35.9 & 302.3 & $6.45 \times 10^{4}$ \\
\hline
\end{tabular}

a. Due to location cr observed procedure, certain data poințs are more represınzative of the technique used. These values are determined using the representative data only.

b. Because pre-test data are not believed țc be indicative of actual contaminaticn prior to flush, and other radiation sources are masking the decontamination results, these reduction factors are not representative of the technique used.

c. Wrong nozzle was used 
Elevation $347^{\prime}-6^{\prime \prime}--$ The results of low and high pressure flushing of the concrete floors and diamond plate on elevation $34^{\prime}-6^{\prime \prime}$ are shown in Table 2-29. On the concrete floor, the best decontamination results were achieved using $6000 \mathrm{psi}$ at $18 \mathrm{gpm}$. Diamond plate did not have decontamination levels comparable to concrete floor levels, suggesting that higher pressure may be necessary on diamond plate to produce the same results. Recontamination was evident at the higher flow rates and pressure, both in the data and in videotapes of the operation. Table 2-30 shows the data on various pressures used for elevation $347^{\prime}-6^{\prime \prime}$.

Strippable Coating Tests--Strippable coating tests were accomplished on low pressure flushed areas, although they could have been conducted over areas that had been high pressure flushed as well. The strippable tests revealed that the coating removed considerable amounts of loose contamination. Because all the loose contamination was not flushed down the drains in the high pressure flush, the strippable coating would have been a good technique to reduce this residue. Also, as indicated in the high pressure tests, more semi-fixed contamination was removed from the surface than in the low pressure tests. The use of strippable coating after high pressure flushing would be appropriate to fix the contamination and produce lower contamination levels.

As for equipment, high pressure spray can produce excellent results if the technique is applied properly. As an alternative for some equipment and surfaces, however, strippable coating can be an excellent decontamination technique and a protective cover against recontamination. 
TABIE 2-29. SLMYARY OF RESJUTS - ELEVATION 347'-6". LOW AND HIGH PRESSURE FLUSH OF CONERE?E FLOORS AND DIAMOND PLATE

\begin{tabular}{|c|c|c|c|c|c|c|c|}
\hline $\begin{array}{c}\text { Area } \\
\text { HP }\end{array}$ & $\begin{array}{l}\text { Pressure } \\
\text { (psi) }\end{array}$ & $\begin{array}{l}\text { Area Exposure } \\
\text { Fieduction Factor/ } \\
\% \text { a } \equiv \text { reduction }\end{array}$ & $\begin{array}{c}\text { Contact RDF } \\
\text { (representative) } \\
\end{array}$ & $\begin{array}{l}\text { Swipe } \\
\text { DF }\end{array}$ & \multicolumn{3}{|c|}{ Representative Data ${ }^{a}$} \\
\hline & \multicolumn{7}{|c|}{$5 \mathrm{gpm}$} \\
\hline $\begin{array}{r}\text { III } \\
\text { II } \\
\text { IV }\end{array}$ & $\begin{array}{l}2000 \\
4000 \\
6000 \\
\text { Area }\end{array}$ & $\begin{array}{c}1.15 / 13 \\
1.08 / 7.5 \\
1.27 ! 21 \\
\text { IV diamond plate }\end{array}$ & $\begin{array}{r}8.5 \\
19.0 \\
9.0\end{array}$ & $\begin{array}{r}7.7 \\
17.1 \\
37.0 \\
4.6\end{array}$ & $\begin{array}{l}10.1 \\
19.1 \\
37.4 \\
4.6\end{array}$ & $\begin{array}{l}4.35 \mathrm{x} \\
4.03 \mathrm{x} \\
1.44 \mathrm{x} \\
4.49 \mathrm{x}\end{array}$ & $\begin{array}{l}10^{5} \\
10^{5} \\
10^{5} \\
10^{5}\end{array}$ \\
\hline \multicolumn{8}{|c|}{$15 \mathrm{gpm}$} \\
\hline I & 2000 & $1.11: 10$ & 15.9 & 119.5 & 119.5 & 1.27. $x$ & $10^{5}$ \\
\hline \multicolumn{4}{|c|}{ Area I diamond plate } & 19.7 & 10.7 & $5.69 \times$ & $10^{5}$ \\
\hline $\begin{aligned} \operatorname{IX} \\
\text { VIII }\end{aligned}$ & $\begin{array}{l}4000 \\
6000\end{array}$ & $\begin{array}{l}1.49,29 \\
1.29,23\end{array}$ & $\begin{array}{l}20.2 \\
29.8\end{array}$ & $\begin{array}{r}1.7 \\
69.9\end{array}$ & $\begin{array}{r}9.3 \\
69.9\end{array}$ & $\begin{array}{l}1.48 \mathrm{x} \\
8.37 \mathrm{x}\end{array}$ & $\begin{array}{l}10^{5} \\
10^{4}\end{array}$ \\
\hline \multicolumn{8}{|c|}{$25 \mathrm{gpm}$} \\
\hline VII & 2000 & $1.13 ; 15$ & 29.6 & 20.9 & 19.8 & $7.28 \times$ & $10^{5}$ \\
\hline VI & 4000 & $1.32 ; 24$ & 30.5 & 18.0 & 37.6 & $3.44 \mathrm{x}$ & $10^{5}$ \\
\hline V & 6000 & $1.23,19$ & 23.1 & 44.9 & 44.9 & $8.70 x$ & $10^{4}$ \\
\hline \multicolumn{4}{|c|}{ Area $V$ diament plate } & 6.2 & 21.4 & $2.85 \mathrm{x}$ & $10^{5}$ \\
\hline
\end{tabular}

a. Due to location ar obserrel procedure, certain data points are more =deally representative of the techrique used. Therefore, separate values have been determined based on these points only. 
TABLE 2-30. SUMMARY OF RESULTS - ELEVATION 347'-6" LOW AND HIGH PRESSURE FLUSH ON CONCRETE FLOORS

\begin{tabular}{|c|c|c|c|c|c|c|}
\hline $\begin{array}{l}\text { Area } \\
\text { HP } \\
\end{array}$ & $\begin{array}{c}\text { gpm } \\
\text { (actual/ } \\
\text { planned) }\end{array}$ & $\begin{array}{l}\text { Area Exposure } \\
\text { Reduction Factor/ } \\
\% \text { of reduczion } \\
\end{array}$ & $\begin{array}{c}\text { Contact RDF } \\
\text { (representative }{ }^{a} \text { ) } \\
\end{array}$ & $\begin{array}{c}\text { Swipe DF } \\
\text { (representative }^{a} \text { ) }\end{array}$ & $\begin{array}{l}\text { Temperature } \\
\text { (F) }\end{array}$ & $\begin{array}{l}\text { LP Flush } \\
\text { (gpm/temp.) }\end{array}$ \\
\hline \multicolumn{7}{|c|}{2000 psi } \\
\hline$\underset{\mathrm{III}}{\operatorname{III}}$ & $\begin{array}{l}5 / 5 \\
15 / 15 \\
18 / 25\end{array}$ & $\begin{array}{l}1.15 / 13 \\
1.11 / 10 \\
1.18 / 15\end{array}$ & $\begin{array}{r}8.5 \\
15.9 \\
28.7\end{array}$ & $\begin{array}{r}10.1 \\
119.5 \\
20.9\end{array}$ & $\begin{array}{l}110 \\
120 \\
120\end{array}$ & $\begin{array}{l}22.5 / 81 \\
14 / \mathrm{Amb} \\
19 / 74\end{array}$ \\
\hline \multicolumn{7}{|c|}{$4000 \mathrm{psi}$} \\
\hline $\begin{array}{l}I I \\
I X \\
V I\end{array}$ & $\begin{array}{c}5 / 5 \\
14 / 15 \\
23.5 / 25\end{array}$ & $\begin{array}{l}1.08 / 7.5 \\
1.40 / 29 \\
1.32 / 24\end{array}$ & $\begin{array}{l}19.0 \\
20.2 \\
30.5\end{array}$ & $\begin{array}{r}19.1 \\
9.3 \\
37.6\end{array}$ & $\begin{array}{l}94 \\
89 \\
72\end{array}$ & $\begin{array}{l}14 / \mathrm{Amb} \\
13 / 92 \\
22.5 / 81\end{array}$ \\
\hline \multicolumn{7}{|c|}{$6000 \mathrm{psi}$} \\
\hline $\begin{array}{l}\text { IV } \\
\text { VIII } \\
\bar{V}\end{array}$ & $\begin{array}{l}7.5 / 5 \\
18 / 15 \\
25 / 25\end{array}$ & $\begin{array}{l}1.27 / 21 \\
1.29 / 23 \\
1.23 / 19\end{array}$ & $\begin{array}{r}9.0 \\
29.8 \\
23.1\end{array}$ & $\begin{array}{l}37.4 \\
69.9 \\
44.9\end{array}$ & $\begin{array}{l}88 \\
95 \\
80\end{array}$ & $\begin{array}{r}22.5 / 81 \\
13 / 92 \\
22.5 / 81\end{array}$ \\
\hline
\end{tabular}

a. Due to location or observed procedure, certain data points are more ideally representative of the techniques used. Therefore, these FDFs have been determined using these points only. 
Summary

The combination of techniques produced sufficient data to select the most effective and most efficient techniques, in combination or singularly, to decontaminate various types of surfaces.

\section{Decontamination Technique Summary}

\section{General Summary of Low Pressure 'lechnique}

'lhe results of thc various tests in the low pressure flushing lechnique do not show any change in decontamination effectiveness due to water temperature changes. It should be noted, however, that the higher water temperatures desired were not reached during the test. The water pressure varied from 400 to 900 psi because the prime constraint was to hold the gallons per minute constant. The flow rate that yielded the best results was approximately 20 to $25 \mathrm{gpm}$ with a nozzle that would allow approximately 60 feet of spray. This assumed that the spray would be used at some distance from the operator. The best low pressure DFs were on stainless steel surfaces. The DFs were large for low pressure flushing where there was a large amount of contamination and debris at the beginning of the test.

\section{General Summary of High Pressure Technique}

Lance Spraying. High pressure spraying with the lance produced excellent results on the cable trays. Reductions on the other types of equipment should result if the procedure is accomplished properly. Indications from the tests show that the higher the pressure, the greater the effecliventss. At jou0 psi, the pressure was not high enough to produce the same cleanliness that was produced at $6000 \mathrm{psi}$ in training on various surfaces. To use the lance safely at high pressures, it must be handled by persons of large stature who can use their size and weight to resist the high forces. The pressure over $3000 \mathrm{psi}$ at 7 to $12 \mathrm{gpm}$ appeared to be the most effective. 
Water Floor Scrubber. Operation of the water floor scrubber indicated considerable recontamination on surfaces that were not flushed after the machine was used. The optimum parameters for horizontal surfaces appear to be $6000 \mathrm{psi}$ and 15 to $18 \mathrm{gpm}$. The nozzle size in the scrubber can change the results visually on the surface. The 15-degree nozzle appeared to be optimum for decontaminating the floor without removing the paint.

\section{Mechanical Scrubber}

The mechanical scrubber produced excellent results on painted concrete surfaces. Its use with high pressure or low pressure produced the same results, and it could be used after each technique and produce the same results. The mechanical scrubber used with acid produced the best decontamination results, while the mechanical scrubber used with detergent reduced contamination levels almost as much as the acid. To obtain the results shown in the mechanical scrubber tests, flushing and wet vacuuming to remove the residue are required. The 20-inch-diameter brush or pad at less than $200 \mathrm{rpm}$ appears to be an optimum combination for the floor surfaces in the reactor building to prevent splatter.

The pad texture used in the test influençed the visual results in training. As a result, the medium coarse nylon pad was selected as the most appropriate. Abrasive pads removed a few mils of the paint surface in tests outside the reactor building; however, abrasive pads were not tested in the reactor building.

\section{Strippable Coatings}

The strippable coating test proved that it was a decontamination technique that rould be used after a high or low pressure flush. The results showed generally lower contamination levels for the technique than high pressure spraying alone. 
On equipment, strippable coating is approximately the same as high pressure spray at the pressures tested. Spraying 30 to $50 \mathrm{mils}$ of ALARA 1146 at 2200 psi at 4 to 6 . inches appeared, to produce the best result.s. The selfstrippable coating was not effective, as it was difficult to remove.

$\underline{\text { Summary }}$

Table 2-31 shows the best results of the various tests on surfaces.

\section{Decontamination Training Program}

(Refer to Appendix D, 'lraining and.Safety, tor details.)

\section{$\underline{\text { Relationship of Training to Entry Planning }}$}

Training is the term applied, to the portion of the entry planning process that occurs between the drafting of individual work packages and their performance in-containment.

The process of transition between the completion of training and actual work package execution is a smooth one, provided that:

- Work techniqucs are developed prior to completion of a work package.

- Work packages are written well in advance to a 1 low adequate review.

o. Personnel arc prescreened for training prerequisites prior to scheduling their training.

o Training feedback to work package content is encouraged; this may require rescheduling of the work item if negative feedback is significant.

o: Adequate training time is set aside. 
TABLE 2-31. SUMMARY OF VARIOUS TEST RESULTS

\begin{tabular}{|c|c|c|c|c|c|c|}
\hline & $\begin{array}{c}\text { Waste } \\
\left(\text { total } \mathrm{gal} / \mathrm{ft}^{2}\right) \\
\end{array}$ & $\begin{array}{r}\text { Area \% } \\
\text { Reduction } \\
\end{array}$ & $\begin{array}{l}\text { Contact } \\
\text { RDF } \\
\end{array}$ & $\begin{array}{l}\text { Swipe } \\
\text { DF }\end{array}$ & $\begin{array}{c}\text { Pre-test } \\
\text { level } \\
\left(\mathrm{dpm} / 100 \mathrm{~cm}^{2}\right) \\
\end{array}$ & $\begin{array}{l}\text { Post-test } \\
\text { results } \\
\left(\mathrm{dpm} / 100 \mathrm{~cm}^{2}\right)\end{array}$ \\
\hline $\begin{array}{l}\text { Low Pressure (Area III } \\
\text { LP - Elevation } 305^{\prime} \text { ) }\end{array}$ & $120 / 0.22$ & 33 & 65.5 & 2.8 & $5.39 \times 10^{6}$ & $1.92 \times 10^{6}$ \\
\hline \multicolumn{7}{|l|}{ High Pressure } \\
\hline $\begin{array}{l}\text { Spin Jet (Area VII - } \\
\left.\text { Elevation } 347^{\prime}-6^{\prime \prime}\right)\end{array}$ & $190.6 / 0.64$ & 23 & 29.8 & 69.9 & $5.85 \times 10^{6}$ & $8.37 \times 10^{4}$ \\
\hline Lance (Cable Trays) & $88 / 0.23$ & -- & 81.6 & 726 & $1.89 \times 10^{7}$ & $2.6 \times 10^{4}$ \\
\hline $\begin{array}{l}\text { Mechanical Scrubber } \\
\text { (MS lII - Acid) }\end{array}$ & $13 / 0.2$ & 2 & 6.5 & 84.8 & $2.66 \times 10^{5}$ & $3.14 \times 10^{3}$ \\
\hline \multicolumn{7}{|l|}{ Strip Coat } \\
\hline $\begin{array}{l}\text { Floor (TSC - Elevation } \\
\left.305^{\prime}\right)\end{array}$ & $\begin{array}{c}3.4 \mathrm{ft}^{3} \\
\text { (solid waste) }\end{array}$ & - & 11.5 & 66.2 & $7.07 \times 10^{6}$ & $1.07 \times 10^{5}$ \\
\hline $\begin{array}{l}\text { Equipment (llead Storage } \\
\left.\text { Stand - Elevat.ion } 347^{\prime}-6^{\prime \prime}\right)\end{array}$ & $\begin{array}{c}1.1 \mathrm{ft}^{3} \\
\text { (solid waste) }\end{array}$ & -- & 9.7 & 1.6 & & $8.3 \times 10^{4}$ \\
\hline
\end{tabular}


Entry planning is enhanced and costs are minimized if the goals of the training program are achieved. The effectiveness of a training program is primarily judged in subjective terms. It relies heavily on the feedback from workers and supervisors during the debriefing process. If work is being accomplished on schedule and the problems listed previously do not occur frequently, then the program is a success. A follow-up system is necessary to identify and correct known deficiencies.

In order to maintain confidence and enthusiasm for the entry program, workers need to feel that their contributions toward policy changes are being incorporated.

\section{$\underline{\text { Training Criteria and Effectiveness }}$}

The criteria for the completion of training were to:

o Locate and adequately screen and qualify personnel for entry

- Allow workers to safely execute each work package with minimal outside direction

o Convey overall knowledge of containment conditions

o Convey nonroutine exit criteria for job termination

- Provide training for worker action in the event of an emergency

- Train adequate backup personnel.

These criteria were achieved through a training engineer"s control of the training. program. The training, program for the Gross Decontamination Experi-ment established standards tor student knowledge with respect to:

- Prerequisite qualifications 
- General knowledge of containment and procedures

- Specific instructions for each work package

o Specific training in site, radiological, and safety requirements

- Worker feedback after job completion.

The program also established standards for instructors and command center task supervisors to enhance effectiveness. The program was administered by a training engineer, who performed an independent review of each work package. During training, the adequacy and clarity of work instructions were validated as workers practiced for the planned entries. During the Decontamination Experiment, the following types of problems occurred, and influenced establishment of the optimum training policy:

- Underutilization of assigned decontamination personnel due to lack of approved procedures, work packages, and associated software

- Underutilization of personnel due to restraints imposed by the remote reporter system (initially a 2-week limit)

- Significant loss of training time to correct prerequisite qualifications or to complete decontamination personnel administrative requirements

- Lost training time due to lack of equipment.

- Retraining or training time extensions to complete the development of techniques

- Frequent rescheduling of entry tasks due to shortcomings in the planning process 
- Failure to train enough individuals to provide backup personnel for specific tasks

- Failure to train enough individuals in a variety of decontamination tasks such that maximum scheduling could be achieved

- Repetition of work packages due to lack of generic packages to cover repeat tasks such as trash removal.

\section{Summary of Training and Safety}

Training. The purpose of training was to provide skilled manpower for the Decontamination Experiment who could perform specific tasks efficiently and safely. The methodology. used for initiating the appropriate training program was to:

o Define the scope of activities and assumptions

o Determine the specific task list

o . Develop an hour estimate by task

o Determine skills needed by task

- Estimate doses for tasks

o Estimate out-of-containment support hours

o Develop a preliminary schedule for task execution

o Determine total worker job-hours

- Determine numbers of personnel required and make up a schedule

o Plan for backup personnel and make up a schedule. 
It should be emphasized that the vulnerability of a tightly scheduled, sequential set of procedures is the availability of trained personnel. The necessity of training backup personnel became apparent due to illness, changed tasks, and/or differences in planned and actual worker hours required for task performance.

There were several sources of manpower that were used to support the Decontamination Experiment:

- Rad-con technicians

- Maintenance department personnel

- Building trades crafts

- Utility employees from remote locations

- Subcontracted technicians and engineers

o Volunteers from the utility.

Personnel from these sources were screened to identify those who qualified for containment entry and work. Prerequisites for training and containment entry included:

- Valid radiological work permit training

- Valid whole body exposure records on file

- Valid whole body count

o Valid respiratory physical examination

o Satisfactory respirator fit test 
- Valid thermoluminescent dosimeter reading

o Valid security badge for access to work areas.

Only the remote reporters did not rely upon their parent department for supervision and personnel support functions. The remote reporters were assigned to a foreman, who fulfilled supervisory and administrative duties. The use of remote reporters allowed the operations to be conducted within the required time frame, although they imposed logistics problems. It was difticult to develop operations and training schedules based on the rotating labor pool arrangements (see Appendix D for a discussion of these problems).

Training was based on a training work package which is described in Appendix D. The training work package served as the written instructions for completion of a task. The packages had specific formats and could be revised by executing the revision procedure.

Training for the specific Decontamination Experiment tasks involved the following phàsès:

- Technique development phase - techniques for specific tasks were developed, evaluated, and refined for training and operations.

- Classroom phase - personnel were acquainted with work packages, areas of work, and safety procedures.

o Walk-through phase - personnel were practiced in actual tasks to be conducted without protective clothing and in similar, but not identïcal, work areas.

- Mockup phase - personnel were in simulated work conditions and conducted dress rehearsals of their assignments. 
Briefings preceded and followed each training phase. The final training briefing preceded entry and execution of assigned work. Debriefing served as a method of determining accomplished work, evaluating techniques, and providing a feedback mechanism to the training program. Details of training equipment and aids are given in Appendix D. These descriptions include specific training aids, equipment, qualification programs, and procedures for operation/coordination throughout the training phases.

The training engineer was responsible for the administration of the training program through the use of approved standards. The efficiency of the Decontamination Experiment was reduced because of the use of more than one training engineer and the lack of a complete training program from the beginning. Although the quality of most in-containment work was high, the cost and program consistency could have been improved significantly by more thorough preliminary planning. The continuation and completion of training program development is a recommended high priority which will ensure a higher degree of success in the future.

Safety. The administration of the safety program was the responsibility of the GPU site safety supervisor, who was supported in a technical capacity by the GPU corporate industrial hygienist. During the Decontamination Experiment, several safety issues arose which required the issuance of new safety policies regarding work instructions, equipment, or training. Implementation of these policies was the responsibility of BNoC Project Construction. Relevant safety issues affecting the experiment included:

o Heat stress of workers

o Protection from falls

o Access to remote work areas, including the polar crane

o Personnel and equipment protection measures

- Confined space requirements 
- Equipment lifting and handling

- Fire protection

For a detailed description of safety issues, refer to Appendix: D. For detailed organizational responsibilities, refer to Appendix E.

\section{Contamination Control and Recontamination}

\section{Contamination Control}

Contamination control for the experiment was limiled to the sequencing of the decontamination activities from the highest point in the reactor building descending down to the lowest elevation involved in the experiment. During the original schedule, this would have resulted in the following sequence:

o Polar crane - low pressure

- D-rings, missile shields, refueling canals, RHSS, . and refueling. bridges - low pressure flush

o Elevation $34^{\prime}-6^{\prime \prime}$ - low pressure and high pressure flush

o Open stairwell

- Elevation 305" low pressure and high pressure flush:

o Mechanical scrubber test

o. Strippable coating tests

The actual sequence of the operation was:

- Elevation 305' low pressure flush: floor only 
Polar crane - low pressure flush

o D-rings, missile shields, etc. - low pressure flush all surfaces

- Elevation $347^{\prime}-6^{\prime \prime}$ - low pressure, high pressure flush floor, and equipment

o Elevation $305^{\prime}$ walls, overheads, and floors - low pressure flush

- Open stairwell connecting elevations 305' and 347'-6" - low pressure flush

o Elevation $305^{\prime}$ - high pressure flush

- Elevation 305' - low pressure reflush

The planned sequence appeared to be adequate, and it was expected that minimal controls would be required between some areas such as a bootie or "sticky pads" change.

However, when the actual sequence occurred, contamination problems were evident. The main problem was that there were no controls to isolate clean areas from contaminated areas. As a result, personnel moved to and from the air lock across clean to contaminated areas (stairs and upper levels) to accomplish decontamination. During the sequence where the upper elevations were being decontaminated to levels of contamination lower than elevation $305^{\prime}$ and the open stairwell, personnel moved across the areas changing air samples, water hose lengths, and crews.

Debris and contamination from overhead decontamination operations occurred several times: (a) when the polar crane was flushed, contamination dripped onto elevation 347'-6" and the missile shields, refueling canals, etc., (b) when the low and high pressure activity took place on elevation $34^{\prime}-6^{\prime \prime}$, debris came down through the floor grating onto elevation 305', (c) after the elevation $305^{\prime}$ 
overheads,. walls,.. and floors. were low. pressure-flushed, debris and water dripped for several. hours, and. (d) when the open stairwell connecting elevation. $347^{\prime}-6^{\prime \prime}$ wi.th. $305^{\prime \prime}$ was flushed, debris and: water contacted walls, floors, and overhead, surfaces on elevation $305^{\prime \prime}$.

Because the walls. (D-rings, outside surfaces, and liner) on elevation $347^{\prime}-6^{\prime \prime}$ were outside. the scope: of work, contamination that was, deposited on the walls (and what was already. there) was not flushed.. Contamination. from the polar crane was depositedi on the top. of the D-rings, missile shield, refueling canal, and bridges; however; it wao fluohed: because all theoe ourfaces were flushed. in. this task..

Similarly during the open stairwell and. elevation' 347'-6" flushing, debris came down. through the grating onto elevation. 305.'.. In some cases, the amount of dirt and debris on the floor was so. great, that footprints, could be seen in it. This contaminationiwas tracked into areas that had.been. decontaminated. to significantly lower levels.

The change in. the sequence of decontamination work, and lack of protection between areas to prevent the tracking. of contamination caused extensive recontamination and increased: contamination: levels. on, the floor surfaces. In: some cases, post-test data acquisition was accomplished prior to, recontamination: of the surfaces. In other instances, the recontamination, took place during the. operation, or; as in. the: case of the polar crane,. over-a few weeks and: during. three distinct. recovery operations tasks on the crane and equipment. Where visual records show. personnel traffic on sample points prior to post-test data. acquisition, the sample points: were-removed from the analysis. Where this. could, not be determinedi exactly, the sample point data: was; usedi iń, the analysıs:.

\section{$\underline{\text { Recontamination: }}$}

All of the techniques, caused: some- recontamination;: however; the: result's variedl greatly, in how much of: an affect the recontamination! had: on: the datia:. Where recontamination, was: recognized by. the- decontamination, crew and; the area: 
where it was deposited was included in the scope of work, the recontamination was cleaned. Where recontamination was recognized by the crew in an area outside the scope of work (walls and equipment), it was not cleaned. Some recontamination was seen from the command center and corrected immediately. Personnel traffic was not rerouted but the problem was recognized and condoned. Some procedures did not allow for deviations in the work sequence or additions to the work scope; some controlling individuals or entry supervisors did permit deviations during the experiment and decontamination procedures while others did not. In some cases, the system did not have timely control procedures to rectify recontamination or to change the sequence of minor activities to prevent recontamination. The CCTV outages had an impact on some of the decontamination activity as the work could not be viewed in several areas (polar crane, refueling canals, bridges, and some areas of elevation $\left.347^{\prime}-6^{\prime \prime}\right)$.

Low pressure recontamination resulted from water hitting angle iron braces, equipment, and protrusions with $25 \mathrm{gpm}$ at $900 \mathrm{psi}$ at close range (5 to 10 feet). The water and debris splashed and in some cases recontaminated areas that had previously been cleaned. Flushing from a distance worked well except from above the refueling canals where the dirt could not be directed to the drains and therefore dried on the floor surface.

High pressure spraying and water floor scrubber operations required additional flushing with low pressure to move the debris removed from the floor surface into the drains. Where the debris caused vertical or higher level surface contamination, flushing was required to remove it. In several cases this was not accomplished and contamination and radiation readings at the end of the test indicated activity added during the decontamination effort. Where overspray from high pressure lance operations contacted the floor or other equipment (especially dirty or corroded items), the debris had to be removed by low pressure flushing.

The strippable coating caused some recontamination when the waste was not handled properly. For instance, the cut strips had to be rolled up the correct way to keep contamination from falling on a "clean" surface. Coating that was 
not removed from the floor would track on shoes and remain as hot spots. It became necessary to ensure all coating material was removed from the surface.

The mechanical scrubber had some splatter from brush or pad rotation that migrated to the walls. Flushing took care of this problem readily as it was easily recognizable.

\section{Summary of the Problems}

Contamination control is necessaxy in any decontamination activity. The sequence of the operations will not control recontamination; personnel and work procedures have to be established that will prevent recontamination of areas being decontaminated. Moving equipment and large tools through contaminated areas to support decontamination efforts at higher elevations has to be protected, or the equipment must be cleaned prior to placing it on clean surfaces. This is especially true if the hoist area is in an area where a great quantity of debris has been dumped or flushed and not cleaned.

Surface contamination spread to other areas and surfaces from the decontamination operations, if not cleaned, will add significantly to the area dose rat.e. This was apparent on elevations $305^{\prime}$ and $347^{\prime}-6^{\prime \prime}$, and on the polar crane. Readings were taken ill several areas to try to detcrmine what contribution this made to the area dose rate increase. Where significant contamination was removed from the floor (visual and data records) and the area dose rates increased, recontamination was evident on other surfaces.

Where data indicated recontamination, an effort was made in each case to determine the cause. 'l'hese investigations showed thal faclurs weite involved such as :

o Insufficient detail in procedures

o Training identification of recontamination

- Inappropriate equipment for the task 
o Technique parameters - over optimum pressure and flow rate

o Inattention to the task

o Supervison of the task

Gross decontamination of a reactor building requires attention to potential recontamination, stringent personnel control, and stringent controls on equipment usage and work areas to minimize the negative impact on decontamination efforts.

\section{Organizations and Special Support Systems}

Various organizations and special support systems not directly related to the decontamination experiment were, nonetheless, key elements necessary to its successful completion. Several organizations were responsible for the approval, planning, and funding requirements of the experiment. In addition, various onsite departments provided support operations essential to the execution of the various decontamination tasks.

\section{Organizations}

Organizational Responsibilities. Several organizations were responsible for the approval, planning, and execution of the decontamination experiment. The client, GPU, reviewed and approved all work scope, funding, and milestone schedules and all procedures, as well as controlling various safety and support operations. The Department of Energy (DOE) contractor, EG\&G, was responsible for the proposal of research tasks and funding of the tasks approved. The technical planning and guidance organization, Bechtel National, Inc. (BNI), defined the data acquisition and program tasks and issued the Decontamination l'aske and Sequence Plan. The prime engineering contractor for recovery, Bechtel Northern ( $\mathrm{BNOC}$ ), provided the engineering for required support systems and technical guidance to the project construction group (within BNoC), who 
executed the decontamination plan, including service and support systems. For a detailed breakdown of organizational responsibilities, approval dul plaining methods, and procedures for support operations, see Appendix E.

Organization Interfaces. With several organizations contributing to the decontamination experiment, the interactions between groups became complicated and, in some instances, slowed progress. During implementation of the decontamination efforts, some of the problems were recognized and adjustments made to correct the siluation.

The funding and approval situation was awkward due to the imbalance of control. EG\&G, as agent for DOE, had essentially unlimited federal resources for t.ests and experiments, while GPU had minimal resources for testing or recovery efforts.

BNI designed the tests and parameters and wrote the sample packages to define the functional criteria. Using these crileria, BNoC, in turn, procured and trained the personnel and executed the experiment. The flow through GPU from $\mathrm{BNI}$ to $\mathrm{BNoC}$ and back resulted in some administrative delays of weeks for even minor issues or changes. During the implementalion of the expcriment, a procedure was adopted by which verbal permission of both respective Bechlel supervisors sufficed to ducument concurence to change the parkages during actual operations.

All pronedures were routed through the NRC. While the NRC requested that several changes be made in some work packages, it was essentially supportive of recovery work and decontamination efforts.

DOE was involved primarily from a generic, lesson=leanted poine of 1nler= est. Its responsibility was to provide input to a national energy policy. In general, i.tems to be developed for DOE include:

- Standards for prevention of additional accidents like TMI-2

o Equipment standards evaluation and modification 
Evaluation of existing radiation monitoring instrumentation capabilities

- Development of better field monitoring instruments.

GPU departments were established for plant operations. As a result, during the recovery operations and experiment, nine departments, each having veto authority, were required to approve each work task procedure before it could be executed. Multiple review cycles occurred when revisions were made and had to be approved. The 20 Decontamination Experiment procedures and 8 Engineering Change Modifications (ECMs) required excessive time for review under this organizational structure. In addition, the structure of the procedures was not in the optimum configuration for easy review (i.e., the work packages contained too much detail). The result was a review process which consumed more man-hours than the task or the training. A large recovery operation, as demonstrated during the experiment, reflected the requirement for a different organizational structure than the one that currently exists, in order to be efficient during decontamination and recovery.

Special Support Systems and Equipment

Equipment. Several pieces of special equipment were brought into or Installed in the contalnment as part of the support operations for the decontamination experiment. These items included:

o Spider work platform

- New radio system (partial)

o High reach scissors lift work platform 
- Elevation $34^{\prime}-6^{\prime \prime}$ lifting device

For detailed descriptions of these support items and their applications, see Appendix E.

Radiological Controls Department Support. The radiological controls department was responsible for compliance with regulations regarding radiation protection. Various groups within the department had responsibilities related to the decontamination activities. Radiological engineering was responsible for ensuring that exposure resulting from work done in radiation areas was as low: as reasonably achievable (ALARA). Radiological field operations, through the use of rad-con technicians, were responsible for identifying radiological conditions throughout the plant and for providing radiological coverage when required by the RWP. Dosimetry was responsible for issuing and reading thermoluminescent dosimeters, tracking exposure history, and recording bioassay and whole body count results. Respiratory training standards were issued and respiratory devices were supplied and decontaminated by the respiratory pro-tection group.

Unit II Opcrations and Maintenance Dcpartment Support. Operations and maintenance technicians and supervisors were provided on a per-task basis by a group coordinator for the Decontamination Experiment. The operations department, among other duties, operated the plant systems, controlled the issue of plant keys and procedures, and provided plant operators for the decontamination water and service air special operating procedures. Among the duties of the maintenance department were repairing or replacing plant system components, maintaining and improving the closed-circuit televisıon system, and providing radwaste interim storage and disposal support. 
Industrial Safety and Health Department Support. The safety department was responsible or assumed the duties for several safety requirements for the decontamination experiment. Among these duties were:

- Screening incoming personnel for respiratory qualifications

o Specifying safety requirements to support work packages

- Administering the Heat Stress Control Program contained in Appendix D - Training and Safety, Attachment D-6

- Publishing training standards and lesson plans for safety issues; providing or qualifying instructors to teach safety items

- Supplying industrial hygiene equipment such as oxygen/combustible gas monitors

- Providing paramedic upon request.

Support Costs: Equipment and Man-hours. The support operations costs for the decontamination experiment were broken down into material and labor costs. The man-hour and material costs were separated into actual and prorated amounts for the period September 1981 to April 1982. Actual costs are those that can be directly related to a given item. Hours and dollars spent toward training, clothing, deessing, daca acquisition, lights, and trash removal cannot be related to a single item and thercfore were prorated for each item. In some cases (the "Blue Goose" water pump for example), the client already owned the equipment, and the only material cost incurred involved repair and maintenance. Table 2-32 shows the breakdown of man-hours and labor and material costs for major support items. Figure 2-18 shows the ratio of nonmanual support manhours to each hour of manual Labor inside the containment versus the time for the duration of the experiment. It is important to note that heavy engineering support was needed up front but decreased as the experiment progressed. GPU, 
HP, and operations support remained proportional to the number of hours of in-containment work through the course of the experiments. The figure emphasizes the expenditure of 5,660 man-hours in the period October 26 to December 18, 1981, in which no flushing was accomplished due to approvals not being received as scheduled. The figure also reflects the improved efficiency as more entries were made and less preparation work was required.

Figure 2-19 shows the man-hours, both manual and nonmanual, expended during the course of the experiment.

\section{Reactor Building Radiation Levels and Environment}

\section{Intensity Maps}

The two maps of elevations 305' and 347'-6" (Figures. 2-20 and 2-21) show the post-decontamination radiation dose for various locations throughout the areas. These maps characterize the major areas involved in the experiment and help to identify high-level contamination spots. The rates are based on the survey taken on March 26, 1982, suppleiliented, in somc cacec, by data collerted on May 13, 1982. Appendix C provides a more detailed reference of dala points.

\section{Comparison of Gamma Spectrometer Resulls with Radiological Recults}

Introduction. The SA.I collimated gamma-ray detector scanned surfaces of the TMI-2 containment building floors and walls both betore and afier the dernntamination experiment. The surface contamination at 10 locations (5 each) on elevations $3.05^{\prime}$ and $347^{\prime}-6^{\prime \prime}$ were measured in the scans. 'I'he pre-decontaminat.ion measurements were made on Lecember 16, 1981, aud Felıua ý 16, 1982, respectively, for. elevations 305' and 347'-6"; the post-decontam1naliun miedsurements were made on March 25 and March 26, 1982. Most of the measurements showed contamination levels. for. Cs.-137 that were less. than $1 \mu \mathrm{Ci} / \mathrm{cm}^{2}$. A. few areas showed levels that were below the minimun detectable limits. In: some cases, the level. of activity after decontamination was above. that measured before decontamination. 
TABLE 2-32. MAN-HOUR AND MATERIAL COSTS FOR SUPPORT

\begin{tabular}{|c|c|c|c|c|}
\hline Item & $\begin{array}{l}\text { Man-Hours } \\
\text { Actual/ } \\
\text { Prorated } \\
\end{array}$ & $\begin{array}{l}\text { Labor (\$) } \\
\text { Actual/ } \\
\text { Prorated } \\
\end{array}$ & $\begin{array}{l}\text { Material (\$) } \\
\text { Actual/ } \\
\text { Prorated }\end{array}$ & $\begin{array}{l}\text { Total (\$) } \\
\text { Actual/ } \\
\text { Prorated }\end{array}$ \\
\hline Spider & $11,421 / 8,425$ & $\begin{array}{l}221,436 / \\
122,476\end{array}$ & $50,437 / 9,505$ & $\begin{array}{l}271,873 / \\
131,981\end{array}$ \\
\hline $\begin{array}{l}\text { Decontamination water } \\
\text { system (incl. orange } \\
\text { duck water pump) }\end{array}$ & $3,957 / 5,055$ & $72,370 / 73,485$ & $88,971 / 5,885$ & $161,341 / 79,370$ \\
\hline $\begin{array}{l}\text { Water pump } \\
\text { (blue goose) }\end{array}$ & $873 / 460$ & $15,793 / 6,680$ & $870 / 513$ & $16,663 / 7,193$ \\
\hline Anteroom & $1,593 / 1,072$ & $25,366 / 15,588$ & $12,224 / 1,197$ & $37,590 / 16,785$ \\
\hline $\begin{array}{l}\text { Equipment } \\
\text { and small tools }\end{array}$ & & & 3,841 & 3,841 \\
\hline $\begin{array}{l}\text { Wet/dry vacuum } \\
\text { and cleaning unit }\end{array}$ & & & 73,331 & 73,331 \\
\hline $\begin{array}{l}\text { Gamma } \\
\text { spectrometer }\end{array}$ & $335 / 306$ & $6,307 / 4,452$ & & $6,307 / 4,452$ \\
\hline Total & $18,179 / 15,318$ & $\begin{array}{l}341,2721 \\
222,681\end{array}$ & $229,674 / 17,100$ & $\begin{array}{l}570,946 / \\
239,781\end{array}$ \\
\hline Grand total & 33,497 & $\$ 563,953$ & $\$ 246,774$ & $\$ 810,727$ \\
\hline
\end{tabular}


Summary. A great deal of difficulty was encountered when an attempt was made to correlate gamma-spectroscopic methods with other measurements, such as swipe and contact radiation data. For most of the points at which gammaspectroscopic measurements were made, other types of data were not collected.

Several of the points analyzed by gamma spectroscopy were located in high traffic areas or in areas that would have become recontaminated during decontamination of surrounding surfaces, e.g., overspray from spin-jet operations. However, without other measurements at the same locations, the validity of gamma spertroscopic results cannot be substantiated or refuted. From the pre-decontamination survey, it can be established that the ratio of the areal activity distribution as measured by ganm spectroscopy to that estimated by contact measurements was 0.08 . Analysis of the post-decontamination point (SAI designation 34) using the above ratio yields a projected contact reading of approximately $1650 \mathrm{mrem} / \mathrm{hr}$, which is within the observed range of 1000 to $3800 \mathrm{mrem} / \mathrm{hr}$. However, this is the only point where a rough comparisun cau be made, and general conclusions cannot be based on one point.

Clearly, the gamma-spectroscopic results are derived from a very small sampling within a large area having a great deal of hcterogene1ty. Therefuce, it should not be surprising if unrepresentative results wert uttained. Somc of the apparent inconsistencies may be explainable when gamma-spectroscopic results and surface deposition analyses can be compared. The analytical results from deposition sampling reflect agreement with the RDFs obtained during the experiment for comparable points. At this point, there has not been an analysis of the gamma-spectroscopic and surface deposition results.

Reactor Building Environment: Analysis of Water Quality, Biological Activity, and Airborne Activity

Water Quality. The qualily of the water uscd for decontamination of the reactor building surfaces during the cxperiment was acceptahle compared to maximum permissible concentrations (mpc). Table 2-33 details both the concentration limits and the actual measured values in the decontamination water. 
Boron concentrations in the water were at 87 percent of the maximum permissible. The boron concentrations were kept at a relatively high level in the event that significant concentration of fuel fines occurred due to the decontamination operations.

Chloride ion-concentration was one-half of mpc values. Tritium was approximately 77 percent of mpc value and was closely monitored in air and by bioassay to ensure that tritium mpc hours were strictly observed in the decontamination work force. The $\mathrm{pH}$ of the water used was acidic, approximately $\mathrm{pH} 5$.

Specific radionuclide concentrations were generally a factor of 1000 less than mpc values. Table 2-34 lists specific isotope concentrations in the water plus those concentrations specifically regulated in the mpcs. 
TABLE . 2-33. GROSS DECONTAMINATHON IFST WATER QUALITY

\begin{tabular}{lcc}
\hline & \multicolumn{2}{c}{ Concentration } \\
\cline { 3 - 3 } Parameter & $\frac{\text { Max. Allowance }}{2000 \mathrm{ppm}}$ & $\frac{\text { Actual }}{1731 \mathrm{ppm}}$ \\
Boron & $2 \mathrm{ppm}$ & $1 \mathrm{ppm}$ \\
Chloride ion & $1.0 \mu \mathrm{Ci} / \mathrm{ml}$ & $0.77 \mu \mathrm{Ci} / \mathrm{ml}$ \\
Tritium & $\geqq 7.5$ & 4.83 \\
pH & & \\
\hline
\end{tabular}


TABLE 2-34. RADIONUCLIDE CONCENTRATIONS IN DECONTAMINATION WATER

\begin{tabular}{|c|c|c|}
\hline \multirow[b]{2}{*}{$\underline{\text { Radionuclide }}^{a}$} & \multicolumn{2}{|c|}{ Concentration } \\
\hline & Max. Allowance & Actual \\
\hline $\mathrm{Cs}-134$ & $1.0 \times 10^{-3} \mu \mathrm{Ci} / \mathrm{ml}$ & $2.3 \times 10^{-6} \mu \mathrm{Ci} / \mathrm{ml}$ \\
\hline $\mathrm{Cs}-137$ & $1.6 \times 10^{-3} \mu \mathrm{Ci} / \mathrm{ml}$ & $2.6 \times 10^{-5} \mu \mathrm{Ci} / \mathrm{ml}$ \\
\hline $\mathrm{Sr}-89$ & $8.0 \times 10^{-4} \mu \mathrm{Ci} / \mathrm{ml}$ & \\
\hline $\operatorname{Sr}-90$ & $2.7 \times 10^{-5} \mu \mathrm{Ci} / \mathrm{ml}$ & $3.0 \times 10^{-5} \mu \mathrm{Ci} / \mathrm{ml}$ \\
\hline $\mathrm{Ce}-58$ & & $1.0 \times 10^{-7} \mu \mathrm{Ci} / \mathrm{ml}$ \\
\hline $\mathrm{Ce}-60$ & & $3.6 \times 10^{-7} \mu \mathrm{Ci} / \mathrm{ml}$ \\
\hline $\mathrm{Ce}-144$ & & $2.7 \times 10^{-6} \mu \mathrm{Ci} / \mathrm{ml}$ \\
\hline$R v-106$ & & $1.2 \times 10^{-6} \mu \mathrm{Ci} / \mathrm{ml}$ \\
\hline$M n-54$ & & $1.5 \times 10^{-7} \mu \mathrm{Ci} / \mathrm{ml}$ \\
\hline $\mathrm{Sb}-125$ & & $1.0 \times 1.0^{-6} \mu \mathrm{Ci} / \mathrm{ml}$ \\
\hline
\end{tabular}

a. With total activily not to exceed $3.5 \times 10^{-3} \mu \mathrm{Ci} / \mathrm{ml}$. 
In summary, the water quality was good. Only the concentration of tritium required specific monitoring in air and by bioassay during decontamination operations.

Biological Activity. No biological activity measurements were made in the reactor building during or following the decontamination experiment. Prior to draining the reactor building sump, a preliminary analysis was made of the biological activity in air and sump water.

'l'he pre-decontamination biological activity data allowed several conclusions to be reached. First, there was signfficant mievbiological activity in air, on reactor building surfaces, and in sump water. Second, microbiological activity was not dissimilar to that found in the natural environment, specifically river water. Opportunistic pathogens were identified but were not of concern as long as respiratory protection was used in the building. Waterborne microorganisms could potentially reduce the efficiency of the SDS, especially by chelating or metabolizing Se-90.

The biological activity in air and resuspendable from building surfaces will need to be reevaluated before respiratory protection is discuulinued. It is possible that some surface decontamination procedures, especially thosc using inorganic chemicals, would reduce biotic titer on surfaces and, therefore, reduce the potential inhalation hazard from microorganisms in the building.

Airborne Activity Results. Table 2-35 summarizes air concentrations of Cs-136 (average BZA samples), tritium, and averagc dose during operations. Detailed information by day and hour is given in Appendix $C$.

Cs-13/ was unchanged or slightly teduced by dccontamination uperations. There was no indication that Cs-137 levels in air were elevated during operations or that there was any significant difference in airborne Cs-137 activity among the various decontamination techniques. The average airborne Cs-137: value following the experiment was $4 \times 10^{-8} \mu \mathrm{Ci} / \mathrm{cc}$. 
TABLE 2-35. AIRBORNE DATA SUMMARY

\begin{tabular}{|c|c|c|c|c|c|c|c|}
\hline $\begin{array}{c}\text { Data } \\
\text { Acquisition } \\
\text { Task } \\
\end{array}$ & $\begin{array}{c}\text { Suriace } \\
\text { Description }\end{array}$ & Technique & $\begin{array}{c}\text { Task } \\
\text { Description } \\
\end{array}$ & $\begin{array}{c}\text { Average } \\
\text { BZA } \\
\mathrm{Cs}-137 \\
(\mu \mathrm{Ci} / \mathrm{CC}) \\
\end{array}$ & $\begin{array}{l}\text { Average } \\
\text { Tritium } \\
(\mu c i / c c \\
\end{array}$ & $\begin{array}{c}\text { Average } \\
\text { Dose } \\
\text { (mrem } / \mathrm{hr}) \\
\end{array}$ & $\begin{array}{c}\text { Average } \\
\text { TLD }\end{array}$ \\
\hline 1 & El. $305^{\prime}$ floor & $\begin{array}{l}\text { LP } \\
\text { flush }\end{array}$ & $\begin{array}{l}\text { Pre-decon } \\
\text { Decon operation } \\
\text { Post-decon }\end{array}$ & 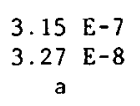 & $3.4_{a}^{a} E-6$ & $\begin{array}{l}239.2 \\
472.5 \\
321.0\end{array}$ & $\begin{array}{l}282.5 \\
396.7 \\
170\end{array}$ \\
\hline 3 & Polar crane & $\begin{array}{l}\text { LP } \\
\text { flush }\end{array}$ & $\begin{array}{l}\text { Pre-decon } \\
\text { Decon operation } \\
\text { Post-decon }\end{array}$ & $\begin{array}{l}1.34 \mathrm{E}-7 \\
8.04 \mathrm{E}-8 \\
5.47 \mathrm{E}-8\end{array}$ & $8.28_{a}^{a} E-7$ & $\begin{array}{l}117.1 \\
130.9 \\
165.3\end{array}$ & $\begin{array}{l}190 \\
a \\
133.3\end{array}$ \\
\hline 4 & $\begin{array}{l}A \approx B \text { D-rings, } \\
\text { missile shields } \\
\& \text { zefueling canal }\end{array}$ & $\begin{array}{l}\text { LP } \\
\text { flush }\end{array}$ & $\begin{array}{l}\text { Pre-decon } \\
\text { Decon operation } \\
\text { Post-decon }\end{array}$ & 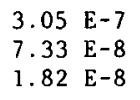 & $\begin{array}{ll}4.5 & E-8 \\
4.0 & E-6 \\
5.4 & E-7\end{array}$ & $\begin{array}{l}246.7 \\
162.6 \\
166.0\end{array}$ & $\begin{array}{c}293.3 \\
a \\
a\end{array}$ \\
\hline & El. $347^{\prime}-6^{\prime \prime}$ floor & $\begin{array}{l}\text { LP } \\
\text { flus } 7\end{array}$ & $\begin{array}{l}\text { Pre-decon } \\
\text { Decon operation } \\
\text { Post-decon }\end{array}$ & $\begin{array}{ll}2.66 & \mathrm{E}-7 \\
2.27 & \mathrm{E}-8 \\
1.31 & \mathrm{E}-7\end{array}$ & $\begin{array}{ll}3.4^{\mathrm{a}} & \mathrm{E}-6 \\
3.0 & \mathrm{E}-7\end{array}$ & $\begin{array}{l}196.9 \\
196.7 \\
148.6\end{array}$ & $\begin{array}{l}226.8 \\
a \\
172.5\end{array}$ \\
\hline & $\begin{array}{l}\text { Equipment } \\
\text { flush }\end{array}$ & $\begin{array}{l}\text { HP } \\
\text { spray }\end{array}$ & $\begin{array}{l}\text { Pre-decon } \\
\text { Deccn operation } \\
\text { Post-decon }\end{array}$ & $\begin{array}{ll}1.82 & \mathrm{E}-8 \\
4.67 & \mathrm{E}-8 \\
2.57 & \mathrm{E}-8\end{array}$ & $\begin{array}{ll}5.4 & \text { E-7 } \\
7.1 & \text { E-7 } \\
6.1 & \text { E-7 }\end{array}$ & $\begin{array}{l}166.0 \\
199.4 \\
201.6\end{array}$ & $\begin{array}{l}a \\
186.7 \\
a\end{array}$ \\
\hline & $\begin{array}{l}\text { Ei. } 347^{\prime}-6^{\prime \prime} \\
\text { flcor \& equipment }\end{array}$ & $\begin{array}{l}\text { HP } \\
\text { spra! }\end{array}$ & $\begin{array}{l}\text { Pre-decon } \\
\text { Decon } \\
\text { Areas } 1,2,3 \\
\text { Areas } 4,5 \\
\text { Areas } 6,7 \\
\text { Areas } 8,9 \\
\text { Post-decon }\end{array}$ & $\begin{array}{ll}2.57 & \mathrm{E}-8 \\
1.53 & \mathrm{E}-8 \\
2.63 & \mathrm{E}-8 \\
1.73 & \mathrm{E}-8 \\
2.11 & \mathrm{E}-8 \\
1.05 & \mathrm{E}-8\end{array}$ & $\begin{array}{ll}6.1 & \text { E-7 } \\
& \\
5.05 & \text { E-7 } \\
1.95 & \text { E-6 } \\
2.8 & \text { E-6 } \\
2.3 & \text { E-6 } \\
8.0 & \text { E-7 }\end{array}$ & $\begin{array}{r}98.8 \\
156.2 \\
143.1 \\
135.1 \\
144.3\end{array}$ & $\begin{array}{c}a \\
130 \\
a \\
a \\
153.5 \\
140\end{array}$ \\
\hline 6 & El. $305^{\prime}$ floor & $\begin{array}{l}\text { HP } \\
\text { spray }\end{array}$ & $\begin{array}{l}\text { Pre-decon } \\
\text { Decon operation } \\
\text { Post-decon }\end{array}$ & $\begin{array}{ll}1.65 & \mathrm{E}-8 \\
3.74 & \mathrm{E}-8 \\
1.22 & \mathrm{E}-8\end{array}$ & \begin{tabular}{ll}
2.36 & $E-6$ \\
2.7 & E-6 \\
\multicolumn{1}{c}{ a } &
\end{tabular} & $\begin{array}{l}372.0 \\
372.8 \\
346.5\end{array}$ & $\begin{array}{l}110 \\
350 \\
274\end{array}$ \\
\hline 4 & E1. $347^{\prime}-6^{\prime \prime}$ floor & $\begin{array}{l}\text { Floor } \\
\text { scrub }\end{array}$ & $\begin{array}{l}\text { Pre-decon } \\
\text { Decon operation } \\
\text { Post-decon }\end{array}$ & $\begin{array}{ll}6.5 & \mathrm{E}-9 \\
1.63 & \mathrm{E}-8 \\
9.65 & \mathrm{E}-9\end{array}$ & $\begin{array}{l}\mathrm{a} \\
\mathrm{a} \\
\mathrm{a}\end{array}$ & $\begin{array}{r}320.6 \\
77.5 \\
163.1\end{array}$ & $\begin{array}{l}122.5 \\
116.7 \\
\quad a\end{array}$ \\
\hline 5 & E1. $305^{\prime}$ floor & $\begin{array}{l}\text { Strip } \\
\text { coat }\end{array}$ & $\begin{array}{l}\text { Pre-decon } \\
\text { Decon operation } \\
\text { Post-decon }\end{array}$ & $\begin{array}{ll}6.5 & E-9 \\
8.8 & E-9 \\
7.35 & E-9\end{array}$ & $\begin{array}{l}a \\
a \\
a\end{array}$ & $\begin{array}{l}320.6 \\
236.7 \\
224.3\end{array}$ & $\begin{array}{l}122.5 \\
380 \\
250\end{array}$ \\
\hline 1 & El. $305^{\prime}$ Floor & $\begin{array}{c}\text { LP } \\
\text { re-flusa }\end{array}$ & $\begin{array}{l}\text { Pre-decon } \\
\text { Decon cperation } \\
\text { Post-decon }\end{array}$ & $\begin{array}{ll}1.31 & \mathrm{E}-7 \\
7.8 & \mathrm{E}-8 \\
1.65 & \mathrm{E}-8\end{array}$ & \begin{tabular}{ll}
\multicolumn{2}{c}{${ }^{\mathrm{a}}$} \\
$4.47^{\mathrm{E}}-6$ \\
2.36 & $\mathrm{E}-6$
\end{tabular} & $\begin{array}{l}148.6 \\
408.8 \\
372.0\end{array}$ & $\begin{array}{l}175 \\
381.7 \\
110\end{array}$ \\
\hline
\end{tabular}


Tritium in air was increased by a factor of 10 or less during decontamination operations. This was due primarily to the concentration of tritium in the water used for operations. The higher tritium values made it necessary to keep track of mpc hours for workers during flushing operations in order to ensure regulatory compliance. Following flushing operations, tritium returned to the pre-experiment levels, averaging approximately $10^{-6} \mu \mathrm{Ci} / \mathrm{cc}$.

In summary, decontamination operations reduced airborne particulate activity and increased tritium only temporarily. It could be expected that the reduced airborne particulates would be sustained through time. Tritium levels could be reduced as alrborne water and vapor are reduced following the termination of the experiment.

\section{Surface Deposition}

The purpose of this task was to obtain surface and subsurface samples of floor, wall, and equipment areas inside the reactor building before and after decontamination tasks. Samples were taken at varying depths and analysed in order to determine the extent and characterization of contamination inside the containment for evaluating the effecliveness of the decontamination efforts. Samples were collected will lie surlace deposition campler shown in Appendix A. The sampler is a drill. with an enclosed housing and attached vacuum unit. With this device, core samples can be obtained at various depths determined by the adjustment controls provided on the unit. Sampling locations are shown in Appendix A.

The data on surface deposition from the Gross Deconcanlmatiun Esperiment are included as Appendix A.

The results of the surface deposition DFs are shown where comparable test points are located with test points for the Gross Decontamination Experiment low/high pressure flush tests. 
Elevation $347^{\prime}-6^{\prime \prime}$

II

$\mathrm{V}_{1}$

$\mathrm{V}_{2}$

VII

VIII

Elevation $305^{\prime}$

IV
19

23

10

29

30

From Tables A-1 and A-2 in Appendix A, it is observed that surface activity for those locations where bore holes were made at various depths is relatively constant. Since the depth of the hole does not affect the activity, the activity must be within the initial layer. Most bore holes were at least 40 mils, which indicates that the majority of the contamination is within this 40-mil layer. Additionally, the agreement between DFs for surface deposition and contact is very good. The computation of these factors implies little or no self shielding of the beta. Hence, if the contaminate was not near the surface, these DFs would vary widely.

The DF data in Tables A-15 through A-17 for horizontal surfaces indicate an average DF of 6 to 25. This agrees well with the direct comparison data of 9 to 36. It seems reasonable to conclude that, gcnerally, a DF of 10 or more was demonstrated. 
Elevation $305^{\prime}$ (44 samples)

DFs

Low

High

Average

Medium
Vertical Surface

0.07

26.0

4.3

1.7
Horizontal Surface

0.7

80.0

25.0

29.0

Elevation $34^{\prime}-6^{\prime \prime}$ (34 samples)

DFs

Vertical Surface

Horizontal Surface

Low

0.4

4.0

High

1.6

29.0

Average

0.8

13.8

Medium

ก.8

16.1

Elevation $367^{\circ}$ (8 samplc3)

DFs

Low

High

Avcrage

Hediun
Vertical Surface

(one measuled point)

2.0
Horizontal Surface

1.0

15.0

6.3

2.0

The ovcrall results reflect that the radioactive activity is located in the paint and dnes not penetrate below approximately $40 \mathrm{mils}$. In addition, the remaining amount of debris on the surfaces, as determined by the surface deposition and the experiment, are relatively the same. 


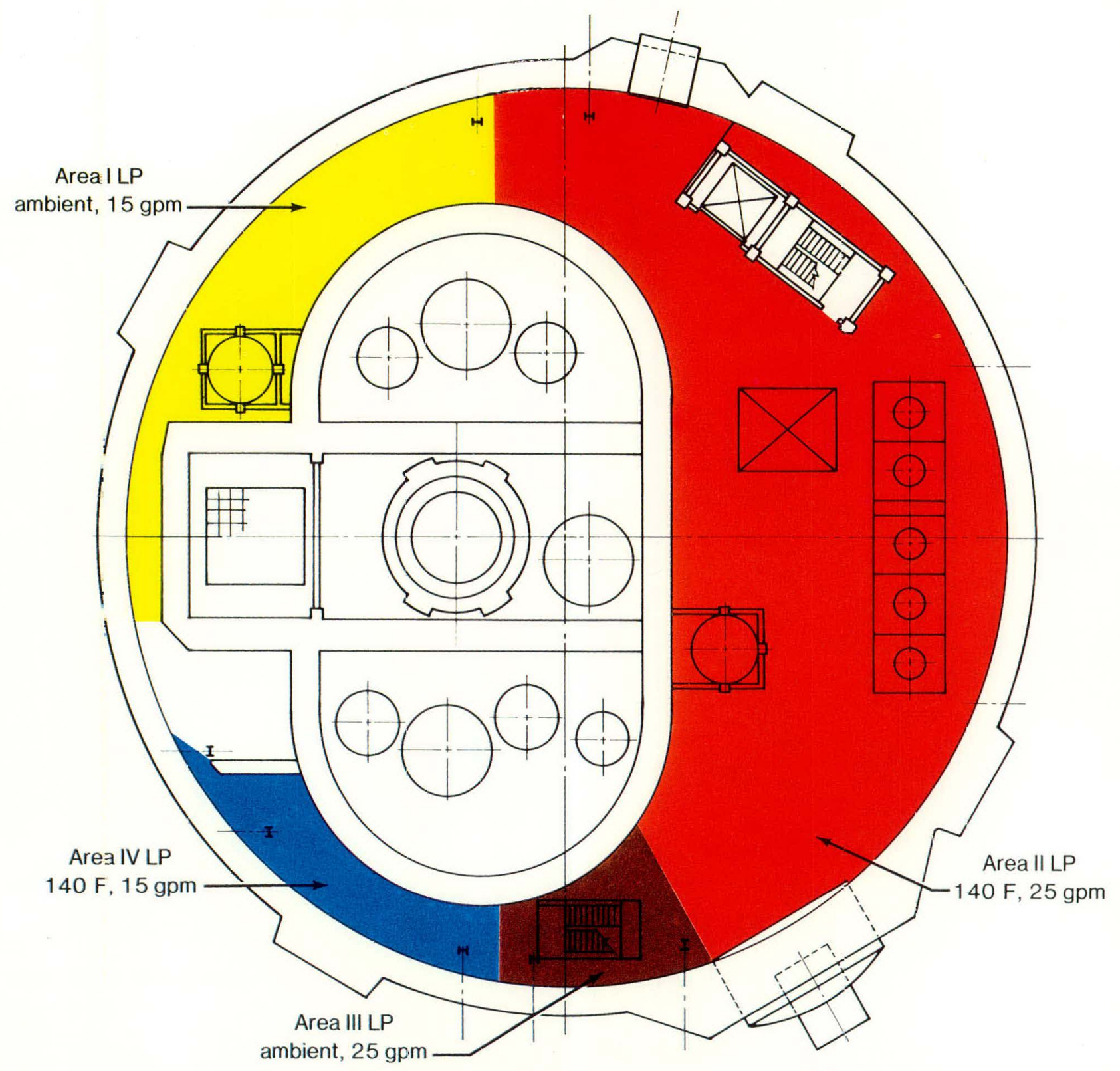

$\leftarrow$ (N)-

Figure 2-1. Elevation 305' low pressure flush - planned. 


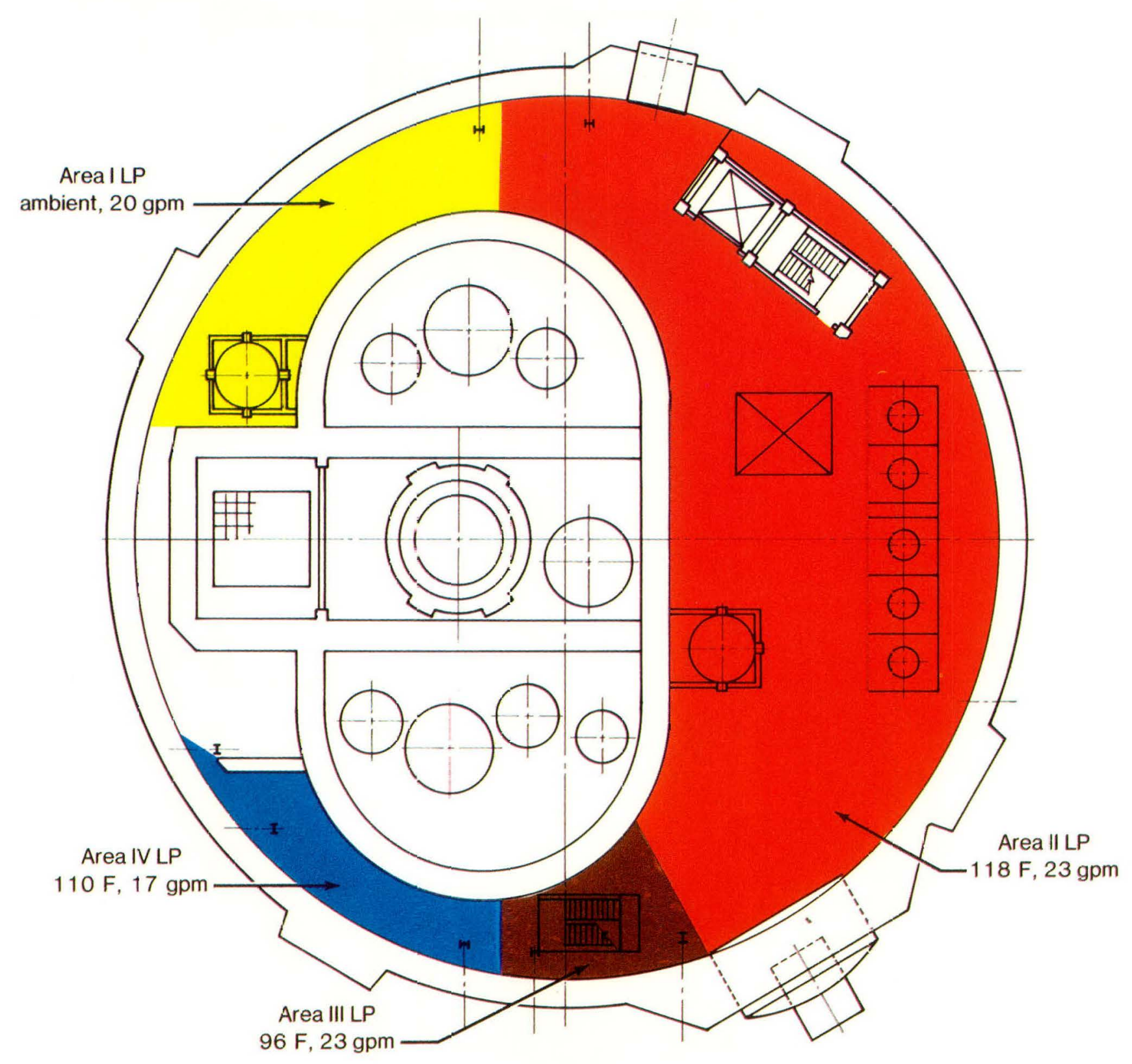

$+(\mathbf{N})$

Figure 2-2. Elevation 305' low pressure flush - actual. 


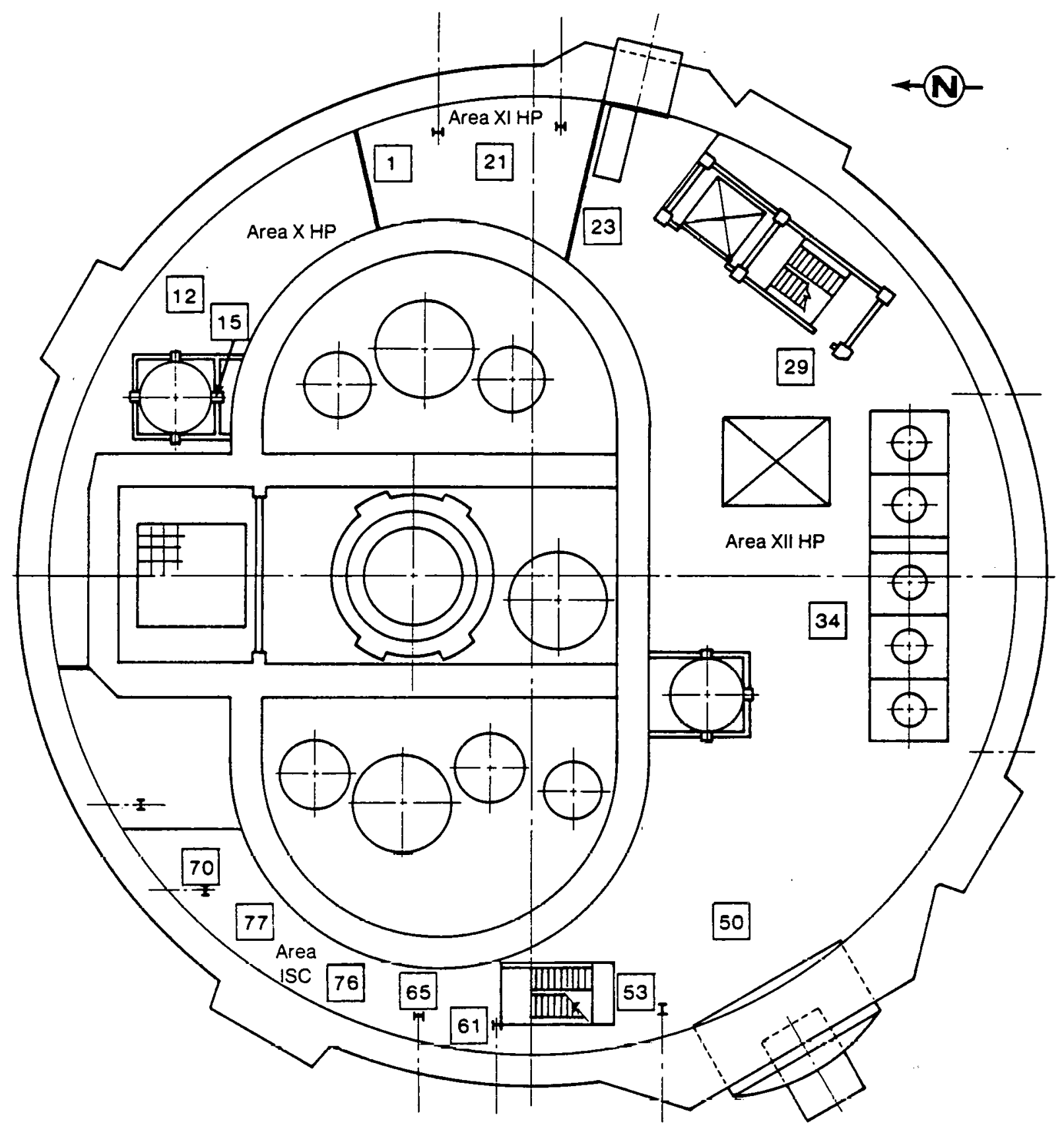

Figure 2-3. Data acquisition survey locations - elevation 305' low pressure, high pressure, and strippable coating tests. 


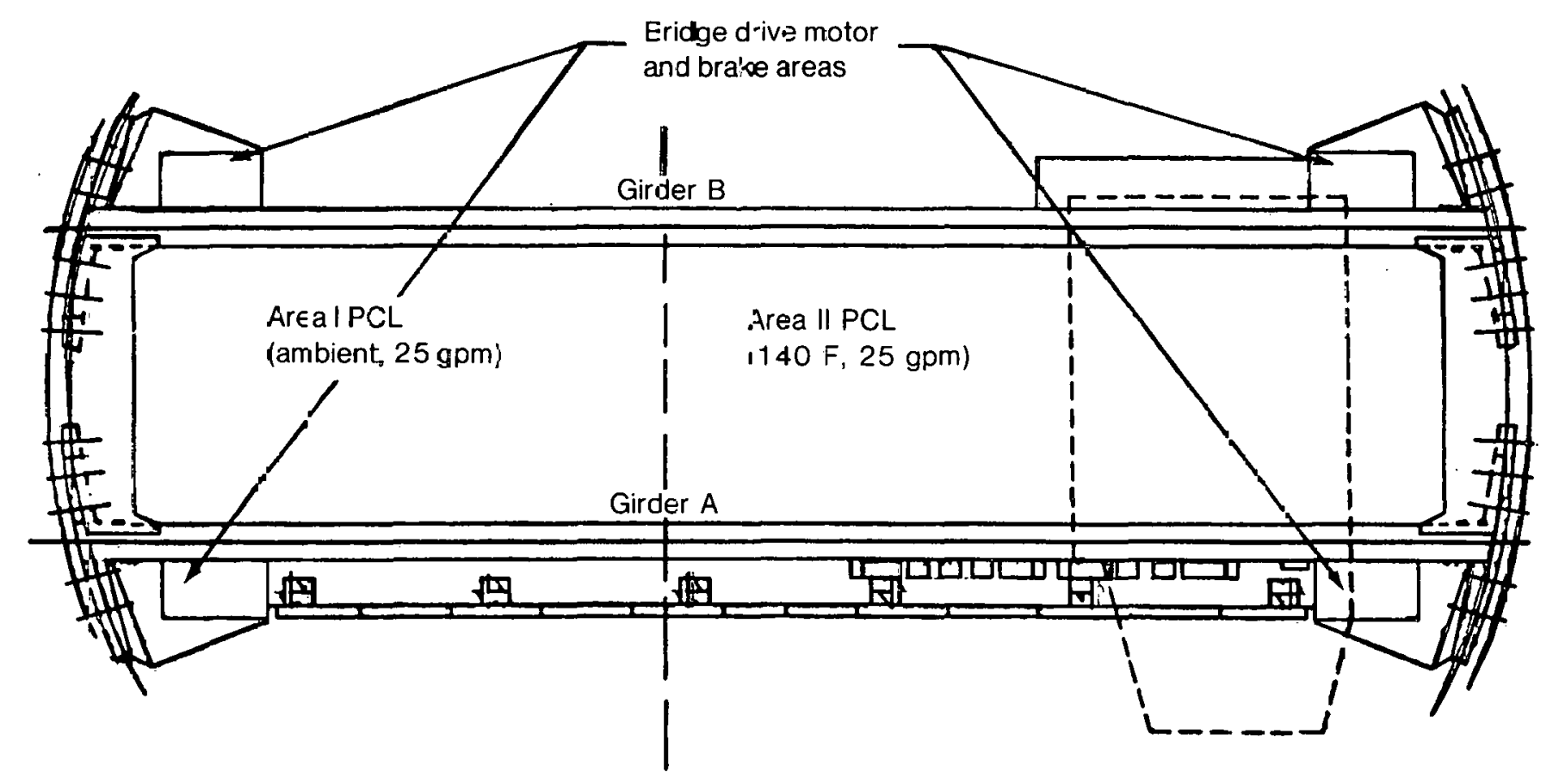

Figure 2-4. Low pressure flush of polar crane. 


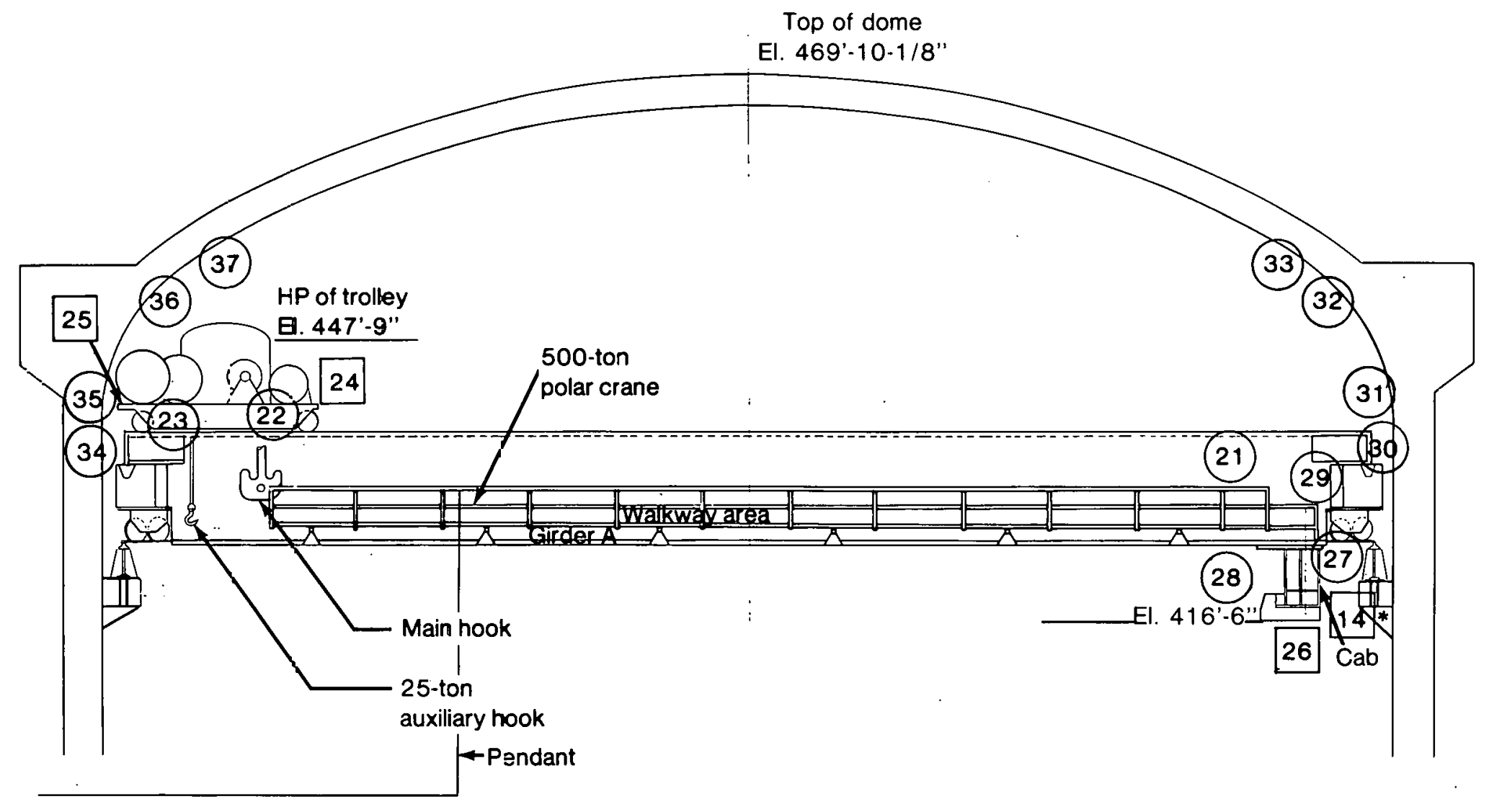

Figure 2-5. Diagram of dome area/polar crane - data acquisition locations. 


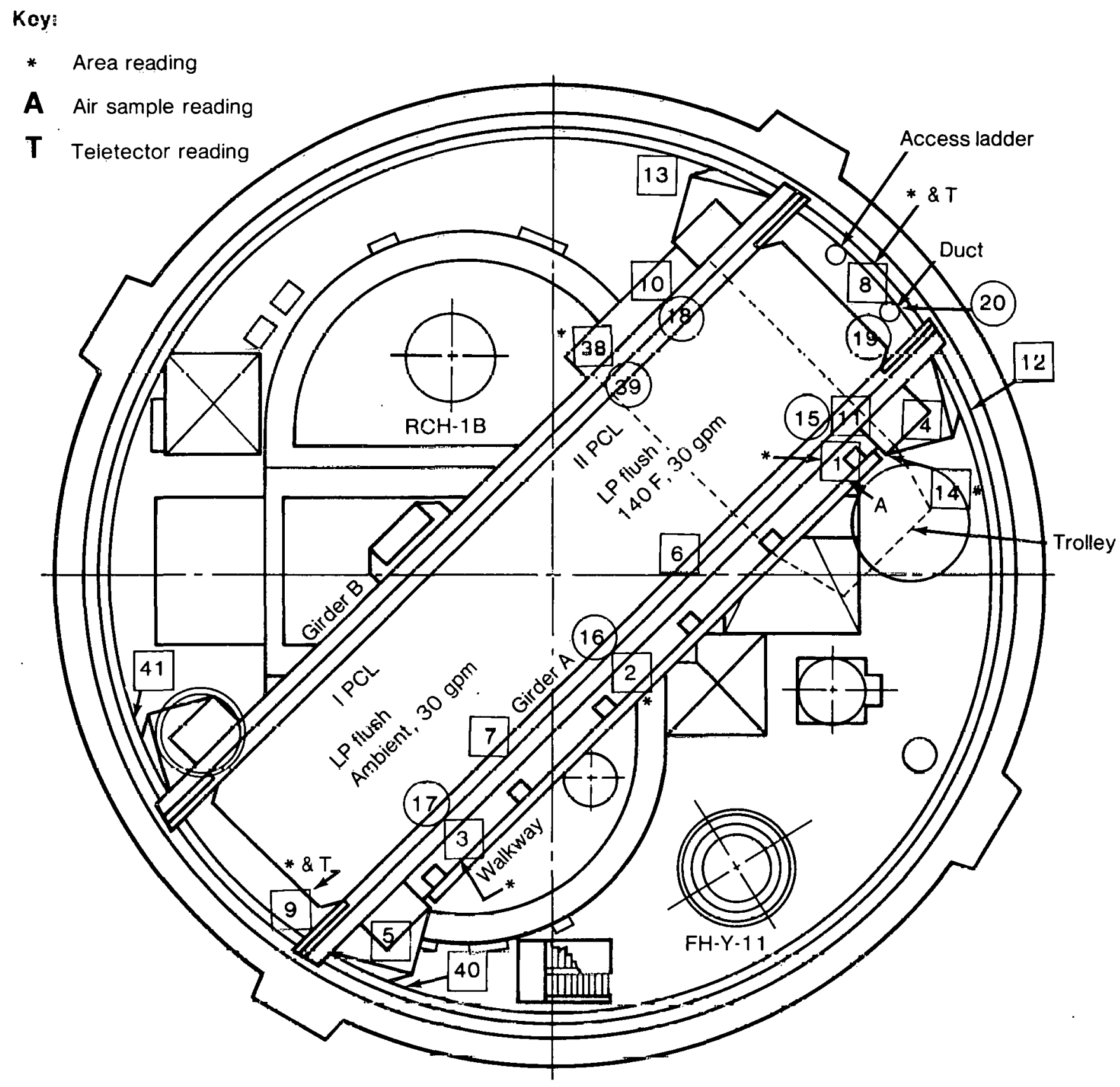

Plan El. 426'-0',

Figure 2-6. Diagram of polar crane - data acquisition locations. 


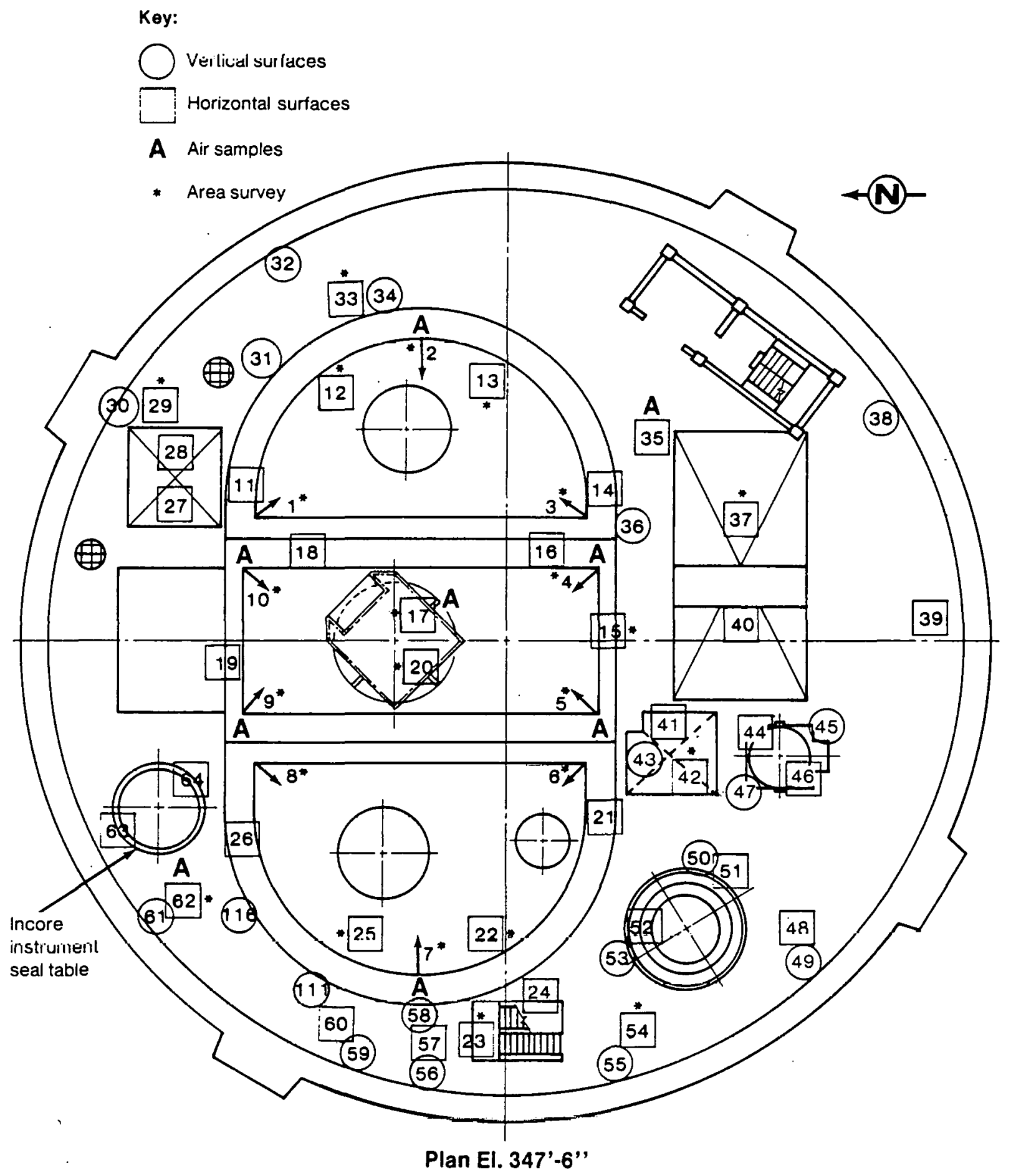

Figure 2-7. Data acquisition locations - elevation 347 '-6" D-rings and missile shield areas. 


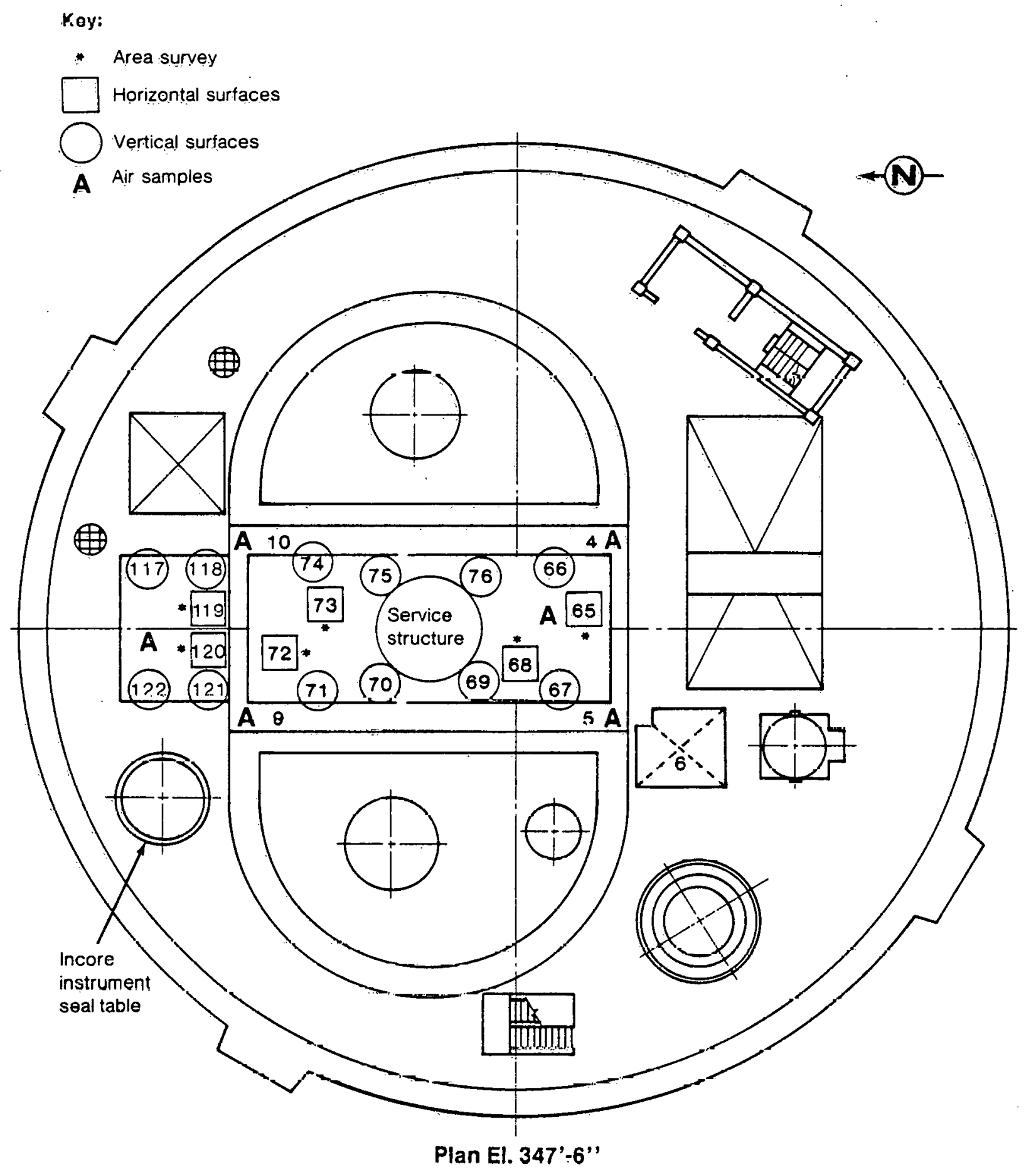

Figure 2-8. Data acquisition locations - refueling canal and service structure. 


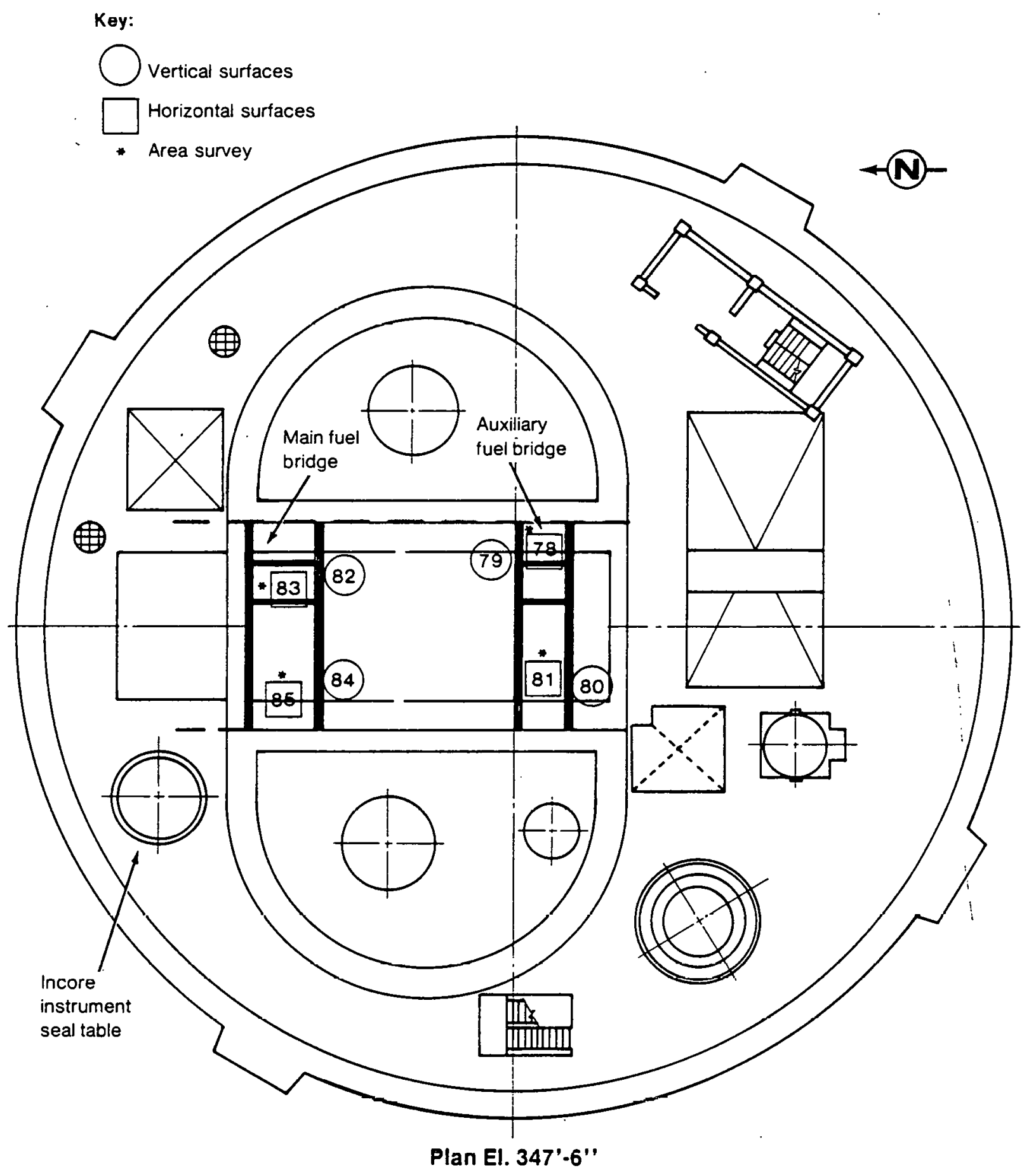

Figure 2-9. Data acquisition locations - fuel handling bridge. 


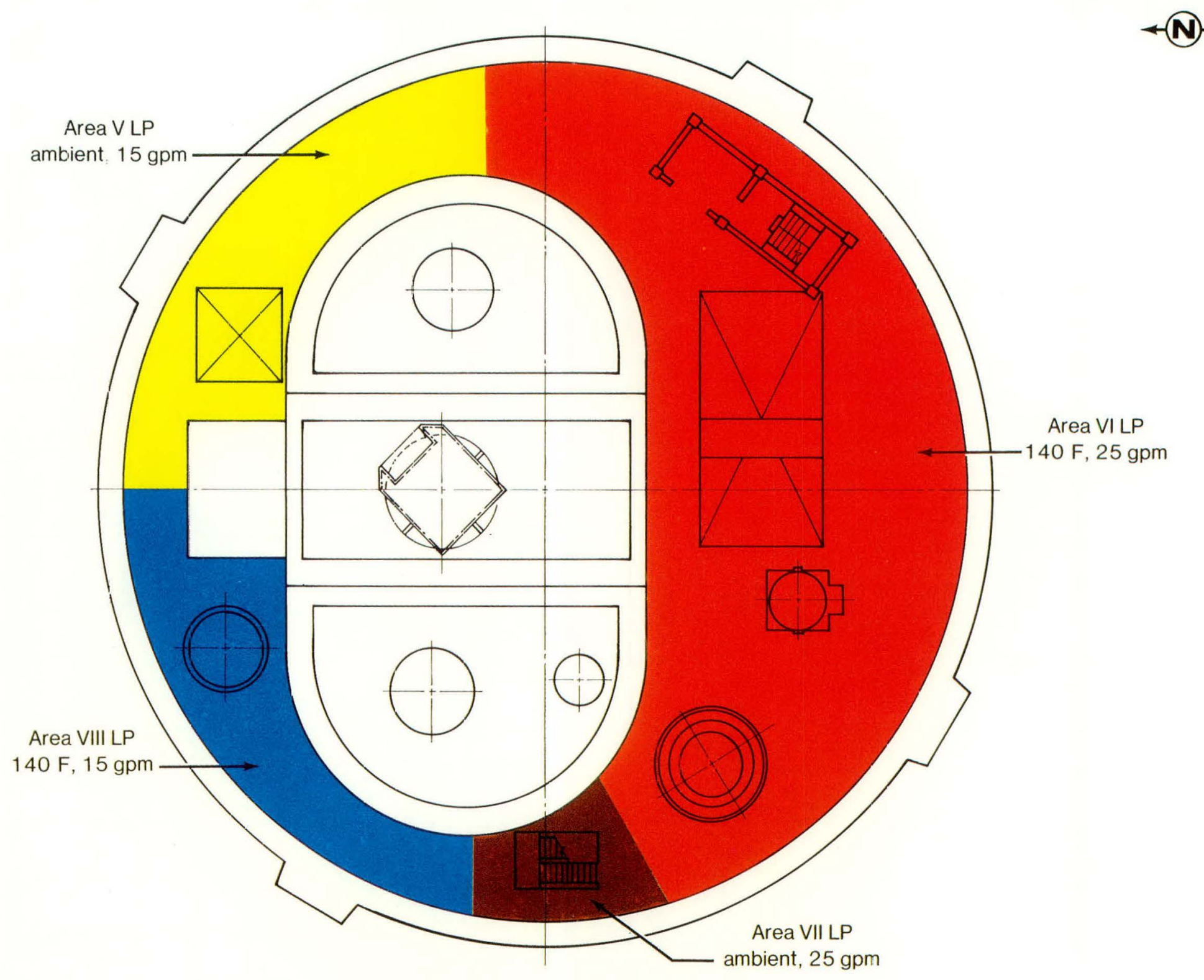

Figure 2-10. Elevation 347'-6'" low pressure flush - planned. 


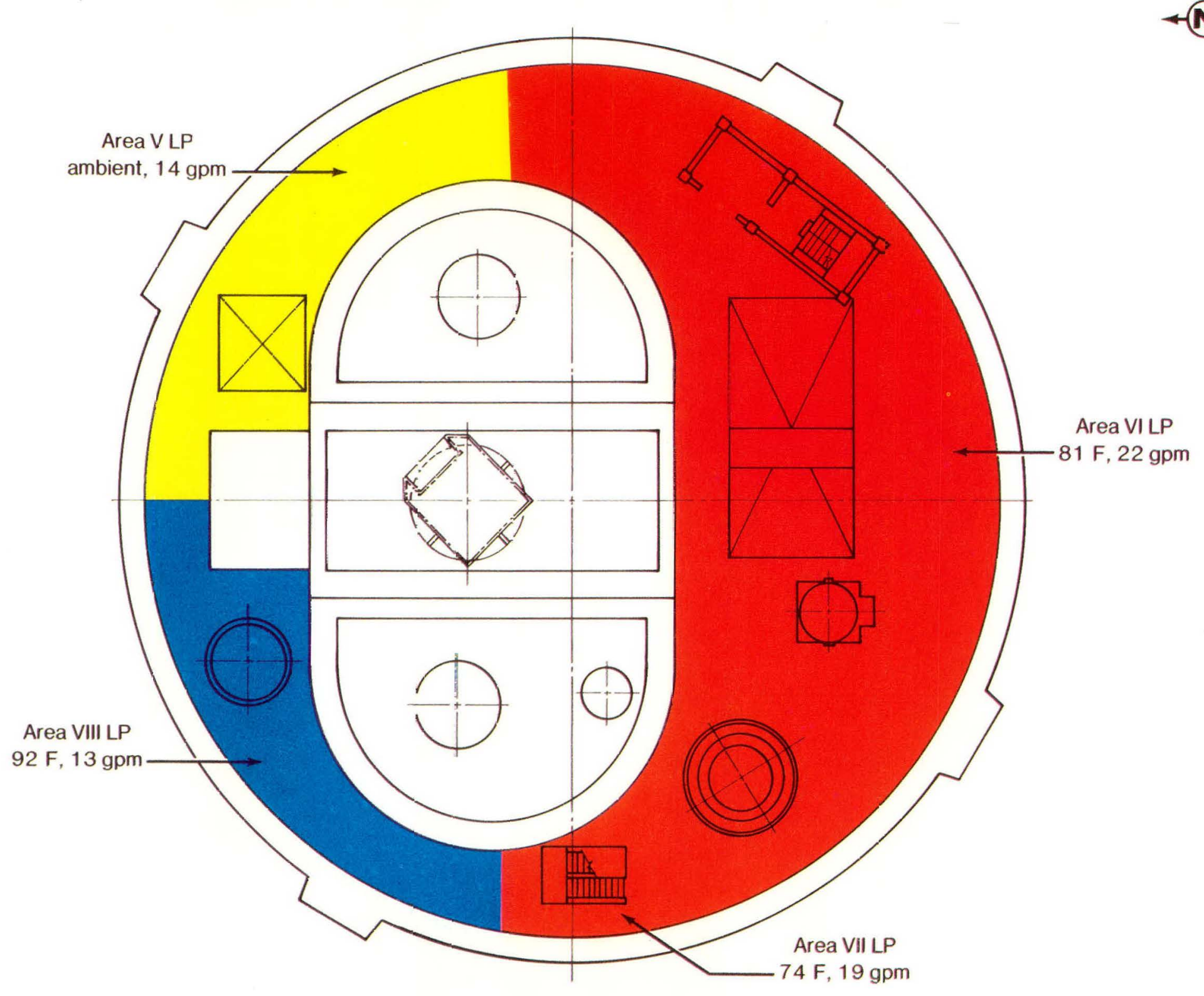

Figure 2-11. Elevation 347'-6'" low pressure flush - actual. 


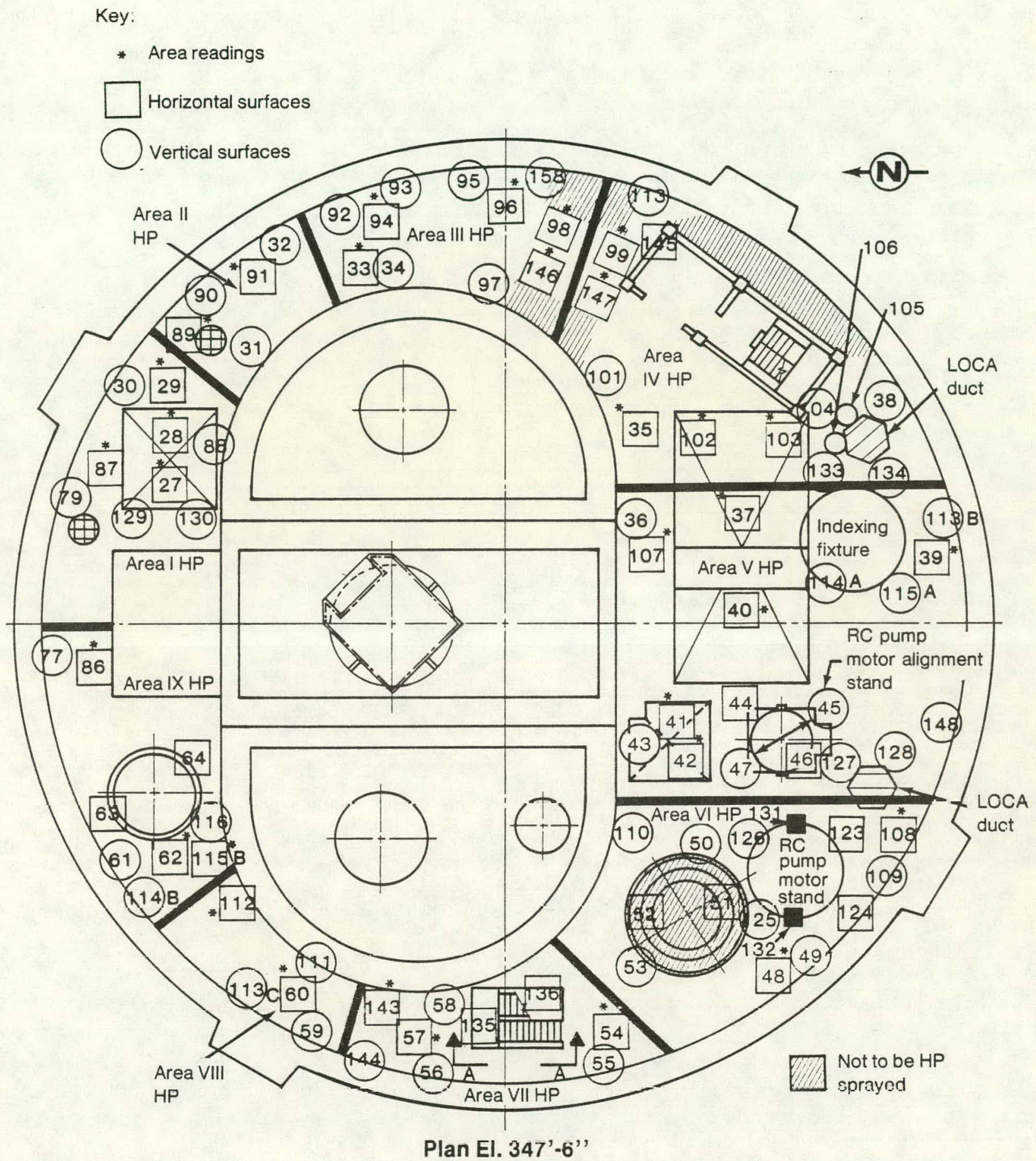

Figure 2-12. Elevation $347^{\prime}-6$ ' ' planned data acquisition locations - low pressure and high pressure flush. 


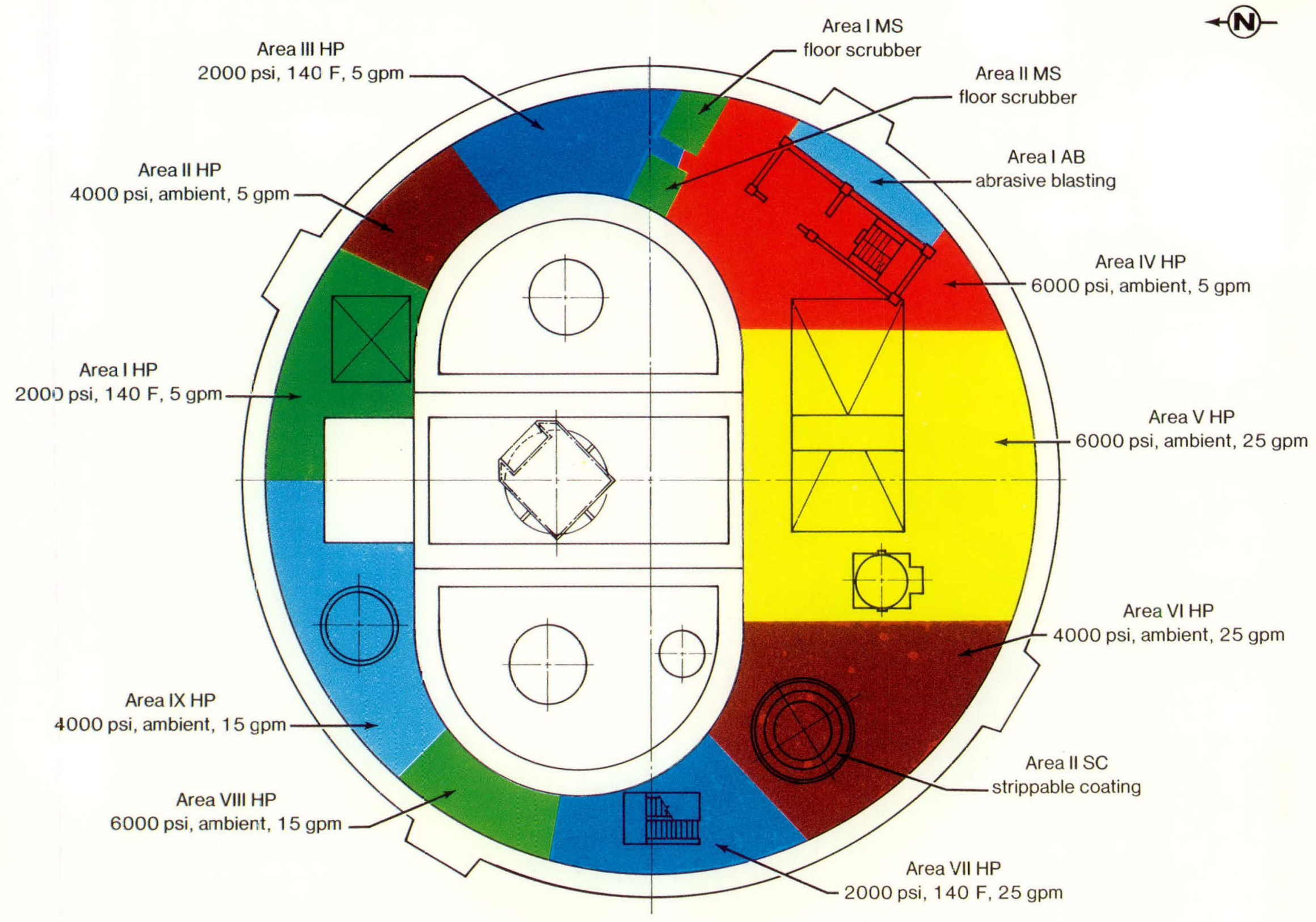

Figure 2-13. Elevation $347^{\prime}-6$ '' high pressure flush - planned. 


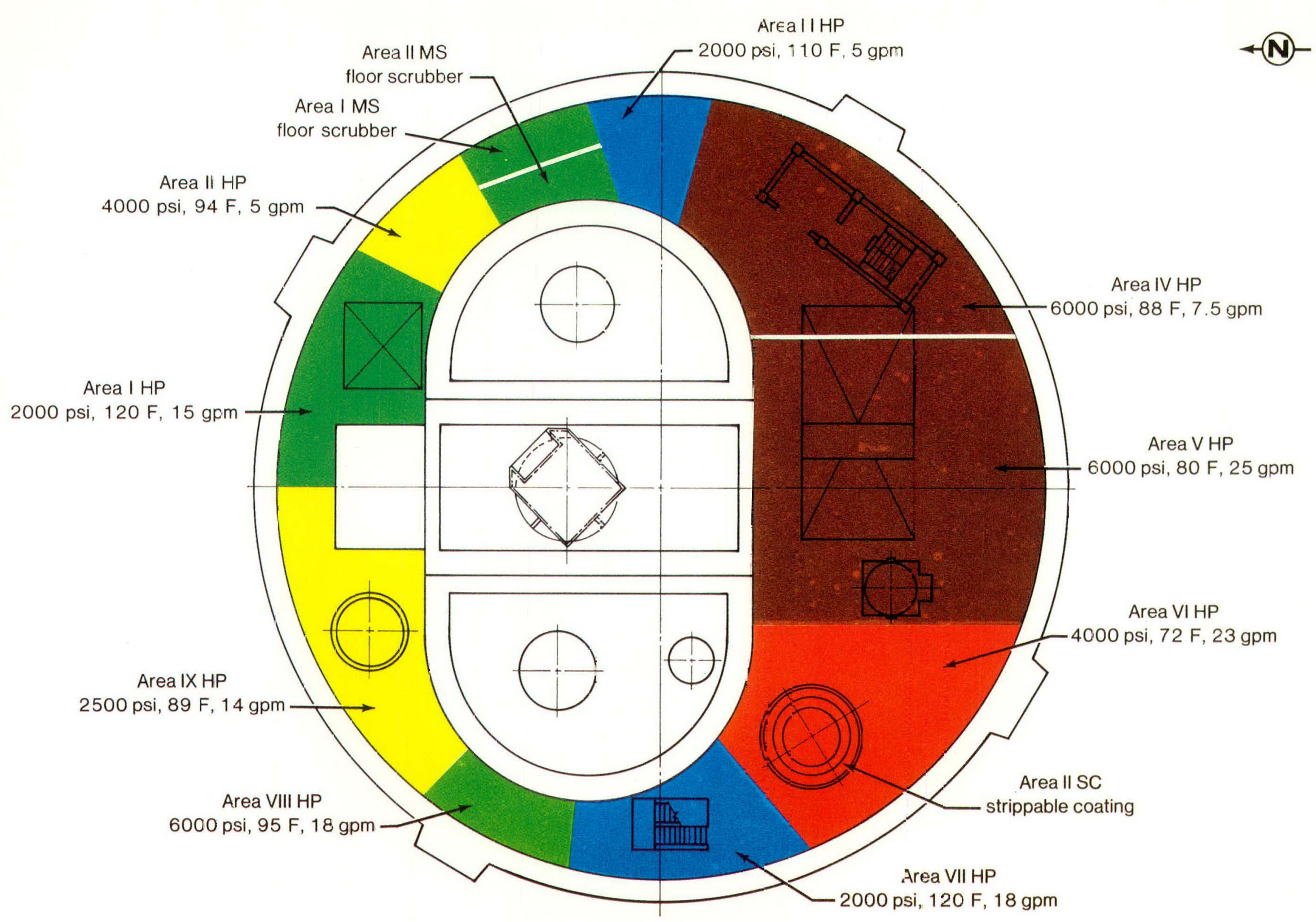

Figure 2-14. Elevation 347'-6' high pressure flush - actual. 


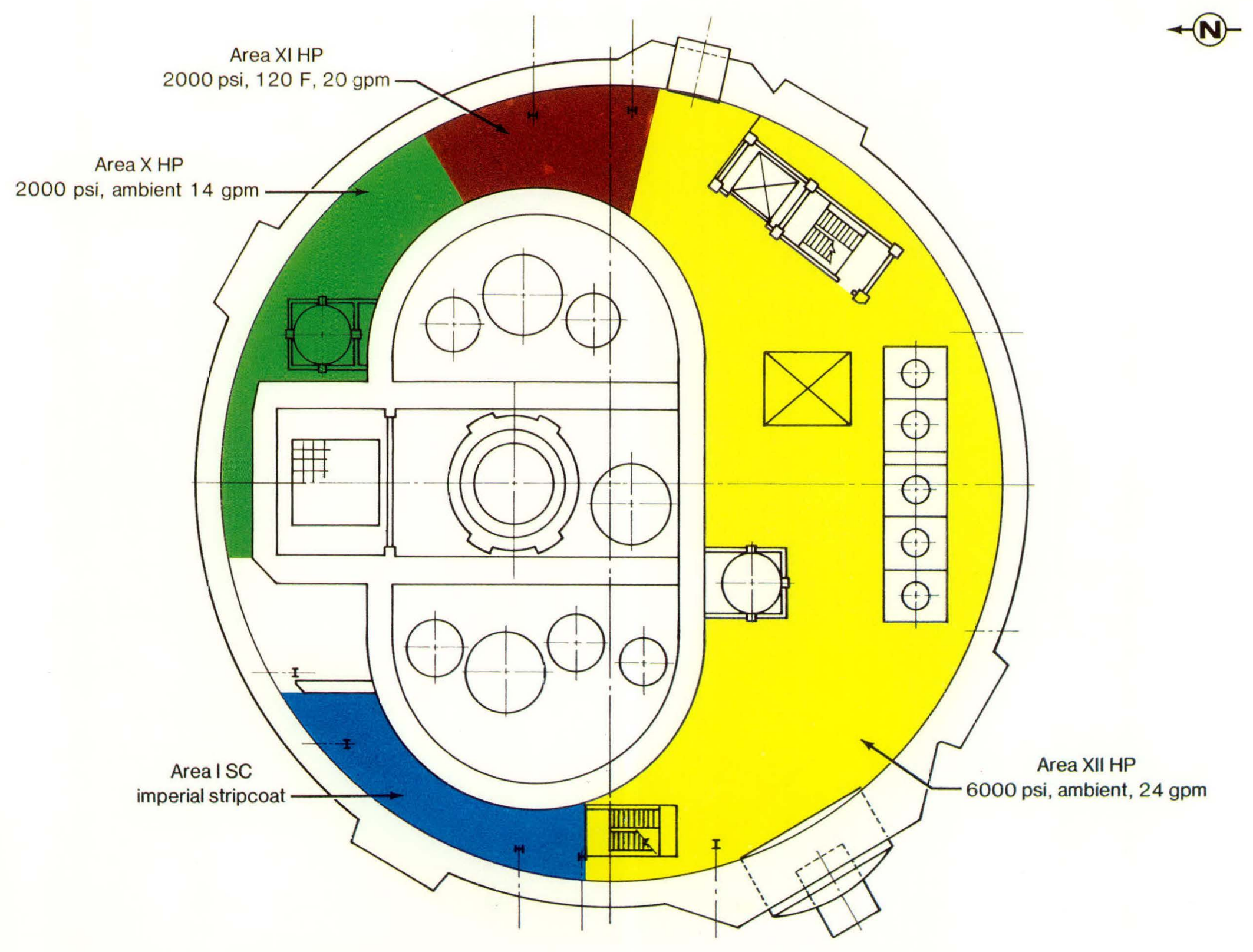

Figure 2-15. Elevation $305^{\prime}$ high pressure flush - actual. 


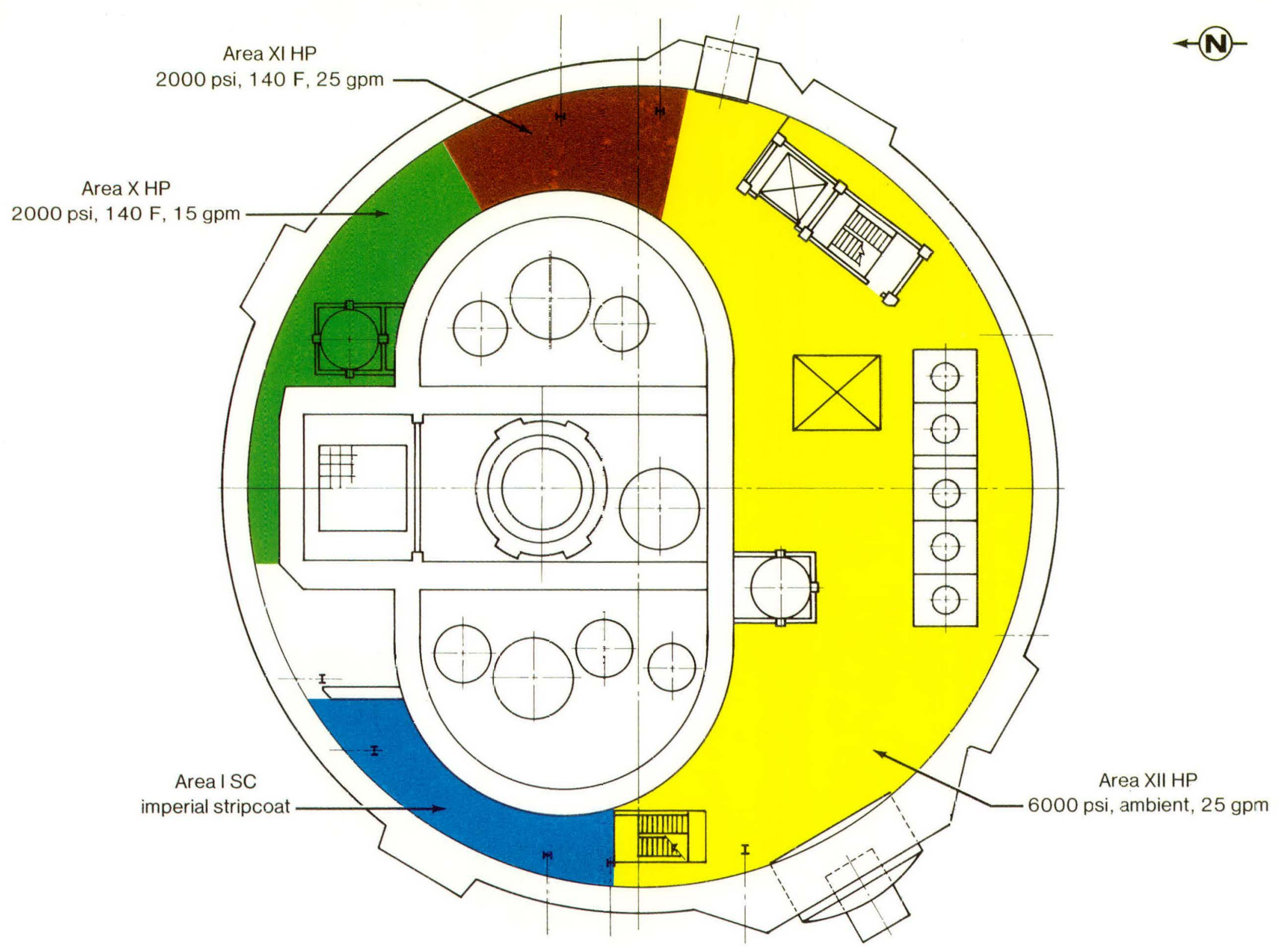

Figure 2-16. Elevat on $305^{\prime}$ high pressure flush - planned. 


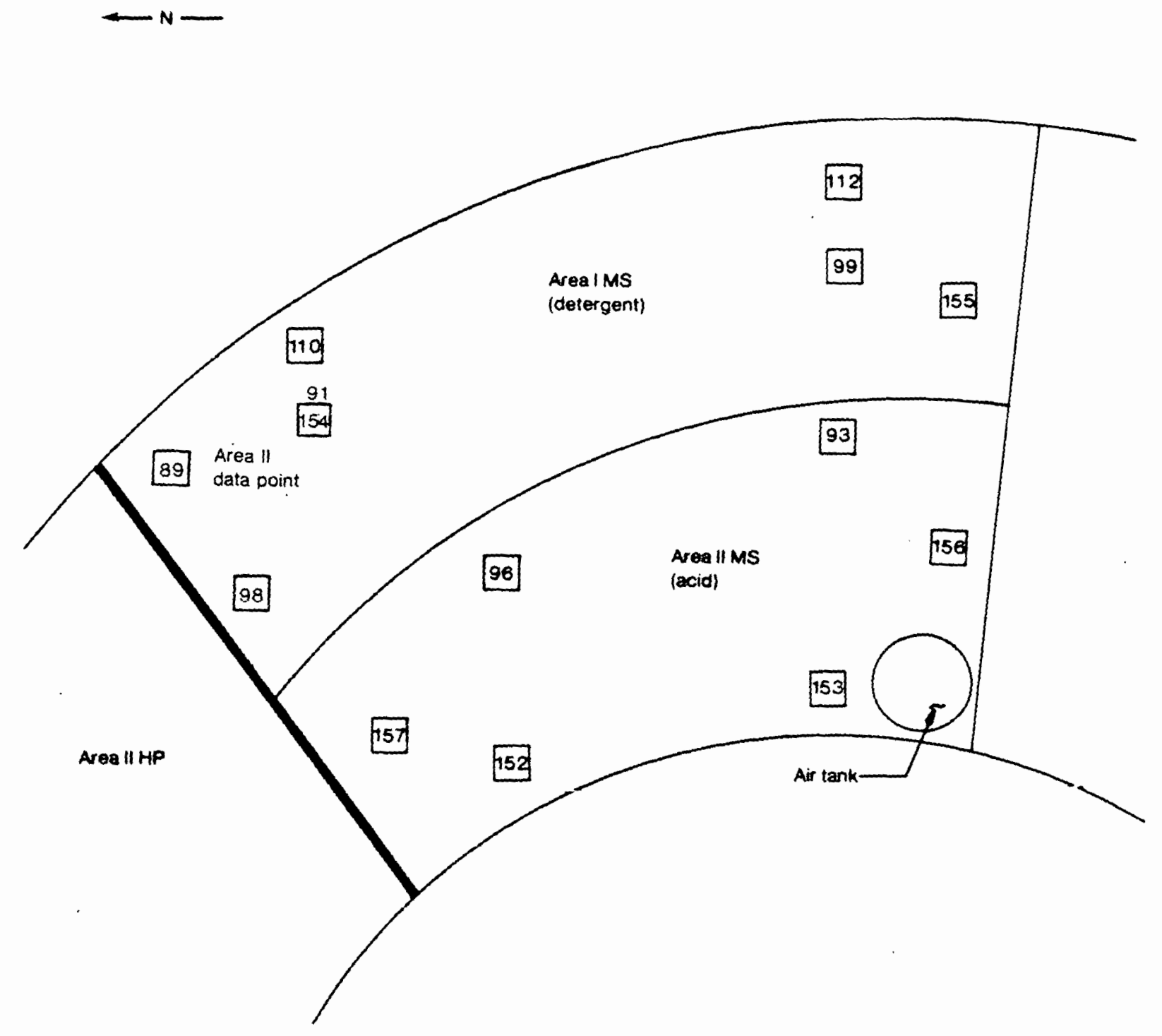

Figure 2-17. Mechanical floor scrubber area - elevation $347^{\prime}-6^{\prime \prime}$. 


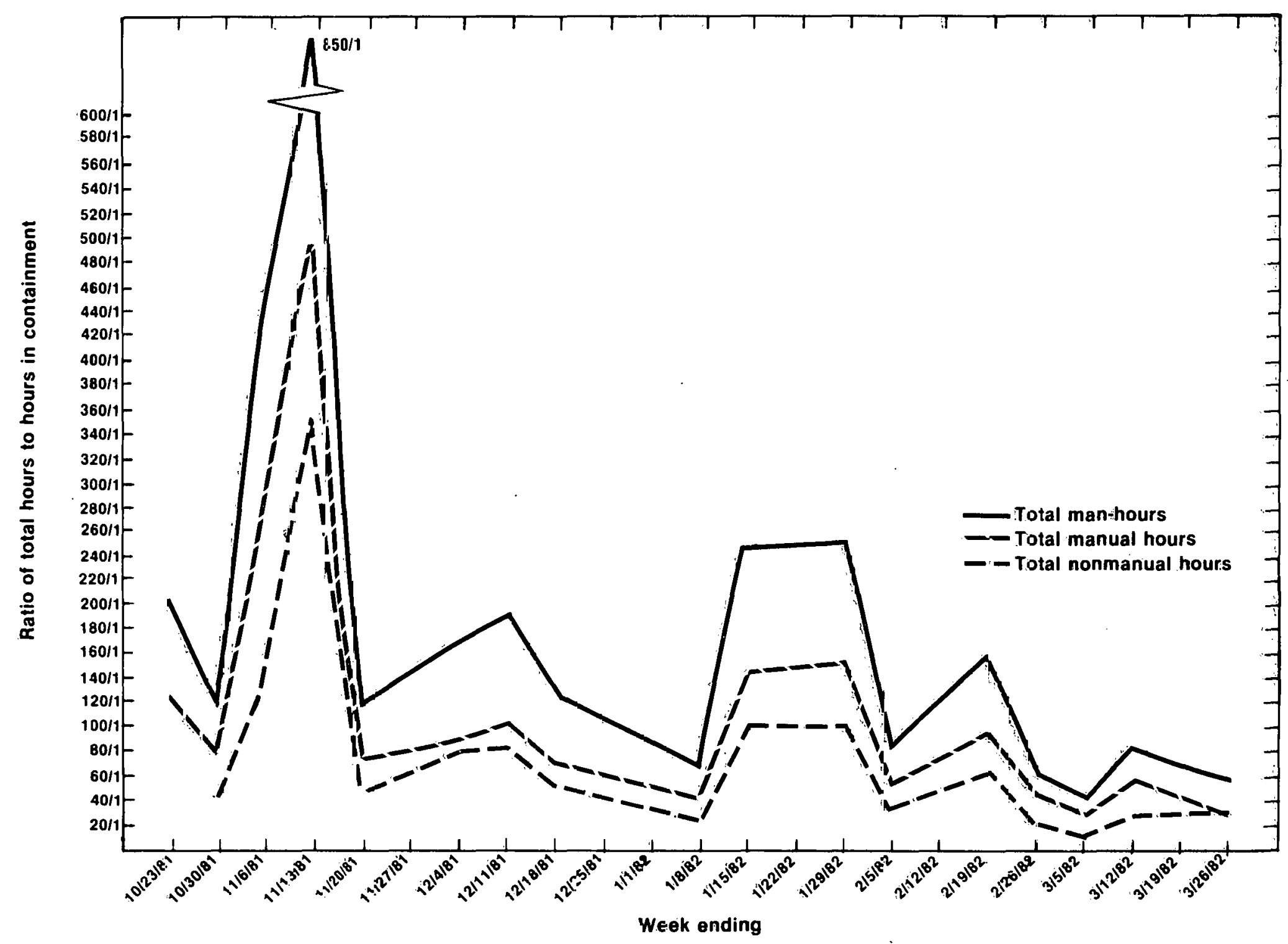

Figure 2-18. Plot of total man-hours per hour in containment versus time. 


$$
\text { Mhand }
$$




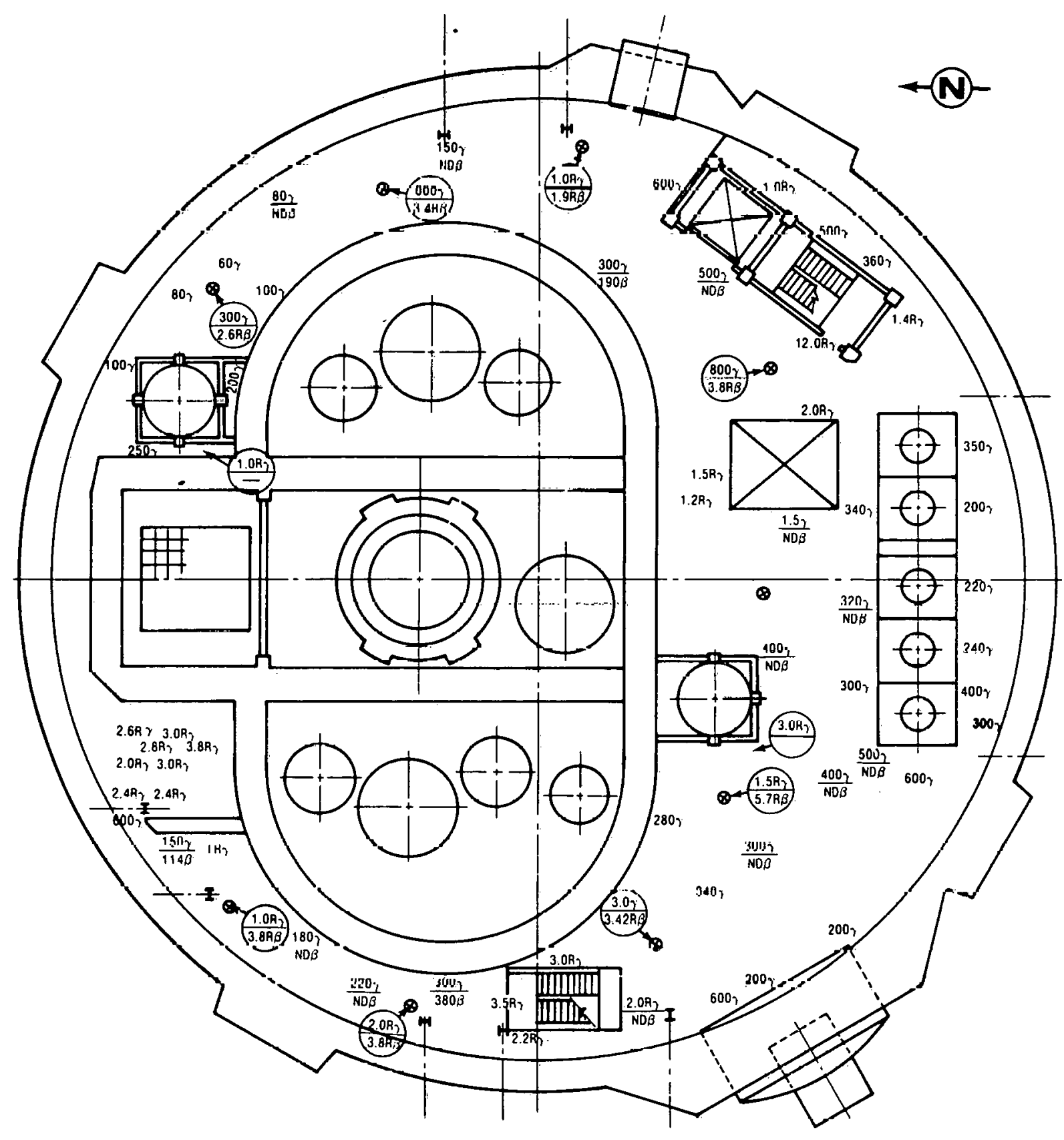

Figure 2.-20. Elevation 305' radiation intensity map. 


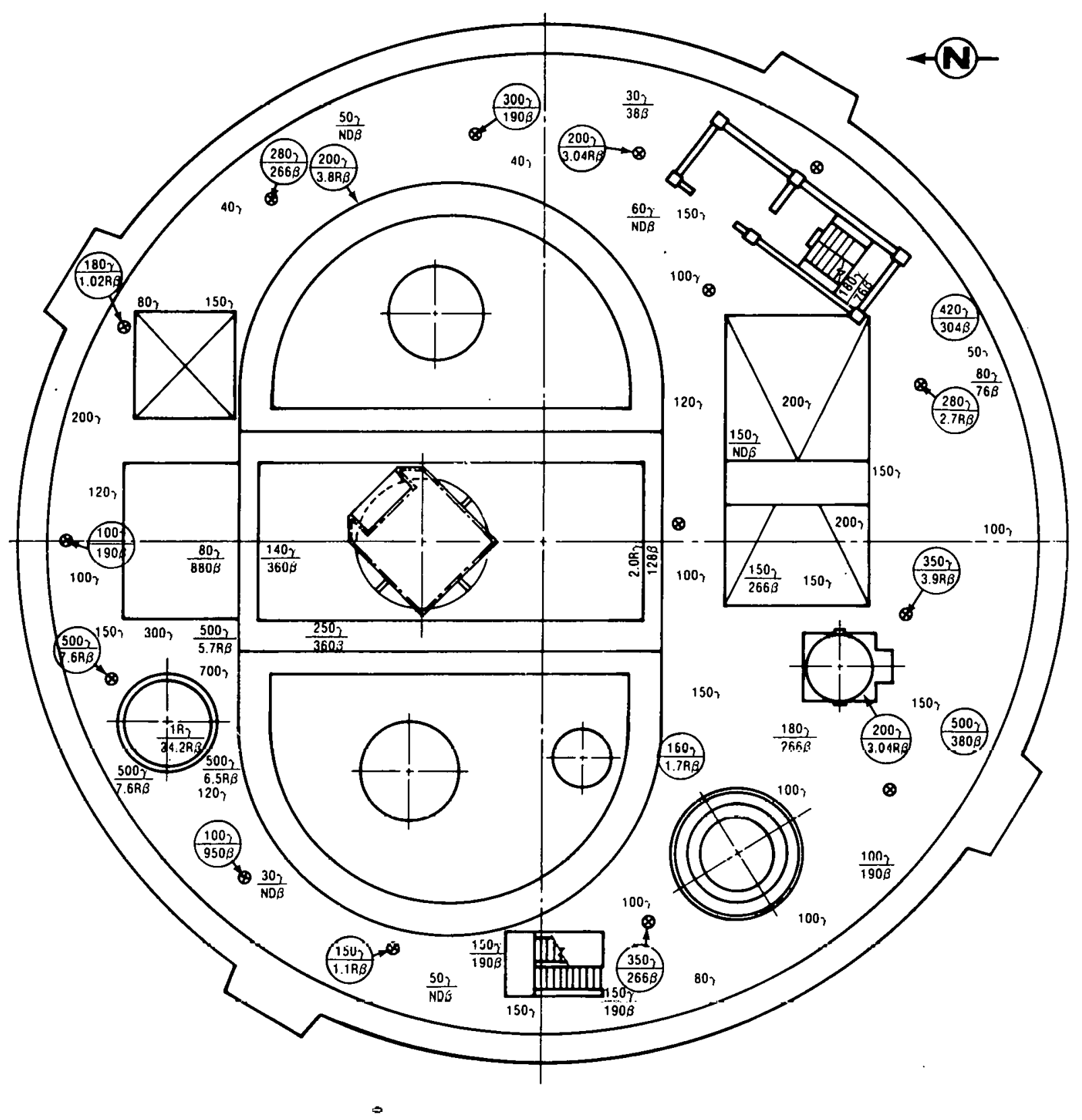

Figure 2-21. Elevation $347^{\prime}-6$ '' radiation intensity map. 


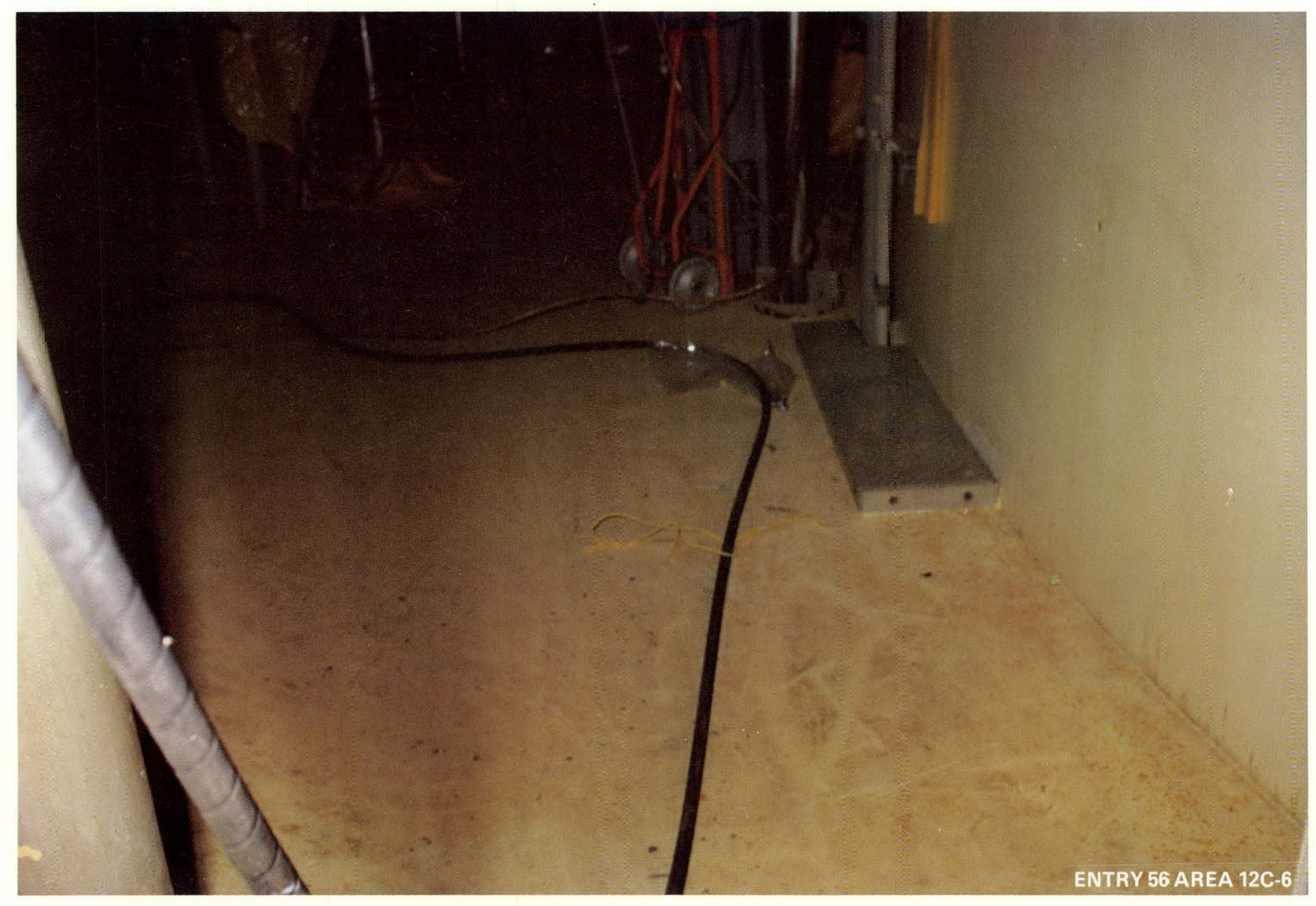

PHOTOGRAPH 1 


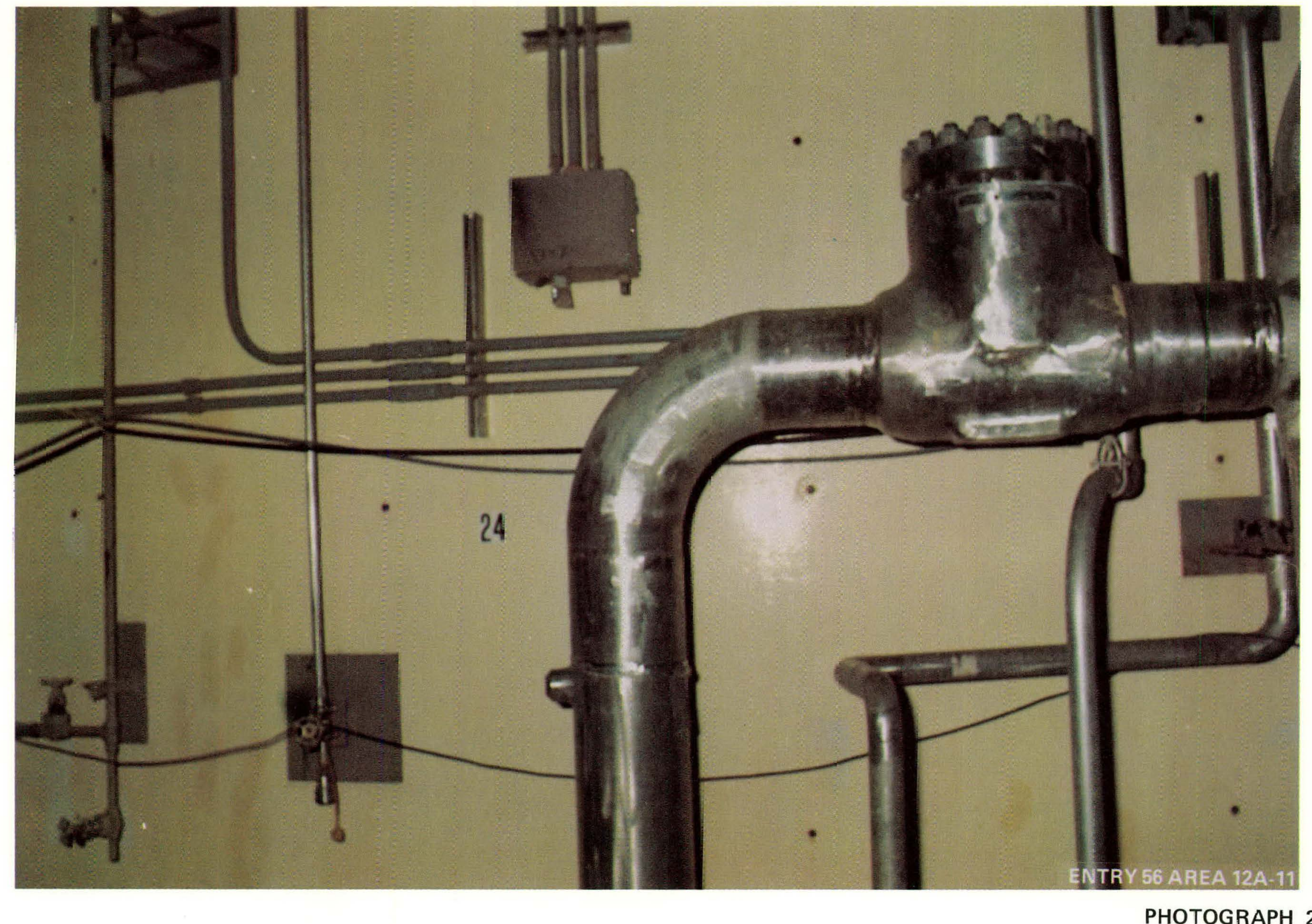

PHOTOGRAPH 2 


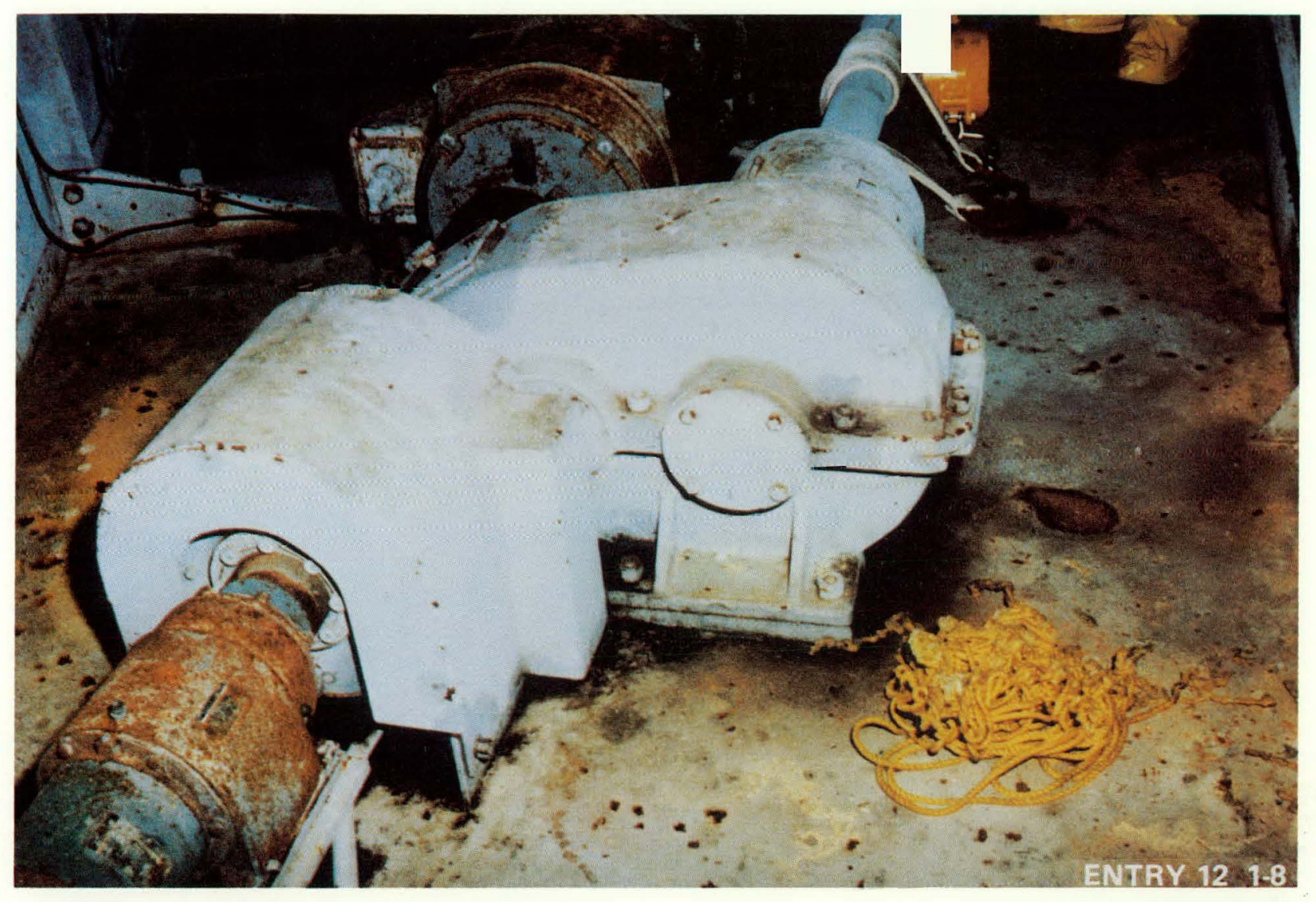

PHOTOGRAPH 3

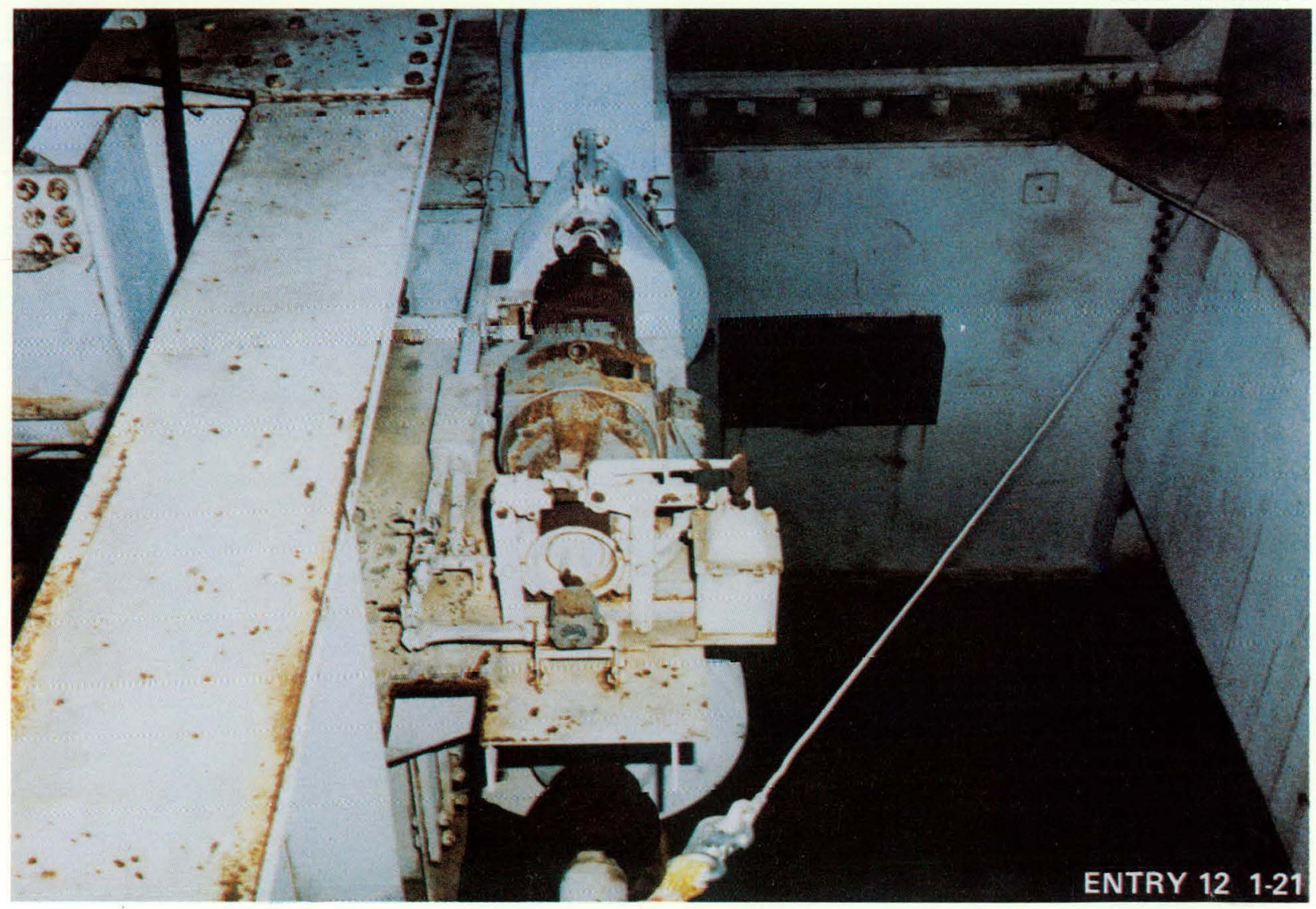




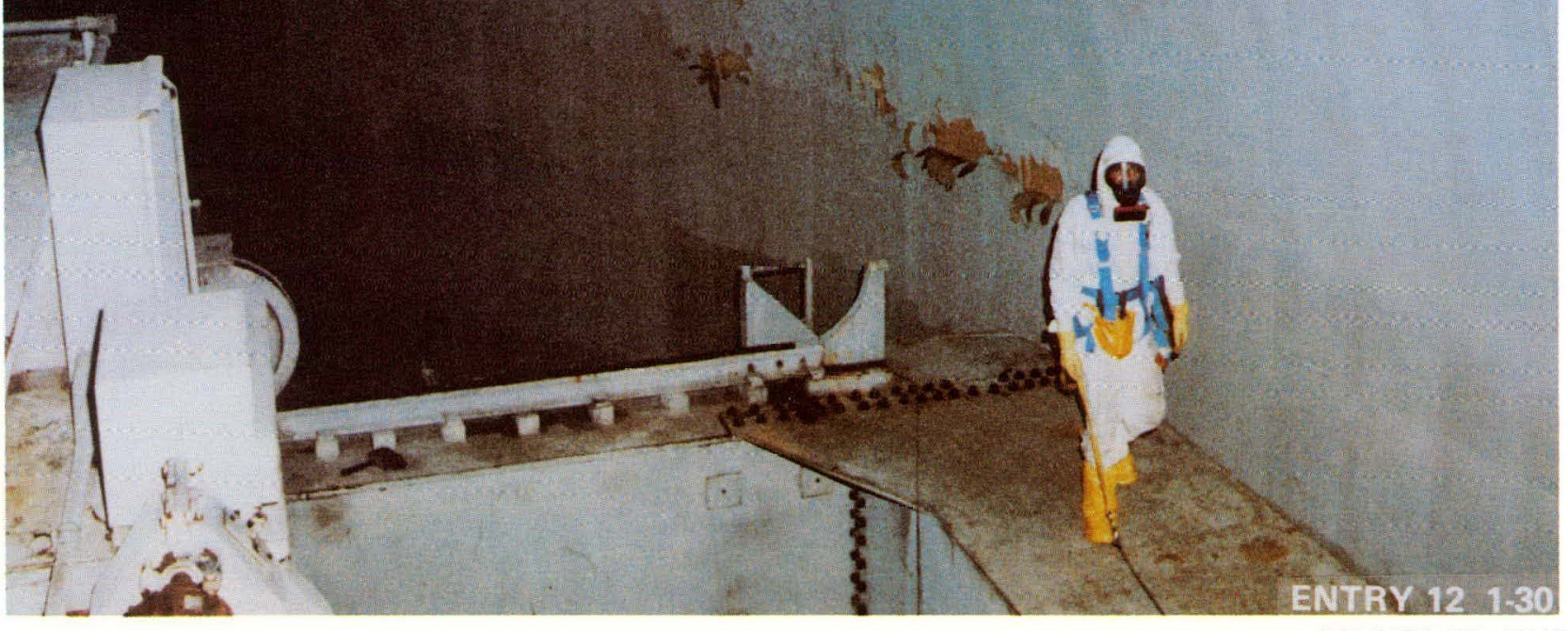

PHOTOGRAPH 5
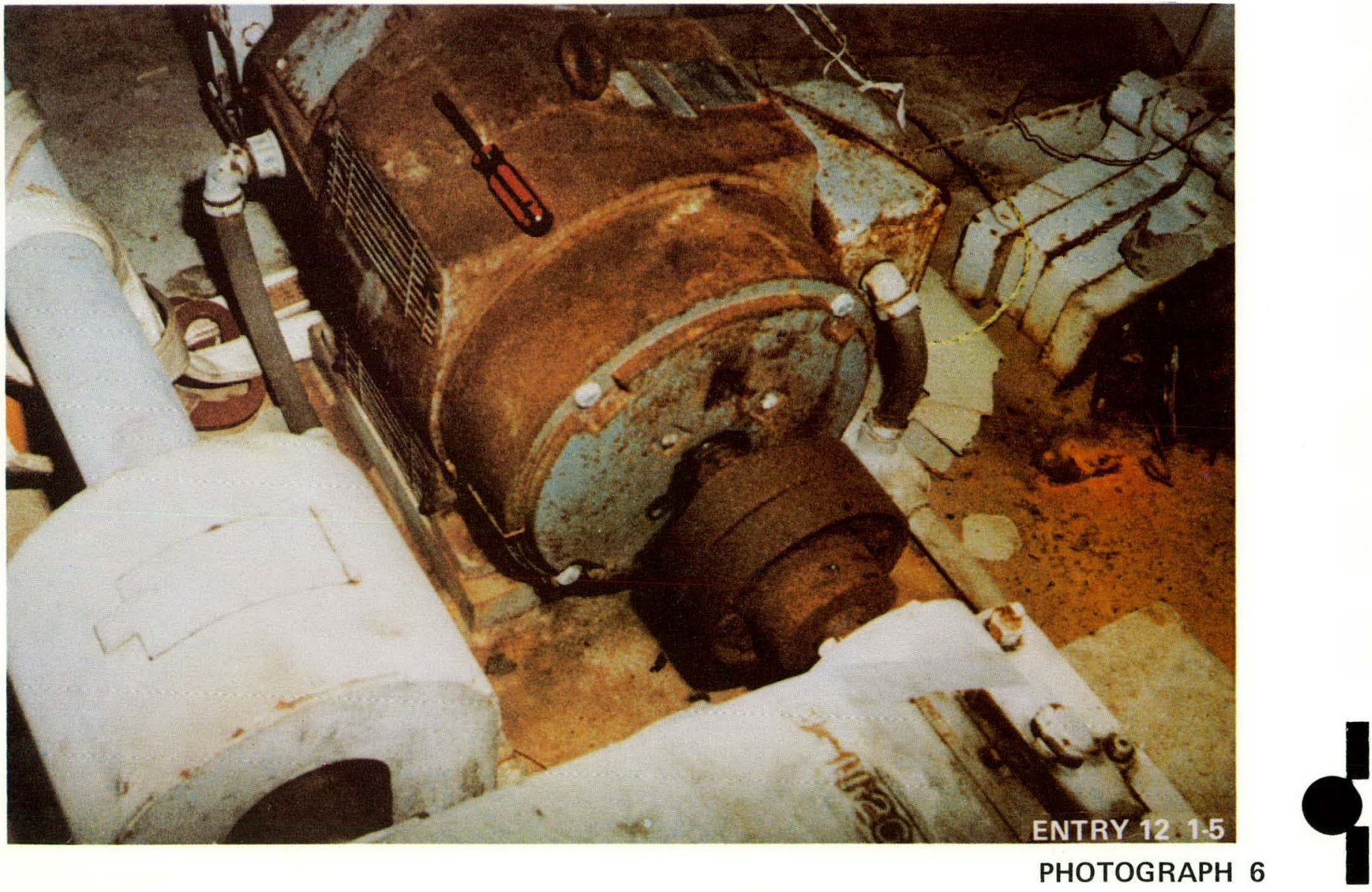


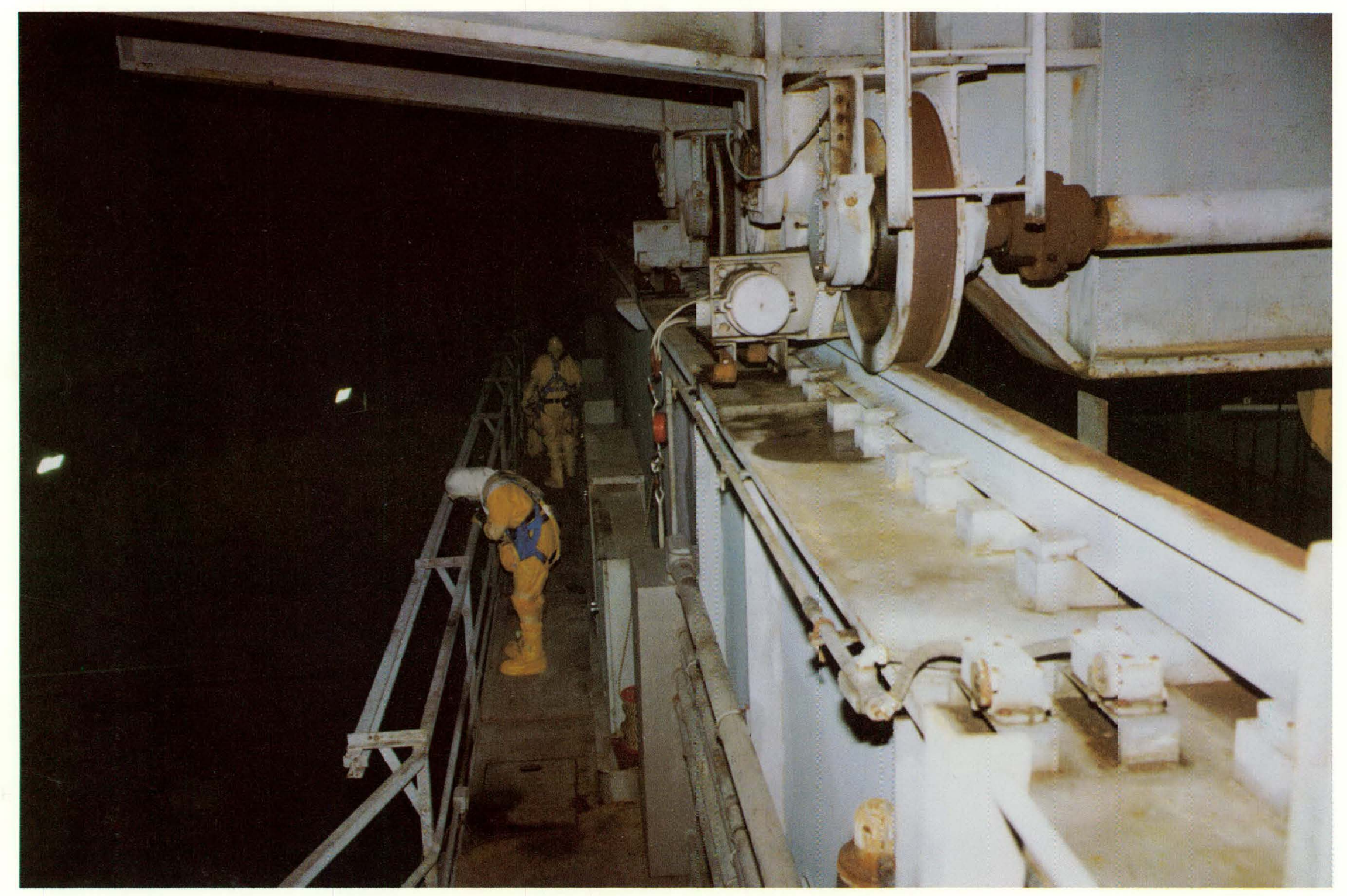




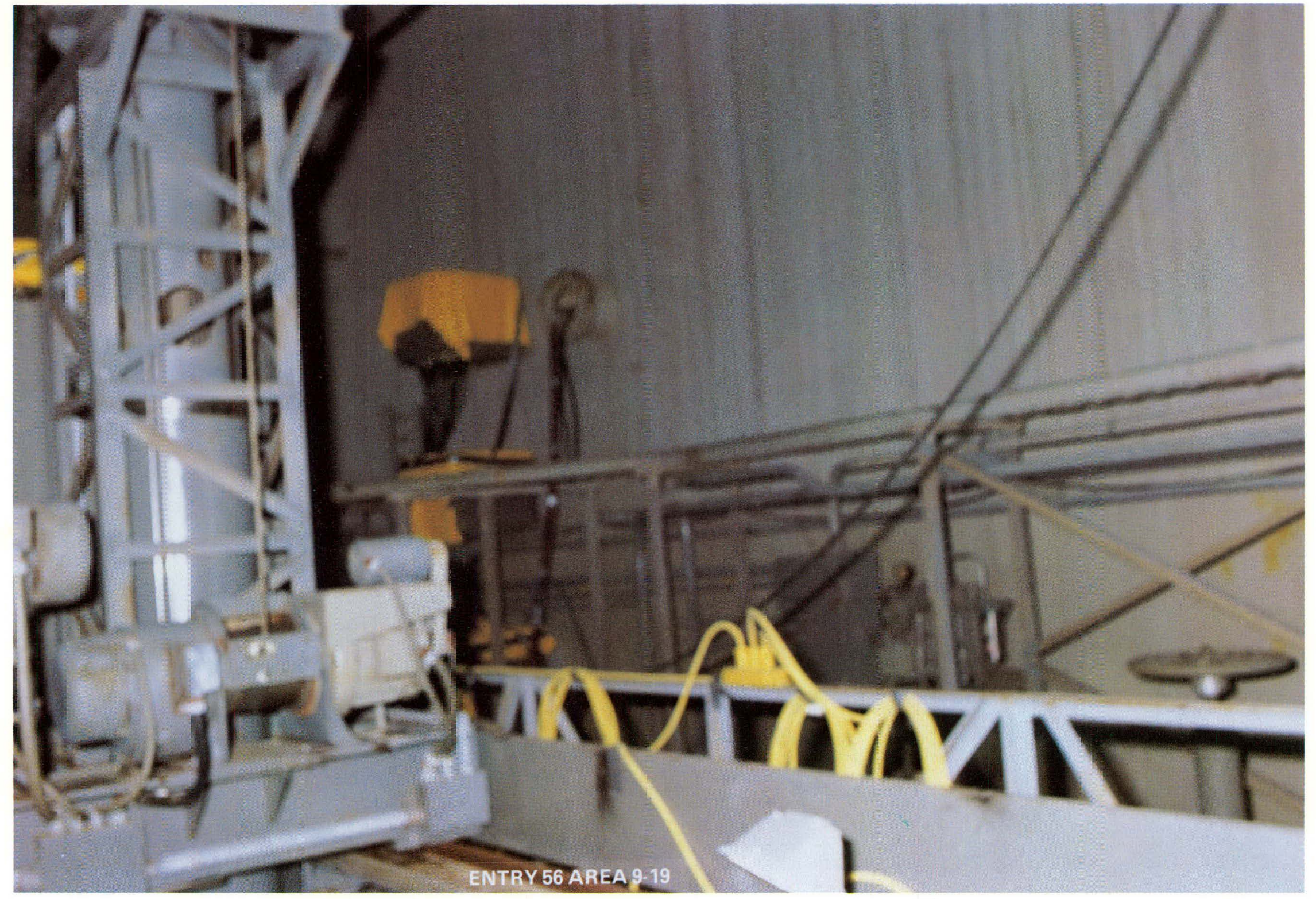

PHOTOGRAPH 8

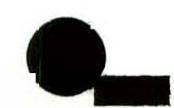




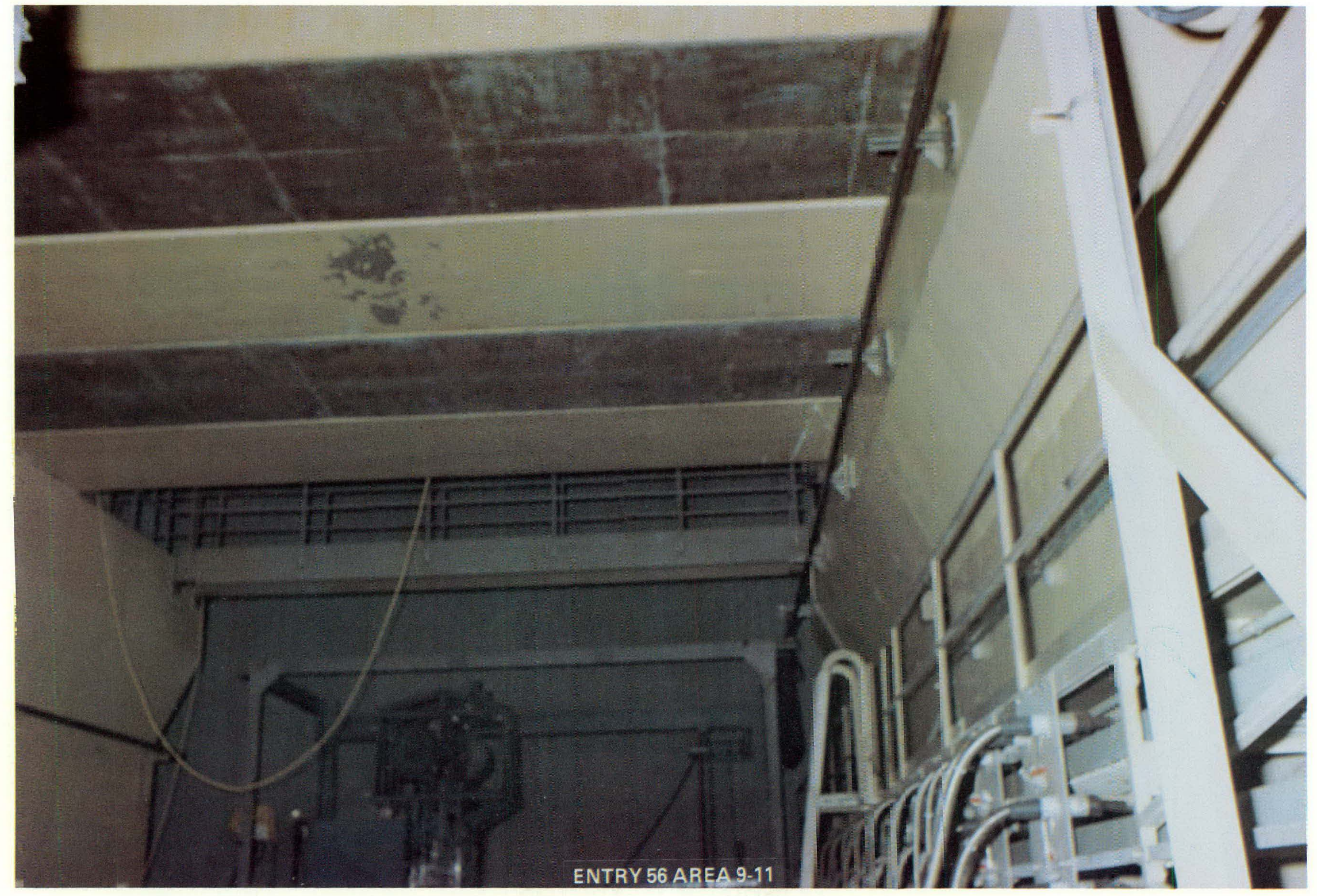




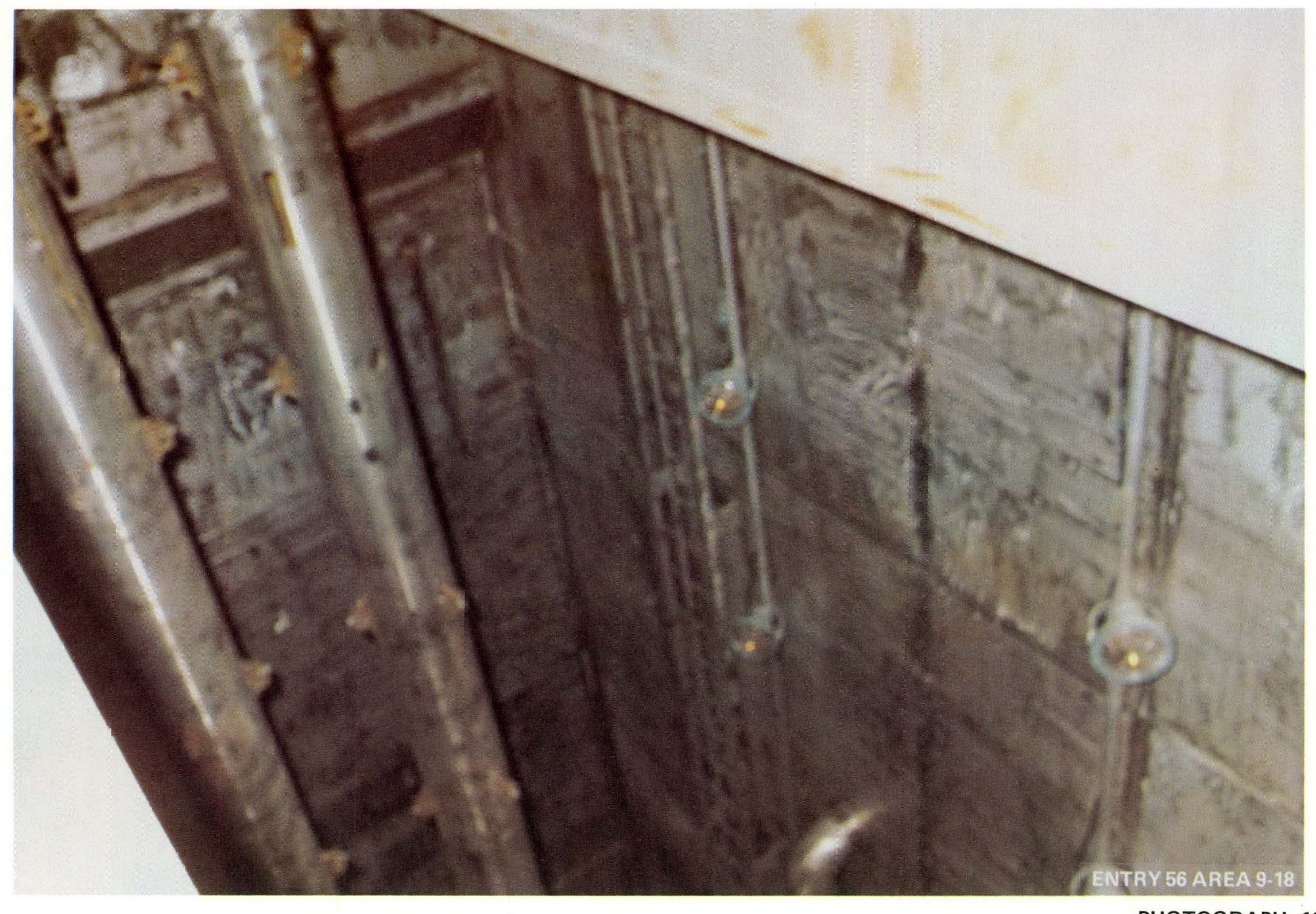

PHOTOGRAPH 10 


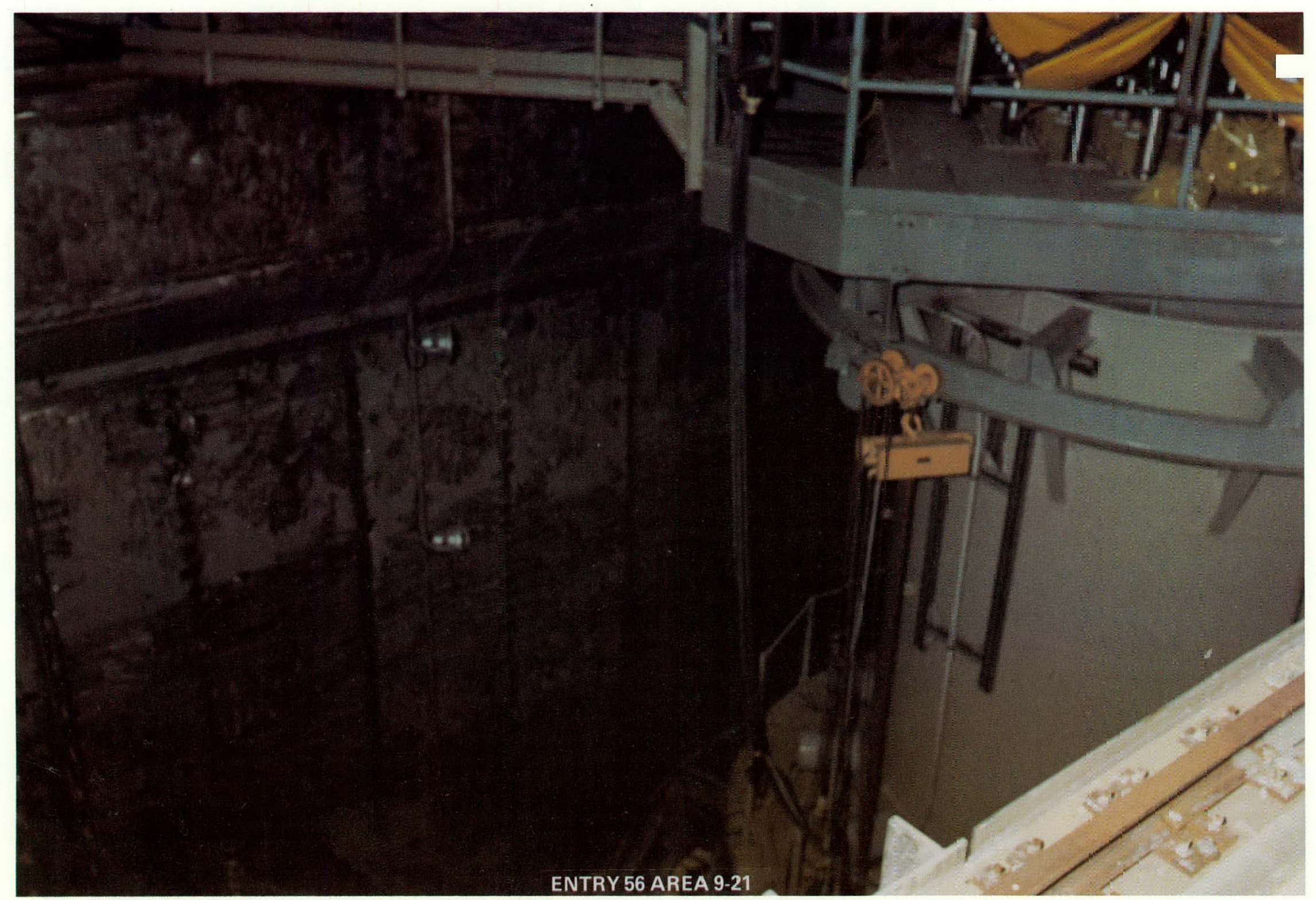

PHOTOGRAPH 11 


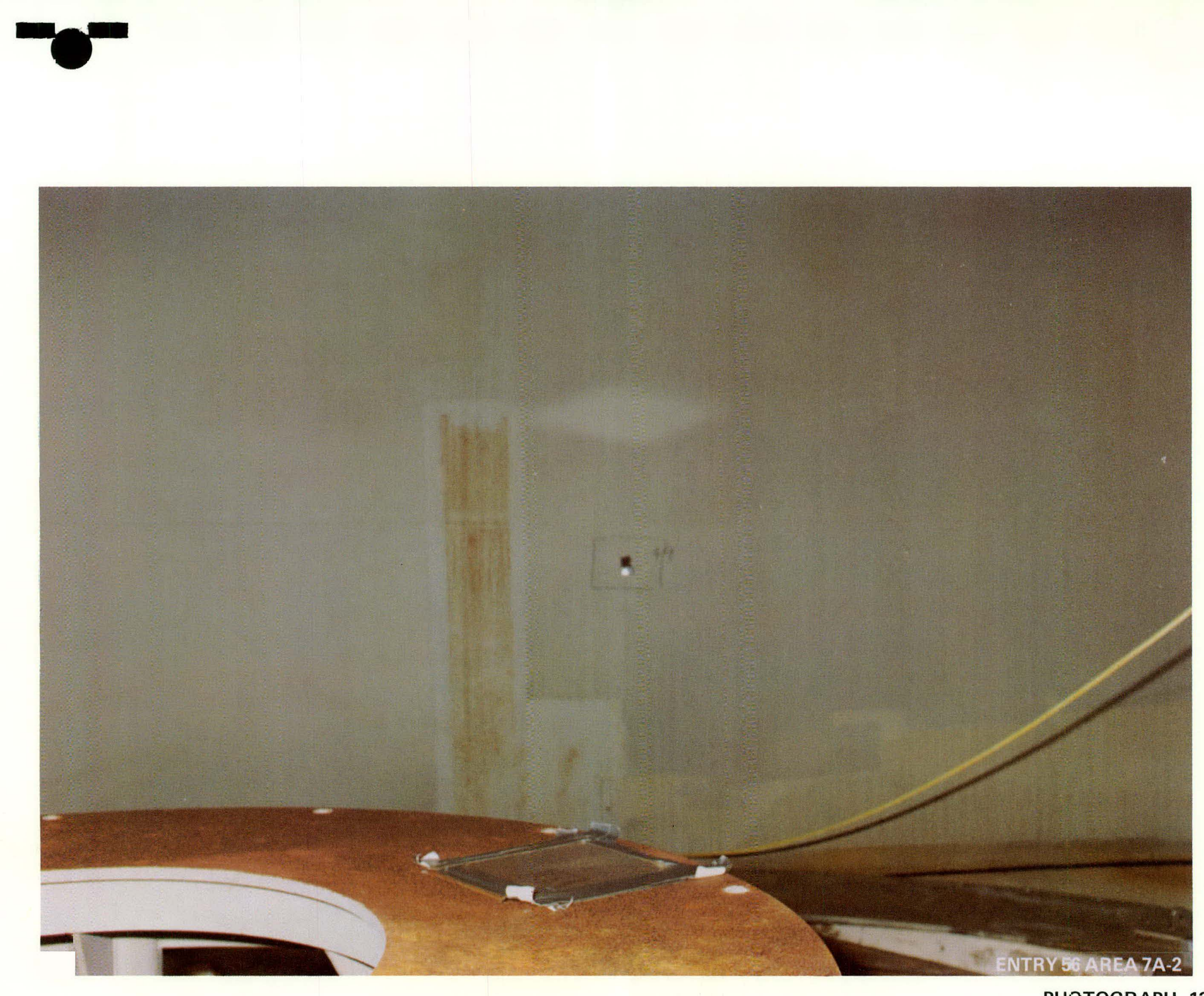

PHOTOGRAPH 13 


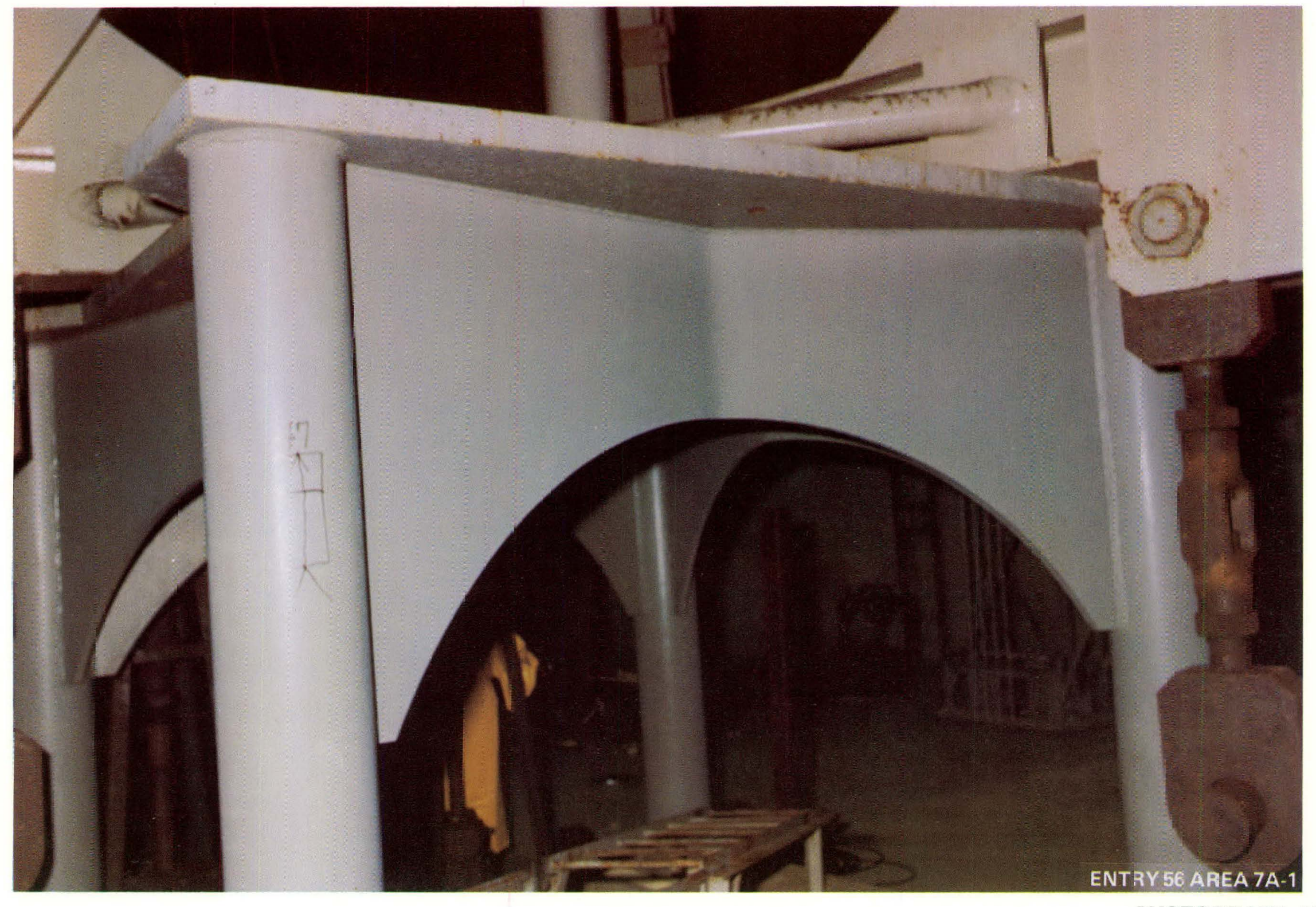

PHOTOGRAPH 14

D 


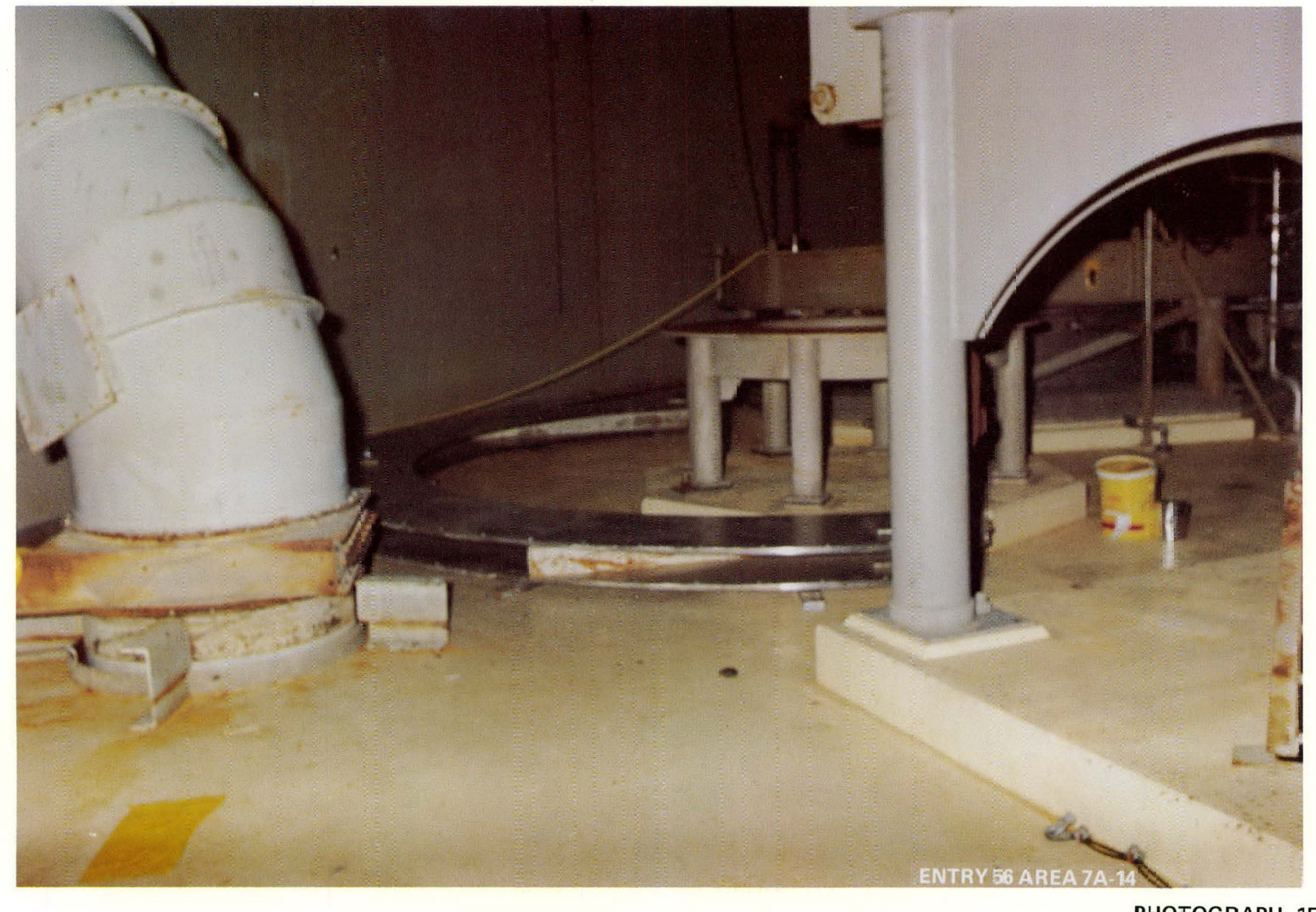




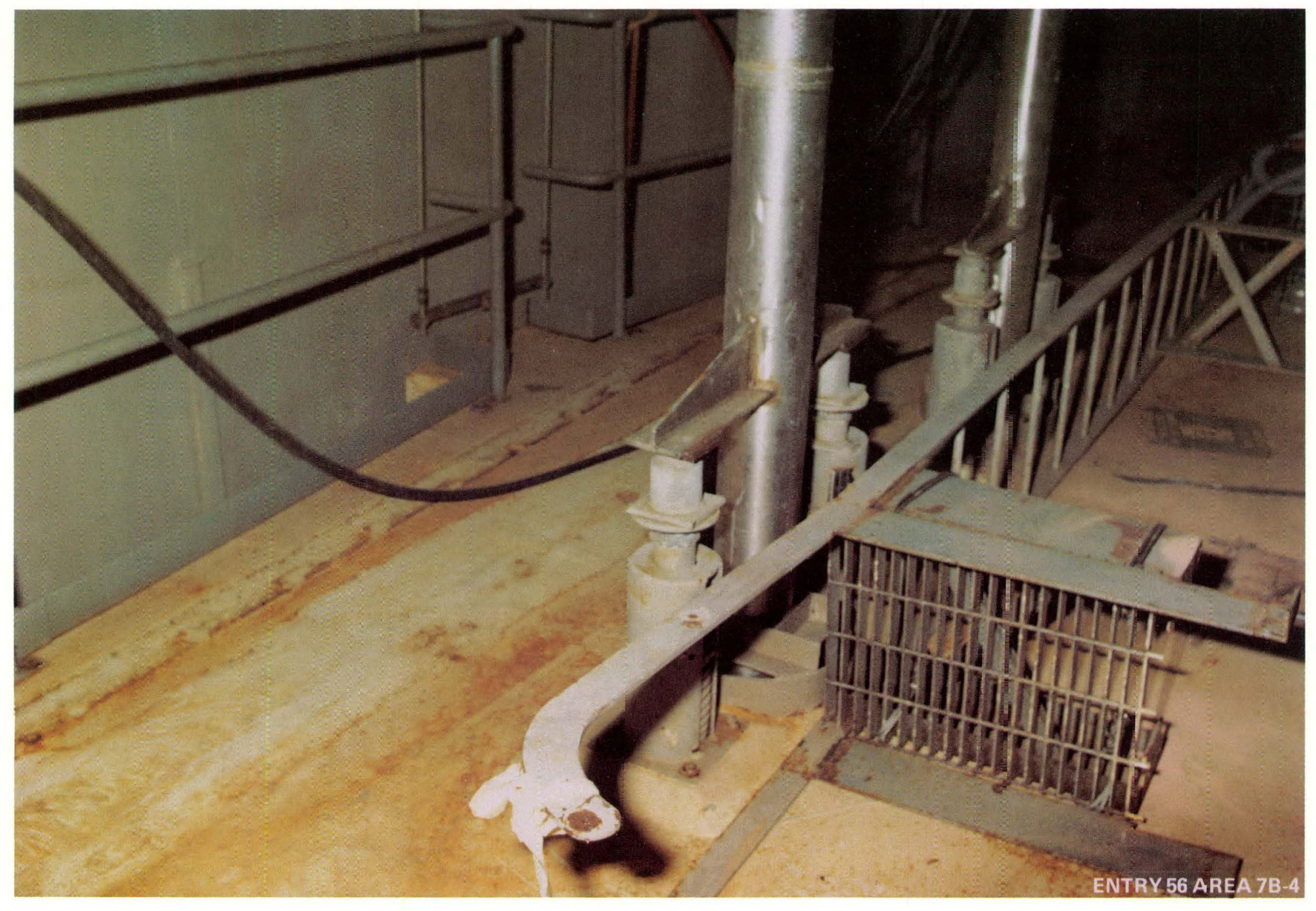

PHOTCGRAPH 16 


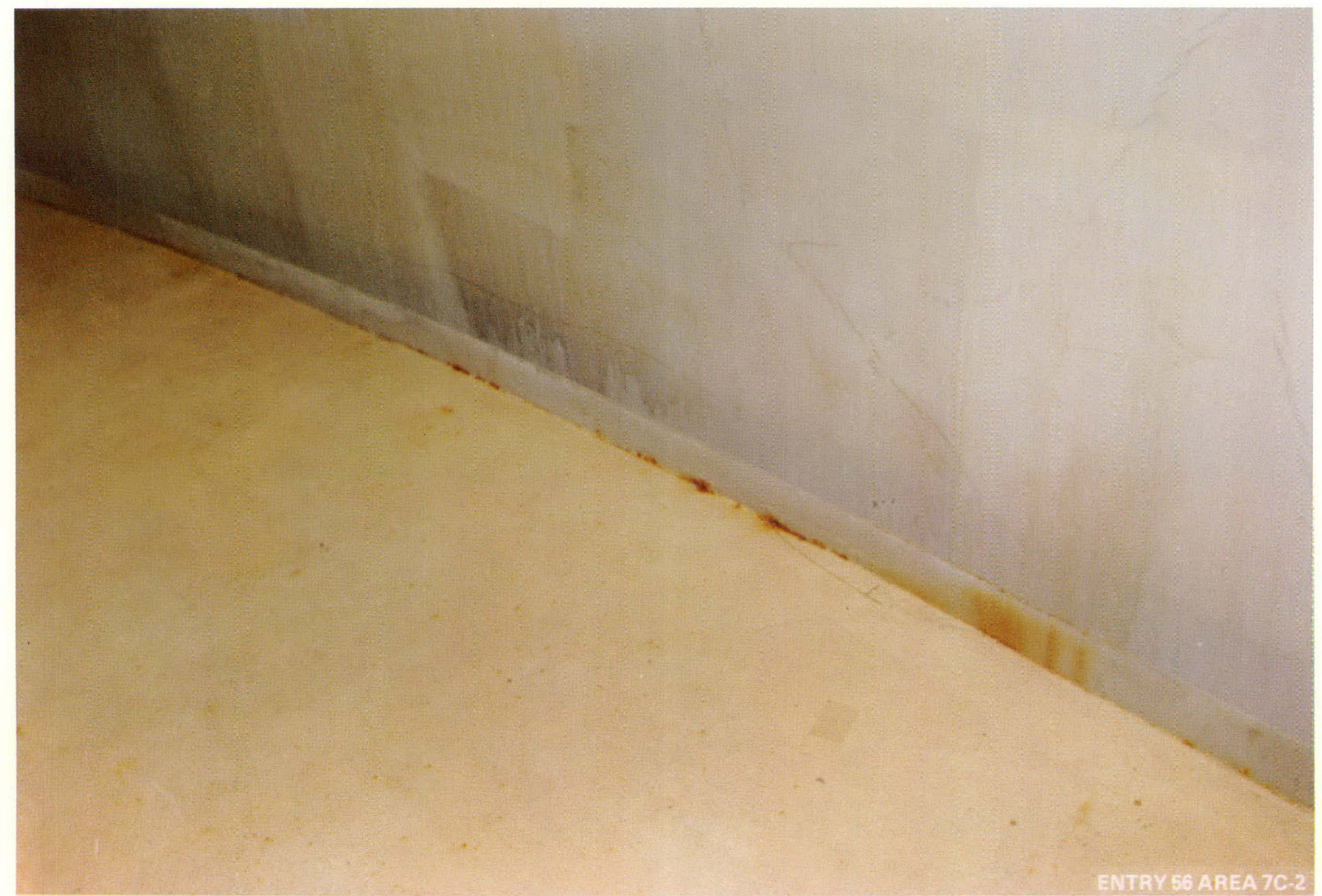

PHOTOGRAPH 17 


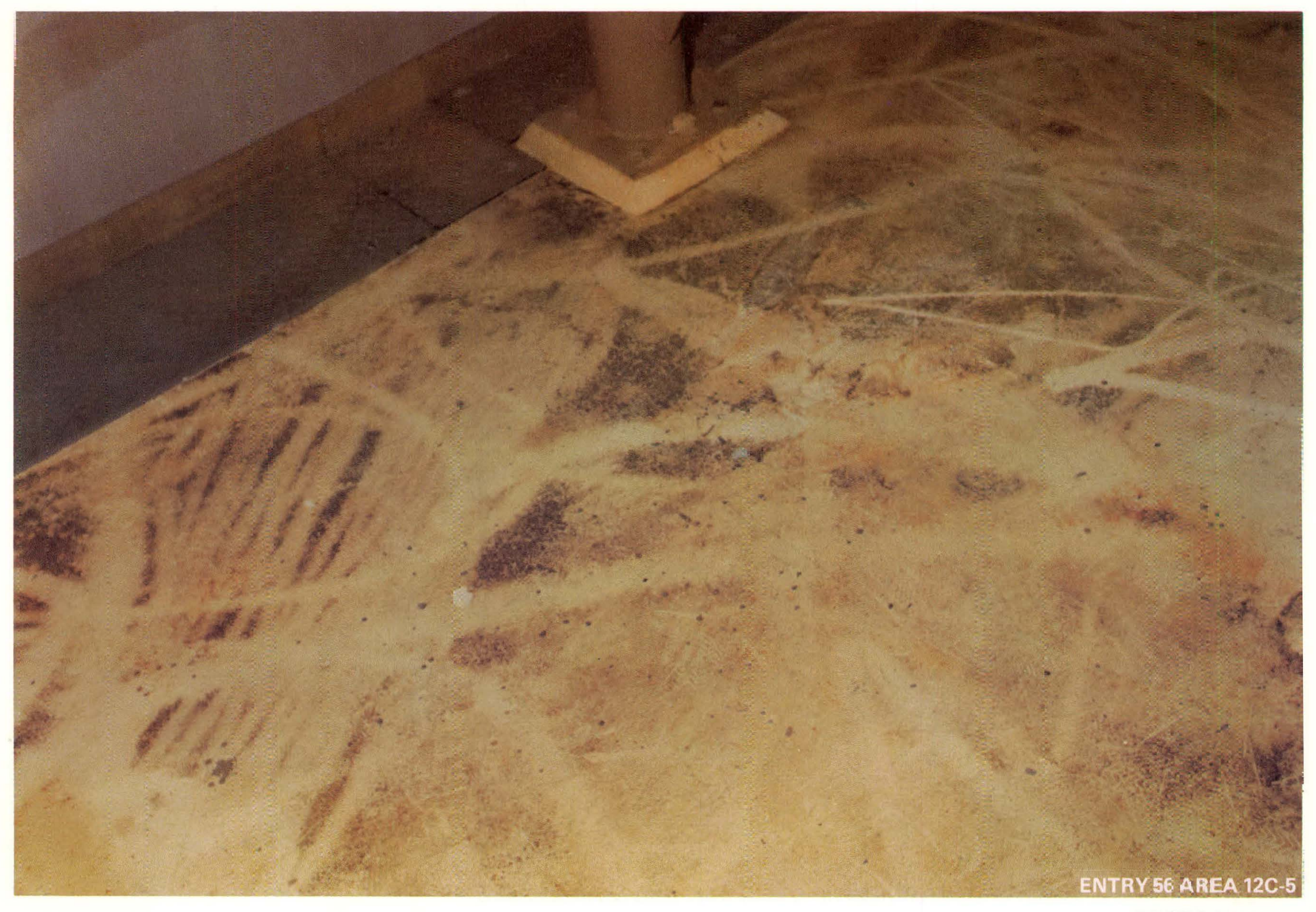

PHOTOGRAPH -8 

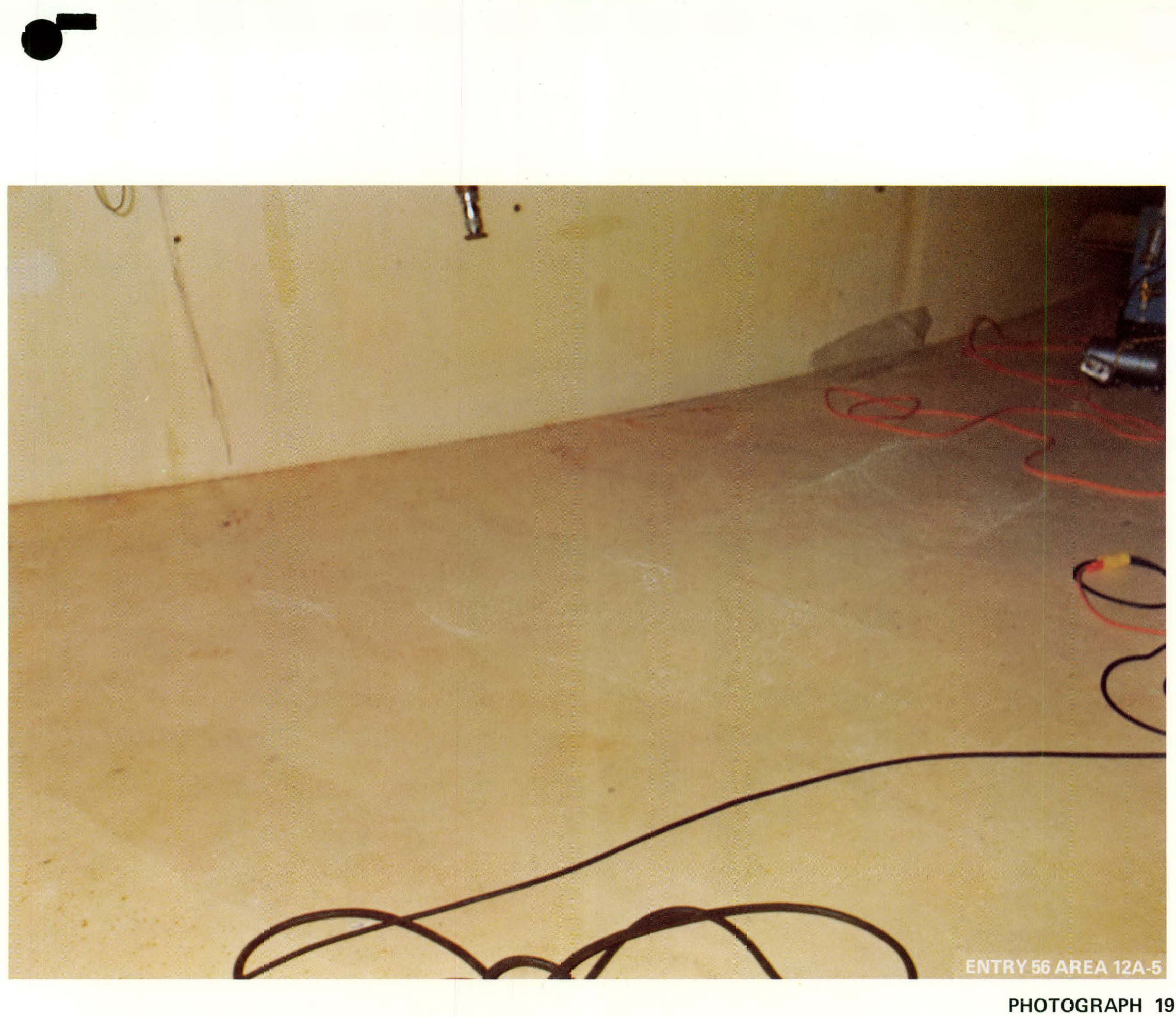


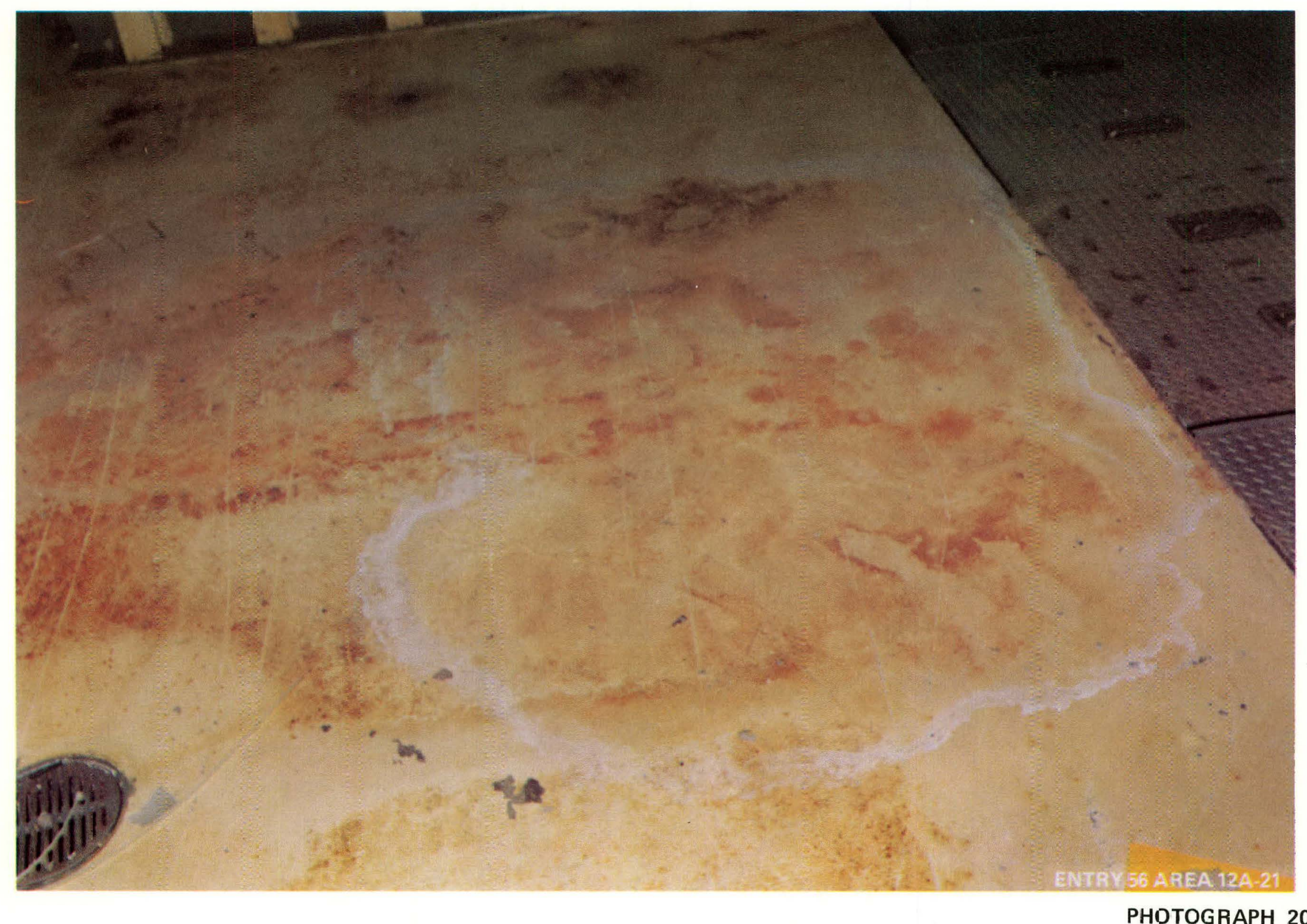

PHOTOGRAPH 20

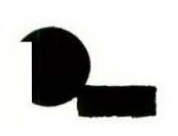




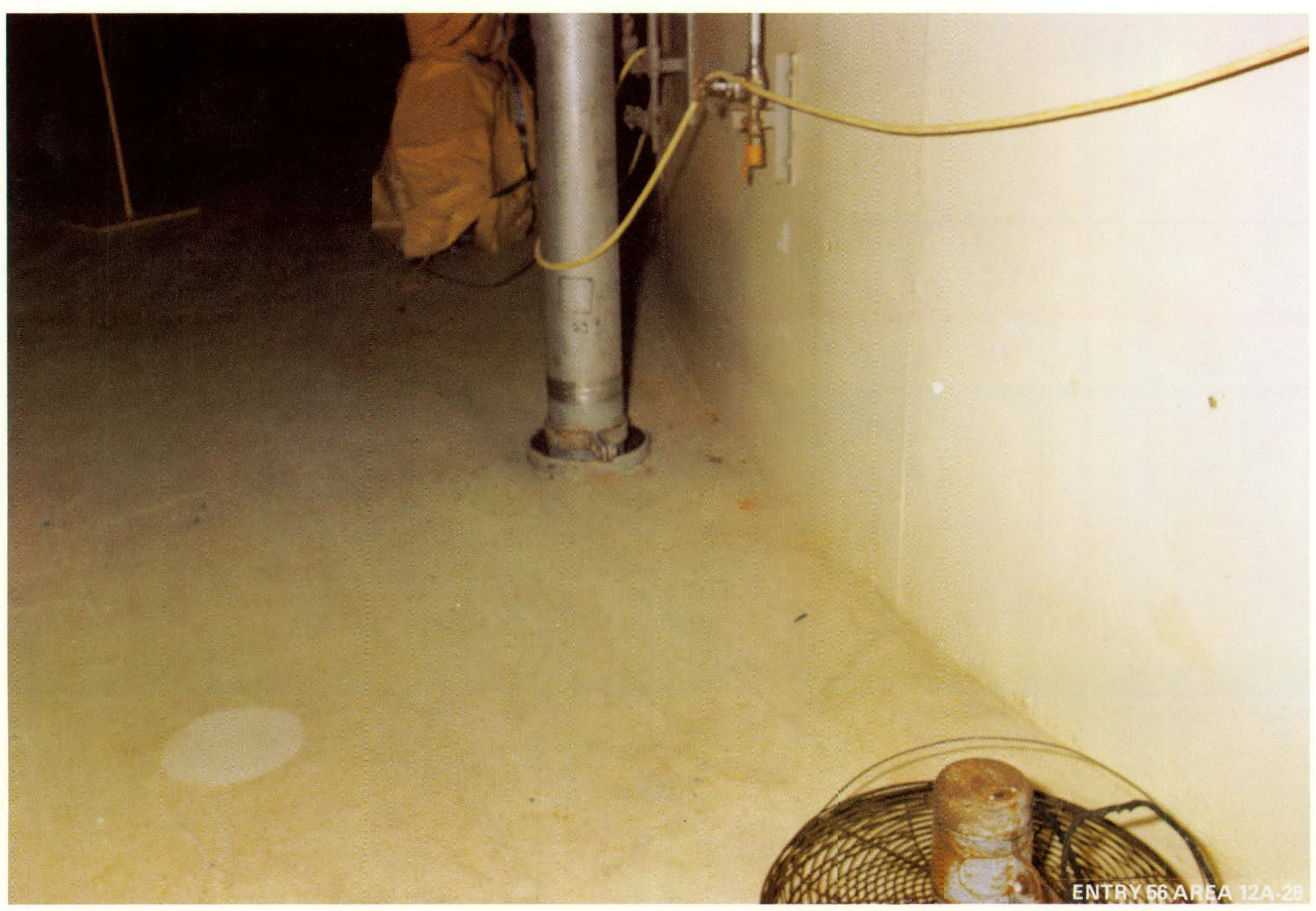

PHOTOGRAPH 21 


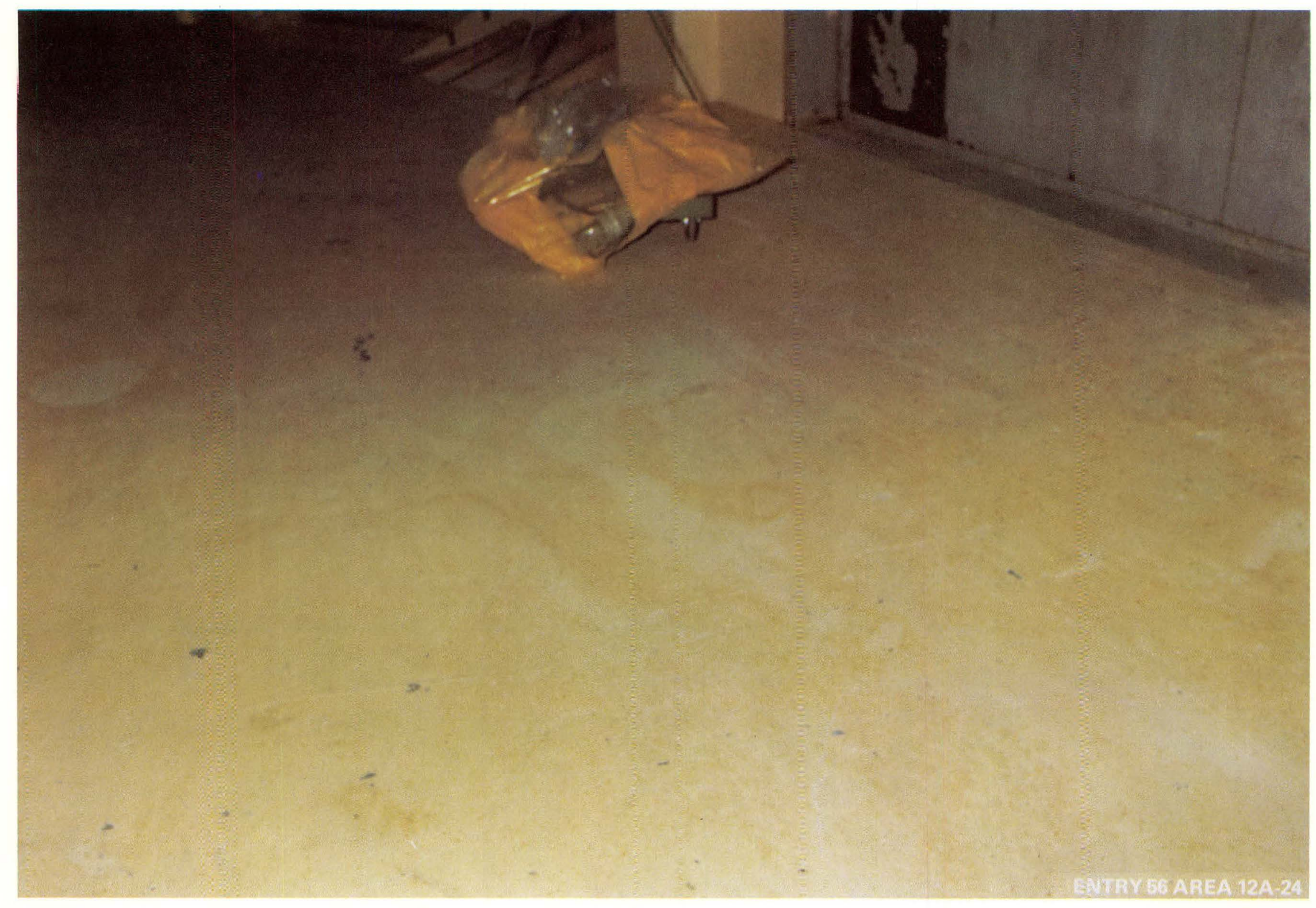

PHOTOGRAPH 22

\section{a}




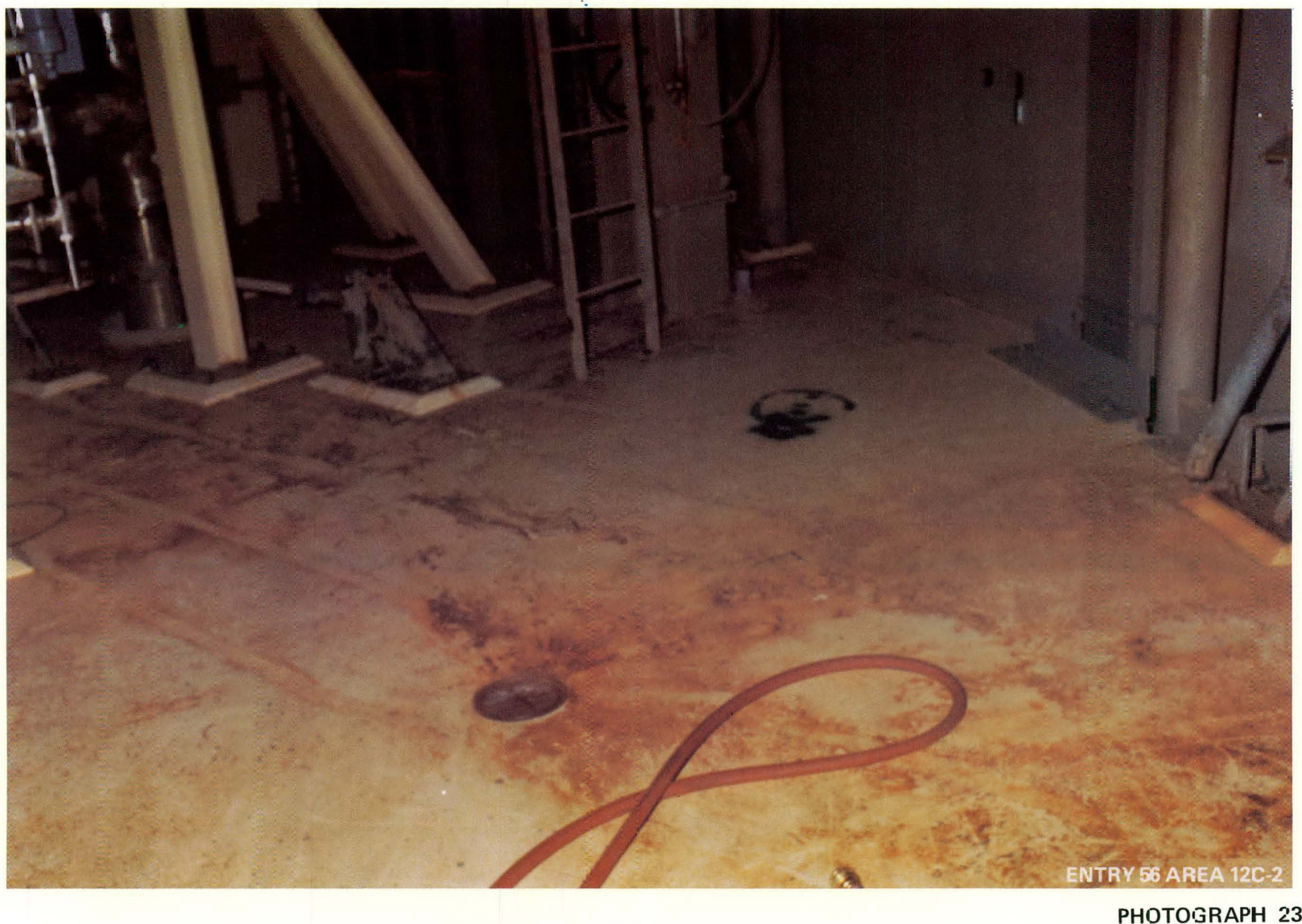




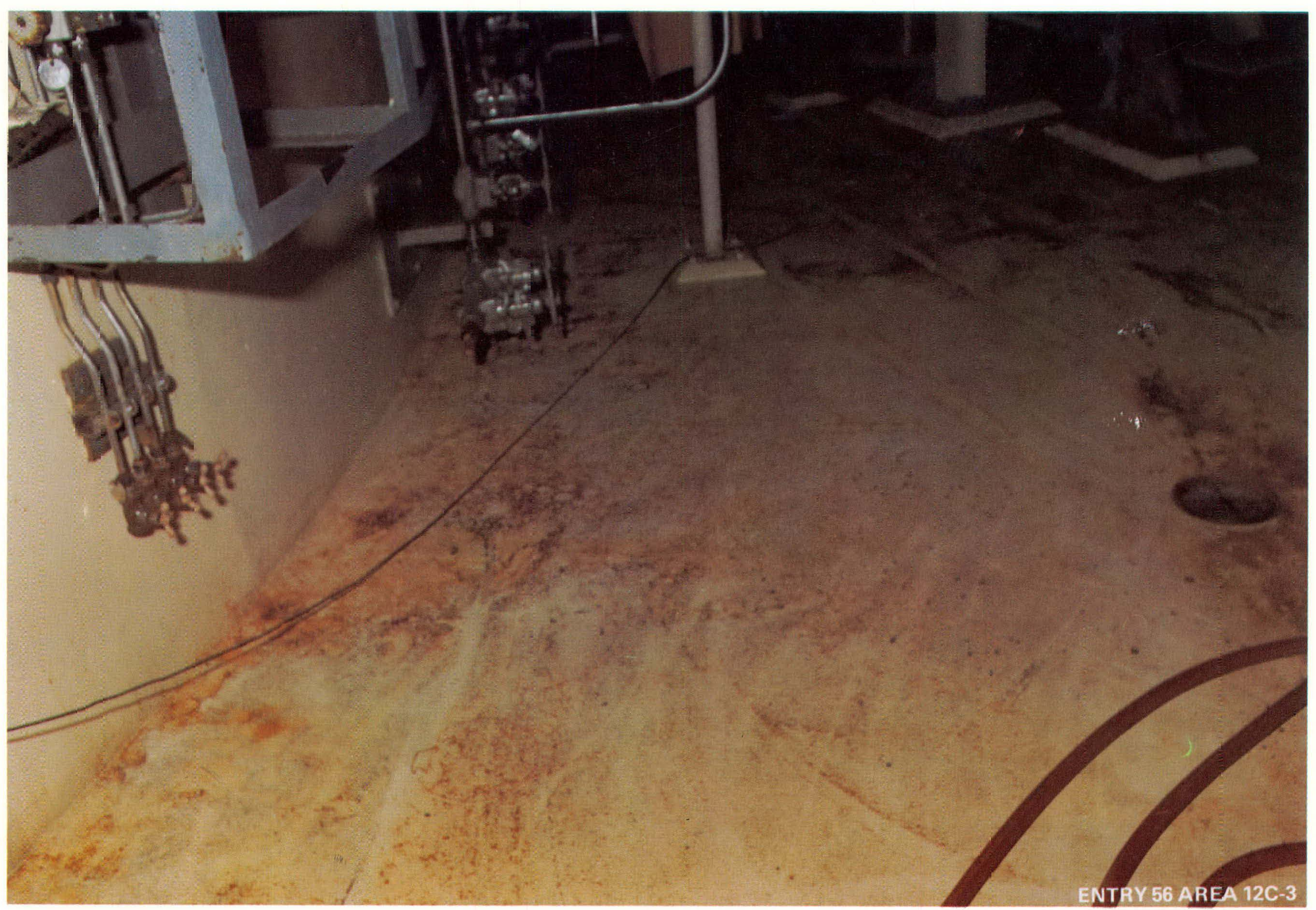

PHOTOGRAPH 24

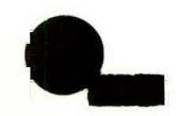




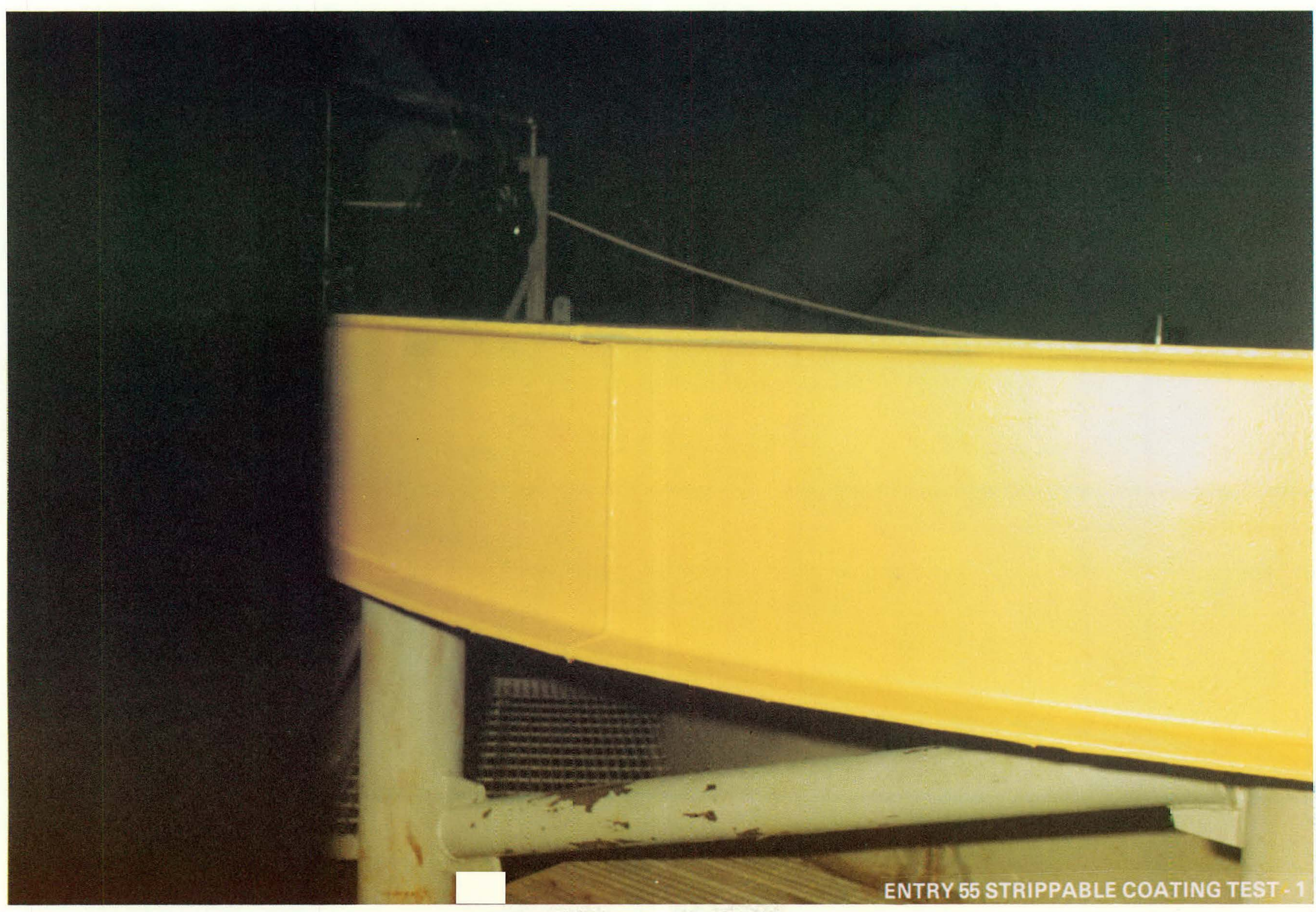




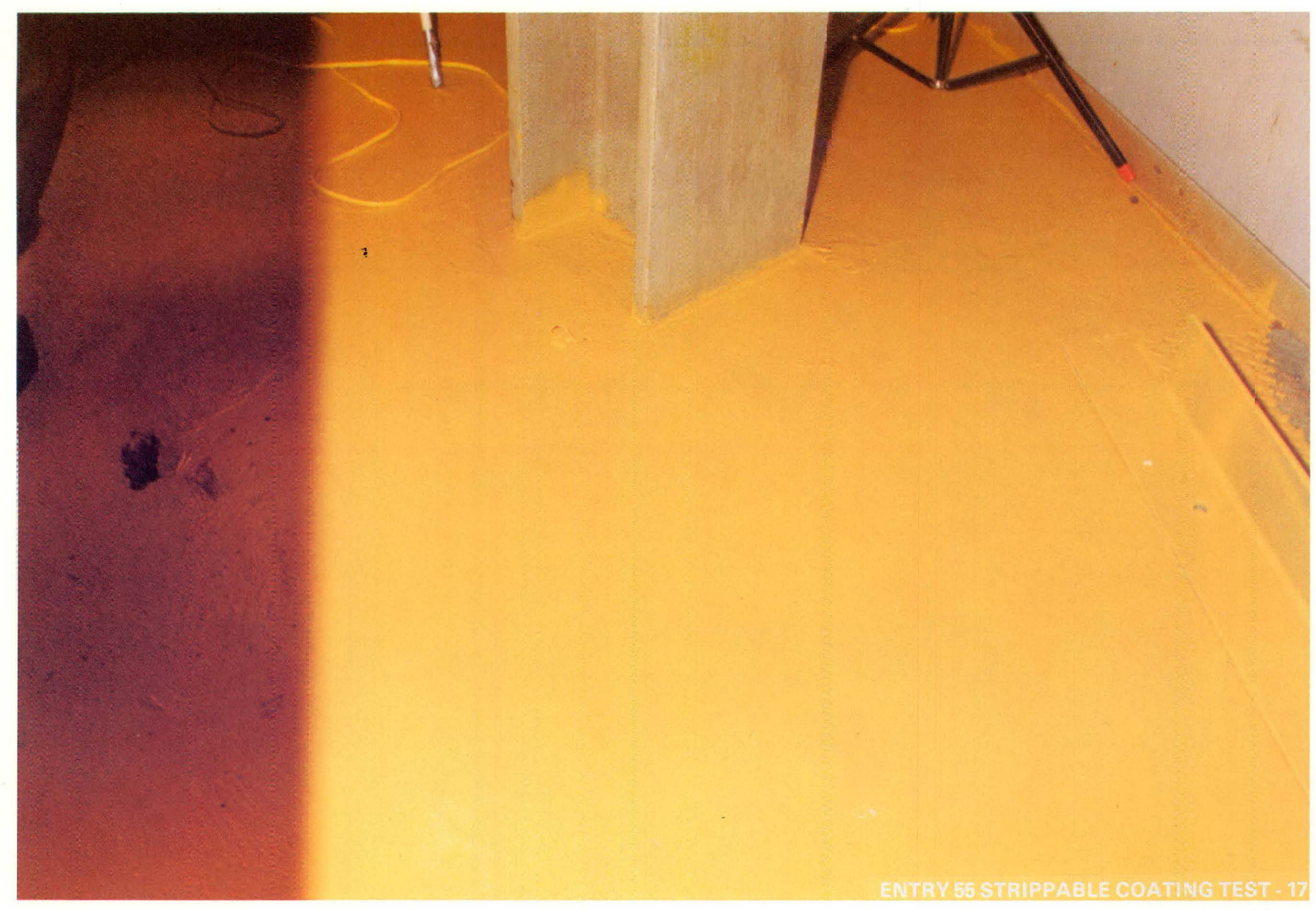

PHGTOGRAPH 26 

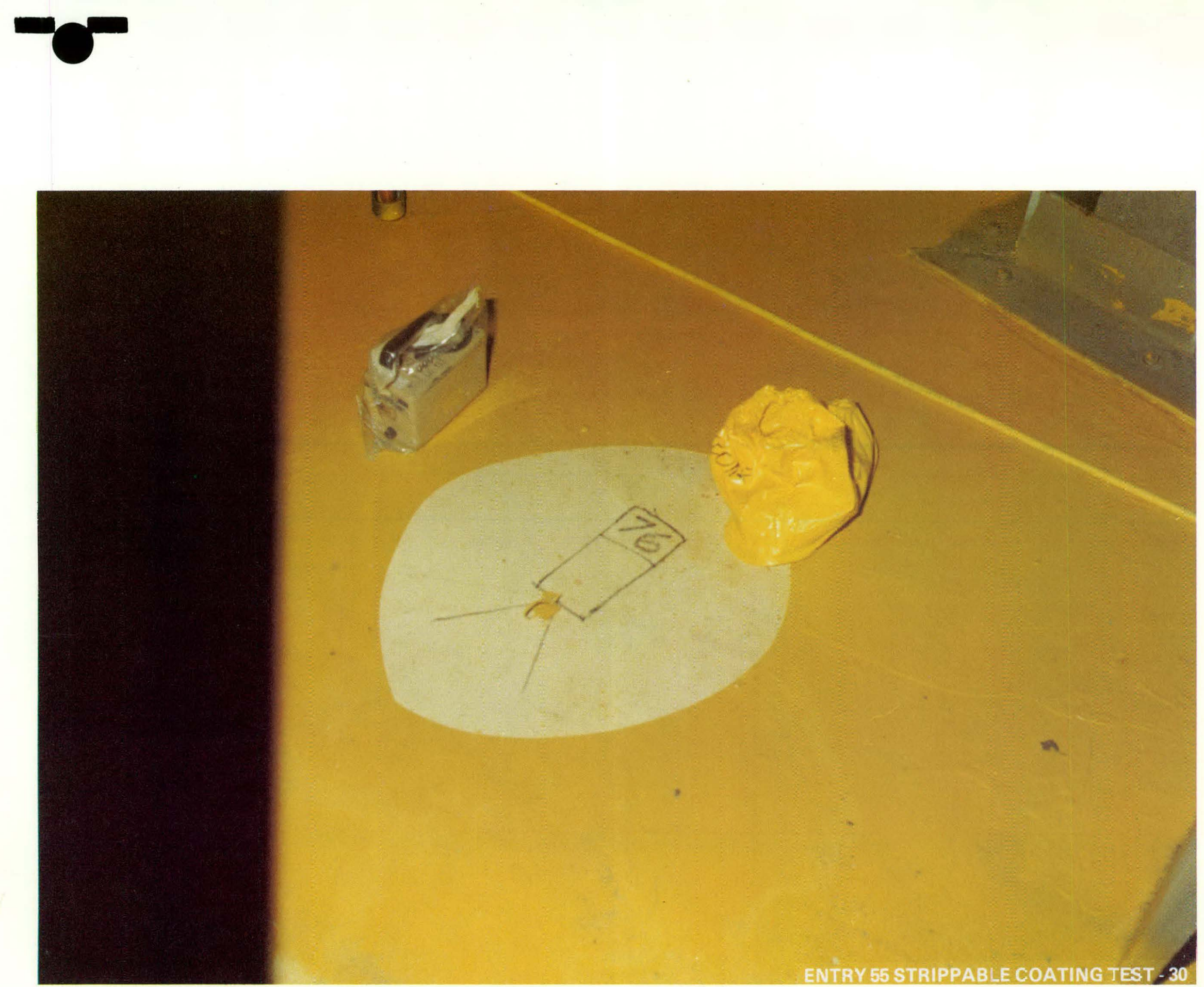


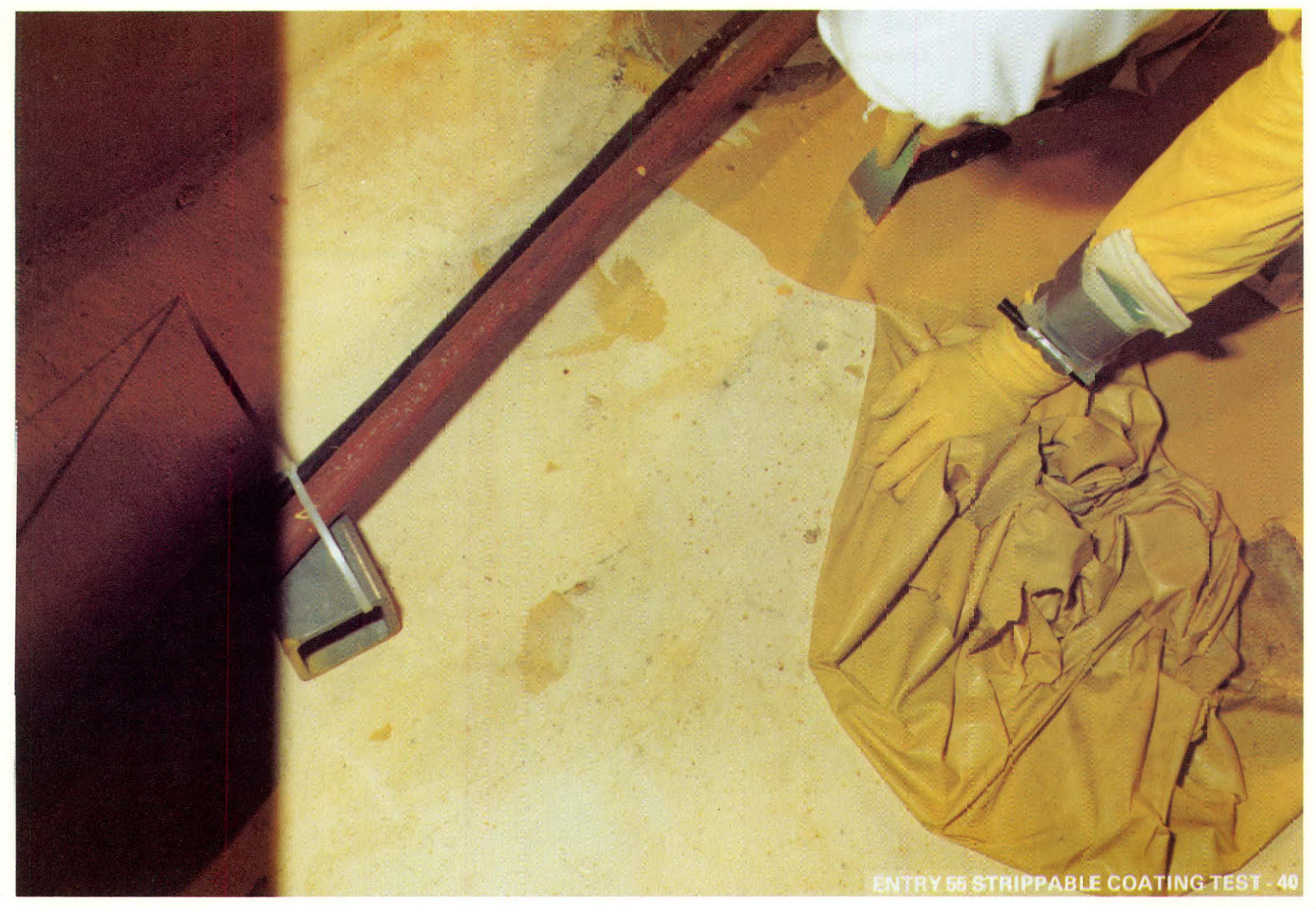

PHOTOGRAPF 28

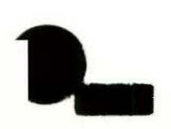




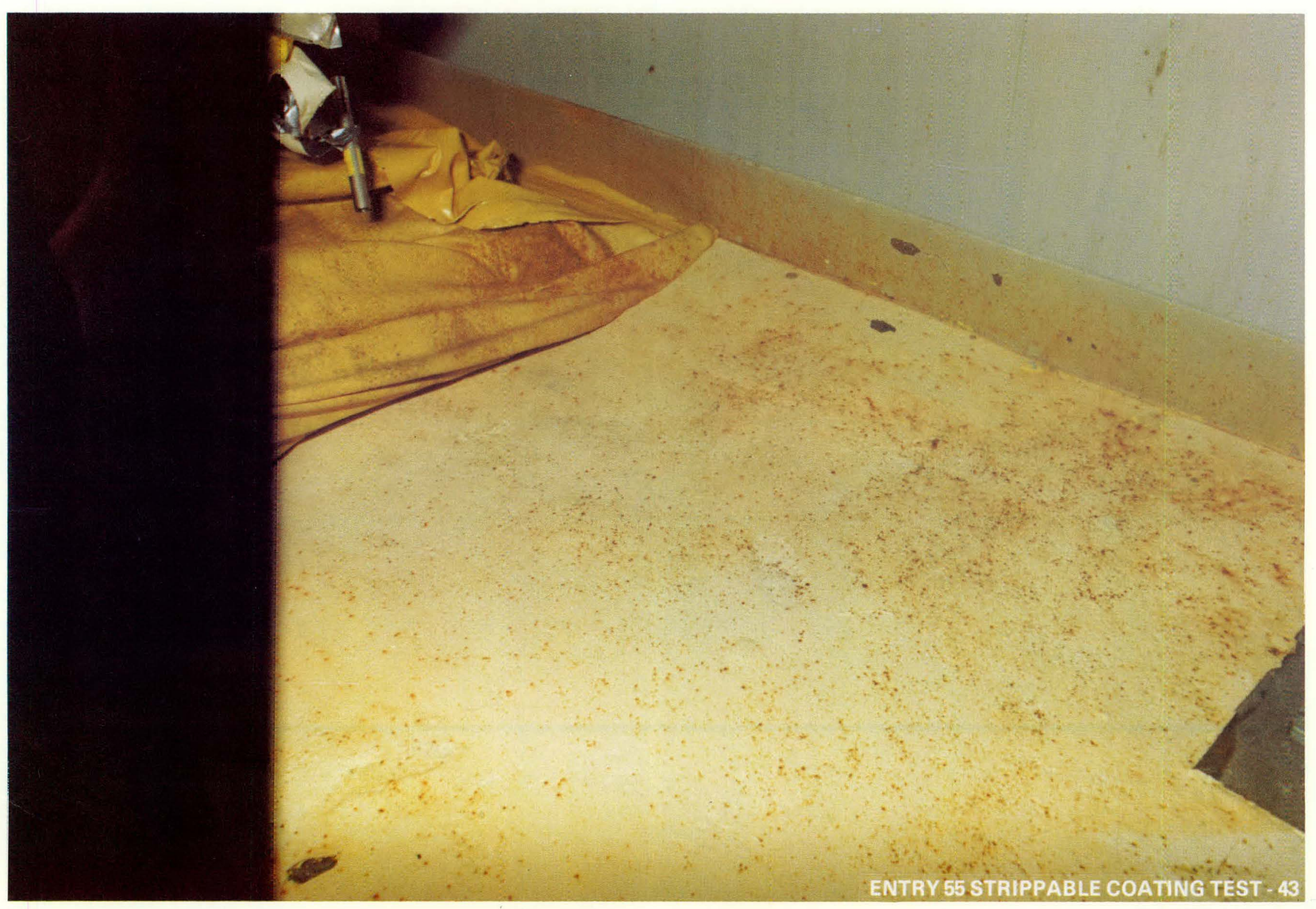




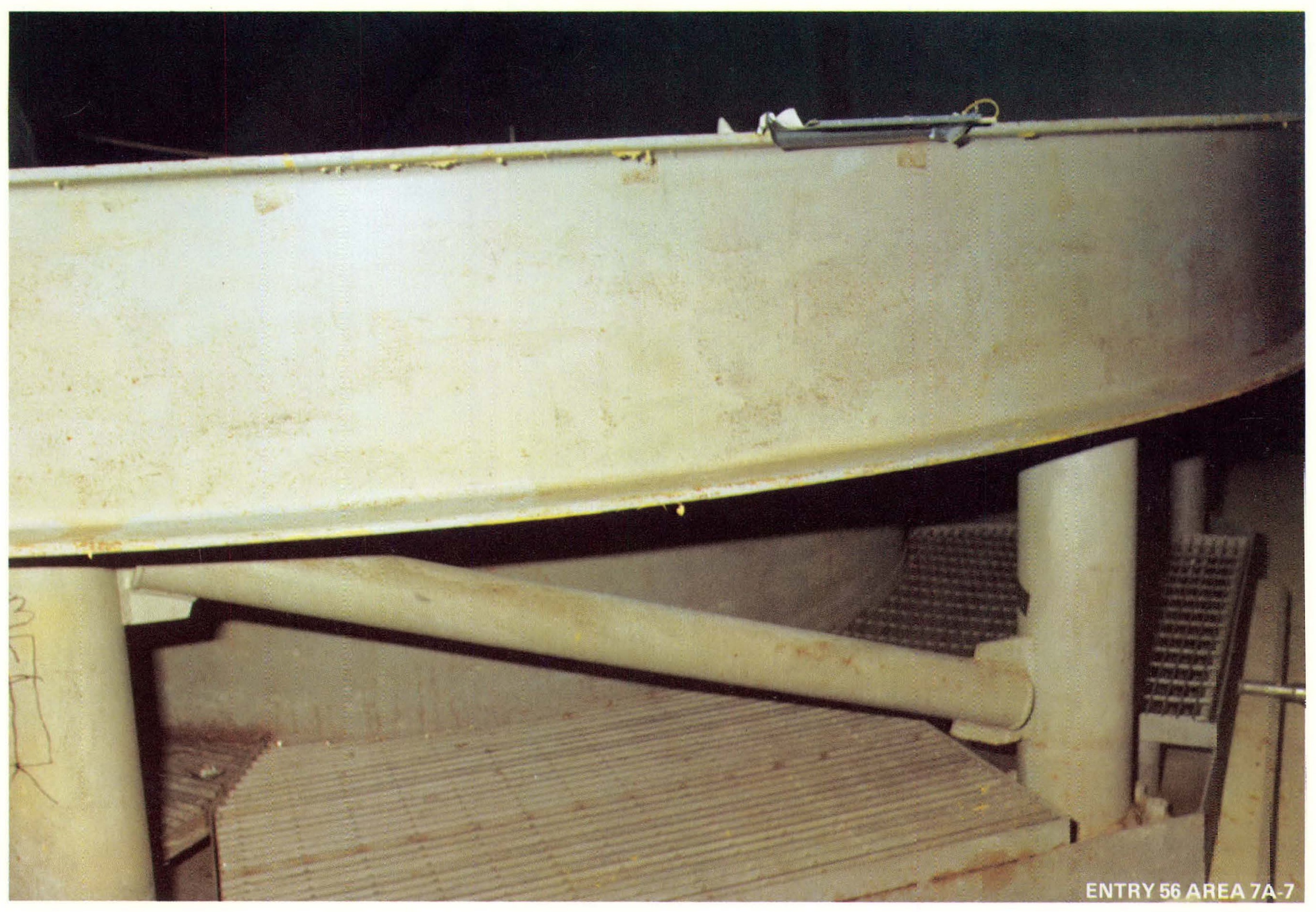

PHOTOGRAPH 30

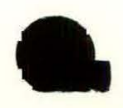




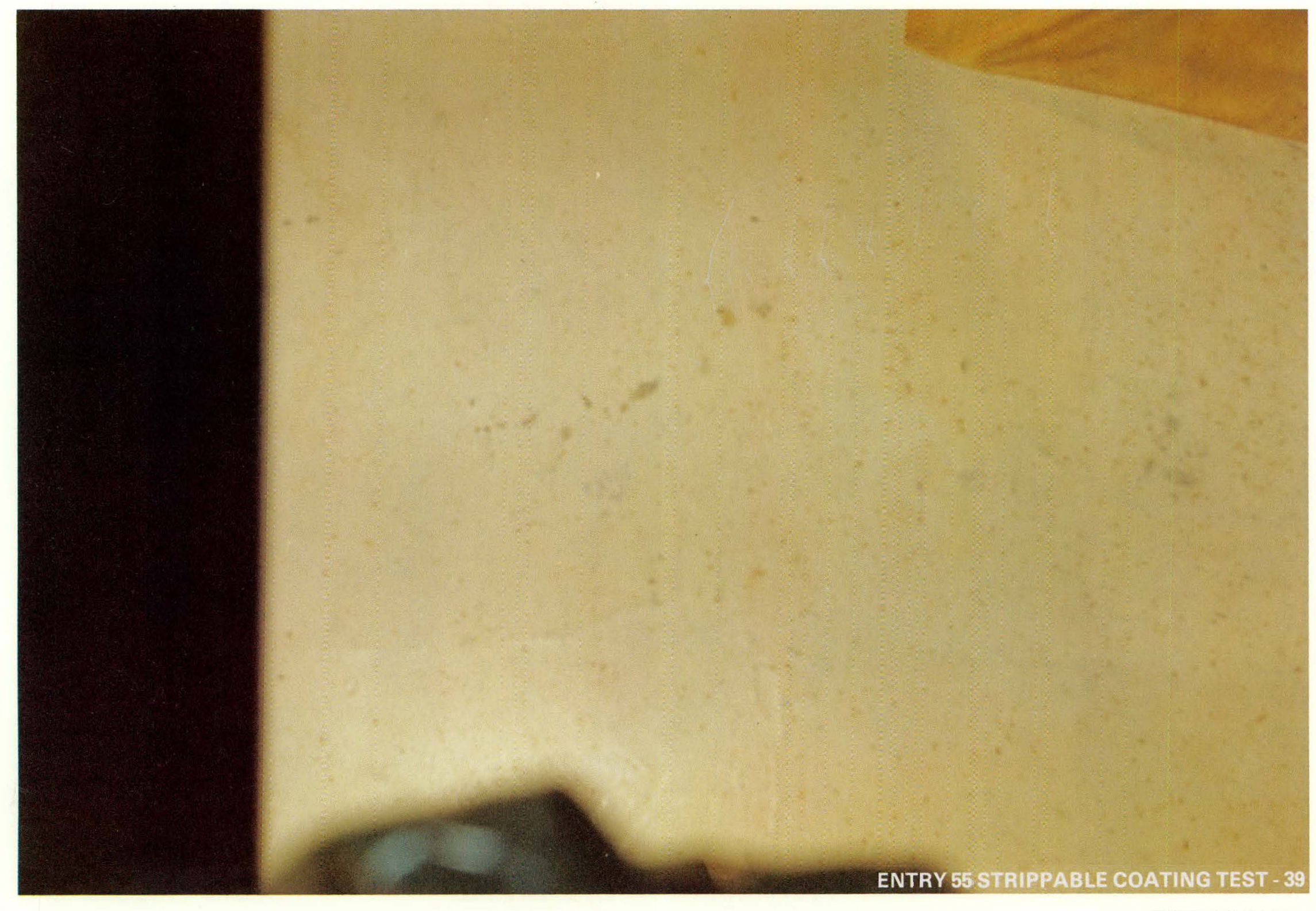

PHOTOGRAPH 31 


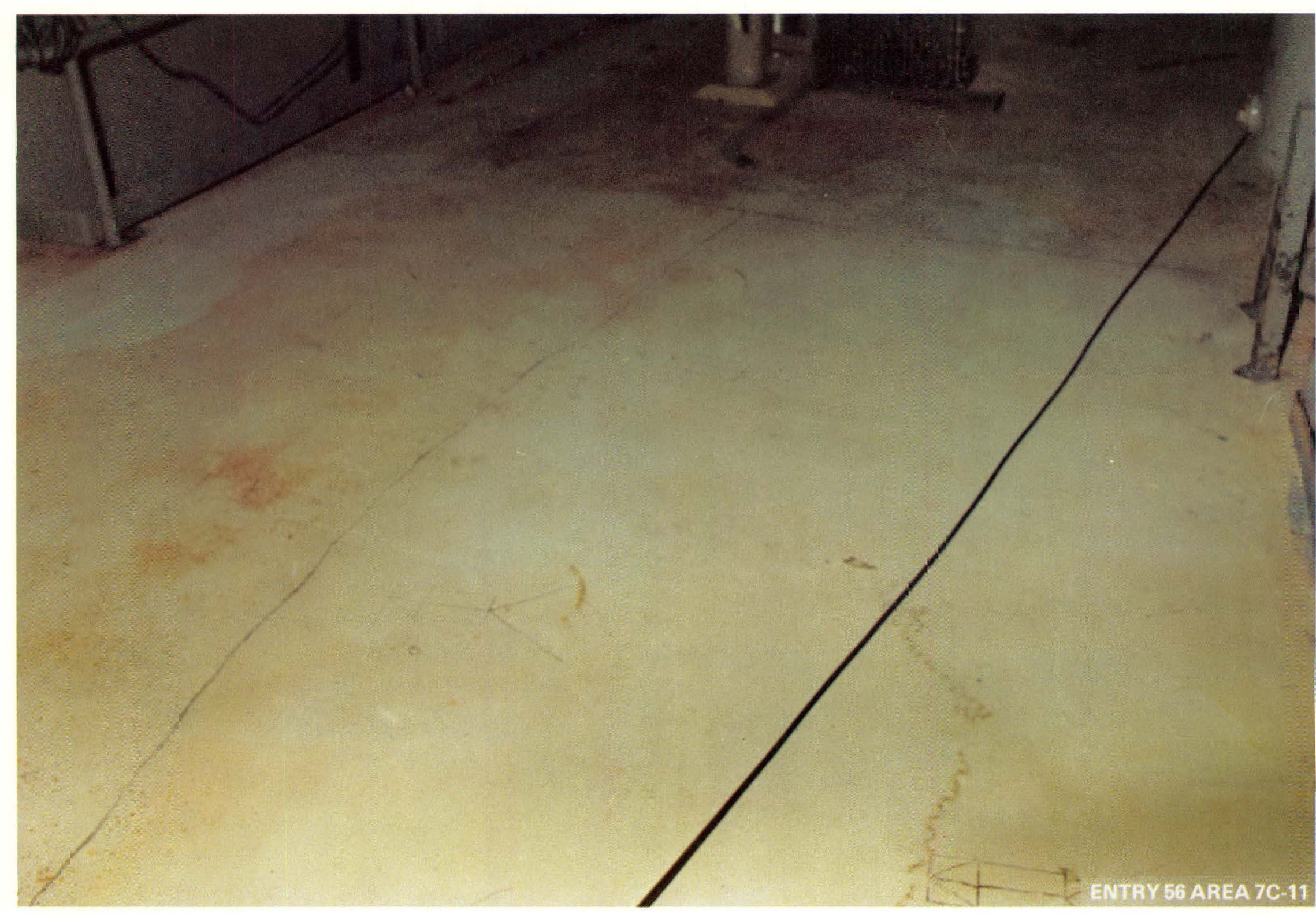

PHOTOGRAPH 32

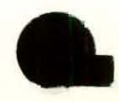




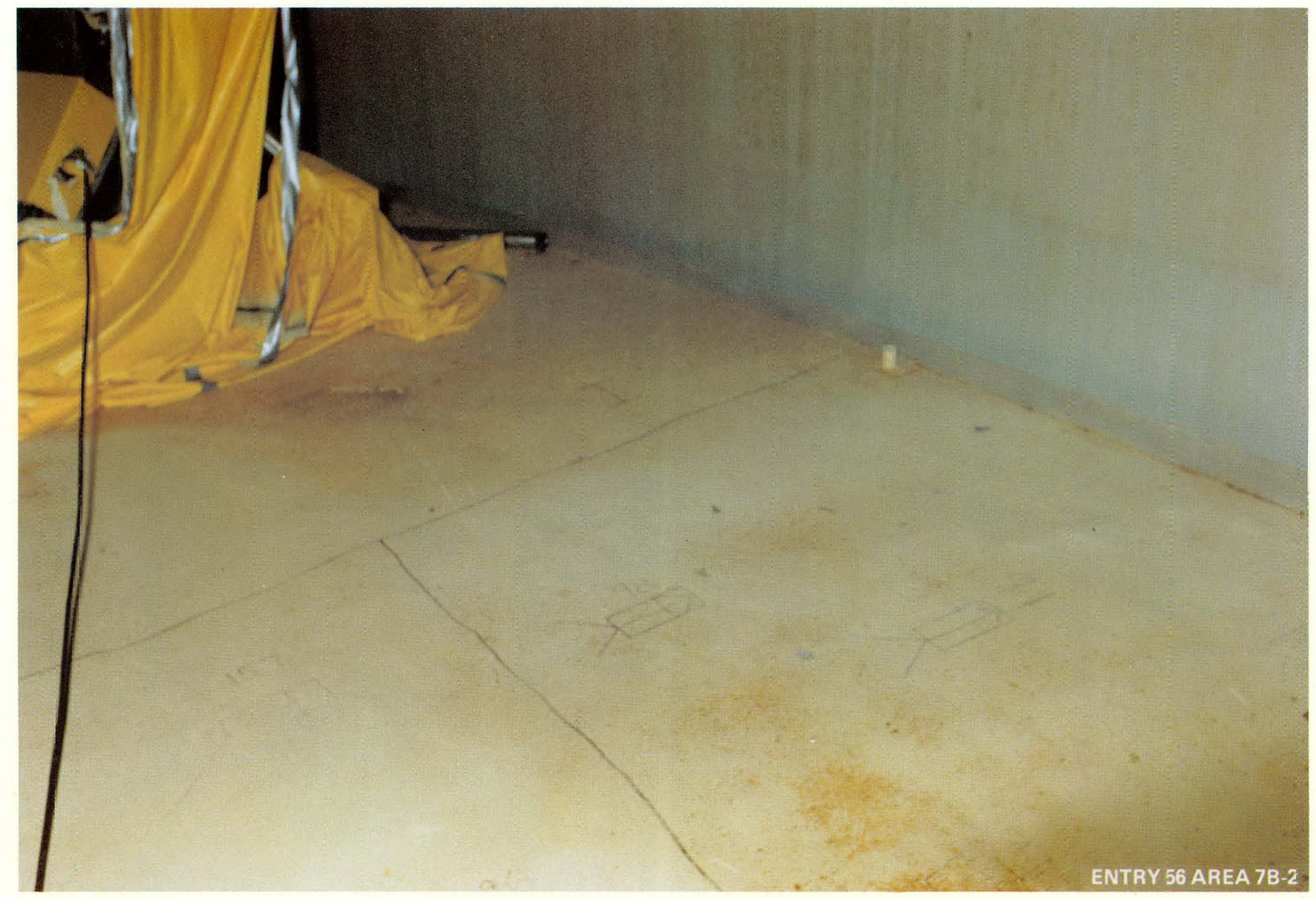




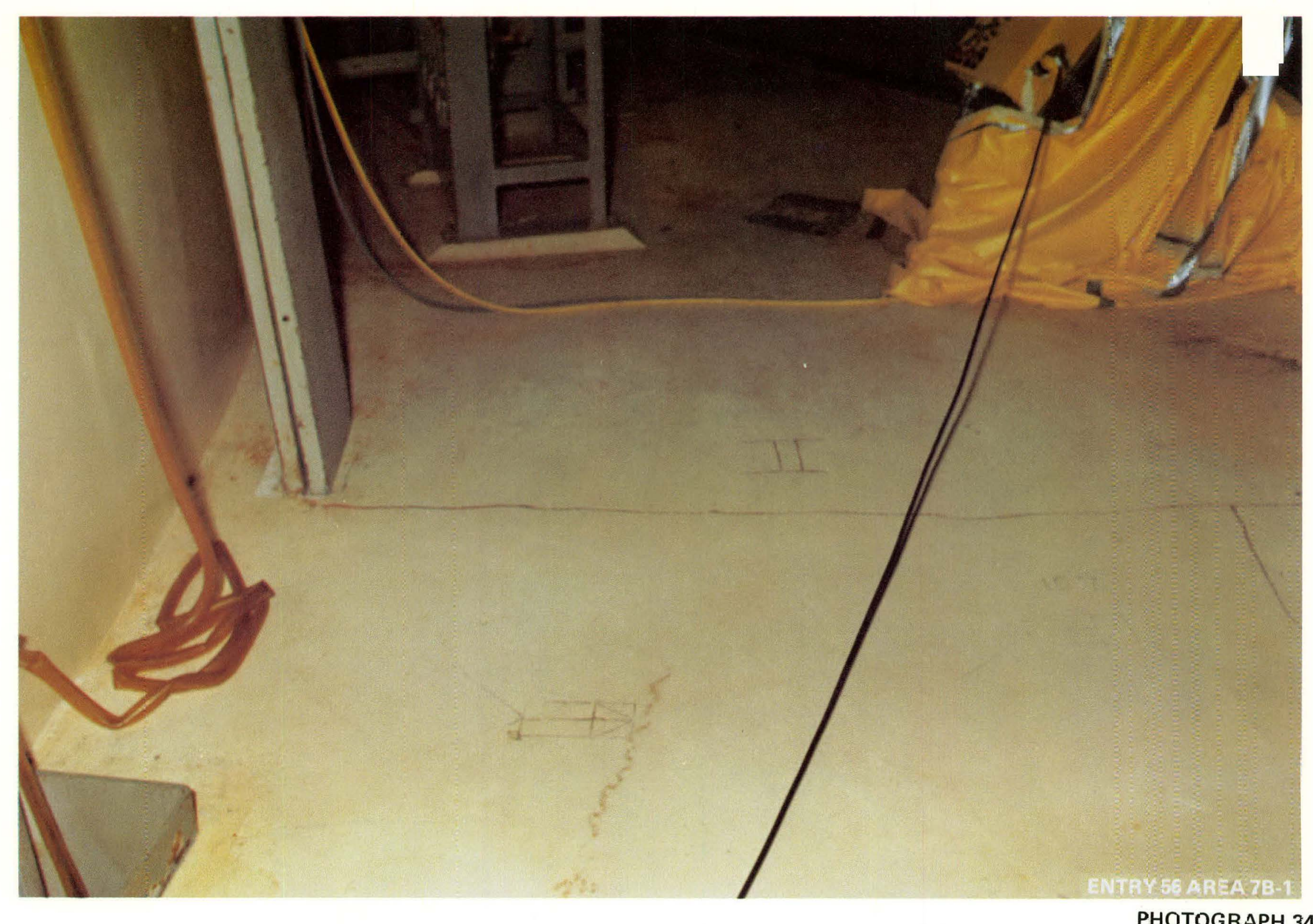

PHOTOGRAPH 34 



\subsection{CONCLUSIONS}

\section{Decontamination Experiment Effectiveness}

The effectiveness of the Decontamination Experiment with regard to the objectives established during planning is summarized below:

o The effectiveness of several decontamination techniques was established, and optimum techniques and technique parameters were selected for various surfaces and circumstances.

- The efficiency of the decontamination technique was established.

- Decontamination training and procedures were documented and evaluated.

- Various decontamination equipment was evaluated and its effectiveness documented.

- Support systems and organization for the experiment were documented and evaluated.

- The safety of the experiment equipment techniques and plan was documented.

- The contamination levels were reduced in some locations during the experiment, but some areas were recontaminated because of technique or procedure.

- Radiation from other sources on hnth elevations masked the contamination reductions achieved during decontamination of several test areas. 
o The area dose rates were not reduced 70 to 150 mrem in the test areas in the reactor bujilding, as was planned.

o Information was obtained to facilitate generic decontamination planining, in addition to planning for TMI - Unit 2 :

- Radiation monitoring results and mapping of the area were partially accomplished for the experiment.

n Suffigiont data scre generated ly the experiment to provide the basis for several fnllow-on studiee of subportions of lhe experiment.

0 The ettectiveness of the Decontamination Experiment was decreased by the changes in work scope and basic criteria in conlamination control.

- A continuing decontamination effort will reduce the area dose rates in the reactor building.

\section{Decontamination EffecLiveness}

In general, the decontamination factor (DH) was dependent upon the water volume applied per unit area, the type and orientation of the surface, and the nature of the existing contaminants.

Figurc 31 shows a graph of DF versus the water volume per unit area (gal/ft ${ }^{2}$ ) fọ floor surfaçes on elpvatinns 305' and 3/17!-6". Rationale fü Llie results shown are discussed helow.

Most of the debris on elevation $305^{\prime}$ was contaminated dirt. Low pressure flushing was effective in removing this loose material. Therefore, the DF, as calculated, is influenced by removal of the dirt as well as contaminants on the surface. From the graph it is clear that after sufficient water has been applied to cover the surface, the DF rises very rapidly and becomes almost 
independent of the quantity of water applied per unit area. This result is expected because once there is sufficient water to move loosely adhering material, the necessity for excess water diminishes. Furthermore, too much water is operationally difficult to control and can result in recontamination of treated surfaces.

The intermediate curve represents the effect of high pressure flushing on floor surfaces that have been successfully treated with low pressure flushing. It is seen that the effect of increasing water volume per surface area decreases substantially, but is still greater than observed on elevation $347^{\prime}-6^{\prime \prime}$. This probably arises from the fact that the low pressure flush on elevation $305^{\prime}$ ' was not totally effective in removing the large quantities of debris, so that further removal was achieved by high pressure flush. The intermediate curve and the lower curves indicate that an optimum value exists for the volume of water applied per unit surface area.

The lower curve represents the effect of combined low pressure/high pressure flushing on the floor surfaces of elevation 347'-6". Note that DFs are lower than those of elevation $305^{\prime}$. Since these data were obtained after a combined low pressure/high pressure treatment and, presumably, the loose debris on elevation 347'-6" was considerably less than that on elevation 305', the removal rate appears to become controlled by dissolution rates and probability of removal of embedded material by the water stream rather than by gross removal of loosely adherent debris. It is seen that for conditions existing on elevation $34^{\prime}-6^{\prime \prime}$, DFs greater than 30 were not achieved by the techniques used.

DFs are less dependent upon pressure and flow when considered separately. It was clear that low flow rates at any pressure were less effective than higher flow rates, simply due to the lack of sufficient water volume to remove contamination from the surfaces. Conversely, high flow rates with high pressures caused problems on horizontal surfaces because of the inability of operators to properly direct the water to drains and the attendant mist that 
recontaminated cleaned surfaces. It appears that 15 gallons per minute at 6000 psi is the optimum flow rate that can be accommodated on horizontal surfaces.

No significant effect of water temperature can be established from this experiment. Cesium compounds are very soluble, and increased water temperature would be expected to increase their dissolution rates. Because of operational characteristics of the in-line water heating system, the actual hot water temperatures were difficult to maintain at constant values. This problem, coupled with the inherent large solubility of cesium, made it impossible to conclusively establish the need for hot water.

All data used in preparing Figure 3-1 resulted from tests in which the water was removed from the area by using squeegees to direct the wastewater to floor drains. Potentially different results would have been achieved if the excess water had been removed by a wet vacuum system. Such an approach would have at least minimized the problem of recontamination due to misdirection of water.

It can be concluded that the decontamination of vertical surfaces proreers somewhat ditterently from that of horizontal surfaces. Vertical surfares, nf course, do not generally have debris embedded in their surfaces as do floors. Beyond that, DFs observed on vertical surfaces were also higher than those observed on some horizontal surfaces. The toe of the curves show in Figure 3-1 is anticipated to be very short, since the water volume per unit area required fur run off is considerably less than that for horizontal surfaces. Additionally, as a vertical surface is flushed from top to bottom, the buildup of watcr flowing down the surface increases the volume per surface area and is cffective in the elution of solubles and transport of particulates. Such elution and transport are not so readily achieved on horizontal surfaces.

It was found that stainless steel surfaces exhibited much higher DFs than concrete and carbon steel surfaces, which were about the same. Such results are expected based upon the relative porosity of the various surfaces. Even in 
the case of stainless steel, however, much larger DFs were observed on vertical surfaces than on horizontal ones, e.g., 110 versus 31 on the walls and floor, respectively, of the shallow end of the refueling canal.

\section{Decontamination Techniques}

Mechanical scrubbing techniques are effective in reducing smearable contaminant levels. The use of chemicals (detergent and phosphoric acid) on a limited scale posed no difficulty in their collection for subsequent waste management activities.

Wet-vacuum collection of the liquids may also have been partially responsible for the success of this technique, but this point remains to be evaluated.

Strippable coatings yielded large DFs (approximately 300), based upon smear sampling results.

When dealing with floor surfaces, it appears that low pressure flushing is not a prerequisite to high pressure cleaning unless a great deal of loose debris has to be removed.

From the data obtained, there is no apparent correlation between RDFs determined by contact readings and those DFs obtained from swipe data. This indicates that the removal of loose contaminants from a surface may or may not influence the amount removable in a swipe sampling process. However, there was a correlation between the RDFs determined by contact readings and surface deposition DFs.

The conclusions regarding decontamination effectiveness and efficiency are summarized in the decontamination logic diagram (Figure 3-2).

The abrasive technique shown in the logic sequence for stainless steel surfaces is necessary to remove contamination from the surface milling marks, 
where it is not sufficiently reduced by low pressure flushing. It has been concluded that another technique, such as chemicals or abrasive blasting, would be required to obtain the same decrease in level of contamination that were obtained by the mechanical scrubber on the horizontal surfaces.

\section{Decontamination Control and Surveillance}

The results of the Decontamination Experiment indicated that:

- Sequencing of decontamination activities to take into consideration gravity flow and location did not prevent recontamination.

o Planning and implementation of control of personnel, equipment, and work areas are necessary to prevent recontamination, even during gross decontamination activities.

o Step-off pads, sticky pads, and barriers are required in a contamination control program.

- Testing various parameters of the hasir dernntamination techniques produced a large amounl of recontaminatinn of surfaces. Where pressures and tlow rates were above the optimum range for the technique, adjacent or additional surfaces were contaminated or recontaminated by overspray or inadequate flushing.

o Surveillance of the area and surfaces being decontaminated during and after the effort is necessary to determine the effectiveness of the decontamination effort. If there is a problem in effertiveness detected that can be readily rectified by changing the decontamination technique, procedure, or equipment, the change should be accomplished as soon as possible. 
The detection method, authority to change generic procedures, and the team of required specialists should be available to coordinate the change. Some of this can be accomplished in preplanning the effort by including decision points and optional techniques, but during the activity some mechanism must exist to accomplish minor changes .

Personnel traffic from the air lock to various areas of the reactor building caused recontamination of surfaces where there was a significant difference in contamination levels between areas traveled.

High pressure spray activity with the lance and water floor scrubber caused contamination of other surfaces. Procedures should contain provisions for an adequate flush after high pressure activity, and the pressures should be constrained sufficiently to reduce contamination overspray and debris splatter.

An insufficient amount of time was spent with the decontamination crews in training on the recontamination problem, i.e., how to recognize it and the corrective actions to be taken during decontamination activities.

$\circ$ Equipment different from that required by the procedures was used during some of the tests, which resulted in recuntamination.

Where an effective contamination control program was outside the scope of the experiment, its absence had a direct impact on post-test data. In some cases, it could not be determined if the lack of success of a test was due to recontamination or to an inadequate technique whose parameters were inadequate to remove contamination.

- Contamination control of personnel leaving the containment and the areas outside the reactor building was excellent. Only three or four 
cases of small area surface contamination occurred on individuals, and these were due to glove punctures or small items contacting the skin during undressing. The low incidence of personnel contamination can be attributed to the procedures and dedicated dressing and undressing assistance.

o

Sampling locations and procedures to locate hot spots during surveillance operation should follow PNL-SA-10433 TRANSTAT series publications as a guide to ensure adequate sampling of the areas.

- CCTV in the command center allowed the work to be closely monitored in the reactor building. However, the poor radio communication and limited number of radios did not allow effective redirection of work when problems were observed in the decontamination work. Only the simplest of problems that required only a few words over the radio were resolved.

\section{Support Systems and Organization}

Operational problems with radios $(\mathrm{e} . \mathrm{g}$. , too few radios, inoperative equipment, poor transmission quality) caused a significant increase in the number of man-hours spent in the containment and decreased the effectiveness of the decontamination tasks and data acquisition.

The amount of radwaste in the reactor building made it difficult to reduce radiation dose levels. Since solid waste cannot be effectively cleaned within the reactor building and it significantly increases dose rates, it should be removed from the containment. Improvements should be made in removing the radwaste to reduce the dose rates and allow decontamination of the areas around the storage, waste, and trash in the building. 
Decontamination equipment and facilities outside the reactor building did not support the test effectively. For example, without a small tool decontamination capability additional tools were needed, which increased expenses, added waste volume, and created storage problems within the reactor building.

During a major decontamination task, personnel assigned solely to the task are required to support the organization controlling the entries and operations. Operational procedures require interfacing several disciplines and crafts. Therefore, it proved cost-effective to dedicate a group of workers who could respond quickly to specific operational requirements and to short-notice changes. The group of laborers who formed this support for the controlling organization accomplished the following tasks:

o Provided general and specialized training on hoists, forklifts, and high lift/reach equipment items

o Moved material among staging areas, anteroom, and the reactor building

o Decontaminated the anteroom and air lock on a frequent basis

- Prepared equipment for the entries

- Functioned as a quick-response rescue team

- Provided dress in/out support for the decontamination crews

o Participated in the entry program within their quarterly and yearly dosc limitalions.

The lack of timeliness in the installation of some support systems caused lost work effort. As a result, work that had been scheduled but which could not be performed had to be accomplished at a later time, thereby causing additional training and support costs. 
The site organization was not the optimum for performing recovery operations. The forced rotation of key personnel, especially remote reporters, during the experiment caused loss of continuity and reduced worker productivity. There was some redundancy in procedures that resulted in excessive coordination and some administrative delays, which impacted the entries. A large number of procedures were required to be understood by all personnel involved in the experiment. These could be reduced to a manageable number with a streamlined organization focused on recovery.

Except for the radios; test. equipment functioned adequately.

Preventive maintenance is required on decontamination equipment such as water floor scrubbers, lances, wet vacuum systems, and high pressure pumps for efficient utilization on a routine basis.

Equipment purchased from commercial vendors may not be suitable for efficient or reliable operation in the harsh reactor building environment without modifications. Therefore, these items should be evaluated and modified in a rimely maner.

The personnel dosimetry system must be responsive to operational activities. If a simple entry plan requires little change; the dosimetry system need not be on a real-time basis. As the dose limitations for workers are approached, it is imperative that a real-time dosimetry system is available. This ensures full worker utilization without excesyive dose commitment, Delays in personnel dosimetry system response and procedures resulted in delaying the start of entries, in crew changes at the last minute, and in substitution of personinel between high- and low-dose-rate tasks. The dosimetry system was not responsive to the entry program and limited the frequency of entries. Quality control of a computerized system used for dosimetry is a necessity. Errors in records did occur and one individual had to be dedicated to quality control of dosimetry at the operations area. 
Radiation work permits (RWPs) were not processed sufficiently in advance of entries, and the required approval cycle resulted in entry delays.

Distribution of data acquisition information included organizations that did not need the data and omitted some that required it. As a result, data management changes occurred in order to improve the efficiency and effectiveness of the system. The experiment required a dedicated individual to obtain the data and ensure the accuracy and coordination of organizations providing data and analysis.

An insufficient number of equipment items such as radios, MSA masks, ice vests, and safety harnesses reduced the efficiency and flexibility of activities during the experiment. The correct support requirements must be forecast in order to have sufficient numbers of equipment available. Training, decontamination, and in-containment requirements must be considered at one focal point.

\section{Decontamination Training}

Training must be completed to rigorous standards.

Snme training deficiencies occurred due to equipment shortages for training and poor instruction. During a few of the later entries, training occurred just prior to the scheduled entry. As a result, there was no time for a review of training effectiveness. 'lhis schedule left the discovery of deficiencies to the task supervicor during the actual entry.

An insufficient number of backup personnel were trained; as a result, considerable scheduling flexibility was lost. The number of crew changes for sickness, absenteeism, accidents, and other incidents for each entry was underestimated. One backup for every four crew members (laborers and crafts) performing decontamination work was shown to be optimal. 
The following tasks have to be accomplished before engaging personnel in training and decontamination operations:

- All training equipment should be available and operationally ready, and a suitable worl arca should be dedlcaced for training.

o Techniques and procedures should be proven and equipment tested before any training occurs.

- All work packages must he reviewed and approved by training personnel, radiological staff, and crafts supervisors.

- An adequate training staff must be provided.

Lesson plans for training can consist of work packages operation and qualification packages .

Work packages should be in an approved format and contain at a minimum:

o Prerequisites for the task

o Work instructions

o Signoff instructions for completion

- Fquip̣ment required

- Work techniques required.

Work packages contained too many administrative and procedural items not associated with the actual work procedures. Fluctuation of these items caused excessive time spent in administrative approval channels, and many time delays that could have been avoided resulted from minor changes in techniques or 
technical equipment. Items such as man-rem estimates, radiological characterization information, technique sheets, RWPs, and $4045 \mathrm{~s}$ should be appended to work packages as references, not included within them.

One individual should be responsible for training and should have a support staff to conduct the training, document the training completed, and provide verification of certification for those individuals who will enter and work in the reactor building.

\section{Decontamination Criteria.}

\section{Gross Decontamination Coals and Criteria}

The goal of gross decontamination is to remove the bulk of relatively loose and readily soluble contaminants, thereby reducing radiation levels and resuspension of contaminants. The reduction in the smearable contamination level was expected to be to $10^{5} \mathrm{dpm} / 100 \mathrm{~cm}^{2}$ of $\mathrm{Cs}-137$, and work area dose rates would be reduced by 70 to $150 \mathrm{mrem}$ gamma. Attainment of these levels would reduce the inhalation hazard as well as reduce overall exposures for work within the reactor containment building.

To accomplish the goal of gross decontamination, several criteria and restrictions are imposed on the activity:

o Water will be the main decontaminating agent used.

- The techniques must have been previously demonstrated in tests in the reactor, auxiliary, or turbine building.

- The techniques will not impair or jeopardize the capability of the facility, component, or structure to perform its operations and safety function. 
- Techniques and reagents should be compatible with NSSS component materials to avoid excessive degradation of such components.

- The use of chemicals will be prohibited where the effluent may impair operation of the submerged demineralizer system (SDS).

- The sequence of activity will be based on the first 13 steps of the Gross Decontamination Plan (Reference 1).

- Sequencing of the decontamination activity will employ gravity flow as the prifiàry method of contamination control.

- Extensive man-hour and man-rem associated activities which do not contribute to general area dose rate reductions will be avoided.

The level of $10^{5} \mathrm{dpm} / 100 \mathrm{~cm}^{2}$ of $\mathrm{Cs}-137$ for gross decontamination is obtainable by the optimum techniques demonstrated during the Gross Decontamination Experiment. During the experiment, contamination equal to or lower than $10^{5} \mathrm{dpm} / 100 \mathrm{~cm}^{2}$ of $\mathrm{Cs}-137$ was achieved on some floor and vertical surfaces, equipment, and cable trays.

Not all equipment and surfaces reached the desired level, heraluse of recontamination or ineffective technique parameters used during the test.

Recontamination was a major problem, and the gravity flow principle and sequencing of the effort should be augmented by stringent controls on the movement of people and equipment through areas of varying contamination levels. Insufficient controls prevented several areas from maintaining the desired goal.

The sequencing of decontamination activities was changed from that in the plan, which established a logical approach to decontamination. By not following the established sequence, and without stringent controls on personnel movement and work areas, recontamination occurred. This will necessitate 
duplication of effort and extensive reaccomplishment of some decontamination activities, such as on the polar crane and the elevation 305' floor and wall surfaces.

Reduction of area dose rate by 70 to 150 mrem gamma is possible in a gross decontamination effort; however, it was not generally attained during the experiment for the following reasons:

- The scope of work did not include decontaminating adjacent surfaces or equipment, which contributed to the final area dose rate.

- Storage areas, trash, and waste stored within the building contributed to the area dose rate. When one storage area was moved during the experiment, the area dose rate decreased approximately 50 percent below post-decontamination data acquisition values ( 30 mrem decrease). Rusted and corroded defueling tools, chains, gang boxes, and equipment not decontaminated to the levels of the floor surfaces added significantly to the area dose rate. The reactor building dose rate can be reduced by removing the trash and waste from the reactor building.

- Areas under equipment, protrusions, or congested areas were not decontaminated to the same level as the floor surfaces during application of high pressure spraying with the water tioor or mechanical scrubber. As a result, there are a number of areas under equipment that exceed the contamination and contact radiation levels reached during the decontamination of the floor surfaces. This contributed to the area dose rate and impacted the anticipated decontamination results. 
Other source terms which contribute to area dose rates and affect the decontamination results in terms of area dose rate reductions are:

- The dome area

- LOCA ducts

- Inside area of the D-ring

- Reactor head service structure

- Reactor coolant system assoriated piping

- Elevation $282^{\prime}-6^{\prime \prime}$

- Enclosed stairwell and clcvation shaft diés

- Incore instrument seal table.

Evencually, some of these sources can be shielded, decontaminated, or removed from the reactor building. The contribution of these sources to the area dose rate is not known and is not within the scope of this report.

The lowest area dose rates achieved in the Decontamination Experiment were: (a) 30 to 40 mrem gamma on elevation $347^{\prime}-6^{\prime \prime}$, which resulted in a total of 75 to 80 mrem hours for work activity on that elevation, including transiting elevation $305^{\prime}$ and the open stairwell, and (b) 18 to 25 mrem gamma in the refueling canal deep end. The refueling canal is stainless steel and isolated from the reactor and elevation $282^{\prime}-6^{\prime \prime}$. Without the influence of other source terms, area readings of at least 18 to 25 mrem can be obtained during gross decontamination. However, the decontamination activity must include thc walls, overheads, and floors.

Surface deposition sampling data are provided in Appendix A. An analysis of some of the surface deposition samples indirates:

- The activity is limited to a thin surface layer

- The surface layer is no thicker than $40 \mathrm{mils}$ 
- The paint layer is approximately 20 to $30 \mathrm{mils}$ (specification called for 28 mils)

- Correlation with the contact radiation reading derived RDFs.

The Gross Decontamination Experiment showed that decontamination could be accomplished safely and not impact the operations or safety functions of the facility, components, or structure.

It will be necessary to use chemicals in areas where flushing or abrasive techniques cannot be used. Chemicals were used safely and it was possible to control the waste.

\section{Conclusion Summary}

- The most effective decontamination technique reduced the gamma dose rates below the target for practical work area for head lift and defueling.

- The mechanical scrubber and strippable coating technique can produce smearable contamination levels of $10^{3}$ to $10^{4} \mathrm{hpm} / 100 \mathrm{~cm}^{2}$ of cesium, arca radiation dose rates of 30 to $40 \mathrm{mrem} / \mathrm{hour}$ gamma on painted concrete surfaces, and 20 to $25 \mathrm{mrem} /$ hour gamma on stainless steel surfaces.

- Tlie surtace deposition boring results indicate that decontamination of the painted concrete surfaces can be accomplished by surface washing and scrubbing with water and chemicals.

- The Decontamination Experiment results shuwed that the particulate 'activity could be reduced to the point where respirator protection is not required. Further decontamination efforts will eliminate the requirement for respirators. 
- DF is dependent upon the type and orientation of the surface; the nature of the contaminants, and the volume of water applicd per unit surface area.

- The water tcmperature did not appear to be a significant parameter in these tests.

- High pressure and high flow rates caused problems :

- Stainless steel exhibited higher DFs than bnth ronrrete and carion steel.

- Mechanical scrubbing is very effective. The need for detergent or other chemicals should be further evaluated.

- Strip coating appears to be effective on floor surfaces. High DFs were observed.

$u$ Combination of low and high pressure flushing may he necessary on floors nnly if the surface is covered by large amounts of loose debris. Ocherwise, high pressure flushing is just as effeclive ac the combination - particularly if mechanical scrubbing is to be used.

- Lack of correlation between RDFs by contact readings and DFs from smears indicates that the smearable fraction may be relatively indepcndent of total loose contaminant $/ \mathrm{cm}^{2}$ at the levels involved in the reactor building.

- High DFs are achievable on vertical surfaces with low pressure flushing alone. High pressure (over $2000 \mathrm{psi}$ ) is probably unnecessary. If further reduction is required, abrasive blasting, chemicals, or mechanical scrubbing could be used. 
- A vacuum system would be a beneficial addition to the water floor scrubber. It would avoid problems of recontamination due to an inability to properly handle water, and, DFs might be increased, since contaminated water would be removed rather than redistributed.

- Smearable contamination levels of $10^{5} \mathrm{dpm} / 100 \mathrm{~cm}^{2}$ of $\mathrm{Cs}-137$ are attainable using low pressure and/or high pressure flushing alone, if proper matching of technique to surface and contamination type is effected.

- Hydrolance operations were limited to $3000 \mathrm{psi}$ because of the inability of workers to maintain their footing while spraying. However, large workmen (in the 250 to 270 pound range) could satisfactorily spray with 6000 to $7000 \mathrm{psi}$. 
Key:

A. LP Elévation 305'

6 iPP Elevation 305' \& LP/HP Elevation 30'

(3) L

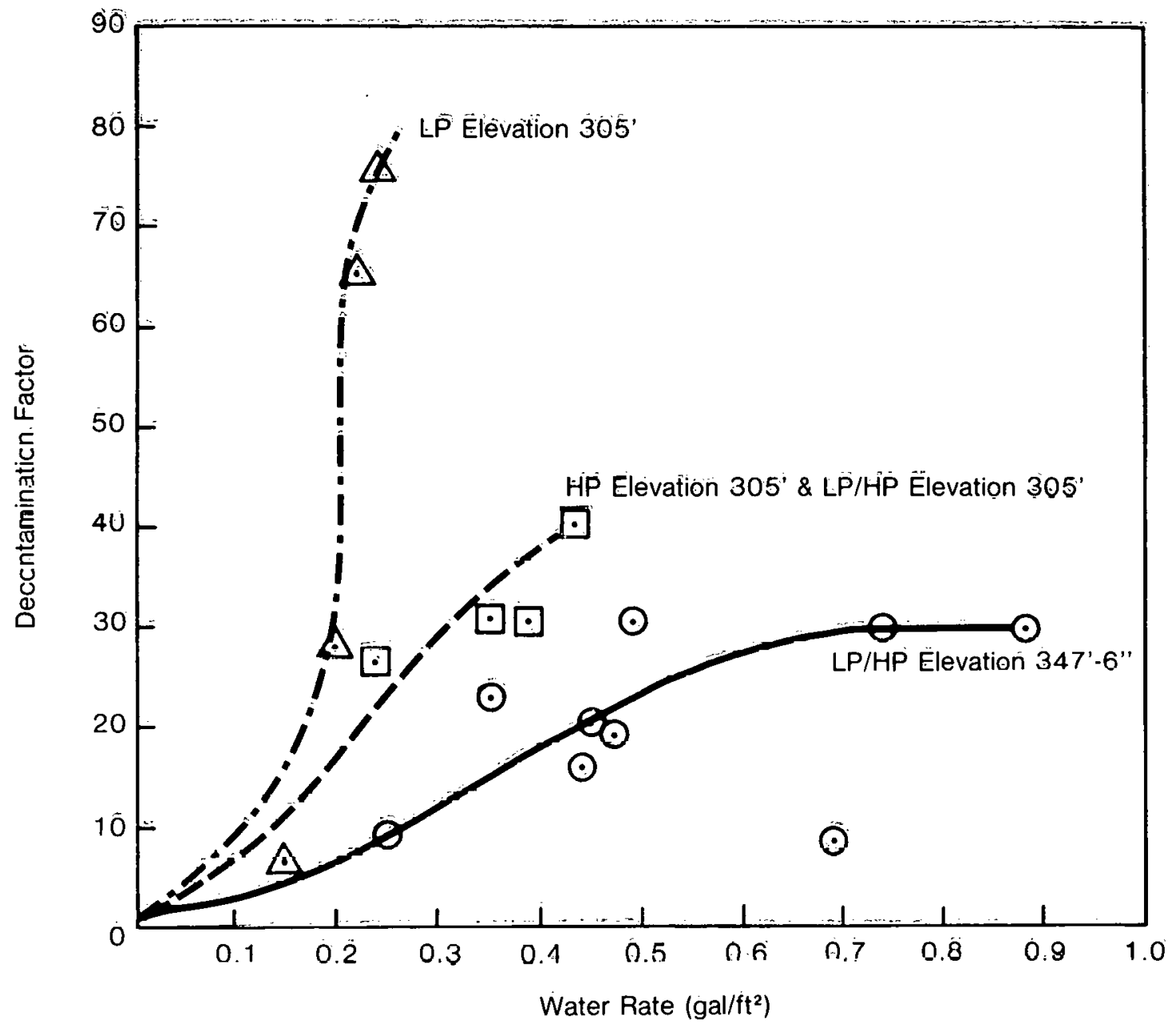

Figure 3-1. Plot of decontamination fáctor (based on contact measurements) versus water raté. 


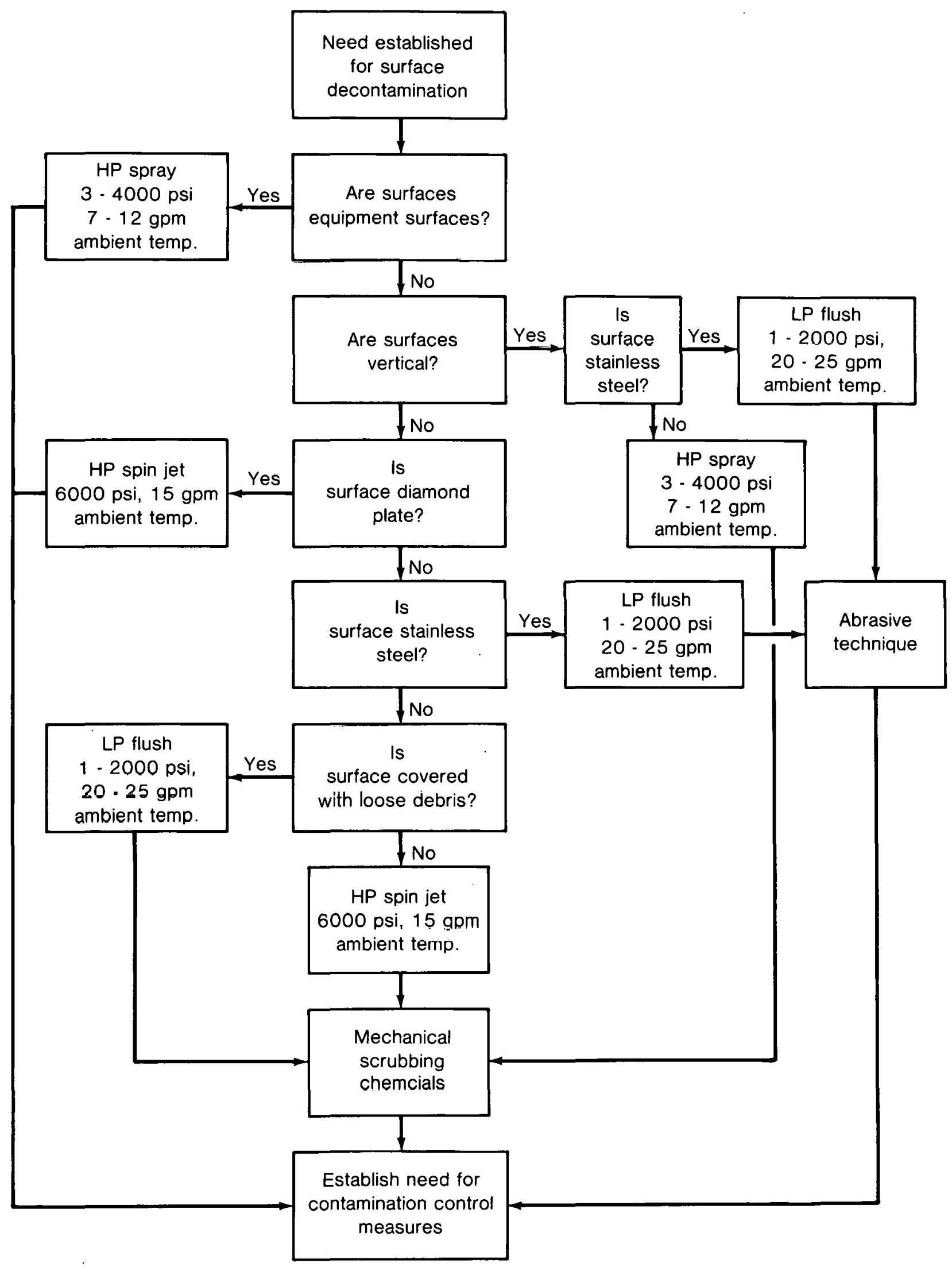

Figure 3-2. Decontamination logic diagram 
DO NOT MICROFILM IHS PAGE 


\subsection{RECOMMENDATIONS}

\section{Additional Testing}

Additional testing should be accomplished and the following techniques should be evaluated:

o Mechanical scrubbing with abrasive pads using water rather than chemicals.

- Abrasive blasting techniques. Conventional methods or methods involving zeolites in water should be tested to assess their effectiveness on vertical and horizontal surfaces of various types. The success of mechanical scrubbing techniques indicates that a related technique, such as abrasive blasting, may be equally successful. Additional abrasive techniques should be tested for use in confined areas, which would possibly avoid recontamination problems encountered with the overspray associated with high pressure flushing.

- Vertical surface cleaning with a mechanical scrubber using water alone and using chemical solutions.

o Vacuum pickup systems for collection of water from the water floor scrubber. If wel-vacuun collection increases the DFs, a design effort will be required to achieve ease of vacuum use by decontamination teams.

- Core and paint samples should be obtained from several surface deposition sampling locations and analyzed to determine: the thickness of the paint in those locations, and the activity contained in the paint, primer, and filler. This information should be obtained in small depth increments to $50 \mathrm{mils}$ to determine how much material needs to be removed to effectively eliminate the contaminants. 


\section{Decontamination Techniques}

Strippable coatings should be considered for decontamination of surfaces possessing a high fraction of smearable contamination. Such coatings should also be used for contamination control after an area is decontaminated since they are waterproof and, by the use of "egg crating," can be employed for contamination control on personnel traffic lanes.

An addendum to the Gross Decontamination Plan shonld be published to incorporate the results of this experiment.

\section{Other Recommendations}

- Improve the reactor building radio communications between the crews and the command center.

- Improve the system of approving entry tasks to provide adequate, but not excessive, review.

u Review site procedures to remove redundancy, duplication, and overlapping responsibility.

- Implement a program to establish source terms and effect dose reductions.

o A method should be established to provide some flexibility during and after decontamination work. This is necessary in order to take full advantagc of what has beenl learued by current progress to have a cost effective, efficient, and safe decontamination work activity.

\section{Additional Decontamination}

It is recommended that decontamination efforts continue. From the results of the experiment, area dose rates were obtained that are below the target 
levels of 50 mrem for defueling activity -- 30 to 40 mrem on the elevation $347^{\prime}-6^{\prime \prime}$ concrete floor, and 18 to $25 \mathrm{mrem}$ in the deep end of the refueling canal. The recommended decontamination sequence is:

- Remove all the storage, trash, and waste.

- Decontaminate the vertical and overhead surfaces, especially those surfaces that have not been decontaminated previously.

- Decontaminate the floor surfaces.

- Locate the hot spots and shield, clean, or remove the source.

- Additional decontamination is recommended because it will eliminate $\because$ the requirement for respirator protection and should increase the efficiency of the reactor building work crews. 


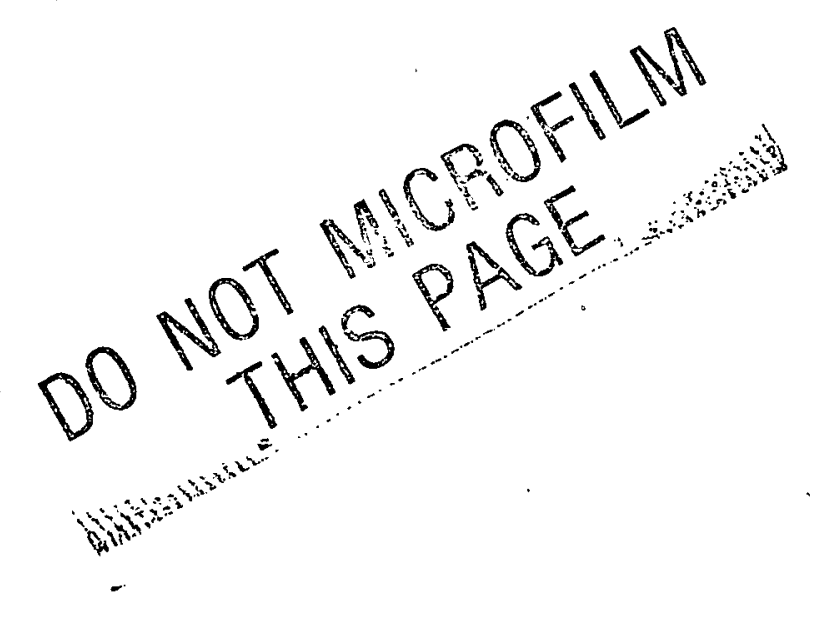

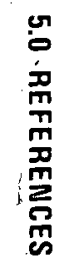




\subsection{REFERENCES}

1. Bechtel National, Inc., Technical Plan for Reactor Building Gross Decontamination, TPO/TMI-009, November 1981.

2. GPU Services, Radiological Measurements of Environment Above 347' Elevation Utilizing Penetration R-626, TDR 068, December 1980.

3. Reactor Building Large-Scale Decontamination Test, Technical Data Book, Volume 2, Decontamination Technology, TP0/TMI-009, June 1981.

4. Bechtel Northern Corporation, Decontamination Experiment Post Execution - Analysis, June 1982.

5. Bechtel National, Inc., Waste Volume Estimates for Reactor Building Gross Decontamination - Predicted and Observed, May 1982.

6. Battelle Memorial Institute, TRAN-STAT, Statistics for Environmental Studies (Prepared for the U. S. Department of Energy, Office of Health and Environmental Research, Office of the Environment). 


\section{DO NOT MICROFILM THS PAGE , was}


APPENDIX A

SURFACF DEPOSITION 
CONTENTS

\author{
INTRODUCTION \\ SECTION I SURFACE DEPOSITION DATA \\ SECTION II TLD AND RO-ZA DATA \\ SECTION III AIRBORNE DATA \\ SECTION IV DECONTAMINATION FACTORS \\ SECTION $V$ RO-2A AND TLD COMPARISONS
}

\title{
TABLES
}

A-1 Surface and Subsurface Gross Decontamination Experiment Results of Elevation 305'

A-2 Surface and Subsurface Gross Decontamination Experiment Results of Elevation $347^{\prime}$ and $367^{\prime}$

A-3 Pre-Gross Decontamination Experiment R0-2A Data

A-4 Post-Gross Decontamination Experiment RO-2A Data

A-5 Pre-Elevation 305' Gross Decontamination Experiment TLD Data

A-6 Pre-Elevations $347^{\prime}$ and $367^{\prime}$ Gross Decontamination Experiment TLD Data

A-7 Post-Elevation 305' Gross Decontamination Experiment TLD Data

A-8 Post-Elevation 347' Gross Decontamination Experiment TLD Data

A-9 Post-Elevation 367' Gross Decontamination Experiment TLD Data

A-10 Pre-Gross Decontamination Experiment TLD Beta and Gamma Measurements of the Dome Monitor and its Environment

A-11 Pre-Gross Decontamination Experiment R0-2A Dome Monitor Measurements

A-12 Pre-Gross Decontamination Experiment RO-2A Measurements A-13 Post-Gross Decontamination Experiment RO-2A Measurements 
CONTENTSS (Conținued)

\section{TABLES (Continued)}

$A=14$ Gross Decontamination Experiment Airborne Concentrations of $\mathrm{I}=12.9, \mathrm{Cs}=134$, and $\mathrm{Cs}=137$

A-15 Elevation 305' Decontamination Factors for the Gross Decontamingtimi Experiment

A-16 Elevation 347" Decontamination Factors for the Gross. Decontamination Experiment

A=17 Elevation $367^{\prime}$ Deconţamination Factors for the Groeg Decontamination Experiment

A-18 Elevation $305^{\prime}$ Gross Decontamination Experiment Decontamination or Contamination Factors Based Upon the I'Lل Mea surements

$A=19$ Eleyations $347^{\prime}$ and $367^{\prime}$ Gross Decuntamination Experiment Decontamination Factors Baced Upon the TLD Measurements

A-20 Pre-Gross Vecontamination Experiment RO-2A and Tr.D Comparịsons

FIGURES

A=1 Elevation 305' Surface Deposition Sample and RO-2A Measurement Locations

A-2 Elevariọn 34/' Surface Depusilion Sample and KU-2A Measurement Locations

A-3 Drill Vacuum System for Surface Deposition

A-4 Pre-Gross Decontamination Experiment TLD and RO=2A Meașurement Locations (Elevațion 305')

A-5 Pre-Gross Decontamination Experiment TLD and RO-2A Measurement Loçations (Elevation 347'-6")

A-6 Post-Gross Decontamination Experiment TLD and RO-2A Measurement Locations (Elevation 305')

A-7 Post-Gross Decontamination Experiment TLD and RO-2A Measurement Locations (Elevation 347'-6") 


\author{
FIGURES (Continued) \\ A-8 Pre-HPR-214 Gross Decontamination Experiment TLD \\ Measurement Locations \\ A-9 Floor Plan of TMI-2 Reactor Building Elevation 305' \\ Showing Sampler Locations \\ A-10 Floor Plan of TMI-2 Reactor Building Elevation 347' \\ Showing Sampler Location
}




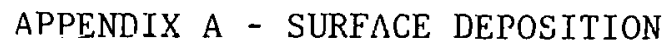

INTRODUCTION

The raw data on the following pages are the most current information available on the surface deposition task. The data are still considered in the preliminary category and should he used with caution until the final report. on this subject is issucd by EG\&G, Idalio. Inquiries on the data may be directed to Mr. Dave Hetzer, EG\&G/TIO, Three Mile Island Nuclear Power Plant, Middletown, Pennsylvania 17057.

The purposes of this task were to quantify surface deposition on the walls, floors, and equipment, and to establish the effectiveness of the decontamination procedures.

In order to measure the effectiveness of the Gross Decontamination Experiment (principally a water spray technique) performed in the TMI-2 reactor building, the Technical Information and Examination Program's Radiation and Environment Program obtained atmospheric and surface deposition measurements and general area radiation measurements within the reactor building before and after the experiment.

Contamination levels at vertical and horizontal metal and concrete surface locations were measured before and after the experiment. Surface deposition samples, and thermoluminescent dosimeter (TLD), RO-2A, and gamma spectrometry measurements were the methods used to measure the contamination levels. Three types of measurements were performed at several predetermined sampling locations to distinguish between radiation and contamination. In addition, the I-129, Cs-134, and $\mathrm{Cs}-137$ airborne concentrations were measured at three elevations. 
Section I gives the data for the surface deposition samples and RO-2A measurements at specific locations. Section II contains the TLD and RO-2A measurements for general areas. Section III presents airborne data (I-129, Cs-134, and Cs-137) for the containment building. Section IV tabulates decontamination factors for the Gross Decontamination Experiment. Section $V$ provides a pre-Gross Decontamination Experiment comparison of RO-2A and ILD measurements. 


\section{SECTTON I}

\section{SURFACE DEPOSITION DATA}

Section I contains the data from surface deposition samples and RO-2A measurements at locations shown in Figures $A-1$ and $A-2$. The associated tables reflect the pre-Decontamination Experiment measurements, postDecontamination Experiment measurements, and the surface sample results.

A drill-vacuum system (see Figure A-3) was developed hy FG\&f to collect the surface deposition samples. The sample sequence consisted of (a) setting up the drill-vacuum system at the sample location, (b) vacuuming an area approximately $40 \mathrm{~cm}^{2}$ (1.4-inch diameler) into a filter, and (c) changing the filter and boring a 1/2-inch-diameter hole with a flat nose bit while continually vacuuming all debris from the bored hole. The drill-vacuum equipment was then moved a short distance away and the sequence was repeated for the deeper hole. Several samples of varying depth were collected at each location to aid in determining the extent of contamination. RO-2 measurements were made at the same locations (with some exceptions) as the surface samples.

The surface deposition sampling technique provided 70 vacuum samples of the loose particulate matter and 111 subsurface samples, varying in depth from approximately $2 \times 10^{-2}$ to $3 \times 10^{-1} \mathrm{~cm}$. (125 mills corresponds to $3 \mathrm{x}$ $\left.10^{-1} \mathrm{~cm}\right)$. The vacuum and subsurface samples were obtained by collecting the loose particulate, paint, and concrete or metal material on a high efficiency particulate filter. Vertical samples were a composite of the loose particulate material on the surface, and the subsurface material. Horizontal samples consisted of a vacuum sample of the surface and a subsurface sample from the same sampling point. The $\mu \mathrm{Ci} / \mathrm{cm}^{2}$ result given in the following tables was determined by dividing the total activity of the samples from the 
same location by the surface area of the drill bit $\left(1.27 \mathrm{~cm}^{2}\right)$ for a subsurface sample. For a vacuum sample (loose particulate), the total activity was divided by the vacuumed surface area $\left(39.02 \mathrm{~cm}^{2}\right)$. 
FIGURE A-1

ELEVATION 305' SURFACE DEPOSITION SAMPLE AND RO-2A MEASUREMENT LOCATIONS

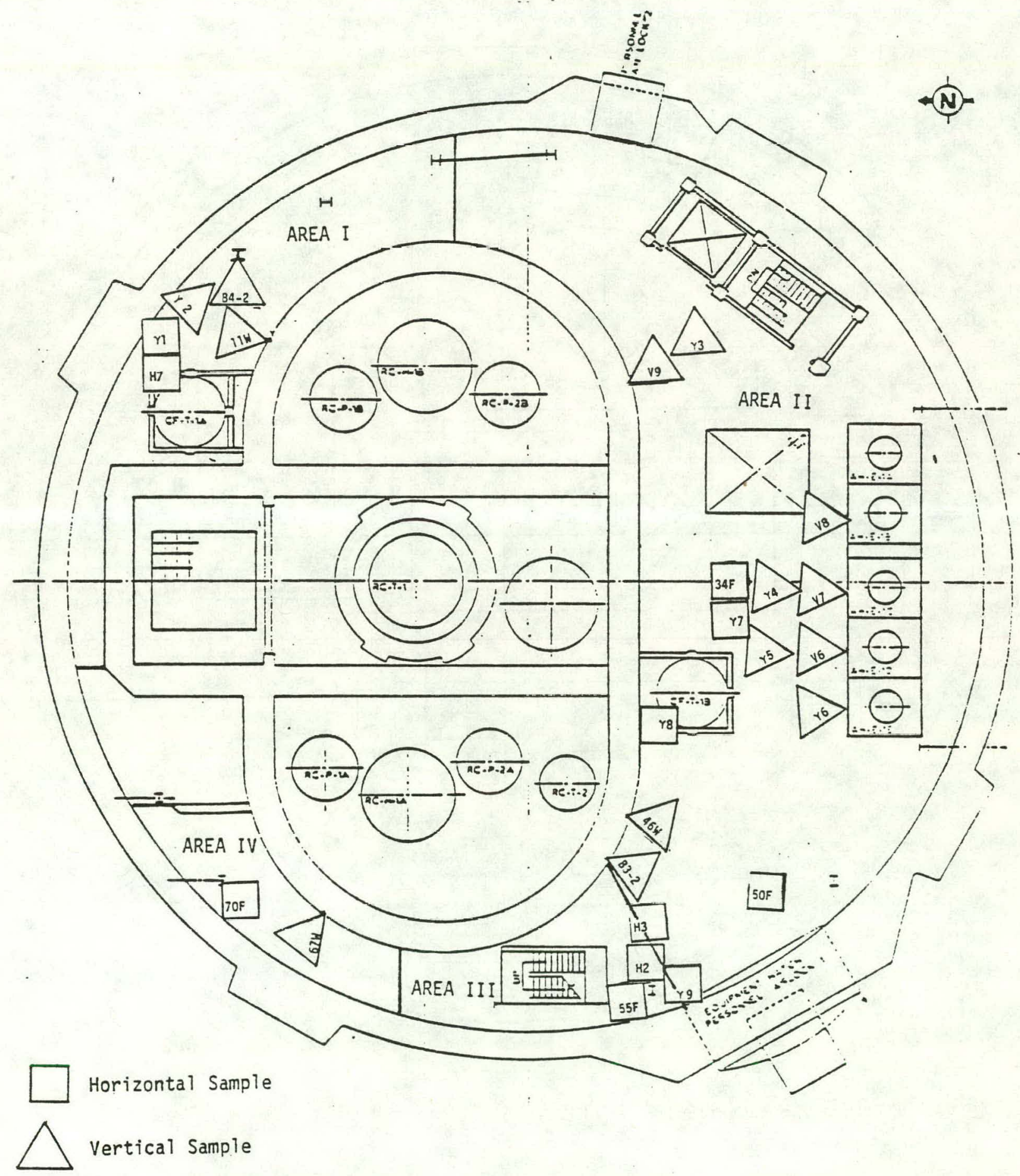


FIGURE A-2

ELEVATION 347' SURFACE DEPOSITION SAMPLE AND RO-2A MEASUREMENT LOCATIONS

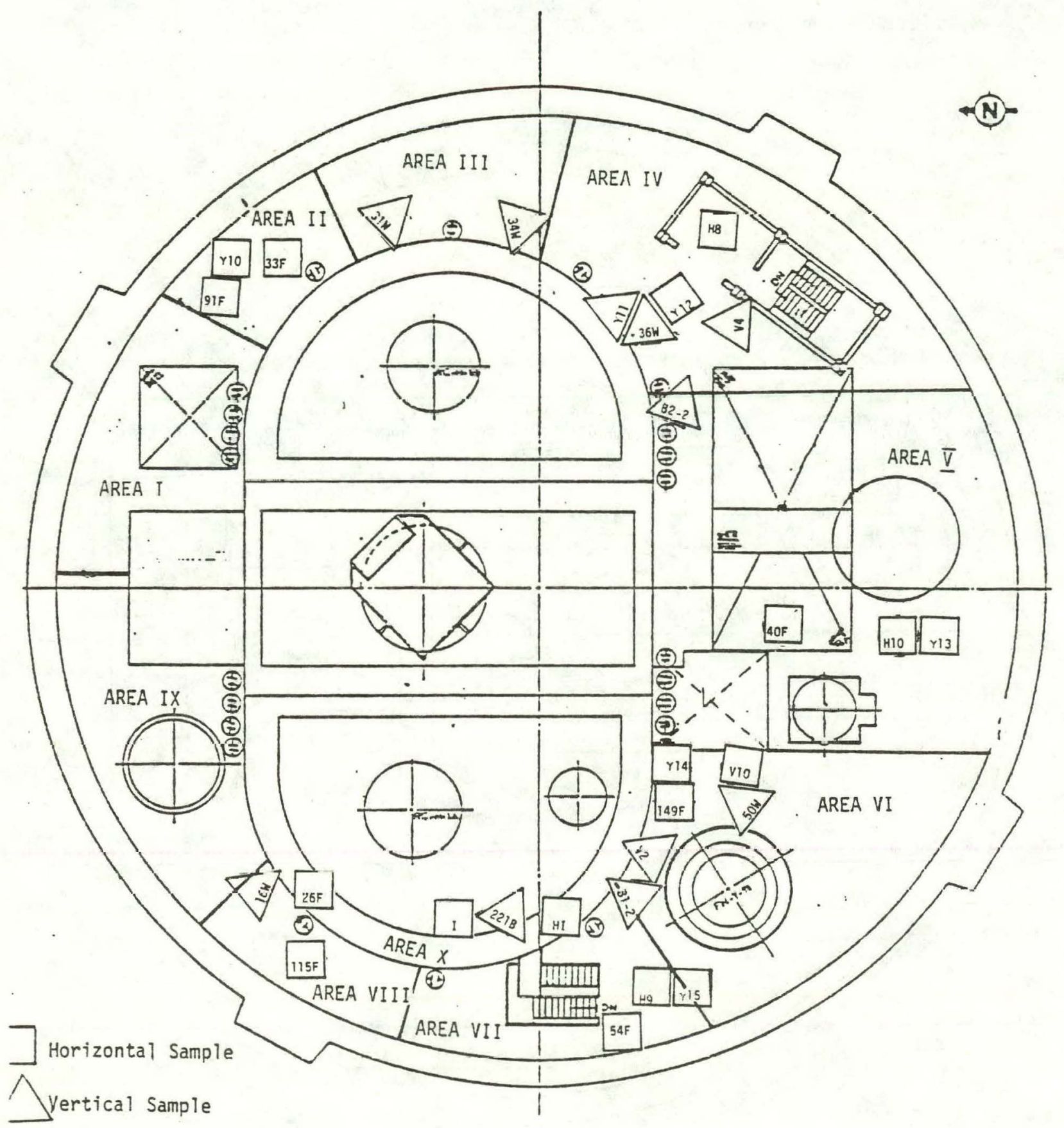

(18) : 120 Yolt Power Receptisals 


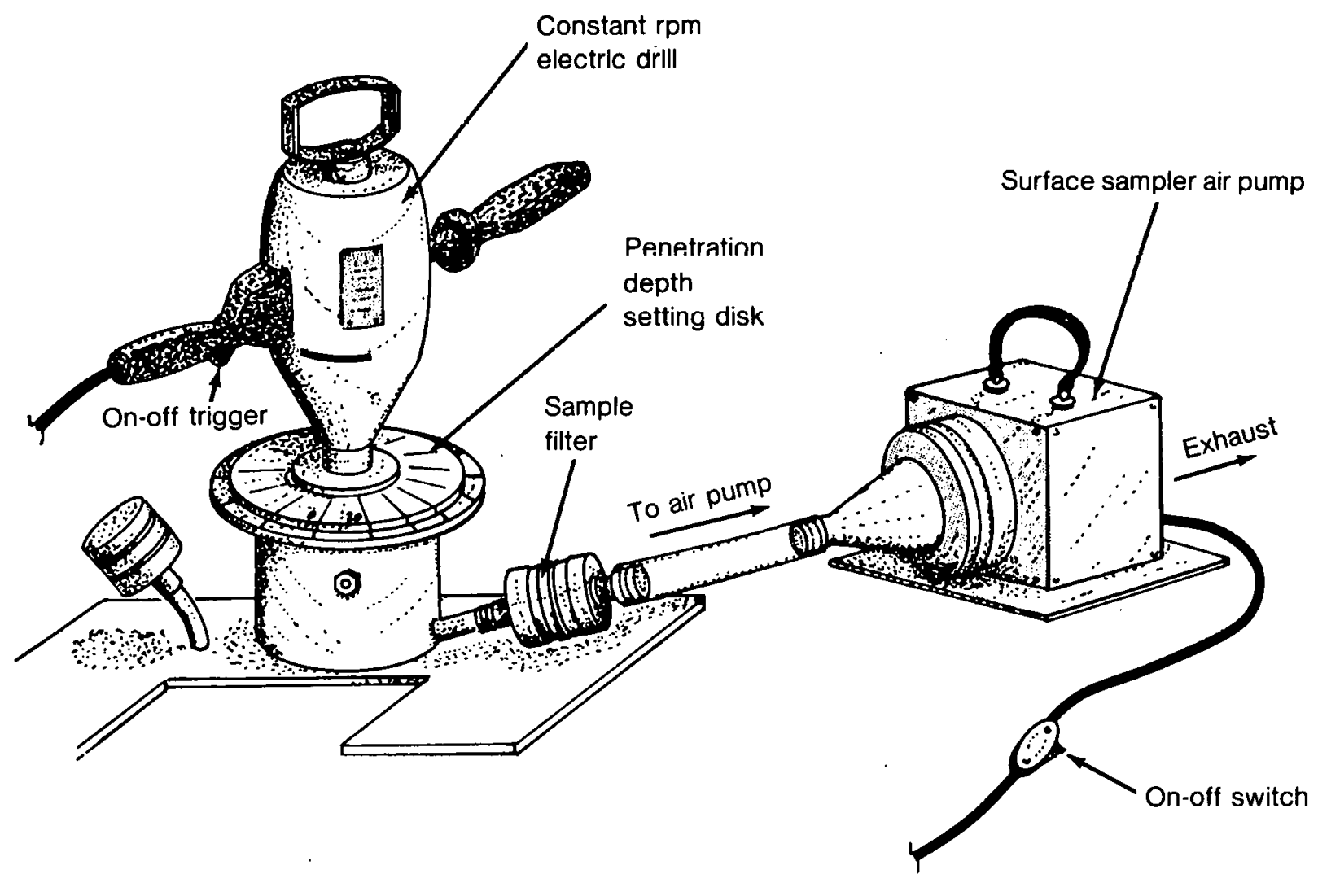

Figure A-3. Drill vacuum system for surface deposition. 
TABLE A-1

SURFACE AND SUBSURFACE GROSS DECONTAMINATION EXPERIMENT RESULTS OF ELEVATION $305^{\prime}$

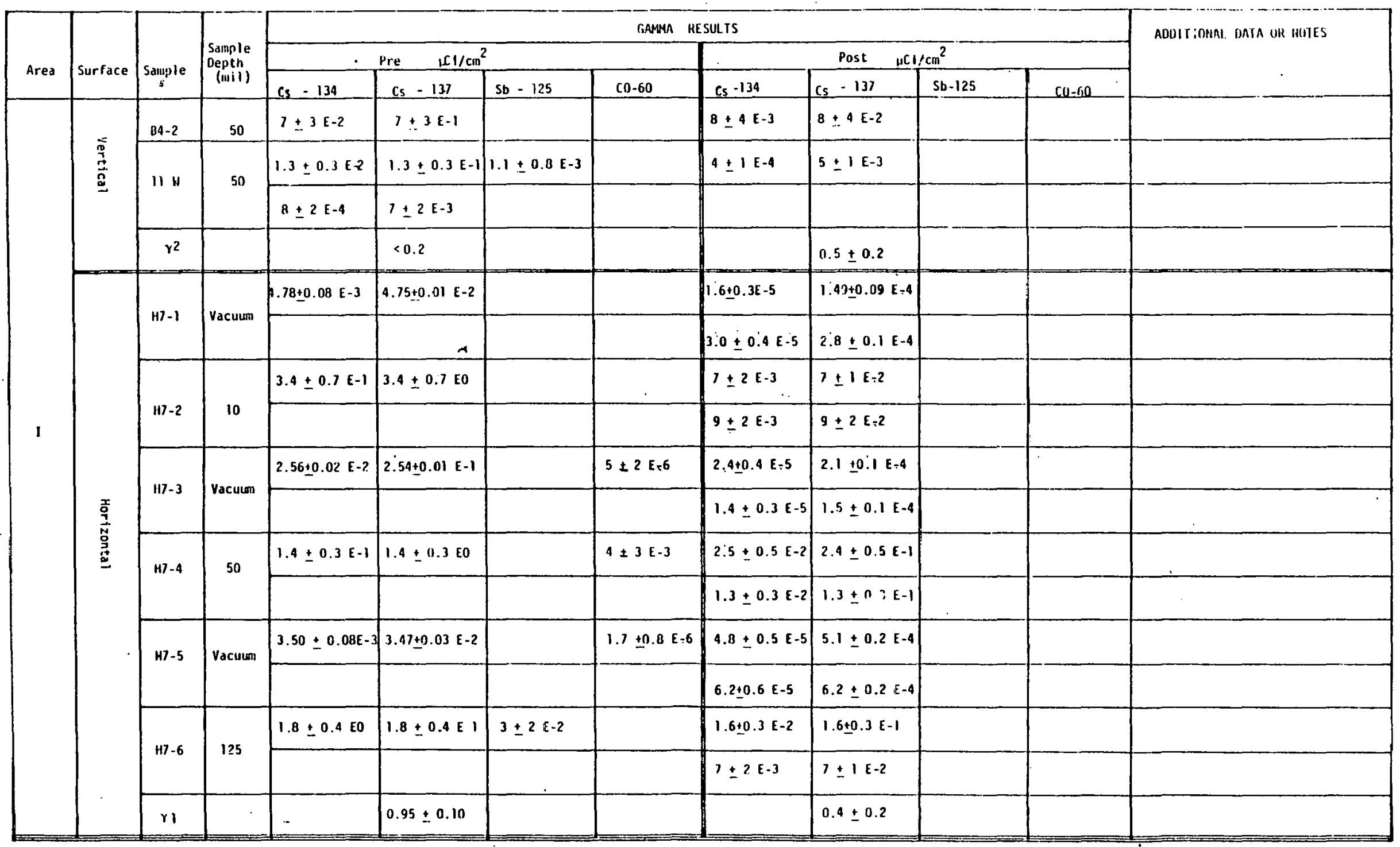


TABLE A-1 (Continued)

\begin{tabular}{|c|c|c|c|c|c|c|c|c|c|c|c|c|}
\hline \multirow{3}{*}{ Ared } & \multirow{3}{*}{ Surface } & \multirow{3}{*}{ Sample } & \multirow{3}{*}{$\begin{array}{l}\text { Sample } \\
\text { Deppti } \\
\text { (niiii) }\end{array}$} & \multicolumn{8}{|c|}{ Gaunua Results } & \multirow[t]{3}{*}{ ADOITIOHAL DATA OH NOTIS } \\
\hline & & & & \multicolumn{4}{|c|}{ Pre $11 \mathrm{c} / \mathrm{cm}^{2}$} & \multicolumn{4}{|c|}{ Post ${ }^{\prime} \mathrm{Ci} / \mathrm{crl}^{2}$} & \\
\hline & & & & $C_{5}-134$ & Cs -137 & Sb-125 & $c_{0}-60$ & $C_{s}=134$ & Cs-137 & $5 b-125$ & co 60 & \\
\hline \multirow{19}{*}{11} & \multirow{13}{*}{ 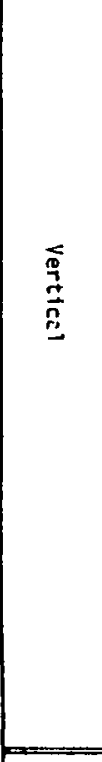 } & vg & 50 & $1.7+0.4 \mathrm{E}-3$ & $1.7 \pm 0.4 \mathrm{E}-2$ & & $3+2 E-5$ & $3.3+0.8 \mathrm{E}-3$ & $3.2 \pm 0.1 \mathrm{E}-2$ & & & \\
\hline & & v日 & 50 & $8 \pm 4 E-3$ & $8 \pm 4 \mathrm{E}-2$ & & & $3 \pm 1 E-3$ & $3 \pm 1 E-2$ & & & \\
\hline & & v7 & 50 & $5 \pm 2 E-3$ & $5 \pm 2 E-2$ & & & $7 \pm 3 E-2$ & $7 \pm 3 E-1$ & & & \\
\hline & & ขร & 50 & $1: 410.7 \mathrm{E}-2$ & $|1.4 \pm 0.6 \mathrm{E}-1|$ & & & $.4 \pm 0,6 E-2$ & $.4 \pm 0.6 \mathrm{E}-1$ & & & \\
\hline & & $46+1$ & 50 & $1.4 \pm 0.4 \mathrm{E}-3$ & $1.4 \pm 0.3 \mathrm{E}=2$ & & & $3.0 \pm 7 E-3$ & $3.7 \pm 3.7 \in-2$ & & & \\
\hline & & B3-2 & 50 & $4 \pm 2 E-3$ & $4 \pm 2 E-\bar{c}$ & & & $3 \pm 2 E-2$ & $3 \pm 2 E=1$ & & & \\
\hline & & $r^{3}$ & & & $0.5 \pm 0.3$ & & & & $<0,6$ & & & \\
\hline & & \multirow{2}{*}{$r^{4}$} & \begin{tabular}{|c|} 
Coils \\
\end{tabular} & $0.5 \pm 0.3 \mathrm{Ci}$ & $5.9 \pm 1.0 \mathrm{C1}$ & & & & & & & \\
\hline & & & prip pan & $0.012^{ \pm}-0.006 \mathrm{C} 1$ & $0.07^{ \pm} 0.03 \mathrm{Cl}$ & & & & & & & \\
\hline & & \multirow{2}{*}{ r5 } & \begin{tabular}{|c|} 
Colls \\
\end{tabular} & $0.2 \pm 0.1 \mathrm{Cl}$ & $1.6+0.4 \mathrm{Cl}$ & & & & & & & \\
\hline & & & prip pan & & $0.02+0.01<1$ & & & & & & & \\
\hline & & \multirow{2}{*}{16} & Coils & & $0.8+0,+c i$ & & & & & & & \\
\hline & & & prip pan & & $0.03 \pm 0.03 \times 1$ & & & & & & & \\
\hline & \multirow{6}{*}{ 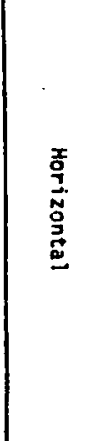 } & $34 F 1$ & Vacuum & $1.01 \pm 0.01 \mathrm{E}-2$ & $1.01 \pm 0.01 \mathrm{E}$ & & & $1.9 \pm 0.4 \mathrm{E}-5$ & $1.8 \pm 0.1 E-4$ & & & \\
\hline & & $34 f_{2}$ & 10 & $3.8 \pm 0.8 \mathrm{E}-1$ & $3.8 \pm 0.810$ & $8+5 E-3$ & $1.2 \pm 0.6 \mathrm{E}-4$ & $4.2 \pm 0.9 \mathrm{E}-3$ & $4.1 \pm 0.9 E=2$ & $4 \pm 2 E=6$ & & \\
\hline & & 3453 & Vacuuri & $1.93 \pm 0.02 \mathrm{E}-2$ & $1.92 \pm 0.0^{\circ} \mathrm{E}$ & & & $1.10 \pm 0: 08 \varepsilon-\epsilon$ & $1.09 \pm 0.03 \mathrm{ES}$ & & & \\
\hline & & 3454 & 50 & $4.1 \pm 0.9 \mathrm{E}-1$ & $4.1 \pm 0.9 \mathrm{EO}$ & & $3 \pm 2 E-4$ & $6 \pm i E-3$ & $6 \pm \mathrm{JE}-2$ & & & \\
\hline & & B4F5 & vacuum & $1.66+0.02 \mathrm{E}-2$ & $1.66 \pm 0.0 .1 \equiv-11$ & & & $1.56 \pm 0.09 \mathrm{E}-\mathrm{C}$ & $1.53 \unrhd 0.03 \varepsilon-3$ & & & \\
\hline & & paf6 & 125 & $8 \pm 2 \mathrm{E}-1$ & $B \pm 2 E 0$ & & & $9 \pm 2 E-3$ & $8 \div 2 E-2$ & & & \\
\hline
\end{tabular}


TABLE A-1 (Continued)

\begin{tabular}{|c|c|c|c|c|c|c|c|c|c|c|c|c|}
\hline \multirow{3}{*}{ Area } & \multirow{3}{*}{ Surface } & \multirow{3}{*}{ Sample } & \multirow{3}{*}{$\begin{array}{l}\text { Sample } \\
\text { nopeth } \\
\text { (mi1.) }\end{array}$} & \multicolumn{8}{|c|}{ Guanua Results } & \multirow{3}{*}{ Additional Data or Hoters } \\
\hline & & & & \multicolumn{4}{|c|}{ Pre $\| \mathrm{Ci} / \mathrm{cm}^{2}$} & \multicolumn{4}{|c|}{ Past $\mu \mathrm{Cl}<\mathrm{CuI}^{2}$} & \\
\hline & & & & Cs-134 & [s-13] & Sb- 125 & $-60-60$ & $C s-134$ & $\mathrm{C}_{\mathrm{s}-132}$ & $S h=125$ & conou & \\
\hline \multirow{11}{*}{ II } & \multirow{11}{*}{ 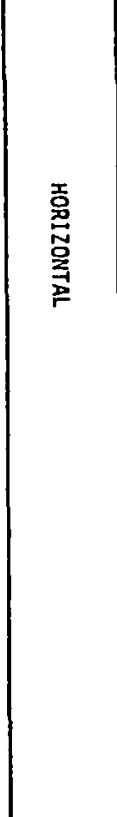 } & $50 \mathrm{Fl}$ & Vacuuin & $4.34 \div 0.08 E-3$ & $4.25 \pm 0.03 E-2$ & $1.6 \pm 0.9 E-4$ & & $1.8 \pm 0.3 E-5$ & $1.8 \pm 0.1 E-4$ & & & \\
\hline & & $50 \mathrm{~F} 2$ & 10 & $1.9+0.4 \mathrm{E}-1$ & $1.9+0.4 E 0$ & & & $2.3+0.5 \mathrm{E}-2$ & $2.3 \pm 0.5 \mathrm{E}-1$ & & & \\
\hline & & $50 \mathrm{~F} 3$ & Vacuum & $3.23 \pm 0.06 E-3$ & $3.19 \pm 0.03 E-2$ & & & $6,4 \pm 0,6 E-5$ & $6.5 \pm 0,2 E-4$ & $1,5 \pm 0,9 \mathrm{E}-5$ & & \\
\hline & & $50 F 4$ & 50 & $1.2+0.3 E-1$ & $1.2 \pm 0.3 \mp 0$ & $4 \pm 2 E-3$ & & $6 \pm 1 E-3$ & $6 \pm 1 E-2$ & & & \\
\hline & & $50 \% 5$ & Vacuum & $6.8 \pm 0.1 E-3$ & $6.63+0.03 E-2$ & & & $4.6 \pm 0.5 E-5$ & $4.1 \pm 0.2 \mathrm{E}-4$ & & & \\
\hline & & $50 F 6$ & 125 & $2.6+0.6 \mathrm{E}-1$ & $2.6 \pm 0.6 £ 0$ & $4 \pm 3 E-3$ & $4 \pm 2 E-4$ & $1.9+0.4 E-1$ & $1.980,450$ & & & \\
\hline & & H3V & vacuum & $1.41 \pm 0.05 E-3$ & $1.39 \pm 0.02 E-2$ & $1.3+0.6 E-4$ & & $5.7 \pm 0.2 E-4$ & $5.66 ! 0.06 E-3$ & & & \\
\hline & & 113C & 125 & $1.9 \pm 0.4 E-1$ & $1.8 \pm 0.4 E 0$ & $1.1 \pm 0.4 E-2$ & $5 \pm 2 E-4$ & $3.5+0.8 E-2$ & $3.4 \pm 0.7 E-1$ & & & \\
\hline & & $\gamma 7$ & & & $0.9 \pm 0.2$ & & & & $5.3+0.4$ & & & \\
\hline & & $\mathrm{r}^{\mathrm{A}}$ & & & $<0.3$ & & & & & & & \\
\hline & & $r^{9}$ & & 2.710 .3 & $28 \pm 2$ & & & & & & & \\
\hline \multirow{4}{*}{ III } & \multirow{4}{*}{ 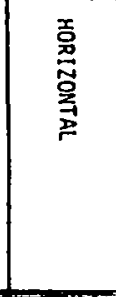 } & HiV & & $2.30 \pm 0.05 E-3$ & $2.23 \div 0.01 E-2$ & $1.8+0.5 E-4$ & $4 \pm 1 E-6$ & $1.8 \pm 0.3 E-5$ & $2.2 \pm 0.1 E-4$ & & & \\
\hline & & H2C & & $2.1 \pm 0.05 E-1$ & $2.1 \pm 0.5 \in 0$ & $3,5 \pm 0,8 E-2$ & $5 \pm 2 \varepsilon-4$ & $3.1 \pm 0.7 E-1$ & $3.0 \pm 0.660$ & $9 \pm 3 E-3$ & $2.1 \pm 0.8 \mathrm{E}-4$ & $55 F 1$ \& $55 F 2$ pre $\| \mathrm{Cl}_{1} / \mathrm{cm}^{2}$ giver seld \\
\hline & & $55 \mathrm{Fl}$ & & $8.9 \pm 0.1 E-3$ & $8.67 \pm 0.03 E-2$ & $7,4+0.2 E-3$ & $1.5 \pm 0.2 \mathrm{E}-4$ & $6.7 \pm 0.2 E-4$ & $6.54+0.05 E-3$ & $1.1+0.3 E-4$ & & $\frac{\mathrm{Ce}-144}{1.0 \pm 0.2 E-3}-\frac{\mathrm{Ag} g-110 \mathrm{~m}}{9} \pm 2 E-5$ \\
\hline & & $55 F 2$ & & $2.3+0.5 E-1$ & $2.3+0.560$ & $2.0+0.4 E-1$ & $\underline{p+1 E-3}$ & $2.6 \pm 0.6 \mathrm{E}-2$ & $2.5 \pm 0.5 \mathrm{E}-1$ & $1.4 \pm 0.3 \mathrm{E}-2$ & $1.4 \cdot 0.5 E-4$ & 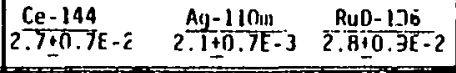 \\
\hline \multirow{3}{*}{ IV } & VERTICAL & $67 \mathrm{~W}$ & & $2.7 \pm 0.7 E-3$ & $2.7 \pm 0.6 \mathrm{E}-2$ & & & $1.6 \pm 0.4 \mathrm{E}-3$ & $1.7 \pm 0.1 \mathrm{E}-2$ & & & \\
\hline & \multirow[t]{2}{*}{ Horizonth fl } & $L_{2}^{20 F 1}$ & & $1.28 \pm 0.01 E-2$ & $1.26 \pm 0.01 E-1$ & & & $6.2+0.6 \mathrm{E}-5$ & $5.6 \pm 0.2 E-4$ & $4 \pm 1 E-5$ & & \\
\hline & & $70 F 2$ & & $4.1 \pm 0.9 E-1$ & 4.110 .950 & & & $2.8 \pm 0.6 \mathrm{E}-2$ & $2.8 \pm 0.6 \mathrm{E}-1$ & & & \\
\hline
\end{tabular}


TABLE A-2

SURFACE AND SUBSURFACE GROSS DECCNTAMINATION EXPERIMENT RESULTS OF ELEVATIONS 34?' AND 367'

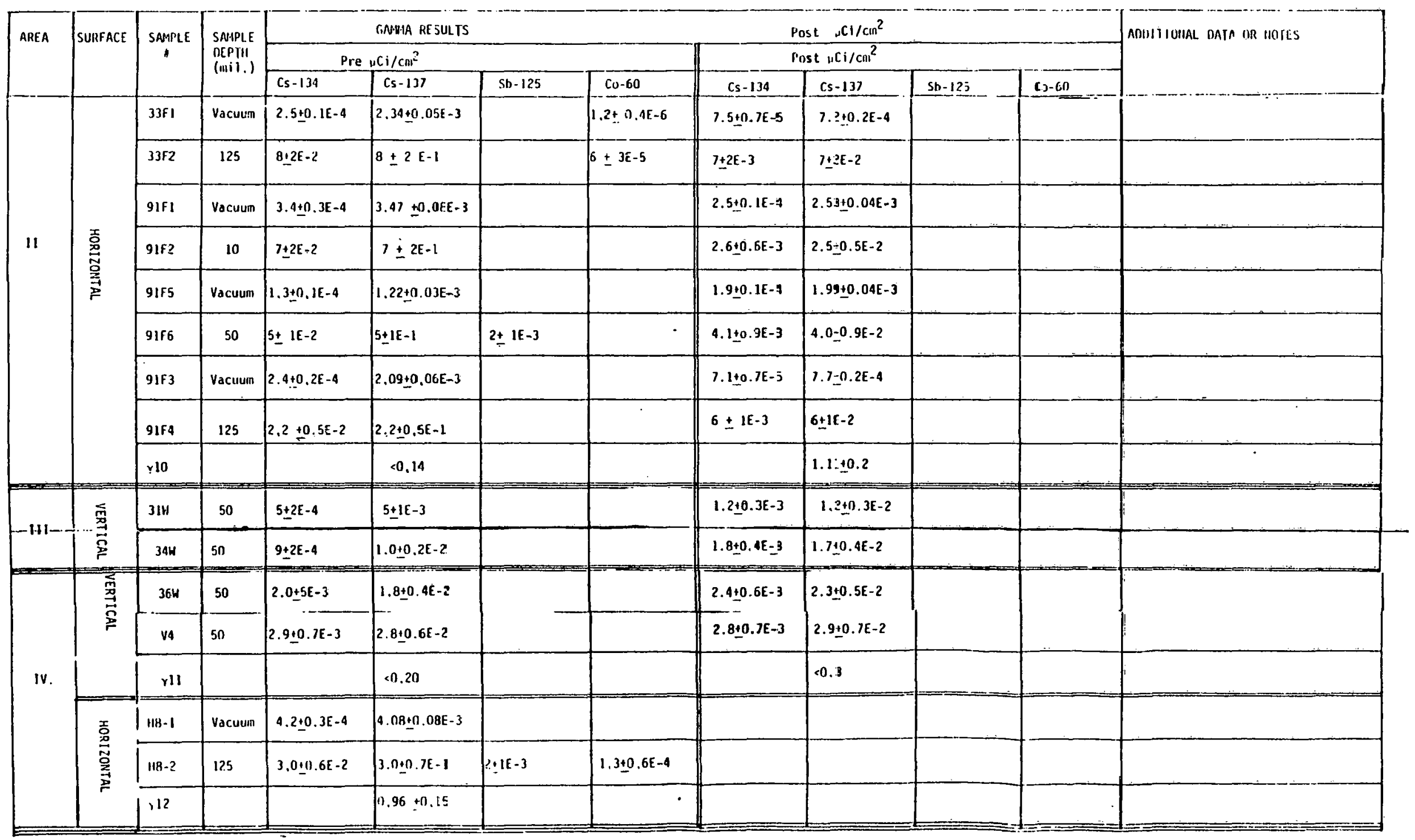


TABLE A-2 (Continued)

\begin{tabular}{|c|c|c|c|c|c|c|c|c|c|c|c|c|}
\hline \multirow{3}{*}{ AREA } & \multirow{3}{*}{ SURFACE } & \multirow{3}{*}{$\begin{array}{c}\text { SMPLIE } \\
\end{array}$} & \multirow{3}{*}{ 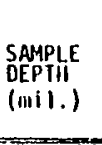 } & \multicolumn{8}{|c|}{ Gaviun Results } & \multirow[t]{3}{*}{ ADDIIIOARL UATA OR NUIES } \\
\hline & & & & \multicolumn{4}{|l|}{ pre ${ }^{\mathrm{Cl}} \mathrm{i} / \mathrm{cm}^{2}$} & \multicolumn{4}{|c|}{ Post ${ }^{\prime C C i} / \mathrm{cm}^{2}$} & \\
\hline & & & & Cs-134 & C.s-137 & $5 b-125$ & Co-160 & C.s-134 & Cs -137 & SD- 125 & $C_{0}-60$ & \\
\hline \multirow{10}{*}{$v$} & VERTISAL & $82-2$ & so & $1.2 \pm 0.5 \mathrm{E}-2$ & $1.1 \pm 0.5 E-1$ & & & $1.2 \pm 0.6 \mathrm{E}-2$ & $1.2 \pm 0.5 \mathrm{E}-1$ & & & \\
\hline & \multirow{9}{*}{ 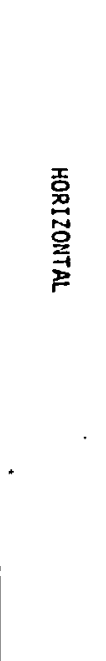 } & for 1 & Vacuun & $1.28 \pm 0.05 E-3$ & $.25 \pm 0.02 E-2$ & & & $1.8+0.1 E-4$ & $1.77+0.03 \mathrm{E}-3$ & & & \\
\hline & & Hor 2 & 50 & $3 \pm 1 E-1$ & $3 \pm 1 E 0$ & & $5 \pm 3 E-5$ & $3 \pm 1 E-2$ & $3 \pm 1 \mathrm{E}-1$ & $6 \pm 3 E-4$ & & \\
\hline & & H10-1 & Vacuum & $1.89 \pm 0.05 E-3$ & $1.87 \pm 0.02 E-2$ & & & $3.5 \pm 0.4 \mathrm{E}-5$ & $3.3 \div 0.1 E-4$ & & & \\
\hline & & $1110-2$ & 10 & $5 \pm 1 E-1$ & $5 \pm \underline{-1 E 0}$ & & $5 \pm 3 E-5$ & $4 \pm 1 E-2$ & $4 \pm 1 E-1$ & & & \\
\hline & & H10-3 & Vacuum & $1.65 \pm 0.05 E-3$ & $1,63+0,02 E-2$ & & & $5.1 \pm 0.5 E-5$ & $5.1 \pm 0.2 E-4$ & & & \\
\hline & & $1110-4$ & 50 & $2.8+0.6 \mathrm{E}-1$ & $2.810 .6 \varepsilon 0$ & $9 \pm 5 E-3$ & $1.6 \pm 0.7 \mathrm{E}-4$ & $1.2 \pm 0.3 E-2$ & $1.2 \pm 0.2 \mathrm{E}-1$ & & & \\
\hline & & H10-5 & Vacuum & $7.0 \pm 0.3 E-4$ & $7.02 \pm 0.08 E-3$ & & & $8.7 \_0.7 E-5$ & 8.8.0.2E-4 & & & . \\
\hline & & $1110-6$ & 125 & $1.3 \pm 0.3 E-1$ & $1.3+0.350$ & & & $2.0 \pm 0.4 E-2$ & $2.0 \pm 0.4 \mathrm{E}-1$ & & & \\
\hline & & $r^{13}$ & & & $0.5+0.16$ & & & & $0.8+0.2$ & & & \\
\hline
\end{tabular}




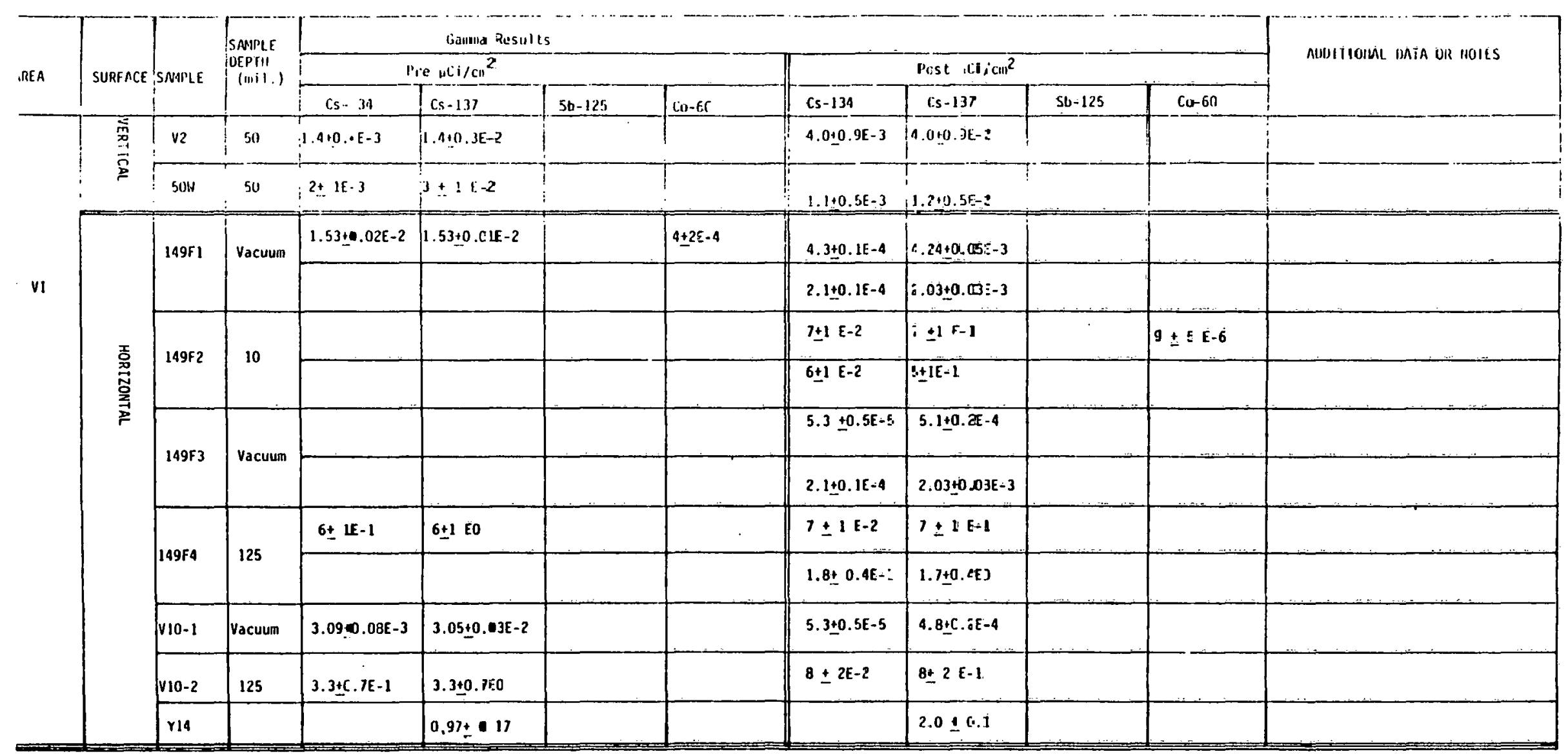


TABLE A-2 (Continued)

\begin{tabular}{|c|c|c|c|c|c|c|c|c|c|c|c|c|}
\hline \multirow{3}{*}{ Irea } & \multirow{3}{*}{ Surface } & \multirow{3}{*}{ Sample } & \multirow{3}{*}{$\begin{array}{c}\text { Sample } \\
\text { Depth } \\
\text { (mii) }\end{array}$} & \multicolumn{8}{|c|}{ Gautria Results } & \multirow{3}{*}{ ADDITIOHAL DATA OR NOTES } \\
\hline & & & & \multicolumn{4}{|c|}{ Pre $: 1 C 1 / \mathrm{cm}^{2}$} & \multicolumn{4}{|c|}{ Post $\| \mathrm{i} \mathrm{i} / \mathrm{cm}^{2-}$} & \\
\hline & & & & $c s-134$ & {$[s-13]$} & $5 \mathrm{sh-125}$ & $C_{0}-60$ & $c_{s-134}$ & $C s-137$ & $5 b-125$ & {$[\overline{c r}-60]$} & \\
\hline \multirow{13}{*}{ VII } & \multirow{2}{*}{ 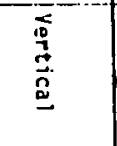 } & \multirow[t]{2}{*}{ Bl -2} & \multirow[t]{2}{*}{50} & $1.6+0.7 \mathrm{E}-3$ & $1.6 \pm 0.7 \mathrm{E}-2$ & & & $4+2 E-3$ & $5 \pm 2 E-2$ & & & . \\
\hline & & & & & & & & $1.6 \pm 0.7 \mathrm{E}-2$ & $1.5 \pm 0.7 \mathrm{E}-1$ & & & \\
\hline & \multirow{11}{*}{ 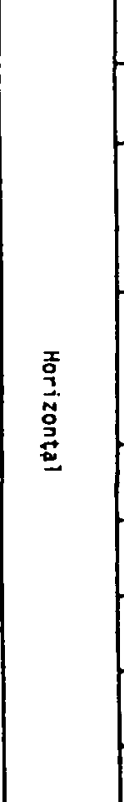 } & $54 F_{1}$ & Vacuum & $1.15+0.01 \mathrm{E}-2$ & $1.14+0.01 \mathrm{E}-1$ & & & $2.7 \pm 0.1 \in-4$ & $2.70+0.04 E=3$ & & & \\
\hline & & 5452 & 10 & $2.8 \pm 0.6 \mathrm{E}-1$ & $2.8 \pm 0.6 \mathrm{EO}$ & & & $\mid 2,3+0.5 \mathrm{E}-2$ & $2.2 \pm 0.5 \mathrm{E}-1$ & & $4 \pm 2 E-5$ & \\
\hline & & \multirow{2}{*}{$54 \digamma 3$} & \multirow{2}{*}{ Vacuun } & $1.47 \pm 0.02 \mathrm{E}-2$ & $1.46 \pm 0.01 \mathrm{E}-1$ & & & $1.6 \pm 0.1 \mathrm{E}-4$ & $1.55 \div 0.03 \mathrm{E}-3$ & & & \\
\hline & & & & '. & & & & $1.8 \pm 0.1 \mathrm{E}=4$ & $1.77+0.03 \mathrm{E}-3$ & & & \\
\hline & & \multirow[t]{2}{*}{5454} & \multirow[t]{2}{*}{50} & $3.7 \pm 0.8 \mathrm{E}-1$ & $3.7 \pm 0.8<0$ & & & $1.7 \pm 0.4 \in-2$ & $1.7 \pm 0.4 E-1$ & & & \\
\hline & & & & & & & & $1.4 \pm 0.3 E-2$ & $1.4 \pm 0.3 \varepsilon-1$ & & & \\
\hline & & $54 F 5$ & Vacuum & $1.82 \pm 0.02 \mathrm{E}-2$ & $1.81 \pm 0.01 \mathrm{E}-1$ & & & $6,7 \div 0.66-5$ & $7.0 \pm 0.2\left[\begin{array}{l}0.4 \\
0\end{array}\right.$ & & & \\
\hline & & $54 F 6$ & 125 & $1.4 \pm 0.3 \mathrm{E}-1$ & $1.4 \pm 0.3 E 0$ & & & $1.4 \pm 0.3 \mathrm{E} \div 2$ & $1.4 \pm 0.3 \mathrm{E}=1$ & & & \\
\hline & & $119-1$ & Vacuum & $1.05 \pm 0.01 \mathrm{E}-2$ & $1.06 \pm 11.01 \mathrm{E}-1$ & & & $P .6 \pm 0.7 \in-5$ & $7.4 \pm 0.2 \quad E \div 4$ & & & \\
\hline & & н9-2 & 125 & $9 \pm 2 \varepsilon-2$ & $9 \pm 2 E=1$ & & & $7 \pm 2 E \div 3$ & $7 \pm 1 \cdot E-2$ & & & \\
\hline & & Y15 & & & $0.85 \div 0.17$ & & & & & & & \\
\hline & $\frac{1}{1}$ & $115 \mathrm{FI}$ & Vacuum & $2.26 \pm 0.06 E-3$ & $2.27+0.02 \mathrm{E}-2$ & & $5 \pm 2 E \div 6$ & $7: 4 \pm 0.7 \varepsilon-5$ & $7.2+0.2 \mathrm{E}=4$ & & & \\
\hline 는 & 竧 & 11552 & 125 & $1.2 \pm 0.2 \mathrm{E}-1$ & $1.1 \pm 0.2 \mathrm{E}-0$ & & & $3.9 \pm 0.9 \mathrm{E}-3$ & $3.7 \pm 0.8 \mathrm{E}-2$ & & & \\
\hline & Vertical & $16 \mathrm{~W}$ & 50 & $1.2 \pm 0.3 \mathrm{E}-2$ & $1.3+0.3 \mathrm{E}=1$ & & & $8 \pm 2 E-3$ & $\mathrm{~B} \pm 2 \mathrm{E}-2$ & & & \\
\hline
\end{tabular}


TABLE A-2 (Contisued)

\begin{tabular}{|c|c|c|c|c|c|c|c|c|c|c|c|c|}
\hline \multirow{3}{*}{ Area } & \multirow{3}{*}{ Surface } & \multirow{3}{*}{ Sample } & \multirow{3}{*}{$\begin{array}{l}\text { Sample } \\
\text { Depth } \\
\text { (mil) } \\
\end{array}$} & \multicolumn{8}{|c|}{ Ganna Results } & \multirow{3}{*}{ AOOITIOHAL DATA OR HOTES } \\
\hline & & & & \multicolumn{4}{|c|}{ Pre $11=1 / \mathrm{cm}^{2}$} & \multicolumn{4}{|c|}{ Po:t $\mathrm{MU} 1 / \mathrm{cm}^{?}$ ? } & \\
\hline & & & & $C_{s}=134$ & $C s-137$ & $S b-125$ & $C 0-60$ & $C 5-134$ & $(s-13)$ & $5 b-125$ & Co-60 & \\
\hline \multirow{8}{*}{$\underline{\bar{x}}$} & \multirow{8}{*}{ 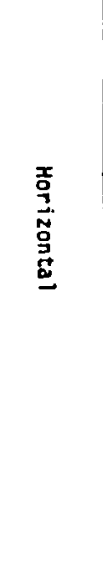 } & $26 \mathrm{~F} 1$ & Vacuum & $5.9+0.3 E-4$ & $5.7 \pm 0 \mid E-3$ & & & $1.28+0.01 \mathrm{E}-$ & $127 \pm 0.01 E-2$ & & & \\
\hline & & $26 \mathrm{~F} 2$ & 125 & $3.9+0.9 \mathrm{E}-2$ & $3.9 \pm 0.3 \mathrm{E}-1$ & & & $5 \pm E-\tilde{a}$ & $4 \pm 1 E-1$ & & & \\
\hline & & HIV & Vacuum & $4.51+0.08[-3$ & $4.47+0.03[-?$ & & & $2.15+0.05 \mathrm{E}-3$ & $2.73 \pm 0.01 E-2$ & & & \\
\hline & & HIC & 125 & $2.5 \pm 0.5 \mathrm{E}-1$ & $2.5 \pm 0.5 \subseteq 0$ & & & $9 \pm 2 E-\hat{a}$ & $9 \pm 2 E-1$ & & & \\
\hline & & 2218 & 50 & $3 \pm 2 E-3$ & $4 \pm 2 E=2$ & & & $2 \pm 11 E=3$ & $2.0+0.9 \mathrm{E}=2$ & & & \\
\hline & & $1-1$ & Vaculam & $1.49+0.05 \mathrm{E}-3$ & $1.50-0.02 \mathrm{E}-2$ & & . & $5.5 \pm 0.2 E=-4$ & $5.35 \pm 0.05 \in-3$ & & & \\
\hline & & \multirow{2}{*}{$1-2$} & \multirow{2}{*}{50} & $9 \pm 4 \quad E \div 2$ & $9 \pm 4 E=B$ & & & $2.1 \pm 0.9 \mathrm{E}-3$ & $2.1 \pm 0.9 \mathrm{E}-2$ & & & . \\
\hline & & & & & & & & $6 \pm 2 E-5$ & $5 \pm 2 E=2$ & $1.3 \pm 0.7 \mathrm{E}-3$ & & \\
\hline
\end{tabular}

NOTES:

1. All gamia results decay corrected to $3 / 26 / 82$ 12:00

2. All garma result uncertainties are 1 sigma
3. $\gamma^{4} 5$ - andr6 $\mathrm{C} s-137$ results are the total curies measares 
TABLE $A-3$

PRE-GROSS DECONTAMINATION EXPERIMENT RO-2A DATA

\begin{tabular}{|c|c|c|c|c|c|c|c|c|c|c|c|}
\hline \multirow[b]{2}{*}{ ELEVATIOH } & \multirow[b]{2}{*}{$\begin{array}{l}\text { DAIA } \\
\text { POIMI }\end{array}$} & \multirow[b]{2}{*}{$\begin{array}{l}\text { VERTICAL } \\
\text { OR } \\
\text { IIOR IZONTAL }\end{array}$} & \multicolumn{2}{|c|}{ ROZA - READIMGS } & \multirow[b]{2}{*}{$\begin{array}{l}\text { MEASUREMENT } \\
\text { DATE }\end{array}$} & \multicolumn{3}{|c|}{ RO - $2 \Lambda$ INTORMATION } & \multicolumn{2}{|c|}{ DOSE RAIES } & \multirow[b]{2}{*}{ COMHERTS } \\
\hline & & & $\begin{array}{l}\text { OPEN XINDOW } \\
\text { MR/hr. }\end{array}$ & $\begin{array}{l}\text { CLOSED WINDOW } \\
\mathrm{HR} / \mathrm{hr} \text {. }\end{array}$ & & $\begin{array}{c}\text { SERIAL } \\
\end{array}$ & $\begin{array}{c}\text { CAL IBRATION } \\
\text { DATE }\end{array}$ & $\begin{array}{l}\text { BETA } \\
\text { FACTOR }\end{array}$ & $\begin{array}{c}r \\
\text { InR/Lir. }\end{array}$ & 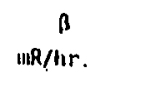 & \\
\hline \multirow{9}{*}{$305^{\circ}$} & $B 4-2$ & Vertical & 1,000 & 1,000 & $12 / 17 / 81$ & 306 & $3 / 15 / 82$ & 3.7 & 1,000 & $\leq$ Eakd. & $\begin{array}{l}\text { Ath l-hean north of air lock } 12 \text {, } \\
\text { facing D-ring wall, } 4 \text { " above floor }\end{array}$ \\
\hline & $\Pi H$ & Vertical & 900 & 900 & $12 / 17 / 81$ & 306 & $3 / 15 / 82$ & 3.7 & 900 & $\leq$ Bakd. & 4 above floor \\
\hline & H7 & Ilorizontal & 400 & 250 & $|2 / 17 / 8|$ & 306 & $3 / 15 / 82$ & 3.7 & 250 & 560 & \\
\hline & $34 \mathrm{~F}$ & Horizontal & 2,400 & 500 & $12 / 17 / 81$ & 306 & $3 / 15 / 82$ & 3.7 & 500 & 7,000 & \\
\hline & $50 F$ & Horizontal & 1,300 & .400 & $12 / 17 / 81$ & 306 & $3 / 15 / 82$ & 3.7 & 400 & 3,300 & . \\
\hline & H3 & Horizonta & 2,000 & 1,000 & $12 / 17 / 81$ & 306 & $3 / 15 / 82$ & 3.7 & 1,000 & 3.700 & \\
\hline & $55 \mathrm{~F}$ & Nlorizonta & 2.000 & 1,500 & $12 / 17 / 81$ & 306 & $3 / 15 / 82$ & 3.7 & 1,500 & 1,900 & \\
\hline & $6 / \mathrm{W}$ & Vertical & 290 & 280 & $12 / 17 / 81$ & 306 & $3 / 15 / 82$ & 3.7 & 280 & 37 & $4^{\text {thabe floor }}$ \\
\hline & $70 \mathrm{~F}$ & Horizonta & 900 & 360 & $12 / 17 / 81$ & 306 & $3 / 15 / 82$ & 3.7 & 360 & 2,000 & \\
\hline \multirow{8}{*}{$347^{\circ}$} & 314 & Vertical & 55 & 35 & $12 / 15 / 81$ & 715 & $2 / 22 / 82$ & 3,5 & 35 & 70 & $4^{\circ}$ above floor \\
\hline & $33 \mathrm{P}$ & Horizonta & 400 & 200 & $12 / 15 / 81$ & 115 & $2 / 22 / 82$ & 3.5 & 200 & 700 & \\
\hline & $91 F$ & Hortzonta & 700 & 300 & $12 / 15 / 81$ & 715 & $2 / 22 / 82$ & 3.5 & $30 n$ & 1,400 & \\
\hline & $34 \mathrm{H}$ & Vertical & 75 & 65 & $12 / 15 / 81$ & 715 & $2 / 22 / 82$ & 3.5 & 65 & 35 & 4" above Ploor \\
\hline & v4 & Vertical & 95 & 75 & $12 / 15 / 81$ & 715 & $2 / 22 / 82$ & 3.5 & 75 & io & 4h abore floor \\
\hline & $36 \mathrm{H}$ & Vertical & 85 & 75 & $12 / 15 / 81$ & 715 & $2 / 22 / 82$ & 3.5 & 75 & 35 & 4" aboye floor \\
\hline & $B 2-2$ & Vertical & 270 & 120 & $12 / 15 / 81$ & 115 & $2 / 22 / 82$ & 3.5 & 120 & $525^{\circ}$ & Front $\mathrm{Cf} \mathrm{JB}$ \\
\hline & $40 F$ & Horizonta & 2,650 & 500 & $12 / 15 / 81$ & 715 & $2 / 22 / 82$ & 3.5 & 500 & 7.530 & \\
\hline
\end{tabular}


TABLE A-3 (Continued)

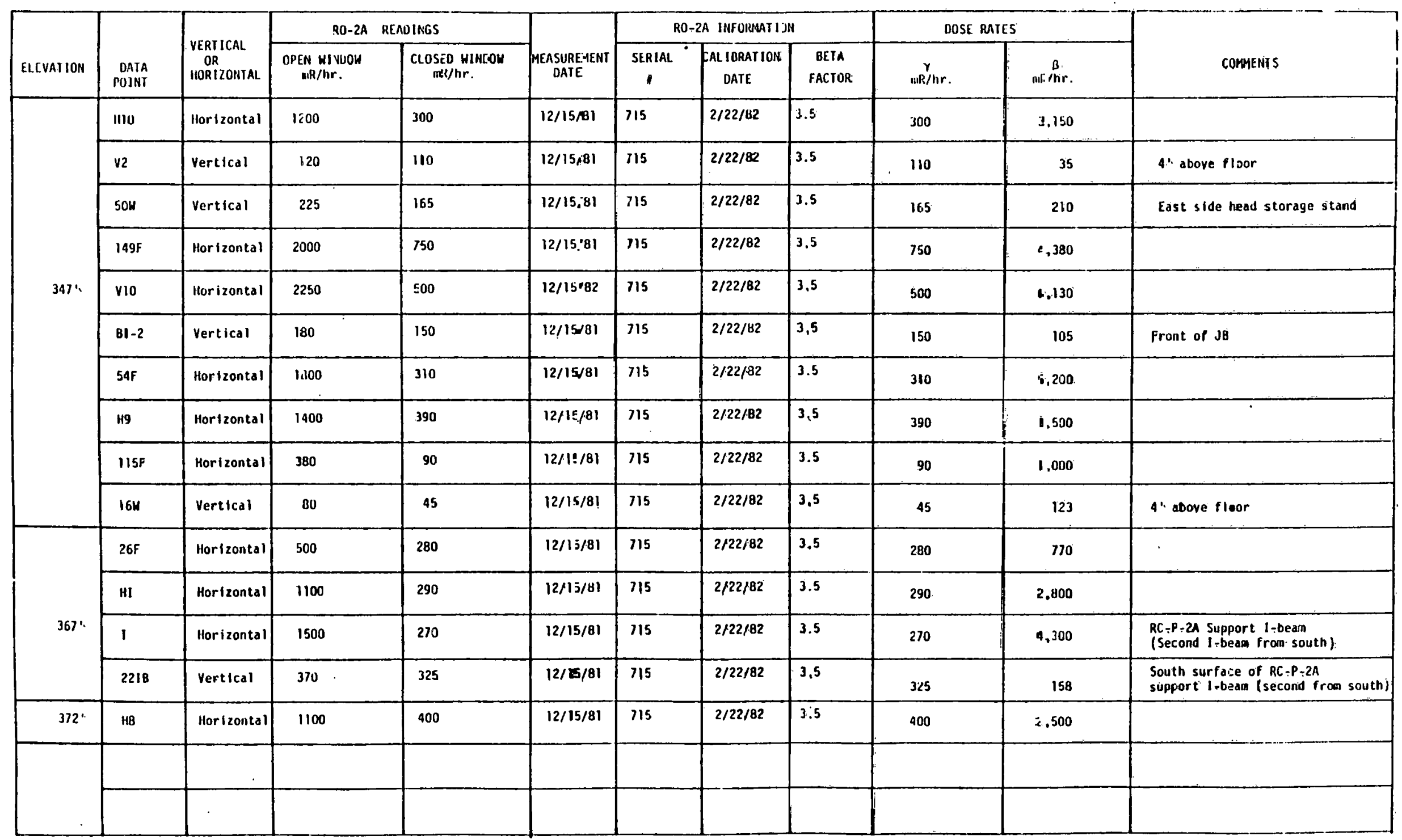


TABLE A-4

POST-GROSS DECONTAMINATION EXPERIMENT RO-2A DATA

\begin{tabular}{|c|c|c|c|c|c|c|c|c|c|c|c|}
\hline \multirow[b]{2}{*}{$\begin{array}{l}\text { ELEVATION } \\
\text {. }\end{array}$} & \multirow[b]{2}{*}{$\begin{array}{l}\text { DATA } \\
\text { POINT }\end{array}$} & \multirow[b]{2}{*}{$\begin{array}{l}\text { VERIICAL } \\
\text { OR } \\
\text { HORILONIAL. }\end{array}$} & \multicolumn{2}{|c|}{ RO-2A READINGS } & \multirow[b]{2}{*}{$\begin{array}{l}\text { MEASUREMENT } \\
\text { DATE }\end{array}$} & \multicolumn{3}{|c|}{ RO-2A INFIORMATION } & \multicolumn{2}{|c|}{ DUSE RATES } & \multirow[b]{2}{*}{ COHAENIS } \\
\hline & & & $\begin{array}{l}\text { OPEN 'IINDOW } \\
\text { WR/hr. }\end{array}$ & $\begin{array}{l}\text { CLOSED WIHDOH } \\
\text { mRS/Ir. }\end{array}$ & & SERIAL & $\begin{array}{c}\text { CAL IBRATION } \\
\text { OATE }\end{array}$ & $\begin{array}{l}\text { BETA } \\
\text { FACTIDR }\end{array}$ & $\stackrel{r}{r}$ & $\stackrel{\beta}{\beta}$ & \\
\hline \multirow{11}{*}{$305^{a}$} & B4-2 & Vertical & 400 & 300 & $3 / 25 / 82$ & A001 & $2 / 24 / 82$ & 4.0 & 300 & 400 & $\begin{array}{l}\text { 4th I-bean north of a irluck i2, } \\
\text { facing } D \text {-ring wall. } 41 \text { above floor }\end{array}$ \\
\hline & $11 W$ & Vertical & 200 & 300 & $3 / 25 / 82$ & A001 & $2 / 24 / 82$ & 4.0 & 300 & $\leq$ Batd. & 4" above floor \\
\hline & H7 & Horizontal & 300 & 80 & $3 / 26 / 82$ & 205 & $2 / 24 / 82$ & 3.9 & 80 & 858 & \\
\hline & v9 & Vertical & 350 & 250 & $3 / 25 / 82$ & A00I & $2 / 24 / 82$ & 4.0 & 250 & 400 & 4" above floor \\
\hline & ve & Vertical & 400 & 375 & $3 / 25 / 82$ & $A 001$ & $2 / 24 / 82$ & 4.0 & 375 & 100 & 4" abave floor \\
\hline & v7 & Vertical & 500 & 400 & $3 / 25 / 82$ & A001 & $2 / 24 / 82$ & 4.0 & 400 & 400 & 4' above floor \\
\hline & v6 & Vertical & 806 & 600 & $3 / 25 / 82$ & $\mathrm{~A} 001$ & $2 / 24 / 82$ & 4.0 & 600 & 824 & 4" above floor \\
\hline & $46 H$ & Vertical & 350 & 200 & $3 / 25 / 82$ & A001 & $2 / 24 / 82$ & 4,0 & 200 & 600 & 4a above floor \\
\hline & $34 F$ & Horizontal & 380 & 250 & $3 / 26 / 42$ & 205 & $2 / 24 / 82$ & 3.9 & 250 & 507 & \\
\hline & $50 F$ & Horizontal & 150 & 150 & $3 / 26 / 82$ & 205 & $2 / 24 / 82$ & 3.9 & 150 & 4 Barod. & \\
\hline & нз & Horizontal & 1000 & 1000 & $3 / 26 / 82$ & 205 & $2 / 24 / 82$ & 3.9 & 1000 & $\leq$ Bakd. & \\
\hline \multirow{4}{*}{. } & 112 & Horizontal & 4700 & 2500 & $3 / 26 / 82$ & 205 & $2 / 24 / 82$ & 3.9 & 2500 & 8580 & \\
\hline & $55 \mathrm{~F}$ & Horizontal & 1500 & 500 & $3 / 26 / 82$ & 205 & $2 / 24 / 82$ & 3.9 & 500 & 3900 & 4" above floor \\
\hline & $67 H$ & Vertical & 600 & 600 & $3 / 25 / 82$ & A001 & $2 / 24 / 82$ & 4.0 & 600 & $\leq B a R A$. & \\
\hline & $70 \mathrm{~F}$ & Ilorizontal & 500 & 500 & $3 / 26 / 82$ & 205 & $2 / 24 / 82$ & 3.9 & 500 & $\leq$ Bakd. & \\
\hline \multirow[t]{2}{*}{347.} & 314 & Vertical & 48 & 36 & $3 / 25 / 82$ & A001 & $2 / 24 / 82$ & 4.0 & 36 & 48 & $4^{\circ}$ above floor \\
\hline & $33 F$ & Horizontal & 140 & 60 & $3 / 25 / 82$ & 205 & $2 / 24 / 82$ & 3.9 & 60 & 312 & \\
\hline
\end{tabular}




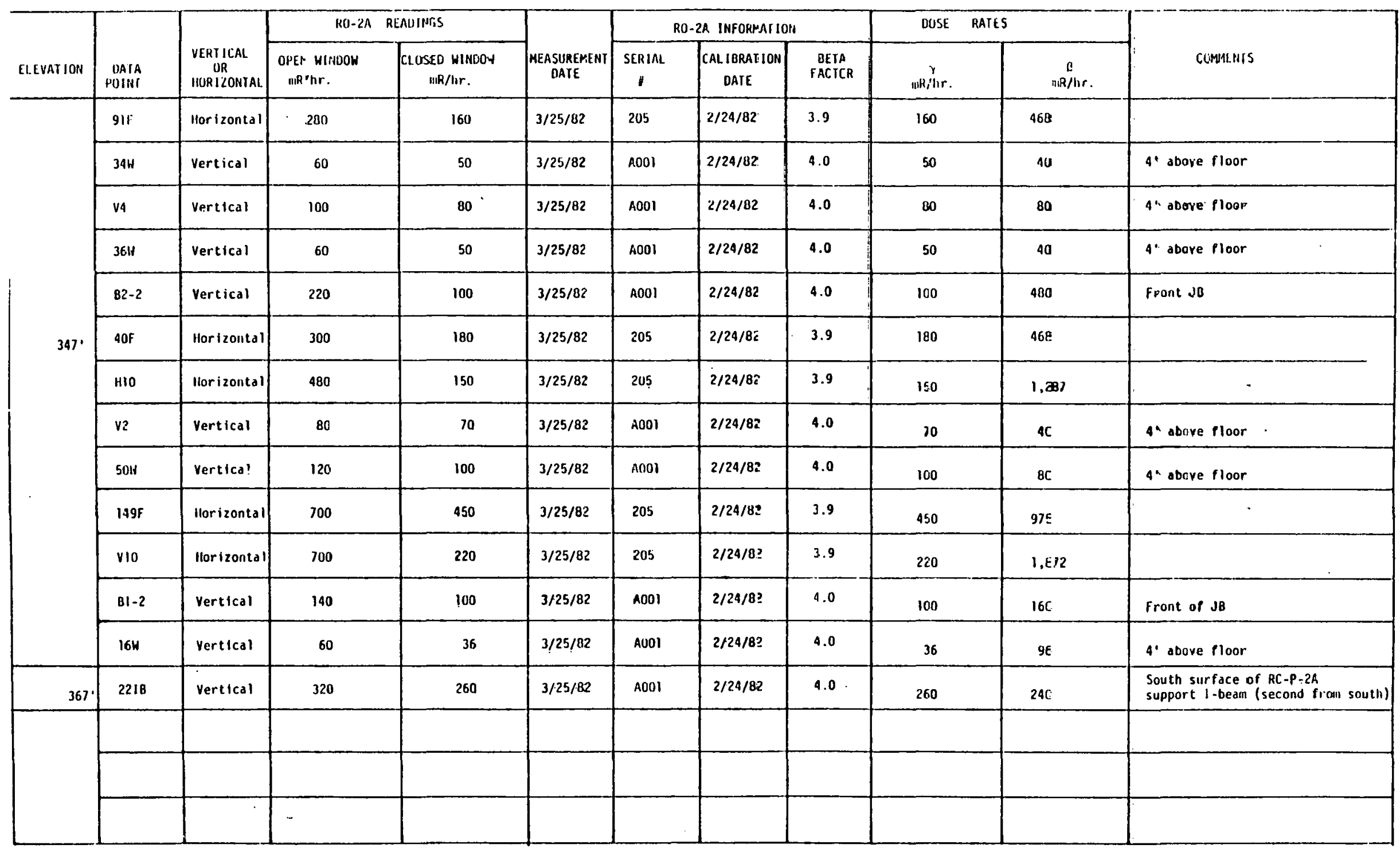




\section{SECTION II}

TLD AND RO-2A DATA

Gamma and beta measurement locations and values are given in Figures A-4 through A-8 and associated tables. The TLD measurements were made using a multichip system. Each TLD system contained 24 or 48 chips oriented such that 12 or 24 chips faced the front and 12 or 24 rhips faced the back. The chips were clustered in groups of three under four or eight different thicknesses of shields. The dosimeters were placed directly on a surface to measure the beta activity level of the contact surface as well as the beta background and general area gamma activity levels detected by the opposite side of the TLD.

The RO-2A instrument (ion chamber type) provided beta and gamma readings for a specific sample location. RO-2A measurements were taken during the surface deposition sampling, HPR-214 (dome monitor) inspection work, and the TLD placements. The RO-2A instrument was held at a $2.54 \mathrm{~cm}$ fixed distance from the surface for the surface deposition sampling work. For the TLD placement work, the RO-2A instrument was held approximately 0.64 to $3.1 \mathrm{~cm}$ from the surface. The RO-2A instrument was held approximately $2.54 \mathrm{~cm}$ and 1.2 meters from the surface for the HPR-214 inspection work.

The gamma spectrometer measurements were performed using a portable, collimated gamma ray spectrometer to determine the surface area concentration of gamma ray emitting nuclides for each level at five vertical and five horizontal locations before and after the Decontamination Experiment. The spectrometer system consisted of a hyperpure germanium detcctor in conjunction with a multichannel analyzer that was calibrated to measure the surface area concentration of sources. 
FTGURE A-4

PRE-GROSS DECONTAMINATION EXPERIMENT TLD AND RO-2A MEASUREMENT LOCATIONS

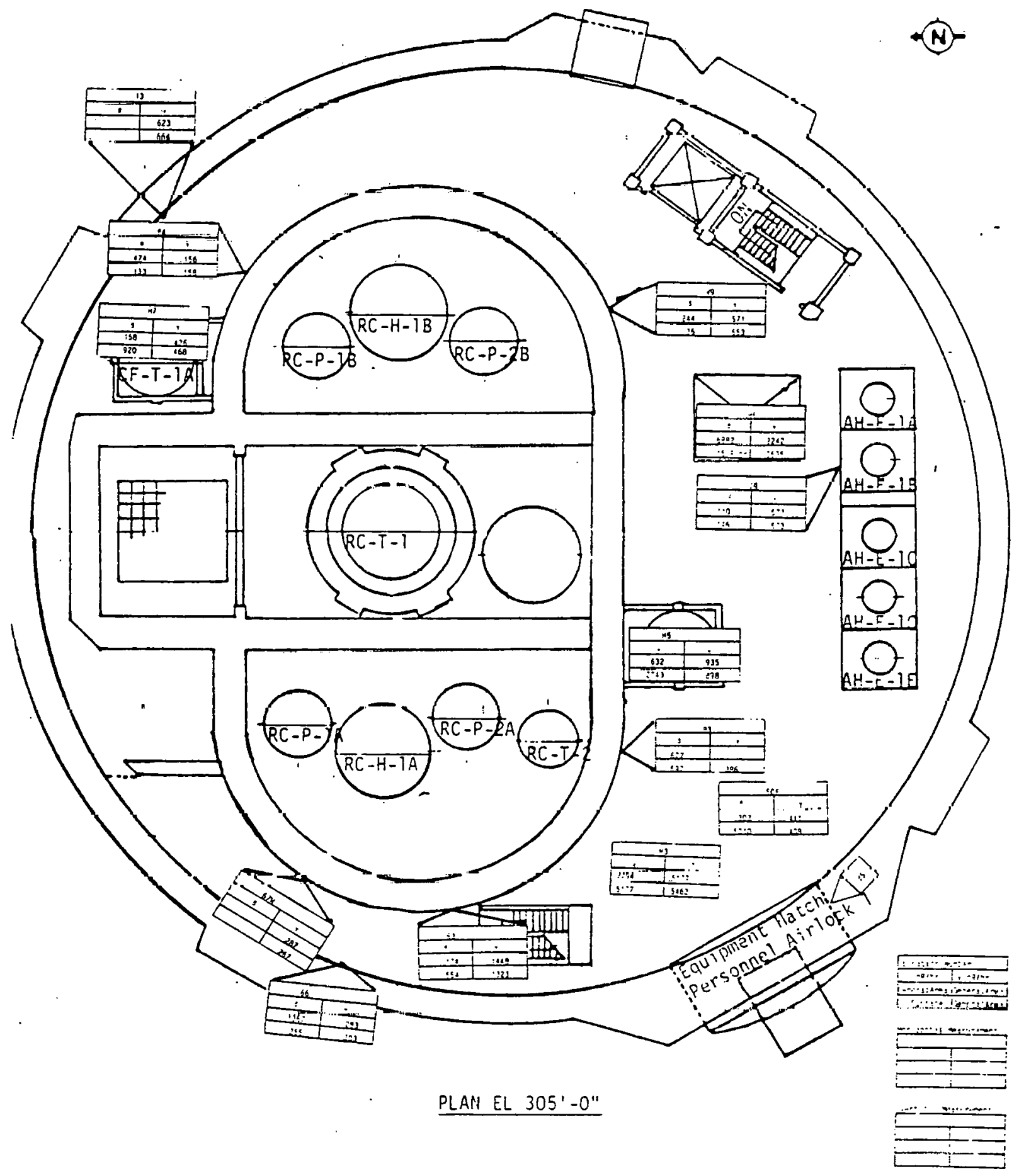


FIGURE A-5

PRE-GROSS DECONTAMINATION EXPERIMENT TLD AND RO-2A MEASUREMENT LOCATIONS

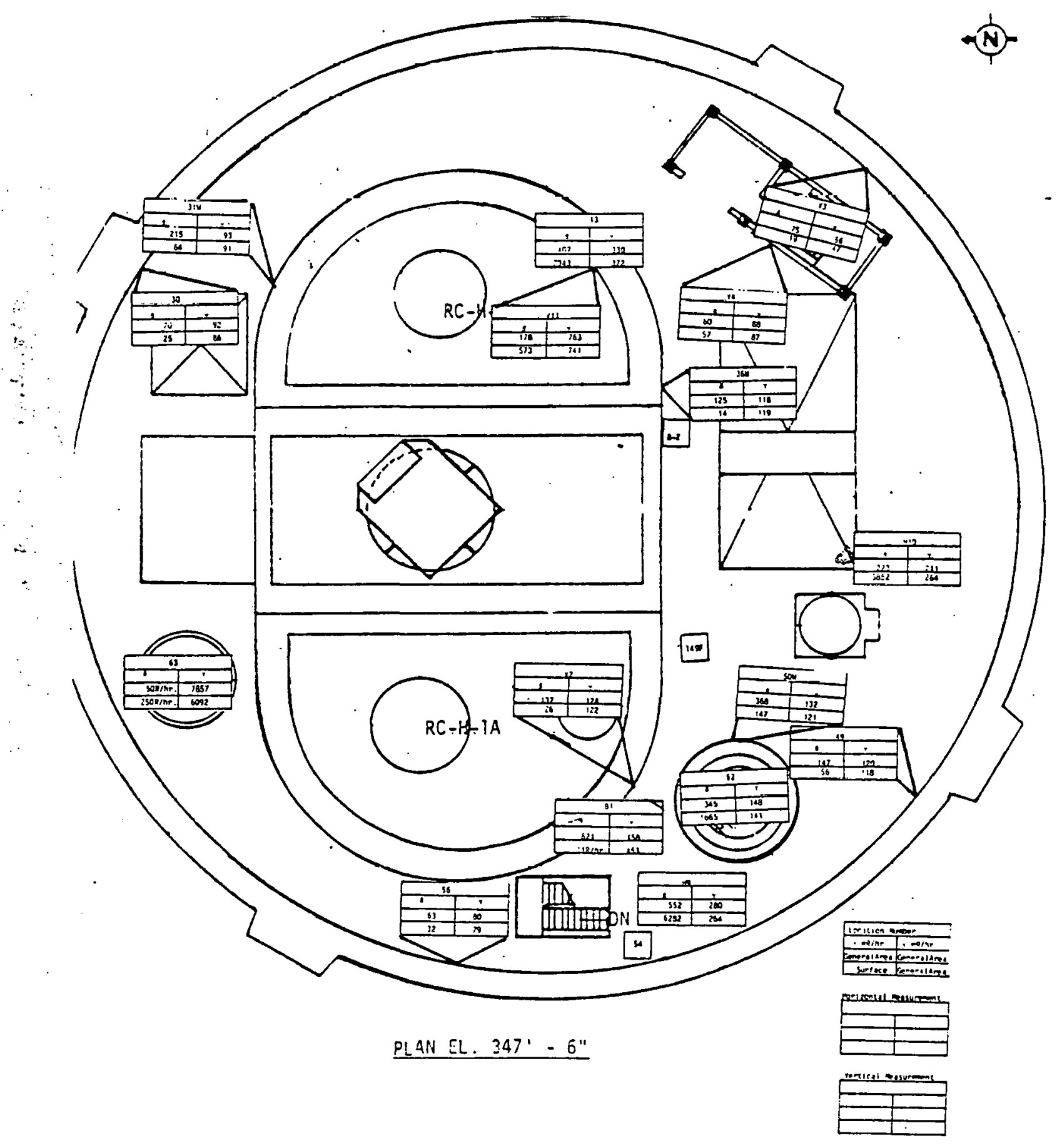


FIGURE A-6

POST-GROSS DECONTAMINATION EXPERIMENT TLD AND RO-2A MEASUREIENT LOCATIONS

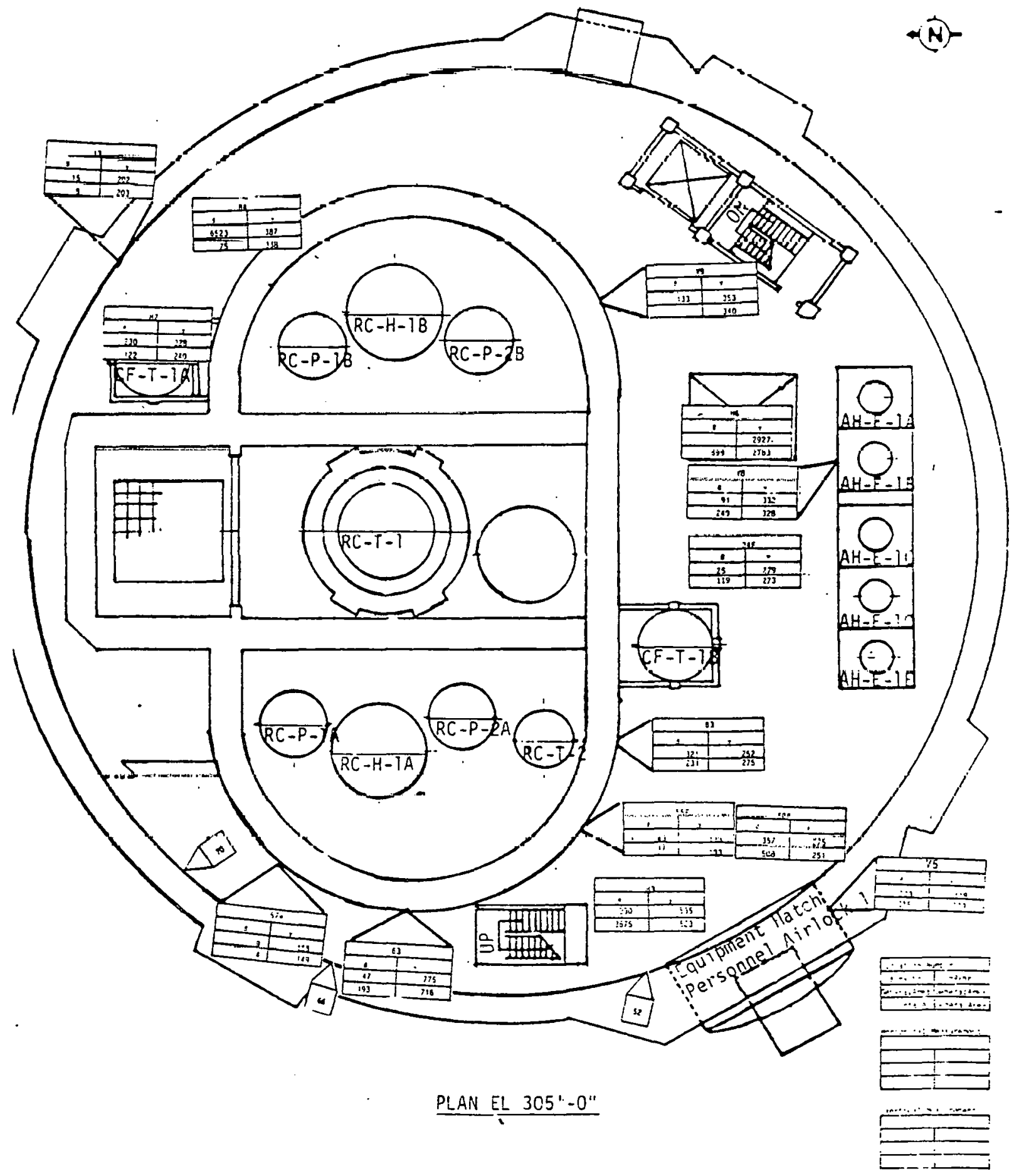


FIGURE $A-7$

POST-GROSS DECONTAMINATION EXPERIMENT TLD AND RO-2A MEASUREIENT LOCATIONS

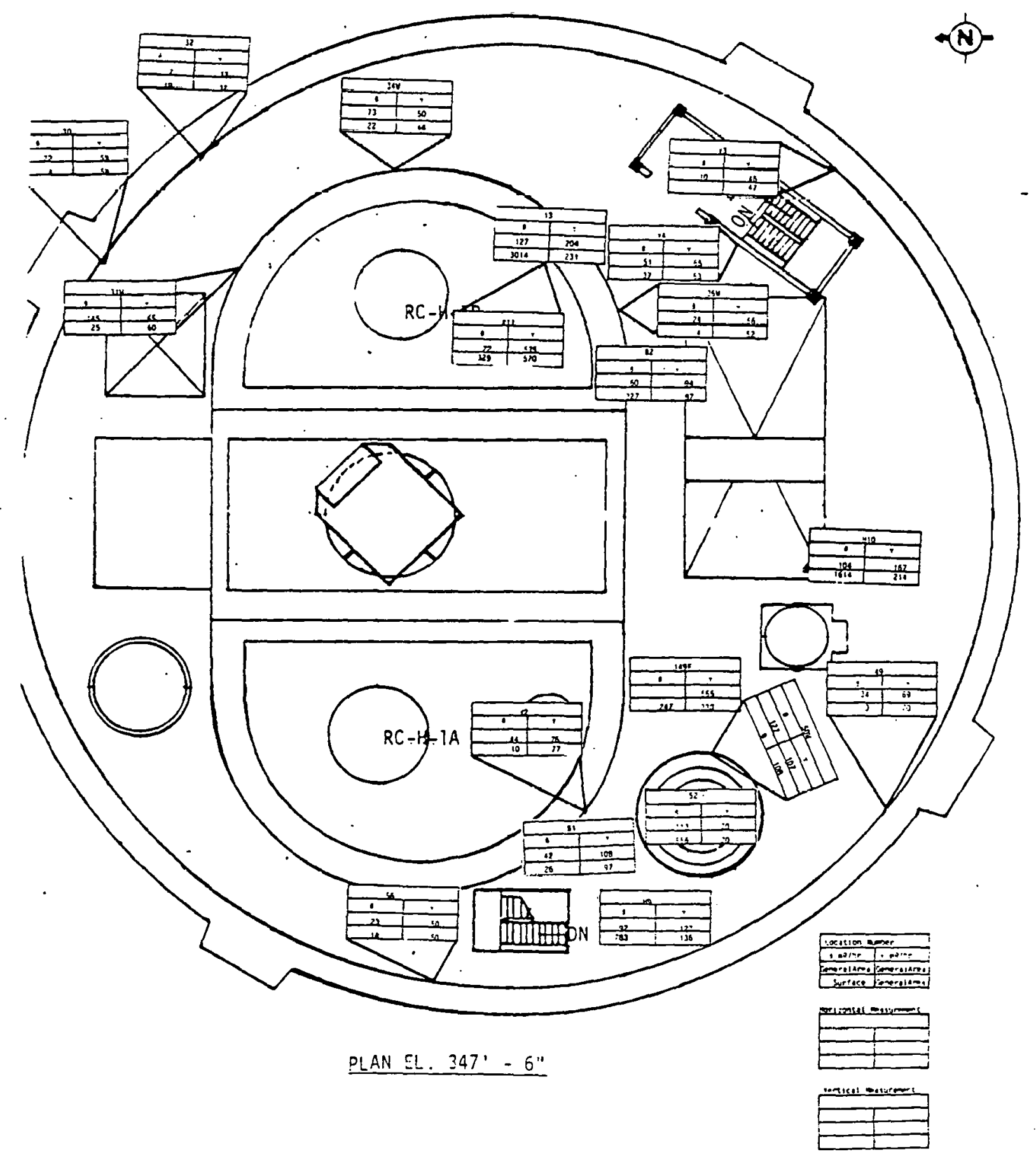


TABLE $A-5$

PRE-ELEVATION 305' GROSS DECONTAMINATION EXPERINIENT TLD DFTA

\begin{tabular}{|c|c|c|c|c|c|c|c|c|c|c|c|c|c|c|c|}
\hline \multirow{3}{*}{ v } & \multirow{3}{*}{$\begin{array}{l}\text { LOCATION } \\
\text { NUMBER }\end{array}$} & \multirow{3}{*}{ LOCATION OESCRIPIIINN } & \multirow{3}{*}{$\begin{array}{l}V \equiv R T I C A L \\
\text { OR } \\
\text { HORIZONTAL }\end{array}$} & \multicolumn{4}{|c|}{ TOTAL EXPOSURE } & \multirow{2}{*}{\multicolumn{2}{|c|}{$\begin{array}{l}\text { DATE \& II MEE OT } \\
\text { EXPOSUFE }\end{array}$}} & \multirow{3}{*}{$\begin{array}{l}\text { EXPOSURE } \\
\text { IIME } \\
\text { HIHS. }\end{array}$} & \multicolumn{4}{|c|}{ EXFESURE RATE } & \multirow{3}{*}{ COMAENTS } \\
\hline & & & & \multicolumn{2}{|c|}{$B$} & \multicolumn{2}{|r|}{$\gamma$} & & & & \multicolumn{2}{|c|}{6} & \multicolumn{2}{|r|}{$y$} & \\
\hline & & & & $\begin{array}{l}r \text { rent } \\
R f D\end{array}$ & Back & $\begin{array}{c}\text { Front } \\
\text { RAD }\end{array}$ & $\begin{array}{r}\text { Back } \\
\text { RMO }\end{array}$ & IN & $\mathrm{Ot}^{-}$ & & $\begin{array}{l}\text { Front } \\
\text { full/hr. }\end{array}$ & $\begin{array}{c}\text { Back } \\
m i 2 / \mathrm{lir}\end{array}$ & $\begin{array}{l}\text { Front } \\
\text { ufithi. }\end{array}$ & Back & \\
\hline 11 & 13 & $\begin{array}{l}\text { Taped to liner approximately } 4 \text { feet above } \\
\text { the floor. NE area fix Bldg. }\end{array}$ & Tertical & NA & NA & 92.70 & 98.66 & $\begin{array}{c}12 / 9 / 81 \\
1427\end{array}$ & $\begin{array}{c}12 / 15 / 81 \\
1838\end{array}$ & 148.2 & NA & NA & 623 & 664 & \\
\hline 12 & 117 & $\begin{array}{l}\text { Taped to the floor. NE ared of Rx Bldg.. SE } \\
\text { area under } C F-T-I A\end{array}$ & Morizontal & 23.79 & 136.74 & 63.37 & 69.67 & $\begin{array}{c}12 / 9 / 81 \\
1427 \\
\end{array}$ & $\left|\begin{array}{c}12 / 15 / 87 \\
1838\end{array}\right|$ & 148.2 & 158 & 920 & 426 & 468 & \\
\hline 13 & B4 & $\begin{array}{l}\text { Taped to the underside of the function box, } \\
\text { NE ared of } R \times \text { Bldg. }\end{array}$ & Tertical & $7 C .60$ & 20.02 & 23.42 & 23.15 & $\begin{array}{c}12 / 9 / 81 \\
1427\end{array}$ & $\begin{array}{c}12 / 15 / 8 i \\
1838\end{array}$ & 148.2 & 474 & 133 & 156 & 158 & \\
\hline 14 & vg & $\begin{array}{l}\text { Taped to D-ring wall approxinlately } 4 \text { feet } \\
\text { above floor. SE area Rx Bldy. }\end{array}$ & Tertical & 36.53 & 5.70 & 84.90 & 82.26 & $\begin{array}{c}12 / 9 / 81 \\
1427\end{array}$ & $\begin{array}{c}12 / 15 / 81 \\
1838\end{array}$ & 148.2 & 244 & 36 & 571 & 553 & \\
\hline 15 & 116 & $\begin{array}{l}\text { Japed to West ared of hatch cover. SE area } \\
\text { of } \mathrm{Rx} B \mid \mathrm{dg} \text {. }\end{array}$ & Iorizontal & $10=0.31$ & 2203.82 & 332.53 & 390.86 & $\begin{array}{c}12 / 9 / 81 \\
1427\end{array}$ & $\begin{array}{c}12 / 15 / 81 \\
1838\end{array}$ & 148.2 & $688=$ & $\begin{aligned} 14.9 R: \\
: i n\end{aligned}$ & 2242 & 2635 & \\
\hline 16 & v8 & $\begin{array}{l}\text { Taped to front side of alrcooler B approx, } \\
4^{\circ} \text { above floor, SE area of } \mathrm{Rx} 81 \mathrm{dg} \text {. }\end{array}$ & lertical & 16.73 & 22.07 & 85.83 & 85,23 & $\begin{array}{c}12 / 9 / 81 \\
1427 \\
\end{array}$ & $\begin{array}{c}\text { 12/ } 16781 \\
18 \div 8\end{array}$ & 198.2 & 110 & 146 & 571 & 573 & \\
\hline 18 & 115 & $\begin{array}{l}\text { Japed to the floor, } S H \text { ared of } R \times B \mid d g_{1} \\
\text { IE area under CF-T-IB. }\end{array}$ & lorizontal & 94.08 & 406.94 & 138.81 & 133.34 & $\begin{array}{c}12 / 9 / 81 \\
1427\end{array}$ & $\begin{array}{c}12 / 15 / 81 \\
10=0\end{array}$ & 148.2 & 632 & .2743 & 935 & 898 & - \\
\hline 27 & $67 \mathrm{M}$ & $\begin{array}{l}\text { Taped to D-ring wall approx, } 4 \text { feet above } \\
\text { floor. NH area Rx Bldg. }\end{array}$ & dertical & AA & NA & 42.79 & 39.37 & $\begin{array}{c}12 / 9 / 81 \\
1427 \\
\end{array}$ & $\begin{array}{c}12 / 15 / 81 \\
18: 8\end{array}$ & 148.2 & MA & NA & 287 & 267 & \\
\hline 26 & 66 & $\begin{array}{l}\text { Taped to liner approx. } 4 \text { feet above the } \\
\text { floor WH area of AX Bidg. }\end{array}$ & dertical & 202.81 & 39.51 & 42.27 & 45.89 & $\begin{array}{c}12 / 9 / 81 \\
1427\end{array}$ & $\begin{array}{c}72 / 1 E / 81 \\
18: 8\end{array}$ & 148.2 & 1367 & 265 & 283 & 303 & \\
\hline 25 & 63 & $\begin{array}{l}\text { Taped to D-ring wall approx. } 4 \text { feet above } \\
\text { floor, } W \text { area of } R x \text { Bidg. }\end{array}$ & dertical & 26.02 & 82.39 & 214.80 & 196.37 & $\begin{array}{c}12 / 9 / 81 \\
1427\end{array}$ & $\begin{array}{c}\text { T27:T/8 } \\
18: B\end{array}$ & 148.2 & 174 & 554 & 1448 & 1323 & \\
\hline 23 & H3 & Taped to fluor, West area of Rx Bldg. & torizontal & A & $1155,2 d$ & 767.44 & 809.81 & $\begin{array}{c}12 / 9 / 81 \\
1427\end{array}$ & $\begin{array}{c}12 / 19 / 8 \\
18: 8\end{array}$ & 148.2 & NA & 3794 & 5177 & 5462 & \\
\hline 19 & 83 & $\begin{array}{l}\text { Taped to underside of Junction box approx. } \\
8 \text { feet of } f \text { the floor. }\end{array}$ & Vert|cal & $100.6 \mathrm{~J}$ & 88.68 & NA & 57,50 & $\begin{array}{c}12 / 9 / 81 \\
1427\end{array}$ & $\begin{array}{c}7275 / 8 \\
18: 8\end{array}$ & 148.2 & 677 & 597 & NA & 386 & \\
\hline 21 & $50 F$ & Taped to floor. $S W$ area of $R \times B / d 9$ & Horizontal & 45.15 & 742.74 & 61.13 & 60.78 & $\frac{12 / 9 / 81}{1427}$ & $\begin{array}{c}12 / 13 / 8 \\
1838\end{array}$ & 148.2 & 303 & 5010 & +11 & 408 & \\
\hline
\end{tabular}


PRE-ELEVATIONS $347^{\prime}$ and $367^{\prime}$ GROSS DECONTAMINATION EXPERIMENT TLD DATA

\begin{tabular}{|c|c|c|c|c|c|c|c|c|c|c|c|c|c|c|c|}
\hline \multirow{3}{*}{1} & \multirow{3}{*}{$\begin{array}{l}\text { LOCAT ION } \\
\text { NUMBER }\end{array}$} & \multirow{3}{*}{ LOCATION OESCRIPTION } & \multirow{3}{*}{$\begin{array}{l}\text { VERTICAL } \\
\text { OR } \\
\text { HORIZOHTAL }\end{array}$} & \multicolumn{4}{|c|}{ TOTAL EXPOSURE } & \multirow{2}{*}{\multicolumn{2}{|c|}{$\begin{array}{c}\text { DAIE \& TIME } \\
\text { Of } \\
\text { EXPOSURE }\end{array}$}} & \multirow{3}{*}{$\begin{array}{c}\text { EXPOSIIRE } \\
\text { TIME } \\
\text { IIRS. }\end{array}$} & \multicolumn{4}{|c|}{ EXPOSLRE RAIE } & \multirow{3}{*}{ COMMEIIS } \\
\hline & & & & \multicolumn{2}{|c|}{$B$} & \multirow{2}{*}{\multicolumn{2}{|c|}{\begin{tabular}{c|c}
\multicolumn{1}{c|}{$Y$} \\
Front \\
RAD
\end{tabular}}} & & & & \multicolumn{2}{|c|}{$\begin{array}{c}B \\
\end{array}$} & \multicolumn{2}{|c|}{$r$} & \\
\hline & & & & $\begin{array}{c}\text { Front } \\
\text { RAD }\end{array}$ & $\begin{array}{l}\text { Back } \\
\text { RAD }\end{array}$ & & & IN & OUT & & $\begin{array}{c}\text { Front } \\
\text { wilhr: } \\
\end{array}$ & $\begin{array}{ll}\text { Back } \\
\text { miR/lir. }\end{array}$ & $\begin{array}{l}\text { Froile } \\
\text { tuR/hr: }\end{array}$ & Back & \\
\hline , & 30 & $\begin{array}{l}\text { Taped to liner approx. } 4 \text { feet above floor } \\
\text { by hatch cover. NE area Rx Bldg. }\end{array}$ & Vertical & 14.89 & 3.60 & 38.69 & 38.61 & $\begin{array}{c}12 / 9 / 81 \\
1507\end{array}$ & $\begin{array}{c}12 / 15 / 81 \\
1838\end{array}$ & 147.52 & 70 & 25 & 92 & 80 & \\
\hline ) & $31 \mathrm{H}$ & $\begin{array}{l}\text { Tapled to D-ring wall approx. } 4 \text { feet above } \\
\text { floor. NE area Rx Bldg. }\end{array}$ & Vertical & 32.41 & 10.03 & 14.12 & 13.83 & $\begin{array}{c}12 / 9 / 81 \\
1507\end{array}$ & $\begin{array}{c}12 / 15 / 81 \\
1838\end{array}$ & 147.52 & 215 & 64 & 93 & 91 & \\
\hline j & v3 & $\begin{array}{l}\text { Taped to liner behind enclosed statruell approx } \\
4 \text { feet above floor. }\end{array}$ & Vertical & 11.68 & 3.47 & 10.04 & 8.45 & $\begin{array}{c}12 / 9 / 81 \\
1507\end{array}$ & $\begin{array}{c}12 / 15 / 81 \\
1838\end{array}$ & 147.52 & 75 & 19 & 66 & 47 & \\
\hline $\bar{y}$ & v4 & $\begin{array}{l}\text { Taped to ourside enclosed stairwell wall approx } \\
4 \text { feet above floor. }\end{array}$ & Vertical & 9.40 & 9.10 & 13.30 & 13.17 & $\begin{array}{c}12 / 9 / 81 \\
1507\end{array}$ & $\begin{array}{c}12715781 \\
1838\end{array}$ & 147.52 & 60 & 57 & 88 & 87 & \\
\hline 4 & $36 \mathrm{~W}$ & $\begin{array}{l}\text { Taped to D-ring wall approx. } 4 \text { feet above floor } \\
\text { SE area Rx Bldg. }\end{array}$ & Vertical & 19.06 & 2.72 & 17.84 & 17.93 & $\begin{array}{c}12 / 9 / 81 \\
1507\end{array}$ & $\begin{array}{c}12 / 15 / 81 \\
1838\end{array}$ & 147.52 & 125 & 14 & 118 & 119 & \\
\hline 1 & $\mathrm{H} 1 \mathrm{O}$ & $\begin{array}{l}\text { Taped to floor near SH corner of hatch } \\
\text { cover. South area of } R \times 81 \mathrm{dg} \text {. }\end{array}$ & Horizontal & 33.52 & 568.94 & 35.87 & 39.32 & $\begin{array}{c}12 / 9 / 81 \\
1507\end{array}$ & $\begin{array}{c}12 / 15 / 82 \\
1838\end{array}$ & 147.52 & 223 & 3852 & 241 & 264 & \\
\hline 3 & $50 \mathrm{H}$ & $\begin{array}{l}\text { Taped to East side of head stand. SW area } \\
\text { of Rx Bldg. }\end{array}$ & Vertical & 55.22 & 22.58 & 19.83 & 18.24 & $\begin{array}{c}12 / 9 / 81 \\
1501\end{array}$ & $\underset{1838}{12715781}$ & 147.52 & 368 & 147 & 132 & 121 & . \\
\hline 4 & 52 & 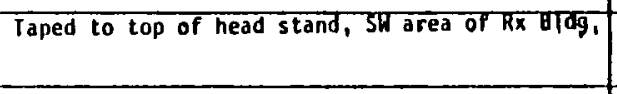 & Hopizontul & 51.91 & 246.62 & 22.21 & 21.52 & $\begin{array}{c}12 / 9 / 81 \\
1507 \\
\end{array}$ & $\begin{array}{c}12 / 15 / 81 \\
1838\end{array}$ & 147.52 & 345 & 1655 & 148 & 141 & \\
\hline 1 & v2 & $\begin{array}{l}\text { Taped to D-ring wall approx. } 4 \text { feet above flaor } \\
\text { West area Rx Bidg. }\end{array}$ & Vertical & 21.10 & 4.85 & 18.62 & 18.32 & $\begin{array}{c}12 / 9 / 87 \\
1507\end{array}$ & $\begin{array}{c}12 / 15 / 82 \\
1838\end{array}$ & 147.52 & 137 & 26 & 124 & 122 & \\
\hline 0 & 81 & $\begin{array}{l}\text { Placed on the floor below Junction box, Nest } \\
\text { area Rx Bldy. }\end{array}$ & Horizontal & 92.94 & 1645.70 & 67.93 & 67.25 & $\begin{array}{c}12 / 9 / 81 \\
1507\end{array}$ & $\begin{array}{c}12 / 15 / 81 \\
1838\end{array}$ & 147.52 & 624 & $11.2 \mathrm{R} / \mathrm{h}$ & 458 & 453 & \\
\hline 6 & H9 & $\begin{array}{l}\text { Taped to floor approx, } 4 \text { feet south of } \\
\text { open stainvell. West area of } R \times \text { Bldg. }\end{array}$ & Horizontal & 77.90 & 927.68 & 41.64 & 39.35 & $\begin{array}{c}12 / 9 / 81 \\
1507\end{array}$ & $\begin{array}{c}12 / 15 / 81 \\
1838\end{array}$ & 147.52 & 522 & 6282 & 280 & 264 & \\
\hline 8 & 56 & $\begin{array}{l}\text { Taped to biner approx. } 4 \text { feet above floor, } \\
\text { Hest area of Rx Bldg. }\end{array}$ & Vertical & 10.17 & 5.74 & 12.20 & 11.97 & $\begin{array}{c}12 / 9 / 81 \\
1507\end{array}$ & $\begin{array}{c}12 / 15 / 81 \\
1838\end{array}$ & 147.52 & 6.3 & 32 & 80 & 79 & \\
\hline 9 & 63 & $\begin{array}{l}\text { Hest axis of the in core instrumentation } \\
\text { area. }\end{array}$ & |lorizonțan| & 7423.62 & $36.8 \mathrm{AE}$ & 1159.49 & 899.03 & $\begin{array}{c}1279781 \\
1507\end{array}$ & $\begin{array}{c}12 / 15 / 81 \\
1838\end{array}$ & 147.52 & $50.3 R / h$ & $\begin{array}{l}250 \\
R ; \mathrm{hr}\end{array}$ & 785: & 6092 & \\
\hline 0 & 13 & $\begin{array}{l}367^{\prime} \text { El., Top D-ring wall, East ared of } \\
\text { Rx BIdq. }\end{array}$ & Norizontal & 60.66 & 172.42 & 49.08 & 55.30 & \begin{tabular}{|c|}
$12 / 9 / 81$ \\
1501 \\
\end{tabular} & $\begin{array}{c}12 / 15 / 81 \\
1838 \\
\end{array}$ & 147.52 & 407 & 7943 & 330 & 372 & \\
\hline I & VII & $\begin{array}{l}367 \cdot \text { El., Taped to Inside } D \text {-ring wall, } \\
\text { East ared Rx Bldg. }\end{array}$ & Vertical & 26.85 & 85.20 & 112.98 & 109.65 & $\begin{array}{c}12 / 9 / 81 \\
1507\end{array}$ & $\begin{array}{c}12 / 15 / 81 \\
1838\end{array}$ & 147.52 & 178 & 573 & 763 & 741 & \\
\hline
\end{tabular}


TABLE A-7

POST-EIEVATION 305' GROSS DECONTAMINA'ION EXPERIMENT I'LD DATA

\begin{tabular}{|c|c|c|c|c|c|c|c|c|c|c|c|c|c|c|c|}
\hline \multirow[b]{3}{*}{ ILI) } & \multirow[b]{3}{*}{$\begin{array}{l}\text { LOCATION } \\
\text { NUMBER }\end{array}$} & \multirow[b]{3}{*}{ LOCATION DESCRIPTION } & \multirow{3}{*}{$\begin{array}{c}\text { VERIICAL } \\
\text { OR } \\
\text { IORIZONIAL }\end{array}$} & \multicolumn{4}{|c|}{ IO'AL EXPOSURE } & \multirow{2}{*}{\multicolumn{2}{|c|}{$\begin{array}{c}\text { UAIE } \\
\text { OPF TIHE } \\
\text { EXPOSUPE }\end{array}$}} & \multirow{3}{*}{$\begin{array}{c}\text { EXPOSURT } \\
\text { TIME } \\
\text { IIRS. }\end{array}$} & \multicolumn{4}{|c|}{ I. IPOSURE RAIE } & \multirow{3}{*}{ COMMEHTS } \\
\hline & & & & \multicolumn{2}{|c|}{8} & \multicolumn{2}{|c|}{$y$} & & & & \multicolumn{2}{|c|}{\begin{tabular}{|r}
$\beta$ \\
\end{tabular}} & \multicolumn{2}{|c|}{$-r_{-1}$} & \\
\hline & & & & $\begin{array}{c}\text { Front } \\
\text { RAD }\end{array}$ & $\begin{array}{r}\text { Back } \\
\text { RAD }\end{array}$ & $\begin{array}{c}\text { Front } \\
\text { RAD }\end{array}$ & $\begin{array}{r}\text { Back } \\
\text { RAD }\end{array}$ & 4 & DUT & & $\begin{array}{l}\text { Front } \\
\text { mR/lin: } \\
\end{array}$ & $\begin{aligned} \text { Back } \\
\text { Bullic. }\end{aligned}$ & $\begin{array}{l}\text { froint } \\
\text { aR/ur }\end{array}$ & isnck & \\
\hline 1 & 13 & $\begin{array}{l}\text { Taped to I Iner approxtinately } 1 \text { feet above } \\
\text { the floor, ME area Rx Building. }\end{array}$ & Vertical & 10.16 & 5.14 & 135.13 & 135.65 & $\begin{array}{l}3 / 25 / 82 \\
1500\end{array}$ & $\begin{array}{l}4 / 22 / 82 \\
1057\end{array}$ & 668 & 15 & 8 & 202 & 203 & \\
\hline 2 & 117 & $\begin{array}{l}\text { Taped to the floor, IIt area of Rx Buituing } \\
\text { SE area under CF-T-IA }\end{array}$ & Hor|zontal| & 153.49 & 31.81 & 152.31 & 160.79 & $\begin{array}{l}3 / 25 / 82 \\
1500\end{array}$ & $\begin{array}{l}4 / 22 / 82 \\
1057\end{array}$ & 668 & 230 & 122 & .228 & 240 & \\
\hline 3 & Bn & $\begin{array}{l}\text { Placed on top of Junction box. NE area of } \\
\text { Rx Building }\end{array}$ & Horizonta & 4357.49 & 49.93 & 258.50 & 225.84 & $\begin{array}{c}3 / 25 / 82 \\
1500\end{array}$ & $\begin{array}{l}1 / 22 / 82 \\
1057\end{array}$ & 668 & 0523 & 75 & 387 & 338 & \\
\hline 4 & vg & $\begin{array}{l}\text { Taped to D-ring wall approxinately } 4 \text { feet } \\
\text { above floor. SE area Rx Building. }\end{array}$ & Vert|cal & 88.60 & NA & 236.16 & 226.99 & $\begin{array}{l}3 / 25 / 82 \\
1500\end{array}$ & $\begin{array}{c}T / 22782 \\
1057\end{array}$ & 668 & 133 & NA & 353 & 340 & \\
\hline 5 & H6 & $\begin{array}{l}\text { Taped to west area of hatch cover, SE area } \\
\text { of P.x Butlding }\end{array}$ & Hopizonta & MA & 467.23 & $1955.2 \$$ & $\{846.07$ & $\begin{array}{c}3 / 25 / 82 \\
1500\end{array}$ & $\begin{array}{l}9 / 22 / 82 \\
1057\end{array}$ & 668 & MA & 697 & 2927 & 2763 & \\
\hline 6 & v8 & $\begin{array}{l}\text { Taped to front side of alrcooler } B \\
\text { approxima tely } 4 \text { " above floor. SE area of Rx } \\
\text { Building }\end{array}$ & Veptical & 61.13 & 166.03 & 222.10 & 219.22 & $\begin{array}{l}3 / 25 / 82 \\
1500\end{array}$ & $\begin{array}{l}7 / 22 / 82 \\
1057\end{array}$ & 668 & 91 & 241 & 332 & 328 & \\
\hline 58 & $34 \mathrm{~F}$ & Taped to floop, south area of Rx Butlding & Horizontal & 76.56 & 79.36 & 186.66 & 182.27 & $\begin{array}{l}3 / 25 / 82 \\
1500\end{array}$ & $\begin{array}{l}4 / 22 / 82 \\
057\end{array}$ & 668 & 25 & 11 & 279 & 273 & - \\
\hline 8 & $67 \mathrm{H}$ & $\begin{array}{l}\text { Taped to D-ring wall approximately } 4 \text { feet } \\
\text { above Pl por. } \mathrm{HW} \text { area Rx Butlding }\end{array}$ & Vertical & 58.59 & 23.87 & $\mid 03.70$ & 100.15 & $\begin{array}{c}3 / 25 / 82 \\
1500\end{array}$ & $\begin{array}{c}0 / 22 / 82 \\
1057\end{array}$ & 668 & 9 & 1 & 155 & 149 & \\
\hline 61 & 63 & $\begin{array}{l}\text { Taped to D-ping wall approximately } 4 \text { feet } \\
\text { above fleor. H area of } R x \text {. Building }\end{array}$ & Vertical & 31.46 & 129.04 & 517.74 & 478.8 & $\begin{array}{c}3 / 25 / 82 \\
15100\end{array}$ & $\begin{array}{l}4 / 22 / 82 \\
1057\end{array}$ & 668 & 47 & 198 & 775 & 716 & \\
\hline 63 & v5 & $\begin{array}{l}\text { Taped to south equiprent hatch wall } \\
\text { approximately } 4 \text { feet above floor }\end{array}$ & Vertical & 135.48 & 210.36 & 79.23 & 23.33 & $\begin{array}{c}3 / 25 / 82 \\
1500\end{array}$ & $\begin{array}{c}4 / 22 / 32 \\
1057\end{array}$ & 668 & 203 & $31 j$ & 118 & 109 & \\
\hline 7 & H3 & Taped to floor, West ared of Rx Building & Horizonta) & $153.6 ?$ & 2455.26 & 357.63 & 349.62 & $\begin{array}{l}3 / 25 / 82 \\
1500\end{array}$ & $\begin{array}{c}4 / 22 / 92 \\
1057\end{array}$ & 668 & 230 & 3675 & 535 & 523 & \\
\hline 64 & $55 p$ & $\begin{array}{l}\text { Taped to D-ring wall approximately } 4 \text { feet } \\
\text { above floor, SW area of Rx Bullding }\end{array}$ & Vertical & 30.05 & 11.16 & 130.27 & 120.94 & $\begin{array}{c}3 / 25 / 82 \\
1500\end{array}$ & $\begin{array}{c}4 / 22 / 82 \\
1057\end{array}$ & 668 & 45 & 17 & 195 & 193 & \\
\hline 65 & 83 & $\begin{array}{l}\text { Taped to underside of Junction box approx. } \\
8 \text { feet off the floor }\end{array}$ & Vertical & 214.26 & 154.39 & 175.19 & 183.76 & $\begin{array}{c}3 / 25 / 82 \\
1500\end{array}$ & $\begin{array}{c}4 / 22 / 118 \\
1057\end{array}$ & 668 & 321 & 23 & 262 & 275 & \\
\hline 66 & 50F & Taped to floor. SW area of Rx Bullating & Horizontal & 238.42 & 339.60 & 183.98 & 168.00 & $\begin{array}{c}3 / 25 / 82 \\
1500\end{array}$ & $\begin{array}{c}4 / 22 / 82 \\
1057\end{array}$ & 668 & 357 & 500 & 275 & 251 & \\
\hline
\end{tabular}


POST-ELEVATION 347' GROSS DECONTAMINATION EXPERIMENT TLD DATA

\begin{tabular}{|c|c|c|c|c|c|c|c|c|c|c|c|c|c|c|c|}
\hline & \multirow[b]{3}{*}{$\begin{array}{l}\text { LOCATION } \\
\text { RUMBER }\end{array}$} & \multirow{3}{*}{ LOCATIUN DESCRIPTION } & \multirow{3}{*}{$\begin{array}{l}\text { VERTICAL } \\
\text { OR } \\
\text { HORIZONIAL }\end{array}$} & \multicolumn{4}{|c|}{ TOIAL EXPOSURE } & \multirow{2}{*}{\multicolumn{2}{|c|}{$\begin{array}{l}\text { DATE \& TIME } \\
\text { OF } \\
\text { EXPOSURE }\end{array}$}} & \multirow{3}{*}{$\begin{array}{l}\text { EXPOSURE } \\
\text { TIME } \\
\text { IORS. }\end{array}$} & \multicolumn{4}{|c|}{ EXPOSURE PAIE } & \multirow{3}{*}{ COMMENTS } \\
\hline & & & & \multicolumn{2}{|c|}{+} & \multicolumn{2}{|c|}{$\gamma$} & & & & B & & & $y$ & \\
\hline & & & & $\begin{array}{c}\text { Front } \\
R A D\end{array}$ & $\begin{array}{l}\text { Back } \\
\text { RAD }\end{array}$ & $\begin{array}{l}\text { Fiont } \\
\text { RAU }\end{array}$ & $\begin{array}{c}\text { Back } \\
\text { RAD }\end{array}$ & III & our & & $\begin{array}{c}\text { Front } \\
\text { mR/hr }\end{array}$ & $\begin{array}{l}\text { Back } \\
\text { mR/hr }\end{array}$ & $\begin{array}{l}\text { Floont } \\
\mathrm{miR} / \mathrm{hr}\end{array}$ & $\begin{array}{l}\text { Back } \\
\mathrm{muR} / \mathrm{hs}\end{array}$ & \\
\hline & 30 & $\begin{array}{l}\text { Taped to liner approx. } 4 \text { feet above floor } \\
\text { by hatch cover, WE area } R \times \text { Bldg. }\end{array}$ & Vertical & 14.89 & 3.60 & 38.69 & 38.61 & $\begin{array}{c}3 \longdiv { 2 6 / 8 2 } \\
1328\end{array}$ & $\begin{array}{c}4 / 22 / 82 \\
1057\end{array}$ & $645: 5$ & 22 & 4 & 59 & 59 & \\
\hline & $31 \mathrm{H}$ & $\begin{array}{l}\text { Taped to D-ring wall approx. } 4 \text { feet above } \\
\text { floor. HE area Rx Bidg. }\end{array}$ & Vertical & 94.43 & 17.27 & 42.34 & 39.56 & $\begin{array}{c}3 / 26 / 82 \\
1328\end{array}$ & $\begin{array}{l}4 / 22 / 82 \\
1057\end{array}$ & 645.5 & 145 & 25 & 65 & 60 & \\
\hline & 32 & $\begin{array}{l}\text { Taped to liner approx. } 4 \text { feet above floor, } \\
\text { NE area Rx Bldg. }\end{array}$ & Vertlcal & 5.11 & 12,62 & 22.04 & 20.99 & $\begin{array}{c}3 / 26782 \\
1328\end{array}$ & $4\}_{057}^{22 / 82}$ & 645.5 & $\lambda$ & 18 & 33 & 32 & \\
\hline & $34 \mathrm{~K}$ & $\begin{array}{l}\text { Taped to } 0 \text {-ring wall approx. } 4 \text { feet above } \\
\text { floor. East areaRx Bldg. }\end{array}$ & Vertical & 48.23 & $15: 23$ & 32.69 & 28.99 & $\begin{array}{c}3 / 26 / \sqrt{2} \\
1328\end{array}$ & $4 / 22 / 82$ & $645: 5$ & 73 & 22 & 50 & 44 & \\
\hline , & v3 & $\begin{array}{l}\text { Taped to Tiner behind enclosed stairwell } \\
\text { approx. } 4 \text { feet above floor. }\end{array}$ & Vertical & 7.30 & NA & 30.41 & 30.73 & $\begin{array}{c}3 / 26 / 82 \\
1328\end{array}$ & $\begin{array}{l}4 / 22 / 82 \\
1057\end{array}$ & 645.5 & 10 & NA & 46 & 47 & \\
\hline & v4 & $\begin{array}{l}\text { Taped to outside enclosed stairwet! wall } \\
\text { approx. \& feet above floor. }\end{array}$ & Vertical & 33.42 & 24.81 & 42.25 & 41.00 & $\begin{array}{r}3 / 26 / 82 \\
1328\end{array}$ & $\frac{4 / 22 / 82}{105 \%}$ & 645.5 & 51 & 37 & 65 & 63 & \\
\hline : & $36 \mathrm{~W}$ & $\begin{array}{l}\text { Taped to D-ring wall approx. } 4 \text { Peet above } \\
\text { floor SE orea Rx BIdg. }\end{array}$ & Vertical & 16,29 & 3.50 & 36.48 & 33.95 & $\begin{array}{c}3 / 26 / 82 \\
1328\end{array}$ & $\begin{array}{c}4 / 22 / 82 \\
1057\end{array}$ & 645.5 & 24 & 4 & 56 & 52 & . \\
\hline 1 & 82 & $\begin{array}{l}\text { Placed on top Junction box, SE area of } R x \\
\text { Bldg. }\end{array}$ & Horizontal & 39.57 & 211.89 & 60.94 & 56.97 & $\begin{array}{c}3 / 26 / 82 \\
1328\end{array}$ & $\begin{array}{c}4 / 22 / 42 \\
1057\end{array}$ & 645.5 & 60 & 327 & 94 & 87 & \\
\hline ) & HIO & $\begin{array}{l}\text { Taped to floor hear SH corner of hatch cover, } \\
\text { South area of RX BIdg. }\end{array}$ & Horizontal & 68.14 & 1042.62 & 209.49 & 138.92 & $\begin{array}{c}3 / 26 / 82 \\
1328\end{array}$ & $\begin{array}{c}4 / 22 / 82 \\
1057\end{array}$ & 645.5 & 104 & 1614 & 167 & 214 & \\
\hline 3 & SOH & $\begin{array}{l}\text { Taped to East Side of head stand, SW area } \\
\text { of Rx Bldg. }\end{array}$ & Veptical & 82.38. & 5.81 & 69.76 & 70.19 & $\begin{array}{c}3 / 26 / 82 \\
1328\end{array}$ & $\begin{array}{c}4 / 22 / 82 \\
1057\end{array}$ & 645.5 & 127 & 9 & 107 & 108 & \\
\hline I & $149 \mathrm{~F}$ & $\begin{array}{l}\text { Taped to floor by D-ring wall, SH area } \\
\text { Rx Bldg. }\end{array}$ & Horizontal & NA & 159.82 & 365.1 & 213.75 & $\begin{array}{c}3 / 26 / 82 \\
1328\end{array}$ & $\begin{array}{c}4 / 22 / 82 \\
1057\end{array}$ & 645.5 & MA & 247 & 565 & 330 & \\
\hline 4 & 52 & $\begin{array}{l}\text { Taped to top of head stand, } S W \text { area of } \\
\text { Rx Bldg. }\end{array}$ & Norizontal & 73.08 & 358.95 & 45.62 & 45.55 & $\begin{array}{c}3 / 26 / 82 \\
1328\end{array}$ & $\begin{array}{l}4 / 22 / 82 \\
1057\end{array}$ & 645.5 & 113 & 556 & 70 & 70 & \\
\hline 5 & 49 & $\begin{array}{l}\text { Taped to liner approx } 4 \text { feet above } \\
\text { rloor, Sw area of } R x \text { Bidg: }\end{array}$ & Vertical & 22.46 & 2.12 & 45.05 & 45.41 & $\begin{array}{c}3 / 26 / 82 \\
1328\end{array}$ & $\begin{array}{c}4 / 22 / 82 \\
1057\end{array}$ & 645.5 & 34 & 3 & 69 & 70 & \\
\hline 6 & v2 & $\begin{array}{l}\text { Taped to D-ring wall approx. } 4 \text { feet above } \\
\text { floor, West Area Rx Bldg. }\end{array}$ & Vertical & 28.79 & 7.09 & 49.23 & 49.90 & $\begin{array}{c}3 / 26 / 82 \\
1328\end{array}$ & $\begin{array}{l}9 / 22 / 82 \\
1057\end{array}$ & 645.5 & 44 & 10 & 76 & 17 & \\
\hline 7 & 81 & $\begin{array}{l}\text { Placed on top of Junction box, West ared of } \\
\text { Rx Bldg. }\end{array}$ & Horizontal & 27.15 & 16.92 & 70.07 & 63.01 & $\begin{array}{l}3 / 26 / 82 \\
1328\end{array}$ & $4 / 224^{82}$ & 645.5 & 42 & 26 & 108 & 97 & \\
\hline 8 & 119 & $\begin{array}{l}\text { Taped to floor approx. } 4 \text { feet South } \\
\text { of open stairwell. West ared of } R x \text { Bldg. }\end{array}$ & Horizontal & 59.91 & 505.63 & 82.34 & 88.56 & $\begin{array}{c}3 / 26 / 82 \\
1328\end{array}$ & $\begin{array}{c}4 / 22 / 82 \\
1057\end{array}$ & 645.5 & 92 & 183 & 127 & 136 & \\
\hline 0 & 56 & $\begin{array}{l}\text { Taped to I iner approx. } 4 \text { feet above floor. } \\
\text { Hest area of Rx Bldg. }\end{array}$ & Vertical & 15.23 & 9.49 & 32.46 & 32.65 & $\begin{array}{c}3 / 26 / 82 \\
1328\end{array}$ & $\begin{array}{c}0,00 / \\
4 / 22 / 82 \\
1057\end{array}$ & 645.5 & 23 & 14 & 50 & 50 & \\
\hline
\end{tabular}


I

TABLE $A-9$

POST-ELFVATION $367^{\prime}$ GROSS DECONTAYINATICN EXPERIMENT TLD [ATA

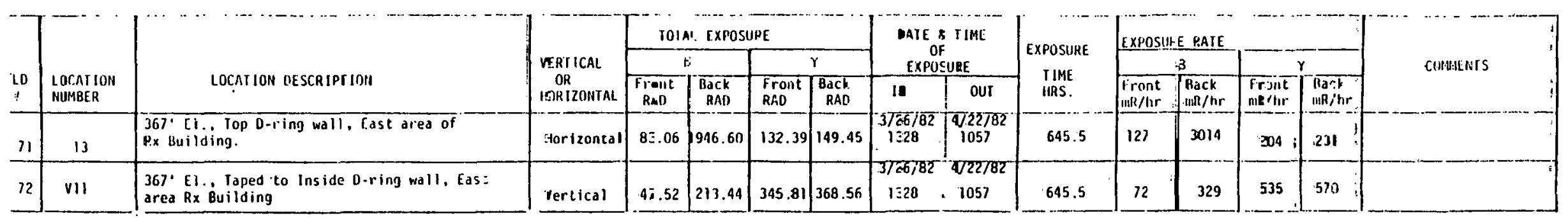




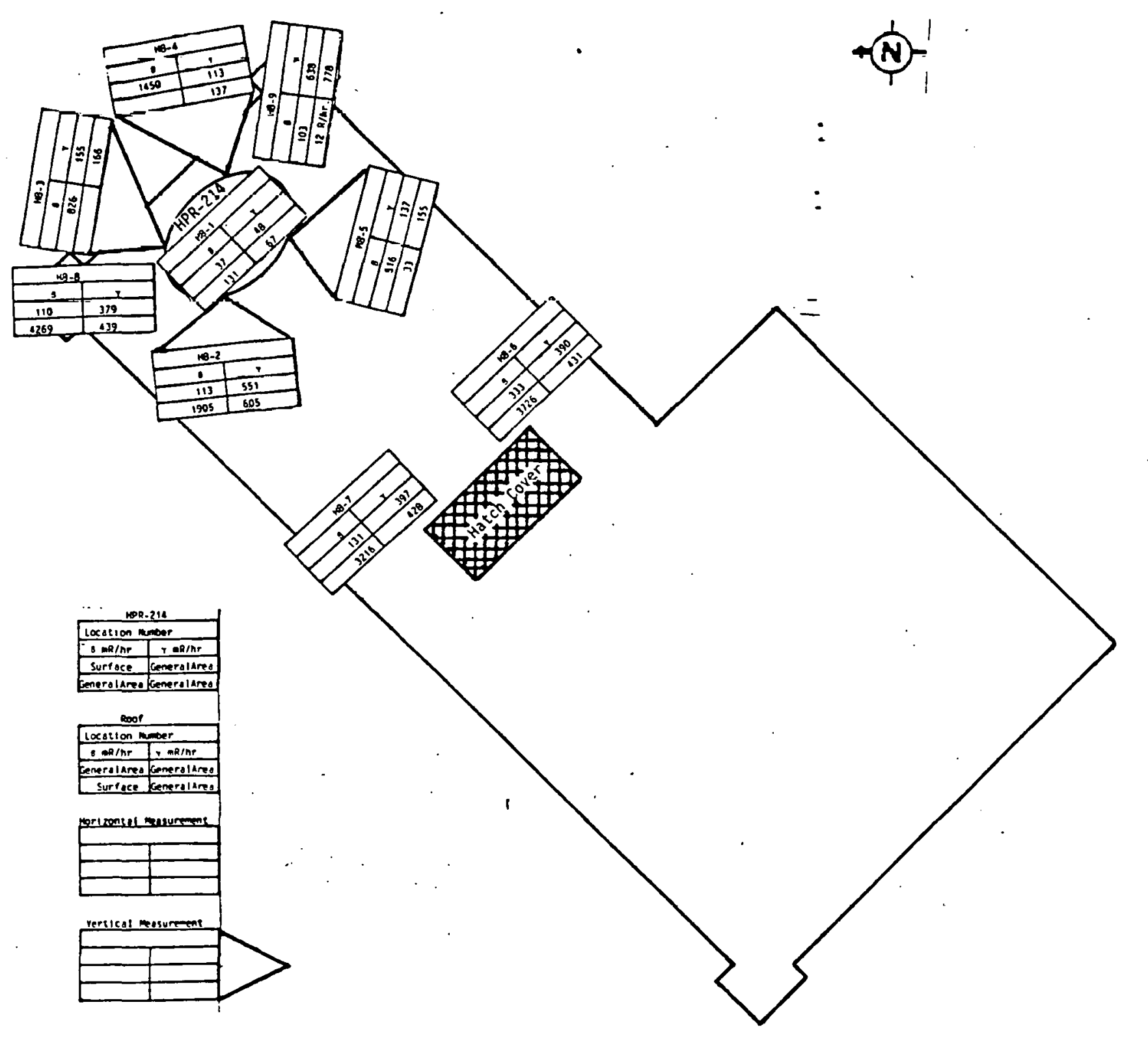

Top of Elevator Shaft - 372' 7 "Elevation 
TABLE $A-10$

PRE-GROSS DECON_AMINATION EXEERIMENT TLD BETA AND GAMMA MEASUFEMENTS DF THE DOME MONITOR AND ITS ENVIRONMENT

\begin{tabular}{|c|c|c|c|c|c|c|c|c|c|c|c|c|c|c|c|c|c|}
\hline \multirow[b]{2}{*}{$\begin{array}{l}\text { Type } \\
\text { urface }\end{array}$} & \multirow[b]{2}{*}{ TLD } & \multirow[b]{2}{*}{$\operatorname{Location}_{z}$} & \multicolumn{2}{|c|}{$\begin{array}{l}\text { TLO f } \\
\text { Exposire }\end{array}$} & \multicolumn{2}{|c|}{\begin{tabular}{|l|l|} 
TLD r \\
Exposure
\end{tabular}} & \multirow{2}{*}{$\begin{array}{l}\text { LOCATION } \\
\text { OESCRIPTION }\end{array}$} & \multicolumn{4}{|c|}{\begin{tabular}{|l|l|} 
TLO Bakd. & Date o r Thite \\
Exposure & Expogure \\
\end{tabular}} & \multirow{2}{*}{\begin{tabular}{|c|} 
Exposure \\
Tiure \\
(hrs) \\
\end{tabular}} & \multicolumn{2}{|c|}{$\begin{array}{l}\text { B-Exposure } \\
\text { Rate }\end{array}$} & \multicolumn{2}{|c|}{$\begin{array}{l}Y=\text { Exposure } \\
\text { Rate }\end{array}$} & \multirow[b]{2}{*}{. } \\
\hline & & & $\begin{array}{l}\text { Front } \\
\text { (RAD) }\end{array}$ & $\begin{array}{l}\text { Back } \\
\text { (RAD) }\end{array}$ & $\begin{array}{l}\text { Front } \\
\text { (RAO) }\end{array}$ & $\begin{array}{l}\text { Bact } \\
\text { (RAU) }\end{array}$ & & $\left(R^{\beta} A D\right)$ & $($ RAul & IN & ous & & $\begin{array}{l}\text { Front } \\
(\sin R / h r)\end{array}$ & $\begin{array}{c}\text { Back } \\
\text { (mR/hr) }\end{array}$ & $\begin{array}{l}\text { Front } \\
(m i R / h r)\end{array}$ & $\begin{array}{l}\text { Buck } \\
\text { (mR/hr) }\end{array}$ & \\
\hline \multirow{5}{*}{ 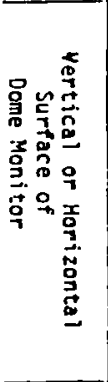 } & 1 & $118-1$ & 10.65 & 37.67 & 14.07 & $B . E M$ & $\begin{array}{l}\text { Horizontal surface, Top of } \\
\text { Monitor }\end{array}$ & 0.05 & 0.22 & $\begin{array}{r}1269 \\
31 \\
12: 06\end{array}$ & $\mid \begin{array}{c}12 / 15 \\
81 \\
12: 00\end{array}$ & 283 & 37 & 131 & 48 & 67 & \multirow{3}{*}{$\begin{array}{l}\text { TLo had falle } \\
\text { and fonmen on } \\
\text { flogr by nonito } \\
\end{array}$} \\
\hline & 2 & $118-2$ & 32.67 & 548.79 & 159.01 & 174.47 & $\begin{array}{l}\text { Yertical Surface, side of } \\
\text { Monitor }\end{array}$ & 0.05 & 0.22 & $\begin{array}{r}12 / 31 \\
81 \\
12 ; 00\end{array}$ & $\begin{array}{c}12 / 15 \\
31 \\
12: 00\end{array}$ & 288 & 173 & 1905 & 551 & 605 & \\
\hline & 3 & $118-3$ & 238.05 & <Bahd. & 44.87 & 17,58 & $\begin{array}{l}\text { Vertical Surface, Side of } \\
\text { Monitor }\end{array}$ & 0.05 & 0.22 & $\begin{array}{l}1263 \\
12: 00\end{array}$ & $\mid \begin{array}{c}12 / 15 \\
81 \\
12: 00\end{array}$ & 288 & 826 & $\leq$ Bahi. & 155 & 166 & \\
\hline & 4 & $148-4$ & 417.6 & SBahd. & 32.69 & 39.14 & $\begin{array}{l}\text { Yertical Surface, side of } \\
\text { Monitor }\end{array}$ & 0.05 & 0.22 & $\begin{array}{c}1273 \\
81 \\
12: 00\end{array}$ & $\mid \begin{array}{c}12 / 15 \\
81 \\
12,00\end{array}$ & 288 & 1450 & SBahd. & .113 & 137 & \\
\hline & 5 & $H 8-5$ & 148.65 & 9.50 & 39.81 & $4 . .3$ & $\begin{array}{l}\text { Vertical Surface, Side of } \\
\text { Monitor }\end{array}$ & 0.05 & 0.22 & $\begin{array}{c}1273 . \\
81 \\
12604\end{array}$ & $\begin{array}{c}12 / 15 \\
81 \\
12: 00 \\
\end{array}$ & 288 & 516 & 33 & 137 & $i^{155}$ & . \\
\hline \multirow{4}{*}{ 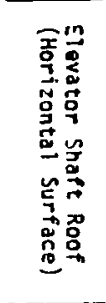 } & 6 & $118-6$ & 95.85 & 1073.03 & 112.61 & 12442 & $\begin{array}{l}\text { Facing stairs and in front of } \\
\text { hatch, TLO on famediate right }\end{array}$ & 0.05 & 0.22 & $\begin{array}{c}12 / 3 ! \\
81 \\
12102 \\
\end{array}$ & $\begin{array}{c}12,15 \\
81 \\
12 i 30 \\
12\end{array}$ & 288 & 333 & 3725 & 390 & 1431 & \\
\hline & 7 & $118-7$ & 37.89 & 926.13 & 114.50 & 12337 & $\begin{array}{l}\text { Facing stairs and in frot of hatch } \\
\text {.TLD on ingediate left }\end{array}$ & 0.05 & 0.22 & {$\left[\begin{array}{c}12 / 31 \\
81 \\
12 i 03\end{array}\right.$} & $\begin{array}{c}12 / 15 \\
81 \\
12 ; 30\end{array}$ & 288 & 131 & 3215 & 397 & 428 & . \\
\hline & 8 & $118-8$ & 31.70 & $\$ 229.50$ & 109.25 & 126.58 & $\begin{array}{l}\text { Facing manitur and Back to Stalrs, } \\
\text { TLD on left corner of roof. }\end{array}$ & 0.05 & 0.22 & $\begin{array}{c}117 / 30 \\
81 \\
12,03 \\
\end{array}$ & $\begin{array}{c}172 / 15 \\
81 \\
12190\end{array}$ & 288 & 110 & 4267 & 379 & 439 & : \\
\hline & 9 & $118-9$ & 29.57 & 3362.59 & 183.90 & 324.37 & $\begin{array}{l}\text { Facing monitar and back to stairs. } \\
\text { TLO on right corner of roof. }\end{array}$ & 0.05 & 0.22 & $\begin{array}{l}12 / 3 \gamma \\
6: 02\end{array}$ & $\begin{array}{l}12 / 15 \\
81 \\
12: 00\end{array}$ & 288 & 103 & $12 \mathrm{R} / \mathrm{hr}$ & 638 & 778 & \\
\hline Contral & 10 & $118-10$. & 0.05 & 0.05 & 0.22 & 0.32 & $\begin{array}{l}\text { Carried to roof and brought } \\
\text { oul after placement of } 9\left\lfloor 0^{t} s \text {. }\right.\end{array}$ & 0.05 & 0.22 & $\mid \begin{array}{c}2 ; 32 \\
01 \\
12 ; 0\end{array}$ & $\begin{array}{c}12 / 31 \\
81 \\
3,00\end{array}$ & 1 & 50 & 50 & 200 & 200 & \\
\hline
\end{tabular}

Motes:

1. $A P R-214$

Horizontal and vertical measurements - front side of ItD system against manitor surface.

2. Elevator Roof Measurement

Horizontal Measurements - back side of TLD system against nouf surface. 
TABLE A-11

PRE-GROSS DECONTAMINATION EXPERIMENT RO-2A DOME MONITOR UEASUREMENTS

\begin{tabular}{|c|c|c|c|c|c|c|c|c|c|c|c|}
\hline \multirow[b]{2}{*}{$\begin{array}{l}\text { DATA } \\
\text { POINT }\end{array}$} & \multirow[b]{2}{*}{$\begin{array}{l}\text { VERIICAL } \\
\text { OR } \\
\text { IIOR IIUHTAL. }\end{array}$} & \multirow[b]{2}{*}{ MLASUREMENT DESCRIPIION } & \multicolumn{2}{|c|}{ RO-2A REAUINGS } & \multirow[b]{2}{*}{$\begin{array}{l}\text { DAIE } \\
\text { MFASUREMENT } \\
\text { IAKEN }\end{array}$} & \multirow{2}{*}{$\begin{array}{c}\text { RO-2A } \\
\text { SER IAL } \\
\vdots \\
\vdots\end{array}$} & \multicolumn{2}{|l|}{ INFORMATIOII } & \multicolumn{2}{|c|}{ DOSE RAIES } & \multirow[b]{2}{*}{ COMAENIS } \\
\hline & & & $\begin{array}{c}\text { OPEN WINDOH } \\
\text { MIR/LR. }\end{array}$ & $\begin{array}{l}\text { Closed } \\
\text { Window } \\
\text { IIR/lir. }\end{array}$ & & & FaL IBRATION & $\begin{array}{c}\text { BETA } \\
\text { FACTOA }\end{array}$ & $\begin{array}{c}r \\
\text { whehr. }\end{array}$ & $\begin{array}{c}\text { B } \\
\text { WR/hr. }\end{array}$ & \\
\hline $118-1$ & Norizontal & $\begin{array}{l}\text { Taken approx, I" from outside } \\
\text { surface of bucket. }\end{array}$ & 100 & 100 & $12 / 15 / 81$ & 681 & $1 / 22 / 82$ & 4.3 & 100 & $\therefore$ Batd. & $\begin{array}{l}\text { Plestic bucket orer munitor, Diase } \\
\text { readings through plastic lucke:. }\end{array}$ \\
\hline $118-2$ & Vertical & $\begin{array}{l}\text { Taken approx. I". from outside } \\
\text { surface of bucket. }\end{array}$ & 200 & 50 & $\mid 2 / 15 / 8\}$ & 681 & $1 / 22 / 82$ & 4.3 & so & 645 & $\begin{array}{l}\text { Plistic bucket over monitor, buse } \\
\text { reading through plastic bucket }\end{array}$ \\
\hline $118-3$ & Vertical & $\begin{array}{l}\text { laken approx. I" froin outs ide } \\
\text { surface of bucket. }\end{array}$ & 150 & 150 & $12 / 15 / 81$ & 681 & $1 / 22 / 82$ & 4,3 & iso & $\leq$ Bakd. & $\begin{array}{l}\text { Plistic bucket over monitor, Dose } \\
\text { reiding tllyoug! plastic bucket }\end{array}$ \\
\hline H8-4 & Vertical. & $\begin{array}{l}\text { Taken approx, } 1 " \text { from outside } \\
\text { surface of bucket. }\end{array}$ & 200 & 100 & $12 / 15 / 81$ & 681 & $1 / 22 / 82$ & 4.3 & 100 & 430 & $\begin{array}{l}\text { Plistic bucket over monitor, orse } \\
\text { reading through plastic bucket. }\end{array}$ \\
\hline $118-5$ & Vertical & $\begin{array}{l}\text { Taken approx. 1" from outside } \\
\text { surface of bucket. }\end{array}$ & NA & 150 & $12 / 15 / 81$ & 681 & $1 / 22 / 82$ & 4.3 & 130 & NA. & $\begin{array}{l}\text { Plistic bucket over monitor, } 0 \text { se } \\
\text { reading through plastic bucket. }\end{array}$ \\
\hline \multirow[t]{2}{*}{$118-6$} & \multirow[t]{2}{*}{ Horizontal } & $\begin{array}{l}\text { Instrument held approx, i" } \\
\text { from surface. }\end{array}$ & 1000 & 150 & $12 / .15 / 81$ & 681 & 1/22/82 & 4.3 & 150 & $36 \leq 5$ & \\
\hline & & $\begin{array}{l}\text { Instrument held opprox. } \\
3^{4} \text { from surface. }\end{array}$ & 150 & 150 & $12 / 15 / 8$ & 681 & 1/22/82 & 4.3 & 150 & $\subseteq$ Bakd. & - \\
\hline \multirow[b]{2}{*}{$118-7$} & \multirow[b]{2}{*}{ Horizontal } & $\begin{array}{l}\text { Instrument held approx, } \\
\text { i" from surface. }\end{array}$ & 1000 & 200 & $2 / 15 / 81$ & 681 & $1 / 22 / 82$ & 4.3 & 200 & 3440 & \\
\hline & & $\begin{array}{l}\text { Instrument held approx. } \\
\text { 3. from surface. }\end{array}$ & 100 & 50 & $2 / 15 / 81$ & 681 & $1 / 22 / 82$ & 4.3 & 50 & 170 & \\
\hline \multirow[b]{2}{*}{$118-8$} & \multirow[b]{2}{*}{ Horizontal } & $\begin{array}{l}\text { Instrument held approx. } \\
\text { i" from surface. }\end{array}$ & bno & 100 & $2 / 15 / 81$ & 681 & $1 / 22 / 82$ & 4.3 & 100 & 2150 & 1 \\
\hline & & $\begin{array}{l}\text { Instrument held approx: } \\
3^{*} \text { from surface. }\end{array}$ & 100 & 100 & $2 / 15 / 81$ & 681 & $1 / 22 / 82$ & 4.3 & 100 & $\leq$ Bard, & \\
\hline \multirow[b]{2}{*}{$118-9$} & \multirow[b]{2}{*}{ Hor |zontal } & $\begin{array}{l}\text { Instrument held approx. } \\
\text { i" from surface. }\end{array}$ & 1203 & 400 & $2 / 15 / 8 \mid$ & 681 & $1 / 22 / 82$ & 4.3 & 400 & 3443 & \\
\hline & & $\begin{array}{l}\text { Instrument held approx. } \\
3^{\circ} \text { from surface. }\end{array}$ & 200 & 150 & $12 / 15 / 81$ & 681 & $1 / 22 / 82$ & 4.3 & 153 & 215 & \\
\hline
\end{tabular}


TABIE A-12

PRE-GROSS DECONTAMINATION EXPERIMENT RO-2A MEASUREMENTS

\begin{tabular}{|c|c|c|c|c|c|c|c|c|c|c|c|c|}
\hline & & & $\cdot$ & $2 U-2 \pi$ & IDINLS & & RO-2 & I INFORMAT & IUN & DUSE RA & & \\
\hline & $\begin{array}{l}\text { DATA } \\
\text { POINT }\end{array}$ & $\begin{array}{l}\text { VIRTILAL } \\
\text { OR } \\
\text { IORIZOHTAL }\end{array}$ & MF.ASUREMENT OESCRIPTIUII & $\begin{array}{l}\text { OPEY } \\
\text { HINDOW } \\
\text { IIR/hr. }\end{array}$ & $\begin{array}{l}\text { CLOSED } \\
\text { WINDOH } \\
\text { IIR } / \mathrm{hr} \text {. }\end{array}$ & $\begin{array}{c}\text { DATE } \\
\text { MEASUREMEHT } \\
\text { TAKEN }\end{array}$ & SERIAL & $\begin{array}{c}\text { CAL IBILAI } \\
\text { ION } \\
\text { DATE }\end{array}$ & $\begin{array}{l}\text { BLTA } \\
\text { FAETOR }\end{array}$ & $\underset{n \in R / h r}{r}$ & $\begin{array}{c}\beta \\
n R / h r\end{array}$ & COMAEITS \\
\hline & 13 & Vertical & $1^{\prime \prime-1} 1 / 2^{\prime \prime}$ irom surface, $4^{\circ}$ flove & 340 & 350 & $12 / 9 / 81$ & 734 & kA & 3.5 & $\overline{350}$ & Bakd. & \\
\hline & 117 & Horizontal & $1 "-11 / 2 "$ fron surface & 300 & 400 & $12 / 9 / 81$ & 734 & NA & 3.5 & 400 & $\overline{140 . ?}$ & \\
\hline & 84 & Vertical & $\begin{array}{l}1 "-1 / 1 / 2 " \text { from surface, } \\
\text { Top of } \mathrm{JB}\end{array}$ & 250 & 220 & $12 / 9 / 81$ & 734 & MA & 3.5 & 220 & 105 & \\
\hline & v9 & Vertical & $\begin{array}{l}\text { T" } 172^{4} \text { froin surface, } \\
\text { 4" abuve floor }\end{array}$ & 500 & 400 & $12 / 9 / 81$ & 734 & MM & 3.5 & 400 & 350 & \\
\hline & H6 & Horizontal & $1 "=11 / 2^{\prime \prime}$ from surpace & $3,0 \mathrm{R} / \mathrm{ur}$ & $3,0 \mathrm{R} / \mathrm{hr}$ & $12 / 9 / 81$ & 734 & $\mathrm{MA}$ & 3.5 & $3.0 \mathrm{R} / \mathrm{hr}$ & bakd. & \\
\hline$\therefore$ & VB & Verticar & $\begin{array}{l}\text { "r-r } 1 / 2 \text { rom surface, } \\
4^{\circ} \text { above floor }\end{array}$ & 900 & 500 & $12 / 9 / 81$ & 734 & NA & 3.5 & 500 & 1400 & \\
\hline & 115 & Horizontal & $1 "=11 / 2^{\prime \prime}$ prom surface & $2,0 \mathrm{R} / \mathrm{hr}$ & 800 & $12 / 9 / 81$ & 134 & NA & 3.5 & 800 & 4200 & \\
\hline & v5 & Vertical & $\begin{array}{l}1 / 4^{n} \text { troni surtace, } \\
4^{1} \text { above floor }\end{array}$ & 175 & 150 & $12 / 9 / 81$ & 705 & $10 / 26 / 81$ & 4.1 & 150 & 103 & \\
\hline & $\mathrm{H}_{3}$ & Horizontal & $1 / 4$ " from surface & $2.0 \mathrm{R} / \mathrm{hr}$ & $1.5 \mathrm{R} / \mathrm{hr}$ & $12 / 9 / 81$ & 705 & $10 / 26 / 81$ & 4.1 & $1.5 \mathrm{R} / \mathrm{hr}$ & 2050 & \\
\hline & 83 & Vertical & 2"-4" from D-ring wal!, 4"be! ow JB & 450 & 375 & $12 / 9 / 81$ & 705 & $10 / 26 / 8$ & 4.1 & 375 & 308 & \\
\hline & v3 & Vertical & 1/4"-1/2" from surface, 4" aboye & 50 & 50 & $12 / 9 / 81$ & 681 & $\begin{array}{c}1 / 22 / 82 \\
\text { DUE }\end{array}$ & 4.3 & 50 & $\leq$ Bakd. & \\
\hline & v4 & Vertical & $1 / 4^{\prime \prime}-1 / 2^{\prime \prime}$ from surface, $4^{\circ}$ abpue & 100 & 75 & $12 / 9 / 81$ & 681 & $\begin{array}{c}1 / 22 / 82 \\
\text { DUE }\end{array}$ & A.3 & 75 & 108 & \\
\hline & $\overline{B 2}$ & Horizontal & $1 / 4^{\prime \prime}-1 / 2^{\prime \prime}$ from surface, top of $B$ & $132 / \mathrm{hr}$ & 150. & $12 / 9 / 81$ & 681 & $\begin{array}{l}1 / 22 / 82 \\
\text { DUE }\end{array}$ & 4.3 & 150 & 4945 & \\
\hline & m10 & Horizontal & $1 / 4^{4-1 / 2 " \text { from surface }}$ & 950 & 250 & $12 / 9 / 81$ & 681 & $\begin{array}{c}7 / 22 / 82 \\
\text { DUE }\end{array}$ & 4.3 & 250 & 3010 & \\
\hline 1. & 50w & Vertical & $14-11 / 2^{\prime \prime}$ from supface & 140 & 120 & $12 / 9 / 01$ & 681 & $\begin{array}{c}1 / 22 / 82 \\
\text { DUE }\end{array}$ & 4.3 & 120 & 86 & \\
\hline & 149 & Horizontal & 1"- 1 1/2" from surface & $10 \mathrm{R} / \mathrm{hr}$. & 200 & $12 / 9 / 81$ & 681 & $\underset{\text { DUE }}{1 / 22 / 82}$ & 4.3 & 200 & $42.1 R / h r$. & \\
\hline & 52 & llorizontal & $1 "-11 / 2^{4}$ from surface & 500 & 200 & $12 / 9 / 81$ & 681 & $\begin{array}{c}\text { T/22782 } \\
\text { DUE }\end{array}$ & 4.3 & 200 & 1290 & \\
\hline & v2 & Vertlcal & $\begin{array}{l}T^{\prime \prime}-T T / 2^{\prime \prime} \text { from surface, } \\
4^{\prime} \text { above floor }\end{array}$ & 140 & 120 & $12 / 9 / 81$ & 681 & $\begin{array}{c}1 / 22 / 02 \\
\text { DUE }\end{array}$ & 4.3 & 120 & 86 & \\
\hline & 01 & Itorizontal & 1" $-11 / 2 "$ from floor helow JB & 3.0R/hr. & 600 & $12 / 9 / 81$ & 681 & $\begin{array}{c}\text { T722782 } \\
\text { DUE }\end{array}$ & 4.3 & 600 & $10.3 R / h r$ & \\
\hline & 119 & Itorizontal & $1 "-1 \quad 1 / 2 "$ from surface & 1. 3R/hr. & $3 n 0$ & $12 / 9 / 111$ & 681 & $\begin{array}{c}1 / 22 / 82 \\
D U E\end{array}$ & 4.3 & 300 & $4.3 R / h r$. & \\
\hline & 54 & liorizontal & $1 "-11 / 2 "$ from surface & 250 & 130 & $12 / 9 / 81$ & 681 & $\begin{array}{c}\text { T/22/B2 } \\
\text { DUE }\end{array}$ & 4.3 & 130 & 516 & \\
\hline & 56 & Vertical & $\begin{array}{l}1^{\prime \prime}-11 / 2^{\prime \prime} \text { from surface. } \\
4^{\circ} \text { above floor }\end{array}$ & 100 & $3 n$ & $12 / 9 / 81$ & 681 & $\begin{array}{c}\text { TIZ2IU2 } \\
\text { DUE }\end{array}$ & 4.3 & 30 & 301 & \\
\hline & 63 & Horizontal & $1^{*}-11 / 2^{\prime \prime}$ from surface & $25 R / \mathrm{hr}$. & IOR/hr. & $12 / 9 / 81$ & 681 & $\begin{array}{c}1 / 22 / 82 \\
\text { OUf }\end{array}$ & 4.3 & $25 \mathrm{R} / \mathrm{hr}$ & $64.5 \mathrm{R} / \mathrm{hr}$. & \\
\hline$r$ & vil & Yertical & Taken perpendicular to surface & $1.2 \mathrm{R} / \mathrm{hr}$ & 650 & $12 / 9 / 81$ & 681 & $1 / 60 t^{82}$ & 4.3 & 650 & 2365 & \\
\hline
\end{tabular}


TABLE A-13

POST-GROSS DECONTAMINATION EXPERIMENT RO-2A MEASUREMENTS

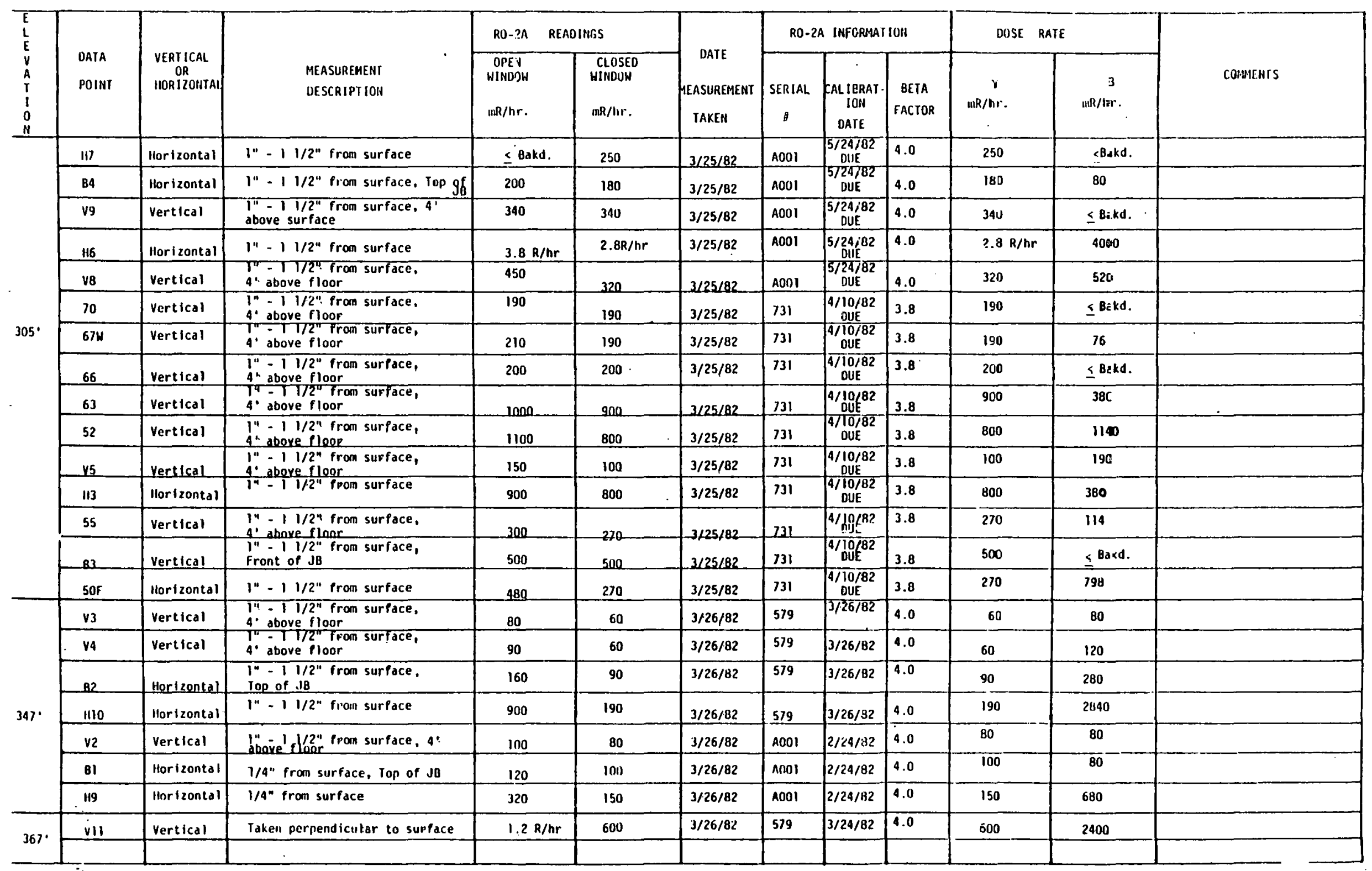


AIRBORNE DATA

Sampler locations for airborne concentration measurements are shown in Figures $A-9$ and $A-10$.

The airborne I-129, Cs-134, and Cs-137 concentrations were measured with a radioiodine molecular species sampler. The radioiodine sampler consisted of a particulate filter, a $\mathrm{CdI}_{2}$ media cartridge, an IPH media cartridge, and two charcoal cartridges in series. As the air was pulled through the sampler, the components selectively absorbed, respectively, particulate I-129, Cs-134, and Cs-137; elemental I-129 and HOI-129; and the organic forms of I-129. During the stated sampling periods for the reactor building basement environment and elevations $305^{\prime}$ and $347^{\prime}$, the deposition and absorption rates of the radionuclides were assumed to be constant. 
FIGURE A-9

FLOOR PLAN OF TMI-2 REACTOR BUILDING ELEVATION 305'

SHOWING SAMPLER LOCATIONS

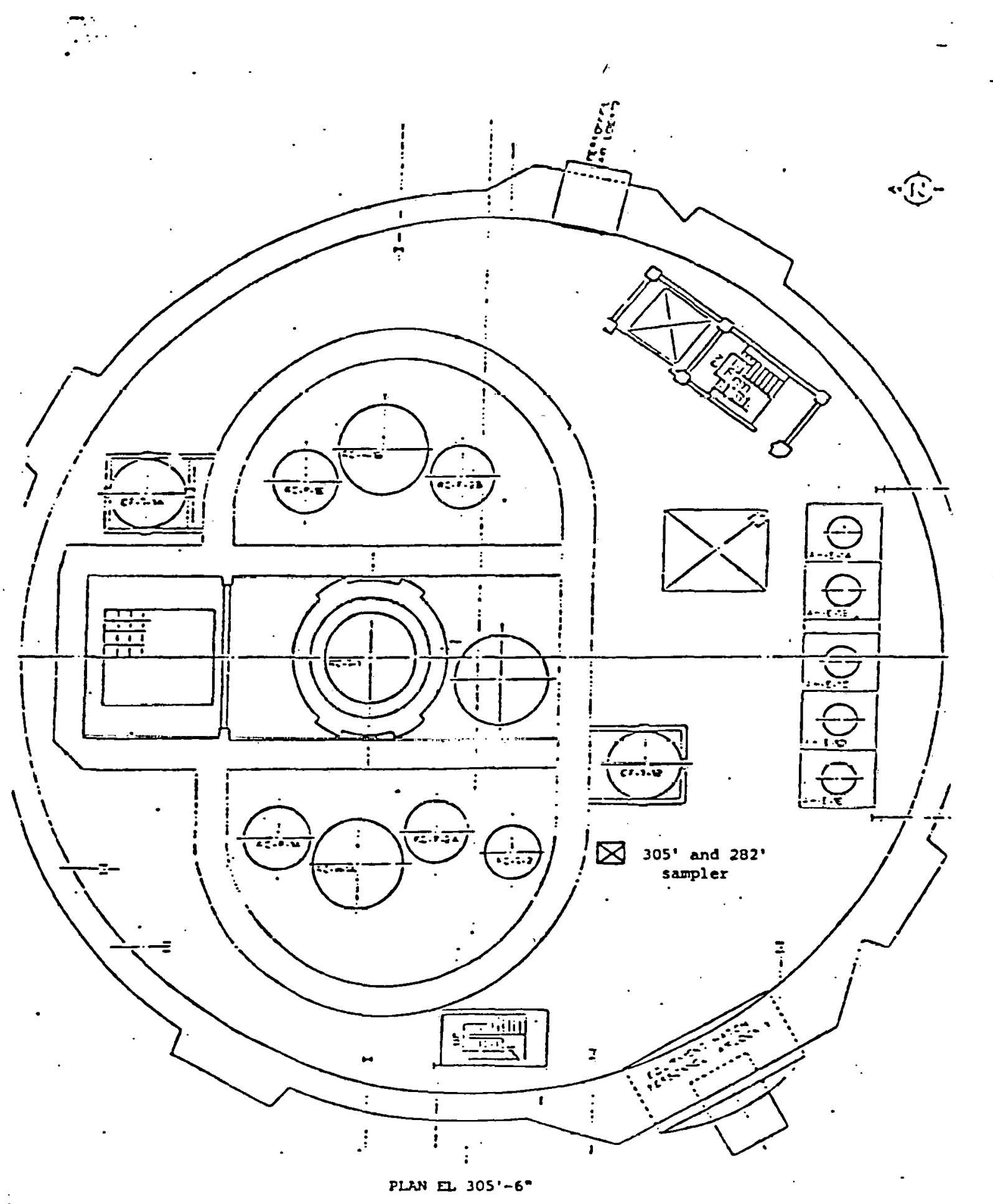


FIGURE A-10

FLOOR PLAN OF TMI-2 REACTOR BUILDING ELEVATION $347^{\prime}$

SHOWING SAMPLER LOCATION

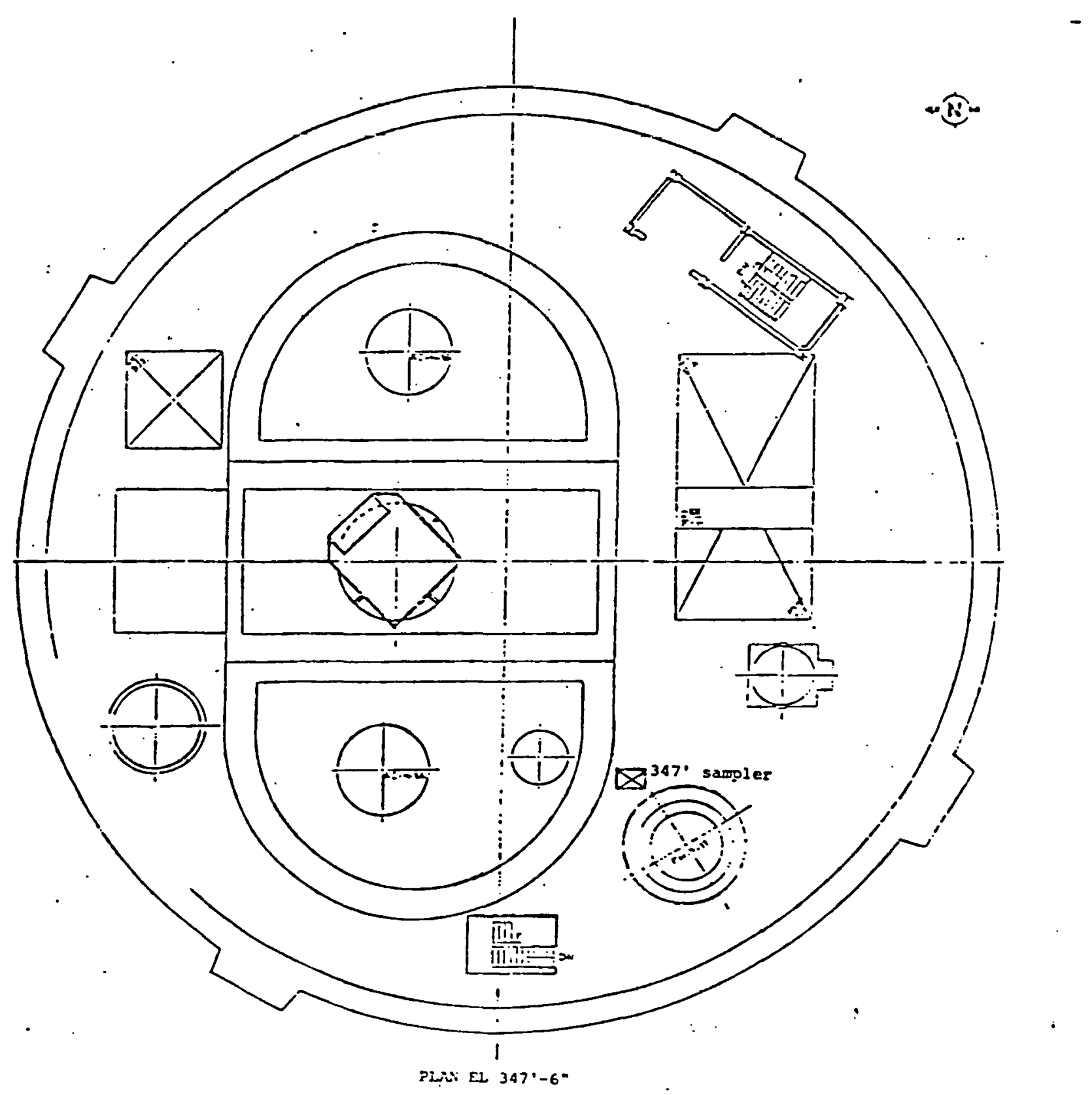


TABLE $\mathrm{A}-14$

GROSS DECONTAMINATION EXPERIMENT A_RBORNE CONCENTRATIONS OF I-129, Cs-134, and Cs-137

\begin{tabular}{|c|c|c|c|c|c|c|c|c|c|c|}
\hline \multirow[b]{2}{*}{ Elevation } & \multirow[b]{2}{*}{ Sailpling Period } & \multirow{2}{*}{$\begin{array}{l}\text { Sanuling } \\
\text { Time } \\
\text { (Hours) }\end{array}$} & \multirow{2}{*}{$\begin{array}{l}\text { Total Volune } \\
\text { Saupled } \\
\text { (cc) }\end{array}$} & \multirow{2}{*}{$\begin{array}{l}{ }^{134} \mathrm{C} \text {; Concentration } \\
\text { (IICi/cc) }\end{array}$} & \multirow{2}{*}{$\begin{array}{l}137 \mathrm{Cs} \text { Concentration } \\
(\mathrm{IICi} / \mathrm{cc})\end{array}$} & \multirow{2}{*}{$\begin{array}{l}1291 \text { Concentration } \\
(\mathrm{AC} \mathrm{C} / \mathrm{CC})\end{array}$} & \multicolumn{3}{|c|}{${ }^{129}($ Species $(i)$} & \multirow[b]{2}{*}{ Conments } \\
\hline & & & & & & & $I_{2}$ & IIUI & Organic & \\
\hline \multirow{6}{*}{$\begin{array}{c}281^{\prime} \\
\text { (Basement } \\
\text { Envi ronnen } t)\end{array}$} & $\begin{array}{ll}12 / 10 / 81 & 12 / 12 / 81 \\
0830 & 1045\end{array}$ & 50.25 & $5.91 \times 10^{7}$ & $5.4 \pm 0.2(-10)$ & $5.5 \pm 0.02(-09)$ & $6.9+0.9(-12)$ & 8 & 2 & 98 & Lucation Vucertain \\
\hline & $\begin{array}{|ll|}12 / 12 / 81 & 12 / 13 / 81 \\
1045 & 1730\end{array}$ & 30.75 & $3.03 \times 10^{7}$ & 1.610. (.11) & $1.7 \pm 0.1(.10)$ & $8.9 \pm 0.8(-12)$ & .5 & 11 & 89 & \\
\hline & \begin{tabular}{|l|l|}
$12 / 13 / 81$ & $12 / 15 / 81$ \\
1730 & 1500
\end{tabular} & 45.50 & $5.18 \times 10^{7}$ & $3: 910.2(-11)$ & $3.9+0.2(-10)$ & $8.3+0.8(-12)$ & 5 & 7 & 93 & \\
\hline & $\mid \begin{array}{ll}12 / 18 / 81 & 12 / 23 / 81 \\
1230 & 1035\end{array}$ & 118.00 & $1.39 \times 10^{8}$ & $1.1 \pm 0.1(-11)$ & $1.2 \pm 0.1(-10)$ & $2.0 \pm 0.2(-12)$ & 6 & 10 & 84 & \\
\hline & $\begin{array}{|ll|}12 / 23 / 81 & 12 / 29 / 81 \\
1035 & -0950\end{array}$ & 143.50 & $1.36 \times 10^{8}$ & $4.0 .0 .:(. .10)$ & $4.2 \pm 0.01(-9)$ & $1.5 \pm 0.2(.11)$ & 45 & 5 & 95 & \\
\hline & $\begin{array}{l}12 / 29 / 81+1 / 4 / 82 \\
0950^{2}+0900\end{array}$ & 143.00 & $1.63 \times 10^{8}$ & $3290.1(-11)$ & $4.0+0.04(-10)$ & $1.6 \pm 0.2(-11)$ & 2 & 2 & 96 & Location Uncertain \\
\hline \multirow{6}{*}{$305^{\circ}$} & $\frac{12 / 10 / 81}{0830}-12 / 12 / 81$ & 50.25 & $5.55 \times 10^{7}$ & 4. $1+0.1 \quad(-11)$ & $4.4 \pm 0.05(+10)$ & $3.2 \pm 0.4(-11)$ & $\mathbf{j}$ & 3 & 96 & \\
\hline & $\begin{array}{ll}12 / 12 / 81 & 12 / 13 / 81 \\
1045 & 1730\end{array}$ & 30.25 & $3.81 \times 10^{7}$ & 4. $0+0 . \geq(-1)\}$ & $4.0+0.1(+10)$ & $1.2 \pm 0.1(-11)$ & $<2$ & $<2$ & 100 & . \\
\hline & $\begin{array}{ll}12 / 13 / 81 & 12 / 15 / 81 \\
1730 & 1500\end{array}$ & 45.50 & $5.10 \times 10^{7}$ & $80,0.1(-11)$ & $8.6+0.2(-10)$ & $7.6+0.6(-12)$ & A & 9 & 92 & \\
\hline & \begin{tabular}{ll|}
$12 / 18 / 81$ & $12 / 23 / 81$ \\
1230 & 1035
\end{tabular} & 118.00 & $1.30 \times 10^{8}$ & $9.210 .1(-11)$ & $9.7 \pm 0.2(-10)$ & $4.1+0.4(-12)$ & $<5$ & 7 & 93 & \\
\hline & \begin{tabular}{|ll}
$12 / 23 / 81$ & $12 / 29 / 81$ \\
1035 & 0950
\end{tabular} & 143.50 & $1.78 \times 10^{8}$ & $6.910 .3(-12)$ & $7.1 \pm 0.2(-11)$ & $1.2+0.1(-11)$ & $\longleftrightarrow 2$ & 2 & $9 \mathrm{u}$ & \\
\hline & $\begin{array}{l}12 / 29 / 81 \\
0950\end{array} \tau_{0900}^{1 / 4 / 82}$ & 143.00 & $1.60 \times 10^{8}$ & $1.940 .2(-11)$ & $2.0 \pm 0.1(-10)$ & $2.3+0.2(-11)$ & $\mathbf{I}$ & 2 & 97 & \\
\hline \multirow{6}{*}{$347^{\prime}$} & $\begin{array}{ll}12 / 10 ; 81 & 12 / 12 / 81 \\
0830 & -1045\end{array}$ & 50.25 & $1.01 \times 10^{8}$ & $2.1+0.7(+10)$ & $2.2+0.1(-09)$ & $6.3 \pm 0.6(-12)$ & 43 & 7 & 93 & \\
\hline & $\begin{array}{|ll|}12 / 12 / 81 & 12 / 13 / 81 \\
1045 & 7730 \\
\end{array}$ & 30.75 & $7.00 \times 10^{7}$ & $39+0.4(-10)$ & $4.0 \pm 0.2(-09)$ & $1.6 \pm 0.2(-17)$ & $<\mathbf{J}$ & 4 & 96 & \\
\hline & \begin{tabular}{|l}
$12 / 13 / 81$ \\
1730
\end{tabular} & 45.50 & $9.74 \times 10^{7}$ & $37+0.4(-10)$ & $4.1+0.1(-09)$ & $5.4 \pm 0.3(-11)$ & 2 & 2 & 96 & \\
\hline & $\begin{array}{ll}12 / 18 / 81 \\
1230 & 12 / 23 / 81 \\
1035\end{array}$ & 118.00 & $2.36 \times 10^{8}$ & $45+00^{-}(-12)$ & $4.8 \pm 0.0 E(-11)$ & $1.0 \pm 0.1(-11)$ & 1 & 2 & 97 & Location Uncertuin \\
\hline & $\begin{array}{|ll|}12 / 23 / 81 & 12 / 29 / 81 \\
1035 & 0950 \\
\end{array}$ & 143.50 & $3.27 \times 10^{8}$ & $1.1+0.05(-10)$ & $1.1 \pm 0.06 \quad(-09)$ & $2.4 \pm 0.2(-11)$ & 1 & 1 & 98 & location Uncertain \\
\hline & $\begin{array}{l}12 / 29 / 81-1 / 4 / 82 \\
0950,1500\end{array}$ & 143.00 & $3.06 \times 10^{8}$ & $34+0 .:(-11)$ & $3.5 \pm 0.1(-10)$ & $1.9+0.2(-12)$ & 5 & 1 & 87 & \\
\hline
\end{tabular}




\section{DECONTAMINATION FACTORS}

The calculated decontamination factors based upon the surface deposition samples and TLD measurements are given in Scction IV. For each surface deposition sample location, the decontamination factor was determined by dividing the pre-mean cesium concentration by the post-mean cesium concentration at the same location. The .TLD-measured beta and gamma decontamination factors were determined by dividing the pre-experiment front or back dose rates by lhe posl-gross tront or back dose rates, respectively. 
TABLE A-15

ELEVATION 305' DECONTAMINATION FACTORS FOR THE GROSS DECONTAMINATION EXPERIMENT

\begin{tabular}{|c|c|c|c|c|}
\hline \multirow[t]{2}{*}{ Surface } & \multirow[t]{2}{*}{$\begin{array}{l}\text { Sample } \\
\text { Loca- } \\
\text { tion }\end{array}$} & \multirow[t]{2}{*}{ Location Description } & \multicolumn{2}{|c|}{$\begin{array}{l}\text { Decontamination } \\
\text { Factors }\end{array}$} \\
\hline & & & $C S-134$ & $C \leq-137$ \\
\hline \multirow{10}{*}{ 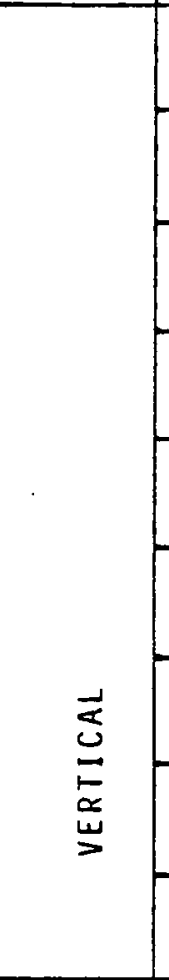 } & B4 & $\begin{array}{l}\text { Surface facing D-ring of } 4 \text { th I- } \\
\text { beam north of airlock } \# 2 \text {, about } 4 \text { ' } \\
\text { above the floor. }\end{array}$ & $9 \pm 6 E O$ & $9 \pm 6 E O$ \\
\hline & \multirow{2}{*}{$11 \mathrm{H}$} & \multirow{2}{*}{$\begin{array}{l}\text { 'B' D-ring wall about. 4' above the } \\
\text { floor, NE loeation. }\end{array}$} & $3 \pm 1 E 1$ & $2.6 \pm 0.8 E 1$ \\
\hline & & & $2.0 \pm 0.7 E 0$ & $1.4 \pm 0.5 \varepsilon 0$ \\
\hline & vg & $\begin{array}{l}\text { 'B' D-ring wall about 4' above } \\
\text { the floer. south side. }\end{array}$ & $5 \pm 2 E-1$ & $5 \pm 2 E-1$ \\
\hline & V8 & $\begin{array}{l}\text { North wall of aircooler ' } B \text { ' about } \\
4 \text { ' above the floor. }\end{array}$ & $3 \pm 2 E 0$ & $3 \pm 2 E 0$ \\
\hline & v7 & $\begin{array}{l}\text { North wall of aircooler ' } C \text { ' about. } \\
4 \text { ' above the floor. }\end{array}$ & $7 \pm 4 F-?$ & $7 \pm 4 \mathrm{E}-2$ \\
\hline & v6 & $\begin{array}{l}\text { North wall of aircooler ' } D \text { ' about } \\
4 \text { ' above the floor. }\end{array}$ & $1.0 \pm 0.7 \mathrm{EO}$ & $1.0 \pm 0.6 \mathrm{EC}$ \\
\hline & $46 \mathrm{~W}$ & $\begin{array}{l}\text { 'A' D-ring wall about } 4 \text { ' above } \\
\text { floor west of CFT 'B'. }\end{array}$ & $5 \pm 2 E-1$ & $5 \pm 1 E-1$ \\
\hline & 83 & $\begin{array}{l}\text { Metal plate on 'A' D-ring wall } \\
\text { west of CFT ' } 8 \text { ' }\end{array}$ & $1 \pm 1 E-1$ & $1 \pm 1 E-1$ \\
\hline & $67 W$ & $\begin{array}{l}\text { 'A' D-Ring wall about } 4 \text { ' above } \\
\text { floor, NW location. }\end{array}$ & $1.7 \pm 0.6 \mathrm{EO}$ & $1.6 \pm 0.5 \mathrm{EO}$ \\
\hline & $H 7$ & $\begin{array}{l}\text { rloor below NE corner of CTT 'A' } \\
\text { support structure. }\end{array}$ & $6 \pm 8 E_{1}$ & $6 \pm 8 E 1$ \\
\hline & $34 \mathrm{~F}$ & $\begin{array}{l}\text { Floor in front of aircooler ' } C^{\prime} \text {, } \\
6^{\prime} \text { from shield wall. }\end{array}$ & $8 \pm 4 E 1$ & $8 \pm 4 E_{1}$ \\
\hline & $50 F$ & Floor in front of equipment hatch. & $3 \pm 4 E O$ & $5 \pm 2 E 0$ \\
\hline & H3 & $\begin{array}{l}\text { Floor near drain by the open } \\
\text { stairwell. }\end{array}$ & $5 \pm 2 E 0$ & $5 \pm 2 E O$ \\
\hline$\sum_{0}^{\vdots}$ & $\mathrm{H} 2$ & $\begin{array}{l}\text { Floor near the open stairwell } \\
\text { entrance under welder. }\end{array}$ & $7 \pm 2 E-1$ & $7 \pm 2 E-1$ \\
\hline 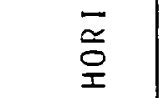 & $55 F$ & $\begin{array}{l}\text { Floor near the open stairwe!l } \\
\text { entrance by the containment wall }\end{array}$ & $9 \pm 3 E 0$ & $9 \pm 3 E 0$ \\
\hline & $70 F$ & Floor, NW sector. & $1.5 \pm 0.5 \mathrm{E} 1$ & $1.5 \pm 0.5 E 1$ \\
\hline
\end{tabular}


TABLE A-16

ELEVATION 347' DECONTAMINATION FACTORS FOR THE GROSS DECONTAMINATION EXPERIMENT

\begin{tabular}{|c|c|c|c|c|}
\hline \multirow[t]{2}{*}{ Surface } & \multirow{2}{*}{$\begin{array}{l}\text { Sample } \\
\text { Loca- } \\
\text { tion }\end{array}$} & \multirow[t]{2}{*}{ Location Description } & \multicolumn{2}{|c|}{$\begin{array}{l}\text { Decontamination } \\
\text { Factors }\end{array}$} \\
\hline & & & $C s-134$ & Cs -137 \\
\hline \multirow{8}{*}{ 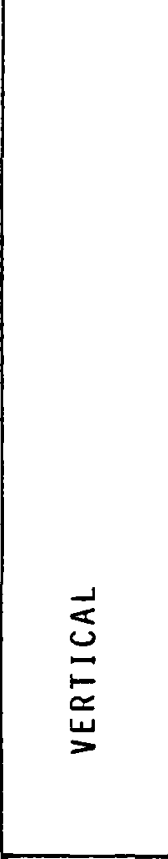 } & $31 \mathrm{w}$ & $\begin{array}{l}\text { 'B' D-ring wall about } 4 \text { 'above } \\
\text { floor, ESE location. }\end{array}$ & $4 \pm 2 E-1$ & $4 \pm 1 E-1$ \\
\hline & $34 W$ & $\begin{array}{l}\text { 'B" D-ring wall about } 4 \text { ' above } \\
\text { floor. ESE location. }\end{array}$ & $5 \pm 2 E-1$ & $6 \pm 2 E-1$ \\
\hline & $\sqrt{ } 4$ & $\begin{array}{l}\text { NW wall of enclosed stairwell } \\
\text { about } 4 \text { 'above floor }\end{array}$ & $1.0 \pm 0.4 \varepsilon 0$ & $1.0 \pm 0.3 E 0$ \\
\hline & $36 \mathrm{~W}$ & $\begin{array}{l}\text { 'B' D-ring wall about } 4 \text { ' above } \\
\text { floor, south side }\end{array}$ & $8 \pm 3 E-1$ & $8 \pm 2 E-1$ \\
\hline & $B 2$ & $\begin{array}{l}\text { Face of junction box on the south } \\
\text { wall of } B{ }^{\prime} D-r i n g .\end{array}$ & $1.0 \pm 0.7 E 0$ & $9 \pm 6 \varepsilon-1$ \\
\hline & v2 & $\begin{array}{l}\text { 'A' D-ring wall about } 4 \text { ' above } \\
\text { floor, near head storage stand. }\end{array}$ & $4 \pm 1 E-1$ & $4 \pm 1 \varepsilon-1$ \\
\hline & $50 \mathrm{~W}$ & $\begin{array}{l}\text { East vertical surface of head } \\
\text { storage stand }\end{array}$ & $4 \pm 1 E-1$ & $4 \pm 1 E-1$ \\
\hline & $16 \mathrm{~W}$ & $\begin{array}{l}\text { 'A' D-ring wall about 4' above } \\
\text { floor, NW side. }\end{array}$ & $1.5 \pm 0.5 \mathrm{EO}$ & $1.6 \pm 0.6 \mathrm{EO}$ \\
\hline \multirow{9}{*}{ 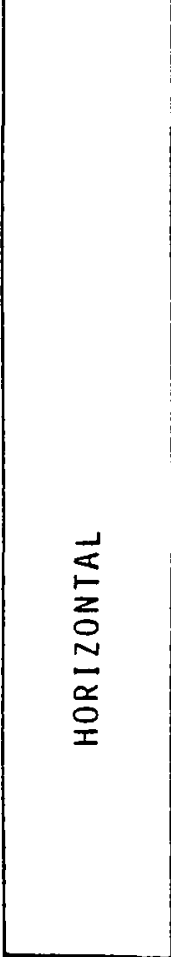 } & $33 F$ & Floor, NE sector & $1.1 \pm 0.4 \mathrm{E} 2$ & $1.1 \pm 0.4 E 1$ \\
\hline & $91 \mathrm{~F}$ & Floor, NE sector & $1.3 \cdot 0.8 E 9$ & $1.3 \pm 0.8 \mathrm{E}$ \\
\hline & $40 F$ & Covered hatch diamond plate & $1.0 \pm 0.5 \mathrm{E} 1$ & $1.0 \pm 0.5 E 1$ \\
\hline & $\mathrm{H} 1 \mathrm{O}$ & $\begin{array}{l}\text { Floor, SE of coolant pump and } \\
\text { motor'alignment stand }\end{array}$ & $2 \pm 1 E 1$ & $2 \pm 1 E 1$ \\
\hline & $149 \mathrm{~F}$ & $\begin{array}{l}\text { Floor, near south wall of 'A' } \\
\text { D-ring. }\end{array}$ & $6 \pm 4 E O$ & $7 \pm 4 E 0$ \\
\hline & $\vee 10$ & Floor, east of head storage stand & $4 \pm 1 E 0$ & $4 \pm 1 E 0$ \\
\hline & $54 F$ & $\begin{array}{l}\text { Floor, near open stairwell, SW } \\
\text { of its entrance. }\end{array}$ & $1.6 \pm 0.8 E 1$ & $1.6 \pm 0.85 i$ \\
\hline & H9 & Floor, south of open stairwell. & $1.4 \pm 0.5 \mathrm{E} 9$ & $1.4 \pm 0.4 \mathrm{E} 1$ \\
\hline & $115 \mathrm{~F}$ & $\begin{array}{l}\text { Floor, near floor drain in NW } \\
\text { sector. }\end{array}$ & $3.0 \pm 0.8 E 1$ & $2.9 \pm 0.8 \mathrm{E} 1$ \\
\hline
\end{tabular}


TABIE $\mathrm{A}-17$

ELEVATION $36 \%$ DECONTAMINATION FACTORS FOR THE GROSS DECONTAMINATION EXPERIMENT

\begin{tabular}{|c|c|c|c|c|}
\hline \multirow[t]{2}{*}{ Surface } & \multirow{2}{*}{$\begin{array}{l}\text { Sample } \\
\text { Loca- } \\
\text { tion }\end{array}$} & \multirow[t]{2}{*}{ Location Description } & \multicolumn{2}{|c|}{$\begin{array}{l}\text { Decontamination } \\
\text { Factors }\end{array}$} \\
\hline & & & $c=-134$ & $C_{5}-137$ \\
\hline $\begin{array}{l}\text { Verti- } \\
\text { cal }\end{array}$ & 22 I $B$ & $\begin{array}{l}\text { South surface of RC-P-2A support } \\
\text { l-beam (2nd beam from south) }\end{array}$ & $2 \pm 1 E 0$ & $2 \pm 1 E 0$ \\
\hline \multirow{3}{*}{ 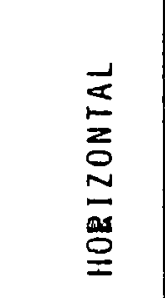 } & $26 \mathrm{~F}$ & $\begin{array}{l}\text { Walkway on top of 'A' D-ring } \\
\text { wall, Nii location }\end{array}$ & $8 \pm 2 E-1$ & $1.0 \pm 0.3 E 0$ \\
\hline & $\mathrm{HI}$ & $\begin{array}{l}\text { Walkway on top of 'A' } D-r i n g \text { wall, } \\
\text { SW location. }\end{array}$ & $2.8 \pm 0.8 \mathrm{EO}$ & $2.8 \pm 0.8 \mathrm{EO}$ \\
\hline & I & $\begin{array}{l}R L-F-2 A \text { supjort } 1 \text { - vedils, top } \\
\text { surface (2nd beam from sollth). }\end{array}$ & $1.3 \pm 0.7 E_{1}$ & $1.5 \pm 0.8 E 1$ \\
\hline
\end{tabular}


ELEVATION 305' GROSS DECONTAMINATION EXPERIMENT DECONTAMINATION OR CONTAMINATION FACTORS BASED UPON THE TLD MEASUREMENTS

\begin{tabular}{|c|c|c|c|c|c|c|c|c|c|c|c|c|c|c|}
\hline \multirow{3}{*}{$\begin{array}{l}\text { Sample } \\
\text { Locat Ion }\end{array}$} & \multirow{3}{*}{$\begin{array}{c}\text { Verifical } \\
\text { or } \\
\text { Horizontal }\end{array}$} & \multicolumn{4}{|c|}{ Pre Dose Rates } & \multicolumn{4}{|c|}{ Past Dose Rates } & \multicolumn{4}{|c|}{ Decontaninaticn or Conismination factors } & \multirow{3}{*}{ Comments } \\
\hline & & \multicolumn{2}{|c|}{ B } & \multicolumn{2}{|c|}{$r$} & \multicolumn{2}{|c|}{$B$} & \multicolumn{2}{|c|}{$\gamma$} & \multicolumn{2}{|c|}{. } & \multicolumn{2}{|c|}{1} & \\
\hline & & $\begin{array}{l}\text { Front } \\
\text { mR/hr. }\end{array}$ & $\begin{array}{l}\text { Back } \\
\text { mR/hr. }\end{array}$ & $\begin{array}{l}\text { Front } \\
m R / / 1 r .\end{array}$ & $\begin{array}{l}\text { Back } \\
\text { mR/hr. }\end{array}$ & $\begin{array}{l}\text { Front } \\
\text { nit:/hr. }\end{array}$ & $\begin{array}{l}\text { Back } \\
\text { arR/hr. }\end{array}$ & $\begin{array}{l}\text { Front } \\
m R / h r .\end{array}$ & $\begin{array}{l}\text { Back } \\
\text { mil/hr. }\end{array}$ & Frent & Back & Fruint & Back & \\
\hline 13 & Vertical & NA & HA & 623 & 664 & 15 & 8 & 202 & 203 & NA & NA & $\begin{array}{l}\text { of } \\
3.08\end{array}$ & $\begin{array}{l}\text { of } \\
3.27\end{array}$ & \\
\hline H7 & Ilorizontal & 158 & 920 & 426 & 468 & 230 & 122 & 228 & 240 & $\begin{array}{l}\text { CF } \\
1: 46\end{array}$ & $\begin{array}{l}\text { DF } \\
7.54 \\
\end{array}$ & $\begin{array}{l}\text { of } \\
1.87\end{array}$ & $\begin{array}{l}\mathrm{DF} \\
1.95 \\
\end{array}$ & \\
\hline 84 & Vertical & 474 & 133 & 156 & 158 & 6523 & 75 & 387 & 338 & $\begin{array}{l}\text { CF } \\
13.76\end{array}$ & $\begin{array}{l}\text { PF } \\
1.77\end{array}$ & $\begin{array}{l}\text { CF } \\
2.48\end{array}$ & $-\quad \begin{array}{l}\text { CF } \\
2.14\end{array}$ & \\
\hline v9 & Vertical & 244 & 36 & 571 & 553 & 133 & NA & 353 & 340 & $\begin{array}{l}\text { DF } \\
1.83\end{array}$ & NA & 1.62 & PF .63 & \\
\hline 116 & Horizontal & 6882 & $14.9 \mathrm{R} / \mathrm{hr}$ & 2242 & 2635 & NA & 699 & 2927 & 2763 & นA & $\begin{array}{l}\text { DFF } \\
21.32\end{array}$ & $\begin{array}{l}\text { CF } \\
i .31\end{array}$ & $\begin{array}{l}\text { Cf } \\
1.05\end{array}$ & \\
\hline v8 & Vertical & 110 & 146 & 577 & 573 & 91 & 249 & 332 & 328 & $\begin{array}{l}\text { DF } \\
1.21\end{array}$ & $\begin{array}{l}\text { CF } \\
1.71\end{array}$ & $\begin{array}{l}\text { DF } \\
1.74\end{array}$ & $\begin{array}{l}\text { DF } \\
1.75\end{array}$ & \\
\hline $67 \mathrm{~W}$ & Vertical & NA & NA & 287 & 267 & 9 & .4 & 155 & 149 & HA & NA & $\begin{array}{l}\text { DF } \\
1.85\end{array}$ & $\begin{array}{l}\mathrm{DF} \\
1.79\end{array}$ & \\
\hline 63 & Vertical & 174 & 554 & 1448 & 1323 & 47 & 193 & 775 & 716 & $\begin{array}{l}\text { DF } \\
3.70\end{array}$ & $\begin{array}{l}\text { DF } \\
2.87\end{array}$ & $\begin{array}{l}\text { DF } \\
1.87\end{array}$ & $\begin{array}{l}\text { DF } \\
1.065\end{array}$ & \\
\hline 113 & Horizontal & NA & 7194 & 5177 & 5462 & 230 & 3675 & 535 & 523 & HA & $\begin{array}{l}\text { DF } \\
2.12\end{array}$ & $\begin{array}{l}\text { Of } \\
9.68\end{array}$ & $\begin{array}{l}\text { DF } \\
10.44\end{array}$ & \\
\hline B3 & Vertical & 671 & 597 & HA & 386 & $32 !$ & 231 & 262 & 275 & $\begin{array}{l}\mathrm{DF} \\
\therefore .11\end{array}$ & $\begin{array}{l}\mathrm{DF} \\
2.58\end{array}$ & HA & $\begin{array}{l}\mathrm{DF} \\
1.40\end{array}$ & \\
\hline $50 \mathrm{~F}$ & Horlzontal & 303 & 5010 & 411 & 408 & 357 & 508 & 275 & 251 & $\begin{array}{l}\mathrm{CF} \\
0.85\end{array}$ & $\begin{array}{l}\text { DF } \\
9.86\end{array}$ & $\begin{array}{l}\mathrm{DF} \\
1.49\end{array}$ & $\begin{array}{l}\text { of } \\
\text { i. } 63 .\end{array}$ & \\
\hline
\end{tabular}


TABLE $A-19$

EIEVATIONS 347' AND 367' GROSS DECONTAMINATION EXPERIMENT DECONTAMINATION FACTORS BASED UPON THE TLD MEASUREMENT i

\begin{tabular}{|c|c|c|c|c|c|c|c|c|c|c|c|c|c|c|c|}
\hline \multirow{3}{*}{ Elevation } & \multirow{3}{*}{$\begin{array}{c}\text { Sample } \\
\text { Location }\end{array}$} & \multirow{3}{*}{$\begin{array}{l}\text { Vertical } \\
\text { or } \\
\text { Horizontal }\end{array}$} & \multicolumn{4}{|c|}{ Pre Dose Rales } & \multicolumn{4}{|c|}{ Post Dose Rates } & \multicolumn{4}{|c|}{ Vecont am: nat ion factors } & \multirow{3}{*}{ Comments } \\
\hline & & & \multicolumn{2}{|c|}{ B } & \multicolumn{2}{|c|}{ r } & \multicolumn{2}{|c|}{ a } & \multicolumn{2}{|c|}{$\gamma$} & \multicolumn{2}{|c|}{ B } & \multicolumn{2}{|c|}{ r } & \\
\hline & & & $\begin{array}{l}\text { Front } \\
\mathrm{mf} / \mathrm{hr} \text {. }\end{array}$ & $\begin{array}{c}\text { Back } \\
m R / h r .\end{array}$ & $\begin{array}{l}\text { Fmont } \\
\text { int/hr. }\end{array}$ & $\begin{array}{l}\text { Bacx } \\
\text { mP/far. }\end{array}$ & $\begin{array}{l}\text { Front } \\
\text { InR/hr. }\end{array}$ & $\begin{array}{l}\text { Back } \\
\text { mR/hr. }\end{array}$ & $\begin{array}{l}\text { Froit } \\
\mathrm{mR} / \mathrm{ir} \text {. }\end{array}$ & $\begin{array}{l}\text { Back } \\
\text { mPR/hr. }\end{array}$ & Front & Back & Front & Back & \\
\hline \multirow{12}{*}{$347^{\prime}$} & 30 & Vertical & 70 & 25 & $a$ & 86 & $2 \hat{\imath}$ & 1 & ? & $5 y$ & 3.18 & 6.25 & 1.56 & 1.46 & \\
\hline & $3 I H$ & Vertifal & 215 & 64 & $\subseteq$ & 91 & 145 & 25 & 65 & 60 & 1.48 & 2.56 & 1.43 & 1.52 & \\
\hline & v3 & Vertical & 75 & 19 & 66 & 47 & 10 & NA & 46 & 47 & 7.50 & MA & 1.43 & 1.00 & \\
\hline & v4 & Vertical & 60 & 57 & 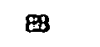 & 87 & 51 & 37 & 65 & 63 & 1.18 & 1.51 & 1.35 & 1.38 & \\
\hline & $36 \mathrm{~W}$ & Vertical & 125 & 14 & 118 & 119 & 24 & 4 & 56 & 52 & 5.21 & 3.50 & 2.11 & 2.29 & \\
\hline & HIO & Horizontal & 223 & 3852 & 241 & 264 & 104 & 1614 & 167 & 124 & 2.14 & 2.39 & 1.44 & 2.13 & \\
\hline & 5ow & Vertical & 368 & 147 & 132 & 121 & 127 & 9 & 107 & 108 & 2.90 & 16.73 & 1.23 & 1.12 & \\
\hline & 52 & llorizontal & 345 & 1665 & 143 & 141 & 113 & 556 & 70 & 70 & 15 & 2.99 & 2.11 & 2.01 & \\
\hline & v2 & Vertical & $13 i$ & 26 & 121 & 122 & 44 & 10 & 76 & 77 & 3.11 & 2.60 & 1.63 & 1.58 & \\
\hline & 81 & Ilorizontal & 624 & $11.2 \mathrm{R} / \mathrm{hr}$ & 45.3 & 453 & 42 & 26 & 108 & 97 & 14.86 & 430.77 & 4.24 & 4.67 & \\
\hline & 119 & Ilorizontal & 522 & 6282 & 200 & 264 & 92 & 783 & 127 & 136 & 5.67 & 8.02 & 2.20 & 1.94 & \\
\hline & 56 & Vertical & 63 & 32 & 84 & 79 & 23 & 14 & 50 & 50 & 2.74 & 2.29 & 1.60 & 1.50 & \\
\hline \multirow{2}{*}{367} & 13 & Horizontal & 407 & 7943 & 330 & 372 & 127 & 3014 & 204 & 231 & 3.20 & 2.68 & 1.62 & 1.61 & \\
\hline & vil & Vertical & 178 & 573 & 763 & 741 & 72 & 329 & 535 & 570 & 2.47 & 1.74 & 1.43 & 1.30 & \\
\hline
\end{tabular}


SECTION $V$

RO-2A AND TLD COMPARISONS

Table A-20 compares the contamination measurements of the RO-2A and TLD methods. 
TABLE A-20

PRE-GROSS DECONTAHINATION EXPERIMENT RO-2A AND OLD COMPARISONS

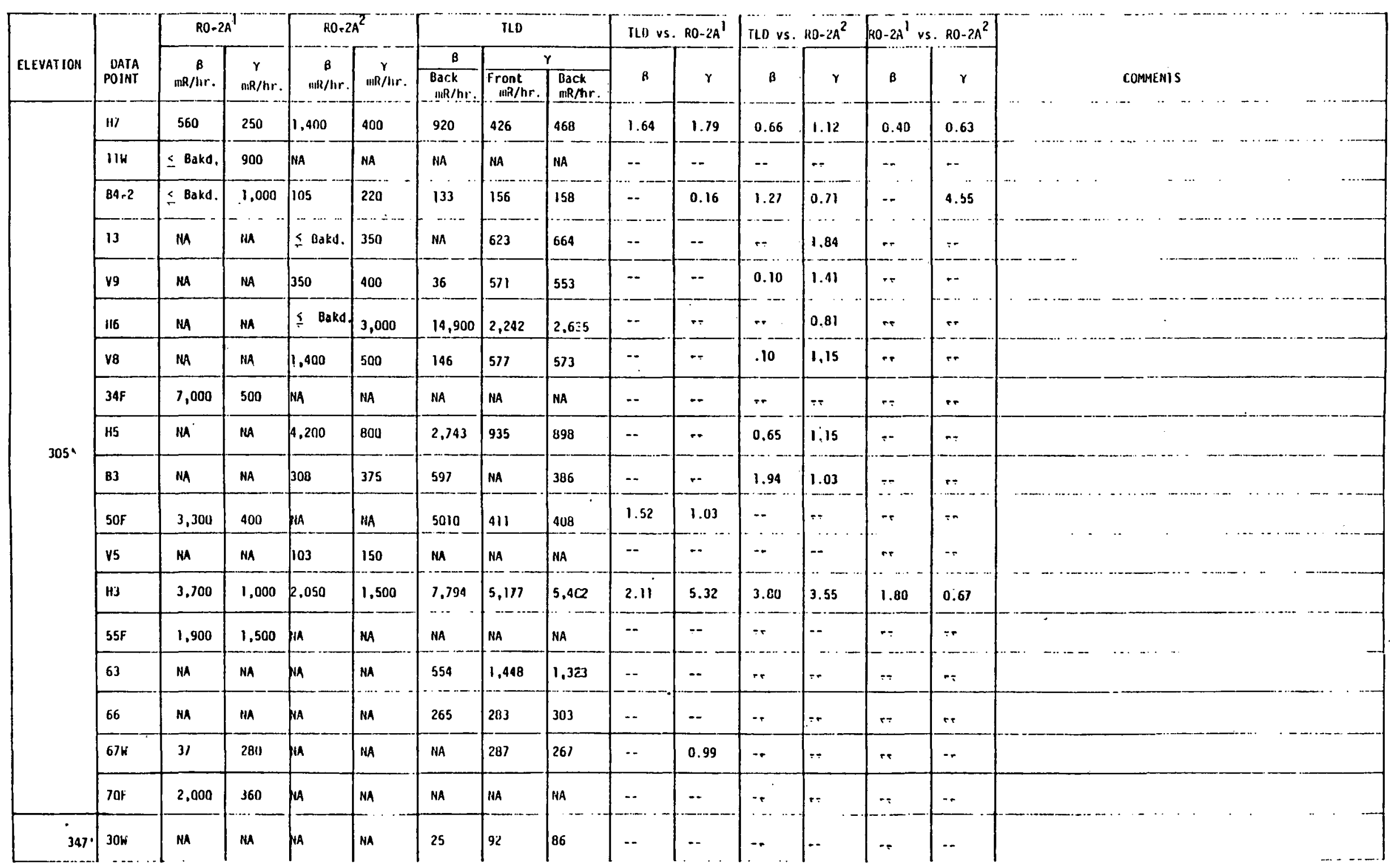


TABLE A-20 (Continued)

PRE-GROSS DECONTAMINATION EXPERIMENT RO-2A AND TLD COMPARISONS

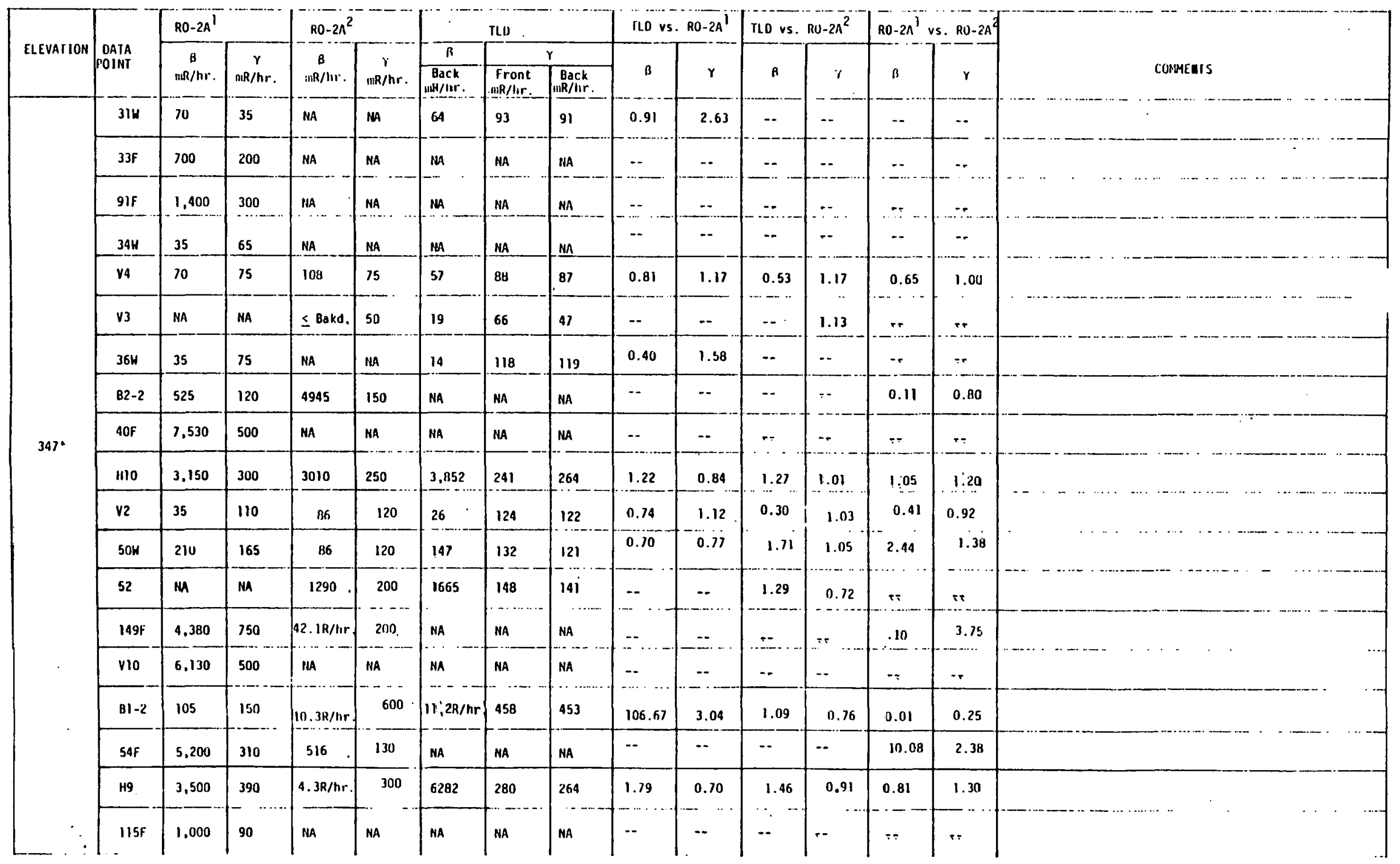


TABLE A-20 (Eontinied)

PRE-GROSS DECONTAMINATION EXXPERI:IENT RJ-2A AND TID COMPARISONS

\begin{tabular}{|c|c|c|c|c|c|c|c|c|c|c|c|c|c|c|c|}
\hline \multirow{3}{*}{ LLEVATION } & \multirow{3}{*}{$\begin{array}{l}\text { DAIA } \\
\text { POINT }\end{array}$} & \multicolumn{2}{|c|}{$R 0-2 A^{\prime}$} & \multicolumn{2}{|c|}{$\mathrm{RO}=2 \mathrm{~A}^{2}$} & \multicolumn{3}{|c|}{ ILO } & \multicolumn{2}{|c|}{ ILD vs. K0-2A' } & \multicolumn{2}{|c|}{110 Ys, RU $-2 A^{2}$} & \multicolumn{2}{|c|}{$B O-2 A^{\prime}$ VS. $B O-2 A$} & \multirow{3}{*}{ COMMEITSS } \\
\hline & & B & $r$ & G & $r$ & 3 & & & & & & & & & \\
\hline & & $\mathrm{mR} / \mathrm{hr}$. & $\mathrm{mll} / \mathrm{hr}$. & mkihr. & unth/wr. & Oa=k & $\begin{array}{l}\text { Pront } \\
\text { mo/hr. }\end{array}$ & $\begin{array}{l}\text { Back } \\
\text { miRilir. }\end{array}$ & B & $\gamma$ & $B$ & $\gamma$ & $B$ & $\begin{array}{c}1 \\
- \\
-\end{array}$ & \\
\hline \multirow{3}{*}{$347^{4}$} & 56 & $\mathrm{HA}$ & NA & 301 & .30 & $3 ?$ & 80 & 79 & $-\cdot$ & -- & 0.11 & 2.65 & $\because$ & -. & \\
\hline & $16 \mathrm{~N}$ & 123 & 45 & MA & III & $M$ & NA & NA & -. & .. & 3.88 & 0.70 & $\because$ & .. & \\
\hline & 63 & $M$ & MA & $64.5 \mathrm{R} / \mathrm{hr}$ & $10 R / h r$. & $25: 3 \mathrm{R} / \mathrm{hr}$ & 7857 & 6092 & -- & -- & 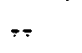 & 0.28 & $\cdots$ & $\because$ & \\
\hline \multirow{6}{*}{367.} & 13 & NA & MA & MA & $\mathrm{MA}$ & 7343 & 330 & 372 & -- & -- & - & $\div$ & +- & -- & \\
\hline & vil & MA & in & 2365 & 650 & 573 & 763 & 741 & -- & $-\div$ & 0,24 & 1.16 & $-r$ & +- & \\
\hline & $26 \%$ & 770 & 280 & NA & NA & 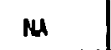 & NA & NA & -- & $\cdots$ & $\div$ & $r$ & $\cdots$ & $r$ & \\
\hline & HI & 2,030 & 290 & $\mathrm{HA}$ & MA & 14 & IIA & NA & -- & $\because$ & .. & $r$ & $\because$ & -- & \\
\hline & 1 & 4.300 & 270 & $N A$ & NA & $M$ & NA & NA & -. & $\because$ & -- & $r$ & $\therefore-$ & - & \\
\hline & 2218 & 158 & 325 & M & NA & M & NA & NA & -- & -- & -- & $r$ & $\cdots$ & -- & • \\
\hline \multirow{9}{*}{$372^{4}$} & H8-1 & $M A$ & MA & $\leq$ Bakd. & 100 & 131 & 48 & 67 & $-\cdot$ & 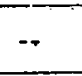 & $\div-$ & 0.56 & $=-$ & $r$ & $\begin{array}{l}\text { RO-2A }{ }^{2} \text { measurements done for DOME Monftor Hork. } \\
\text { I" prom surface. }\end{array}$ \\
\hline & H8-2 & $M A$ & NA & 645 & 50 & 1305 & 551 & 605 & -- & $\cdot \cdot$ & 2.95 & 11.56 & $\cdots$ & + & $\begin{array}{l}\text { R0-2A readings done for DOME Monitor Work. } \\
\text { I" fron subface }\end{array}$ \\
\hline & H8-3 & MA & NA & $\leq$ 8akd. & 150 & 14 & 155 & 166 & -- & -- & $\because$ & 1.07 & -- & $\because$ & $\begin{array}{l}\text { RO-2A readings done for DOME Monitor Work. } \\
I^{1 "} \text { Prom surface }\end{array}$ \\
\hline & $118-4$ & $\mathrm{MA}$ & NA & 430 & 100 & M & 113 & 137 & -- & - & -- & 1.25 & $-r$ & -- & $\begin{array}{l}\text { RO- } 2 A^{2} \text { readings done for DOME Monitor Hork, } \\
\text { I" from surface }\end{array}$ \\
\hline & $110-5$ & MN & MA & NA & 150 & 33 & 137 & 155 & -- & $-\cdot$ & -- & 0.97 & $\because$ & $-\infty$ & $\begin{array}{l}\text { RO } 2 \mathrm{~A}^{2} \text { readings done for DOME Monitor Hork. } \\
\mathrm{I}^{4} \text { from surface }\end{array}$ \\
\hline & $118-6$ & 2,500 & 400 & 3555 & 150 & 3726 & 390 & 431 & 1.49 & 1,03 & 1.02 & 2.74 & 0.68 & 2.67 & $\begin{array}{l}\text { RO-2A readiugs done for DOME Monitor Hork, } \\
1 \text { I" from surface. RO-2A not same location iLO \& Ho-2 }\end{array}$ \\
\hline & $118-7$ & 2,500 & $40 n$ & 3400 & 200 & 3216 & 397 & 428 & 1.29 & 1.03 & 0.93 & 2,06 & 0.73 & 2.00 & $\begin{array}{l}\text { R0-2A reading, done for DOME Monitor Wurk, } 1 " \text { from } \\
\text { surface. } R O-2 A^{2} \text { not same location ILO \& RO-2A }\end{array}$ \\
\hline & $118-8$ & NA & MA & 2150 & 100 & $4 ? 65$ & 379 & 439 & -- & - & 1,99 & 4.09 & -- & - & $\begin{array}{l}\text { R0- } 2 A^{-2} \text { reading done for DOME Monitor Work, } \\
1 \text { fron surface }\end{array}$ \\
\hline & H8-9 & MA & NA & 3440 & 400 & 12R/hr & 638 & 778 & $\cdots$ & -- & 3.49 & 1.71 & -- & -- & $\begin{array}{l}\text { RO-2A }{ }^{2} \text { readings done for DOME Monitur Work, } \\
I^{4} \text { from surface }\end{array}$ \\
\hline
\end{tabular}


TABLE A-20 (Continued)

POST-GROSS DECONTAMINATION EXPERIMENT RO-2A AND TLD COMPARISONS

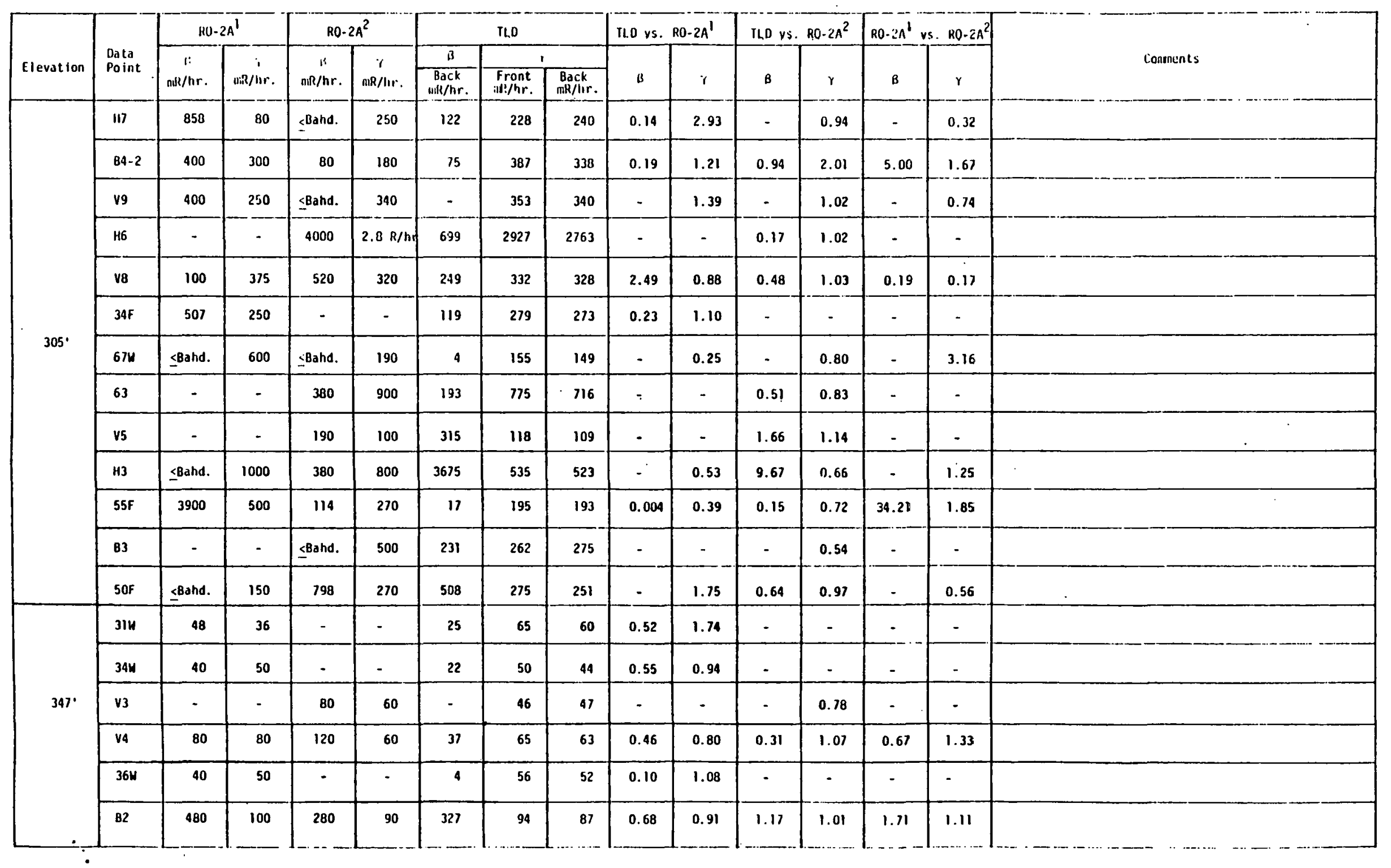


T.9BLE A-20 (Continued)

POST-GROSS DECONTAMINATION EXPERIMENT RO-2A AND TLD COMPARTSONS

\begin{tabular}{|c|c|c|c|c|c|c|c|c|c|c|c|c|c|c|c|}
\hline \multirow{3}{*}{ Elevation } & \multirow{3}{*}{$\begin{array}{l}\text { Data } \\
\text { Point }\end{array}$} & \multicolumn{2}{|c|}{$R 0-2 A^{\prime}$} & \multicolumn{2}{|c|}{$R 0-2 A^{2}$} & \multicolumn{3}{|c|}{ TLO } & \multicolumn{2}{|c|}{ TLO VS. RO-2A } & \multicolumn{4}{|c|}{$T L O$ vs. $R O-2 A^{2}$ RRA- $2 A^{\prime}$ vs.. $R 0-2 A^{2}$} & \multirow{3}{*}{ Comments } \\
\hline & & \multirow{2}{*}{$\begin{array}{c}\text { u } \\
\mathrm{mR} / \mathrm{hr} .\end{array}$} & \multirow{2}{*}{$\mathrm{n} \mathrm{R}^{\prime} / \mathrm{hr}$. } & \multirow{2}{*}{$M R^{B} / \mathrm{hr}$. } & \multirow{2}{*}{$\stackrel{\gamma}{\gamma / h r .}$} & \multicolumn{3}{|c|}{$r$} & \multirow[b]{2}{*}{$\beta$} & \multirow[b]{2}{*}{$r$} & \multirow[b]{2}{*}{ B } & \multirow[b]{2}{*}{$r$} & \multirow[b]{2}{*}{ e } & \multirow[b]{2}{*}{$r$} & \\
\hline & & & & & & $\begin{array}{l}\text { Back } \\
\text { ilR/hr. }\end{array}$ & $\begin{array}{c}\text { Front } \\
\text { unk } / \mathrm{hr} \text {. }\end{array}$ & $\begin{array}{l}\text { Ba 涼 } \\
\mathrm{mR} \cdot \mathrm{hr} \text {. }\end{array}$ & & & & & & & \\
\hline \multirow{5}{*}{$347^{\circ}$} & 1110 & 1287 & 150 & 2840 & 190 & 1614 & 167 & 214 & 1.25 & 1.27 & 0.57 & 1.00 & 3.45 & 0.79 & \\
\hline & $50 \mathrm{~W}$ & 80 & 100 & - & - & 9 & 107 & 108 & 0.11 & 1.08 & - & - & - & - & \\
\hline & v2 & 40 & 10 & 80 & 80 & 10 & 76 & .7 & 0.25 & 1.09 & 0.13 & $0: 96$. & 0.50 & 0.88 & \\
\hline & BI & 160 & 100 & 80 & 100 & 26 & 108 & 97 & 0.16 & 1.03 & 0.33 & 1.03 & 2.00 & 1.00 & \\
\hline & H9 & - & - & 680 & 150 & 783 & 127 & $1: 6$ & - & - & 1.15 & 0.88 & - & - & \\
\hline $367^{\circ}$ & vil & - & - & 2400 & 600 & 329 & 535 & $5: 0$ & - & - & 0.14 & 0.92 & - & - & \\
\hline
\end{tabular}




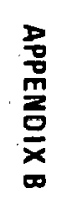

DO NOT MICROFILM THIS PAGE. 
APPENDIX B

EQUIPMENT 
CONTENTS

EQUIPMENT PROCUREMENT

B-1

MAJOR EQUIPMENT OPERATIONS

$\mathrm{B}-4$

EQUIPMENT SPECIFICATIONS

$\mathrm{B}-8$

PHOTOGRAPHS

\section{TABLES}

B-1 Elevation 305' Low Pressure Flush

$\mathrm{B}-10$

B-2 Polar Crane Low Pressure Flush

B-11

B-3 D-Rings, Missile Shields, Refueling Canal, and Service Structure Low Pressure Flush

B- 12

B-4 Elevation 347'-6" Low Pressure Flush

B-13

B-5 Elevation 347'-6" High Pressure Flush

B-14

B-6 Elevation 305' High Pressure Flush

B- 15

B-7 Pressure, Flow, and Temperature Adjustment

B- 16 


\section{APPENDIX B - EQUIPMENT}

\section{EQUIPMENT PROCUREMENT}

The purpose of this section is to describe the administrative system used to identify, procure, and track equipment during the decontamination experiment, to list problems encountered during the experiment, and to describe the planned and implemented improvements made to the procurement system since the end of the decontamination experiment.

\section{Equipment Procurement System}

The procurement system uscd during the decontamination experiment was fairly simple. The engineers identified equipment items necessary to perform specific work tasks and gave equipment requirements to the equipment engineer along with a need date for each item. The equipment engineer then had three options for procuring the items: (a) draw the item from stock on site, (b) fabricate the item on site, or (c) purchase the item from an offsite vendor. Either the equipment engineer or the equipment expediter, provided by Catalytie, would then complete the appropriate form, depending on the chosen procurement option (material requisition, work authorization, or purchase requisition form). Once an item arrived on site, it was delivered to a location specified by the requesting engineer for use.

The equipment tracking system used was also fairly simple. A chronological log of equipment items ordered (from on site or off site) was kept, which listed for each item: description of item, number ordered, number received of total requested, and number still on order. This system was later modified to include the purchase order number for each piece of equipment. 
Most of the problems encountered with this system were associated with the administrative tracking of orders or the physical tracing of equipment.

- Equipment items were not tracked in logical major groups, such as National Liquid Blasting Company (NLB) pump and associated equipment, spin jet and hydrolance and associated equipment, air and water hoses, etc. This made it difficult to trace exactly which items had been procured and to identify the purpoce of oome itemo. The procurcment list eventually became long and unwieldy, which also made the tracing of equipment difficult and occasionally led to the duplication of orders. Tracking by major groups would have eased this problem.

- The equipment engineer did not keep a file of purchase orders and corresponding material received forms. This led to an equipment accountability problem. It was also difficult to assess the status of orders without a complete file of purchase orders indicating what was ordered, when it was ordered, and when it was expected.

o The lack of either a central equipment storage area or an equipment storage location $\log$ led to accountability problems as well as operational problems. Often, the equipment that could not be traced through the existing paperwork tracking system could not be physically located. This resulted in duplicate orders and made it difficult to find equipment on short notice. Searching for equipment nul unly hejt valuable workers busy, but frequently delayed training and entries.

o The equipment tracking system did not track the equipment used for entries. This meant that no records were kept as to what equipment went into and out of the containment or where used equipment was stored, sent for decontamination, or sent for repair. This led to the duplication of many small tool items. 
- Failure of minor or major parts of major equipment, such as the NLB pump, spin jet, and hydrolances, was not anticipated early in the program. Thus, replacement parts were occasionally required on an emergency basıs. I'his delayed training activities and entries.

\section{$\underline{\text { Planned Improvements }}$}

Most of the equipment tracking problems experienced during the decontamination experiment could be solved by implementing additional administrative control, as follows:

- Place group equipment orders into logical categories. Record on the order log the following information:

- Purchase order number

- Item description/quantity

- Purchase order issuance date

- Material received date

o Keep each purchase order and material received form in a file.

o Notify the equipment engineer of equipment needs as early as possible.

- Keep a master storage $\log$ as to where each piece of equipment is stored. This should be grouped into logical categories as above.

o Collect and store all equipment items required for each work package together for use during mock-up training and during the entry. This requires a dedicated staging area. 
- Purchase each piece of major equipment with a complete set of manufacturer's recommended replacement parts.

\section{MA.JOR EQUIPMENT OPERATIONS}

This section describes major pieces of equipment used in the decontamination experiment, and some of the specific mechanical problems encountered in uperalium. The major equipmenl used was the NLB high pressure pump, water heater, spin jet, and hydrolance.

\section{NLB 10150 Liquid Blasting Pump and Instantaneous \\ Water Heater}

The NLB high pressure water pump system consisted of a water supply source Lu the NLB pump, the Instantaneous hot water heater and NLB pump, recirculation and drain lines from the NLB pump back to the water supply source, and supply lines from the NLB pump to containment penetration R-501 and into the containment (see Figures $\mathrm{B}-1$ and $\mathrm{B}-2$ ). The system is intended to supply a reliable source of pressurized, processed water to the liquid blaster equipment inside the containment building. The water will range in flow rate from 5 to $25 \mathrm{gpm}$, in temperature between 70 and $180 \mathrm{~F}$, and in pressure between 1,000 and 10,000 psig. Water from the containment processed through the submerged demineralizer system (SDS) and the EPICOR system (process water) was used for the decontamination experiment. However, the process water contained tritium and therefore was treated as a radioactive liquid. Figure B-3 shows the decontamination experiment water system circulation.

This system was, on the whole, very dependable throughout the decontamination experiment. However, several problems were encountered.

o Rupture Disk

As the pump system used contaminated process water, the rupture disk was a potential source of radioactive water release, and therefore 
needed to be connected to a drain line and routed to a contaminated drain.

The rupture disk was located in an inconvenient spot on the pump, and a 6-inch extension pipe was needed to connect a drain line around the rupture disk. The installation of the 6-inch pipe, however, led to the rupture disk blowing at 5000 to 6000 psig below its rated value. It was determined that this was due to harmonic oscillations produced in the pipe by the water flowing past the pipe (see figure below).

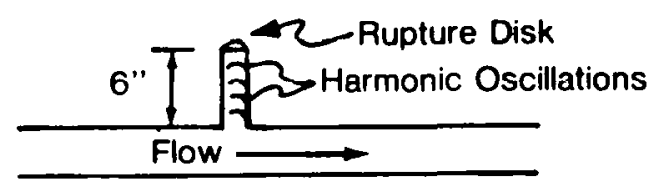

This problem was solved by replacing the 6-inch pipe with a 50-foot rubber hose that damped the oscillations before they reached the rupture disk.

It should be noted that the need for providing a contained drainage path for the rupture disk was identified at a late date in the experimental planning.

- Pulsation Dampener

A weld between the pulsation dampener and the NLB pump discharge began to leak. The pulsation dampener was removed and replaced with a straight pipe until a new unit could be supplied by the vendor. Before the new dampener arrived, an administrative limit of 4000 psig was placed on the pump operation. 
- Leaks

Several points in the pump system developed leaks:

- Solenoid operated damp valve - The solenoid was removed after causing some electrical problems, and the valve was made manual.

Manual dame valve - develuped packlng leaks

- Reliet valve - developed packing leaks

- Flowmeters in thè supply and drain lines - developed gas jet leaks

o Hot Water Heater

The hot water heater was designed to produce water up to $140 \mathrm{~F}$ at $25 \mathrm{gpm}$. System temperatures, as measured at the heater, averaged about $120 \mathrm{~F}$, temperatures as measured at the pump storage tank averaged about $110 \mathrm{~F}$, and temperatures at the hydrolance or spin jet averaged about $100 \mathrm{~F}$. The desired temperature of $140 \mathrm{~F}$ at the spin jet. or hydrolance was never rearhed.

\section{Spin Jet and Hydrolance}

\section{$\underline{\text { Spin Jet }}$}

- The water seal on the rotating nozzles developed leaks and needed replacement. The leaks were probably caused by operation of the nozzle rotational motor without water flow provided to the seal.

o The hand-operated water supply trigger assembly on both spin jet units failed after use during training and had to be replaced. In both these cases, the loss of the spin jet units delayed personnel training activitics. 


\section{Hydrolance}

- The trigger assemblies on several lances failed and were stuck partially open both during training and in-containment. Water was shul off using the manual safety valve on the lance.

o The lances, as shipped from NLB, were deemed ton short by site safety personnel because of the potential for the lance operator to shoot his foot during high pressure flushing. To accommodate the safety department's requésl, Lle sliurl Lip lances were replaced with longer tips, thus minimizing the accident potential.

In addition to the equipment for major operations of the experiment, a mechanical scrubber and wet vacuum system were tested in a small area. The mechanical scrubber was a 20-inch-diameter Clark industrial buffer with a 3-gallon-capacity liquid dispenser. The rotor was operated at less than $200 \mathrm{rpm}$ to prevent excessive splatter.

The wet vacuum system consisted of three drums, pickup, and air hoses. A particulate filter was in the intake drum, and one drum contained a high efficiency particulate adsorber (HEPA) filter. The waste drum was modified to dump directly into a drain to keep the radiation levels at a minimum.

\section{Command Center}

The command center contained the control functions for entry into the reactor building with positions for safety, radiological engineering, operations, entry coordinator, and command center management. The center had provisions for videotaping, audio recording, communication, video cameras, and direct lines with the personnel, facilities, and functions necessary to control an entry. 
The equipment used in the decontamination experiment was specified by the engineers associated with each task. The technical data pertaining to the equipment are summarized below.

\section{NLB High Pressure Pump and Instantaneous Water Heater}

- Model No. 10150E

o 460-volt, 3-phase power

- 0 to $25 \mathrm{gpm}$ flow rate

o .70 to $180 \mathrm{~F}$ water temperacure

- Up to 10,000 psig pressure

o Purchase cost $-\$ 59,485$

\section{NLB High Pressure Spin Iet}

- Spin Jet Floor Cleaner

- Model No. 1100E-24

- 110-volt, single phase power

- Flow rate dependent upon nozzle

- Up to 10,000 psig

-. Purchase cost - $\$ 54,185$ 
- Hydrolance

- Model No. NCG-300-1 by NLB

- Flow rate dependent upon nozzle

- Up to 10,000 psig

- Purchase cost - $\$ 7475$

- High pressure hose

- Model No. WP4 by NT.B

- Inside diameter - 0.5 inch

- Outside diameter - 1.10 inches

- 40,000 psi burst pressure rating

- Purchase cost - \$6500 for 1200 feet

Losses due to hoses, lances, and nozzles for each area were determined for varying flow rates in order to find the required pump pressure to deliver desired pressure at the nozzle. These flow rates and pressures are summarized by area in Tables B-1 through B-6. During each operation, pump pressures, water temperatures, and water flow rates were monitored and recorded on a $10 \mathrm{~g}$ sheet (see Table B-7) by the pump operator. Readings were taken every 15 minutes or whenever the pump started and stopped. 


\section{TABLE B-1. ELEVATION $305^{\circ}$ LOW PRESSURE FLUSH}

\begin{tabular}{|c|c|c|c|c|c|}
\hline \multirow[b]{2}{*}{ Area } & \multirow[b]{2}{*}{ Temperature } & \multirow[b]{2}{*}{ Rate } & \multicolumn{2}{|c|}{ Pressure } & \multirow[b]{2}{*}{ Nozzle } \\
\hline & & & No Flow & Flow & \\
\hline Misting & . & & & & \\
\hline I LP & Ambient & $20 \mathrm{gpm}$ & 5100 psig & 4900 psig & 0020 \\
\hline IT LP & Ambient & $20 \mathrm{gpm}$ & 5400 psig & 5200 pэig & 0020 \\
\hline T.LI LP & Ambient & $20 \mathrm{gpm}$ & $5400 \mathrm{psig}$ & 5200 psig & 0020 \\
\hline IV LP & Ambient & $20 \mathrm{gpm}$ & 5600 psig & $5400 \mathrm{psig}$ & 0020 \\
\hline \multicolumn{6}{|c|}{ Flushing } \\
\hline$T$ TAP & Ambient & $15 \mathrm{gpm}$ & 1800 psig & 1600 psig & 0050 \\
\hline TT T.P & $140 \mathrm{~F}$ & $25 \mathrm{gpm}$ & $4200 \mathrm{psig}$ & 4000 psig & 0050 \\
\hline III LP & Ambient & $25 \mathrm{gpm}$ & 4200 psig & 4000 psig & 0050 \\
\hline IV LP & $140 \mathrm{~F}$ & $15 \mathrm{gpm}$ & $2100 \mathrm{psig}$ & 1900 psig & 0050 \\
\hline
\end{tabular}


TABLE B-2. POLAR CRANE LOW PRESSURE FLUSH

\begin{tabular}{|c|c|c|c|c|c|}
\hline \multirow[b]{2}{*}{ Area } & \multirow[b]{2}{*}{ Temperature } & \multirow[b]{2}{*}{ Flow Rate } & \multicolumn{2}{|c|}{ Pressure } & \multirow[b]{2}{*}{ Nozzle } \\
\hline & & & No Flow & Flow & \\
\hline Misting & Ambient & $20 \mathrm{gpm}$ & 7000 psig & 6800 psig & 0020 \\
\hline I PCL & Ambient & $25 \mathrm{gpm}$ & 5700 psig & 5500 psig & 0050 \\
\hline II PCL & $140 \mathrm{~F}$ & $25 \mathrm{gpm}$ & 5700 psig & 5500 psig & 0050 \\
\hline
\end{tabular}


TABLE B-3. D-RINGS, MISSILE SHIELDS, REFUELING CANAL, AND SERVICE STRUCTURE LOW PRESSURE FLUSH

\begin{tabular}{|c|c|c|c|c|c|}
\hline \multirow[b]{2}{*}{ Area } & \multirow[b]{2}{*}{ Temperature } & \multirow[b]{2}{*}{ Flow Rate } & \multicolumn{2}{|c|}{ Pressure } & \multirow[b]{2}{*}{ Nozzle } \\
\hline & & & No Flow & Flow & \\
\hline Misting & Ambient & 20. gpm & 6500 psig & 6300 psig & 0020 \\
\hline Flushing & Ambient & $25 \mathrm{gpm}$ & 5000 psig & 4800 psig & 0050 \\
\hline
\end{tabular}


TABLE B-4. ELEVATION 347'-6" LOW PRESSURE FLUSH

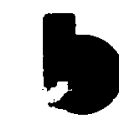

\begin{tabular}{|c|c|c|c|c|c|}
\hline \multirow[b]{2}{*}{ Area } & \multirow[b]{2}{*}{ Temperature } & \multirow[b]{2}{*}{ Flow Rate } & \multicolumn{2}{|c|}{ Pressure } & \multirow[b]{2}{*}{ Nozzle } \\
\hline & & & No Flow & Flow & \\
\hline LP & Ambient & $20 \mathrm{gpm}$ & 5400 psig & $5200 \mathrm{psig}$ & 0020 \\
\hline I LP & Ambient & $20 \mathrm{gpm}$ & 5800 psig & 5600 psig & 0020 \\
\hline II LP & Ambient & 20 gpm & 5800 psig & 5600 psig & 0020 \\
\hline $111 \mathrm{LP}$ & Ambient & $20 \mathrm{gpm}$ & 6100 psig & 5900 psig & 0020 \\
\hline lushing & & & & & \\
\hline LP & Ambient & 15 gpm & 2000 psig & 1800 psig & 0050 \\
\hline I LP & $140 \mathrm{~F}$ & $25 \mathrm{gpm}$ & 4700 psig & $4500 \mathrm{psig}$ & 00.50 \\
\hline II LP & Ambient & $25 \mathrm{gpm}$ & 4700 psig & 4500 psig & 0050 \\
\hline III LP & $140 \mathrm{~F}$ & $15 \mathrm{gpm}$ & 2400 psig & 2200 psig & 0050 \\
\hline
\end{tabular}


TABLE B-5. ELEVATION 347'-6" HIGH PRESSURE FLUSH

\begin{tabular}{|c|c|c|c|c|c|c|}
\hline \multirow[b]{2}{*}{ Area } & \multirow[b]{2}{*}{ Temperature } & \multirow{2}{*}{\multicolumn{2}{|c|}{ Flow Rate }} & \multicolumn{2}{|c|}{ Pressure } & \multirow[b]{2}{*}{ Nozzle } \\
\hline & & & & No Flow & Flow & \\
\hline \multicolumn{7}{|l|}{ I HP } \\
\hline Spin Jet & $140 \mathrm{~F}$ & 15 & gp̣m & 3300 psig & 3100 psig & (4) 非2506 \\
\hline Hydrolance & Ambient & 10 & $\mathrm{gpm}$ & 2600 psig & 2400 psig & 非 2510 \\
\hline \multicolumn{7}{|l|}{ II HP } \\
\hline Spin Jet & Ambient & 5 & gpm & 4600 psig & 4400 psig & (4) 非 2502 \\
\hline Hydrolance & Ambient & 10 & $\mathrm{gpm}$ & 2600 psig & 2400 psig & 非2510 \\
\hline \multicolumn{7}{|l|}{ III HP } \\
\hline Spin Jet & $140 \mathrm{~F}$ & 5 & gpm & 2600 psig & 2400 psig & (4) 非2502 \\
\hline Hydrolance & Ạmbient & 10 & gpm & 2600 psig & 2400 psig & 非 2510 \\
\hline IV HP. & & & & 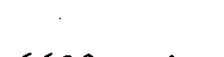 & & \\
\hline Spin Jet & Ambient & 5 & $\mathrm{gpm}$ & $6600 \mathrm{psig}$ & 6400 psig & (4) 非 2502 \\
\hline Ilydrolance & Ambient & 10 & $\mathrm{gpm}$ & $2600 \mathrm{psig}$ & $2400 \mathrm{psig}$ & 非 2510 \\
\hline \multicolumn{7}{|l|}{ V HPP } \\
\hline Spin Jet & Ambient & 25 & $\mathrm{gpm}$ & 8210 psig & 8000 psig & (4) 非2.506 \\
\hline Hydrolance & Ambient & 10 & gPm & $2600 \mathrm{psig}$ & $2400 \mathrm{psig}$ & 非 2510 \\
\hline \multicolumn{7}{|l|}{ VI HP } \\
\hline Spin Jet & Ambient & 25 & gpm & 6500 psig & 6300 psig & (4) 非2506 \\
\hline Hydrolance & Ambienl & 10 & gpm & 2700 psig & 2500 psig & 非 2510 \\
\hline \multicolumn{7}{|l|}{ VII HP } \\
\hline Spin Jet & $140 \mathrm{~F}$ & 25 & gpm & 4500 psig & 4300 psig & (4) 非2510 \\
\hline Hydrolance & Ambient & 10 & gpm & 2700 psig & 2500 psig & $\$ 2510$ \\
\hline \multicolumn{7}{|l|}{ VIII HP } \\
\hline Spin Jet & Ambient & 15 & $\mathrm{gpm}$ & $7400 \mathrm{psig}$ & $\begin{array}{l}7200 \text { psig } \\
2500 \text { psig }\end{array}$ & 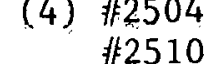 \\
\hline Hydrolance & Anibient & 10 & gpm & 2700 psig & & 372010 \\
\hline \multicolumn{7}{|l|}{ IX HP } \\
\hline Spin Jet & Ambient & 15 & gpm & 5500 psig & 5300 psig & (4) 非 2504 \\
\hline Hydrolance & Ambient & 10 & gpm & 2800 psig & 2600 psig & 非 2510 \\
\hline
\end{tabular}


TABLE B-6. ELEVATION 305' HIGH PRESSURE FLUSH

\begin{tabular}{|c|c|c|c|c|c|c|}
\hline \multirow{2}{*}{ Area } & \multirow[b]{2}{*}{ Temperature } & \multirow[b]{2}{*}{ Flow } & \multirow[b]{2}{*}{ Rate } & \multicolumn{2}{|c|}{ Pressure } & \multirow[b]{2}{*}{ Nozzle } \\
\hline & & & & No Flow & Flow & \\
\hline \multicolumn{7}{|l|}{$\mathrm{X}$ HP } \\
\hline Spin Jet & $140 \mathrm{~F}$ & 15 & gpm & 2900 psig & 2700 psig & (4) 非2506 \\
\hline Hydrolance & Ambient & 10 & $\mathrm{gpm}$ & 2500 psig & 2300 psig & 非 2510 \\
\hline \multicolumn{7}{|l|}{ XI HP } \\
\hline Spin Jet & $140 \mathrm{~F}$ & 15 & gpm & 3500 psig & 3300 psig & (4) 非2510 \\
\hline Hydrolance & Ambient & 10 & gpm & 2500 psig & 2300 psig & 非 2510 \\
\hline \multicolumn{7}{|l|}{ XII HP } \\
\hline Spin Jet & Ambient & 15 & gpm & 8000 psig & 7800 psig & (4) 非2506 \\
\hline Hydrol ance & Ambient & 10 & $\mathrm{gpm}$ & 2600 psig & 2400 psig & 非 2510 \\
\hline
\end{tabular}


TABLE B-7. PRESSURE, FLOW, AND TEMPERATURE ADJUSTMENT

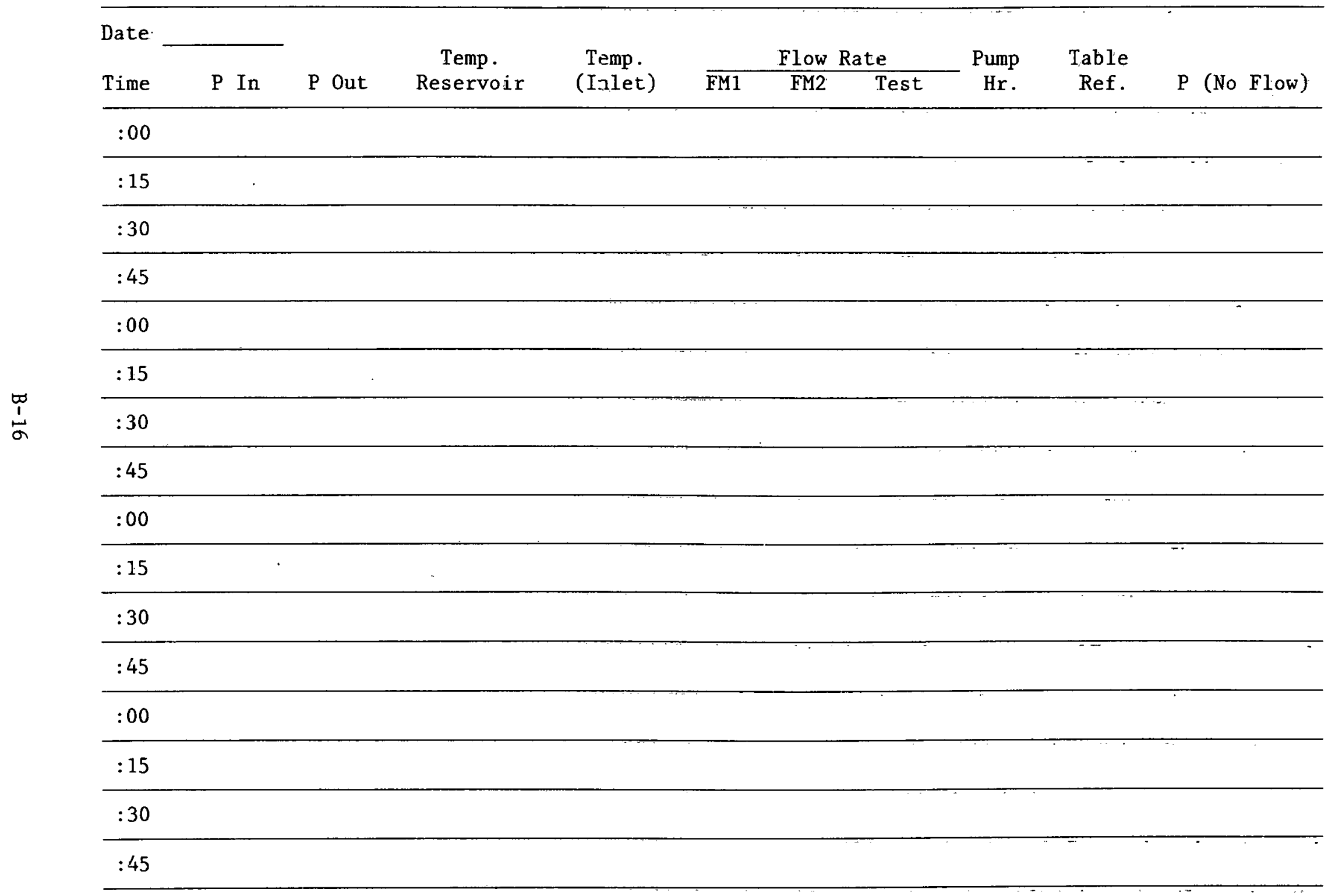




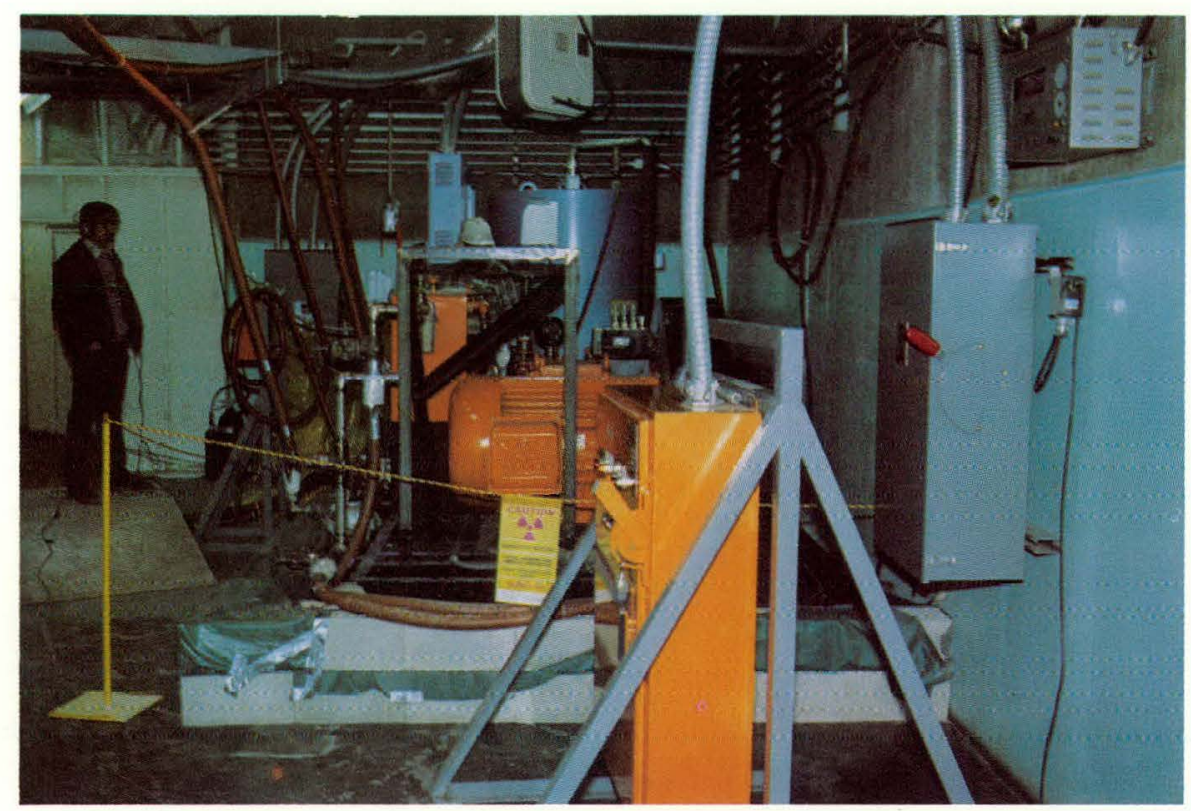

Figure B-1. Pump equipment layout.

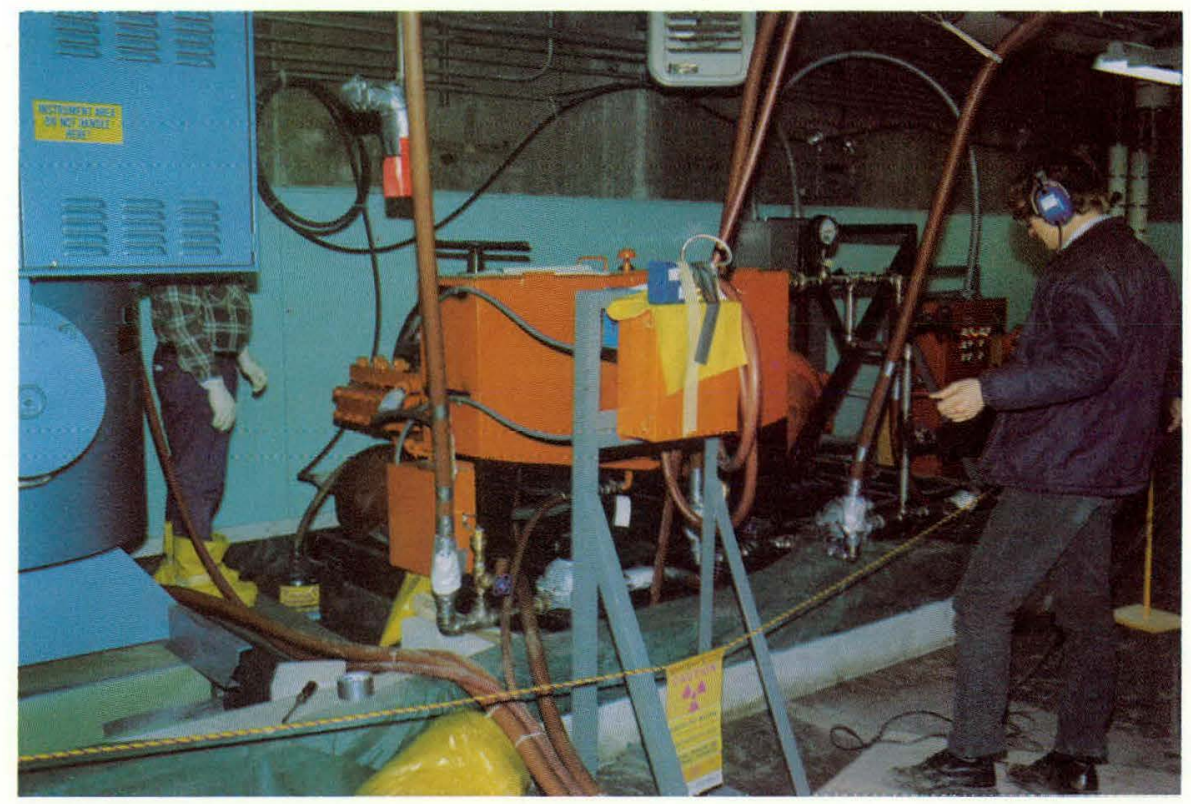

Figure B-2. Pump equipment layout. 


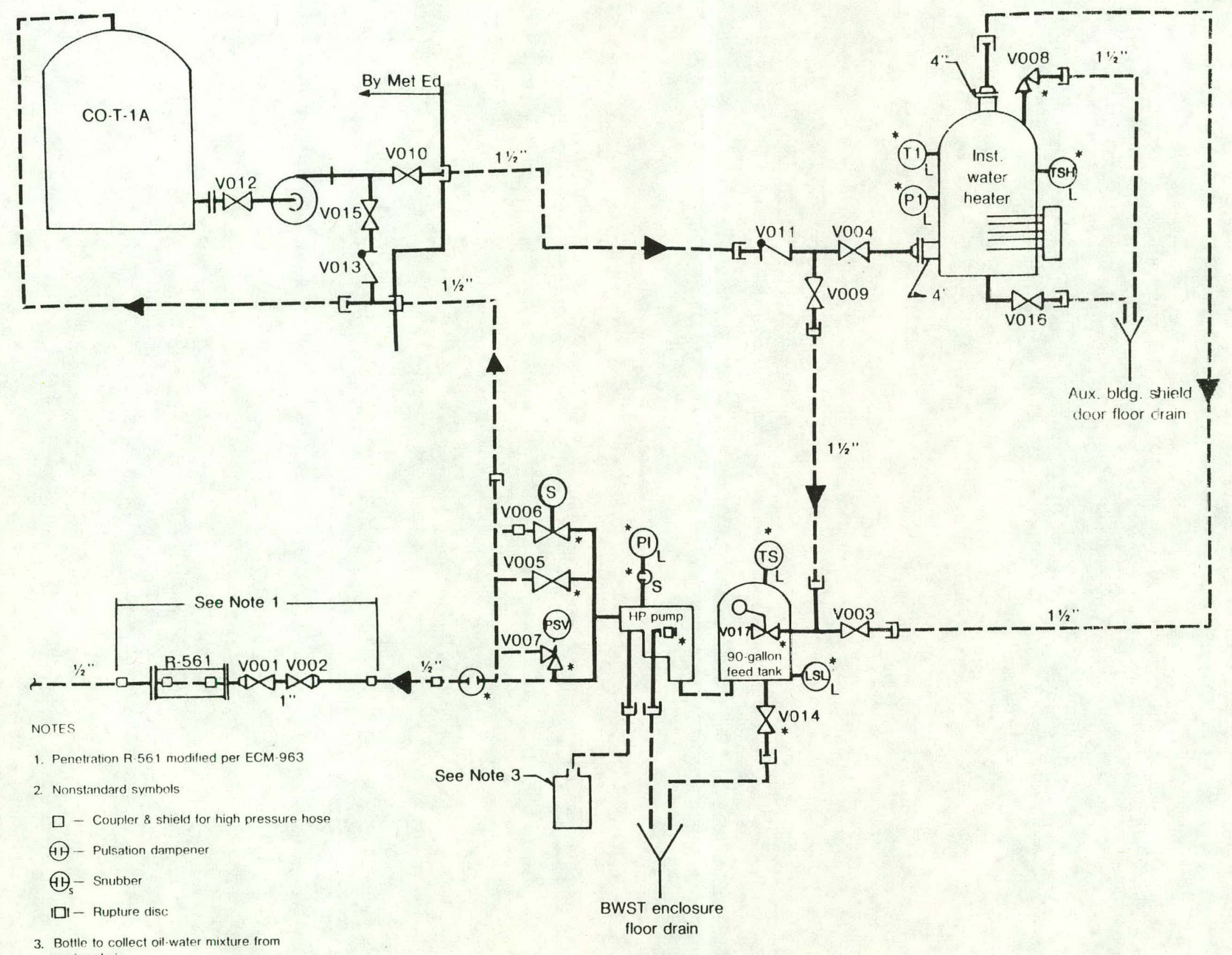

Figure B-3. Decontamination experiment water system. 


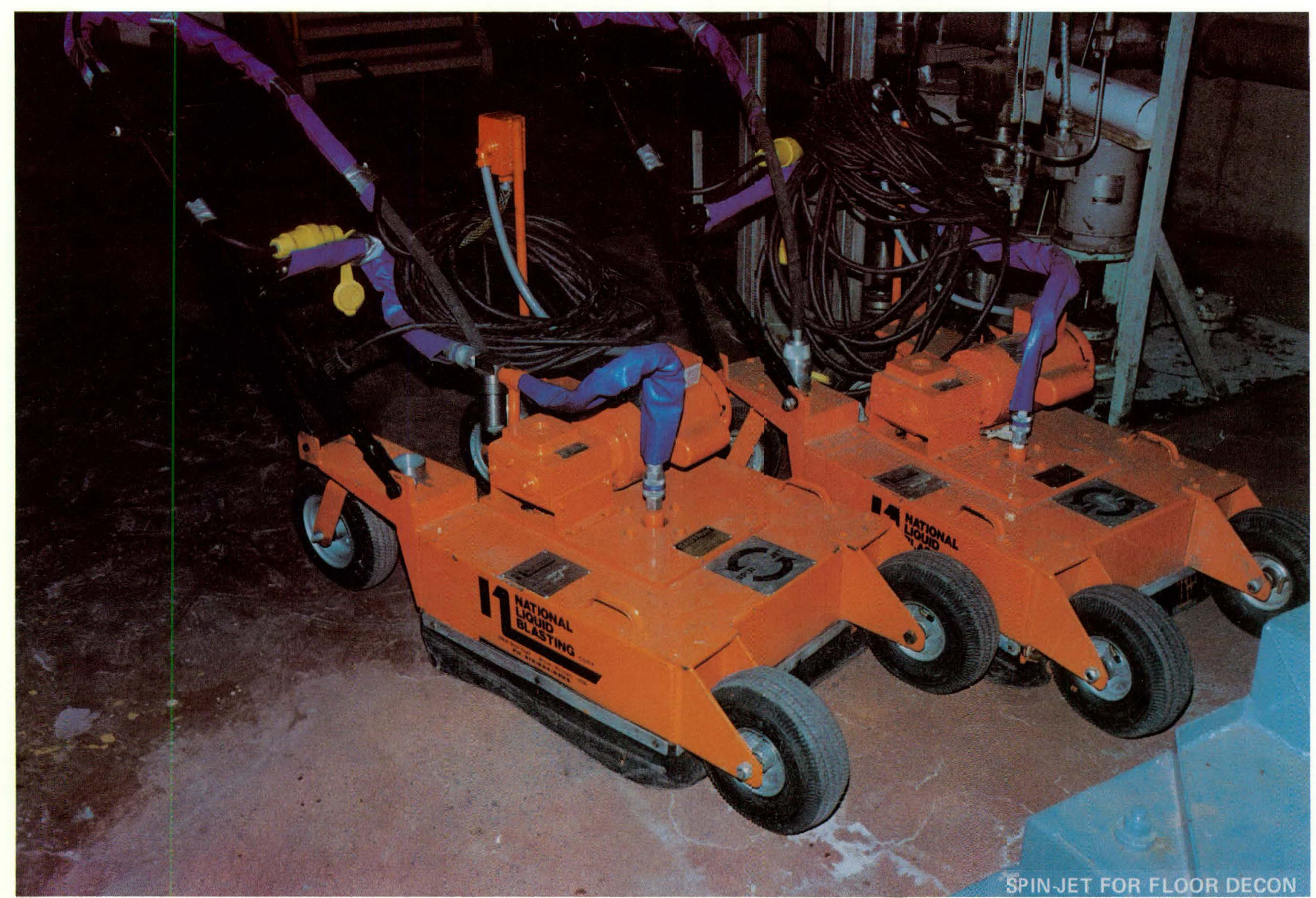

Figure B-4. Spin jet. 


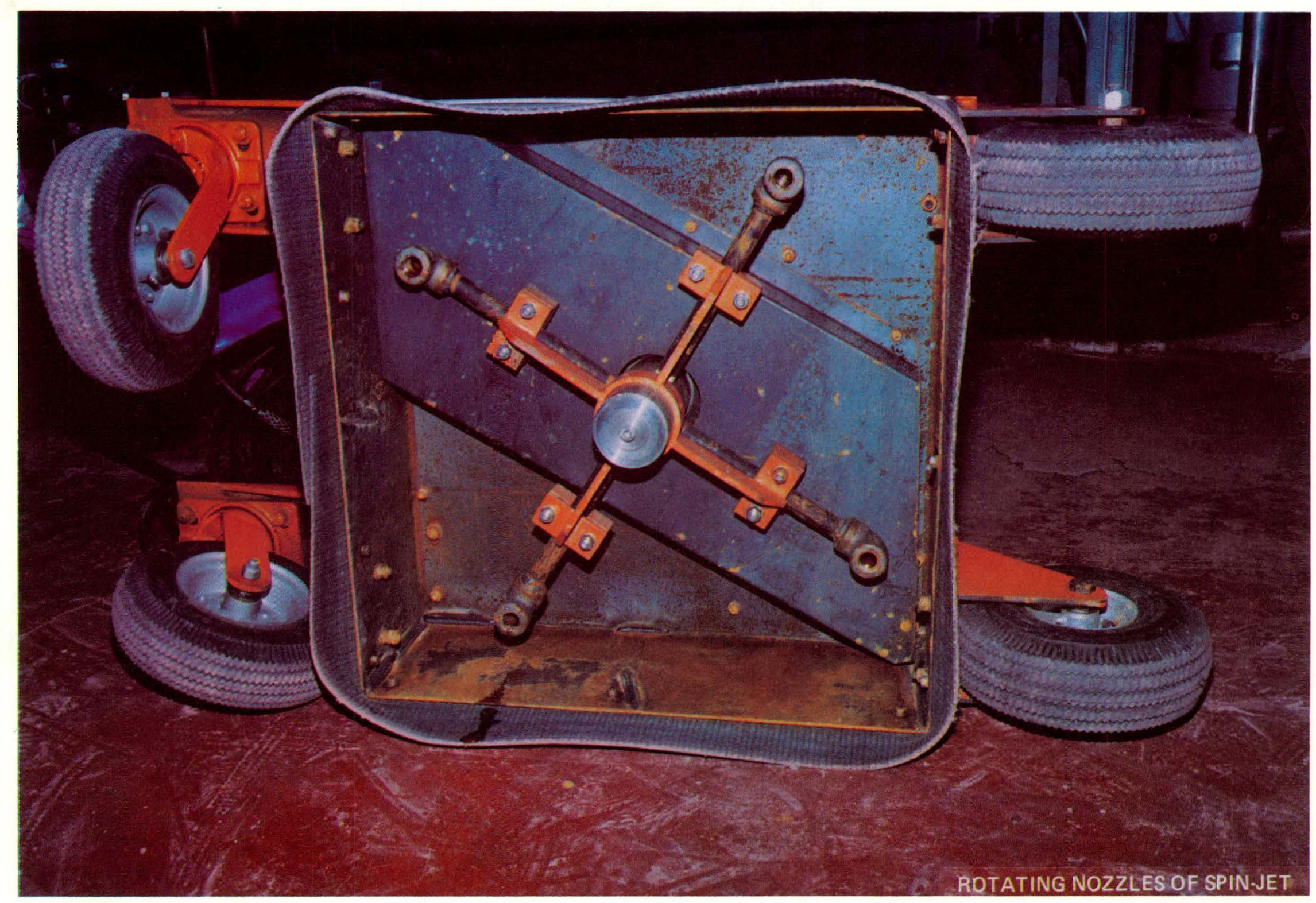

Figure B-5. Spin jet nozzles. 


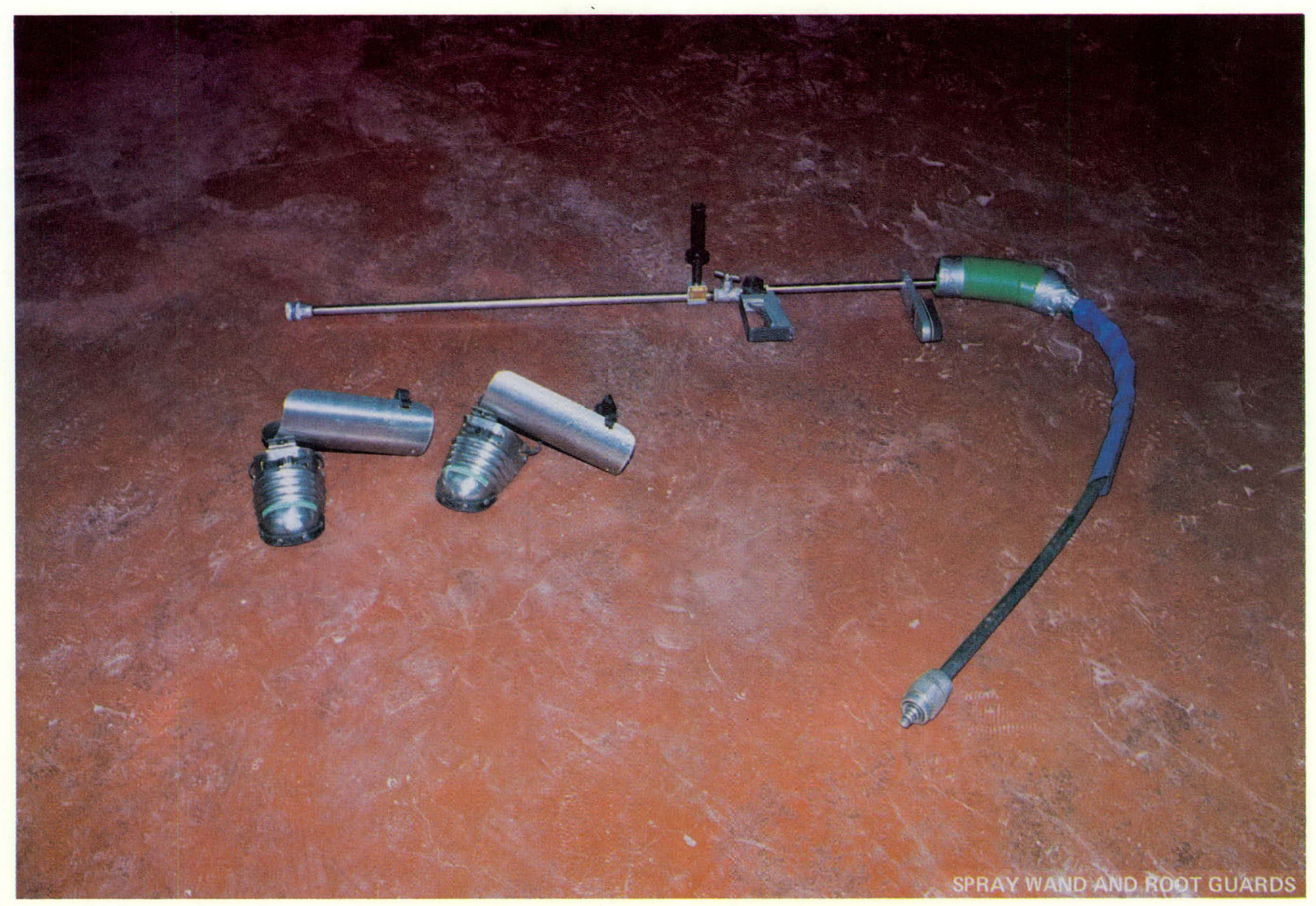

Figure B-6. Hydrolance. 


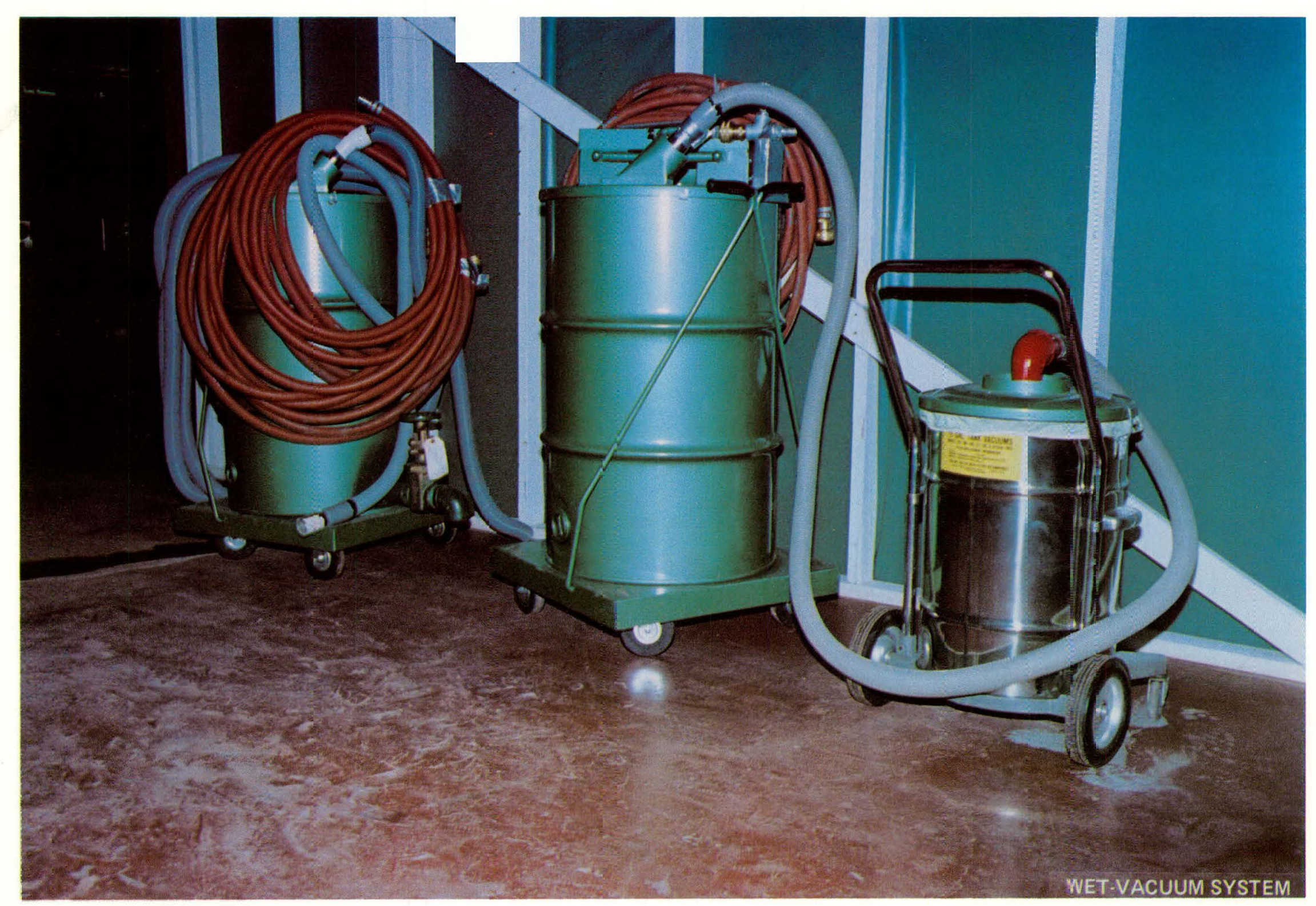

Figure B-7. Wet-vacuum system. 


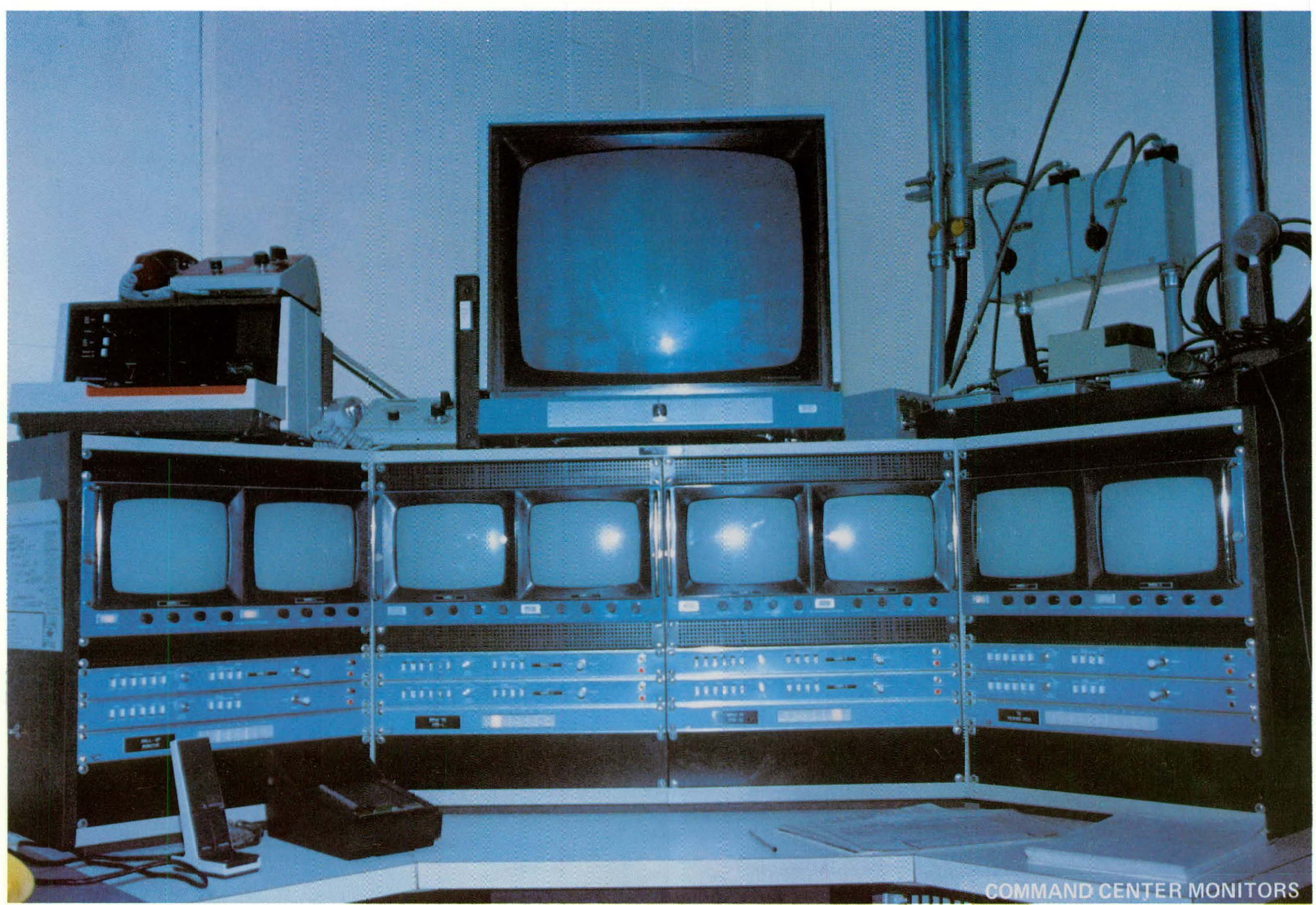

Figure B-8. Command center. 
DO NOT MICROFILM
IHIS PAGE 
APPENDIX C

RAW DATA 
CONTENTS

HIGH PRESSURE FLUSH - ELEVATION $305^{\circ}$

LOW PRESSURE FLUSH - ELEVATION 305'

STRIPPABLE COATING TEST - ELEVATION 305' and HEAD STORAGE STAND

- ELEVATION $347^{\prime}-6^{\prime \prime}$

LOW PRESSURE AND HIGH PRESSURE FLUSH - ELEVATION 347'-6"

MECHANICAL SCRUBBER TEST - ELEVATION 347'-6"

LOW PRESSURE FLUSH - D-RINGS, REACTOR SERVICE STRUCTURE, MISSILE SHIELDS, REFUELING CANALS, AND BRIDGES

LOW PRESSURE FLUSH - POTAR CRANE

REACTOR BUILDING AIR SAMPLE DATA - FEBRUARY 26 THROUGH MARCH 26, 1982

OPERATIONAL PARAMETERS - ELEVATION 305' LOW PRESSURE FLUSH

OPERATIONAL PARAMETERS - ELEVATION 305' HIGH PRESSURE FLUSH

OPERATIONAL PARAMETERS - ELEVATION 305' OVERHEAD, WALLS, ETC. HIGH PRESSURE FLUSH

OPERATIONAL PARAMETERS - ELEVATION 347'-6" LOW PRESSURE FLUSH

OPERATIONAL PARAMETERS - ELEVATION 347'-6" HIGH PRESSURE FLUSH

OPERATIONAL PARAMETERS - POLAR CRANE

OPERATIONAL PARAMETERS - MISSILE SHIELDS, D-RINGS, CANALS

LOW PRESSURE REFLUSH AFTER HIGH PRESSURE FLUSH - ELEVATION 305' 
IIIGH PRESSURE FLUSH - ELEVVATION 305'

\begin{tabular}{|c|c|c|c|c|c|c|c|c|c|c|c|c|c|c|}
\hline $\begin{array}{l}\text { IIP } \\
\text { Arca }\end{array}$ & A Ircillim & sumface & $\begin{array}{l}\text { Pre:Fi:st } \\
\text { Area } \\
\text { Ganmma } \\
\text { (116rem) }\end{array}$ & $\begin{array}{l}\text { Post-Test } \\
\text { Area } \\
\text { ('aminua } \\
\text { (mrenı) }\end{array}$ & $\begin{array}{l}\text { Pre-Tes! } \\
\text { Contact } \\
\text { Gamma } \\
\text { (1urent) }\end{array}$ & $\begin{array}{l}\text { Pust-Test } \\
\text { Contact } \\
\text { Gomma } \\
\text { (Inrem) }\end{array}$ & $\begin{array}{l}\text { Pre.Test } \\
\text { Cont act } \\
\text { Bela } \\
\text { (Inrem) }\end{array}$ & $\begin{array}{l}\text { Pust Test } \\
\text { Conlact } \\
\text { Beta } \\
\text { (inrem) }\end{array}$ & $\mathrm{Cs}_{\mathrm{C} \cdot 1.37}$ & Pre-Test Swipe - dpt & Sr.MO/Y.XOX & $\Gamma_{\text {c.s.137 }}$ & Post-Test Swipe- & Sr.40/Y.9) \\
\hline$x$ & $12-1$ & Floor & 100 & 120 & 150 & 130 & 608 & 190 & & & & & & . \\
\hline$x$ & $12-?$ & Floor & 100 & 100 & 150 & 120 & 722 & 304 & & 1 & & & & \\
\hline $\mathrm{x}$ & $12-3$ & Floor & 108 & 120 & 130 & 120 & 494 & 114 & $4.22 \times 10^{6}$ & $4.0 \times 10^{5}$ & $1.42 \times 10^{5}$ & $1.7 \times 10^{5}$ & $1.9 \times 10^{4}$ & $6.88 \times 10^{3}$ \\
\hline$x$ & $12-4$ & Floor & 120 & 140 & 150 & 150 & 190 & 76 & & & & & & \\
\hline$x$ & $12-5$ & Floor & 110 & 120 & 140 & 110 & 684 & 266 & & & & & & \\
\hline$x$ & 15 & CFT A Pipe & $\mathrm{NA}$ & 170 & 100 & 100 & 228 & 152 & $3.77 \times 10^{5}$ & $4.0 \times 10^{4}$ & $2.66 \times 10^{4}$ & $4.2 \times 10^{5}$ & $3.96 \times 10^{\circ}$ & $2.88 \times 10^{4}$ \\
\hline$P$ & 1 & Floor & 220 & 180 & 290 & 250 & 1930 & 1330 & $4.88 \times 10^{6}$ & $4.88 \times 10^{5}$ & $1.22 \times 10^{5}$ & $3.33 \times 10^{5}$ & $3.3 \times 10^{4}$ & $7.77 \times 10^{3}$ \\
\hline $\mathrm{XI}$ & 21 & Floor by $\$ 19$ & 210 & 200 & 250 & 240 & 608 & $\$ 14$ & $3.33 \times 10^{6}$ & $3.11 \times 10^{5}$ & $5.77 \times 10^{4}$ & $8.86 \times 10^{4}$ & $7.99 \times 10^{3}$ & $3.1 \times 10^{3}$ \\
\hline$X I I$ & 2.3 & Floor by $\| 12$ & 350 & 350 & 420 & 380 & 684 & 456 & $2.15 \times 10^{5}$ & $2.44 \times 10^{4}$ & $4.66 \times 10^{3}$ & $1.11 \times 10^{6}$ & $1.08 \times 10^{5}$ & $2.89 \times 10^{1}$ \\
\hline$x \mid 1$ & 29 & Floor by $\| 19$ & 800 & 1000 & 1900 & 1400 & 9880 & 4290 & $1.22 \times 10^{6}$ & $1.22 \times 10^{5}$ & $2.89 \times 10^{4}$ & $1.64 \times 10^{6}$ & $1.58 \times 10^{5}$ & $1.42 \times 10^{4}$ \\
\hline XIt & 34 & Floor & 330 & 330 & $2 \mathrm{BO}$ & 280 & 1590 & 507 & $8.44 \times 10^{6}$ & $8.44 \times 10^{5}$ & $1.09 \times 10^{5}$ & $9.55 \times 10^{5}$ & $9.32 \times 10^{7}$ & $2.2 \times 10^{4}$ \\
\hline$x 11$ & 42 & CFT B Pipe & $\mathrm{NA}$ & $\mathrm{N} \Lambda$ & 3700 & NA & 1140 & IA & $1.15 \times 10^{6}$ & $1.15 \times 10^{5}$ & $2.2 \times 10^{5}$ & & & \\
\hline xit & 50 & Floor & 420 & 400 & 340 & 300 & 2120 & 1170 & $2.44 \times 10^{6}$ & $2.22 \times 10^{5}$ & $8.66 \times 10^{1}$ & $1.5 .3 \times 10^{5}$ & $1.42 \times 10^{7}$ & $5.1 \times 10^{3}$ \\
\hline XI. & $5.3-3$ & Floor & 600 & 1200 & 900 & 1800 & 2660 & 780 & $1.75 \times 10^{6}$ & $1.78 \times 10^{5}$ & $1.35 \times 10^{5}$ & $7.5 \times 10^{5}$ & $7.54 \times 10^{1}$ & $2.66 \times 10^{1}$ \\
\hline$x+1$ & $53-1$ & leor & & 1300 & & 3600 & & 9360 & & & & & & \\
\hline XII & $5.3-2$ & Floor & & 1100 & & 1500 & & 1170 & & & & & & \\
\hline XII & $53-4$ & Flonr & & 1100 & & 1600 & & 3900 & & & & & & \\
\hline XII & $53-5$ & Flonr & & 900 & & 1200 & & 780 & & & & & & \\
\hline
\end{tabular}


LICW PRFSSURE FLUSH - ELEVATIIN 305'

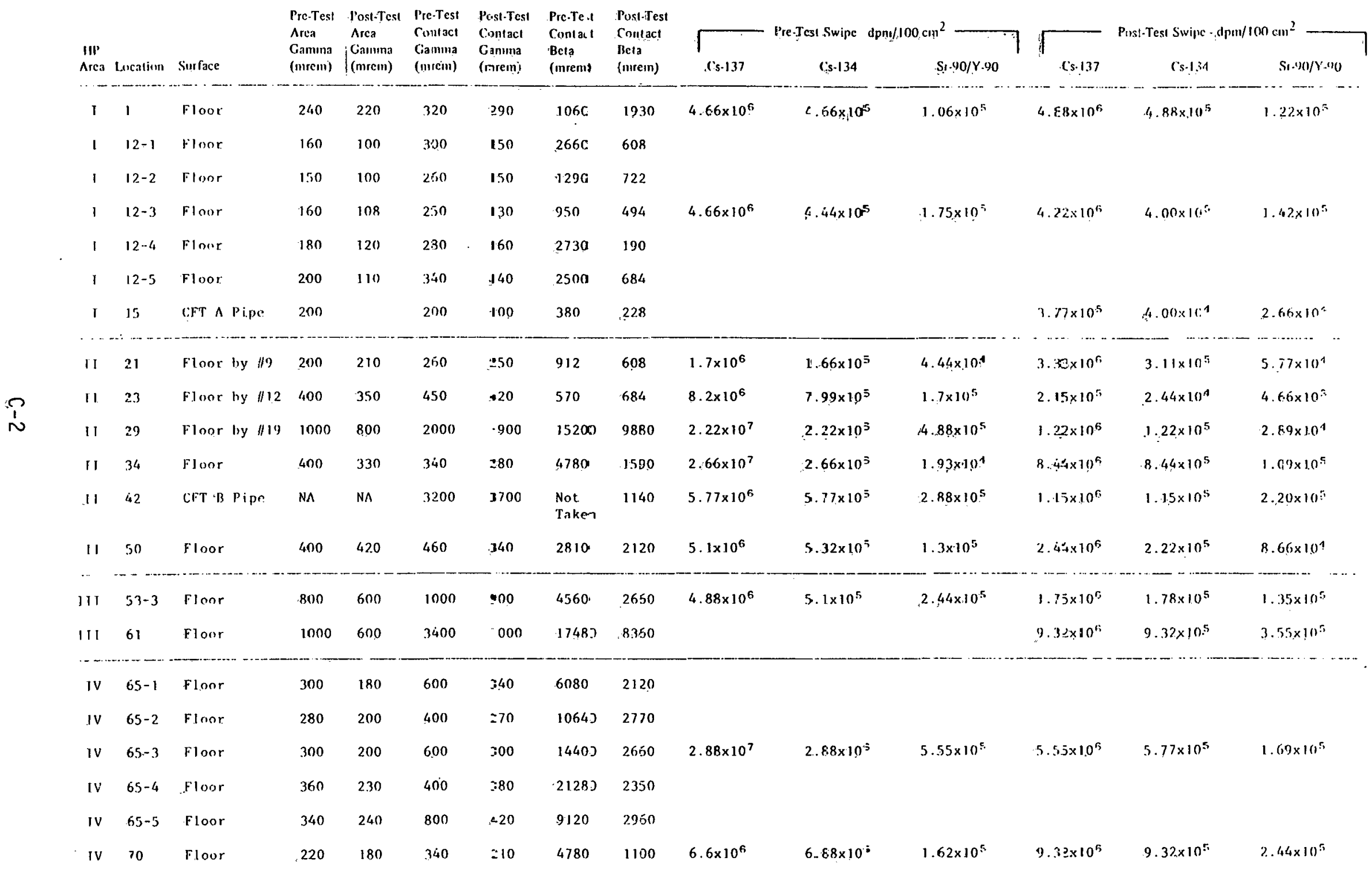


ST'RIPPABLE COATING TF.ST - F.L.F.VATION 305' AND IEAD STORAGF, STAND - EL.FVGTTION 347'-6"

\begin{tabular}{|c|c|c|c|c|c|c|c|c|c|c|c|c|c|c|c|c|}
\hline $\begin{array}{l}|, P| \\
\text { III } \\
\text { Area }\end{array}$ & Lacarion & Surface & $\begin{array}{l}\text { Pre-Test } \\
\text { Alcit } \\
\text { Ganuma } \\
\text { (Inrem) }\end{array}$ & $\begin{array}{l}\text { Pusl-Test } \\
\text { Area } \\
\text { (armuma } \\
\text { i (mrem) }\end{array}$ & $\begin{array}{l}\text { Pre-Test } \\
\text { Conlict } \\
\text { Camuma } \\
\text { (Imremili) }\end{array}$ & $\begin{array}{l}\text { P'ost-Tes1 } \\
\text { Comlact } \\
\text { Gaminana } \\
\text { (Inrem) }\end{array}$ & $\begin{array}{l}\text { Pre-Test } \\
\text { Cont act } \\
\text { Beta } \\
\text { (Inremii) }\end{array}$ & $\begin{array}{l}\text { Pusl-Test } \\
\text { Comtact } \\
\text { Beta } \\
\text { (Imrem) }\end{array}$ & \multicolumn{3}{|c|}{ - Pre-Jest Swipe $\cdot d p m / 100 \mathrm{~cm}^{2}$} & \multicolumn{3}{|c|}{ - Post:Test Swipe - dpro/ $/ 100 \mathrm{~cm}^{2}$} & $\begin{array}{l}\text { Intermediale } \\
\text { Contact } \\
\text { Cianmus }\end{array}$ & $\begin{array}{l}\text { fulcrinsal ate } \\
\text { centract } \\
\text { Beta }\end{array}$ \\
\hline & 65 & & - & - & 300 & 300 & 2240 & 2400 & $1.35 \times 10^{6}$ & $1.3 .3 \times 10^{5}$ & $4.22 \times 10^{4}$ & $5.99 \times 10^{4}$ & $5.55 \times 10^{3}$ & $7.77 \times 10^{3}$ & 300 & 800 \\
\hline & 70 & & - & - & 290 & 200 & 572 & 880 & $1.27 \times 10^{7}$ & $1.62 \times 10^{5}$ & $4.22 \times 10^{4}$ & $5.77 \times 10^{-4}$ & $5.99 \times 10^{3}$ & $3.11 \times 10^{3}$ & 280 & 400 \\
\hline & 76 & & - & - & 500 & 200 & 5440 & 3600 & $1.07 \times 10^{7}$ & $1.02 \times 10^{6}$ & $3.11 \times 10^{5}$ & $1.95 \times 10^{5}$ & $1.91 \times 10^{4}$ & $1.86 \times 10^{4}$ & 600 & 2000 \\
\hline & 77 & & - & - & 700 & 800 & 1280 & 1000 & $2.02 \times 10^{6}$ & $2.0 \times 10^{5}$ & $3.55 \times 10^{4}$ & $7.55 \times 10^{4}$ & $8.46 \times 10^{3}$ & $8.66 \times 10^{3}$ & 600 & 800 \\
\hline & 50 & & - & - & 90 & 110 & 96 & 40 & $7.10 \times] 0^{4}$ & $5.99 \times 10^{3}$ & $1.82 \times 10^{3}$ & $2.89 \times 10^{3}$ & L.I.D & $3.33 \times 10^{2}$ & 120 & NIDH \\
\hline & 51 & & - & - & 60 & 150 & 4928 & 3800 & $2.44 \times 10^{6}$ & $2.44 \times 10^{5}$ & $4.66 \times 10^{5}$ & $4.44 \times 10^{4}$ & $4.44 \times 10^{3}$ & $3.11 \times 10^{4}$ & 150 & 3000 \\
\hline & 52 & & - & - & 140 & 100 & 4672 & 4400 & $1.24 \times 10^{6}$ & $1.22 \times 10^{5}$ & $1.73 \times 10^{5}$ & $5.11 \times 10^{4}$ & $4.22 \times 10^{3}$ & $1.53 \times 10^{1}$ & 150 & 3000 \\
\hline & 1.50 & & - & - & $1 / 40$ & 110 & 4672 & 4560 & $3.77 \times 10^{6}$ & $3.77 \times 10^{5}$ & $5.55 \times 10^{5}$ & - & - & - & 120 & 3920 \\
\hline & 1.51 & & - & $-\cdot$ & 60 & 80 & 128 & 100 & $4.44 \times 10^{4}$ & $3.77 \times 10^{3}$ & $3.55 \times 10^{3}$ & - & - & - & 80 & 120 \\
\hline & 1.59 & & - & - & 100 & - & 128 & - & $6.66 \times 10^{4}$ & $6.22 \times 10^{3}$ & $1.51 \times 10^{9}$ & - & - & - & - & - \\
\hline & 160 & & - & - & 120 & - & 64 & - & $5.33 \times 10^{4}$ & $5.77 \times 10^{3}$ & $2.13 \times 10^{3}$ & - & - & - & - & - \\
\hline & 162 & & - & - & 140 & 140 & 5312 & 5440 & $5.55 \times 10^{6}$ & $5.33 \times 10^{5}$ & $6.88 \times 10^{5}$ & $7.55 \times 10^{1}$ & $7.99 \times 10^{3}$ & $4.44 \times 10^{4}$ & 125 & 4.300 \\
\hline & 163 & & - & - & 80 & 100 & 224 & 200 & $5.11 \times 10^{4}$ & $4.0 \times 10^{3}$ & $5.77 \times 10^{3}$ & $2.44 \times 10^{.3}$ & 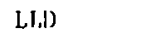 & $4.0 \times 10^{2}$ & 110 & 40 \\
\hline \multicolumn{17}{|c|}{$\begin{array}{l}\text { Intermediate Test Results } \\
\text { (before stripping) }\end{array}$} \\
\hline & 6.5 & & & & & & & & & & & $7.55 \times 10^{4}$ & $1.36 \times 10^{4}$ & $1.31 \times 10^{4}$ & & \\
\hline & 70 & & & & & & & & & & & $4.0 \times 10^{4}$ & $4.22 \times 10^{3}$ & $2.44 \times 10^{3}$ & & \\
\hline & 76 & & & & & & & & & & & $2.22 \times 10^{5}$ & $2.22 \times 10^{4}$ & $6.44 \times 10^{3}$ & & \\
\hline & 77 & & & & & & & & & & & $1.67 \times 10^{4}$ & $2.44 \times 10^{3}$ & $1.20 \times 10^{3}$ & & \\
\hline & 50 & & & & & & & & & & & $6.66 \times 10^{2}$ & (.IJ) & $2.44 \times 10^{2}$ & & \\
\hline & 51 & & & & & & & & & & & $3.33 \times 10^{4}$ & $3.11 \times 10^{3}$ & $4.0 \times 10^{3}$ & & \\
\hline
\end{tabular}




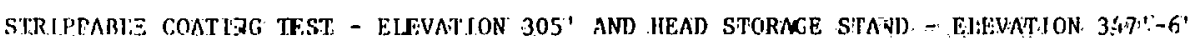

\begin{tabular}{|c|c|c|c|c|c|c|c|c|c|c|c|c|c|c|c|c|}
\hline \multirow{2}{*}{$\begin{array}{l}\text { LPI } \\
\text { LiP' } \\
\text { Arcil }\end{array}$} & \multirow{2}{*}{ Lxatiou } & \multirow{2}{*}{ Surface } & \multirow{2}{*}{ 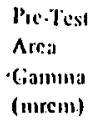 } & \multirow{2}{*}{ 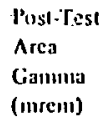 } & \multirow{2}{*}{ 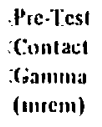 } & \multirow{2}{*}{ 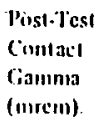 } & \multirow{2}{*}{ 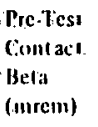 } & \multirow{2}{*}{ 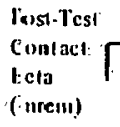 } & \multicolumn{3}{|c|}{ - Prectest Swipe - Ipmatiou cin: } & \multicolumn{3}{|c|}{ 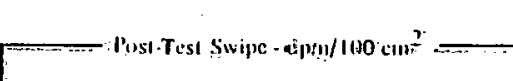 } & \multirow{2}{*}{ 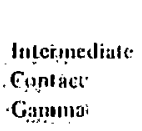 } & \multirow{2}{*}{ 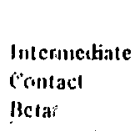 } \\
\hline & & & & & & & & & (cs. 13 ? & Cs. -134 & SR-40/Y-90: & Cs 137 & $\operatorname{cs.} ! 34$ & $s: 10 / Y \cdot 90$ & & \\
\hline & 52 & & & & & & & & & & & $2.44 \times 10^{4}$ & $2.09 \times 7 \times 10^{3}$ & 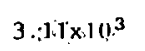 & & \\
\hline & 150 & & & & & & & & & & & - & - & $=$ & & \\
\hline & 151 & & . & & & & & & & & &.- & - & - & & \\
\hline & 1.59 & & & & & & & & & & & $\therefore$ & - & - & & \\
\hline & $16 n$ & & & & & & & & & & & - & - & - & & \\
\hline & 162 & & & & & & & & & & & - & - & .- & & \\
\hline & 163 & & & & & & & & & & & $1.15 \times 10^{3}$ & LI, B & Eth & & \\
\hline & . & & & & & & & & & $\begin{array}{r}\text { Self-Stripping } \\
\text { (after } \\
(750\end{array}$ & $\begin{array}{l}\text { ins-Samp le } \\
\text { ing: }\end{array}$ & $9.32 \times 10^{6}$ & $9.10 \times 10^{5}$ & $2.18 \times 10 \%$ & & \\
\hline
\end{tabular}


. LOW PRESSURE AND HIGH PRESSURE FLUSH - ELEVATION 347'-6"

\begin{tabular}{|c|c|c|c|c|c|c|c|c|c|c|c|c|c|c|c|}
\hline \multirow{2}{*}{\multicolumn{2}{|c|}{ LP/IIP Area }} & \multirow[b]{2}{*}{ Location } & \multirow[b]{2}{*}{ Surface } & \multirow{2}{*}{$\begin{array}{l}\text { Pre-Test } \\
\text { Area } \\
\text { Gamına } \\
\text { (mirem) }\end{array}$} & \multirow{2}{*}{$\begin{array}{l}\text { Post-Tesl } \\
\text { Area } \\
\text { Cramma } \\
\text { | (nirem) }\end{array}$} & \multirow{2}{*}{$\begin{array}{l}\text { Pre-Test } \\
\text { Contact } \\
\text { Gamma } \\
\text { (mrem) }\end{array}$} & \multirow{2}{*}{$\begin{array}{l}\text { Post-Test } \\
\text { Contact } \\
\text { Gamma } \\
\text { (mrem) }\end{array}$} & \multirow{2}{*}{$\begin{array}{l}\text { Pre-Test } \\
\text { Contact } \\
\text { Beta } \\
\text { (ntrem) }\end{array}$} & \multirow{2}{*}{$\begin{array}{l}\text { Post-Test } \\
\text { Cortact } \\
\text { Reta } \\
\text { (mrem) }\end{array}$} & \multicolumn{3}{|c|}{ l're.Test Swipe - dpm/100 $\mathrm{cm}^{2}$} & \multirow[b]{2}{*}{ Cs- 1.37} & \multicolumn{2}{|c|}{ Post-Tast Swipe $\cdot d p m / 100 \mathrm{~cm}^{2}$} \\
\hline & & & & & & & & & & Cs. 137 & Cs-134 & Sr.90/Y.90 & & Cs. 134 & Sr.90/Y.90 \\
\hline v & $\mathbf{I}$ & 27 & $\begin{array}{l}\text { Di.amond } \\
\text { Plate }\end{array}$ & 180 & 90 & 320 & 150 & 7520 & 370 & $7.1 \times 10^{6}$ & $7.1 \times 10^{5}$ & $1.55 \times 10^{5}$ & $5.32 \times 10^{5}$ & $4.88 \times 10^{4}$ & $4.66 \times 10^{3}$ \\
\hline $\mathrm{v}$ & $I$ & 28 & $\begin{array}{l}\text { Diamond } \\
\text { Plate }\end{array}$ & 110 & 100 & 210 & 100 & 6360 & 851 & $4.0 \times 10^{6}$ & $3.77 \times 10^{5}$ & $7.99 \times 10^{4}$ & $5.11 \times 10^{5}$ & $4.66 \times 10^{4}$ & $1.63 \times 10^{4}$ \\
\hline v & I & $29-1$ & $\begin{array}{c}\text { Concrete } \\
\text { Floor }\end{array}$ & 100 & 100 & 160 & 140 & 1760 & 333 & & & & & & \\
\hline$v$ & 1 & $29-2$ & & 80 & 90 & 100 & 60 & 480 & 185 & & & & & & \\
\hline v & I & $29-3$ & & 100 & 90 & 160 & 100 & 1760 & 296 & $1.53 \times 10^{7}$ & $1.53 \times 10^{6}$ & $7.39 \times 10^{5}$ & $4.44 \times 10^{4}$ & $4.22 \times 10^{3}$ & $3.11 \times 10^{3}$ \\
\hline$v$ & I & $29-4$ & & 120 & 80 & 160 & 100 & 2560 & 222 & & & & & & \\
\hline$v$ & I & $29-5$ & & 100 & 90 & 180 & 100 & 2480 & 14.8 & & & & & & \\
\hline v & I & 87 & $\downarrow$ & 100 & 90 & 260 & 180 & 4560 & 2294 & $1.24 \times 10^{7}$ & $1.24 \times 10^{6}$ & $4.88 \times 10^{5}$ & $1.53 \times 10^{5}$ & $1.46 \times 10^{4}$ & $6.4 / 4 \times 10^{3}$ \\
\hline$v$ & $\mathbf{I}$ & 129 & Cable Tray & NA & NA & 300 & 180 & 2000 & 518 & $2.13 \times 10^{7}$ & $2.11 \times 10^{6}$ & $8.88 \times 10^{5}$ & $3.11 \times 10^{4}$ & $2.66 \times 10^{3}$ & $1.75 \times 10^{3}$ \\
\hline$v$ & $\mathbf{I}$ & 130 & Cable Tray & NA & NA & 300 & 180 & 6000 & 333 & $1.33 \times 10^{7}$ & $1.33 \times 10^{6}$ & $5.11 \times 10^{5}$ & $1.65 \times 10^{4}$ & $1.86 \times 10^{3}$ & $4.22 \times 10^{2}$ \\
\hline v & II & $89-1$ & $\begin{array}{c}\text { Concrete } \\
\text { Flnor }\end{array}$ & 60 & 80 & 160 & 110 & 1760 & 703 & & & & & & \\
\hline$v$ & 11 & $89-2$ & & 60 & 70 & 120 & 120 & 2720 & 666 & & & & & & \\
\hline v & I I & $89-3$ & & 80 & 6.5 & 160 & 80 & 2560 & 777 & $1.35 \times 10^{7}$ & $1.35 \times 10^{6}$ & $5.55 \times 10^{5}$ & $5.77 \times 10^{5}$ & $5.99 \times 10^{4}$ & $1.46 \times 10^{4}$ \\
\hline v & I I & $89-4$ & & 100 & 60 & 240 & 130 & 7040 & 1147 & & & & & & \\
\hline v & 11 & $89-5$ & & 80 & 70 & 120 & 60 & 1920 & 333 & & & & & & \\
\hline$v$ & II & $91-1$ & & 50 & 60 & 50 & 40 & 440 & 333 & & & & & & \\
\hline v & II & $91-2$ & & 50 & 50 & 60 & 48 & 480 & 341 & & & & & & \\
\hline$v$ & II & $91-3$ & & 60 & 55 & BO & 60 & $56 a$ & 407 & $5.33 \times 10^{5}$ & $5.11 \times 10^{4}$ & $3.11 \times 10^{4}$ & $1.53 \times 10^{5}$ & $1.53 \times 10^{4}$ & $5.11 \times 10^{3}$ \\
\hline$v$ & II & $91-4$ & & 60 & 50 & BO & 70 & 720 & 333 & & & . & & & \\
\hline v & II & $91-5$ & $\downarrow$ & 60 & 50 & 180 & 130 & 2480 & 1258 & & & & & & \\
\hline
\end{tabular}


LOW PRFSSURE AFD IU GH PRESSURE FLUSH - ELCVAT 1ON 347'-6"

\begin{tabular}{|c|c|c|c|c|c|c|c|c|c|c|c|c|c|c|}
\hline LP/HP Area: & Location & Surface & $\begin{array}{l}\text { Pre-Test } \\
\text { Area } \\
\text { Gamma } \\
\text { (Inrem) }\end{array}$ & $\begin{array}{l}\text { Post-Test } \\
\text { Area } \\
\text { Gamnia } \\
\text { (mrenı) }\end{array}$ & $\begin{array}{l}\text { Pretest } \\
\text { Contact } \\
\text { Ganmat } \\
\text { (mena) }\end{array}$ & $\begin{array}{l}\text { Post-Test } \\
\text { Contart } \\
\text { Gamna } \\
\text { (mrem) }\end{array}$ & $\begin{array}{l}\text { Pre-Test } \\
\text { Costact } \\
\text { Be a: } \\
\text { (nrem) }\end{array}$ & $\begin{array}{l}\text { Pust-Test } \\
\text { Contact } \\
\text { Reta. } \\
\text { (mrem) }\end{array}$ & Cs.137 & $\begin{array}{c}\text { Fre-Test Swipe-dpu } \\
\text { Cs-139. }\end{array}$ & $\begin{array}{l}\mathrm{cm}^{2}- \\
\mathrm{Sr} \cdot 90 ; \times 90\end{array}$ & cs: 137 & Post-Test-Suipci- dp & $.5 r \cdot 40 / Y \cdot 90$ \\
\hline VITI VIII & $60-5$ & & 60 & 50 & 250 & 150 & 4875 & $25: 35$ & & & & & & \\
\hline VIII. VIII & 111 & n-Ring Wall & $\mathrm{NA}$ & 50 & 160 & - & 2496 & - & & & & & & \\
\hline VIIE VIII & 112 & $\begin{array}{c}\text { Concrete } \\
\text { Floor }\end{array}$ & 70 & 60 & 360 & 90 & 2496 & 468 & $6.88 \times 10^{6}$ & $6.66 \mathrm{r}: 10^{5}$ & $3.8 .9 \times 10^{5}$ & $7.55 \times 10^{4}$ & $5.99 \times 10^{3}$ & $4.88 \times 10^{3}$ \\
\hline VIII IX & $62-1$ & $\begin{array}{c}\text { Concrete } \\
\text { Floor }\end{array}$ & 140 & 100. & $1 \div 0$ & 100 & $8: 8$ & $\cdot 741$ & & & & & & \\
\hline VIJI IX & $62-2$ & & 200 & 100 & $1: 0$ & 110 & 468 & 468 & & & & & & \\
\hline VIIE I:X & $62-3$ & & 180 & 140 & 110 & 80 & 663 & 234 & $4.88 \times 10^{5}$ & $5.11 \times 10^{4}$ & $1.55 \times 10^{4}$ & $6.44 \times 10^{4}$ & $5.55 \times 10^{3}$ & $5.55 \times 10^{3}$ \\
\hline VIII IX & $62-4$ & & 140 & 150 & $1: 00$ & 80 & 525 & 390 & & & & & & \\
\hline VIIL IX & $62-5$ & $t$ & 200 & 120 & 130 & 150 & 1638 & 1170 & & & & & & \\
\hline VIIIIX & 63 & $\begin{array}{l}\text { Incore } \\
\text { Instrument } \\
\text { Seal Tablee }\end{array}$ & 500 & - & - & 1.20 & - & 234 & - & - & - & 8. $2 \times 10^{4}$ & $9.99 \times 10^{3}$ & $9.10 \times 10^{3}$ \\
\hline VIII IX & 64 & $\downarrow$ & - & - & - & 180 & - & 468 & - & - & - & $1.69 \times 10^{5}$ & $1.58 \times 10^{4}$ & $1.42 \times 30^{4}$ \\
\hline VIIII IX & 86 & $\begin{array}{l}\text { Concrete } \\
\text { Floor }\end{array}$ & 160 & 130 & 220 & 180 & $3 \cdot 042$ & 2028 & $3.33 \times 10^{6}$ & $3.33=10^{5}$ & $1.2 \times 10^{5}$ & $3.11 \times 10^{6}$ & $3.11 \times 10^{5}$ & $1.06 \times 10^{5}$ \\
\hline VIII IX & 1158 & $\begin{array}{l}\text { Floor- } \\
\text { Concrele }\end{array}$ & 100 & 70 & 120 & 80 & 732 & 468 & $1.62 \times 10^{6}$ & $1.57=10^{5}$ & $8.44 \times 10^{4}$ & $9.06 \times 10^{5}$ & $2.06 \times 10^{4}$ & $5.33 \times 10^{3}$ \\
\hline I & 79 & Liner Wall & & & & & & & & & & $3.77 \times 10^{4}$ & $4.88 \times 10^{3}$ & $1.49 \times 10^{3}$ \\
\hline
\end{tabular}


LOW PRESSURE AND HIGH PRFSSURE FLUSH - ELEVATION 347'-6"

\begin{tabular}{|c|c|c|c|c|c|c|c|c|c|c|c|c|c|c|c|}
\hline \multicolumn{2}{|c|}{ I.P/IIP Area } & Lication & Surfacc & $\begin{array}{l}\text { Pre-Test } \\
\text { Area } \\
\text { Gamma } \\
\text { (mrem) }\end{array}$ & $\begin{array}{l}\text { Posl-Tesl } \\
\text { Area } \\
\text { Gamma } \\
\text { (mrem) }\end{array}$ & $\begin{array}{l}\text { Pre-Test } \\
\text { Contact } \\
\text { Gamma } \\
\text { (mucm) }\end{array}$ & $\begin{array}{l}\text { Post-Test } \\
\text { Contact } \\
\text { Ganmma } \\
\text { (mreın) }\end{array}$ & $\begin{array}{l}\text { Pre-Test } \\
\text { Cont act } \\
\text { Beta } \\
\text { (mrem) }\end{array}$ & $\begin{array}{l}\text { Post-Test } \\
\text { Contact } \\
\text { Beta } \\
\text { (mrem) }\end{array}$ & \multicolumn{3}{|c|}{ Pre-Test Swipe - dpm/100 $\mathrm{cm}^{2}$} & Cs.137 & \multicolumn{2}{|c|}{ Post-Test Swipe - I $1 \mathrm{pm} / 100 \mathrm{~cm}^{2}$} \\
\hline VI & IV & 133 & $\begin{array}{l}\text { Index Fix- } \\
\text { Vert. }\end{array}$ & NA & 180 & 120 & 120 & 80 & 111 & $9.1 \times 10^{4}$ & $8.44 \times 10^{3}$ & LLD & $2.44 \times 10^{4}$ & $2.09 \times 10^{3}$ & $5.11 \times 10^{2}$ \\
\hline vi & IV & 1.34 & Index Fi.x & NA & 160 & 80 & 90 & 80 & 111 & $2.22 \times 10^{5}$ & $2.44 \times 10^{4}$ & $2.44 \times 10^{3}$ & $2.44 \times 10^{4}$ & $1.44 \times 10^{3}$ & $5.11 \times 10^{2}$ \\
\hline vI & IV & 145 & $\begin{array}{l}\text { Concrele } \\
\text { Floor }\end{array}$ & 80 & 150 & 140 & 160 & 660 & - & $2.44 \times 10^{6}$ & $2.44 \times 10^{5}$ & $1.38 \times 10^{5}$ & & & \\
\hline VI & IV & 147 & $\begin{array}{l}\text { Concrete } \\
\text { Floor }\end{array}$ & - & & - & - & & & & & & & & \\
\hline vi & $\mathrm{v}$ & 37 & $\begin{array}{l}\text { Diamond } \\
\text { Plate }\end{array}$ & 310 & 260 & 460 & 200 & 8560 & 666 & $5.33 \times 10^{6}$ & $5.33 \times 10^{5}$ & $1.51 \times 1.0^{5}$ & $2.13 \times 10^{5}$ & $1.89 \times 10^{4}$ & $5.99 \times 10^{3}$ \\
\hline VI & $\mathrm{v}$ & $39-1$ & $\begin{array}{c}\text { Concrete } \\
\text { Floor }\end{array}$ & 80 & 80 & 150 & 120 & 1400 & 1776 & & & & & & \\
\hline VII & $v$ & $39-2$ & & 100 & 80 & 150 & 140 & 1400 & 888 & & & & & & \\
\hline VI & $\mathrm{v}$ & $39-3$ & & 100 & 100 & 180 & 125 & 2480 & 685 & & & & $9.7 \div \times 10^{5}$ & $8.88 \times 10^{4}$ & $5.33 \times 10^{4}$ \\
\hline V.I & v & $39-4$ & & 100 & 90 & 250 & 180 & 3800 & 1554 & & & & & & \\
\hline VI & $v$ & $39-5$ & $\downarrow$ & 100 & 90 & 250 & 200 & 3000 & 925 & & & & & & \\
\hline vI & $\mathrm{v}$ & 40 & $\begin{array}{r}\text { Diamond } \\
\text { Plate }\end{array}$ & 300 & 200 & 250 & 150 & 5360 & 1147 & $5.77 \times 10^{6}$ & $5.55 \times 10^{5}$ & $1.31 \times 13^{5}$ & $3.11 \times 10^{5}$ & $2.66 \times 10^{4}$ & $1.02 \times 10^{4}$ \\
\hline VI & $\mathrm{v}$ & 41 & $\begin{array}{l}\text { Diamond } \\
\text { Plate }\end{array}$ & 200 & 130 & 200 & 100 & 2340 & 370 & $3.55 \times 10^{5}$ & $3.55 \times 10^{4}$ & $1.06 \times 12^{4}$ & $1.42 \times 10^{5}$ & $1.33 \times 10^{4}$ & $3.77 \times 10^{3}$ \\
\hline VI & $v$ & 42 & $\begin{array}{l}\text { Di amond } \\
\text { Plate }\end{array}$ & 180 & 140 & 220 & 110 & 2262 & 185 & $6.66 \times 10^{5}$ & $6.44 \times 10^{4}$ & $1.89 \times 13^{4}$ & $4.66 \times 10^{4}$ & $4.88 \times 10^{3}$ & $2.89 \times 10^{3}$ \\
\hline VII & v & 44 & RCPS-Hor. & NA & NA & 200 & 240 & 312 & 4662 & $1.46 \times 10^{7}$ & $1.46 \times 10^{6}$ & $2.89 \times 12^{5}$ & $1.69 \times 10^{7}$ & $1.65 \times 10^{6}$ & $3.55 \times 10^{5}$ \\
\hline VI & v & 45 & RCPS-Vert. & NA & NA & 100 & 80 & 195 & 259 & $1.24 \times 10^{5}$ & $1.24 \times 10^{4}$ & $7.77 \times 13^{3}$ & $1.89 \times 10^{5}$ & $1.95 \times 10^{4}$ & $4.22 \times 10^{3}$ \\
\hline VI & $v$ & 46 & RCPS-Hor. & NA & NA & 200 & 200 & 1950 & 5920 & $1.06 \times 10^{7}$ & $1.06 \times 10^{6}$ & $3.55 \times 13^{5}$ & $7.99 \times 10^{6}$ & $7.77 \times 10^{5}$ & $1.82 \times 10^{5}$ \\
\hline VI & v & 47 & RCPS-Vert. & NA & NA & 140 & 105 & 78 & 370 & $3.33 \times 10^{4}$ & $3.55 \times 10^{3}$ & $2.22 \times 10^{3}$ & $1.98 \times 10^{5}$ & $1.99 \times 10^{4}$ & $3.77 \times 10^{3}$ \\
\hline
\end{tabular}


LOY PRTSSURE AND NIGH PRESSURE FLUS: - EIEVATIOA 347'-6"

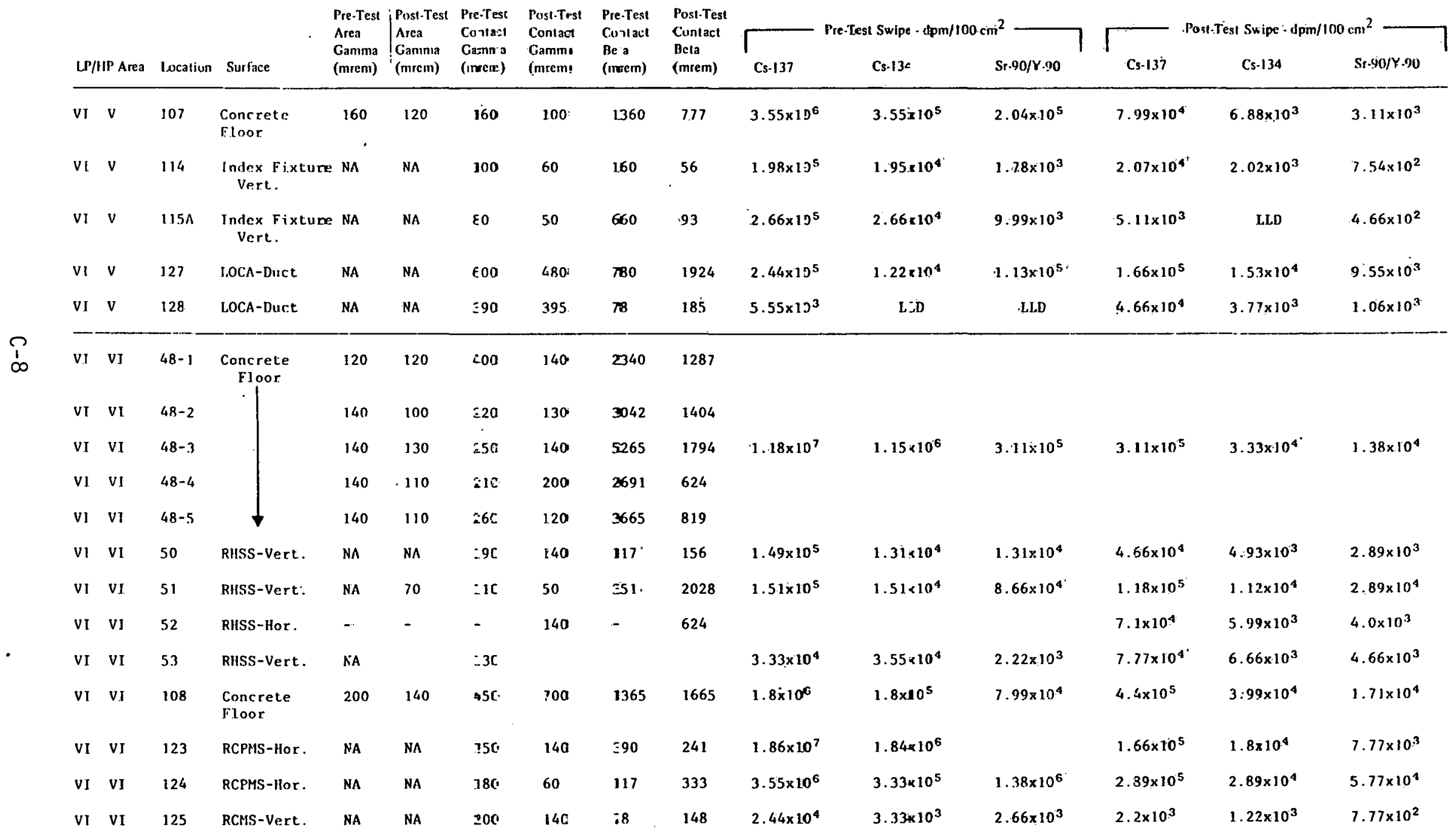


LOW PRESSURE AND HIGH PRESSURE FIUSH - ELEVATION 347'-6"

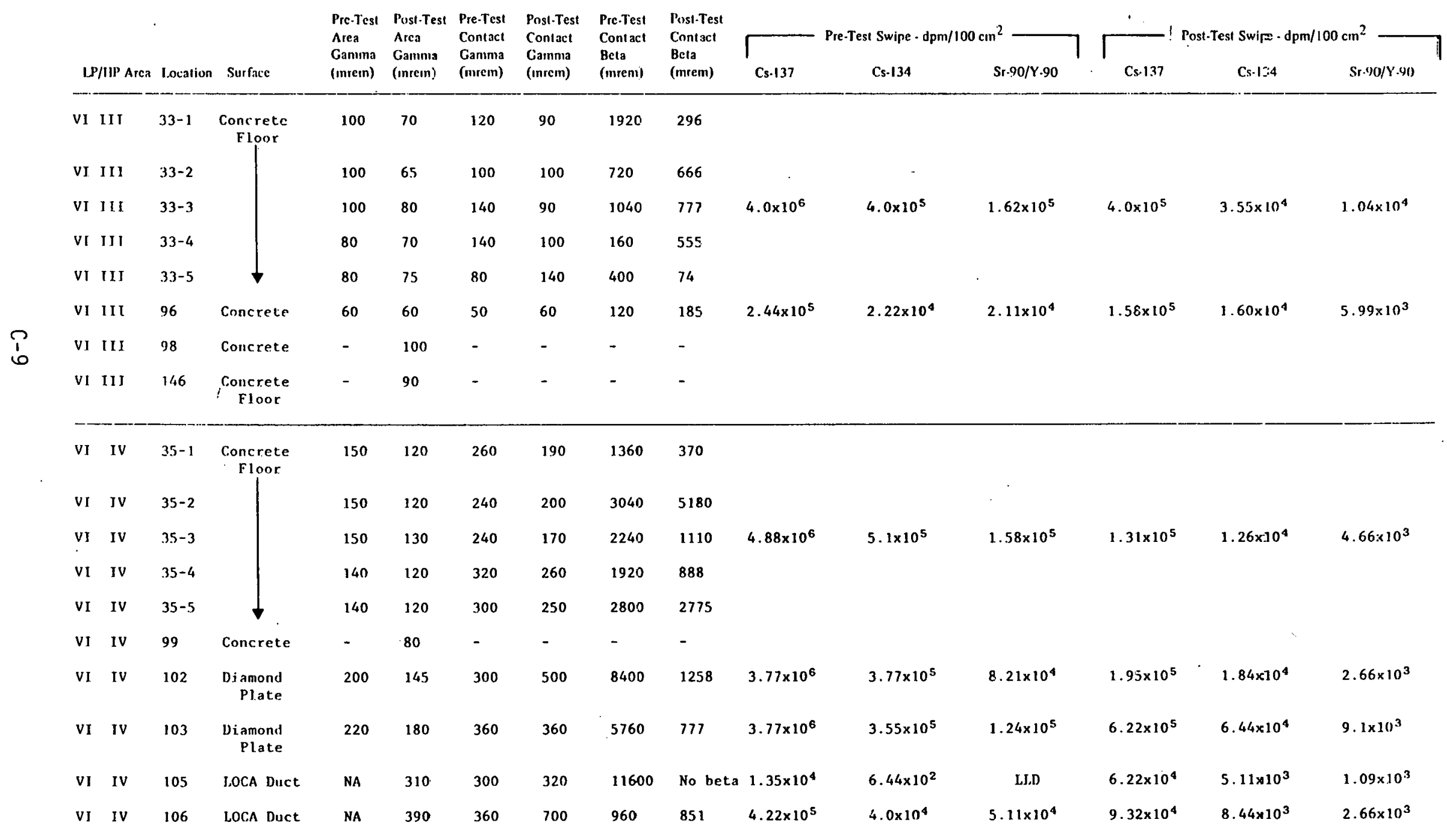




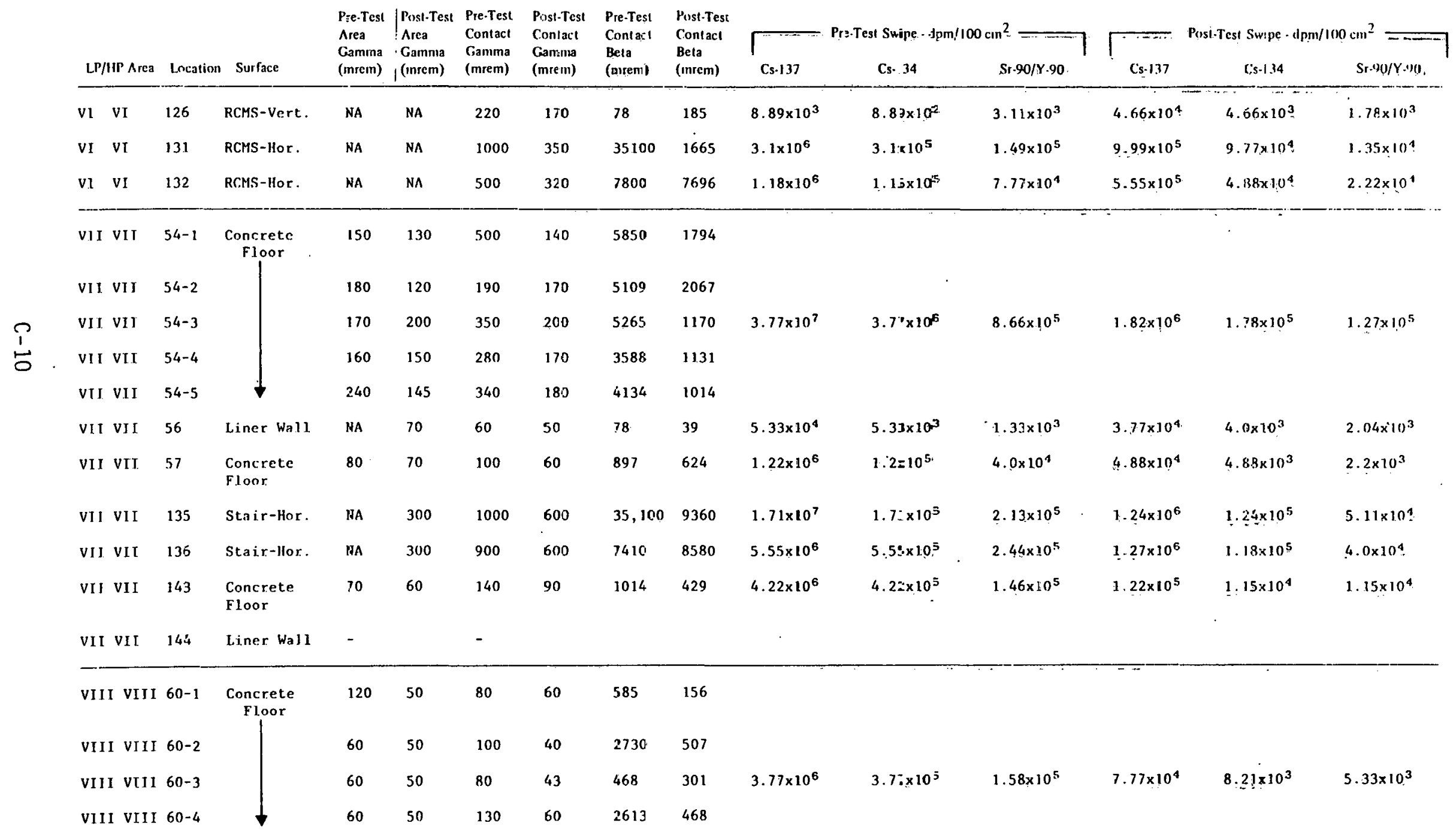


MECHANICAL SCRUBBER TEST - ELEVATION 347'-6"

\begin{tabular}{|c|c|c|c|c|c|c|c|c|c|c|c|c|c|c|c|}
\hline \multirow{3}{*}{$\begin{array}{l}\text { II/ I ! } \\
\text { Irea } \\
\text { Area } \\
\text { AREA }\end{array}$} & \multirow{3}{*}{$\frac{\text { Location }}{153}$} & \multirow[b]{2}{*}{ Surface } & \multirow{2}{*}{$\begin{array}{l}\text { Prc.Test } \\
\text { Area } \\
\text { Gamma } \\
\text { (nrem) }\end{array}$} & \multirow{2}{*}{$\begin{array}{l}\text { Post. Test } \\
\text { Arca } \\
\text { Ganmia } \\
\text { (miremi) }\end{array}$} & \multirow{2}{*}{\multicolumn{2}{|c|}{ 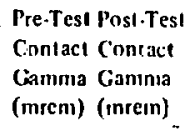 }} & \multirow{2}{*}{\multicolumn{2}{|c|}{ 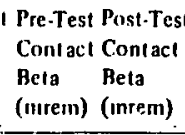 }} & \multirow{2}{*}{$\Gamma_{C s .137}^{1}$} & \multicolumn{2}{|c|}{ Test Swipe - dpm/100 $\mathrm{cm}^{2}$} & \multirow[b]{2}{*}{ Cs. 1.37} & \multicolumn{2}{|c|}{ Post-Test Swipe - dpin $/ 100 \mathrm{~cm}^{2}$} & \multirow[b]{2}{*}{$\begin{array}{l}\text { Chemicit } \\
\text { Sulutution }\end{array}$} \\
\hline & & & & & & & & & & Cs.134 & Sr. $.90 / Y \cdot 90$ & & C..134 & Sr $-00 / \mathrm{Y} \cdot 90$ & \\
\hline & & $\begin{array}{c}\text { Concrete } \\
\text { Floor }\end{array}$ & - & - & 110 & 120 & 160 & 64 & $2.89 \times 10^{5}$ & $2.89 \times 10^{4}$ & $1.44 \times 10^{4}$ & $2.22 \times 10^{3}$ & L.J.J & L.t.1. & \\
\hline \multirow[t]{5}{*}{ IMS } & 156 & & - & .- & 50 & 50 & 320 & 224 & $1.29 \times 10^{5}$ & $1.31 \times 10^{4}$ & $7.1 \times 10^{3}$ & $3.11 \times 10^{4}$ & $3.55 \times 10^{3}$ & $1.22 \times 10^{3}$ & \\
\hline & 93 & & 38 & 39 & 60 & 60 & 320 & 256 & $1.07 \times 10^{5}$ & $1.07 \times 10^{4}$ & $9.1 \times 10^{3}$ & $3.33 \times 10^{3}$ & L[d] & I.I.D & \\
\hline & 96 & & 39 & 40 & 80 & 80 & 256 & 288 & $1.42 \times 10^{5}$ & $1.22 \times 10^{4}$ & $1.13 \times 10^{4}$ & $2.66 \times 10^{3}$ & LIת & LLD & 1 \\
\hline & 157 & & - & - & 60 & 49 & 288 & 227 & $1.22 \times 10^{5}$ & $1.11 \times 10^{4}$ & $8.21 \times 10^{3}$ & $2.66 \times 10^{3}$ & L[ת & LC.D & \\
\hline & 152 & $\downarrow$ & 60 & 60 & 50 & 46 & 160 & 109 & $1.6 \times 10^{5}$ & $1.44 \times 10^{4}$ & $1.44 \times 10^{4}$ & $1.78 \times 10^{3}$ & LID & L.J.D & \\
\hline AREA & 99 & $\begin{array}{c}\text { Concrete } \\
\text { Floor }\end{array}$ & 35 & 34 & 34 & 30 & 131 & 96 & $7.10 \times 10^{4}$ & $7.10 \times 10^{3}$ & $6.44 \times 10^{3}$ & $3.11 \times 10^{3}$ & LL.D & I. . . D & \\
\hline \multirow[t]{5}{*}{ I IMS } & 155 & & - & - & 32 & 29 & 154 & 99 & $7.77 \times 10^{4}$ & $7.55 \times 10^{3}$ & B. $88 \times 10^{3}$ & $2.44 \times 10^{3}$ & LLD. & I.L.II) & \\
\hline & 112 & & - & - & 50 & 44 & 224 & 51 & $5.77 \times 10^{5}$ & $5.55 \times 10^{4}$ & $3.11 \times 10^{4}$ & $4.22 \times 10^{3}$ & LLD & $1.33 \times 10^{2}$ & 2 \\
\hline & 110 & & 31 & 30 & 38 & 34 & 262 & 147 & $3.11 \times 10^{5}$ & $3.11 \times 10^{4}$ & $2.02 \times 10^{4}$ & $3.77 \times 10^{3}$ & I.t.d & $1.55 \times 10^{2}$ & \\
\hline & 154 & & - & - & 60 & 60 & 352 & 256 & $1.98 \times 10^{5}$ & $1.93 \times 10^{4}$ & $1.18 \times 10^{4}$ & $2.2 \times 10^{3}$ & LlD & $2.64 \times 10^{4}$ & \\
\hline & 98 & $t$ & 36 & 36 & 60 & 60 & 320 & 224 & $2.22 \times 10^{5}$ & $2.06 \times 10^{4}$ & $1.35 \times 10^{4}$ & $3.11 \times 10^{3}$ & LLD & $3.55 \times 10^{2}$ & \\
\hline
\end{tabular}




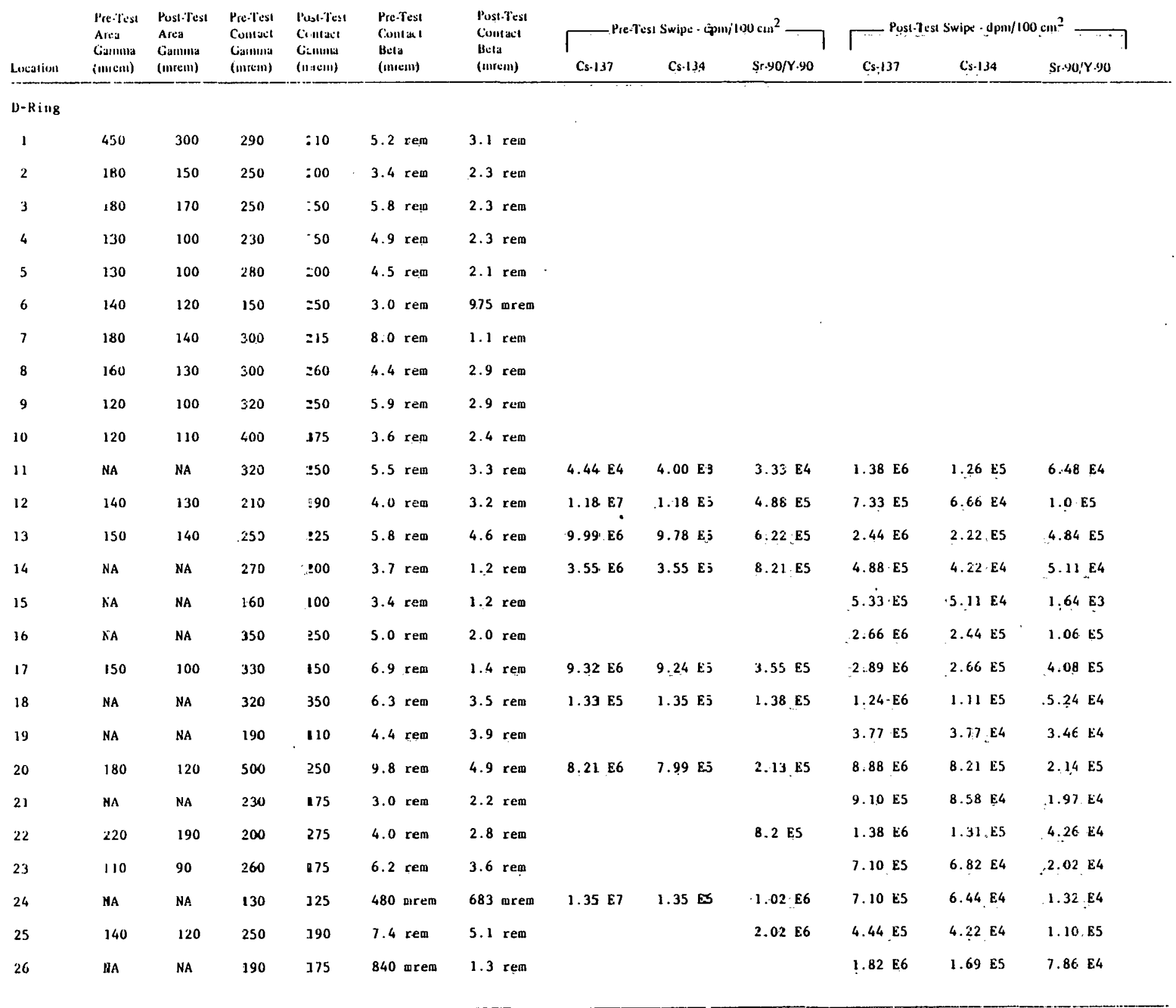




\begin{tabular}{|c|c|c|c|c|c|c|c|c|c|c|c|c|c|c|c|}
\hline \multirow{2}{*}{$\begin{array}{l}\text { Lucation } \\
\text { Refucl ing } \\
\text { Canal }\end{array}$} & \multirow[t]{2}{*}{$\begin{array}{l}\text { Pre-Test } \\
\text { Arca } \\
\text { Gamuna } \\
\text { (Inrem) } \\
\end{array}$} & \multirow[t]{2}{*}{$\begin{array}{l}\text { Posl-Test } \\
\text { Area } \\
\text { Cammana } \\
\text { (inretin) } \\
\end{array}$} & \multirow[t]{2}{*}{$\begin{array}{l}\text { Pre-Test } \\
\text { Contact } \\
\text { Gammaa } \\
\text { (1mrem) }\end{array}$} & \multirow[t]{2}{*}{$\begin{array}{l}\text { Post-Test } \\
\text { Comlacl } \\
\text { Gammat } \\
\text { (Imretil) }\end{array}$} & \multirow[t]{2}{*}{$\begin{array}{l}\text { Pre-Test } \\
\text { Cont act } \\
\text { Beta } \\
\text { (Inrem) }\end{array}$} & \multirow[t]{2}{*}{$\begin{array}{l}\text { Post-Test } \\
\text { Contait } \\
\text { neta } \\
\text { (mrent) }\end{array}$} & \multirow{2}{*}{\multicolumn{2}{|c|}{$\begin{array}{l}\text { Pre-T } \\
\text { Cs. } 1.37\end{array}$}} & \multicolumn{3}{|c|}{ Swipe $\cdot d \mathrm{pm} / 100 \mathrm{~cm}^{2}$} & \multicolumn{4}{|c|}{ Г Pust-Test Swipe $\cdot \mid l p m / 100 \mathrm{~cm}^{2}-$} \\
\hline & & & & & & & & & & & & & & & \\
\hline 6.5 & 210 & 110 & 360 & 180 & $7.4 \mathrm{rem}$ & $3.9 \mathrm{rem}$ & & & & & $9.77 \mathrm{ES}$ & $3.55 \mathrm{~F}$ & F.7 & $3.55 \mathrm{EG}$ & $3.55 \quad 5.6$ \\
\hline 66 & NA & NA & 60 & 42 & 80 inrem & $68 \mathrm{mrem}$ & & & & & $2.89 \mathrm{EJ}$ & $1.09 \mathrm{~F}$ & E.5 & 1.24 F.4 & $4.88 \quad F .3$ \\
\hline 67 & NA & NA & 60 & 44 & $80 \mathrm{mrem}$ & 35 mrem & $1.64 \mathrm{E}$ & E4 & $1.58 \mathrm{E}$ & E3 & LI,D & $5.11 \mathrm{E}$ & E4 & $4.22 \mathrm{~F} .3$ & $1.02 \mathrm{E} .3$ \\
\hline 68 & 340 & 120 & 600 & 200 & $10.4 \mathrm{rem}$ & $3.8 \mathrm{rem}$ & $2.44 \mathrm{E}$ & E7 & $2.44 \mathrm{E}$ & E6 & $1.49 \mathrm{ES}$ & & & & \\
\hline 69 & NA & NA & 460 & 380 & 560 mrem & Neg. & $2.13 \mathrm{E}$ & 65 & $2.15 \mathrm{~F}$ & 54 & $4.88 \mathrm{E} 3$ & 8.66 & F4 & $8.88 \mathrm{E} .3$ & $5.77 \mathrm{~F} .3$ \\
\hline 70 & NA & NA & 600 & 460 & Neg. & $96 \mathrm{mrem}$ & $2.44 \mathrm{~F}$ & E.5 & $2.44 \mathrm{~F}$ & E4 & $7.10 \mathrm{E3}$ & 3.62 & E5 & $3.30 \mathrm{E} 4$ & $1.69 \mathrm{E} .4$ \\
\hline 71 & NA & NA & 100 & 90 & 80 mrem & 32 mrem & $3.55 \mathrm{E}$ & E4 & $3.55 \mathrm{E}$ & E3 & $2.66 \mathrm{E} 3$ & 2.44 & E4 & $2 . \dot{4} 2 E .3$ & $1.46 \mathrm{E} 3$ \\
\hline 72 & 140 & 80 & 300 & 60 & 6.0 rem & 832 mrem & $1.13 \mathrm{E}$ & E7 & $1.09 \mathrm{E}$ & E6 & $5.99 \mathrm{ES}$ & 5.33 & F.6 & $5.11 \mathrm{ES}$ & $4.84 \mathrm{E} .5$ \\
\hline 73 & 100 & 80 & 220 & 60 & $5.5 \mathrm{rem}$ & 704 mrem & $1.75 \mathrm{E}$ & E7 & $1.73 \mathrm{E}$ & E6 & $1.62 \mathrm{E}$ & 2.891 & F.6 & 2.89 E.5 & 5.11 E. \\
\hline 74 & NA & NA & 110 & 90 & $80 \mathrm{mrem}$ & 32 mrem & $6.66 \mathrm{E}$ & E4 & $6.22 \mathrm{E}$ & E3 & $4.44 \mathrm{E.3}$ & 3.55 & E4 & $4.00 \mathrm{E3}$ & 7.1083 \\
\hline 75 & NA & NA & 600 & 410 & Neg. & $32 \mathrm{mrem}$ & $9.10 \mathrm{E}$ & $E 4$ & $8.66 \mathrm{~F}$ & $\mathbf{E 3}$ & $5.99 \quad 6.3$ & 6.44 & E.4 & $7.55 \quad 5.3$ & 5.33 E.3 \\
\hline 76 & NA & NA & 650 & 600 & $600 \mathrm{mrem}$ & Neg. & $4.22 \mathrm{E}$ & ES & $4.00 \mathrm{E}$ & E4 & $1.95 \mathrm{E}$ & 3.77 & F.5 & $4.00 \mathrm{E} 4$ & $4.44 \quad 1.4$ \\
\hline $\begin{array}{l}\text { Fuel } \\
\text { Handil in } \\
\text { Rrivige }\end{array}$ & & . & & & & & & & & & & & & & \\
\hline 78 & 190 & 110 & 220 & 180 & $62 \mathrm{rem}$ & $4.5 \mathrm{rem}$ & $1.4 \times 10$ & $0^{6}$ & $1.4 \times 10$ & & $1.64 \times 10^{5}$ & 1.04 & E6 & $9.55 \quad 84$ & $1.29 \mathrm{F.3}$ \\
\hline 79 & $\mathrm{NA}$ & NA & 180 & 130 & 245 mrem & $96 \mathrm{mrem}$ & $6.44 \mathrm{E}$ & $E 4$ & $6.44 \mathrm{E}$ & E3 & $3.33 \mathrm{E} 3$ & $1.75 \mathrm{t}$ & F.5 & $1.66 \mathrm{E} 4$ & $9.46 \mathrm{K3}$ \\
\hline 80 & NA & NA & 140 & 100 & 140 mrem & $32 \mathrm{mrem}$ & $4.66 \mathrm{E}$ & $E 4$ & $4.66 \mathrm{E}$ & E3 & $4.00 \mathrm{E} .3$ & 9.32 & E4 & $3.55 \mathrm{E} 3$ & 5.318 .3 \\
\hline 81 & 180 & 100 & 230 & 175 & $7.9 \mathrm{rem}$ & $4.2 \mathrm{rem}$ & 355 E6 & 6 & $3.77 \mathrm{E}$ & E5 & $2.66 \mathrm{E5}$ & 2.22 & E5 & $2.18 \mathrm{ES}$ & $2.24 \mathrm{ES}$ \\
\hline 82 & NA & NA & 160 & 140 & 245 mrem & 160 mrem & $6.66 \mathrm{~F}$ & 54 & $7.10 \mathrm{E}$ & E3 & $6.66 \mathrm{E} .3$ & 9.32 & F. 4 & $9.10 \quad \mathrm{~F} .3$ & $4.79 \quad F .3$ \\
\hline 83 & 160 & 140 & 250 & 220 & 8.6 rem & $7.3 \mathrm{rem}$ & $3.33 \mathrm{~F}$ & E6 & $3.11 \mathrm{E}$ & E5 & $1.69 \mathrm{ES}$ & 5.55 & F.5 & $5.11 \mathrm{E.5}$ & $7.57 \mathrm{E} 4$ \\
\hline 84 & $\mathrm{~N} \Lambda$ & $\mathrm{N} \Lambda$ & 120 & 105 & 70 mrem & $48 \mathrm{mrem}$ & & & & & & 7.77 & E.4 & $6.66 \mathrm{~F} .3$ & $8.06 \mathrm{E} .3$ \\
\hline 85 & 250 & 180 & 230 & 210 & $3.7 \mathrm{rem}$ & $2.4 \mathrm{rem}$ & $7.99 \mathrm{~B}$ & E5 & $7.99 \mathrm{E}$ & E4 & $7.33 \mathrm{E} 4$ & LL & D) & LLD & I.LD \\
\hline
\end{tabular}


I.OW PRESSURE FLUSR - D-RINGS, REACTOR SERVICE STRUCTURE, MISSILE SHIELDS, REFUELING CANALS, AND BRINGES

\begin{tabular}{|c|c|c|c|c|c|c|c|c|c|c|c|c|}
\hline Lecation & $\begin{array}{l}\text { Pre.Test } \\
\text { Area } \\
\text { Gamma } \\
\text { (mieıI) }\end{array}$ & $\begin{array}{l}\text { Post. Test } \\
\text { Area } \\
\text { Ganumia } \\
\text { (mremin) }\end{array}$ & $\begin{array}{l}\text { Pre-Test } \\
\text { Contact } \\
\text { Gamma } \\
\text { (mrem) }\end{array}$ & $\begin{array}{l}\text { Post-Test } \\
\text { Contaut } \\
\text { Ganima } \\
\text { (mrela) }\end{array}$ & $\begin{array}{l}\text { Pre.Test } \\
\text { Cont act } \\
\text { Beta } \\
\text { (mrein) }\end{array}$ & $\begin{array}{l}\text { Po:st-Test } \\
\text { Contact } \\
\text { Bela } \\
\text { (mrent) }\end{array}$ & LPre-1 & Swipe - dpm/ & $5 r .90 / Y-90$ & $\ldots=$ Post $-\mathrm{T}$ & wipe - dpm/1 & Sr.904Y.90 \\
\hline \multicolumn{13}{|c|}{$\begin{array}{l}\text { Refueling } \\
\text { Deep End }\end{array}$} \\
\hline 117 & NA & NA & 40 & 18 & 140 mrem & 32 mrem & $4.66 \mathrm{E} 4$ & $4.88 \quad E 3$ & & $3.11 . E 4$ & $3.33 \mathrm{E} 3$ & $2.53 \mathrm{E3}$ \\
\hline 118 & NA & NA & 35 & 19 & 158 mnrem & 131 mrem & $8.66 \mathrm{E} 4$ & B. 21 E3 & 4.00:E3 & $2.89 \mathrm{ES}$ & $2.66: E 4$ & $1.13 \mathrm{E4}$ \\
\hline 119 & 50 & 28 & 200 & 60 & $4.5 \mathrm{rem}$ & 448 mrem & $3.77 \mathrm{E} 6$ & $3.77 \mathrm{E} 5$ & 2.89 ES & $6.44 \mathrm{E} 6$ & $6.94 \mathrm{ES}$ & $6.44 \mathrm{ES}$ \\
\hline 120 & 80 & 18 & 150 & 60 & $3.7 \mathrm{rem}$ & $1.7 \mathrm{rem}$ & $2.89 \mathrm{E} .7$ & $2.89 \mathrm{E} 6$ & 1. $18 \mathrm{E} 6$ & $2.06 \mathrm{E} 7$ & $2.04 \mathrm{E} .6$ & $2.73 \mathrm{E} 7$ \\
\hline 121 & NA & NA & 120 & 22 & 105 mrem & 250, mrem & $8.66 \cdot 84$ & $8.44 \mathrm{E} 3$ & 2.69 E3 & $2.89 \cdot \mathrm{E5}$ & $2.89 \mathrm{E} 4$ & $2.26, E 4$ \\
\hline 122 & NA & NA & 60 & 34 & 595 mrem & 602 . mrem & $7.10 \mathrm{E} 6$ & $6.88 \mathrm{E} 5$ & 2.22 ES & $₫ 1.20 \mathrm{E} 7$ & $1.22 \cdot .6$ & $.5 .39 \mathrm{E5}$ \\
\hline
\end{tabular}


LOW PRESSURE FLUSH - POLAR CRANE

FNTRIES 43 AND 45

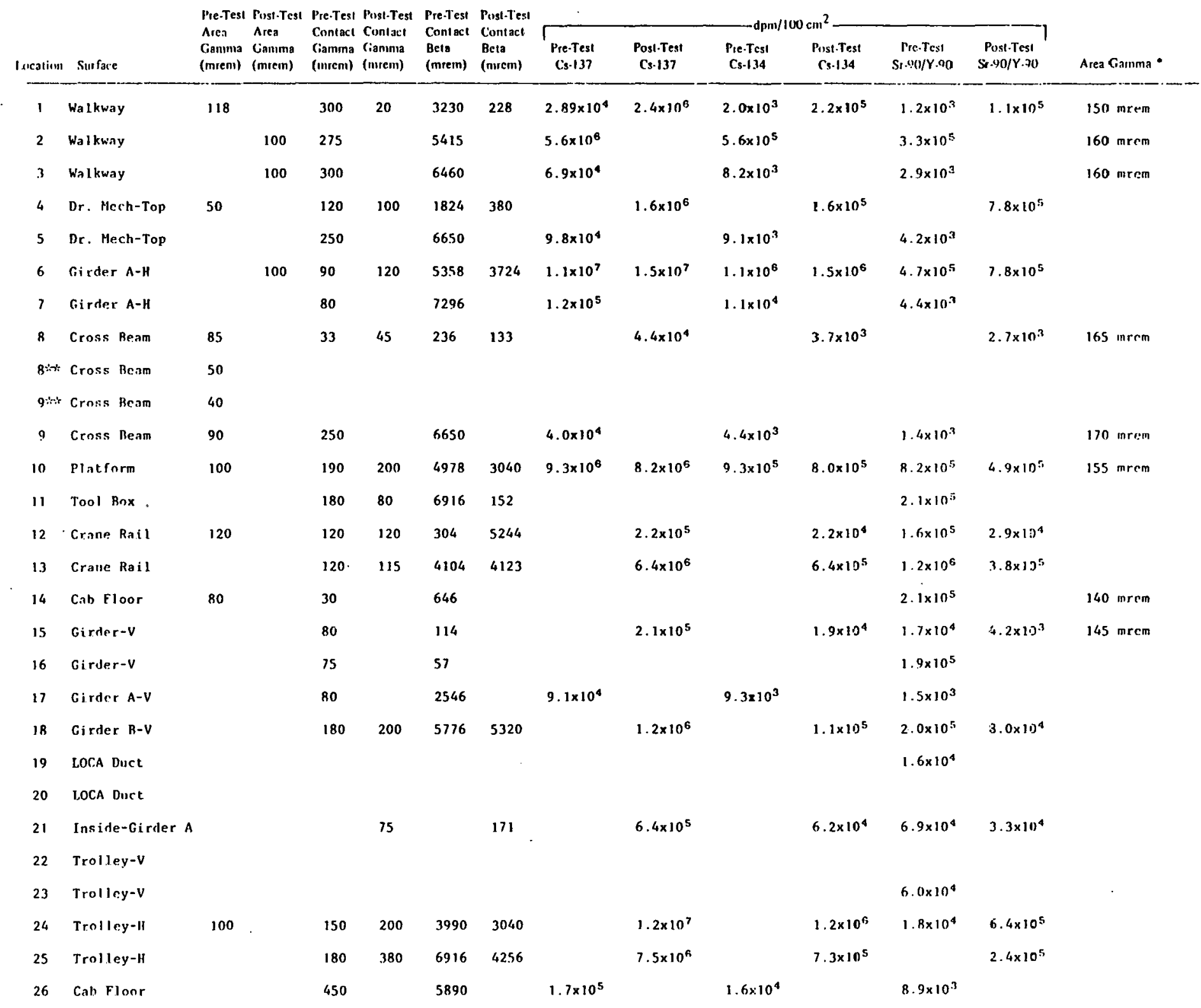


LOW , PRESSURE ELUSH -- POLAR CRANE ENTRIES 43 AND 45

\begin{tabular}{|c|c|c|c|c|c|c|c|c|c|c|c|c|c|c|}
\hline Location & in Surface & $\begin{array}{l}\text { Pre.Test } \\
\text { Area } \\
\text { Gamma } \\
\text { (mrem) }\end{array}$ & $\begin{array}{l}\text { Post-Test } \\
\text { Arça } \\
\text { Gamma } \\
\text { (mrein) }\end{array}$ & $\begin{array}{l}\text { Pre:Test } \\
. \text { Contact } \\
\text { Ganmas } \\
\text { (mrena) }\end{array}$ & $\begin{array}{l}\text { Pcst-Test } \\
\text { Ccntacl } \\
\text { G: mma } \\
\text { (nrem) }\end{array}$ & $\begin{array}{l}\text { Pre-Test } \\
\text { Cont act } \\
- \text { Beta } \\
(\text { (mrem) }\end{array}$ & $\begin{array}{l}\text { Post-Test } \\
\text { Contact } \\
\text { Beta } \\
\text { (mrem) }\end{array}$ & $\begin{array}{l}\text { Pre-Test } \\
\text { Cs-137 }\end{array}$ & $\begin{array}{l}\text { Past-Test } \\
\text { Cs-137 }\end{array}$ & $\begin{array}{l}\text { Pre-Tes! } \\
\text { Cs: 134 }\end{array}$ & $\begin{array}{l}\text { Post. Test } \\
\text { Cs } 134\end{array}$ & $\begin{array}{l}\text { iFre-Trut } \\
\text { sr.90/\%. } 90\end{array}$ & $\begin{array}{c}\text { A Post:Test } \\
\text { Sr-90/Y.90 }\end{array}$ & Arca Gamma * \\
\hline 27 & Cab-Vert. & & & 200 & & 380 & & $3.6 \times 10^{5}$ & & $3.5 \times 10^{3}$ & & $1.7 \times: 0^{4}$ & & \\
\hline 28 & Cab-Vert. & & & 150 & & 190 & & $1.2 \times 10^{5}$ & & $1 . \div \times 10^{3}$ & & $6.4 x: 0^{3}$ & & \\
\hline 29 & Inside Girder-A & & & 100 & 80 & NDB & 209 & $.3 .1 \times 10^{5}$ & $1.2 \times 10^{5}$ & $2: 9 \times 10^{9}$ & 1. $3 \times 10^{4}$ & $1.8 x: .0^{4}$ & $5.6 \times 10^{3}$ & \\
\hline 30 & Liner Wall & 60 & & 60 & $: 0$ & .209 & 266 & $5.8 \times 10^{5}$ & $2.4 \times 10^{5}$ & $-5: 6 \times 10^{3}$ & $2: 7 \times 10^{4}$ & $.4 .0 x: 0^{4}$ & $1: 4 \times 10^{4}$ & \\
\hline 31 & Liner Wall & 50 & & 20 & 95 & 38 & 57 & & $.9 .8 \times 10^{4}$ & & $9.1 \times 10^{3}$ & & $3.1 \times 10^{3}$ & \\
\hline 32 & Dome & & & & $\because 0$ & & 76 & $9.3 \times 10^{4}$ & $6.9 \times 10^{4}$ & $8.2 \times 10^{3}$ & $6.9 \times 10^{4}$ & $3.6 \times: 0^{3}$ & $2.4 \times 10^{3}$ & \\
\hline 33 & Dome & & & & $: 0$ & & 114 & $1.1 \times 10^{5}$ & $6: 2 \times 10^{4}$ & $1: \times 10^{7}$ & $.6 .2 \times 10^{3}$ & $3.6 \times 10^{3}$ & $1.5 \times 10^{3}$ & \\
\hline 34 & Liner.Wall & & & 50 & & 95 & & & & & & & & \\
\hline 35 & Liner WaJ.l & & & 130 & & 1026 & & $1.4 \times 10^{6}$ & & $1: 4 \times 10^{5}$ & & $2.7 \times 10^{4}$ & & \\
\hline 36 & Dome & & & & & & & $2: 7 \times 10^{4}$ & & $2 .{ }^{-} \times 10^{3}$ & & $1.8 \times 10^{3}$ & & \\
\hline 37 & Dome: & & & & & & & & & & & & & \\
\hline 38 & Platform Floor & & & 35 & 200 & 50 & 3040 & & $1.7 \times 10^{6}$ & & $.1 .7 \times 10^{5}$ & & $5: 8 \times 10^{4}$ & \\
\hline 39 & Girder B-Vert. & & & 110 & 200 & 4142 & 3040 & $6.2 \times 10^{6}$ & $3.6 \times 10^{6}$ & $6.2 \times 10^{5}$ & $3.6 \times 10^{5}$ & $2.7 x: 0^{5}$ & $1.1 \times 10^{5}$ & \\
\hline 40 & Rail Top & & & 200 & & 190 & & $2.9 \times 10^{6}$ & & $2.9 \times 10^{5}$ & & $1: 4 \times: 0^{5}$ & & \\
\hline 41 & Rail'Top & & 150 & $18 \mathrm{C}$ & & 8436 & & $4.7 \times 10^{5}$ & & $.4 .4 \times 10^{4}$ & & $5.1 \times: 0^{4}$ & & \\
\hline
\end{tabular}

\section{*Readings taken May 11, 1982}

$\frac{25 \text { e } 10^{\prime}}{60 \text { a }} \frac{1}{1}$ post-test area gamma (teletector instrument)

$H=$ horizontal,$V=$ vertical 
REACTOR BUILDING AIR SAMPLE DATA

February 26, 1982

\begin{tabular}{|c|c|c|c|c|c|c|c|c|c|c|c|c|c|c|c|}
\hline Date & Time & Time & Activity & Gross Alplia & Gross Bela & Cs-137 & Cs. 134 & St.90 & H. 3 & 11 B Bioassay & Gross Alplua & Grost Bets & {$[. s .137$} & C. 134 & sr. $90 / Y \cdot 20$ \\
\hline \multicolumn{16}{|c|}{$\begin{array}{l}2 / 26 / 82 \\
10: 00\end{array}$} \\
\hline & $10: 46$ & $12: 30$ & $\begin{array}{l}\text { HP sur- } \\
\text { vey }\end{array}$ & $1.36 \times 10^{-11}$ & $2.37 \times 10^{-9}$ & $1.6 \times 10^{-9}$ & $1.4 \times 10^{-10}$ & $2.45 \times 10^{-10}$ & $4.5 \times 10^{-8}$ & & $<1.19 \times 10^{-12}$ & $1.15 \times 10^{-7}$ & $1.2 \times 10^{-7}$ & $1.1 \times 10^{-8}$ & $1.8 \times 10^{-3}$ \\
\hline \multirow[t]{5}{*}{$11: 00$} & $11: 00$ & $12: 00$ & $\begin{array}{l}\text { Polar } \\
\text { crane } \\
\text { Protec- } \\
\text { ti.on }\end{array}$ & & & & & & & & $<2.57 \times 10^{-12}$ & $2.28 \times 10^{-7}$ & $1.2 \times 10^{-6}$ & $1.1 \times 10^{-7}$ & $1.1 \times 10^{-3}$ \\
\hline & & & $\begin{array}{l}\text { Instal- } \\
\text { lation } \\
\text { of } 110 \\
\text { extenn- } \\
\text { sion }\end{array}$ & & & & & & & & $<2.37 \times 10^{-12}$ & $5.57 \times 10^{-8}$ & $1.7 \times 10^{-7}$ & $1.5 \times 10^{-8}$ & $2.6 \times 10^{-3}$ \\
\hline & $11: 30$ & $16: 00$ & $\begin{array}{l}\text { Pre- } \\
\text { decon }\end{array}$ & & & & & & & & $1.5 \times 10^{-1.2}$ & B. $47 \times 10^{-8}$ & $2.1 \times 10^{-7}$ & $1.9 \times 10^{-8}$ & $2.5 \times 10^{-7}$ \\
\hline & & & $\begin{array}{l}\text { test } \\
\text { data } \\
\text { acquisi- } \\
\text { tion }\end{array}$ & & & & & & & & $1.92 \times 10^{-12}$ & $1.41 \times 10^{-7}$ & $3.2 \times 10^{-7}$ & $2.8 \times 10^{-8}$ & $3.7 \times 10^{-7}$ \\
\hline & & & & & & & & & & & $<9.08 \times 10^{-13}$ & $4.15 \times 10^{-8}$ & $2.3 \times 10^{-7}$ & $9.9 \times 10^{-9}$ & $9.7 \times 10^{-3} 3$ \\
\hline \multirow[t]{4}{*}{$12: 00$} & & & & & & & & & & & $<8.82 \times 10^{-13}$ & $3.62 \times 10^{-8}$ & $6.3 \times 10^{-8}$ & $5.6 \times 10^{-9}$ & $1.2 \times 10^{-9}$ \\
\hline & $12: 30$ & $14: 00$ & $\begin{array}{l}\text { Protect } \\
\text { rCTV }\end{array}$ & & & & & & & & $4.0 \times 10^{-12}$ & $3.03 \times 10^{-7}$ & $4.4 \times 10^{-7}$ & $3.9 \times 10^{-8}$ & $4.0 \times 10^{-9}$ \\
\hline & & & $\begin{array}{l}\text { Relocate } \\
\text { CCTV }\end{array}$ & & & & & & & & $<1.62 \times 10^{-12}$ & $1.68 \times 10^{-7}$ & $2.3 \times 10^{-7}$ & $2.0 \times 10^{-8}$ & $2.8 \times 10^{-9}$ \\
\hline & & & & & & & & & & & $<1.62 \times 10^{-12}$ & $3.11 \times 10^{-7}$ & $4.5 \times 10^{-7}$ & $4.1 \times 10^{-8}$ & $3.6 \times 10^{-9}$ \\
\hline
\end{tabular}


REACTOR BUILDING AIR SAMPLE DATA

February 26, 1982

\begin{tabular}{|c|c|c|c|c|c|c|c|c|c|c|c|c|c|c|c|}
\hline Dale & Time & Time & Activity & Gross Alpha & Gross Bela & Cs- 1.37 & Cs. 134 & $\mathrm{Sr}_{r} \cdot 90$ & $1 \mathrm{H} \cdot 3$ & H-3 tionsmy & Gross Alpha & Gross neta & C.s. 137 & Cs. 13.4 & 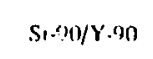 \\
\hline 13:00 & & & $\begin{array}{l}\text { Install } \\
\text { addi- } \\
\text { tional } \\
\text { lighting } \\
\text { at refuel } \\
\text { ing canal. }\end{array}$ & & & & & & & & $<1.5 \times 10^{-12}$ & 5. $1.4 \times 10^{-8}$ & $1.1 \times 10^{-7}$ & $9.4 \times 10^{-3}$ & $1.6 \times 10^{-9}$ \\
\hline \multirow[t]{3}{*}{$14: 00$} & & & & & & & & & & & $2.01 \times 10^{-152}$ & $5.51 \times 10^{-8}$ & $1.1 \times 10^{-3}$ & $1.0 \times 10^{-8}$ & 3. $0 \times 10^{-3}$ \\
\hline & & & & & & & & & & $.0 \times 10^{-5}$ & $<1.21 \times 10^{-12}$ & $1.29 \times 10^{-8}$ & $2.4 \times 10^{-8}$ & $2.0 \times 10^{-9}$ & $6.6 \times 10^{-10}$ \\
\hline & & & & & & & & & & & $1.78 \times 10^{-12}$ & $2.08 \times 10^{-8}$ & $3.9 \times 10^{-8}$ & $3.7 \times 10^{-9}$ & $7.0 \times 10^{-10}$ \\
\hline \multirow[t]{3}{*}{$15: 00$} & & & & & & & & & & & $<5.3 \times 10^{-14}$ & $1.75 \times 10^{-8}$ & $2.3 \times 10^{-8}$ & $2.3 \times 10^{-9}$ & $6.3 \times 10^{-10}$ \\
\hline & & & & & & & & & & & $1.34 \times 10^{-12}$ & $1 . y 1 \times 10^{-8}$ & $3.5 \times 10^{-8}$ & $2.9 \times 10^{-9}$ & $1.0 \times 10^{-9}$ \\
\hline & & & & & & & & & & $3.4 \times 10^{-5}$ & $<1.84 \times 10^{-12}$ & $1.87 \times 10^{-7}$ & $3.1 \times 10^{-7}$ & $2.8 \times 10^{-8}$ & $3.0 \times 10^{-9}$ \\
\hline \multirow[t]{3}{*}{$16: 00$} & & & & & & & & & & $=.7 \times 10^{-5}$ & $3.23 \times 10^{-12}$ & $2.35 \times 10^{-7}$ & $3.2 \times 10^{-7}$ & $2.8 \times 10^{-8}$ & $7.1 \times 10^{-9}$ \\
\hline & & & & & & & & & & & $3.11 \times 10^{-12}$ & $8.7 \times 10^{-8}$ & $1.2 \times 10^{-7}$ & $1.1 \times 10^{-8}$ & $2.6 \times 10^{-9}$ \\
\hline & & & & & & & & & & & $<2.3 \times 10^{-12}$ & $2.7 \times 10^{-8}$ & $4.2 \times 10^{-8}$ & $3.9 \times 10^{-9}$ & $9.8 \times 10^{-10}$ \\
\hline
\end{tabular}

$17: 00$ 
REACTOR BUILDING AIR SAMPLE DATA March 3, 1982

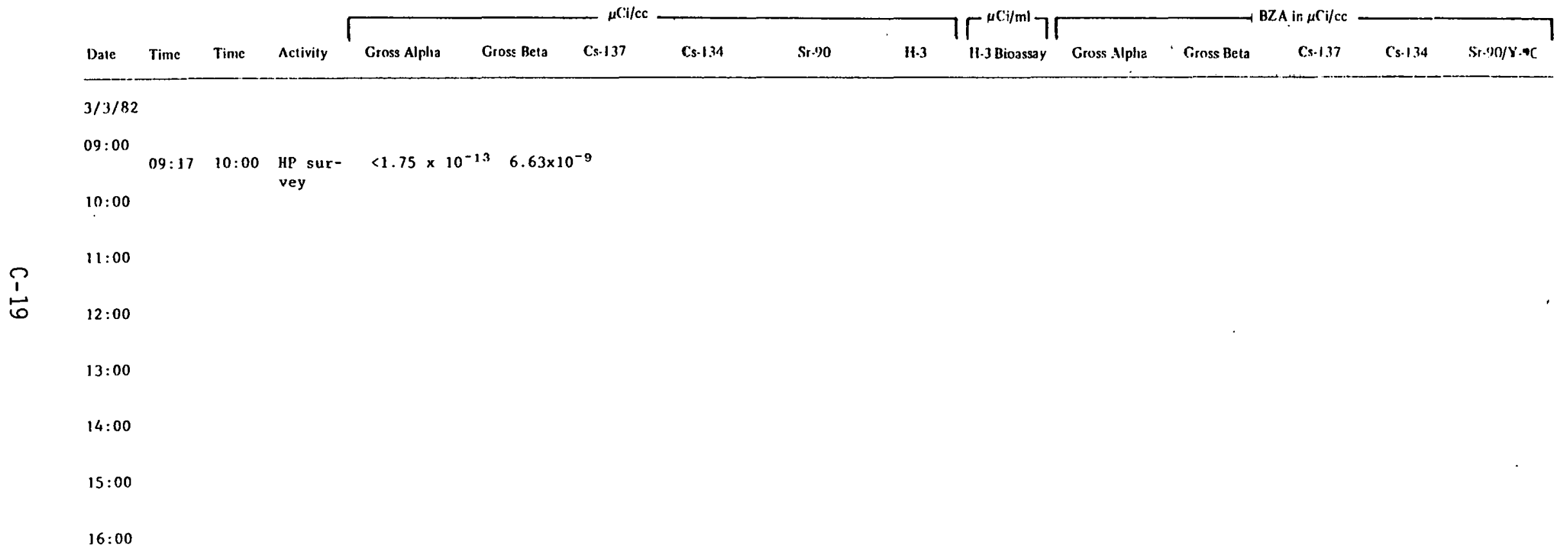


REACTOR RUILDING AIR SAMPLE DATA

March 4, 1982

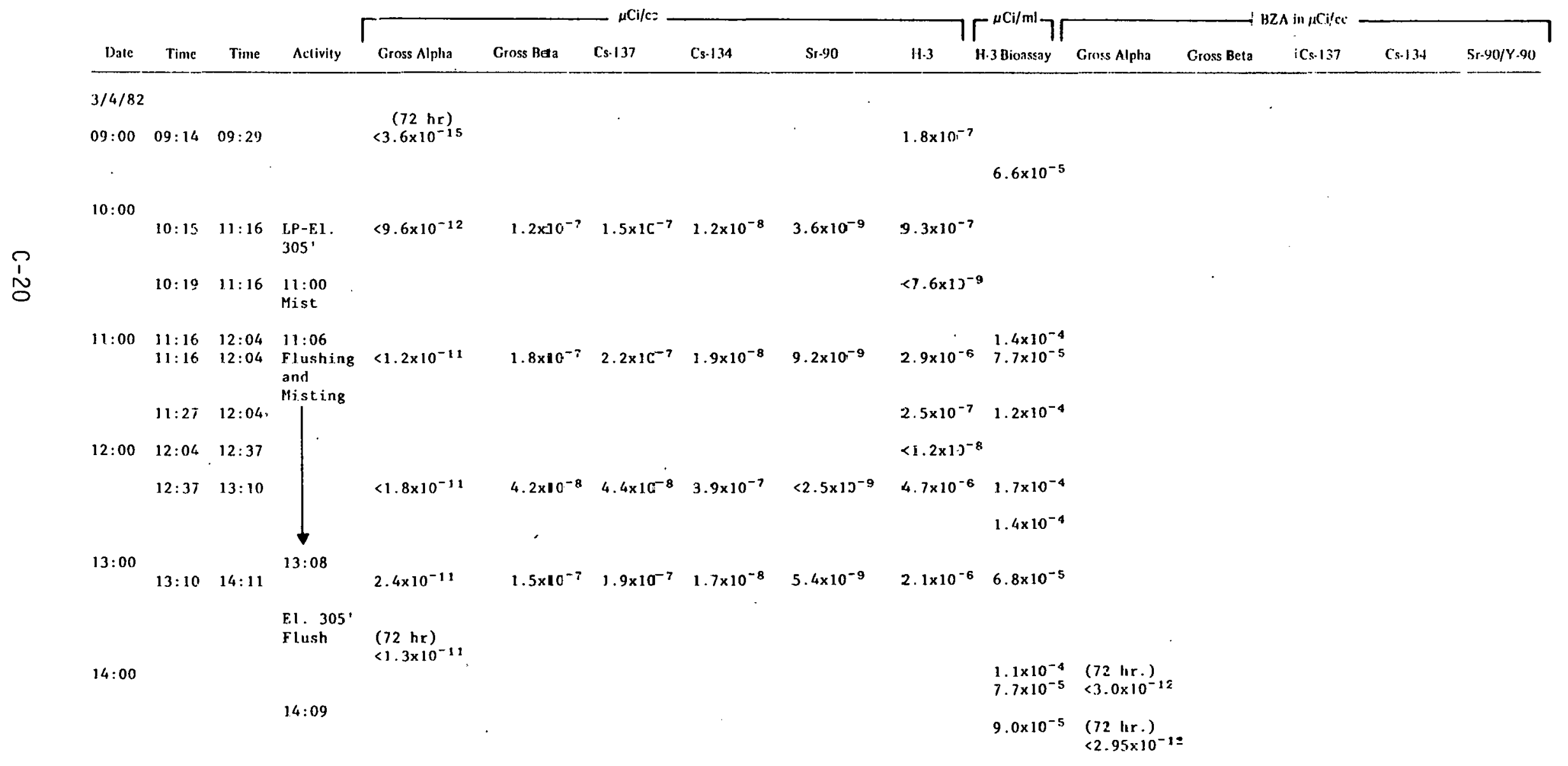


REACTOR BUILDING AIR SAMPLE DATA

$$
\text { March 4, } 1982
$$

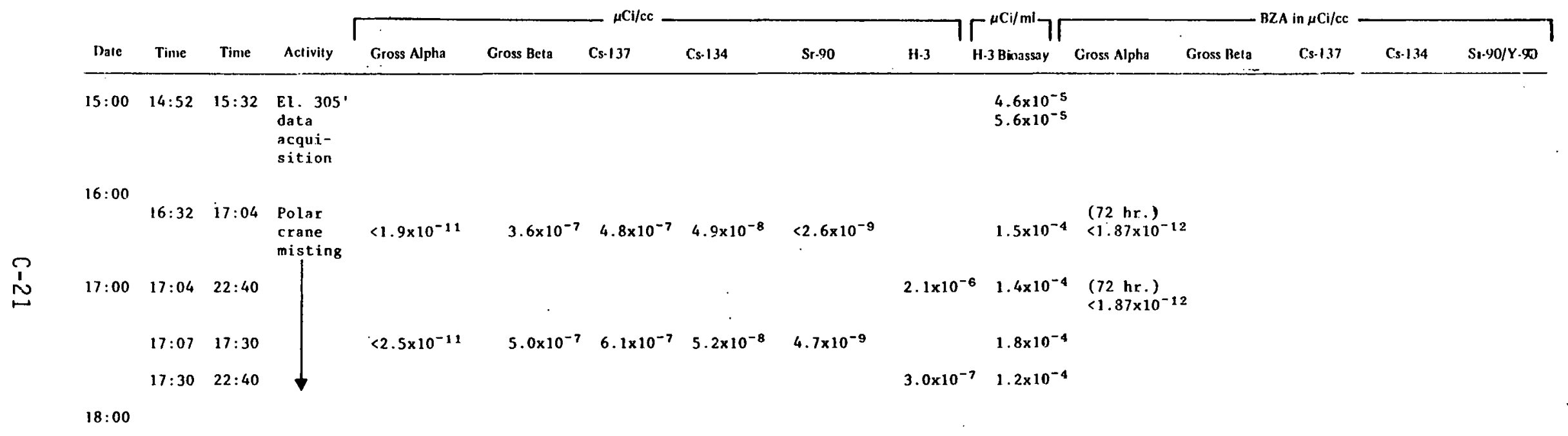


REACTOR BUIIDING AJR SAMPLE DATA

March 5, 1982

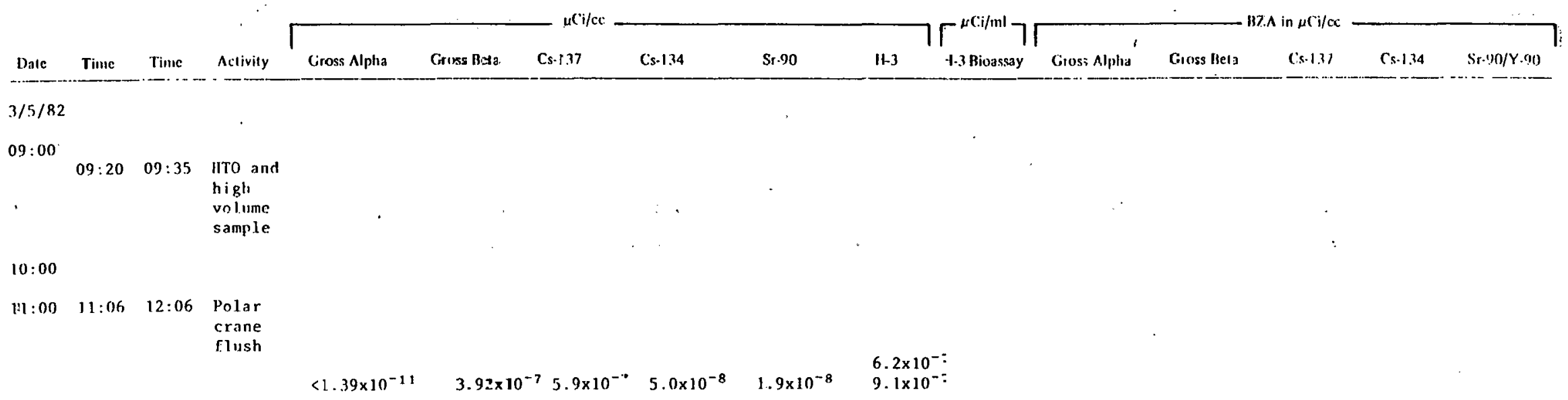

Entry ahorted - high press.tre spray pump leak - no flushing accomplisied 
REACTOR BUILDING AIR SAMPIE DATA

March 8, 1982

\begin{tabular}{|c|c|c|c|c|c|c|c|c|c|c|c|c|c|c|c|}
\hline Date & Time & Time & Activily & Giross Aiplia & Gross Bcta & Cs. 137 & C.s.1.34 & Sr.90 & H.3 & 11. 3 Bioassay & Gross Alphia & Gross Beta & Cs-1.37 & C's.134 & Sr.90/r 90 \\
\hline \multicolumn{16}{|l|}{$3 / 8 / 82$} \\
\hline $09: 00$ & $09: 29$ & $09: 1,4$ & $\begin{array}{l}\text { High } \\
\text { voliume } \\
\text { and } \\
\text { HTO } \\
\text { samples }\end{array}$ & & . & & & & $2.1 \times 10^{-7}$ & $7.4 \times 10^{-5}$ & $<1.97 \times 10^{-12}$ & $7.4 \times 10^{-8}$ & $1.1 \times 10^{-7}$ & $1.2 \times 10^{-8}$ & $4.2 k a^{-9}$ \\
\hline $10: 00$ & $10: 15$ & $10: 32$ & $\begin{array}{l}\text { Collect } \\
2 \text { HTO's }\end{array}$ & & . & & & & & & $<9.0 \times 10^{-12}$ & $2.0 \times 10^{-8}$ & $2.6 \times 10^{-8}$ & $2.7 \times 10^{-9}$ & $<7.2=10^{-10}$ \\
\hline & $10: 39$ & $12: 19$ & $\begin{array}{l}\text { Polar } \\
\text { crane } \\
\text { fjush }\end{array}$ & & & & & & & & $\begin{array}{l}<1.12 \times 10^{-12} \\
<1.14 \times 10^{-12} \\
<1.1 \times 10^{-12}\end{array}$ & $\begin{array}{l}6.3 \times 10^{-8} \\
1.0 \times 10^{-7} \\
6.13 \times 10^{-8}\end{array}$ & $\begin{array}{l}6.6 \times 10^{-8} \\
1.4 \times 10^{-7} \\
8.0 \times 10^{-8}\end{array}$ & $\begin{array}{l}5.7 \times 10^{-9} \\
1.4 \times 10^{-8} \\
8.6 \times 10^{-9}\end{array}$ & $\begin{array}{l}1.6 \times c^{-8} \\
9.6 \times c^{-9} \\
7.5 \times C^{-9}\end{array}$ \\
\hline $11: 00$ & & & & & & & & & & & & & & & \\
\hline $12: 00$ & & & & & & & & & & & & & & & \\
\hline $13: 00$ & & & & & & & & & & & & & & & \\
\hline $14: 00$ & & & & & & & & & & & & & & & \\
\hline $15: 00$ & $15: 22$ & $16: 33$ & $\begin{array}{l}\text { HTO } \\
\text { samples }\end{array}$ & & & & & & $3.0 \times 10^{-6}$ & . & - & & & & \\
\hline $16: 00$ & $15: 42$ & $16: 41$ & $\begin{array}{l}\text { Flush B } \\
\text { D-ring, } \\
\text { Missile } \\
\text { shiclds }\end{array}$ & & , & & & & & $\begin{array}{l}3.2 \times 10^{-4} \\
1.6 \times 10^{-4} \\
1.7 \times 10^{-4}\end{array}$ & $\begin{array}{l}<2.46 \times 10^{-12} \\
<1.6 \times 10^{-12} \\
<1.69 \times 10^{-12}\end{array}$ & $\begin{array}{l}1.2 \times 10^{-7} \\
3.2 \times 10^{-8} \\
9.2 \times 10^{-8}\end{array}$ & $\begin{array}{l}2.0 \times 10^{-7} \\
4.0 \times 10^{-8} \\
1.2 \times 10^{-7}\end{array}$ & $\begin{array}{l}2.1 \times 10^{-8} \\
3.5 \times 10^{-9} \\
1.1 \times 10^{-8}\end{array}$ & $\begin{array}{l}1.9 \times C^{-8} \\
4.1 \times \mathrm{IC}^{-8} \\
1.2 \times \mathrm{iC}^{-8}\end{array}$ \\
\hline
\end{tabular}

$17: 00$

18:00 
FFACTOR BUILDING AIR SAMFLE DATA March 10, 1982

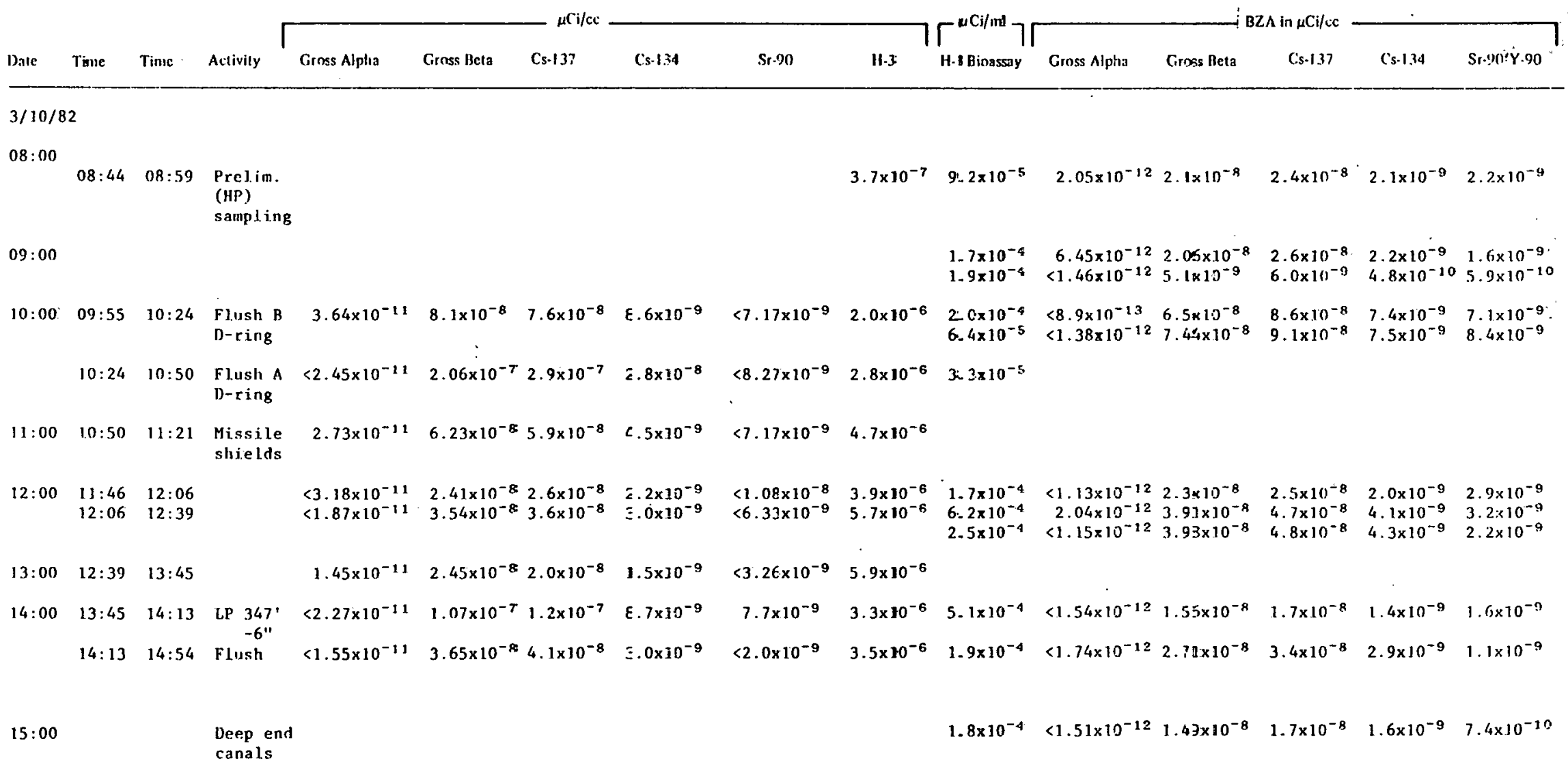


REACTOR BUILDING AIR SAMPLE DATA

March 11, 1982

\begin{tabular}{|c|c|c|c|c|c|c|c|c|c|c|c|c|c|c|c|}
\hline Date & Time & Time & Activity & Gross Alpliã & Gross Beta & Cs. 137 & C.s. $1 \leqslant 4$ & Sr-90 & H.3 & H.3 Bioassay & Gross Alplıa & Gross Beta & C.s -137 & Cs-1.34 & Sr.90/Y.c $\subseteq 0$ \\
\hline \multicolumn{16}{|c|}{$3 / 11 / 82$} \\
\hline \multicolumn{16}{|l|}{ 09:00 } \\
\hline \multicolumn{16}{|l|}{$10: 00$} \\
\hline & $10: 05$ & $10: 58$ & $\begin{array}{l}\text { Data } \\
\text { acquisisi- } \\
\text { tion }\end{array}$ & & & & & & & $5.1 \times 10^{-4}$ & & & & & \\
\hline & $10: 21$ & $11: 24$ & Refueling & & & & & & & $3.5 \times 10^{-5}$ & $2.9 \times 10^{-12}$ & $7.19 \times 10^{-9}$ & $8.7 \times 10^{-9}$ & $8.7 \times 10^{-10}$ & $1.6 \times 10^{-9}$ \\
\hline $11: 00$ & & . & D-rings & & & & & & & & & & & & \\
\hline \multicolumn{16}{|l|}{$12: 00$} \\
\hline $13: 00$ & $12: 53$ & $14: 19$ & & & & & & & & $2.3 \times 10^{-4}$ & $2.9 \times 10^{-12}$ & $7.5 \times 10^{-9}$ & $8 . B \times 10^{-9}$ & $8.9 \times 10^{-10}$ & $6.7 \times 10^{-10}$ \\
\hline & $13: 04$ & 13:59 & Flushing & $2.38 \times 10^{-11}$ & $1.24 \times 10^{-8}$ & $1.8 \times 10^{-8}$ & $1.7 \times 10^{-9}$ & $<4.5 \times 10^{-9}$ & $8.2 \times 10^{-7}$ & $3.2 \times 10^{-5}$ & $2.1 \times 10^{-12}$ & $3.5 \times 10^{-8}$ & $4.5 \times 10^{-8}$ & $4.4 \times 10^{-9}$ & $2.4 \times 10^{-9}$ \\
\hline $14: 00$ & $13: 59$ & $14: 13$ & $\begin{array}{l}\text { on } \\
\text { El. } 3471\end{array}$ & $<4.28 \times 10^{-11}$ & $1.26 \times 10^{-8}$ & $3.3 \times 10^{-8}$ & $1.5 \times 10^{-9}$ & $<1.75 \times 10^{-8}$ & $5.9 \times 10^{-7}$ & & $\begin{array}{c}<.2 \times 10^{-12} \\
2.15 \times 10^{-12}\end{array}$ & $\begin{array}{l}6.8 \times 10^{-8} \\
2.93 \times 10^{-8}\end{array}$ & $\begin{array}{l}6.1 \times 10^{-8} \\
3.4 \times 10^{-8}\end{array}$ & $\begin{array}{l}5.4 \times 10^{-9} \\
2.9 \times 10^{-9}\end{array}$ & $\begin{array}{l}1.2 \times 10^{-9} \\
8.8 \times 10^{-10}\end{array}$ \\
\hline $15: 00$ & & & & & & & & & & & & & & & \\
\hline & $15: 18$ & $16: 09$ & & & & & & & & $\begin{array}{l}3.1 \times 10^{-4} \\
3.6 \times 10^{-5}\end{array}$ & $\begin{array}{l}<2.3 \times 10^{-12} \\
<2.1 \times 10^{-12}\end{array}$ & $\begin{array}{l}8.8 \times 10^{-9} \\
3.4 \times 10^{-8}\end{array}$ & $\begin{array}{l}1.2 \times 10^{-8} \\
4.1 \times 10^{-8}\end{array}$ & $\begin{array}{l}8.6 \times 10^{-10} \\
3.4 \times 10^{-9}\end{array}$ & $\begin{array}{l}7.3 \times 10^{-30} \\
2.7 \times 10^{-9}\end{array}$ \\
\hline $16: 00$ & $15: 49$ & $16: 15$ & $\downarrow$ & $<2.48 \times 10^{-11}$ & $2.9 \times 10^{-8}$ & $3.7 \times 10^{-8}$ & $3.9 \times 10^{-9}$ & $4.4 \times 10^{-9}$ & $6.1 \times 10^{-7}$ & $8.9 \times 10^{-4}$ & $3.2 \times 10^{-12}$ & $2.2 \times 10^{-8}$ & $2.4 \times 10^{-8}$ & $2.2 \times 10^{-9}$ & $1.5 \times 10^{-9}$ \\
\hline
\end{tabular}

$17: 00$

$18: 00$ 


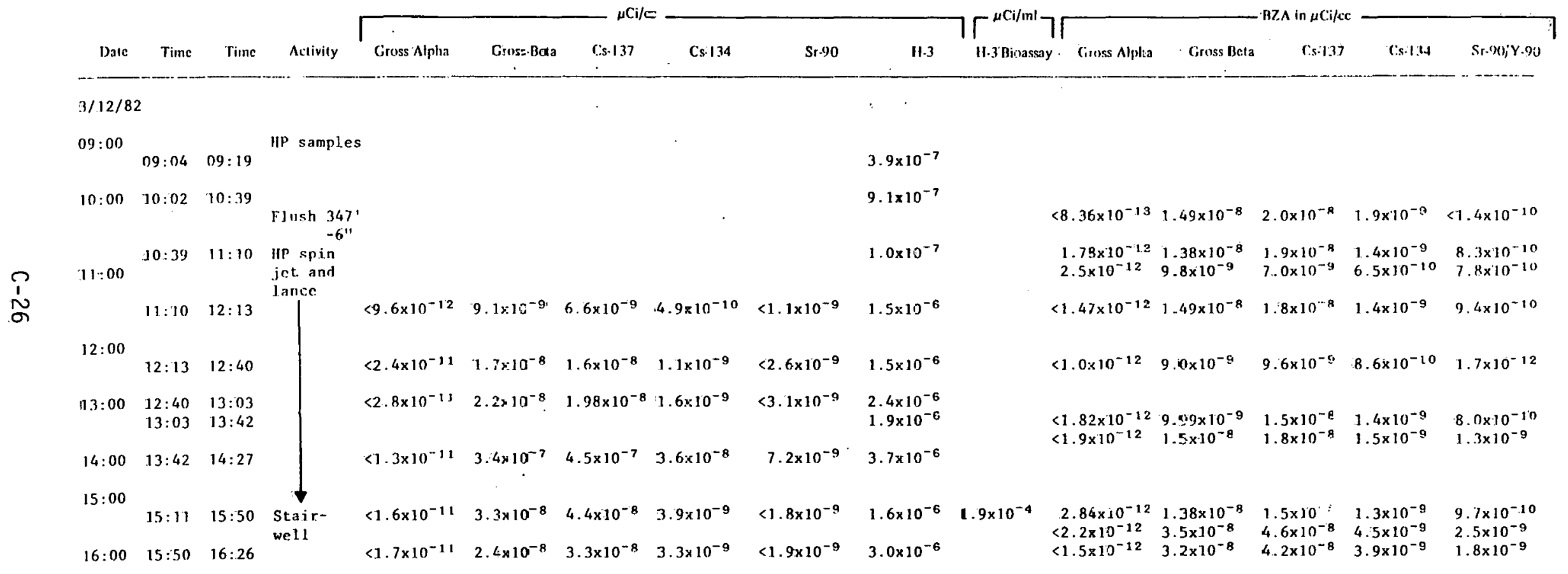

$17: 00$

$18: 00$ 
REACTOR BUILDING AIR SAMPLE DATA March 15, 1982

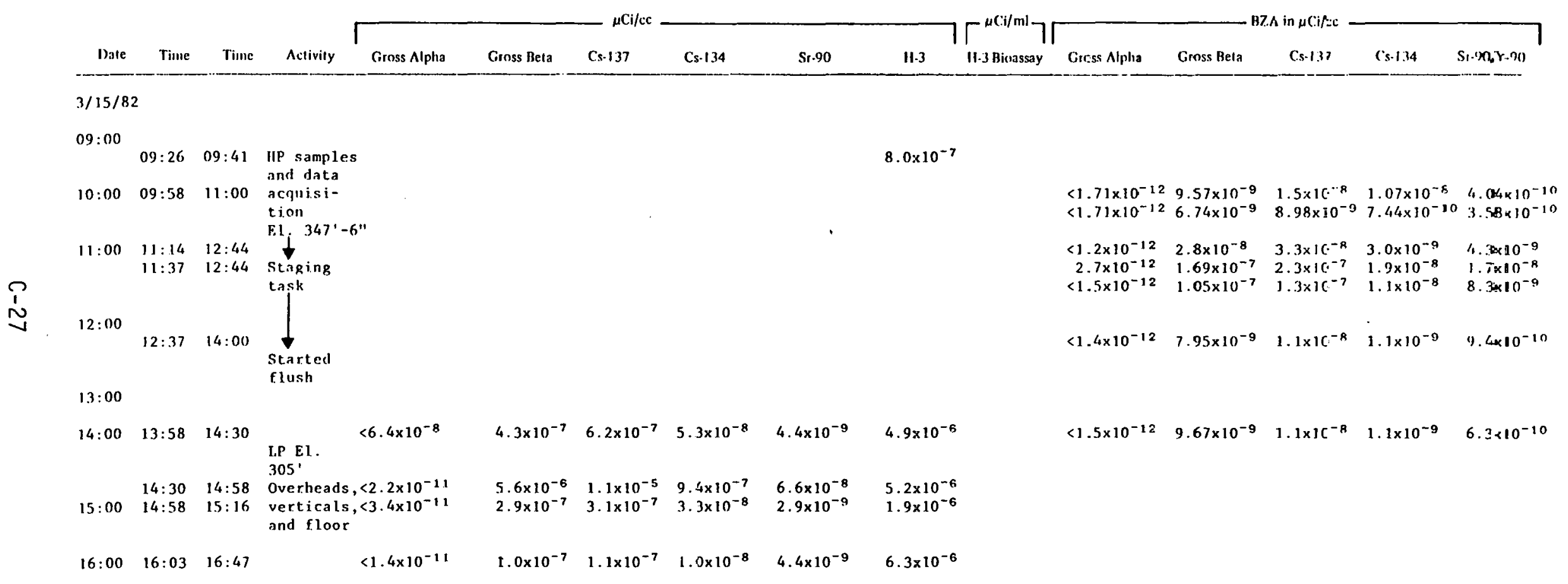

$17: 00$

$18: 00$ 
ZEACTOR BUILDING AIR SAMPLE DATA

March 17, $19: 32$

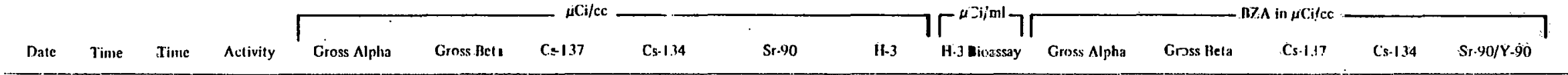

$3 / 17 / 82$

09:00 09:10 09:25

$14 \times 10^{-\epsilon}$

$10: 00$

$$
\text { I.P flush }
$$

$N_{\infty}^{1}$

$\underbrace{1}_{\infty}$

$11: 00$

open
open

stair-

wel.l

$<1.4 \times 10^{-11}$

$(10: 45)$

IIP f.lush

open

stair

$11: 38 \quad 12: 07 \quad$ well

12:00 12:08 12:48 Spin jet

flush

$(12: 04)$

I.ance

flush

13:00

$(12: 42)$

$14: 00$

15:00 14:59 15:34 Area 10

$\begin{aligned} & \text { ambient } \\ & \text { spin jet } \\ & (15: 13)\end{aligned}$

$\begin{aligned} & \text { ambient } \\ & \text { spin jet } \\ & (15: 13)\end{aligned}$

$\begin{aligned} & \text { ambient } \\ & \text { spin jet } \\ & (15: 13)\end{aligned}$
$<1.7 \times 10^{-14} \quad 6.43 \times 10^{-8} \quad 6.7 \times 10^{-8} \quad 5.7 \times 10^{-9} \cdot 2.9 \times 10^{-9}$

$<1.6 \times 10^{-12} \quad 5.26 \times 10^{-8} \quad 5.5 \times 10^{-8} \quad 4.8 \times 10^{-9} \quad 2.1 \times 10^{-9}$

$7.0 \times 10^{-12} \quad 5.7 \times 10^{-8} \quad 2.0 \times 10^{-9} \quad 1.8 \times 10^{-10} \quad 3.35 \times 10^{-9}$

$<2.06 \times 10^{-11} \quad 1.43 \times 10^{-7} \quad 2.2 \times 10^{--} \quad 1.8 \times 10^{-8} \quad 2.25 \times 10^{-8} \quad 4.8 \times 10^{-6}$

$4.9 \times 10^{-7}$

$\begin{array}{rrrrr}1.89 \times 10^{-12} & 4.55 \times 10^{-8} & 5.3 \times 10^{-8} & 4.4 \times 10^{-9} & 3.0 \times 10^{-9}\end{array}$

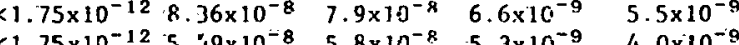

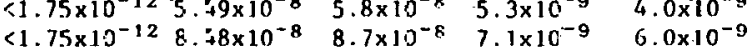

$3.0 \times 10^{-6}$ 
REACTOR BUILDING AIR SAMPLE DATA March 17, 1982

\begin{tabular}{|c|c|c|c|c|c|c|c|c|c|c|c|c|c|c|c|}
\hline \multirow[b]{2}{*}{ Date } & \multirow[b]{2}{*}{ Timc } & \multirow[b]{2}{*}{ Time } & \multirow[b]{2}{*}{ Activity } & & & $\mu^{\mu}, 1 / 4$ & \multirow[b]{2}{*}{ Cs -134} & \multirow[b]{2}{*}{ St.90 } & \multirow[b]{2}{*}{ H.3 } & \multirow{2}{*}{$\left.\mid \Gamma_{\mathrm{H}-3 \text { Bicassay }}^{\mu \mathrm{Ci} i m \mathrm{ml}}\right\rceil \mid$} & \multirow[b]{2}{*}{ Gross Npha } & \multirow[b]{2}{*}{ Gross Beta } & \multirow{2}{*}{$\begin{array}{l}\text { in } y_{\mathrm{C}} \mathrm{C} / \mathrm{cc} \\
\mathrm{C} \cdot 137\end{array}$} & \multirow[b]{2}{*}{ C.s.1.34 } & \multirow{2}{*}{ Sr-90/Y $\cdot 90$} \\
\hline & & & & Cross Alpla & Gross Bcla & Cs. 137 & & & & & & & & & \\
\hline & & & $\begin{array}{l}\text { Area } 10 \\
\text { ambient } \\
\text { lance } \\
(15: 16)\end{array}$ & & & & & & & & & & & & \\
\hline & & & $\begin{array}{l}\text { Area } 11 \\
\text { flush } \\
(15: 32)\end{array}$ & & & & & & & & & & & & \\
\hline $16: 00$ & & & & & & & & & & & & & & & \\
\hline
\end{tabular}


EeActor ruilding air sample data

March 18, 1982

\begin{tabular}{|c|c|c|c|c|c|c|c|c|c|c|c|c|c|c|c|}
\hline Dalc & Time & Timinc & Activity & Gross Alpha & Gross Beta & Cs.137 & $C_{s-1134}$ & $\mathrm{Sr} \cdot 90$ & H.3 & H1.3 Rivassay & Grisss Alpla & Grnss Beta & Cs. 137 & Cs.1.144 & $\operatorname{Sr} \cdot 90 / Y \cdot 90$ \\
\hline \multicolumn{16}{|c|}{$3 / 18 / 82$} \\
\hline $12: 00$ & & & & & & - & & & & & & & & & \\
\hline & $12: 30$ & $14: 00$ & $\begin{array}{l}\text { HP survey } \\
\text { coverage }\end{array}$ & & & & & $\cdot$ & & & & & & & \\
\hline 13:00 & $13: 00$ & $14: 00$ & $\begin{array}{l}\text { Trash } \\
\text { removal }\end{array}$ & & & & & & & & $\begin{array}{l}<1.82 \times 10^{-12} \\
<1.93 \times 10^{-12} \\
<2.05 \times 10^{-12} \\
<2.2 \times 10^{-12}\end{array}$ & $\begin{array}{l}7.1 \times 10^{-9} \\
5.7 \times 10^{-9} \\
1.9 \times 10^{-8} \\
1.2 \times 10^{-8}\end{array}$ & $\begin{array}{l}1.0 \times 10^{-8} \\
9.3 \times 10^{-3} \\
2.8 \times 10^{-8} \\
1.6 \times 10^{-8}\end{array}$ & $\begin{array}{l}1.1 \times 10^{-9} \\
9.1 \times 10^{-10} \\
2.2 \times 10^{-9} \\
1.5 \times 10^{-9}\end{array}$ & $\begin{array}{l}3.0 \times 10^{-16} \\
2.4 \times 10^{-16} \\
1.3 \times 10^{-9} \\
8.1 \times 10^{-10}\end{array}$ \\
\hline
\end{tabular}

$14: 00$

$15: 00$ 
REACTOR RUILDING AIR SAMPLE DATA

March 19,1982

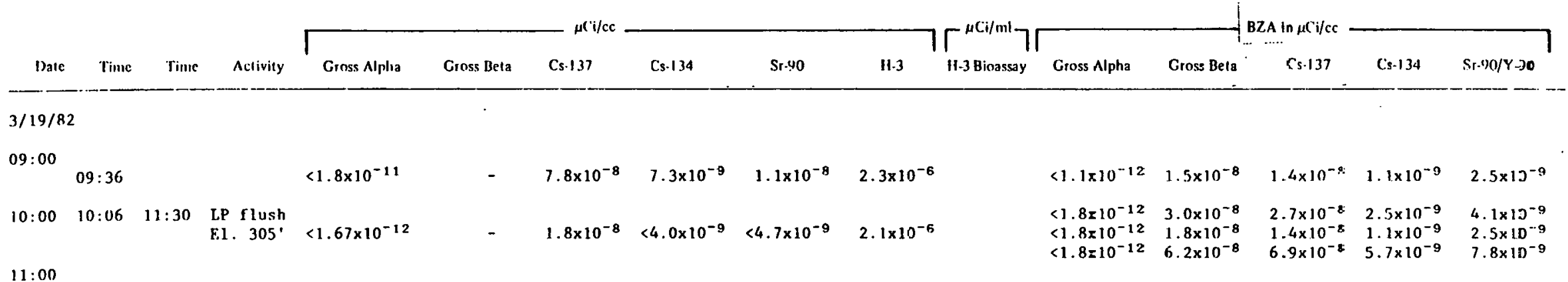

w 12:00 
REACTOR BUILDING AIR SAMPLE DATA

March 25, 1982

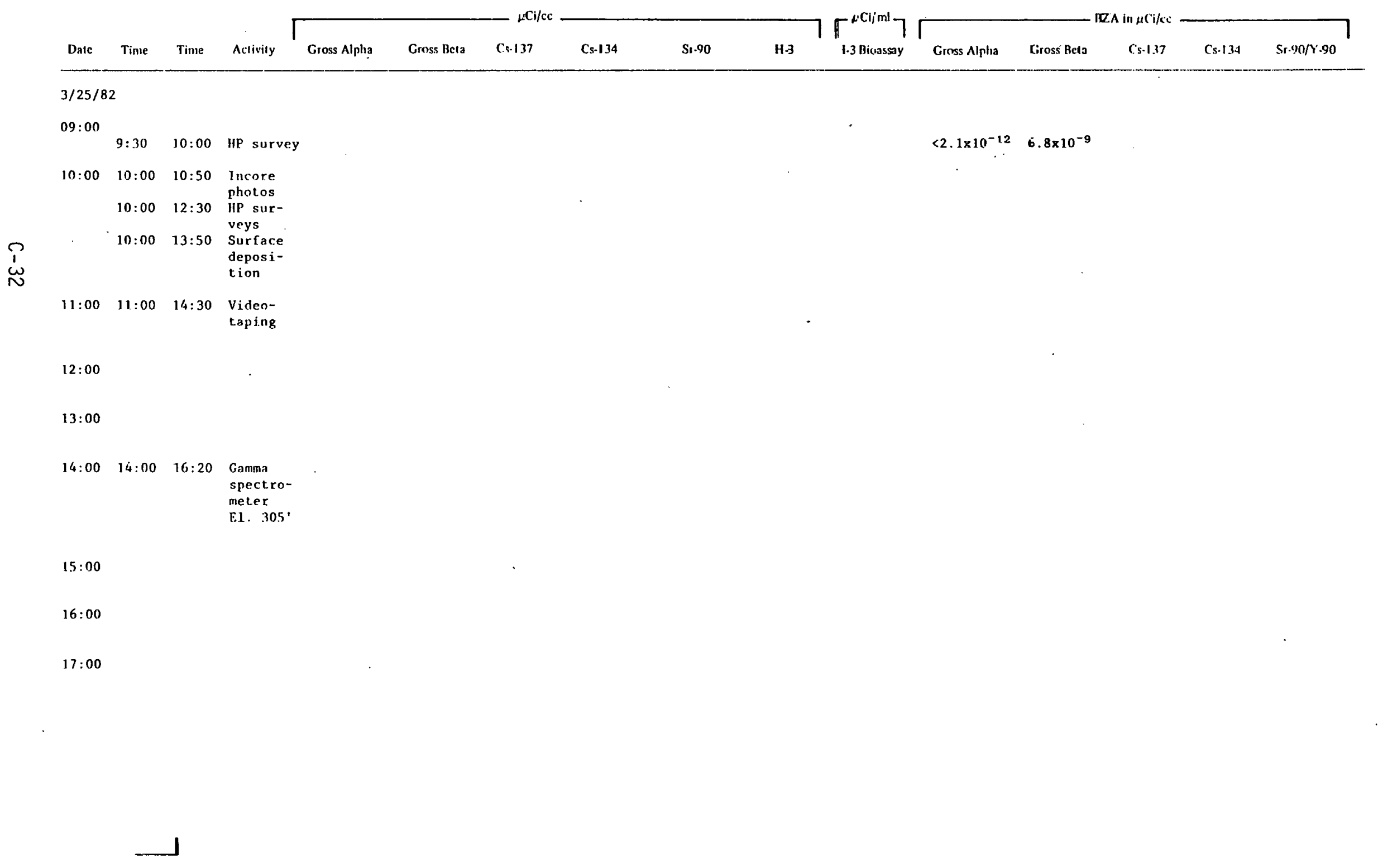


REICTOR BUILDING AIR SAMPLE DATA

$$
\text { March 26, } 1982
$$

\begin{tabular}{|c|c|c|c|c|c|c|c|c|c|c|c|c|c|c|c|}
\hline Date & Time & Time & Aclivity & Gross NIpha & Gross Beta & Cs-137 & Cs. 134 & Sr.90 & H. 3 & H.3 Bioassay & Gross Alpha & Gross Beta & C.s. 37 & Cs 134 & Sr-90; Y-90 \\
\hline \multicolumn{16}{|c|}{$3 / 26 / 82$} \\
\hline $09: 00$ & $09: 30$ & $10: 00$ & HP survey & . & & & & & & & $3.09 \times 10^{-12}$ & $1.8 \times 10^{-8}$ & $1.9 \times 10^{-8}$ & $1.6 \times 10^{-9}$ & $2.3 \times 10^{-9}$ \\
\hline $10: 00$ & $10: 00$ & $13: 00$ & $\begin{array}{l}\text { Surface } \\
\text { deposi- } \\
\text { tion } \\
\text { samples }\end{array}$ & $\cdot$ & & & & & & & $<402 \times 10^{-13}$ & $2.2 \times 10^{-10}$ & $1.2 \times 10^{-9}$ & $<1.6 \times 10^{-10}$ & $<2.7 \times 10^{-10}$ \\
\hline & $10: 30$ & $12: 30$ & $\begin{array}{l}\text { Polar } \\
\text { crane }\end{array}$ & & & & & & & & $\begin{array}{l}3.2 \times 10^{-12} \\
4.29 \times 10^{-12}\end{array}$ & $\begin{array}{l}4.1 \times 10^{-8} \\
5.97 \times 10^{-9}\end{array}$ & $\begin{array}{l}5.3 \times 10^{-8} \\
4.4 \times 10^{-8}\end{array}$ & $\begin{array}{l}4.2 \times 10^{-9} \\
3.5 \times 10^{-9}\end{array}$ & $\begin{array}{l}2.7 \times 10^{-9} \\
2.2 \times 10^{-9}\end{array}$ \\
\hline 11:00 & & & $\begin{array}{l}\text { survey } \\
\text { and } \\
\text { photoss }\end{array}$ & & & & & & & & $6.95 \times 10^{-12}$ & $5.27 \times 10^{-8}$ & $6.7 \times 10^{-8}$ & $5.4 \times 10^{-9}$ & $2.3 \times 10^{-9}$ \\
\hline $12: 00$ & $12: 30$ & $12: 50$ & $\begin{array}{l}\text { Rig gamma } \\
\text { spectro- } \\
\text { meter/ } \\
\text { equipment }\end{array}$ & & & & & & & & $\begin{array}{c}2.8 \times 10^{-12} \\
3.2 \times 10^{-12} \\
<2.14 \times 10^{-12}\end{array}$ & $\begin{array}{l}5.8 \times 10^{-9} \\
7.2 \times 10^{-9} \\
1.63 \times 10^{-8}\end{array}$ & $\begin{array}{l}5.4 \times 10^{-3} \\
8.5 \times 11^{-9} \\
2.6 \times 11^{-8}\end{array}$ & $\begin{array}{l}4.2 \times 10^{-10} \\
8.5 \times 10^{-10} \\
1.8 \times 10^{-9}\end{array}$ & $\begin{array}{l}4.3 \times 10^{-10} \\
8.7 \times 10^{-10} \\
1.4 \times 10^{-9}\end{array}$ \\
\hline 13:00 & $13: 30$ & $15: 00$ & $\begin{array}{l}\text { Gamma } \\
\text { spectro- } \\
\text { meler. } \\
\text { measure- } \\
\text { ment }\end{array}$ & & & & & & & & & & & & \\
\hline 14:00 & $14: 00$ & $17: 00$ & $\begin{array}{l}\text { Strip- } \\
\text { patle } \\
\text { coating } \\
\text { test } \\
\text { E1. } 347^{\prime}-6^{\prime \prime} \\
\text { and } 305^{\prime}\end{array}$ & & & & & & & & & & & & \\
\hline
\end{tabular}


SEACTOR BUILDING AIR SAMPIE DATA

March 26, 1982

\begin{tabular}{|c|c|c|c|c|c|c|c|c|c|c|c|c|c|c|c|}
\hline Datc & Time: & Time & Activity & Cross Alphia & Gross Beta & C. 137 & Cs-1.34 & Sr-90 & H.3 & ;-3 Bioassay & Gross Alpha & J̈ross Bela & Cs-1.17 & Cs 1.34 & $S \mathrm{r} \cdot(n) / Y-20$ \\
\hline
\end{tabular}

$15: 00$

15:30 16:00 Video-

Laping

16:00 16:00 16:30 Rig out

gamma

spectro-

meter

$\stackrel{p}{\omega}$

$\omega_{\rho}^{\infty} 17: 00$ 


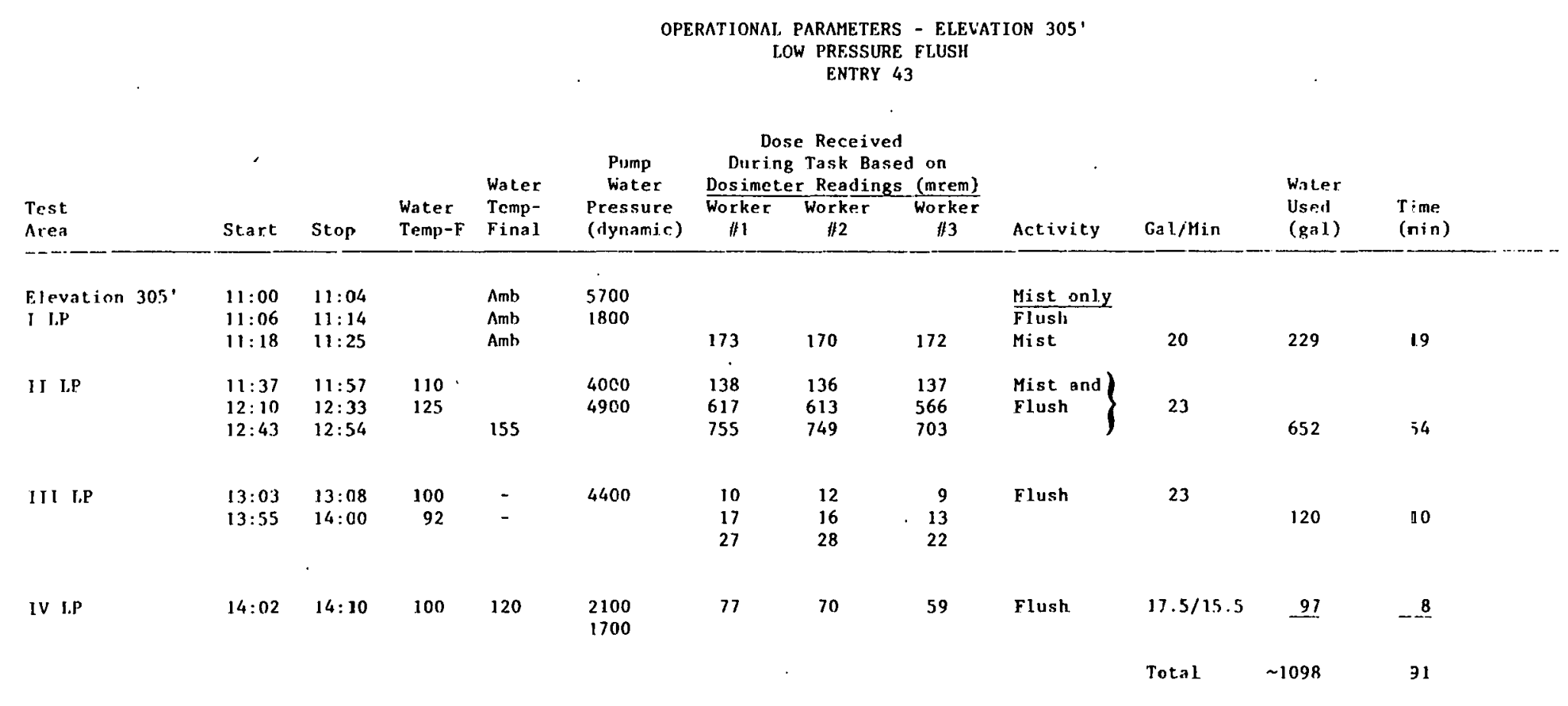




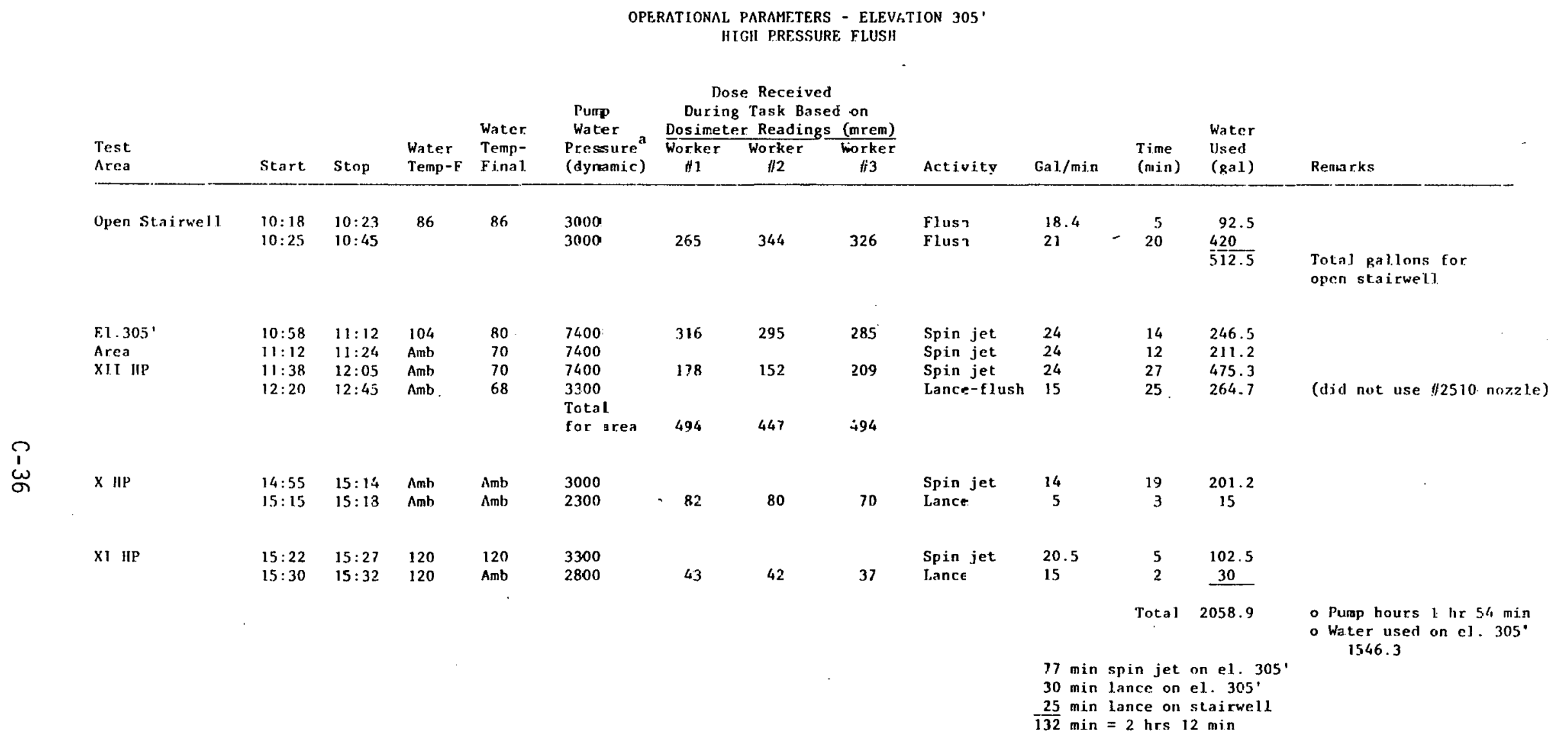

a. HF flush pump pressures required to provide test pressure of 2000,4000 , or 6060 psi at lance or spin jet. 
OPERATIONAL PARAMETERS - ELEVATION 305'OVERHEAD, WALLS, ETC. HIGH PRESSURE FLUSH ENTRY 49

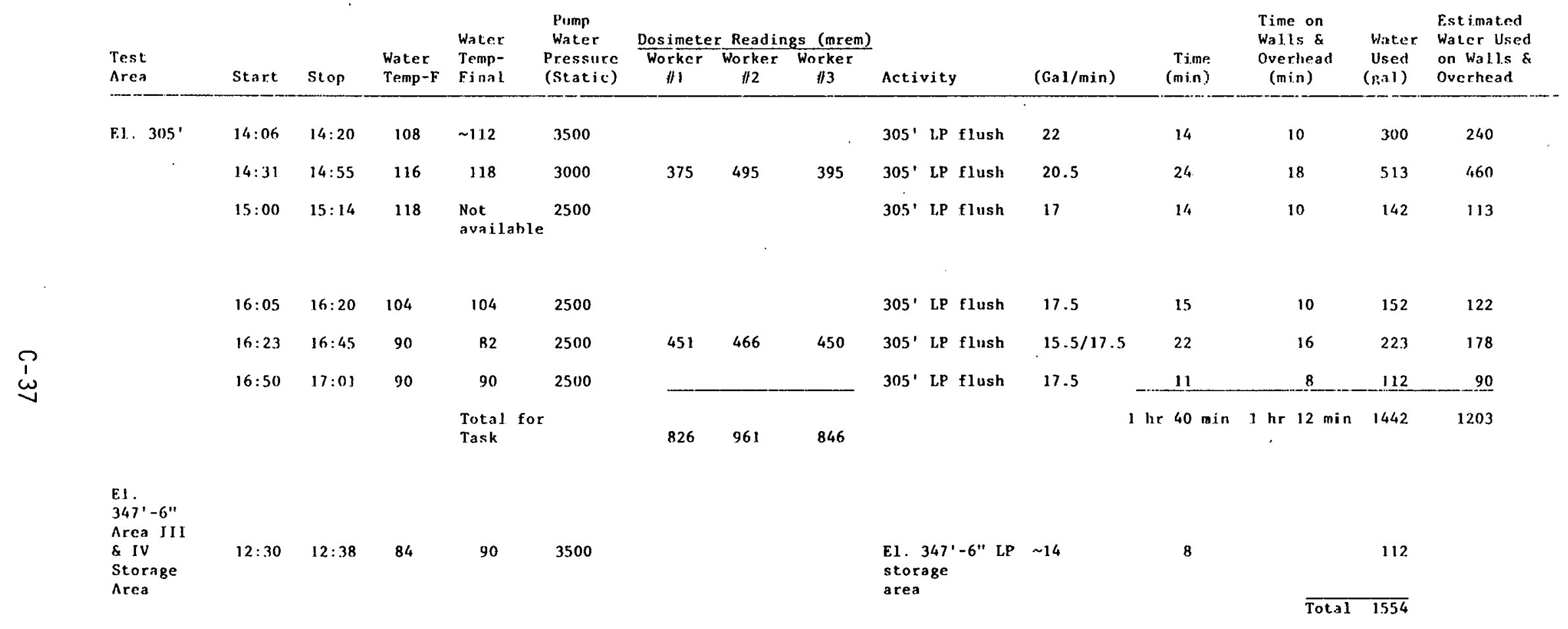


OPERATIONAL PARAMETERS - ELEVATICN 347' -6" LOW PRESSURE FLUSH

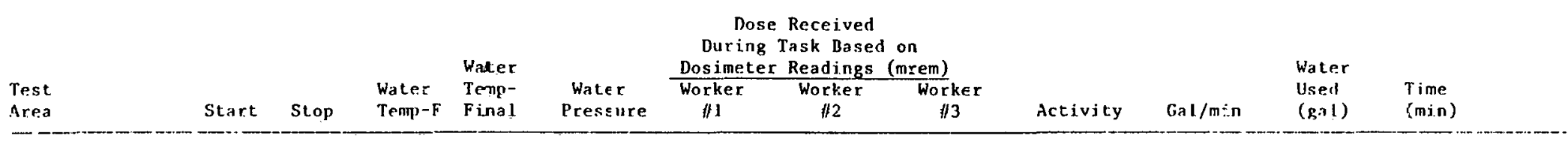

\section{I.P Area}

vI

$\omega_{\infty}^{\infty}$

$\begin{array}{lrrr}11: 48 & 12: 11 & 70 \\ 12: 12 & 12: 35 & 117 & 74 \\ 13: 05 & 13: 29 & 90 & 96 \\ 13: 47 & 13: 52 & 103 & \end{array}$

Amb
74
96
74

2000

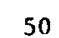

4200
4700

50

so

45

F]ush

14

208

23

4700
4200

Tola

$\begin{array}{r}102 \\ 16 \\ \hline\end{array}$

118

$\begin{array}{lllll}13: 52 & 14: 10 & 103 & 74 & 4200\end{array}$

56

$\begin{array}{lllll}14: 10 & 14: 28 & 102 & 88 & 2200 \\ 14: 46 & 14: 58 & 105 & 92 & 4200\end{array}$

$14: 46 \quad 14: 58 \quad 105$

94

59

F].ush 22.5

$334 \quad 23$

$\begin{array}{rrrr}\text { Flush } & 19 & 348 & 24 \\ & & 95 & 5\end{array}$

Vri

98

Flush

19

$221 \quad 13$

VII

(2)

(2)

$\begin{array}{llrr}\text { Flush } & 14.5 & 168 & 13 \\ & 13 & 101 & 12 \\ & \text { Total } & 1475 & 123\end{array}$


OPERATICNAI, PARAMETERS - ELEVATION 347'-6" HIGH PRESSURE FLUSH

$$
\text { ENTRY } 48
$$

\begin{tabular}{|c|c|c|c|c|c|c|c|c|c|c|c|c|c|}
\hline $\begin{array}{l}\text { Test } \\
\text { Area }\end{array}$ & Start & Stop & $\begin{array}{l}\text { Water } \\
\text { Temp-F }\end{array}$ & $\begin{array}{l}\text { Water } \\
\text { Temp- } \\
\text { Final }\end{array}$ & $\begin{array}{l}\text { Water } \\
\text { Pressure }\end{array}$ & $\begin{array}{r}\text { Dur } \\
\text { Dosin } \\
\text { Worker } \\
\# 1\end{array}$ & $\begin{array}{l}\text { se Rece } \\
\text { Task Ba } \\
\text { r Readir } \\
\begin{array}{c}\text { Worker } \\
\text { \#2 }\end{array}\end{array}$ & $\frac{\substack{\text { on } \\
\text { (mrem) } \\
\text { Worker } \\
\$ 3}}{13}$ & Activity & $\begin{array}{l}\text { Water } \\
\text { Used } \\
\text { (gal) }\end{array}$ & $\begin{array}{l}\text { Time } \\
(\min )\end{array}$ & Gal/Min & Remarks \\
\hline \multicolumn{14}{|c|}{$3 / 12 / 82$} \\
\hline J & $\begin{array}{l}10: 05 \\
10: 13\end{array}$ & $\begin{array}{l}10: 12 \\
10: 27\end{array}$ & 140 & 120 & $\begin{array}{l}3100(D) \\
4400(D) \\
\text { Lance }\end{array}$ & 21 & 19 & 22 & $\begin{array}{l}\text { Spin jet } \\
\text { Lance }\end{array}$ & $\begin{array}{r}60.47 \\
121.83\end{array}$ & $\begin{array}{r}7 \\
14\end{array}$ & $\begin{array}{r}15 \\
5\end{array}$ & $\begin{array}{l}\text { Confined area - pipes, } \\
\text { protrusions }\end{array}$ \\
\hline II & $\begin{array}{l}10: 28 \\
10: 33\end{array}$ & $\begin{array}{l}10: 3,3 \\
10: 40\end{array}$ & 109 & 94 & $\begin{array}{l}4400(D) \\
2400(D)\end{array}$ & 9 & 8 & 9 & $\begin{array}{l}\text { Spin jet } \\
\text { Lance }\end{array}$ & $\begin{array}{l}43.19 \\
60.9\end{array}$ & $\begin{array}{l}5 \\
7\end{array}$ & 5 & $\begin{array}{l}\text { Confined area - pipes, } \\
\text { Eabinets, etc. }\end{array}$ \\
\hline 111 & $\begin{array}{l}10: 42 \\
11: 00\end{array}$ & $\begin{array}{l}10: 58 \\
11: 03\end{array}$ & 110 & 110 & $\begin{array}{l}2400(D) \\
2400(D)\end{array}$ & 31 & 28 & 32 & $\begin{array}{l}\text { Spin jet } \\
\text { lance }\end{array}$ & $\begin{array}{c}138.23 \\
26.1\end{array}$ & $\begin{array}{r}16 \\
3\end{array}$ & 5 & $\begin{array}{l}\text { Confined area - pipes, } \\
\text { cabinets }\end{array}$ \\
\hline IV & $\begin{array}{l}11: 18 \\
11: 39\end{array}$ & $\begin{array}{l}11: 26 \\
11: 45\end{array}$ & 88 & 88 & $\begin{array}{l}6400(D) \\
2400(D)\end{array}$ & $\begin{array}{l}16 \\
16 \\
\end{array}$ & $\begin{array}{r}15 \\
-15 \\
\end{array}$ & $\begin{array}{l}14 \\
16 \\
\end{array}$ & $\begin{array}{l}\text { Spin jet } \\
\text { lance }\end{array}$ & $\begin{array}{l}69.1 \\
52.2\end{array}$ & $\begin{array}{l}B \\
6\end{array}$ & 7.5 & $\begin{array}{l}\text { Storage in } 50 \% \text { of arca } \\
\text { Cabinets blocking spin } \\
\text { jet area }\end{array}$ \\
\hline v & $\begin{array}{l}11: 49 \\
12: 43\end{array}$ & $\begin{array}{l}12: 35 \\
12: 57\end{array}$ & 92 & 80 & $\begin{array}{r}6600(D) \\
821(D) \\
2600(D)\end{array}$ & 185 & $\begin{array}{r}30 \\
156\end{array}$ & $\begin{array}{r}30 \\
186\end{array}$ & $\begin{array}{l}\text { Spin jet } \\
\text { Lance }\end{array}$ & $\begin{array}{l}397.4 \\
121.8\end{array}$ & $\begin{array}{l}46 \\
14\end{array}$ & 5 & $\begin{array}{l}\text { Did the area twice } \\
\text { (30 min. the first } \\
\text { time - tools on the } \\
\text { floor. }\end{array}$ \\
\hline vi & $\begin{array}{l}13: 18 \\
13: 46\end{array}$ & $\begin{array}{l}13: 35 \\
14: 00\end{array}$ & 72 & 72 & $\begin{array}{l}6500(S) \\
6300(D) \\
3500(S) \\
3300(D)\end{array}$ & 106 & 99 & 96 & Lance & 121.8 & 14 & 5 & - \\
\hline VII & $\begin{array}{l}14: 19 \\
15: 20\end{array}$ & $\begin{array}{l}14: 26 \\
15: 27\end{array}$ & 110 & 120 & $\begin{array}{l}4500(\mathrm{~S}) \\
4300 \\
3500(\mathrm{~S}) \\
3300(\mathrm{D})\end{array}$ & $\begin{array}{l}18 \\
17\end{array}$ & $\begin{array}{l}16 \\
17\end{array}$ & $\because 16$ & $\begin{array}{l}\text { Spin jet } \\
\text { Lance }\end{array}$ & $\begin{array}{l}60.4 \\
60.9\end{array}$ & $\begin{array}{l}7 \\
7\end{array}$ & $\begin{array}{r}18 \\
5\end{array}$ & $\begin{array}{l}\text { Confined area - small. } \\
\text { floor space }\end{array}$ \\
\hline VIII & $\begin{array}{l}15: 35 \\
15: 51\end{array}$ & $\begin{array}{l}15: 48 \\
16: 00\end{array}$ & 102 & 95 & $\begin{array}{l}7400(\mathrm{~S}) \\
7200(\mathrm{D}) \\
3500(\mathrm{~S}) \\
3300(\mathrm{D})\end{array}$ & 53 & 54 & 42 & Spin jet & 112.3 & 13 & 18 & \\
\hline IX & $16: 0 n$ & $16: 15$ & 89 & 89 & $\begin{array}{l}3500(\mathrm{~S}) \\
3300(\mathrm{~S})\end{array}$ & 36 & 27 & 20 & $\begin{array}{l}\text { Lance } \\
\text { only }\end{array}$ & 130.5 & 15 & 14 & $\begin{array}{l}\text { Spin jet would not } \\
\text { fi.t in area }\end{array}$ \\
\hline & & & & & & & & & Total & 1889.0 & & & $\begin{array}{l}\text { Pump hours } 3 \text { hrs } 6 \text { inill } \\
774.5 \text { gal - lance } \\
1114.5 \text { ga.l - spin jet }\end{array}$ \\
\hline
\end{tabular}

\footnotetext{
a. $D=$ dynamic, $S=$ static.
} 
- OPERATIONe L PARAMETERS - ELEVATION $347^{\prime}-6$ " EqUiPHFNT

HIGH PRESSURE FLUSH

ELEVATION $347^{\prime}-6^{\prime \prime}$

Dose Received

During Task Based on

\begin{tabular}{|c|c|c|c|c|c|c|c|c|c|c|c|c|}
\hline $\begin{array}{l}\text { Test } \\
\text { Area }\end{array}$ & Start & Stop & $\begin{array}{l}\text { Whater } \\
\text { Temp-F }\end{array}$ & $\begin{array}{l}\text { Water } \\
\text { Temp- } \\
\text { Final. }\end{array}$ & $\begin{array}{l}\text { Water } \\
\text { Eressure }\end{array}$ & $\frac{\text { Dosime }}{\begin{array}{c}\text { Worter } \\
\| 1\end{array}}$ & $\frac{c \text { Readin }}{\begin{array}{c}\text { Worker } \\
\| 2\end{array}}$ & 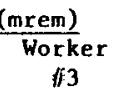 & Activity & Gal/min & $\begin{array}{l}\text { Water } \\
\text { Used } \\
\text { (ga1) }\end{array}$ & $\begin{array}{l}\text { Time } \\
(\min )\end{array}$ \\
\hline \multicolumn{13}{|l|}{$3 / 11 / 82$} \\
\hline $\begin{array}{l}\text { Stairwell } \\
\text { No. } 1\end{array}$ & $13: 05$ & $13: 30$ & 88 & 88 & 3200 & 78 & 76 & 73 & $\begin{array}{l}\text { HP spray } \\
\text { (laice) }\end{array}$ & 7.5 & 31 & 5 - stopped for $20 \mathrm{~min}$ (nct $5 \mathrm{~min}$ ) \\
\hline Seal Ring & $13: 30$ & $13: 40$ & 88 & 100 & 3200 & & & & & 7.5 & 62 & 10 \\
\hline $\begin{array}{l}\text { RC. Pump } \\
\text { Motor Stand }\end{array}$ & $13: 41$ & & 100 & & 3200 & & & & & 7.5 & & \\
\hline \multicolumn{13}{|l|}{$\begin{array}{l}\text { RC Pımp } \\
\mathrm{Al} \text { i gnament }\end{array}$} \\
\hline $\begin{array}{l}\text { Stand } \\
\text { Incernals } \\
\text { Imlex Fix }\end{array}$ & & $13: 54$ & & 110 & & $\begin{array}{l}\text { Altroug } \\
\text { were mo } \\
\text { could } n \\
\text { dowr fo }\end{array}$ & $\begin{array}{l}\text { these ta } \\
\text { tored, d } \\
\text { be brok } \\
\text { each tas }\end{array}$ & & $\downarrow$ & 7.5 & B1 & 13 \\
\hline \multicolumn{13}{|l|}{ West l.och } \\
\hline Duct & $13: 55$ & $13: 56$ & Drain & plugged & 3400 & 55 & 63 & 53 & $\begin{array}{l}\text { Did not } \\
\text { complete } \\
\text { becanse of } \\
\text { plugged } \\
\text { drain }\end{array}$ & 7.5 & 6 & 1 \\
\hline Cable & $14: 00$ & $14: 11$ & 100 & 86 & 3400 & & & & & 7.5 & 59 & 11 \\
\hline \multirow[t]{2}{*}{ Tray } & $15: 53$ & $15: 56$ & 86 & 86 & 3800 & 87 & 101 & $186^{*}$ & HP spray & 19.75 & $\underline{19}$ & 3 \\
\hline & & & & & & \multicolumn{4}{|c|}{ *otter tasks on El. $305^{\circ}$} & Total & 258.1 & 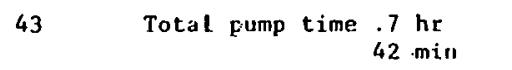 \\
\hline
\end{tabular}


OPERATIONAL PARAMETERS - POIAR CRANE

EIEVVATIONS $426^{\prime}$ TO $447^{\prime}-6^{\prime \prime}$

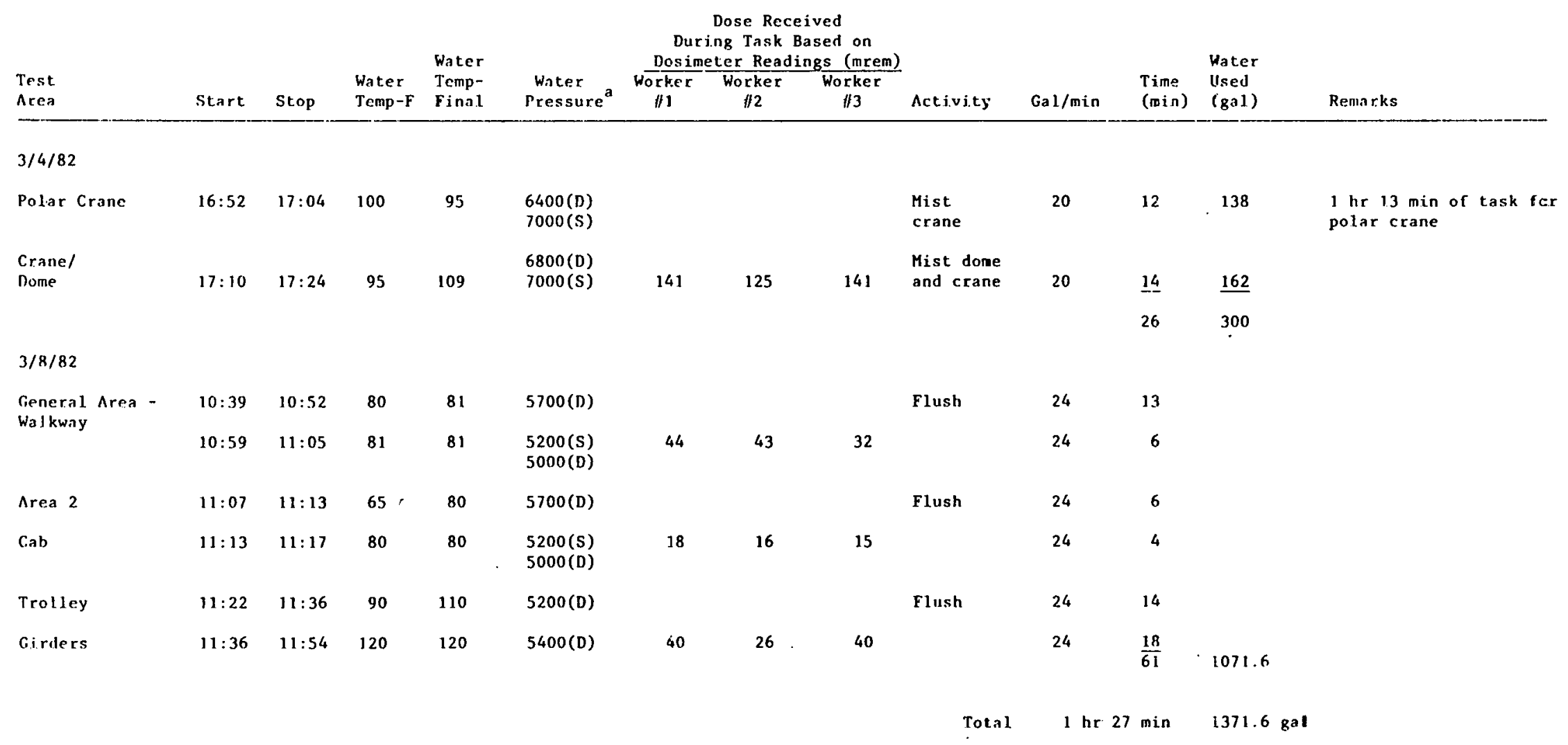

A. $D=$ dynamic, $S=$ static. 
OPERATIONAL PARAMETERS - MISSILE SHIELDS, D-RINGS, CANALS

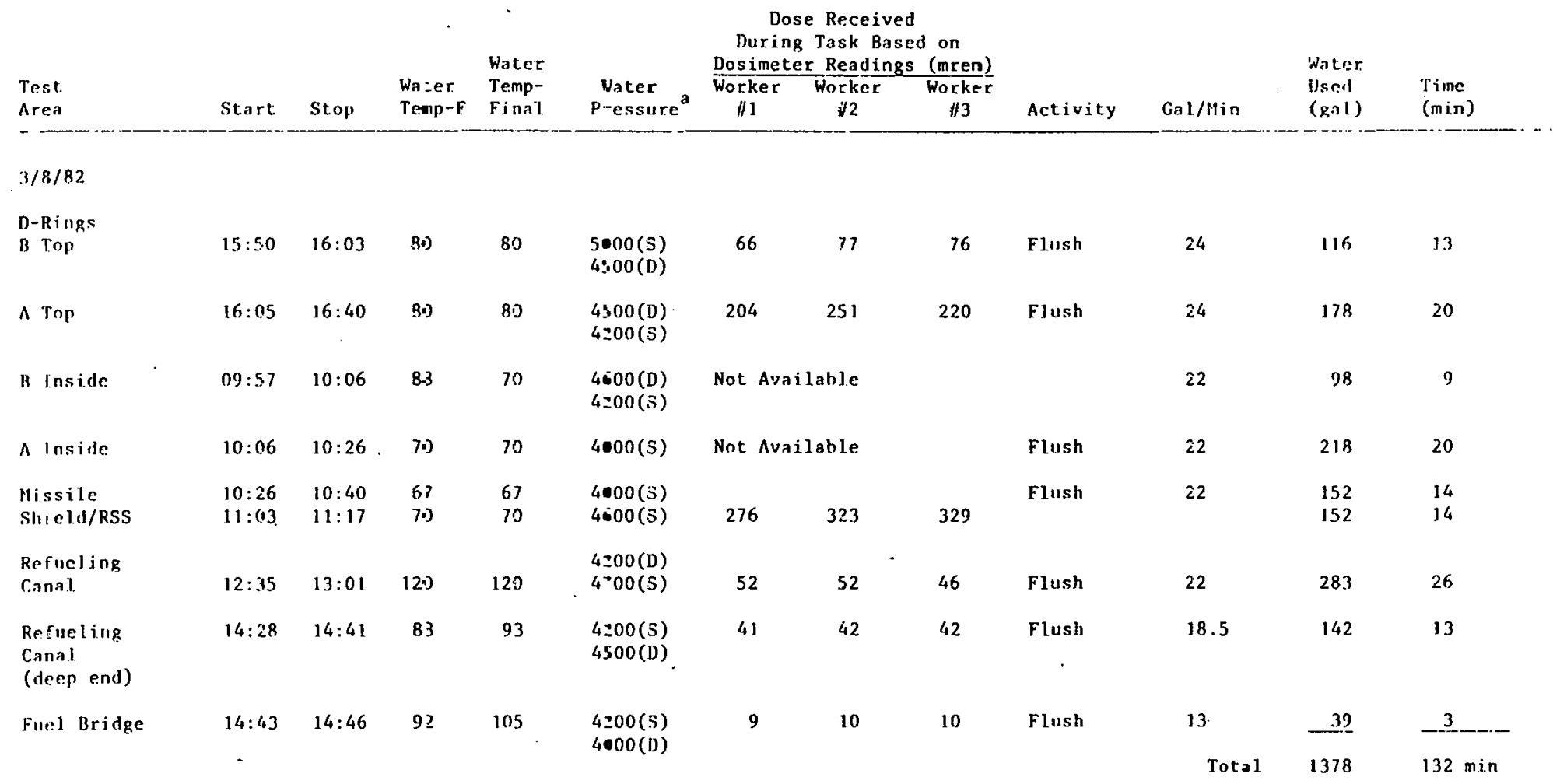

a. $D=$ dynamic, $s=$ static. 
LOW PRESSURE REFLUSH AFTER HIGH PRESSURE FLUSH ELEVATION 305'

ENTRY 52

\begin{tabular}{|c|c|c|c|c|c|c|c|c|c|c|c|c|c|c|c|c|c|c|c|c|c|}
\hline$\underset{\text { Arca }}{\text { IIP }}$ & Lucation & Surface & $\begin{array}{l}\text { Pre- } \\
\text { Gamma } \\
\text { Test } \\
\text { (nirem) }\end{array}$ & $\begin{array}{l}\text { Post- } \\
\text { First } \\
\text { I. } \\
\text { (mrem) }\end{array}$ & $\begin{array}{l}\text { Pre. } \\
\text { IIP } \\
\text { (Imrem) }\end{array}$ & $\begin{array}{l}\text { Post. } \\
\text { HP } \\
\text { (nirem) }\end{array}$ & $\begin{array}{l}\text { Pre. } \\
\text { Contact } \\
\text { Ganuma } \\
\text { (mirem) }\end{array}$ & $\begin{array}{l}\text { Post. } \\
\text { LP } \\
\text { Gamma } \\
\text { (mrem) }\end{array}$ & $\begin{array}{l}\text { Posl- } \\
\text { HP } \\
\text { Gamma } \\
\text { (nrrem) }\end{array}$ & $\begin{array}{l}\text { Post- } \\
\text { Reflush } \\
\text { LP } \\
\text { Gamına } \\
\text { (mrem) }\end{array}$ & $\begin{array}{l}\text { Pre- } \\
\text { Test } \\
\text { Beta } \\
\text { (mrem) }\end{array}$ & $\begin{array}{l}\text { Post. } \\
\text { LP } \\
\text { Beta } \\
\text { (tnrem) }\end{array}$ & $\begin{array}{l}\text { Post. } \\
\text { HP } \\
\text { Reta } \\
\text { (mrem) }\end{array}$ & $\begin{array}{l}\text { Post- } \\
\text { Reflusli } \\
\text { LP } \\
\text { Beta } \\
\text { (mrem) }\end{array}$ & $\begin{array}{l}\text { Pie- } \\
\text { Test } \\
\text { C3.137 }\end{array}$ & $\begin{array}{l}\text { Post- } \\
\text { LP } \\
\text { Cs-1.37 }\end{array}$ & $\begin{array}{l}\text { Pos1- } \\
\text { HIP } \\
\text { Cs-137 }\end{array}$ & $\begin{array}{l}\text { l'ost- } \\
\text { Reflush } \\
\text { UP } \\
\text { Cs.137 }\end{array}$ & $\begin{array}{l}\text { Pre- } \\
\text { Strij, } \\
\text { Conat } \\
\text { Cs.1.37 }\end{array}$ & $\begin{array}{l}\text { lincr- } \\
\text { mellite } \\
\text { Strin } \\
\text { Cont } \\
\text { Cs-137 }\end{array}$ & $\begin{array}{l}\text { Pust. } \\
\text { Slipp } \\
\text { Coal } \\
\text { Cs-1.1: }\end{array}$ \\
\hline & $53-1$ & Floor & & & 1300 & 1200 & & & & 3800 & & & 9360 & 12,800 & & & & & & & \\
\hline & $53-2$ & Fuoor & & & 1100 & 1300 & & & & 1800 & & & 1170 & 2000 & & & & & & & \\
\hline 111 & $53-3$ & Flnor & 800 & 600 & 1200 & 1300 & 1000 & 900 & 1800 & 1900 & 4560 & 2660 & 780 & 1200 & $4.8 \times 10^{6}$ & $1.7 \times 10^{E}$ & $7.5 \times 10^{5}$ & $6.2 \times 10^{5}$ & & & \\
\hline & $53-4$ & Floor & & & 1100. & 900 & & & & 1600 & & & 3900 & 800 & & & & & & & \\
\hline 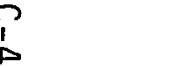 & $53-5$ & Floor & & & 900 & 900 & & & & 1200 & & & 780 & 6400 & & & & & & & \\
\hline & 61 & Floor & 1000 & 600 & . & 400 & 3400 & 1000 & 900 & 1000 & 17,480 & 8360 & 8190 & 10,000 & & $9.3 \times 10^{\epsilon}$ & & $9.5 \times 10^{5}$ & & & \\
\hline & & & & & & Area & ISC - & no high & h press & sure $f$ & lush - s & trip $c$ & oat +1 & Post-LP & and I.P $W_{0}$ & alls and 0 & Overheads & & & & \\
\hline & $65-1$ & Floor & 300 & 180 & $\begin{array}{l}\text { No } \\
\mathrm{HP}\end{array}$ & & 600 & 340 & 300 & & 6080 & 2120 & 1950 & & & & & & & & \\
\hline & $65-2$ & Flnor & 280 & 200 & $\begin{array}{l}\text { flush } \\
\text { of }\end{array}$ & & 400 & 270 & 260 & & 10,640 & 2770 & 2496 & & & & & & & & \\
\hline IV & $65-3$ & Floor & 300 & 200 & $\begin{array}{l}\text { this } \\
\text { area }\end{array}$ & & 600 & 500 & 300 & & 14,400 & 2660 & 2730 & & $2.9 \times 10^{7}$ & $5.5 \times 10^{8}$ & & & $1.3 \times 10^{6}$ & $7.5 \times 10^{4}$ & $5.9 \times 10^{7}$ \\
\hline & $65-4$ & Flnor & 360 & 230 & & & 400 & 380 & 370 & & 21,280 & 2350 & 2067 & & & & & & & & \\
\hline & $65-5$ & Floor & 340 & 240 & & & 800 & 420 & 420 & & 9120 & 2960 & 2652 & & & & & & & & \\
\hline & 70 & Floor & 220 & 180 & & & $3 / 40$ & 210 & 200 & & 4780 & 1100 & 1014 & & $6.6 \times 10^{6}$ & $9.3 \times 10^{6}$ & & & $1.2 \times 10^{7}$ & $4.0 \times 10^{4}$ & $5.7 \times 10^{4}$ \\
\hline
\end{tabular}


DO NOT MCROFILM
WHIS PAGE 
APPENDIX D

TRAINING AND SAFETY 


\title{
CONTENTS
}

SELECTION AND CONTROL OF PERSONNEL FOR TRAINING

$\mathrm{D}-1$

TRAINING PROGRAM METHODS

D-4

TRAINING EQUIPMENT

D-9

TRAINING ADMINISTRATION

D- 16

FINAL MOCK-UP METHODS

D-20

DATA TAKING

D-24

TRAINING EFFECTIVENESS

D-26

TRAINING EFFICIENCY

D-28

SAFETY ISSUES AFFECTING THE DECONTAMINATION EXPERIMENT

D-29

\author{
ATTACHMENTS \\ D-1 SAMPLE WORK PACKAGE \\ D-2 TECHNIQUE SHEETS \\ D-3 GENERAL ENTRY TRAINING \\ D-4 PRE-JOB BRIEFING OUTLINE \\ D-5 POST-JOB DEBRIEFING OUTLINE \\ D-6 HEAT STRESS PROGRAM \\ D-7 TRAINING PROGRAM EFFECTIVENESS EVALUATION \\ D-8 TRAINING HOURS ESTIMATE BY MANPOWER SOURCE
}




\section{APPENDIX D - TRAINING AND SAFETY \\ SELECTION AND CONTROL OF PERSONNEL FOR TRAINING}

During the planning of the Decontamination Experiment, a scope of work was defined in order to make estimates of manpower requirements for training. These estimates were based upon specific task lists, man-hour estimates by task, skills requirements for each task, dose estimates for tasks, and allowances for backup personnel.

\section{Sources of Manpower}

Several sources of manpower with a wide range of skills and talents were utilized during the experiment.

\section{Health Physics Technicians}

Health physics (HP) technicians were either supplied or subcontracted by the licensee to perform radiological surveys and otherwise support the experiment. These personnel already possessed a high level of training and were the easiest to assimilate into the program. Approximately 1 HP man-hour was required in containment per 20 man-hours of experimental work.

\section{Client Maintenance Department}

Instrument and control technicians, electricians, and mechanics were supplied by the client utility on a limited basis. Their duties consisted of repairs to operating plant systems required during the experiment, including the CCTV system used to monitor containment activity. 
Building Trades Crafts

Building trades crafts personnel, supplied by Catalytic, Inc., represented the following trades: ironworker, pipe fitter, electrician, carpenter, and laborer. They were utilized for installation of most of the support systems, such as decontamination water, electric power, and the spider work platform. In addition, the laborers gave general support both in and out of containment, did salwasle semuval, and performed some data collection.

\section{Remote Reporters}

Individuals employed by the client in other job locations not related to power planls were periodically assigned to decontamination work at the site. This permitted the dose to be spread more evenly among the available employees. These workers performed all of the experimental decontamination tasks and most of the data collecting. Remote reporters were requested by the client to report on a specified day, for a predetermined time, to work exclusively on the experiment.

\section{Subcontracted Technicians and Engineers}

Subcontracted technicians and engineers were required when the needed cxpcrtise was not available from the other sources already discussed. Requirements in this category included photography and data collection (Bechtel National, Inc.), gamma spectrometer survey (SAI), surface deposition tests (EG\&G), and decontamination techniques (Vikem). This work accounted for about 10 percent of the total time expended.

\section{Volunteers}

A small number of personnel, usually engineers, were also available from the client under certain conditions as part of a volunteer program. During the Decontamination Experiment, however, this resource was supplanted for the most part by the remote reporters. 


\section{Supervision and Coordination}

The remote reporters were assigned to a foreman who assumed supervisory and administrative responsibilities not specifically related to the experiment. Additionally, the foreman assisted the instructors in determining the training status and performance of each individual and made recommendations for efficient utilization of thc manpower resource. All other personnel were supervised by their parent departments. Working foremen were designated for the building tradesmen to supervise and help perform work.

Union regulations and rotating work shifts complicated scheduling. Better coordination resulted when a single individual scheduled all training and the parent department retained a dedicated coordinator to assist in scheduling and supplying manpower. Ultimately, the coordination was broken down by health physics support (GPU), building trades (Bechtel), and site maintenance (GPU).

\section{$\underline{\text { Prescreening }}$}

All individuals who entered the training program were screened to ensure that prerequisites were met. These prerequisites consisted of radiological requirements that were not under the control of the implementation group, Bechtel Northern, and included:

o Valid radiological work permit training

- Valid whole body exposure record on file

o Valid whole body count

- Valid respirator physical

- Satisfactory respirator fit test 
- Valid thermoluminescent dosimeter

- Security badge for access to required plant areas.

The individuals who did not satisfy all of the requirements were returned to their respective organizations for reassignment.

\section{TRAINING PROGRAM METHODS}

\section{Training Work Package}

The training work package consisted of detailed written instructions for completion of each task. Some task descriptions were specific and were used only once; others were generic and were used several times. An example of a generic work package is removal of trash from the containment. The content of the training work package and the standards for instruction provided the starting base for the training program.

In addition to the instructions for the task, the work package contained sketches, photographs, equipment lists, and other attachments to enhance the overall comprehension of the work requirements. (See Attachment D-1 for examples of typical work package contents.)

Lessons learned in this area were:

- Use one format for work packages.

- Establish methods and the status for revisions to work packages.

- Establish responsive review procedures for training quality and responsibility for training records and policies. 


\section{Technique Development Phase}

Before a work package was undertaken, an initial training phase was completed to determine the optimum way of accomplishing each task. This is knưwu as lechnlque development. It is an optimization process giving the highest probability for success. An example is to determine the assembly process fur a heavy piece of equipment, which would consider the difficulty of performing each assembly step and determine which steps are sequence dependent. In addition, endurance issues must be settled, such as what size subassemblies can be prepared outside containment and carried in, or whether all parts have to be carried in separately.

Decontamination methods are also classified as techniques. Examples of technique descriptions for flushing are contained in Attachment D- 2 .

Lessons learned during this phase were:

- Ensure that work packages are fully developed prior to training people on the package.

- Prepare a work package structure that can accommodate revisions quickly and that contains the items that are appropriate for the task.

\section{Classroom Phase}

In the classroom phase, the decontamination workers and an instructor reviewed the work package as well as routine procedures for working in radiologically controlled areas. (Topics in general entry training and typical procedure handouts are contained in Attachment D-3.) Some of the procedures and subjects especially highlighted during training include dress-out procedure, contamination control, heat stress, and fire protection. 
During the classroom sessions the job was discussed, and training aides such as photographs, videotapes, and models were used to develop better understanding of the procedures. At the end of the sessions, all participants should have felt satisfied with the level of knowledge attained and ready to proceed to the next phase of training.

Lessons learned during this phase were:

- Establish rigid instructor classroom standards.

- Ensure that only finalized work packages and procedures are used for instruction.

\section{Walk-through Phase}

A walk-through is a timed execution of the work package involving all participants and feasible equipment. During the walk-through, personnel were not required to dress in protective clothing or use respirators. However, during tasks requiring manual dexterity, protective gloves and work gloves, if applicable, had to be worn. The walk-through was preceded by a briefing describing the work situation and any simulations in effect. A walk-through. was considered successful when the job was performed efficiently and without cuacling.

Lessons learned during this phase were:

o Written standards are required for the walk-through phase of training.

- Provide equipment for those parts of the task that require some protection in handling; e.g., gloves for rigging tasks. 
o Ensure that the walk-through conforms exactly with the work package.

- Document the training at the time it is accomplished.

\section{Mock-up Phase}

This phase of training consisted of dress reliearsals for the tasks, creating working conditions as realisticly as possible. In some cases this required constructing full-size replicas of plant equipment or areas. For the final mock-up of a work package, protective clothing was worn to demonstrate endurance requirements. The purpose of this phase was to identify problems or areas that needed special attention before actual entry, so that exposure time could be minimized and tasks accomplished as efficiently as possible.

Lessons learned during the mock-up phase were:

o Written standards are required for the conduct of mock-up training.

o Ensure that the mock-up is as representative as possible of the actual work to be accomplished.

- The persons performing the task should wear the protective clothing that will be required in the reactor building.

- All equipment for the task should be used during the mock-up.

- Ensure that a sufficient number of spare or reserve personnel are trained on the mock-ups to allow for sickness or task slippages which may require substitutions.

o The trainer should be in the command center and should direct that task during the entry, if possible. 


\section{$\underline{\text { Final Briefing }}$}

Prior to each decontamination entry, each worker team received a final briefing, done in compliance with 10 CFR 19 for instructions to workers in radiologically controlled areas. The briefing also served to reinforce previous training and allowed an opportunity for final questions. Items covered included:

- Jöb sequence

- Information regarding coordination with other groups

- Dose estimate

- Keading and acknowledgement of KW

- Criteria for termination of job

o Schedule for the day.

Attachment D-4 is a complete pre-job briefing outline of items discussed.

Lessons learned during the final briefing phase were:

- Written standards for the briefing are effective.

- One organization and procedure should be responsible for and should provide the guidelines for the briefings.

- Ensure that interfacing entry teams are briefed together. 


\section{Post-entry Debriefing}

An important phase of the training program was the post-entry debriefing. Through this session, descriptions of conditions within the containment building were reported, and some evaluations of procedures could be made. Also, adequacy of planning, equipment, and training was determined. Therefore, the debriefing was a vital tool in judging the training and determining improvements for future operations. Attachment D-5 is an example of the guidelines used during the debriefing and illustrates the thoroughness of topics covered.

Lessons learned during this phase were:

- Written standards for the debriefing are effective and are required. These should include:

- Debriefing time and location

- The person responsible to conduct the debriefing

- The materials to be provided at the debriefing, such as records, tapes, RWPs, etc.

\section{TRAINING EQUIPMENT}

The use of proper equipment helps ensure high training quality. For work done in radiation areas, workers needed to understand and be able to demonstrate that they could perform all details of the assigned task. 
$\underline{\text { Training Aids }}$

Aids.were used in the training program to make'a given objective more understandablc.

\section{Lesson Plans}

l'he most basic training aid was the lesson plan. It identified the training objective, guided the instructor in the use of all required teaching materials, and described the methods for conducting the lesson. Elements included a list of student handouts, training aid summary, support services required, and the lesson discussion outline.

A lesson plan was prepared in advance by the training administrator and was kept on file until needed.

Work Package. When the lesson plan used was a work package, a cover sheet was attached to document any additional training information. In most cases, the work package could stand by itself as a lesson plan.

Special Equipment. For each piece of equipment requiring training, a lesson plan was prepared to describe the principles and methods of operation.

General Entry Training. This was an indoctrination course administered to all personnel who trained for reactor building entry. The course lesson plan is given in Attachment D-6. Refresher training was also required at 90-day intervals or as often as necessary when policy or procedure changes required a more frequent update. 


\section{Photographs}

Photographs were an invaluable training aid for work done in radiation areas and were particularly important when students were not familiar with the work area. Photographs could be used to verify installation details, define access routes and methods, and assist in proper tool selection and construction of mock-ups.

\section{Closed-Circuit Television System and Videotape}

Training at TMI-2 was enhanced by the use of a CCTV system installed in the containment. Eight cameras were installed in locations that permitted a large percentage of the containment to be seen from the command center, where work was monitored. The cameras could be remotely panned, tilted, zoomed, and focused. This system was used in the following ways:

- All personnel received a containment familiarization as part of general entry training by viewing the containment from the command center.

o Work done was recorded on videotape for historical, debriefing, and subsequent training purposes.

- Specific training tapes could be made with input from the installed cameras or filmed elsewhere with a portable camera.

- Portable cameras could also be used in the reactor building to film areas that would not otherwise be in view by the main system of cameras.

Videotape provided information similar to that provided by photographs, but required no processing time. Still photography was usually preferable to portable videotaping because it required fewer personnel and no support services for electric power and signal path out of containment. 


\section{Plant Model}

A plant scale model was available as a training aid. Although it was not highly detailed, it could be used for worker orientation, distance measurements, and job planning. Its best applications were to show students the access paths to remote work areas and to brief personnel who would be working at different locations at the same time. A job walk-through in this situation improved coordinatiun of lhe eeparate groups and improved overall understanding of the task.

Mock-up

A mock-up is the physical representation of a work area for training purposes. This full-scale training aid may be as small as a single piece of equipment or as large as a major component of the reactor plant. In addition to training benefits, mock-ups also demonstrate the feasibility and function of special tooling and verify proposed operating procedures and worker techniques.

The following mock-ups were required for TMI-2 decontamination:

Q Personnel air lork and loading rampe

o Spider work plat.fnrm sunports

o Spider work platform operating area

o Elevation $347^{\prime}-6^{\prime \prime}$ lifting rig (1500 pounds)

o Polar crane lifting system (300 pounds) 
- Gamma spectrometer (size and weight only)

o Decontamination surface mock-ups

- Stairwell

- Vertical surface

- Horizontal surface

- Polar crane (turbine building crane used)

- Decontamination equipment checkout

- High pressure pump (for decontamination)

- High pressure pump (for training)

- Spin jet

- Wet vacuum system 
- Strippable coat pump

- Hydrolance fittings

- Dccontamination services penetration

o. Special equipment checkout

- High reach work platform

- Forklift

- Spider work platform

- Elevation 305' to elevation 347'-6" lifting system

- Elevation 347'-6" to clevation 426' lifting system

- Surface deposition samplers.

Most of the mock-ups were located together in a centralized training area; some with special size requirements were located outside the area, and olhers already existed elsewhere in the plant. 


\section{Operating Systems}

Since all system valve operations took place outside containment, the actual plant systems were used as training aids during final systems checkout. However, a training system was also constructed to allow training and decontamination at the same time.

\section{Qualification Program}

Each piece of training equipment described had to be operated by a qualified individual. Decontamination techniques were consolidated into a series of classes to help qualify an individual to operate all equipment. For special equipment, qualifications were met either through a separate course or as part of the work package that installed the equipment.

\section{Supply of and Repairs to Training Equipment}

Training equipment had to be available in sufficient quantities to support the program and to meet requirements for inspections and repairs. When only one item going into containment was purchased because of exceptional expense, a reservoir of qualified personnel had to be established before installation. In other cases, one of each training item was required if the task was to be performed on a one-time basis. When a piece of equipment was to be used repeatedly, a special training unit had to be allotted or a realistic mock-up constructed in order to meet training objectives. When the cost of an item was not prohibitive, if its use was critical to the program, or if its reliability was questioned, more than two units might be required.

Most large pieces of equipment were delivered with a list of recommended parts, and stocking of these parts was recommended. 


\section{Use of Procedures and Work Instructions}

A procedure is a client-approved document, usually involving operation of plant systems, which requires verbatim compliance. Work instructions, on the other hand, are less strictly controlled and may be used to accomplish a variety of tasks. Validation of these documents through training is essential for a successful program. Any item that cannot be completed as written should be brought lo the allention of lhe inslruclur.

Simulations and other differences between the training system and the actual system had to be understood by all students. Operational communications needed to provide a syslem procedure, such as special telephone circuits, also had to be set up in training. Checkout of the actual communications network was a prerequisite to the real work proceeding. When more than one procedure was to be in use at the same time, coordination procedures were often required. Supervisory personnel had to be trained in these coordination procedures.

TRAINING ADMINISTRATION

\section{Training Engineer}

The training engineer is responsible for the administration of the training program. He pcrforms the following functions:

- Review work packages for training impact

- Select personnel from available resources

- Screen individuals for prerequisite requirements

- Specify training requirements

o Schedule and monitor training activities 
o Notify scheduling group when training is complete

o Debrief entry team members, recommending follow-up action within the area of responsibility

- Maintain all. lesson plans and individual records of training.

The preceding policies and methods resulted from the following problems experienced during the decontamination test:

o More than one training engineer was involved in the same program.

o The training engineer was not a dedicated individual with no other duties.

\section{Instructor}

The instructor is the individual assigned by the training engineer to teach an individual lesson plan. Instructors for work packages were either the cognizant engineer (writer of the work package) or the craft supervisor responsible for completion of the work package. For other lesson plans, the best qualified individual, or one qualified in an instruction program, was used, including client personnel when required (e.g., in lesson plans for safety training).

Instructor responsibilities are:

- Teach and document training in accordance with the lesson plan

o Ensure that scheduled personnel are present

- Make recommended changes to the lesson plan

- Inform the training engineer of problems. 
The preceding policies and methods resulted from the following problems experienced during the decontamination test:

o No written standards existed for establishing instructor performance.

o Cognizant engineers were not sufficiently involved in training and in feedback from training.

\section{Task Supervisor}

The task supervisor is the individual responsible for direction of the task from the command center. Normally, he is either the cognizant engineer or the craft supervisor. For decontamination work; he may be a specifically assigned ${ }^{2}$ operation engineer. The duties of the task supervisor are:

- Attest to the readiness for final mock-up training

o. Conduct and document walk-through and mock-up training

o. Attest to the adequacy of all work instruction and procedures

- Conduct and document pre-job briefings

- Thoroughly understand command center operations

o Attend debriefings.

A qualification program is recommended for task supervisors.

The preceding policies and methods resulted from the following problems experienced during the decontamination test:

o No written standards existed for task supervisors with respect to training responsibilities. 
- Mock-up performance was inadequately documented.

o Mock-ups were scheduled prior to issuance and accountability procedures of final work packages.

- Some task supervisors were unfamiliar with command center equipment and procedures.

\section{Documentation}

The use of training documentation helps ensure that training is being carried out in accordance with prescribed standards. The following records are maintained:

o Prescreening reports for validation of prerequisite training

- Master lesson plan file

- Individual work package file

- Special equipment file

- Safety training file

- General entry training file

- Radiological instruments and data file

- Decontamination techniques file

o Debriefing file

- Individual qualification record file 
- Schedules file

o Certification records.

The preceding policies and methods resulted from the following problems experienced during the decontamination test:

- More than one set of training records was in use.

- No written standards cxisted for recordkeeping.

\section{Qualification and Certification}

Qualification is the process whereby the training engineer acknowledges that a student has satistactorily completed a particular lesson plan. Cerl1fication is a two-step process whereby the training engineer specifies all requirements before an individual can enter the containment, and the health physics engineer attests that these requirements have been completed.

FTNAT, MOCK-UP METHODS

Final mock-up refers to the last practice session for any given work package. Final mock-up may encompass one or more of the following:

o Walk-through

- Full mock-up

- Prove out shown by heat stress test and walk-through.

The factors considered for determining the requirements were:

- Previous worker experience 
- Number of available personnel and scheduling flexibility

o Radiation dose field in work area

o Previous job results with similar work packages

- Status and validily of existing job-time estimates.

\section{Work Package Walk-through}

This is a timed execution of the work package involving all participants and either actual equipment or mock-up equipment. Actual equipment should be used if feasible, but individuals do not have to wear protective clothing or use respirators. Tasks involving manual dexterity do require the wearing of protective gloves and work gloves, if applicable. The instructor for these sessions will normally be the task supervisor. Walk-throughs always precede a full mock-up, if it is required.

Walk-throughs as final training are limited to:

o Repeat jobs or highly experienced individuals

- Uncomplicated new work done by craft personnel or health physics technicians within their normal scope of work.

\section{Work Package Full Mock-up/Prove Out}

In a full mock-up, a dress rehearsal is completed by all workers in the protective clothing expected for the in-containment work. In other respects, it is identical to the requirements of a walk-through previously described. The instructor is normally the task supervisor. A prove out is a specialized form of full mock-up designed to obtain all approvals for performance of the package (time, dose estimate, adequacy of techniques, etc.). The individuals 
doing the prove out do not, however, have to be the ones to actually perform the package, and the package may be done several times with additional personnel. In either case, following an acceptable prove out, a walk-through and heat stress test may bc substituted for all follow-on personnel.

Full mock-ups are done for new work packages, for jobs done in high radiation dose fields, and when worker endurance may be a controlling factor. This places the highest level of control possible on the work package and increases its charres for success.

When using remote reporters or any other dedicated group to accomplish a wide range of work packages in a specific interval of time, the prove-out methor is most effeclive. Each work package is validated with onc crew. Walk-throughs and heat stress tests for follow-on personnel save time and allow the training engineer to form an availability matrix of personnel and jobs for which they are qualified. Time constraints prohibited full mock-ups in this situation for all personnel for all work packages, and experience has shown that trying to match selecled individuals to each decontamination work package caused work stoppages because of absence, repetition of work, or changes to the decontamination sequence schedule. The matrix provides qualified alternates and sufficient flexibility to place manpower where it is most needed.

\section{Heat Stress Test}

The heat stress test is a physiological test performed by the GPUN safety department to determine an individual's suitability for working in protective clothing. Requirements for completion of this test are contained in Appendix D, Attachment D-6. Prior to an initial entrance into containment, all individuals must complete one of the following:

o Heat stress test and walk-through

- Full mock-up for estimated work time. 
At the end of the heat stress test, physiological monitoring is performed for pulse and body temperature. This monitoring must also be performed for any individual wearing a full wet suit, regardless of the other training requirements. Once passed, a heat stress test is good for 90 days.

\section{Standard Mock-up Techniques}

Bcfore a final mock-up is carried out, the individual conducting the mock-up must do the following:

- Conduct a briefing, noting simulations in effect, communication methods, and the role of support personnel and equipment.

o Ensure that the job is performed within the spacc allowcd in-containment; if no mock-up exists, place tape'on the floor or otherwise mark the work area.

- Ensure that lighting conditions simulate actual containment conditions as closely as possible.

- Begin and end training at the air lock mock-up, using all required equipment, and ensure that each individual understands the transportation requirements.

- Allow the students to work without coaching.

- If climbing or other physical exertion is part of the job, insert an equivalent amount in the training session.

- If data are being recorded as part of the work package, ensure that individual assignments are understood, including delivery of the data to an assigned individual.

- Hold a debriefing session. 
The preceding policies and methods resulted from the following problems experienced during the decontamination test:

- No written performance standards existed.

- First mock-ups were not complete in time to secure final approvals : without use of overtime.

- Either final mock-ups were not fully representative of actual work or time estimales were questionable because of coaching of the workers.

- Workers were in poor physical condition, showing lack of endurance and physical stamina.

DATA TAKING

Data Types

All containment work requires one or more of the following types of data:

$u$ Wusk package slep sighufls

- Radiological surveys

- Air samples

o Smears or scrapes

- Data tables

- Sketches and measurements 
- Physical samples

- Other subjective evaluations and observations.

All workers, task supervisors, and support personnel need to be trained in the proper techniques for data handling.

\section{Data Taking Training Program}

Non-health physics personnel required to take radiological data must be qualified in accordance with the lesson plan for radiological instruments and data. All other requirements for data collection are specified by the cognizant engineer in the appropriate work package.

The role of support personnel in data handling logistics is defined through briefings. The task supervisor must ensure that all data coming out of containment are properly recorded or otherwise processed. All work package signoffs must be made on the official work copy for permanent retention, and omission of data collection must be noted at the work package debriefing.

The preceding policies and methods resulted from the following problems experienced during the decontamination test:

o Logistics of data handling were not understood by team members, support personnel, and supervisors.

- Data were lost in processing.

- Data sheets were incorrectly or incompletely filled out. 
o Radiological data were obtained by remote reporters at a much slower pace than by health physics technicians.

- Because of difficulty in following the work package, some work package signoffs were not made, and physical parameters were not recorded in the command center.

\section{I'RAINING EFFECTIVENESS}

\section{Self-Evaluation}

Attachment $\mathrm{D}-7$ contains a list of questions that can be used as a guide for evaluating the effertiveness of the training program. The evaluation compares various aspects of worker productivity and administrator effectiveness to the prescribed standards. Although some items on the list can be put into quantitative form, the majority of the judgements are subjeclive.

\section{Debriefing Policy}

The majority of the feedback for determining training effectiveness comes from debriefing. Workers must be aware of their responsibility to report problems freely, and the training engineer must create an environment and an administrative system by which these problems can be tracked and corrected.

Attendees at dehriefings include:

o Debriefing chairman (represents training engineer)

o Task supervisor

o Cognizànt engineer

- Entry team members 
- Entry team foreman (union employees only)

- Site liaison engineer

- Client radiological engineer (ALARA) (optional).

Records of the debricfing include:

o Summary sheet

- Entry data

- l'eam members

- Craft

- Work package number

- Individual job-hours and job-rems

- Total job-hours and job-rems

- Clock hours of entry

o Team record (for each team)

- Team member comments

- Command center log sheets

- Radiation work permit

- Radiation surveys, if taken. 
These records are assembled the day following the entry and reviewed for action items by the training engineer and the containment access group supervisor.

The preceding policies and methods resulted from the following problems experienced during the decontamination test:

o No written standards of performance existed for the training program.

o Effectiveness evaluations were not conducted.

\section{TRAINING EFFİCIENCY}

For budgetary reasons, it is desirable to train entry personnel in as short a time as possible, as long as appropriate standards are maintained. Attachment D-8 gives approximate Lraining times on a per work package basis for the type of personnel listed in "Selection and Control of Personnel for Training." It should be recognized that the training times for more complex jobs may vary considerably from those shown in Attachment $D-8$, which are only intended to bc typical values. Attachment D-8 gives no time for prerequisite activities, such as RWP, respirator training, physicals and qualification, fit tests, and whole body counts. These activities should be completed prior to scheduling containment entry training. The table in Attachment D-8 further acsumes that no retraining is required and that the required training can be scheduled in blocks that result in full use of each work day, including the part of the day when training is not scheduled.

The following conclusions can be drawn from the table:

o It is more cost-effective from a training standpoint to use health physics technicians to gather radiological data than to train other personnel. 
- Cost savings are realized in training when all personnel make several entries.

- It takes at least 2 full weeks to adequately train entry support Lechnicians.

- Remote reporter training requirements drop off significantly after the initial indoctrination program. This allows the personnel to make effective use of their available quarterly dose in about 3 weeks, given current radiological conditions.

- Polar crane workers require an additional 9 hours of safety training.

SAFETY ISSUES AFFECTING THE DECONTAMINATION EXPERIMENT

\section{Heat Stress}

Preventing heat stress is a primary concern of the containment entry program. A complete description of this subject and policies, as promulgated by the client, is contained in Attachment D-6. It was prepared by GPU's corporate industrial hygenist and the site safety supervisor over a period of months during which the problems incurred during past containment entries were evaluated. The resulting policies acknowledge that:

o Extended work times cause heat stress.

o When impermeable clothing (plastic wet suits) is worn, some type of body cooling is necessary.

- The best form of body cooling is the ice vest.

o Proper training and physiological screening reduce the chances of heat stress. 


\section{Fall Protection and Working at Heights}

When required, several types of fall protection are available to workers. These requirements are specified by the safety department to comply with federal regulations. Some of these measures include:

o Use of safety belts

o Use of center rail ladder belts

o Proper use of ladders and erected platforms

- Use of mobile work platform (high reach scissors lift)

- Pulas viane fall protection system (use ot retractable lifelines and rescue equipment)

- Use of polar crane access work platform (spider).

\section{Belts, Ladders, and Scaffolding}

Safety requirements for belts, ladders, and scaffolding are specified in each work package rcquiring their use. Safety belts are required when personnel must work outside constructed work platform handrails or when grating from the floor has been removed. Center rail belts are used in conjunction with climbing center rail ladders. These ladders are required to be installed in areas where the vertical ascent exceeds 20 feet. The amount and type of scaffolding constructed depends on its application, available space, and the length of time it is required. Constructed scaffolding, including access ladders, must be securely fastened and inspected before its use. 


\section{Mobile Work Platform}

A mobile work platform was purchased for use in the Decontamination Experiment. It is a battery-operated, self-propelled scissors lift, capable of working at heights between 6 and 20.5 feet. It is limited to a capacity of 750 pounds on the main platform (usually two men, tools, and equipment). A 2.5-foot overreach platform, which also has a capacity of 250 pounds, allows access to most wall penetrations. The device was used only on elevation 305'. Built-in safety features prevented overloading the platform or tipping the unit and allowed several means of emergency shutdown. The principal advantage of this device is the job-rem and time savings it affords when less scaffolding is built.

\section{Polar Crane Safety}

One of the most challenging problems encountered was to establish a method for access to the polar crane, which, at the time of the accident, was positioned away from the parked position. This meant that the normal access ladder did not line up properly with the crane, made the climb much more difficult, and required the use of fall protection equipment. The following key steps were taken to establish an acceptable access route:

- Climbing and rescue procedures were written.

- The safety department performed the initial climb and installed a system of fall prevention equipment and rescue devices.

- Subsequent climbs received a safety department escort until a method of instruction could be developed for regular training of polar crane workers.

o Several inspections of the crane were conducted, including taking the measurements needed to install a work platform. 
- An acceptable work platform, capable of lifting four men from elevation 347'-6" to the polar crane walkway, was procured and engineered for installation.

- Concurrent with the work platform procurement, application was made by GPU for minor variances from OSHA regulations.

- Lifting systems werè installed on elevation $34^{\prime} 7^{\prime}-6^{\prime \prime}$ and on the polar cräne.

- The work platform was installed and tested; this included support installation, electric power, and platform assembly.

- The current training program was established, requiring all personnel to learn the climbing technique, use of safety equipment, and operation of the work platform.

The time frame for developing crane access routes resulted from the desire for early inspection of the polar crane and its decontamination in the proper sequence for the Deconlamination Experiment.

\section{Protective Devices for Decontamination}

Use of high pressure cleaning systems required the use of foot and skin protective devices as well as hearing protection.

Aluminum foot and skin guards were used. These devices were acceptable even though they were awkward Lo walk in, particularly on stairs. For this reason, they were put on and removed at the reactor building work area.

Standard industrial ear plugs were used for hearing protection. Unfortunately, these plugs were not truly compatible with the radio earpieces used, and a better solution would have been to use a radio headset that also sealed 
out background noise. Although a system of this type was tested, it was not implemented because of reception problems with the radio. If headsets had been used, modification of the type of protective hood worn would have been required, since the hood used was not large enough to accommodate a headset.

Worker safety was also enhanced by direct radio communications between the command center and the entry teams, and by telephone headset communications between the command center and the high pressure pump. Almost all decontamination work was also visible on closed-circuit television as well. Equipment requiring protection from high pressure spray mist was covered with plastic.

\section{Confined Space Requirements}

If unventilated for a period greater than 7 days, a reactor building is considered a "confined space." This requires monitoring the atmosphere for sufficient oxygen levels ( 19.5 to 21 percent) and for the presence of combustible gases (less than 20 percent of the lower explosive limit). These measurements are performed by the first individual entering the air lock and containment. If measurements cannot be taken or if their results are either unsatisfactory or in question, subsequent entries are performed using selfcontained breathing air only. Several instances of questionable readings have occurred in the past. The following factors have been determined to cause erroneous readings:

- Transmissions from the radio system

- Fluctuations in reactor building pressure and air lock pressure

- Lower-than-recommended shelf life of the oxygen cell portion of the detector. (The actual acceptable replacement interval is about 2 months; the vendor-recommended shelf life is 6 months.) 


\section{Equipment Movement}

Lifting and handling heavy equipment have the potential for causing personnel injury. Detailed rehearsals for these work items are required to ensure that the techniques employed are safe and efficient. This is particularly true when lifting devices and heavy equipment (forklift, winch, etc.) are involved. When equipment is to be carried, rehearsals must include instructions on prevenlion of back injury and controls that limit individual loads to about 50 pounds. Worker endurance must also be validated in mock-up training.

\section{Fire Protection}

A full fire protection capability was restored to the accessible areas of the containment building by implementation of the following measures:

o Replasement. and test. of fire hnses on elevatinns $305^{\prime}$ and $367^{\prime}$

- Installation of portable fire extinguishers in the anteroom and on elevations $305^{\prime}$ and $347^{\prime}-6^{\prime \prime}$

- Maintenance of a log of transient combustibles by the command center; use of fire-resistant materials where possible

- Training of entry personnel on casualty procedures and use of fire extinguishers

- Training of fire brigades on containment conditions

- Welding, cutting, burning, and soldering controlled per site procedure 1410-Y-26, with fire watches in radio contact with the command center

- Monitoring of containment with CCTV following entry. 
ATTACHMENT D-1

SAMPLE WORK PACKAGE 
Work Package No.: 53 Charge No.:

Revision No.: Original

TITLE: Gross Decontamination Test: Low Pressure Flush of Polar Crane ORIGINATOR: J. R. Kannard

ESTIMATED WORKER REQUIREMENTS:

1. Manhours in Containment 30.5

2. Manrem 4. 39

3. Entry Hours

$$
6
$$

APPROVAL :

- Decon Superintendent Date

- CAG/Decon ALARA Review Date

- Decon Operations Review

- Cognizant Engineer

- Training Review

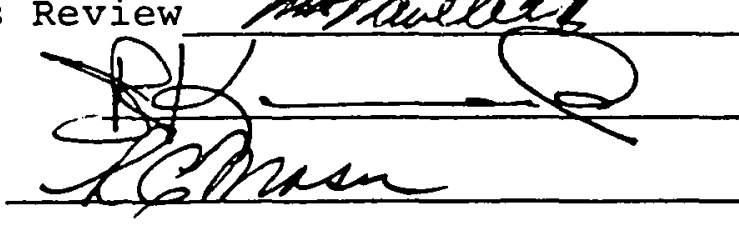
Date Date $\frac{12 / 14 / 81}{12 / 12 / 81}$ DISTRIBUTION :

D. M. Lake (1)

T. E. Morris (3)

J. P. Pope (1)

W. H. Shirey (1)

P. R. Bengel (6)

J. Renshaw (I)

R. E. Walker (1)

R. L. Rider (1)

R. W. Jackson (1)

J. Schork (1) 


\subsection{PURPOSE AND SCOPE}

The purpose of this experiment is to mist and low pressure water flush, the polar crane (and dome) area. A flow rate of $25 \mathrm{gpm}$ will be used at both ambient temperature and $140^{\circ} \mathrm{F}$. All surfaces expect the underside of the polar crane will be flushed.

2.0 LIST OF REFERENCES

2.1 TMI Unit No. 2 Operating Procedure 2104-4.55, Reactor Building Entry and Pre-Decon (Rev. 5).

2.2 Data Acquisition Sample Package for Task No. 3.

- Part 3.1 - Initial Data Collection and Misting of the Polar Crane:

- Part 3.2 - LP Flushing of Polar Crane and Dome Area.

2.3 Work Package 41; Hose Installation and Test.

2.4 Work Package 47; Low Pressure Misting and Flushing of 305' Elevation.

2.5 Work Package 5; Equipment Protection

2.6 Work Package 48.2; Flushing of Stairwell No. 2.

2.7 Procedure for Accent To and Descent from the Unit 2 Polar Crane, 2104.9-1.

\subsection{LIST OF ATTACHMENTS}

3.1 Equipment List

3.2 Manpower Assignments

3.3 Pre-Job Briefing Outline

3.4 Post-Job De-Briefing Outline

3.5 Prerequisite Verification Sheet

3.6 Technique Sheet - Data Collection

3.7 Data Collection Sheets

$$
D-A 1-2
$$


3.8 Figures.

3.9 Technique Sheet - Hydrolance Operations for Misting and Flushing.

3.10 Representative Schedule

4.0 PREREQUISITES - (to be verified on Attachment 3.5 for each entry this Work Package is used).

4.1 The Spider Access System is installed and operational.

4.2 The following Work Packages are complete:

- \#1: Hose Installation \& Test (Applicable Sections)

- \#47: Elevation 305 LP Flush

- \#5: Equipmenț Protection

4. 3 No other work may be in progress in the building during the execution of this work package.

4.4 The Decontamination Experiment Water (DEW) System has been installed, operationally tested and is functional and standing by for operation.

4.5 See Misting and Flushing Caution \#5.

4. 6 Equipment Protection has been accomplished on the Polar Crane.

4.7 Operation of the Reactor Building Purge system must be in compliance with GPU and NRC Directives for flushing activities.

\subsection{GENERAL REQUIREMENTS}

5.1 The equipment required for performance of this Work Package is listed on Attachment 3.1. The amount of this equipment required for each team entering the containment Building will be determined on a case basis by the Decon Operations Superivosr and staged in the anteroom. No equipment staged for an entry shall be left behind in the anteroom. $\mathrm{D}-\mathrm{Al}-3$ 
5.2 Crew members shall be designated " $A$, " "B, " $C$," and "D," for purposes of this Work Package, and they shall have this designation marked distinctively on the outside of their Anti-C's for monitoring purposès.

5. 3 Work specified by this work Package is under the direction of the Decontamination Operations Supervisor located in the Command Center. If work cannot proceed in accordance with the Work Package instructions, personnel should request further direction from the command center.

5.4 In order to reduce exposure, personnel within the containment shall remain in the lowest radiation fields practicable and consistent with performance of the work. These areas will be identified during training and may be marked with signs within the containment Building.

5.5 The sequence of work presented in this document is the preferred sequence. Only the Decontamination Operations Supervisor may direct that the work proceed in alternate sequences :

5.6 Epccific cquipment will bc ocalcd in poly bago prior to staging. The purpose is to maintain this equipment in a non-contaminated state until use. Routine opening of poly bags within the containment can be accomplished using large hand shears. Caution should be taken not to cut Anti-C clothing or the contents of the bag. If a bagged item of equipment is not used during performance of this Work Package, it will be removed to the Anteroom. Poly bags from which equipment has been removed shall be disposed of in the appropriate waste bag.

$$
D-A]-4
$$


5.7 Operations specified by this Work Package shall be videotaped to the maximum extent practicable using hand held and/or existing, installed TV cameras.

5.8 For the purpose of evaluation and documentation of the effectiveness of each tecnhique, the following data will be recorded in the Command Centerduring the task operations on Data Sheets 3-H or 3-P (Attachment 3.7) as applicable.

- Time task initiated and concluded.

- Time elapsed for operations on each equipment item or area.

- Flow meter readings in order to determine approximate volume of water used for each technique on this designated equipment item or area.

- Efficiency of application method including number of personnel used; support services; access; safety hazard and effectiveness of equipment used (redundance, ease of moving from tops to side, etc.)

5.9 Collection of pre-test data on the polar crane and 347'6" elevation shall have been completed per section 6.2 of this Work Package before proceeding with Section 6.3.

5.10 Workers will follow safety procedures as outlined in reference 2.7 .

5.11 Verbal notification shall be given to Command Center before initiating decon of each work area. 
5.12 Those items marked "Reserved" are steps which are not currently planned as a normal part of the operation. These steps may be selected for completion by the Decontamination Operations Supervisor prior to the planned entry provided the workers have been trained in the specific operation.

5.13 Instructions within individual steps which are bracketed, $($ ), are "Reserved" in the same manner as indicated for steps in Item 5.13 above.

\subsection{WORK INSTRUCTIONS}

\subsection{Access to Work Station (Typical)}

6.1.1 Enter the anteroom and check the availability of equipment required for this Work Package.

6.1.2 When directed open the airlock door.

6.1.3 Transfer staged equipment to the airlock. Enter the airlock.

6.1.4 Close the outer airlock door.

6.1.5 Open inner airlnrk donr.

6.1.6 Transfer equipment out of airlcok and stage equipment.

6.1.7 If staged equipment remains in the anteroom, return to airlock and repeat the loading sequence.

6.1.8 Close the inner airlock door.

6.1.9 Transfer equipment to elevation $347^{\prime}$ by use of spider lift, "gooseneck hoist" or, if unavailable, by carrying up open stairwell.

6.1.10 Stage equipment for use on elevation 347' or polar crane as applicable. Any equipment to be 
lifted from 347.' elevation to the polar crane should be staged adjacent to the pick up point for the "gooseneck" hoist or spider lift.

6.1.11 If basic equipment and hoses have not been previously staged on/to the polar crane, perform applicable sections of reference 2.3 at this time with three team members in lieu of going to the polar crane. Team member " $D$ " will remain on elevation $347^{\prime}$ until all hoses are properly staged and operational.

6.2 Pre-Misting Data Acquisition

6.2.1 Take airborne samples per Attachment 3.6 at the locations identified on Figures $3-\mathrm{C}$ and $3-\mathrm{H}$ (Attachment 3.8). Initial Data Collection Sheet 3.7.1 upon completion at each point. Report completion to the Command Center. 


\section{NOTES FOR MISTING \& FLUSHING OPERATIONS}

1. Hose tender should assist squeegee operator whenever possible. In addition, the squeegee operator should assist the hose tender when necessary.

2. Prior to initiating work in each area, ensure that sufficient slack hose is available. Additional hose may be added as required per Reference 2.3 . 


\section{CAUTIONS FOR MISTING AND FLUSHING OPERATIONS}

1. Prior to use, the lance operator will inspect the connection of the lance with the water hose per Technique Sheet (Attachment 3.9) to verify a positive connection. A non-positive connection could result in a personnel injury upon pressurization.

2. Care should be taken to ensure that hose does not bind or rub against any sharp or cornered objects. This is the hose tender's responsibility, and he should move the hose as required.

3. Personnel should avoid getting wet to the maximum extent practicable. This may best be accomplished by staying behind the lance operator.

4. Depressurize hose and lance during any climbing operations. In addition, the lance should never be pointed at personnel. Inadvertent operation of the pressurized lance could result in personnel injury.

5. Insure that TMI \#2 plant operations has identified energized circuits and that non-energized circuits have been tagged out. Energized circuits equipment can represent an electrical hazard to misting/flushing personnel and direct misting/flushing on these should be avoided. 


\subsection{Test Operations (Misting)}

6.3.1 Connect the high pressure spray wand to the supply hose if not previously accomplished. Insure that a $0^{\circ}$ nozzle is installed on wand (Nozzle \#20).

6.3.2 Notify the Command Center, "Ready to Mist."

6.3.3 Command Center will notify pump operator, "Supply Water for Misting of the Polar Crane." Pump operator will notify Command Center, "Pressure psig, Temperature ${ }^{\circ}$, Flow Rate ."

6.3.4 Command Center will notify the Entry Team, "Commence Misting."

6.3.5 Mist all accessible surfaces of Area I PCL The (dome area around the crane' and the) crane rails should also be misted.

6.3.6 Upon completion notify Command Center, "area I PCL Misting Complete."

6.3.7 Command Center will notify the pump operator, "Secure the pump."

6.3.8 The pump operator will notify the Command Center, "Pump is secured." Command center will notify the Entry Team, "Pump secured."

6.3.9 Pressure should be released at the spray wand. Do not disconnect the wand from the supply hose. 


\subsection{Test Operations (LP Flush)}

6.4.1 Release pressure at the spray wand and disconnect the nozzle to be used for low pressure flush (if applicable) .

6.4.2 Notify the Command Center, "Ready to flush Area I PC."

6.4.3 Command Center will notify pump operator, "Supply Ambient temperature water for low pressure flushing of the polar crane."

Pump operator will notify Command Center, "Pressure psi, Temperature ${ }^{\circ}$, Flow Rate -"

6.4.4 Command Center will notify the entry team, "Commence flushing of Area I PC."

6.4.5 Flush all accessible surfaces of the polar crane in Area I PCL (Figure 3-A, Attachment 3.8). (This should be sequenced first by flushing the dome area over the polar crane). The crossbeam and girder "B" should be flushed. Girder "A" and walkway sould then be flushed. At completion repeat steps 6.3 .6 through 6.3.9. 
6.4.6 Squeegee the crane surfaces where practicable.

6.4.7 Repeat step 6.2.1.

6.4.8 Repeat steps 6.3.1 through 6.4 .6 for Area II PCL (Figure 3-A, Attachment 3.8) except using water at $140^{\circ} \mathrm{F}$ for flushing. (The dome area should be flushed first. Special attention should be given to flushing of the area above the IOCA duct opening and the south dome area.) Next flush the polar crane trolley, girder "A", walkway, crossbeam girder "B," crane rails and last the polar crane cab. At completion repeat steps 6.3 .6 through 6.3 .9 .

6.4.9 Repeat step 6.2.1.

6.4.10 Disconnect equipment and stage for lowering to the top of the D-Rings.

6.5 Post Flushing Data Acquisition

6.5. I Perform a general area beta and gamma survey per Attachment 3.6 at 1 meter from the floor at the locations identified on Data Collection sheet 3.7 .2 (Attachment 3.7).

6.5.2 After surfaces have dried, perform a contact gamma, beta, and swipe survey per Attachment 3.6 at the locations specified on Data Collection 3.7.2 (Attachment 3.7). The survey includes points on the polar crane, D-Ring area, 347'6" floor elevation, and. refueling canal areas. 
(6.5.3 Take teletector measurements of the dome area. This measurement will be taken by placing the teletector above the points marked in Figure 3-C (Attachment 3.8 ) at 1 meter from the marked surface. The teletector probe should extend perpendicular to the polar crane. These measurements stiould be recorded on Data Collection Sheet 3.7.7 (Attachment $3.7)$. )

6.5.4 Take photographs of the polar crane locations and in directions specified on Figure 3-F. (Attachment $3.8)$.

\section{6 Exit from Work Station}

6.6.1 Lower eqiupment and hoses from the polar crane to the top of the D-rings using the "gooseneck" hoist or the spider lift.

6.6.2 Exit from the polar crane.

6.6.3 Proceed from elevation $347^{\prime}$ to elevation $305^{\prime}$ via the open stiarwell (\#). Proceed to vicinity of personnel airlock.

6.6.4 Upon concurrence from the Command Center, equalize pressure between containment Building and airlock, and unlatch and open inner airlock door. (See Reference 2.1 for details on airlcok operation):. 6.6.5 One team member should enter the airlock (while shedding one pair of booties). Team members should transfer items into airlock as they are bagged by team member in airlock. 
6.6.6 After items are transferred into airlock, other team members should enter airlock (while sheeding one pair of booties each)

6.6.7 Close inner airlock door and equalize pressure between airlock and anteroom.

6.6.8 Unlatch and open outer airlock door.

6.6.9 Exit airlock and undress per instruction of anteroom attendants. Equipment in airlock will be removed by anteroom attendants after work crew is prócessed.

6.6.10 After having been processed by Radiological Control personnel and taking a shower, report to the Decon Operations Supervisor for de-briefing. De-briefing will be conducted per Attachment 3.4. 


\begin{tabular}{|c|c|c|c|}
\hline & & & \\
\hline QUANTITY & ITEM & STAGED & TO AIRLOCK \\
\hline 1 & $\begin{array}{l}\text { Hydrolance w/long lance } \\
\text { adapted for LP misting } \\
\left(15^{\circ}, 10 \mathrm{gpm} \text { nozzle) }\right.\end{array}$ & & \\
\hline 1 & Squeegee & & \\
\hline 3 & $\begin{array}{l}\text { High pressure hose seg- } \\
\text { ments - } 50 \mathrm{ft.} \text {. W/quick } \\
\text { disconnect couplings }\end{array}$ & & \\
\hline 2 & $\begin{array}{l}\text { High pressure hose seg- } \\
\text { ments - } 50 \text { ft. w/ quick } \\
\text { disconnect couplings, } \\
\text { adapted for suspension } \\
\text { from polar crane }\end{array}$ & & \\
\hline 3 & $\begin{array}{l}\text { Underwater high intensity } \\
\text { Lamps - portable }\end{array}$ & & \\
\hline 2 & $\mathrm{RO}-2 \mathrm{~A}$ & & \\
\hline 50 & $\begin{array}{l}\text { Rad swipes and 8" } \times 9 " \\
\text { poly bags }\end{array}$ & & \\
\hline 2 & Templates & & \\
\hline 2 & Air sampler units & & \\
\hline 2 & Swipe holders & & . \\
\hline 4 & Felt tip marking pens & & \\
\hline 50 & $\begin{array}{l}\text { Petri dishes, plastic } \\
\text { millipore, } 47 \mathrm{~mm}\end{array}$ & & \\
\hline 1 & Meter stick & & \\
\hline 1 & Teletector & & \\
\hline
\end{tabular}


ATTACHMENT D-2

TECHNIQUE SHEETS 


\section{TECHNIOUE SHEET}

\subsection{FLUSH TEAM OPERATION}

A flush team consists of three personnel, a liqu1d blaster lance operator, a hose tender, and squeegee operator. To maintain all personnel in good physical condition for continued flush operation, the tean members will rotate anong the three position at about 15 monute intervals or as directed by Command Center.

1.1 Blaster Orarator - Team Leader, operates the blaster lance of the spin-jet and is responsible for assuring safe operation of the liquid blaster or spin-jet. He is responsible that other tean members are alerted prior to pressurizing the system and are in a safe locations prior to depressing the operating nandle, activating the system.

1.2 Hose Tender - Provides assistance to the Blaster Operator. Prevents hose from snagging on obstructions and keeps hose clear of areas being cleaned. Positions himself directly behind the Blaster Operator at a safe distance (10-20 feet) and maintains slack for smooth lance operations. Assists with squeegee operation during spin-jet operations.

1.3 Squeegee Operator - Positions hiaself behind and to one side of the Blaster Operator. Directs floor run-off with his squeegee to floor drains. Prevents run-off from recontaminating areas already flushed. Viay be positioned in alternate locations by procedure or by instruction fron the Comand Center.

\subsection{CENERAL INSTRUCTICNS}

To begin liquid blasting the following guidelines should be followed:

2.1 All equipment is staged and nozzle is installed on lance with nozzle fan angle properly set.

2.2 Visually inspect all lines and connections.

2:3 Place the blaster shoulder piece firmly against right shoulder.

2.4 Grasp side handle firmly with left hand. 
2.5 Establish a firm footing with one foot in front of the other by several Inches to absorb the backwards force of the lance.

2.6 Open safety valve on the side of the lance.

2.7 Point the nozzle toward the starting point of the area to be cleaned.

2.8 Notify Command Center to pressurize the lance. (Be prepared for a sudden Jerk upon pressurization).

2.9. Disengage the safety latch.

2.10 Begin blasting by fully depreșsing the operatịng handle. (Maințain operating handle in full operating position of in full off position).

2.11 Whenever possible, flush from low dose areas. Avoid walking within 5 feet of floor drains.

\subsection{SAFETY}

3.1 Hosec are rated at 30,000 p9i.

3.2 Operating pressure shall not exceed 10,000 pst.

3.3 All personnel w11l wear safety equipment as designated, this will normally include anti-contamination clothing, full face respirators, rain suits, shin guards, hard-hats, and car protection.

3.4 The blaster lance system shall never be left unattended when pressurized.

3.5 Only trained personnel will be permitted to operate the Ifquid Blaster or Spin-Jet.

3.6 Equipment safety features will be maintalned in an operable condition.

3.7 The system must be depressurized and isolation valve closed on lance prior to performing any maintenance and prior to changing nozzles.

3.8 The Blaster Lance Operator will avold direct flushing or blasting of area Identified for equipment protection between yellow arrows taped on walls or covered with yellow herculite. 


\subsection{IIOUID BLAST MISTING}

4.1 The misting nozzle (0020) is installed in lance note! While misting the squeegee operator will remain in low dose area.

4.2 The Liquid Blast iance Operator will spray all overheads, walls and floor within flushing area.

4.3 At end of misting the Liquid Blast Lance Operator will notify the Command Center to shut down the pump. As the hose tender and lance Operator move back to the starting point the lance operator will depressurize system close safety valve on lance and install the flusing nozzle.

\subsection{LIQUID BLASTING OPERATION ON HORIZONTAL SURFACES}

5.1 Low Pressure Flushing

NOTE: Misting will be performed prior to all flushing operations. (Refer to Section 4.0).

5.1.1 The Ilquid blaster nozzle is held at least 2 feet away from the surface to be flushed and as far away from the surface to be flushed as the effective range of the flush stream.

5.1.2 The blaster lance should be held at no more than a $30^{\circ}$ angle fron the floor surface.

5.1.3 Flushing is accomplished with a side to side motion maintain flushing such that runoff flow back toward the operator is mininized.

5.2 High Pressure liquid Blasting Of Horizontal Areas.

5.2.1 The nozzle or blaster discharge is held approximately six to ten Inches above the surface being cleaned.

5.2.2 The blaster lance is held at an angle to the surface between $30^{\circ}$ and $60^{\circ}$ (Typically $45^{\circ}$ ).

5.2.3 The blaster is moved from side to side covering a path approximately 4 feet wide. Tach pass will overlap the previous pass in order to assure full coverage of the surface beling cleaned.

$$
D-A 2-3
$$


5.2.4 The fan nozzle is installed in the Blaster Lance such that the fan is parallel to the operating handle and perpendicular to the side to side motion of the lance.

5.2.5 The operator performs the side to side motion while moving slowly forward approxtmately 8 feet. The operator then backs up to a new starting point parallel to his prevlous path and begins liquid blasting a second path that will overlap his previous path on one sile.

NOTE: When approaching a drain, stop blasting the floor approximately 5 feet from the drain. Place the nozzle 6" from the drain cover and blast into drain slots from two directions in order to minimize dose. Blasting should NOT be towards support personnel.

NOTE: While blasting areas with insulation, such as cable insulation that could be damaged, that could be damaged, the lance operator should blast at a minimum distance of approximately 2 feet in order to reduce the force applied on such materials.

\subsection{LIOLID BLSSIEP OPERATION ON VERTICAL SLRFACES}

\subsection{Low Pressure Fl:-shing}

6.1.1 The nozzle or blaster discharge is held at least 2 feet from surface to be flushed and as far away from the surface to be flushed the effective range of the flush stream.

6.1.2 The lance operator w11l angle the blast stream in such a way as to direct the water deflected from the surface being flushed toward areas not yet flushed. This wili minimize recontarination and flushẹ surfaces, 
6.1.3 Flushing is accomplished with a up and down sweeping motion.

6.1.4 Particular care should be employed while flushing corners. Water should not be impacted directly. Into corners.

\subsection{High Pressure Liquid Blasting}

6.2.1 The lance operator will angle the blast stream in such a way as to direct the water deflected from the surface being flushed toward areas not yeat flushed. This will minimize recontamination of flushed surfaces.

6.2.2 Fan tip will be installed or postioned parallel to floor.

6.2.3 The operator moves the blasting lance in a vertical motions with the nozzle remaining 6 - 10 inches from the surface. In one continuous motion the operator should cover an area beginning at the top and blasting down to the bottom of the vertical surface.

6.2.4 Corners will be blasted side to side and from top to bottom. This Technique =rquires rinsing areas of the vertical surfaces already completed which may have become recontaminated due to splatter from blasting the corner. Rinse by backing up to the last area completed and blading with the nozzle at least 2 feet away from the vertical surface.

\subsection{HIGH PRESSURE LIOUID BLASTING OF STAIRWELLS.}

7.1 The starting point is at top level of the stairwell and initiates with misting operations.

7.2 Blast the entry to the stairweli with a fan tip nozzle:

7.3 At the platform of the stairwell, blast from the furthest point from the stalrs toward the downward dtairs. Blast surfaces beginning with the walls, (from top to bottom) then the rallings and then the platofmr over to first descending step. 
7.4 The runoff is directed by the operator across the platform and down the stalrwell using the lance.

7.5 Begin blasting the descending stalrs.

7.6 Order of Stairwell Liqu1d Blasting

7.6.1 Blast overheads, then walls- (From top to bottom) and the rallings.

7.6.2 Blast stair streads, descending steps are sequentially blasted.

7.6.3 After srepping down on third completed step repeat the steps for blasting of overheads, walls, railings, and steps for next step areas (7.6.1 and 7.6.2).

7.6.4 This process contlnuous unt 11 next lower platcorm is reached. Then at section 7.3 to repeat blasting of overheads, wall, railings, and steps for next flight of stairs. $(7.6 .1-7.6 .4)$.

NOIt: Avold direct blasting of lighting fixtures, recpeitcals and other electrical equipient.

\subsection{IIOUID BLASTING OF OVERTEADS}

8.1 Overhead Flushing will be accorplished using a 25 gpw open nozzle. This will direct a stream of water with sufficlent force to reach 10 feet above the level of the overheads.

6.2 The lance operator moves the lance in a side to side motion at approximately $45^{\circ}$ angle to the floor Into the area being flushed.

8.3 Flush overheads as far forward of the operator as the effective vater stream will aliow.

NOTE: Do not spray items marked for equipsent protections by on either slde of the area yellow herculite arrows.

8.4. The blaster lance operator after flushing all reachable overheads then begins flushing the walls and vertical surfaces, and then the horfzontal areas Including floors.

8.5 The lance operator will continue to flush cuerheads as he moves foniard to next start1rg point.

$$
D-A 2-6
$$




\subsection{H.P. SPINT-JFI OPERATION}

9.1 Visually check all the connect Lons for leaks.

9.2 Operator moves spin-jet to starting a $; a$.

9.3 Starting area will be to elther extreme side of floor (next to either the liner wall of $D-R$ ing wall).

9.4 After notification from the command center that high pressure water is available, the operator depresses the operating handle of the spin-fet. After flow water staits, he will swith the spin fet motor on.

9.5 The spln - jet operator completes one pass to end of work area.

9.6 At end of the pass the operator will wove the spin jet into position to blast an area parallel and overlaping back to the earlier pass, then completes the next pass back toward the starting point.

9.7 Continue overlaping passes up to the floor drain in middle of the work area.

9.8 The spin-jet operator then moves the spin jet into position to begin passes on the extreme oposite s1de of work area and proceeds (9.4-9.7) making parellel passes and continuing up to the floor drain.

\subsection{LIOUID BLASTING SUPPORT PERSONNEL}

10.1 The hose tender 1s positioned behind the operator at a safe distance, and will assist the operator by maintaining a suffictent slack in the hose in order to assure blaster operator mobility.

10.1.1 Prevent the hose from rubbing agalnst sharp corners.

10.1.2 Keep the hose from impeding water runoff into drains.

10.1.3 Inspect the hose and connections for leaks.

10.2 The squeegee operator is positioned behind and to the side of the operator with a squeegee in order to push water runoff towards floor drains.

10.2.1 Keep the water runoff fron recontaminating previous by completed areas.

10.2.2 Assist the hose tender. 
ATTACHMENT D-3

GENERAL ENTRY TRAINING 
GENERAL ENTRY TRAINING

\section{SECTION}

1. Organization Chart and Telephone Numbers

2. Entry Team Requirements and Training

3. Reactor Building Exit Criteria

4. Conditions Inside the Reactor Building w/Elevation Maps

5. Personnel Airlock Drawings and Operation Description

6. Equipment

7. RINP Requirements/Minimum Protective Clothing and Dosimetry/ Whole Body Count/Bioassay Requirements

8. Dress Out Procedure/Checklists

9. Communication with Command Center

10. Contamination Control/RIR Lessons/Skin Contaminations

11. Undress Procedure

12. Ante-Room Layout/Support Personnel/Conditions

13. Safety Work Practices (Heat Stress Exposure/Confined Spaces)

14. Casualty Procedure for High Radiation In Containment

15. Casualty Procedure for Fire In Containment

16. Casualty Procedure for Personnel Injury or Sickness In Containment

17. Fire Protection

18. Debriefing

19. Typical Entry Day Summary

20. Typical Entry Day Schedule 


\subsection{ENTRY REOUIREMENTS}

Current RWP Training

Current Who le' Body Count

Current Respirator Physical

Current MSA Fit Test - if the MSA purifier is used, otherwise current Scott fit is acceptable. (Glasses must be obtained if required)

MSA Furifier Training - onily if MSA purifier is used, one time qualification; may be completed during week of training.

Reactor Building Training includes:

1. General Entry Training or GET refresher; as appiticable.

2. Work Package Training

3. Airlock door training

4. Walktinru (may be omitted in some cases)

5. Final mockip (may be full dress/partial dress or heat stress test)

NOTE: Eritry team members must sign training sheet for each phase of training.

Persuridl Requiremerits/Suggesliunis:

a. Protection of valuables - each person is, responsible for his own valuables.

b. Tennis shoes - it is suggested that you wear an old pair of tennis shoes during your entry to prevent possible loss of good shoes via contamination.

c. Change of under clothes, towe1, soap, shampoo and comb - for use after your mock-up or entry.

d. Bring this outiine to training and mockup sessions for your use and rotes. 


\subsection{REACTOR BUILDING EXIT CRITERIA}

A. Sickness and/or fatigue - affected individual to be escorted to the airlock as quickly as possible. All team members do not have to exit unless individual who is exiting cannot be readily replaced and is required to perform team tasks.

A11 team members are responsible for informing the Command Center of any feeling of sickness or heat stress. In addition, team members are responsible for monitoring the well being of other entry personnel and informing the Command Center of suspected $i l l n e s s$ or fatigue. USE THE BUDDY SYSTEM WHILE IN THE CONTAINMENT!

B. Dose Pull Point - as specified by the daily entry schedule. Each individual is responsible for monitoring the dosimeter and exiting at the specified pull point.

C. Communication - Total ioss of communication with team. If team member can hear the Command Center and make himself understood via CCTV, activities may continue. If team members try to contact the Command Center and do not get any response, they should stay in sight of a CCTV camera as much as possible, pick uD their equipment and exit the Reactor Building.

D. Radiation Detection Gear - loss of radiation dose rate instrumentation to the dearee that personnel dose rate levels cannot be determined. Each team member will have a digital dosimeter and a pencil dosimeter with which to monitor his dose. In the event of failure of the digital dosimeter: 1) read pencil dosimeter; 2) call Command Center; 3) ask if exit is required.

E. Respirator - failure of respirator to perform properiv. Removal of the respirator while in the reactor building is acceptable in case of failure of the unit or sickness.

F. As ordered by the Command Center.

G. Failure of building lighting.

H. Use of Ice Vests - ice vests will be used for tasks involving extreme physical exertion or of long duration. In order to avoid over stressing individuals involved in these types of tasks, a 60 minute time limit has been set from the time the individual notifies the Command Center that all the $i c e$ in his vest has melted until the time he exits from the Reactor Building.

For all exits, the prime criterion is the safety of the individuals. All other team members do not have to exit if they are in sight of another entry team member and/or a CCTV camera so that the Command Center can be made aware of their locations.

If an emergency arises, notify the Command Center and wait for instructions. 


\subsection{CONDITIONS INSIDE THE REACTOR BUILDING}

Radiation Dose Rates

$$
\begin{aligned}
60 \mathrm{mRem} / \mathrm{hr} & -28 \mathrm{Rem} / \mathrm{hr} \\
100 \mathrm{mRad} / \mathrm{hr} & -200 \mathrm{Rad} / \mathrm{hr}
\end{aligned}
$$

Refer to dose rate maps (Make special note of dose rates and hot spots in your work area).

Typical hot spots include but are not limited to:

\section{Elevation 305'}

Enclosed Stairwell and elevator Open Stairweil

Holes in Flonir

Drains

Air Coojers

Hatches

Highifight low dose areas and highlight high dose or exclusion areas on maps.

Stay times for entry team members varies from 30 minutes to 3.5 hours.

Atrborne Actquity (Atter Purge)

TYPE

Particulate $\mathrm{Cs}^{137}$ $\mathrm{Cs}^{134}$ $\mathrm{Sr}^{90}$

Inert Gas $k^{85}$

Tritium $\quad H^{3}$ MINIMUN

\begin{tabular}{|c|c|}
\hline AVERAGE CONCENTRATION & MPC \\
\hline $4.7 E-8$ & $1 E-8$ \\
\hline $3.7 E=9$ & $1 E-\varepsilon$ \\
\hline $1.4 E-10$ & $1 E-9$ \\
\hline Less than $1 E-6$ & $1 E-5$ \\
\hline $1.4 E-8-6.3 E-6$ & $5 E-6$ \\
\hline
\end{tabular}

ELEVATION $347^{\prime}$

Incore Instrumentation Table

HPC $=$ permissible concentration per 10 CFR 20

.

If isotope being measured is not yet known, 1 E-9 is MPC (assumed to be most restrictive, i.e. Strontium 90 ) and appropriate respiratory protection should be unrn.

Purge remains on during the reactor building entry under most conditions.

Respirator must be working in reactor building and in anteroom in accordance with RiNP. Respirator may be removed from exiting entry personnel during approved undress sequence even if ai $r$ is greater than MPC.

\section{Protection Factor}

- MSA Purifier 1000

- Particulate Mask 50

- For tritium, any device other than self contained air $=1.0$.

Loose Surface Contamination

Levels vary from $10^{5} \mathrm{dpm} / 100 \mathrm{~cm}^{2}$ to $7.5 \times 10^{6} \mathrm{dpm} / 100 \mathrm{~cm}^{2}$ 
Noise

Noise level on El. 305' is substantial (approximately 85-90 db) due to air coolers. Noise level on El. $347^{\prime}$ is relatively low in comparison.

Lighting

An area of poor lighting exists on El. $305^{\prime}$ northeast quadrant by CFT "A" (see page 6).

Step-off. Pads

1. Prior to entering airlock from reactor building, place boots and any extra external gloves in trash drum near ramp.

2. Prior to entering ante room from airlock; place 1 pair of boots in bag - in airlock.

3. After exiting the ante room - final pair of boots arid gloves at control point.

General Arrangements and Equipment Locations

(See Attached Maps)

\section{PHOTOGRAPHS}

See previous entry photographs (Make special note of photographs of your work area). Photographs are kept in Trailer 105 Room and may be reviewed upon request.

Camera Locations

(See Attached Maps)

\section{Enclosed Stairwel1 Lighting}

The lights in the enclosed stairwell are temporary lights which have been strung down from El. $347^{\prime}$ between the handrails. The on/off switch is tie-wrapped to the handrail in the center of the stairs. Since access to El: $347^{\prime}$ is via the open stairwell and access to the elevator machinery room or polar crane ladder is via the enclosed stairwell, these lights have been left on and should NOT be turned on/off unless ordered by Command Center.

(NOTE: Area at El. $305^{\prime}$ inside enclosed stairwell is $28 \mathrm{r} / \mathrm{hr}$ gamma).

This area is now roped off to traffic between El. 305' and El. 347'. The light bulbs are burnt out and will not be replaced until dose rates can be reduced in this area. 


\section{5:0 AIRLOCK}

To be operated by operations department and other authorized (trained) personnel only.

$\therefore \therefore$ Both doors a re locked. when not in use:.

Unlocking of inner door requires stationing of security at both exits.

Inner and outer doors are interlocked to prevent the opening of both doors at once.

Interlock may be-defeated by: mechanical means: in airlock (see figure).

Doors swing (1). into airlock and (2). into reactor buildina.

Do not allow door to swing open by itself; hold it. as it opens. to avoid "banging".

Be careful not to step or bump the alrlock door seal surface.

When: closing doors, make sure handwheel. is turned to stod. in "open"- direction. Always wipe door seal. down with. "spot check" prior to last closing operation. Door Operation. (per. 2104.-4.55).

To open:

1. rotate handwheel $3 / 4$ turn to crack open equalizing valve; handwheel: directions are specified above the handwhee 1 .

2. allow pressure to equalize; note differential pressure by placing hand near air outlet pipe above handwheel.

3. rotate handwheel a second $3 / 4$ turn until the mechanical stop is felt*

4. hold door and push open slowly untilit is completely open.

To cliose:

1. swing door to noar closed.

2. insure door latch rollers are fully retracted; do so by turning handwheel in open direction until mechanical stop is felt

3. close door and turn handwheet in shut direction until mechanical stop is felt.

*NOTE: Inner Door requires more rotations of handwheel to open/close door. 
Restoring Airlock.

1. Obtain seal to seal interlock cabinet.

2. Enter airlock per section 5.5

3. Insure both doors are closed.

NOTE: Reference Figures $I$ and 2 for detailed drawing of interlock system.

4. Remove clamp knob ( $\$ 48)$ and open cover ( $\$ 52)$.

5. Press down on camyoke ( 149 ) until it is parallel with shaft as in Figure 1 and interlock disks are together.

6. Close cover ( $\$ 52)$ screw in clamp knob ( $\$ 48)$ and apply seal.

7. Notify Shift Foreman that interlock is in force and seal is applied. Violating the interlock system.

1. Obtain Shift Supervisor/Foreman approval prior to violating interlock. Enter afrlock per section 5.5:

NOTE: See Figures 1 and 2 for detailed drawlng of interlock system.

2. Break seal and remove clamp knob (" $\$ 48$ ).

3. Open hinged cover ( 152 ) and remove tape from camyoke, if present. Pull or push on camyoke (\$49) until yoke is perpendicular to the shaft. Upper interlocking disk ( 150 ) should slide toward camyoke violating interlock as in Figure 2.

4. Close cover and start clamp knob (\$48) into hole. Do not turn in fully and do not apply seal.

5. Notify Shift Supervisor/Foreman that interlock is violated. 


\subsection{EQUIPMENT}

\section{CAG Equipment}

Radio/Microphone/Earphones*

Small Lights

Spot1ights

Digital dosimeters

Cameras*

Data Sheets/Clipboards/Maps/etc.

HP FOREMAN

$\mathrm{RO}-2 \mathrm{~A}^{*}$

$E-530^{*}$

$\mathrm{RO}-7^{*}$

Teletector*

Dosimeters

BZA personal air sampler

RAD ENGINEERING

TLD's and dosimetry placement

*Special training required prior to use.
EQUIPMENT FOR ENTRY TASKS

Tools

Meters

Buckets

Well Wheels

Rope

Ramps

Carts

Ladders

Grease Guns

Others as needed

SPECIAL IZED EQUIPMENT*

Safety [quipment

High Reach Scissors Lift

Raymond Forklift

Spider Lift Platform

Tugger
Chainfall), On Lifting, Rig 
1. Two Bets of cloth PC's with corresponding muber of gloves and hootice. Det suits or other additlonal protective clothing determined by team member activicies.

2. Rubber boots/personal shoes.

3. Battery powered MSA A1r Purlfier Masks, Atr Roods, or Particulate Face Mask. (MSA Alr Purffler unless otherwlse opecifled).

4. TID's - See following sheets.

5. Self-Reading Dosimetry - each man will carry one pencil dosimeter outside the PC's and two penc1l dosimeters inside the PC's. D1gital dosimeters wili also be utillzed by all entry personnel.

It is very important that you know the scale and milisem/division of the peacll dosimeters that you are assigned as jou nay be asked to give the Command Center a reading from jour wrist dosimeter while In the Reactor Bullding (See attached page). 
1. Underwear and socks

2. ThD'8: Finger rings and wist ILD's (1f required), facing pain side of hand.

3. Peroosal shoes

4. Ankle ThD's (1f required)

5. One pasr plast1c bootles over personal shoes - taped around ankles loosely

6. One pair cloth PC's with chest and thigh TLD artached - taped over flrst booties, pulled up to waist only.

7. Second pair of plactlc bootles taped to firet PC's.

9. Two self-readers (low range and high range) taped to chest ares on first PC's.

10. One palr cotton gloves.

11. Rubber boots, fastened, and taped to outer PC's.

12. Four sets of non-skid booties; cut through elastic at top.

13. When Instructed, put on 1ce vest and pull up PC's; tape z1pper on outer pals.

14. Second pa1r neoprene gloves taped over firat PC'G.

15. Eceond eloth coverall taped to oecond bootit.

16. Palr of yellow gloves taped to outer PC's.

17. Additional prorective clothing (1f required), 1.e., wet suits, wet sult bottoms, aprons, etc.

18. Resplrator belt with battery/blower pack (rad1o \& digltal pouches, if required).

19. Digltal dosimeter in pouch on hip and one self-reader (high range) attached to either arm.

20. Skull cep.

21. Mask; turn on MSA (If powered resplrator is used).

22. Rad1o equipment (1f required); mike and earphone, (Tape wires to PC's - do not wrap around belt. Ensure freedom of movement of head without pulling on earphone).

$$
D-A 3-10
$$




\section{0 (Continued)}

Protective Cloth1ng Dress out

Sequence (W1th Ice Vest)

23. Attach TWD inside first hood (1f requ1red).

24. P1rst cloth hood.

25. Second cloth hood - taped to outer PC's.

26. Attach

27. B2A aampler attached to belt in back; do not turn on unt1l just prlor to actual entry.

28. Check and adjust equiprent:

1. Test radio with Comand Center; rolume should be "h1gher than normal" if worklng on El. 305'

2. If picking up digital dosineter in ente-roos, be sure to test by pushing "read" button; red light should light-up for at least two beconds. 
1. Observe all etep-off pads.

2. Wear extra yellow boots in case you need to enter the airlock more times than ent1c1pated. (Four pa1rs ere required by dress-out procedure).

3. Be consc1ous of your own protect1ve clothing; be alert for oust beconing wet and for IPB in gloves or wet ouits; be careful to avold coming in contact with contaninated surfaces wh your body.

4. Bag all contaminated 1tems lmediately after use or renoval. Rebag Items agatn when entering alrlock and ante-room.

5. Be careful to avold putting yourself into any unusual positions by climbing on or over anything, pulling cable, or kneeling down on the floor unless it has been 1dentifled as part of your task and your clothing requirements have been odjusted to pzotect you.

6. Allow the ente-room eupport personael to undress you vithout helping them outside of their instructions to you. Th1s will help to keep your gloves clean and intect.

7. While undressing in the ante-room or frisking out, be careful to avold tcuching yourself or anything which may be contaminated on bare akin. Th1s in:ludes the hose of your purlfler and the ante-room door.

Note: If skin contamination is discovered while frlsking out, a Skin ContaminatIon Record (4170) must be completed by the HP who will assist in decontaminating you, followed by a whole body count. In addition, a critique is norwally called by Radiological Baglneering (ALARA) and a Radiolog1sel Investigative Report (RIR) 18 written to oummarize lessons learsed anc corrective actlons. Inform Command Center if you become contam¿nated.

8. Wear cxira yellow gloves or take several pairs with you when you enter the Reactor Bullding so that if your gloves rip or become very dirty you can pull on or peel off a palr as needed. Extra gloves are needed when cilmbing to the polar crane. Work gloves are required if job requires heavy plijsical work.

9. Be aware of what the anteroom personnel are dolng and make sure they change the1: gloves periodically to preveat any contaminatlons. Refer questions to the Ante Room HP. Tech.

10. Laundered protective clothing previously used in Radiologically controlled areas is not to be used for training. For this purpose, only new PC's and specifically designated boots, respirators, etc. may be used for mockups outside RWP areas. 


\section{SAFETY WORK PRACTICES \\ A. HEAT STRESS EXPOSURE}

These requirements establish work time guidelines for workers exposed to not envircnments befcre a rest period is given for recovery from heat stress.

Work time guijelires refiect the actual time protective clothing andior respiratory protection are worn while performing work assignmencs and does not include suiting up, unsuiting of going to and/or from the work location. Breaks should follow exposure to heat stress. Duration of breaks, extent of clothing removal, ard the area where breaks are taken, shall be at the discretion or supervisory personnel.

The foliowing definitions apoly:

Ant1-C's

Impermeable clothing

Respiratory Protection

Supplied Air Auod or Suits

Temperature
Paper or cotton coveralls, cotton hood, rubber boots, and gloves.

Rein suits, water resistant clothing.

Negative pressure full-facepiece respirator, sCBA or supplied-air respirator.

Hood or suit with at least 6 cubic feet per minute continuous air flow.

ambient temperatures at a relative hunidity $75 \%$ at the work location.

If an extension of tine work time guidelines identified herein is reguired, due to the nature or criticality of the task being performed, pernission must be obtained from the supervisor ir. charge of the job.

Employee heat stress briefing, when required, should be arranged through and providec by the site Safety and Health Department.

When work is pianned in hot environments where relative hunidities are known to be greater than 90\%, the schedule for AntiC's under Impermeable Cicthing with Respiratory protection shall be utilized.

When temperatures exceer $120^{\circ} \mathrm{F}$ or where hot radiant heat surfaces are encountered, direction sinail be provided by the supervisor - Safety and Health for personal protective equipment.

When an individual feels discomfort from heat stress, he/she must immediately notify the person in charge and leave the area. 
Protective Equipment

Conventional

Work Clothing

Anti-C's (Only)

Anti-c's under

Impermeable Clothing

Anti-C's (oniy) With

Respiratory Protection

Anti-C's Under

Impermeable Clothing

With Respiratory

protection

Anti-C's With or Under

Supplied Air Hood/Suit
Temperature

Less than $100^{\circ} \mathrm{F}$

$100-100^{\circ} \mathrm{F}$

$110-120^{\circ} \mathrm{F}$

$80=90^{\circ} \mathrm{F}$

$90-100^{\circ} \mathrm{F}$

$100-110^{\circ} \mathrm{F}$

$110-120^{\circ} \mathrm{F}$

$80-90^{\circ} \mathrm{F}$

$90-100^{\circ} \mathrm{F}$

$100-110^{\circ} \mathrm{F}$

$110-120^{\circ} \mathrm{F}$

Less than $80^{\circ} \mathrm{F}$

$80-90^{\circ} \mathrm{F}$

$90-100^{\circ} \mathrm{F}$

$100-110^{\circ} \mathrm{F}$

$110-120^{\circ} \mathrm{F}$

$70-80^{\circ} \mathrm{F}$

$80-90^{\circ} \mathrm{F}$

$90-100^{\circ} \mathrm{F}$

$100-120^{\circ} \mathrm{F}$

$80-100^{\circ} \mathrm{F}$

$100-110^{\circ} \mathrm{F}$

$110-120^{\circ} \mathrm{F}$
Guidelines

For Work Time

None

2 Hrs.

45 Min.

3 Hrs.

2 Hrs.

$1 \mathrm{Hr}$.

$30 \mathrm{Min}$.

1.5 Hrs.

$1 \mathrm{Hr}$.

$30 \mathrm{Min}$.

$15 \mathrm{Min}$.

4 Hrs.

2 Hrs.

1.5 Hrs.

$1 \mathrm{Hr}$.

30 Min.

$1 \mathrm{Hr}$.

$45 \mathrm{Min}$.

$30 \mathrm{Min}$.

$15 \mathrm{Min}$.

4 Hrs.

2 Hrs.

1 Hr.

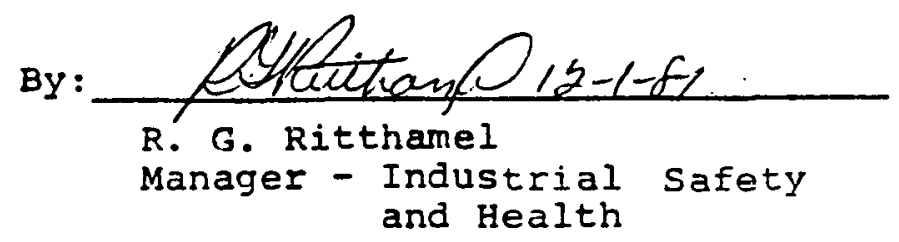




\section{GENERAL ENTRY TRAINING}

\section{SECTION}

1. Organization Chart and Telephöte Numbers

2. Entry Team Requirements and Training

3. Reactor Building Exit Criteria

4. Conditions Inside the Reactor Bullding w/Elevation Maps

5. Personnel Airlock Drawings and Operation Description

6. Equipment

7. RWP Requirements/Minimum Protective Clothing and Dosimetry/ Whole Body Count/Bloassay Requirements

8. Dress Out Procedure/Checklists

9. Communication with Command Center

10. Contamination Control/RIR Lessons/Skin Contaminations

11. Undress Procedure

12. Ante-Room Layout/Support Personnel/Cond1tions

13. Safety Work Practices (Heat Stress Exposure/Confined Spaces)

14. Casualty Procedure for High Radiation In Containment

15. Casualty Procedure for Fire In Containment

16. Casualty Procedure for Personnel Injury or Sickness In Contalnment

17. Fire Protection 59

18. Debrlefing 62

19. Typical Entry Day Sumary 63

20. Typical Entry Day Schedule $\quad 64$ 
HP2 (x8092)

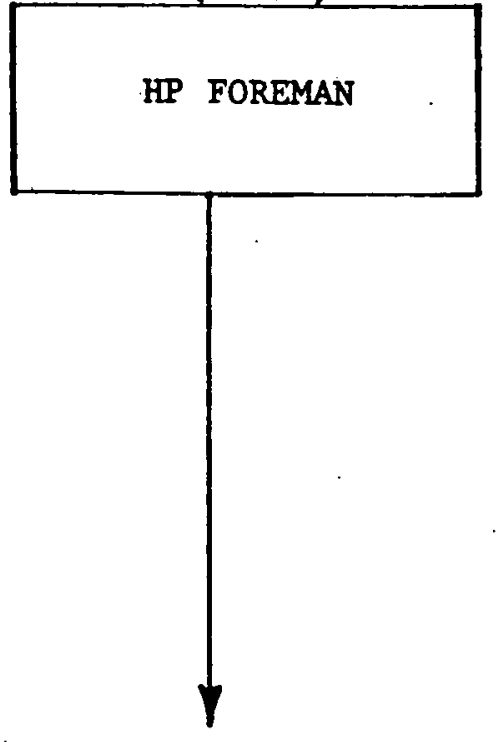

CUNILROL POINT

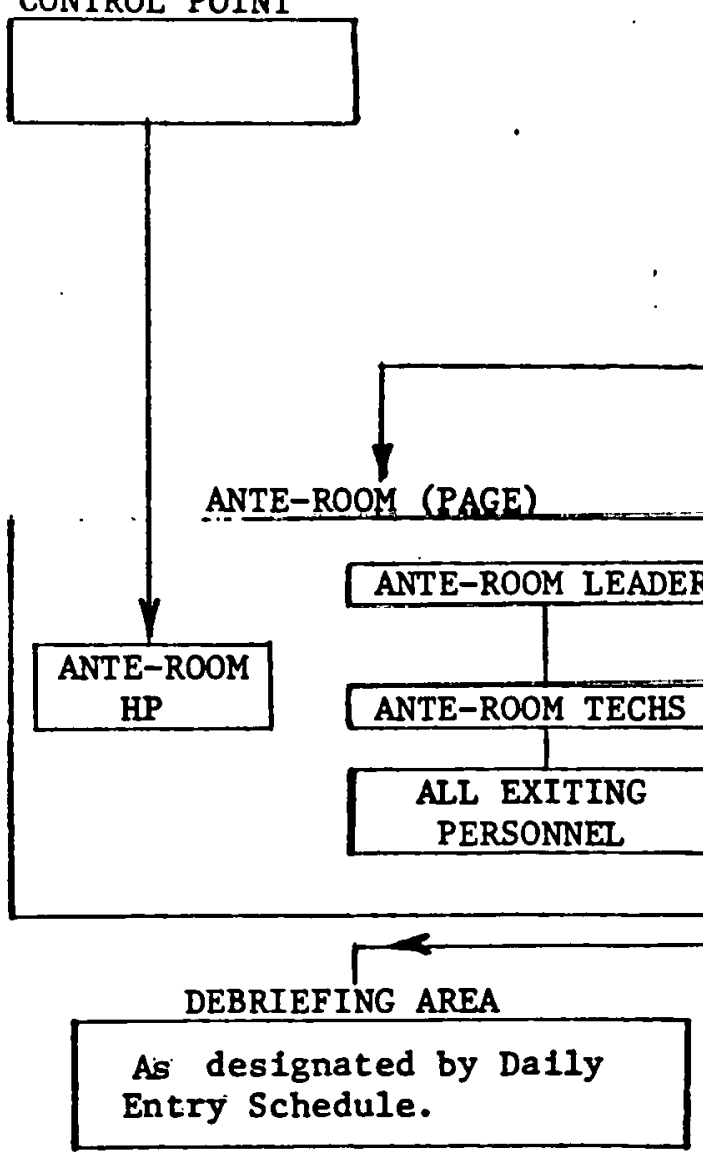

rane pre

Bechtel: Cig supervieor - Ponl Beprel zosu Pince Gilbert a 1092 Den Machiela ze603

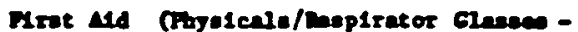

b) eppostent - (xs0)

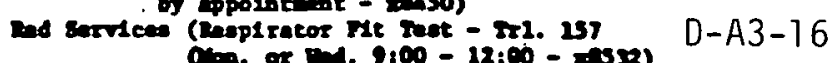

COMMAND CENTER $(\times 8390)$

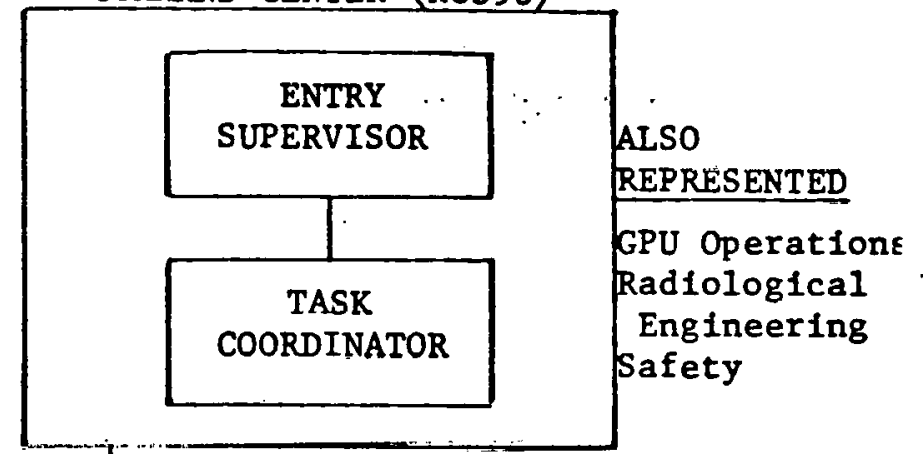

REACTOR BUILDING

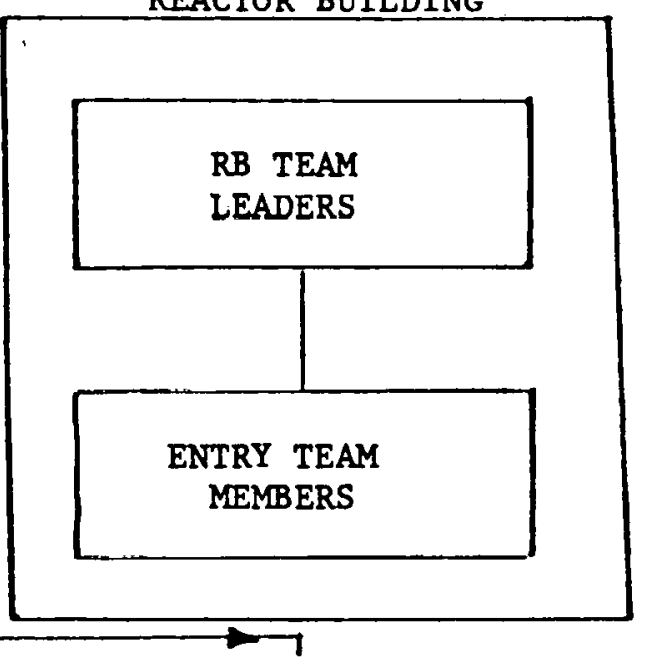




\subsection{ENTRY REOUIREMENTS}

Current RWP Training

Current Whole Body Count

Current Respirator Physical

Current MSA Fit Test - if the MSA purifier is used, otherwise current Scott fit is acceptable. (Glasses must be obtained if required)

MSA Purifier. Training - only if MSA purifier is used, one time qualification; may be completed during week of training.

Reactor Building Training includes:

1. General Entry Training or GET refresher, as applicable.

2. Work Package Training

3. Airlock door training

4. Walkthru (may be omitted in some cases)

5. Final mockup (may be full dress/partial dress or heat stress test)

NOTE: Entry team members must sign training sheet for each phase of training.

Personal Requirements/Suggestions:

a. Protection of valuables - each person is responsible for his own valuables.

b. Tennis shoes - it is suggested that you wear an old pair of tennis shoes during your entry to prevent possible loss of good shoes via contamination.

c. Change of under clothes, towel, soap, shampoo and comb - for use after your mock-up or entry.

d. Bring this outline to training and mockup sessions for your use and notes. 


\subsection{REACTOR BUILDING EXIT CRITERIA}

A. Sickness and/or fatigue - affected individual to be escorted to the airlock as quickly as possible. All team members do not have to exit unless individual who is exiting cannot be readily replaced and is required to perform team tasks.

All team members are responsible for informing the command Center of any feeling of sickness or heat stress. In addition, team members are responsible for monitoring the well being of other entry personnel and informing the Command Center of suspected illness or fatigue. USE THE BUDDY SYSTEM WHILE IN THE CONTAINMENT! You must be escorted out by another tean member if you exit under this criteria.

B. Dose Pull Point - as specified by the daily entry schedule. Each individual is responsible for monitoring the dosimeter and exiting at the specified pull point.

C. Communication - Total loss of communication with team. If team member can hear the Command Center and make himself understood via CCTV, activities may continue. If team members try to contact the Command Center and do not get any response, they should stay in sight of a CCTV camera as much as possible, pick up their equipment and exit the Reactor Building.

D. Radiation Detection Gear - loss of radiation dose rate instrumentation to the degree that personnel dose rate levels cannot be determined. Each team member will have a digital dosimeter and a pencil dosimeter with which to monitor his dose. In the event of failure of the digital dosimeter: 1) read pencil dosimeter; 2) call Command Center; 3) ask if exit is required.

E. Respirator - failure of respirator to perform properiy. Removal of the respirator while in the reactor building is acceptable in case of failure of the unit or sickness.

F. As ordered by the Command Center.

G. Failure of building lighting.

H. Use of Ice Vests - Ice vests will be used for tasks involving extreme physical exertion or of long duration. In order to avoid over stressing individuals involved in these types of tasks, a 60 minute time limit has been set from the time the individual notifies the Command Center that all the ice in his vest has melted until the time he exits from the Reactor Building.

For all exits, the prime criterionis the safety of the individuals. All other team members. do not have to exit if they are in sight of another entry team member and/or a CCTV camera so that the Command Center can be made aware of their locations.

If an emergency arises, notify the Command Center and wait for instructions. 
Radiation Dose Rates

$$
\begin{array}{r}
60 \mathrm{mRem} / \mathrm{hr} \\
100 \mathrm{mRad} / \mathrm{hr}
\end{array}
$$

- $28 \mathrm{Rem} / \mathrm{hr}$

- $200 \mathrm{Rad} / \mathrm{hr}$

Refer to dose rate maps (Make special note of dose rates and hot spots in your work area).

Typical hot spots include but are not limited to:

\section{Elevation $305^{\prime}$}

Enclosed Stairwell and elevator Open Stairwell

Holes in Floor

Drains

Air Coolers

Hatches

Highlight low dose areas and highlight high dose or exclusion areas on maps.

Stay times for entry team members varies from 30 minutes to 3.5 hours.

\section{Airborne Activity (After Purge)}

TYPE

Particulate

$$
\begin{aligned}
& \mathrm{Cs}^{137} \\
& \mathrm{Cs}^{134} \\
& \mathrm{Sr}^{90}
\end{aligned}
$$

Inert Gas

$$
k^{85}
$$

Tritium

\section{AVERAGE CONCENTRATION}

$1.2 E-8$

$1.2 E-9$

5. DE- 10

Less than $1 E-6$

$1.2 E-7$

$\checkmark 1$

$1.2 E \cdots 7$
MPC

$1 E-8$

1 E-8

$1 \mathrm{E}-9$

$1 E-5$

$5 E-6$

$M P C=$ Maximum permissible concentration per 10 CFR 20

If isotope being measured is not yet known, 1 E-9 is MPC (assumed to be most restrictive, i.e. Strontium 90 ) and appropriate respiratory protection should be worn.

Purge remains on during the reactor building entry under most conditions.

Respirator must be working in reactor building and in C.C.C. in accordance with RWP. Respirator may be removed from exiting entry personnel during approved undress sequence even if air is greater than MPC.

\section{Protection Factor}

- MSA Purifier 1000

- Particulate Mask 50

- For tritium, any device other than self contained air $=1.0$

Loose Surface Contamination

Levels vary from $10^{5} \mathrm{dpm} / 100 \mathrm{~cm}^{2}$ to $7.5 \times 10^{6} \mathrm{dpm} / 100 \mathrm{~cm}^{2}$ 
Noise

Noise level on El. $305^{\prime}$ is substantial (approximately 85-90 db) due to air coolers. Noise level on El. $347^{\prime}$ is relatively low in comparison.

\section{Lighting}

An area of poor lighting exists on El. $305^{\prime}$ northeast quadrant by CFT "A" (see page 6).

\section{Step-0ff: Pads}

1. Prior to entering airlock from reactor building, place boots and any extra exterilal gloves in trash drum near ramp.

2. Prior to entering ante room from airlock; place 1 pair of boots in bag in airlock.

3. After exiting the antc room - final pair of boots and gloves at control point.

\section{Genera 1 Arrangements and Equipment Locations}

(See Attached Maps)

\section{PHOTOGRAPHS}

Sep previous entry phuluyraplis (Make special note of photographs of your work area). Photographs are kept in Trailer 105 Room and may be reviewed upon request.

Camera Locations

(See Attached Maps)

\section{Enclosed Stairwell Lighting}

The lights in the enclosed stairwell are temporary lights which have been strung down from ET. 347' between the handrails. The on/off switch is tie-wrapped to the handrail in the center of the stairs. Since access to El. $347^{\prime}$ is via the open stairwell and access to the elevator machinery room or polar crane ladder is via the enclosed stairwell, these lights have been left on and should NOT be turned on/off unless ordered by Command Center.

(NOTE: Ared al ET. 305' inside enclosed stairwell is $28 \mathrm{r} / \mathrm{hr}$ gamma).

This area is now roped off to traffic between El. 305' and El. 347'. The light bulbs are burnt out and will not be replaced until dose rates can be reduced in this area. 
$\mapsto$ Access ladders

F] DRY CHEMICAL FIRE EXTINGUISHER

(1) FIRE HOSE REEL

- 4 -fire water ststem. - sUPPLY VAlVES

3. CAMERA

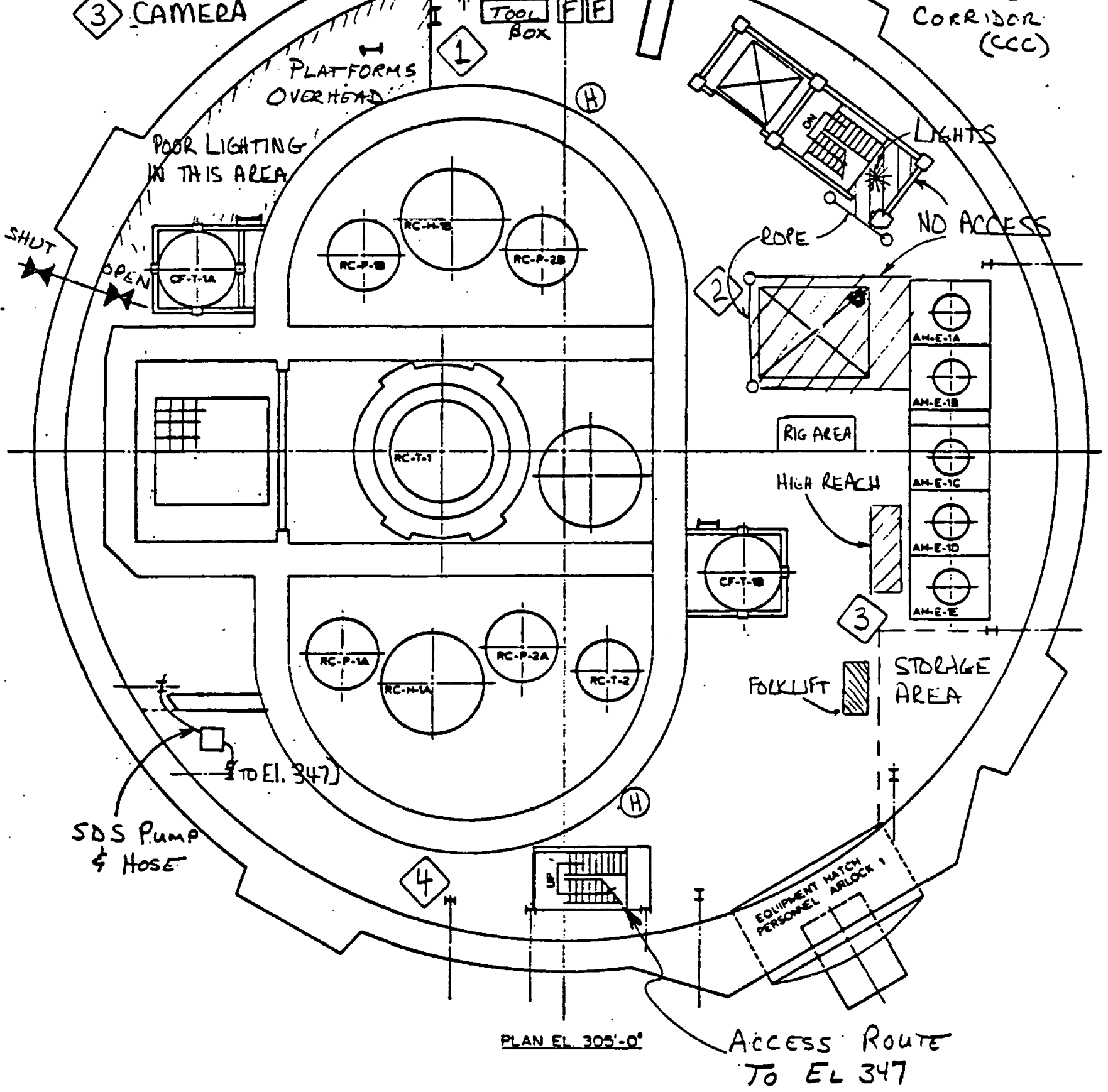




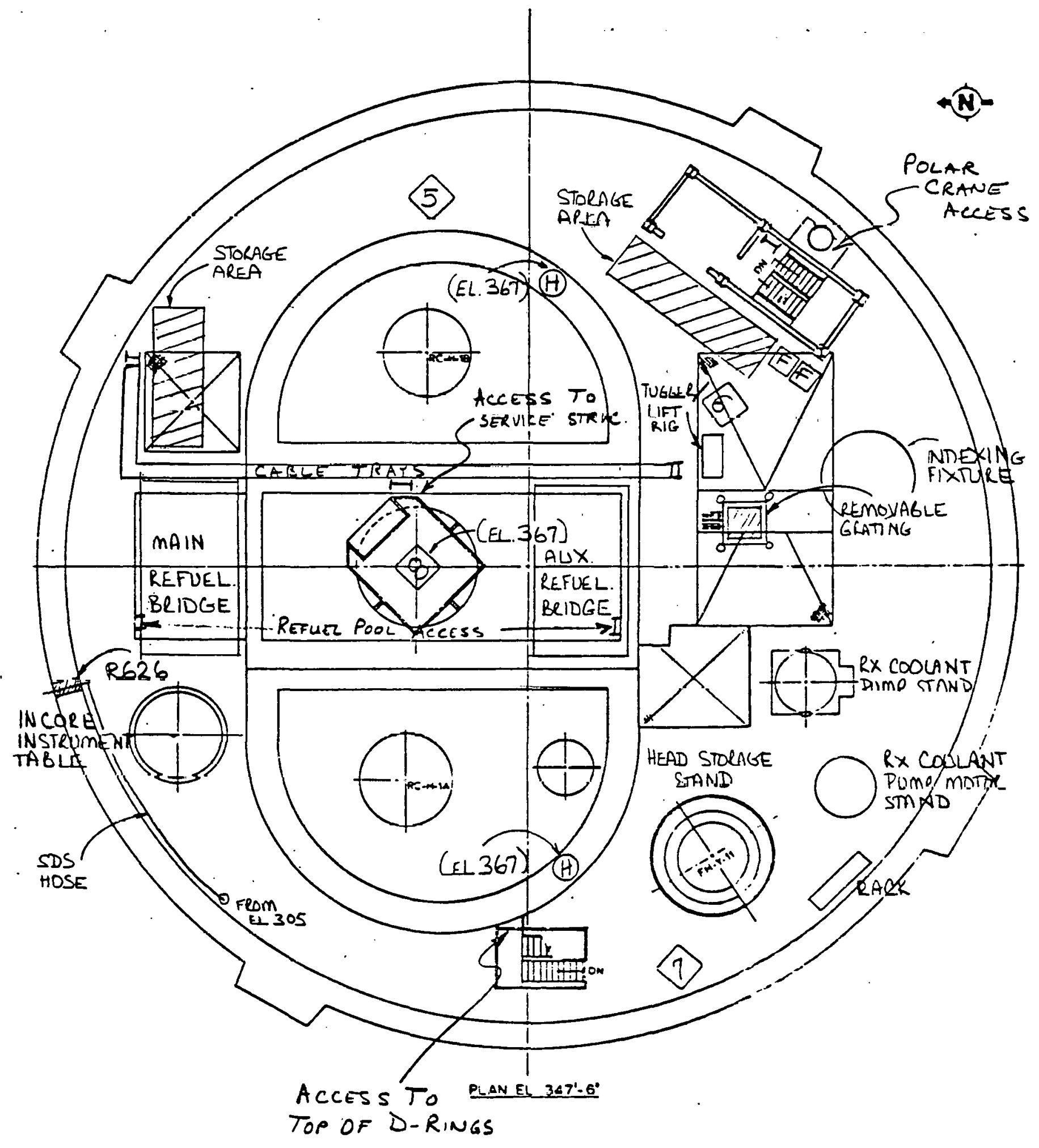




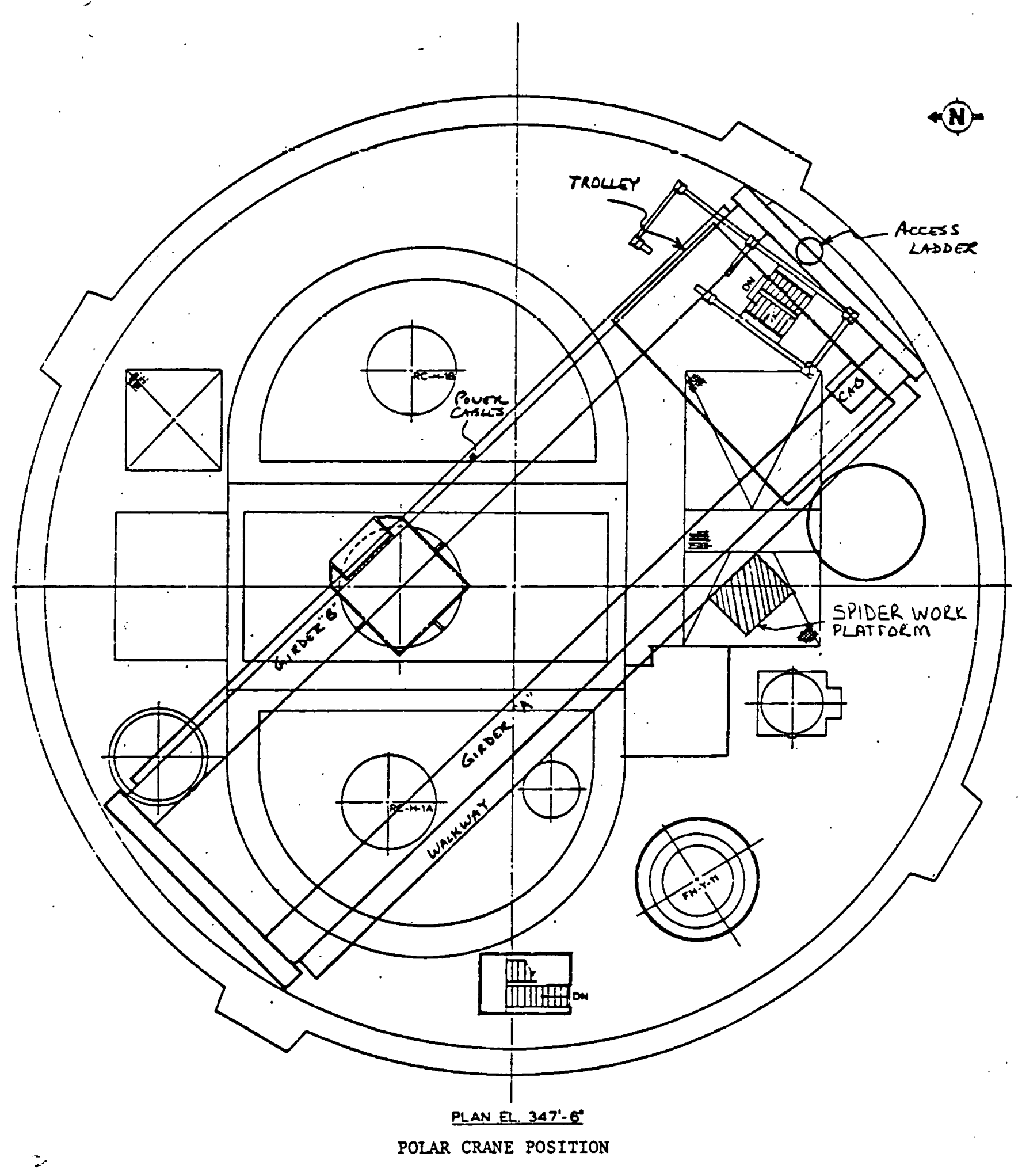




\subsection{AIRLOCK}

To be operated by operations department and other authorized (trained) personnel on ly.

Both doors are locked when not in use.

Unlocking of inner door requires stationing of security at both exits.

Inner and outer doors are interlocked to prevent the opening of both doors at once.

Interlock may be defeated by mechanical means in airlock (see figure).

Doors swing (1) into airlock and (2) into reactor building.

Do not allow door to swing open by itself; hold it as it opens to avoid "banging".

Be careful not to step or bump the airlock door seal surface.

When closing doors, make sure handwheel is turned to stoo in "open" direction. Always wipé door seal down with "spot check" prior to last closing operation. Door Operation (per 2104.-4.55)

To open:

1. rotate handwheel $3 / 4$ turn to crack open equalizing valve; handwheel directions are specified above the handwheel.

2. allow pressure to equalize; note differential pressure by placing hand near air outlet pipe above handwheel.

3. rotate handwheel a second $3 / 4$ turn until the mechanical stop is felt*

4. hold door and push open slowly until it is completely open..

To close:

1. swing door to near closed

2. insure door latch rollers are fully retracted; do so by turning handwheel in open direction until mechanical stop is felt

3. close door and turn handwheel in shut direction until mechanical stop is felt.

*NOTE: Inner Door requires more rotations of handwheel to open/close door. 


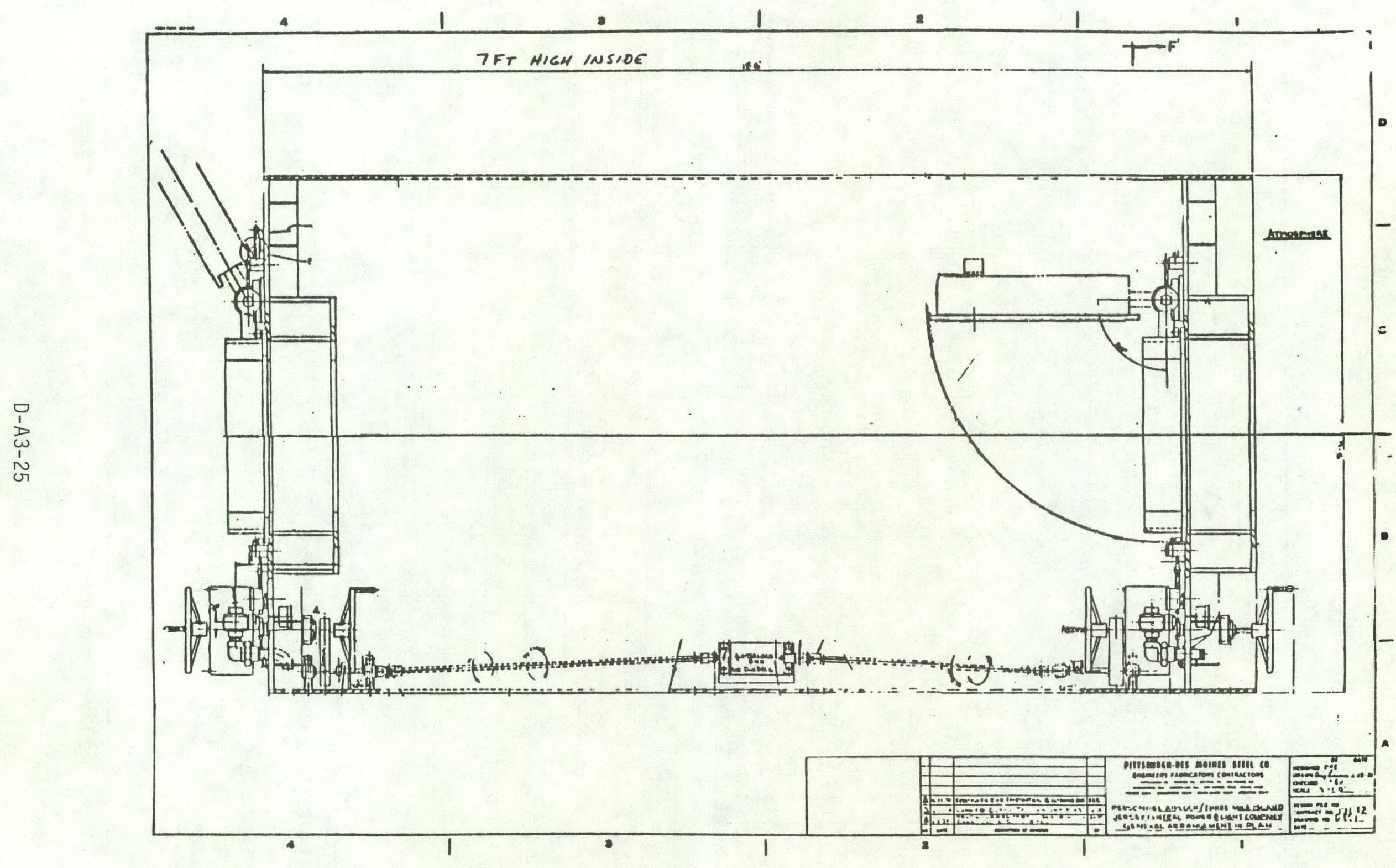




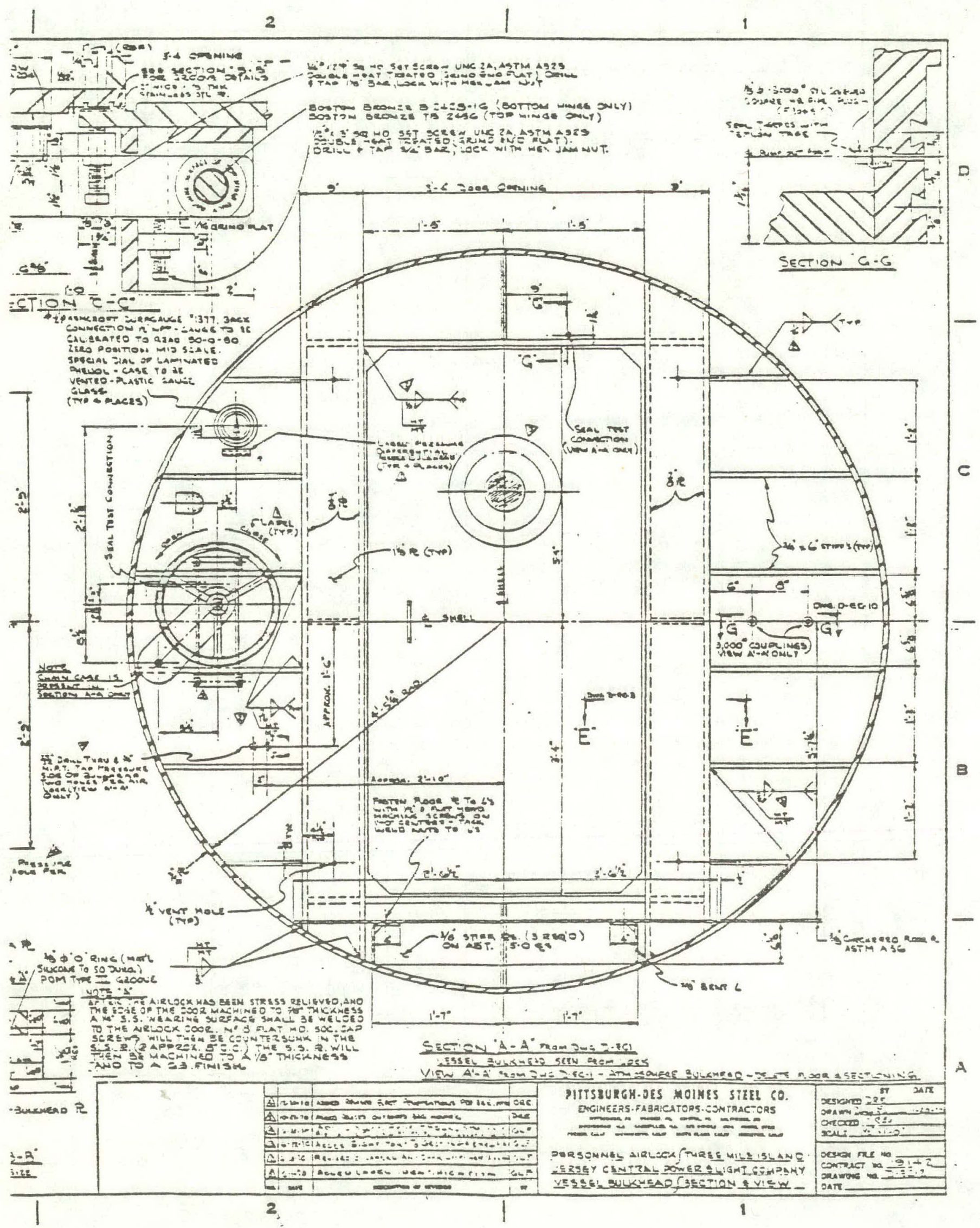




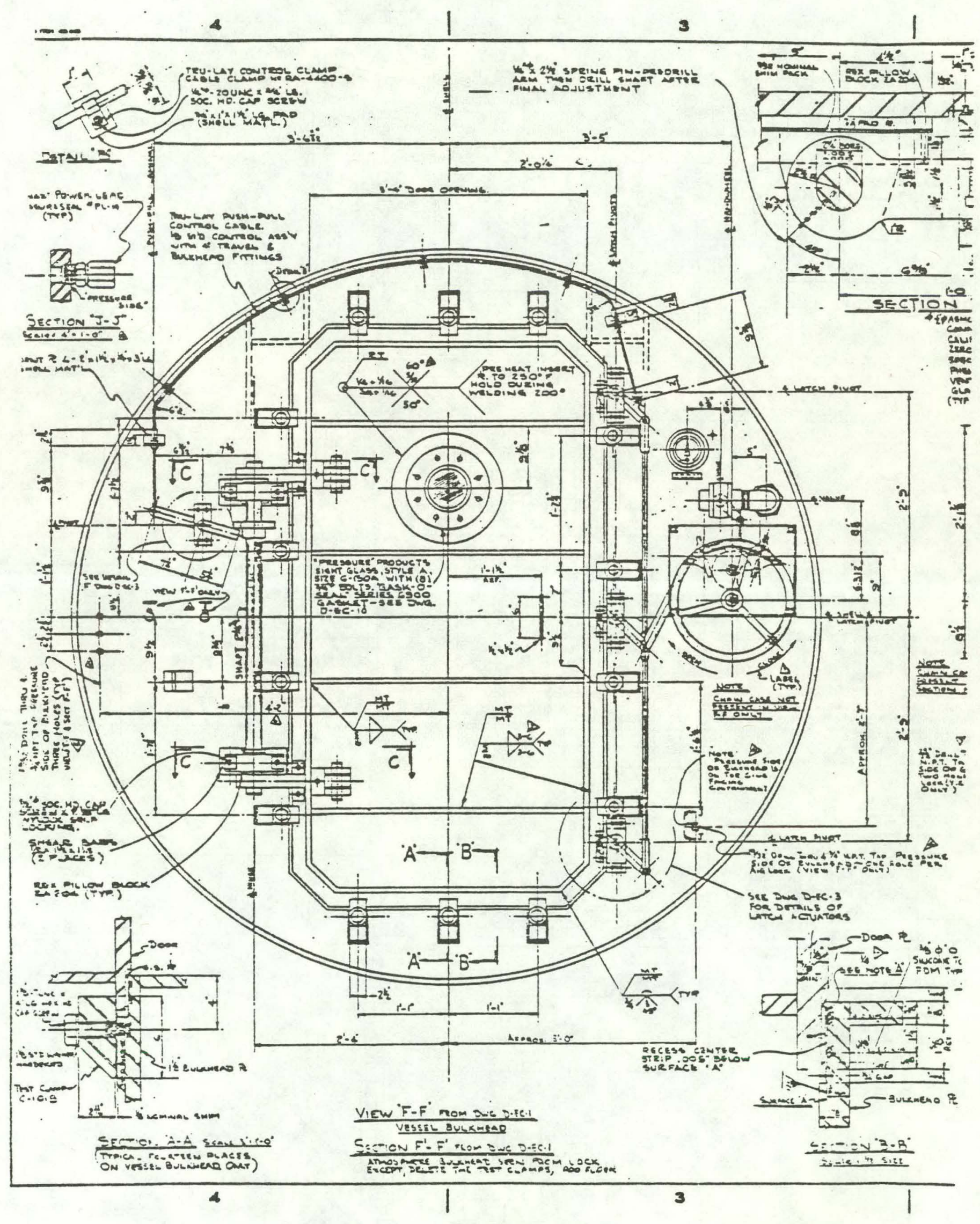




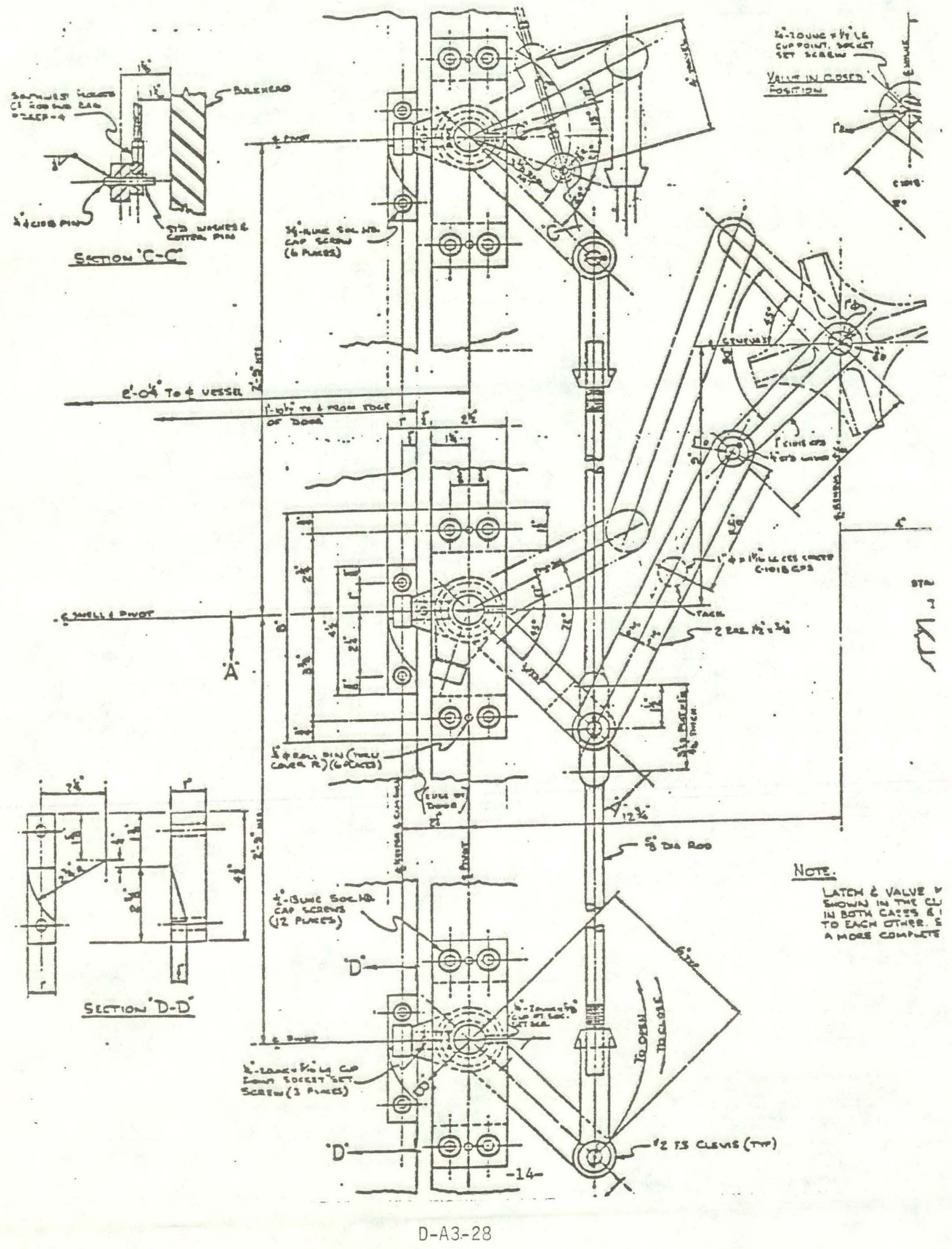


Restoring Atrlock.

1. Obtain seal to seal interlock cabinet.

2. Enter airlock per section 5.5

3. Insure both doors are closed.

NOTE: Reference Figures 1 and 2 for detalled drawing of interlock system.

4. Remove clamp knob (\$48) and open cover (\$5 2).

5. Press down on camyoke (\#49) unt1l it is parallel with shaft as in Figure 1 and interlock disks are together.

6. Close cover (\$52) screw in clamp knob (\$48) and apply seal.

7. Notify Shift Foreman that interlock is in force and seal is applied. Violating the interlock system.

1. Obtain Sh1ft Supervisor/Foreman approval prior to violating interlock. Enter airlock per section 5.5 .

NOTE: See Figures 1 and 2 for detalled drawing of interlock system.

2. Break seal and remove clamp knob (\$48).

3. Open hinged cover $(\$ 52)$ and remove tape from camyoke, if present. Pull or push on camyoke (\$49) until yoke is perpendicular to the shaft. Upper interlocking disk (\$50) should slide toward camyoke violating interlock as in Figure 2.

4. Close cover and start clamp knob (\$48) into hole. Do not turn in fully and do not apply seal.

5. Notify Shift Supervisor/Foreman that interlock is violated. 


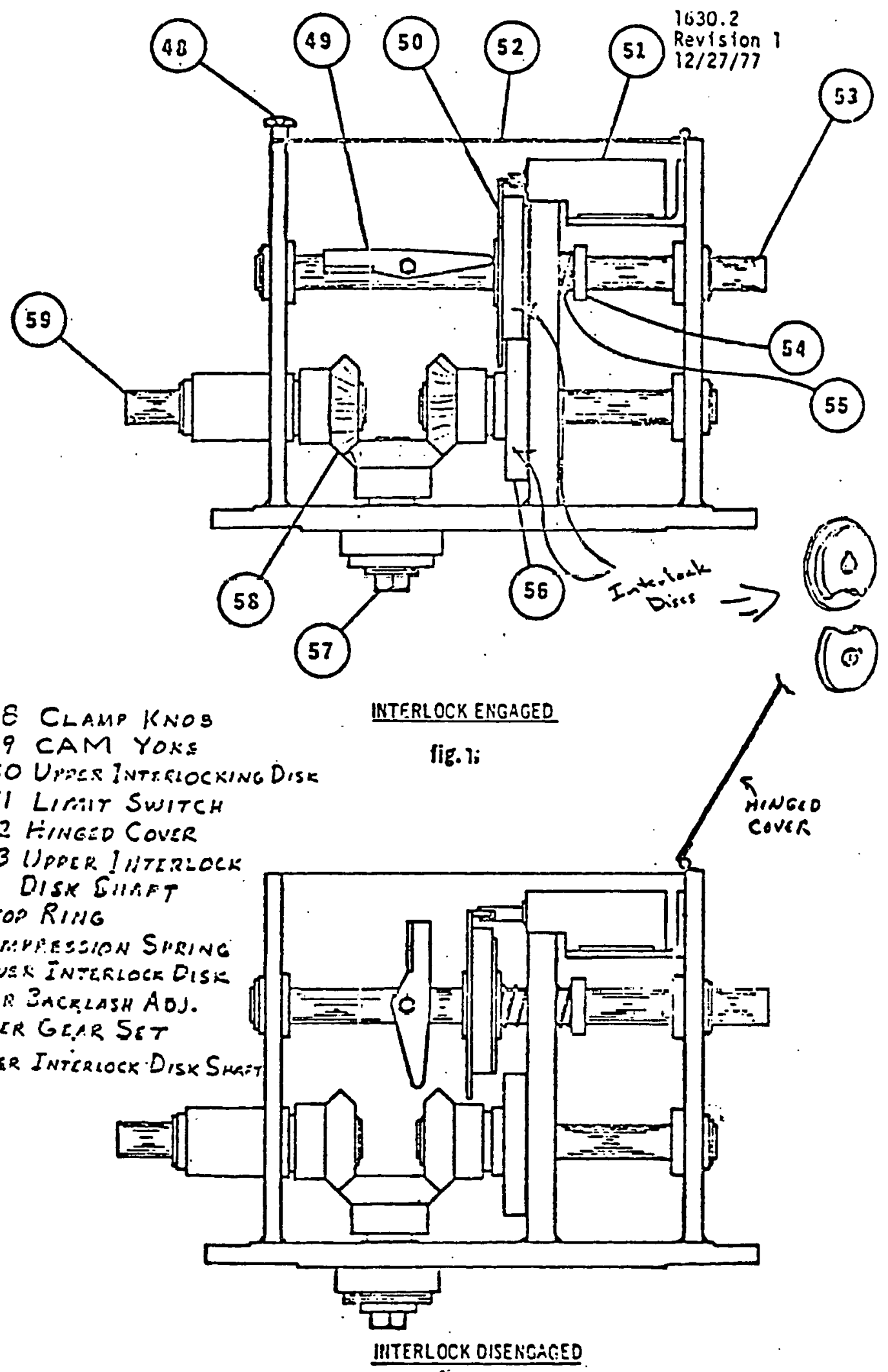




\subsection{EQUIPMENT}

\section{CAG Equipment}

Radio/Microphone/Earphones*

Small Lights

Spotlights

Cameras*

Data Sheets/Cl ipbiards/Maps/Etc.

HP FOREMAN

$\mathrm{RO}-2 A^{*}$

$E-530 *$

$\mathrm{RO}-7 *$

Teletector*

Dosimeters

BZA Personnel Air Sampler

Digital Dosimeters

RAD ENG INAERING

TLD's and dosimetry placement
EQUIPMENT FOR ENTRY TASKS

$\begin{array}{ll}\text { Tools } & \text { Rope } \\ \text { Meters } & \text { Ramps } \\ \text { Buckets } & \text { Carts } \\ \text { Well Wheels } & \text { Ladders } \\ & \text { Grease Guns }\end{array}$

Others as needed

SPECIAL IZED EQUIPMENT*

Safety Equipment

High Reach Scissors Lift

Raymond Forklift

Spider Lift Platform

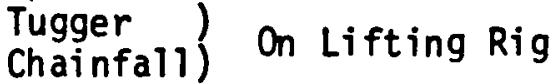

* Special training required prior to use. 


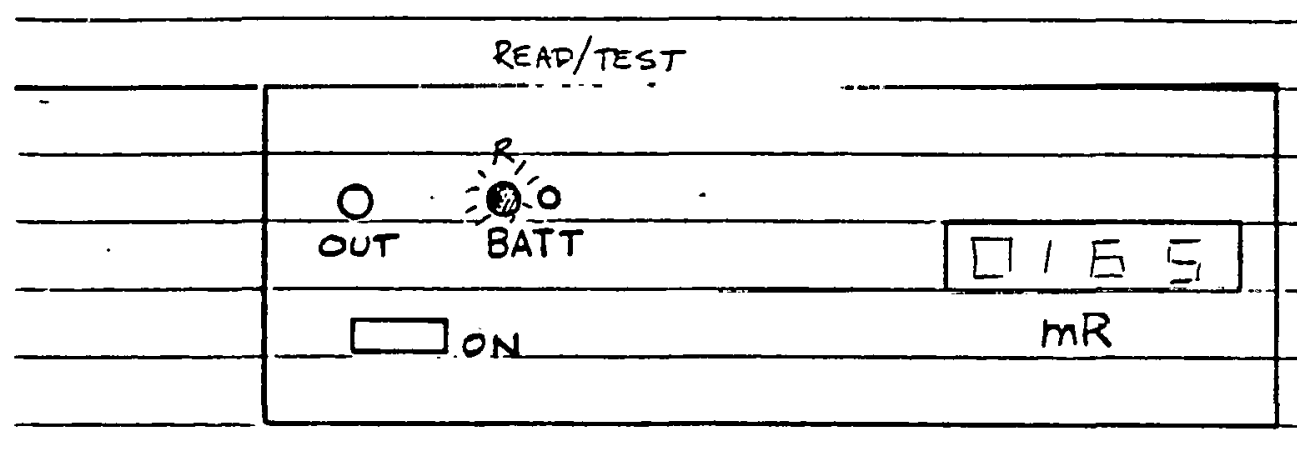

TOR VIEW DIGLTAL DOSIMETER

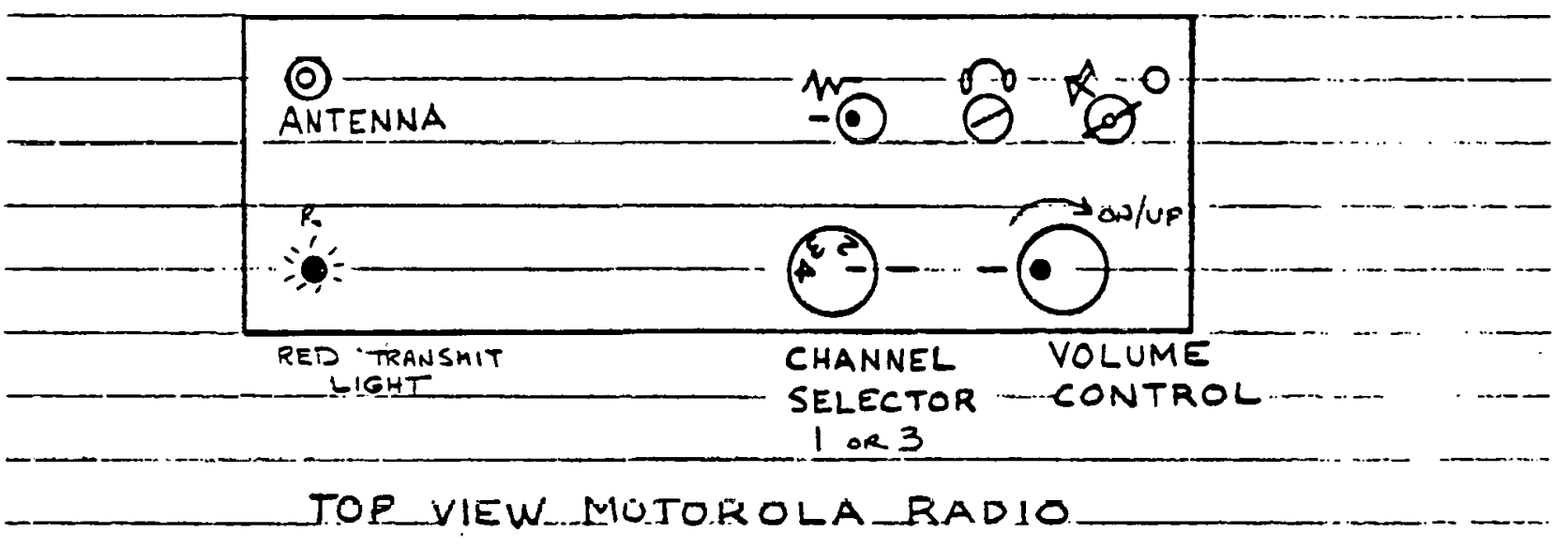

$$
\frac{-f^{20 m R}}{\text { SCALE OF O TO } 500 \mathrm{mR} \text { SRPD }}
$$

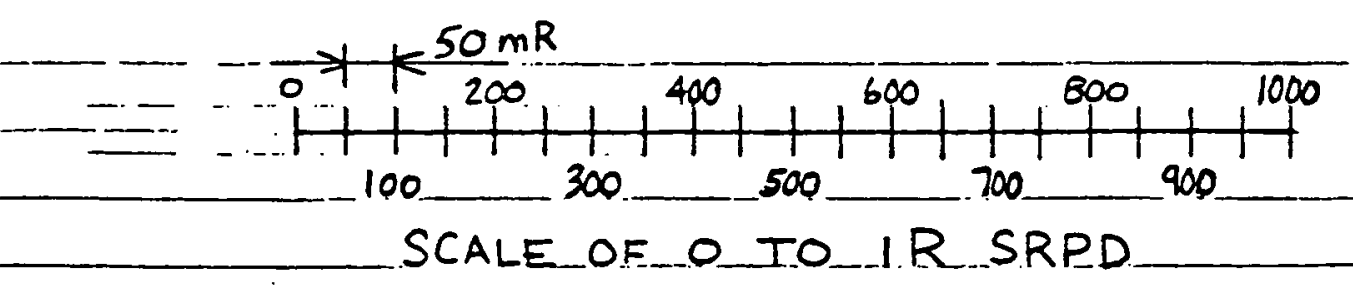




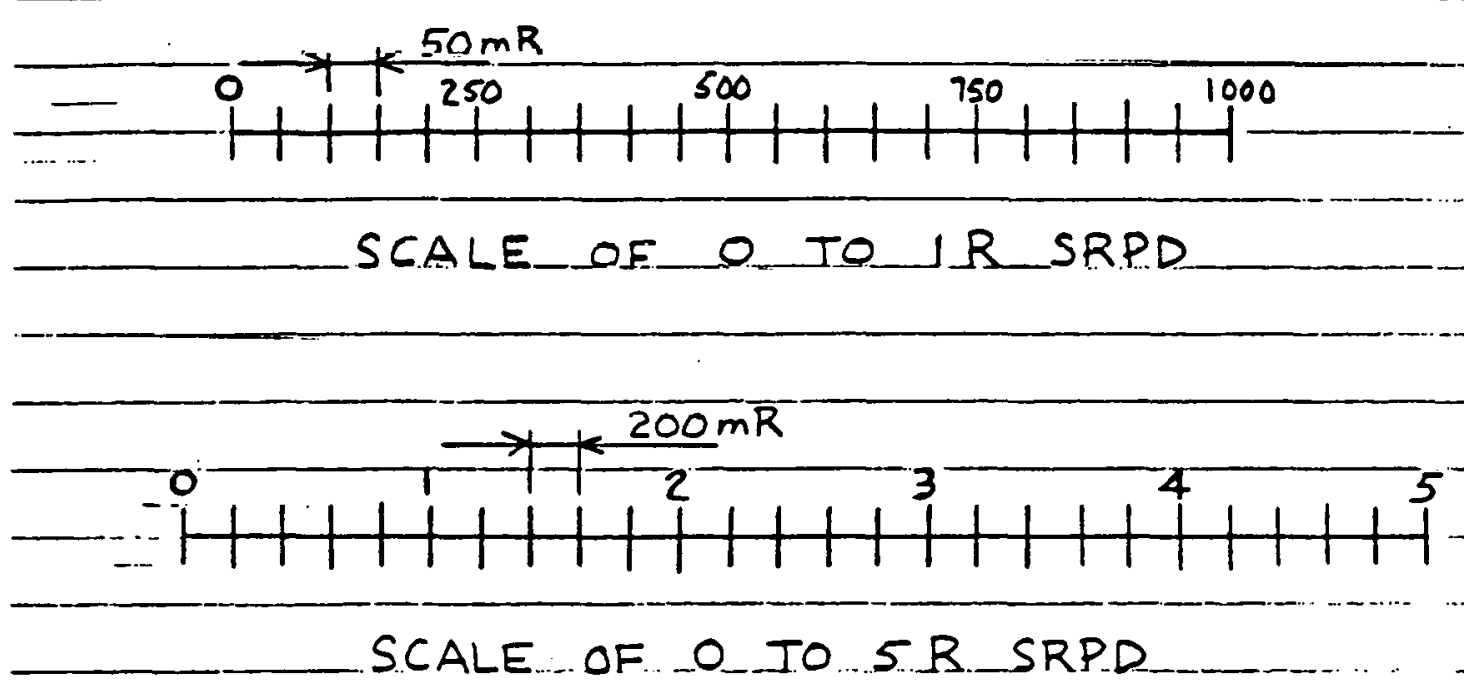

SPOTLIGHT

REAR VIEW

SIDE VIEW

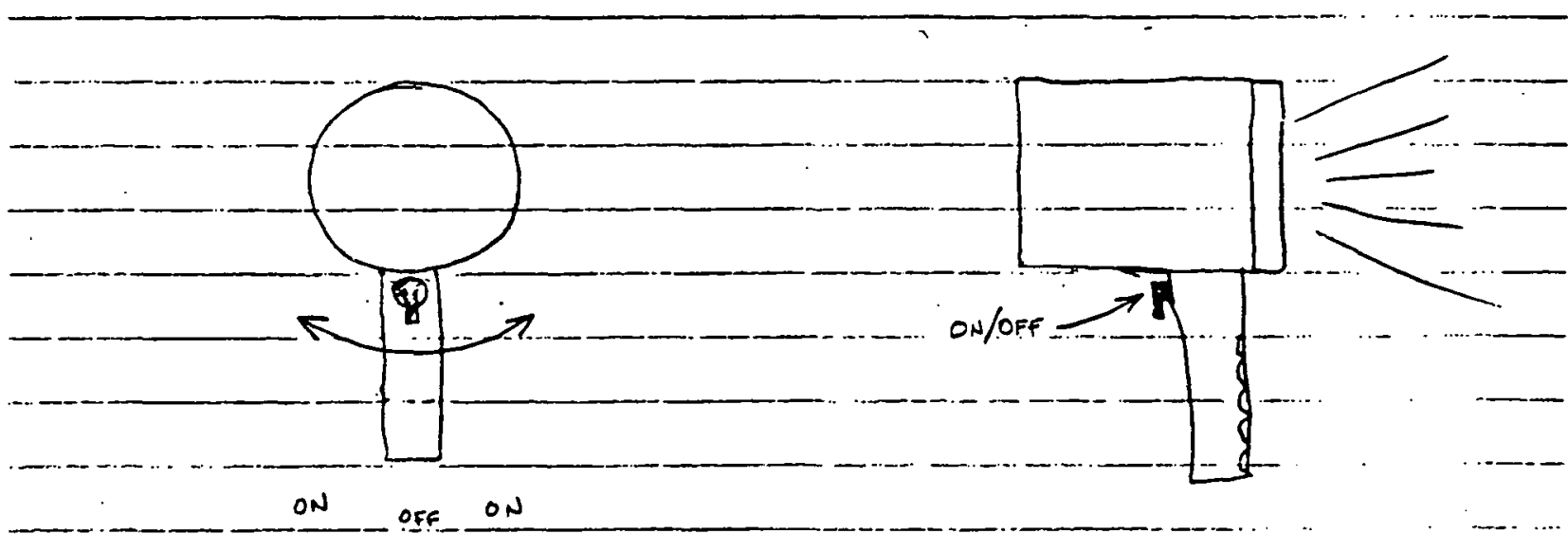


7.0 Minimum RWP Requirements

1. Two sets of cloth PC's with corresponding number of gloves and bootles. Det. suits or other additional protective clothing determined by team member activities.

2. Rubber boots/personal shoes.

3. Battery powered MSA Air Purifier Masks, Air Hoods, or Particulate Face Mask. (MSA Air Purifier unless otherwise specifled).

4. TLD's - See following sheets.

5. Self-Reading Dosimetry - each man will carry one pencil dosimeter outside the PC's and two pencil dosimeters inside the PC's. Digital dosimeters will also be utilized by all entry personnel.

It is very important that you know the scale and millirem/division of the pencil dosimeters that you are assigned as you may be asked to give the Command Center a reading from your wrist dosimeter while in the Reactor Bullding. (See attached page). 


\section{Infor-Orfico fHomoramdus}

Date October 19, 1981

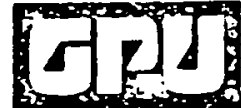

Subject

Minimum Protective Clothing and Dosimetry

Required for Entries into the Reactor Building

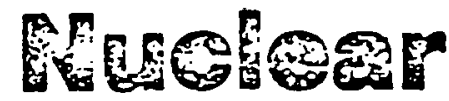

$9240-223$

SOM $\$ 007$ C, Revision 3

To

SOM Manual Holders

Location TMI-II Nuclear Station Bidg. 222

The following defines the minimum protective clothing and dosimetry requirements for entry into the Reactor Building

Protective Clothing

\begin{tabular}{|l|l|}
\hline \multicolumn{1}{|c|}{ PROTECTIVE CLOTHING } & \multicolumn{1}{|c|}{ QUANTITY } \\
\hline Cotton Coveralls & See Note 1 \\
\hline Wet Suit & See Note 1 \\
\hline $\begin{array}{l}\text { Cotton Hoods } \\
\text { See Note 1 }\end{array}$ \\
\hline Cotton Gloves & 1 Pair \\
\hline Neoprene Gloves & 1 Pair \\
\hline Rubber Gloves & 1 Pair (Note 2) \\
\hline Inside Boot Liners & 2 Pair \\
\hline Firemans Boots/Tingley Boots & 1 Pair \\
\hline Plastic Shoe Covers & 2 Pair (Note 2) \\
\hline Full Face Neg. Pres. Resp. & 1 (Note 3) \\
\hline
\end{tabular}

- .

Note 1: If the task involves possible exposure to radioactive liquids, liquid protection is mandatory. If the task involves possible exposure to high levels of dry particulate activity, contamination protection is mandatory. "Wet Suit" protective clothing is suitable to provide liquid and contamination protection. This may be provided by wet suit pants, tops, apron or plastic wrappings as appropriate. Individuals entering the Reactor Building shall wear as a minimum two layers of protective ciothing (i.e:, cotton coveralls plus wet suit or two cotton coveralls, etc.). 
Note 2: Additional as required dependent on number of step-off pads or tasks being performed.

Note 3: Depending on task and/or anticipated airborne activity levels additional protection type respiratory equipment to be determined.

External Dosimetry

\begin{tabular}{|c|l|l|}
\hline DOSIMETRY TYPE & LOCATION & \multicolumn{1}{|c|}{ REMARKS } \\
\hline TLD & Chest & $\begin{array}{l}\text { Worn on front of body near center } \\
\text { of chest }\end{array}$ \\
\hline TLD & Right Thigh & $\begin{array}{l}\text { Worn on front of thigh approximately } \\
\text { 6" above knee }\end{array}$ \\
\hline SRPD & $\begin{array}{l}\text { Low Range (Note 1) and High Range } \\
\text { (Note 1) worn near center of chest }\end{array}$ \\
\hline SRPD & $\begin{array}{l}\text { High range worn outside all } \\
\text { protective clothing }\end{array}$ \\
\hline
\end{tabular}

Note 1: The low range SRPD shall be selected such that the individuals anticipated exposure shall not exceed $3 / 4$ of full scale. The high range SRPD shall be selected such that the individuals anticipated exposure shall not exceed $1 / 2$ of full scale. The high range and low range SRPD may have the same range.

TLD's are to be placed beneath protective clothing with the open (beta) window facing away from the body surface. Open window shall not be taped or otherwise obscured.

Additional dosimetry such as finger rings, wrist TLDs, forehead TLDs, ankle TLDs or digital dosimeters may be needed depending on task being performed. Radiological Technical Support will determine these needs.

Specific dosimetry required for each individual will be defined on the dosimetry placement sheet attached to the RWP for the entry.

\section{Internal Dosimetry}

1. All individuals entering the Reactor euilding shall be equipped with an operating breathing zone air sampler.

2. All individuals entering the Reactor Building shall collect a urine sample the day following the entry and shall submit the sample for analysis the next working day following the entry.

3. The individual(s) with the highest assigned MPC-hours for an entry shall be analyzed with the whole body counter prior to the end of the next working day.
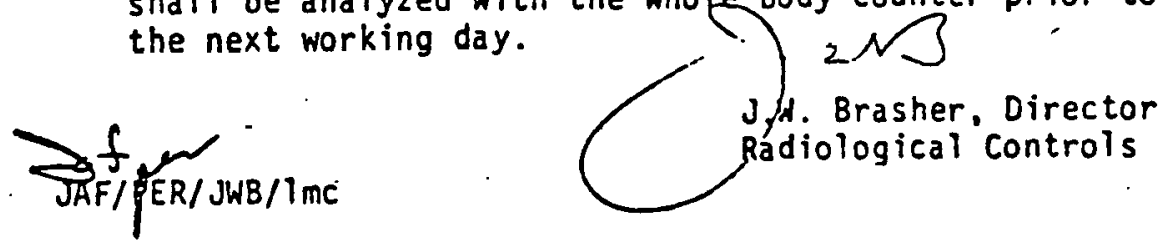
NAME

SS"

AGE

Dose Record: (Dose Assessment Report Dated _ _ _ _ )

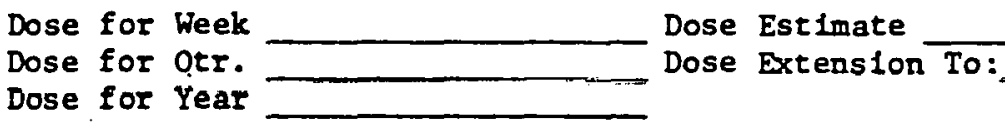

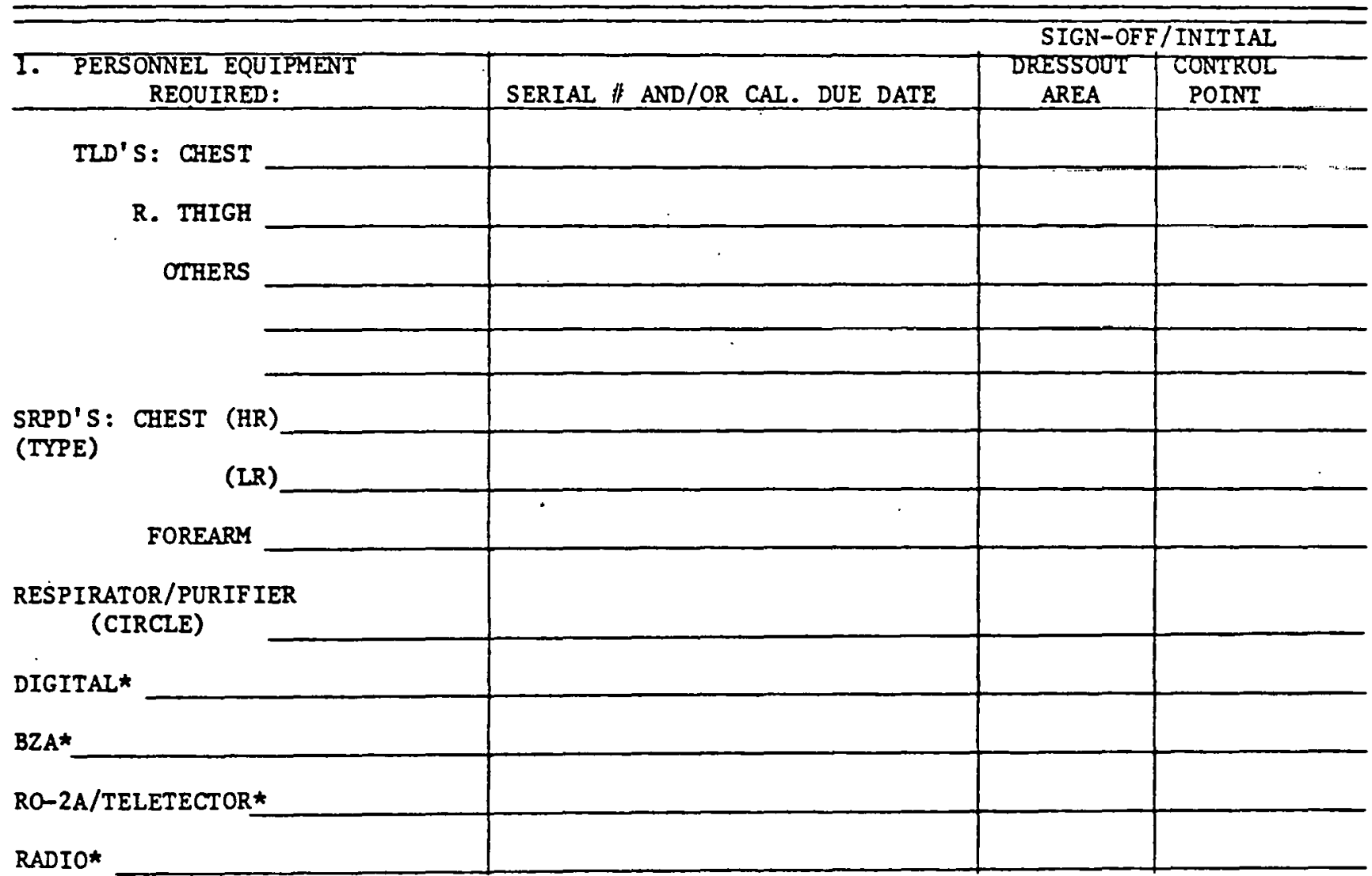

2. Dress Requirements:

PC'S: 1 Patr 2 Pair Other

(Includes gloves, boots, hoods, etc per dress out procedure). Wet Sult: Full Bottoms Sleeves Apron

Ice Vest

Safety Equipment*

*May be put on or obtained in Anteroom - Control Point to verify. 
1. Underwear and socks.

2. TLDs: a Finger rings and wrist TLDs (if required) facing palm side of hand.

3. Personal shoes.

4. Ankle TLDs (if required).

5. Two pairs plastic bootles over personal shoes - each taped around ankles loosely.

6. One pair cloth PC's with chest and thigh TLD attached - taped over second booties.

7. Third pair of plastic bootles taped to first PC's.

8. Two self-readers (low range and high range) taped to chest areas on first Pris.

9. One palr cotton gloves.

10. One pair neoprene gloves under first PC's.

11. Second pair neoprene gloves taped over fist PC's.

12. Second cloth coverall taped to third bootie, tape zipper.

13. Pair of yellow gloves taped to outer PC's.

14. Rubber boots, fastened, and taped to outer PC's.

15. Additional protective clothing (1f required), 1.e., wet suits, wet suit bottoms, aprons, etc.

16. Four sets of non-skid booties; cut through elastic at top.

17. Respirator belt with battery/blower pack (radio \& digital pouches, if required).

18. Digital dosimeter in pouch on hip and one self-reader (high range) attached to elther arm.

19. Skull cap.

20. Mask; turn on MSA (if powered respirator is used).

21. Have smoke test performed.

22. Radio equipment (if required) mike and earphone. (Tape wires to PC's - do not wrap around belt. Ensure freedom of movement of head without pulling on earphone). 


\section{0 (Continued)}

Protective Clothing Dress Out

Sequence (Without Ice Vest)

23. Attach TLD inside first hood (1f required).

24. FIrst cloth hood; tuck under several PC.

25. Second cloth hood - taped to outer PC's.

26. Proceed to control point for RWP sign-on and equipment check.

27. BZA sampler attached to belt in back with head located near MSA pack.

28. Check and adjust equipment:

1. Test radio with Command Center; volume should be "higher than normal" if working on El. 305'

2. Test digital dosimeter; turn unit on and push "read" button; four zeros should appear in window and red light should light for at least 2 seconds.

29. Proceed into Ante Room when directed to do so by Command Center.

30. Obtain equipment required for task and small light in Ante Room. 
1. Underwear and socks

2. TLD's: a. Finger rings and wrist TLD's (1f required), facing palm side of hand.

3. Personal shoes

4. Ankle TLD's (if required).

5. Two pairs plastic bootles over personal shoes - Each taped around ankles loosely.

6. One pair cloth PC's with chest and thigh TLD attached - taped over booties.

7. Third pair of plastic booties taped to first PC's.

9. Two self-readers (low range and high range) taped to chest area on first PC's.

10. One pair cotton gloves.

11. Rubber boots, fastened, and taped to outer PC's.

12. Four sets of non-skid booties; cut through elastic at top.

13. When instructed, put on 1ce vest and pull up PC's; tape zipper on outer pair.

14. Second palr neoprene gloves taped over first PC's.

15. Second cloth cuverall taped to third bootic, tape zipper.

16. Pair of yellow gloves taped to outer PC's.

17. Additional protective clothing (if required), 1.e., wet suits, wet suit bottoms, aprons, etc.

18. Respirator belt with battery/blower pack (radio \& digital pouches, if required).

19. Digital dosimeter in pouch on hip and one self-reader (high range) attached to either arm.

20. Sku1l cap.

21. Mask; turn on MSA (if powered respirator is used).

22. Have smoke test performed. 


\section{0 (Continued)}

Protect Ive Clothing Dress Out

Sequence (With Ice Vest)

23. Radio equipment (if required); mike and earphone, (Tape wires to PC's - do not wrap around belt. Ensure freedom of movement of head without pulling on earphone).

24. Attach TLD inside first hood (if required).

25. First cloth hood, tuck under second PC.

26. Second cloth hood - taped to outer PC's.

27. Proceed to control point for RWP sign-off and equipment check.

28. BZA sampler attached to belt in back with head located near MSA pack. Control point to verify operation.

29. Check and adjust equipment :

1. Test radio with Command Center; volume should be "higher than normal" if working on El. 305'.

2. Test Digital Dosimeter; turn unit on and push "read" button, four zeros should appear in window and red light should light for at least 2 seconds.

30. Proceed into Ante Room when directed to do so by Command Center.

31. Obtain equipment required for task and small light in Ante Room. 


\subsection{Communication with Command Center}

In order to effectively communicate with the command center, the following methods are to be used:

1) Always initfate transmission with: "(Your name) to Base; (Message)"

2) End transmission with: "..., Over"

3) Always give numbers individually 1.e. 123 is "One, two, three" not "one hundred twenty three"

4) When speaking do not run words together, 1.e. pronounce each word individually "....digical, 1s, one, four, two, over"

5) Do not shout, speak in a normal volce

6) Do not attempt to transmit while anyone else is transmitting - we will not recelve you

7) When your digital dosimeter reading is requested, you will recleve the following meooagos "Bace to (your name), Wo noed your digital, over"

Your reply should be: "(Your name) to Base: my digltal, is, two, four, seven, over"

(Leading zero's do not need to be included)

The base will confirm your response with: "Base to (Your name); Roger, we copy two, four, seven, over"

NOTE: If communication vla radio is difficult to understand, the digital readings can be given via the CCTV System by giving the readings in sequence with your fingers and the comnand center will repeat them to you on the radio as you are giving the numbers.

8) Polar Crane Communication - at least one radio must be worn and operational at all times (exact scenarlo to be discussed at team briefing and will be incorporated in each polar crane work package).

RADID PATH

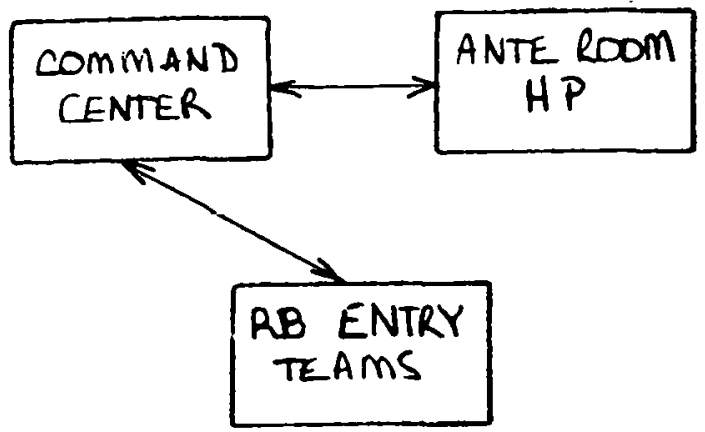

INTERCOM PATH

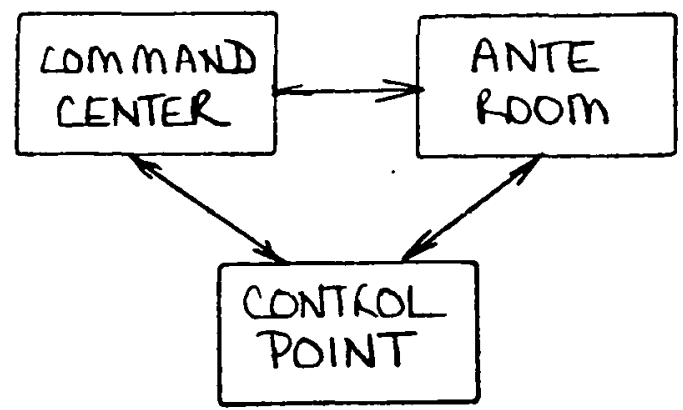


1. Observe all step-off pads.

2. Wear extra yellow boots in case you need to enter the alrlock more times than anticlpated. (Four pairs are required by dress-out procedure).

3. Be conscious of your own protective clothing; be alert for sult becoming wet and for rips in gloves or wet suits; be careful to avold coming in contact with contaminated surfaces with your body.

4. Bag all contaminated 1tems Immediacely after use or removal. Rebag items again when entering alrlock and ante-room.

5. Be careful to avold putting yourself into any unusual positions by climbing on or over anything, pulling cable, or kneeling down on the floor unless il has been identifled as part of your task and your clothing requirements have been adjusted to protect you.

6. Allow the ante-room support personnel to undress you without helping them outside of their instructions to you. This will help to keep your gloves clean and intact.

7. While undressing in the ante-room or frisking out, be careful to avold touching yourself or anything which may be contaminated on bare skin. This includes the hose of your purifler and the ante-room door.

Note: If skin contamination is discovered while frisking out, a Skin ContaminatIon Record (4170) must be completed by the HP who will assist in decontaminating you, followed by a whole body count. In addition, a critique is normally called by Radiological Englneering (ALARA) and a Radiological Investigative Report (RIR) is written to summarize lessons learned and corrective actions. Inform Command Center if you become contaminated.

8. Wear extra yellow gloves or take several pairs with you when you enter the Reactor Building so that if your gloves rip or become very dirty you can pull on or peel off a palr as needed. Extra gloves are needed when climbing to the polar crane. Work gloves are required if job requires heavy physical work.

9. Be aware of what the anteroom personnel are doing and make sure they change their gloves periodically to prevent any contaminations. Refer questions to the Ante Room HP Tech.

10. Laundered protective clothing previously used in Radiologically controlled areas is not to be used for training. For this purpose, only new PC's and specifically designated boots, respirators, etc. may be used for mockups outside RWP areas. 
Upon entering the CCC from the alrloc, a varlety of people will be there to assist you. They are people who have been trained to do this fob and you should follow their directions during the unsuiting process. There will be at least one assistant in the CCC to, help you during some of the more awkward undress steps and assistance will be provided via the glove parts. Be patient during the undress sequence as the orderly removal of equipment and PC's will prevent the loss of equipment and reduce the possibility of skin contaminations.

If you do not feel well upon exiting the alrlock, tell one of these persons and they will expedite your exit from the Ante Room:

There will be at least one HP in the Ante Room. His job is to be familiar with, and maintain under control, the radiological conditions in the ante-room. This includes collecting dosimetry and BZA heads, running air samples and reporting their results, doing smear and radiation surveys, and monitoring work done on the ante room RWP.

Another HP will man the control point outside the ante room. His fob is to keep the records on the RWP's and account for TLD's dosimeters. He also assists all entering personnel with RWP requirements, assists ante room personnel by handing material across the step-off pad, and assista exiting personnel in frisking out. Both HP's report to the HP foreman and have full authority on decisions made within this area of responsibility, so follow. any instructions they give you. 


\section{ANTE ROOM LAYOUT}

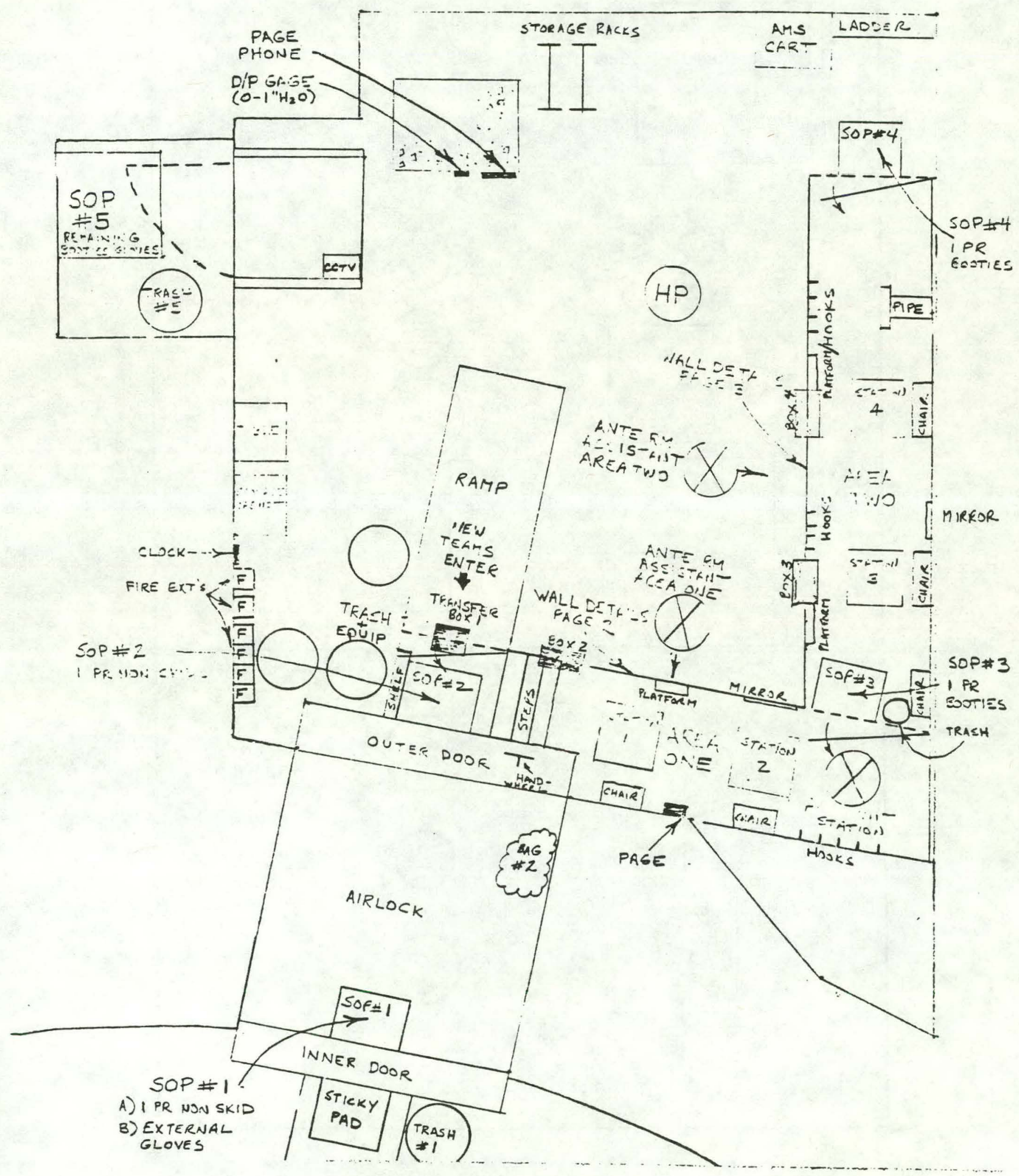




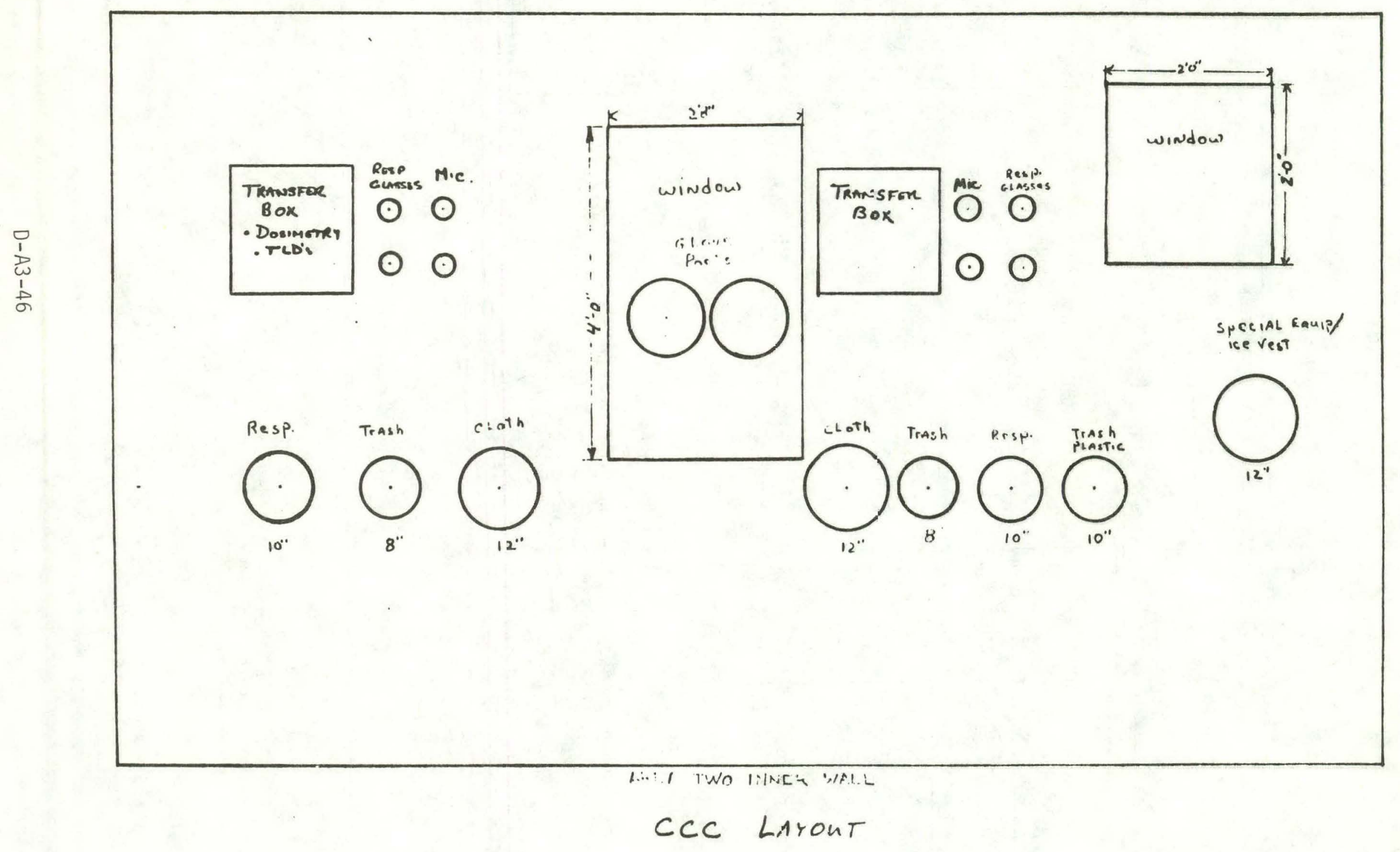




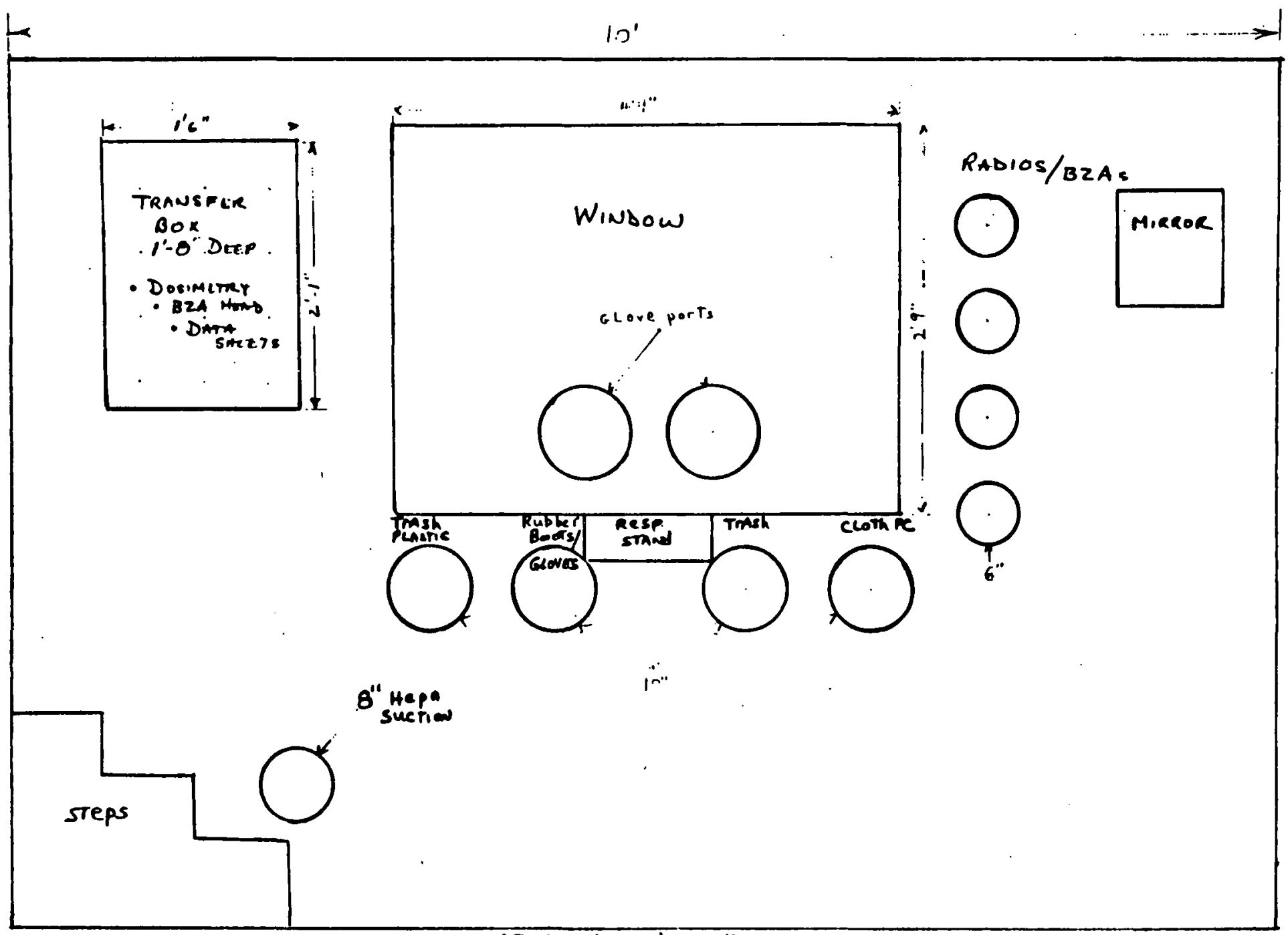

AREA ONE INNER WALL

cCC LAYOUT 


\section{TECH SHEET}

USE OF ANTE ROOM TENTED ENCLOSURE

CONTAMINATION CONTROL CORRIDOR (CCC)

\subsection{DESCRIPTION}

The Ante Room tented enclosure is an engineering effort to reduce the need for respirators and maintain contamination control in the Ante Room during the processing out of entry teams. Refer to attachment 1 for sketches.

\subsection{GENERAL}

2.1 The Ante Room tented enclosure is designed to facilitate unsuiting of personnel exiting the TMI-2 Containment Building with a minimum number of support personnel in respirators.

2.2 One person in a respirator will normally be inside the tented enclosure in area one while personnel are unsuiting; to assist, remove air sampler heads and wipe down equipment portals for bag removal.

2.3 Glove ports are available for personnel outside the enclosure to provide supporting activities such as holding respirators and removing equipment.

2.4 Prior to utilizing the Ante Room tented enclosure the entry personnel will have been trained on the mock up.

2.5 Each team will normally undress using the "Buddy" system and place equipment and Anti-C's in designated receptacles. A mirror is available for individuals unsuiting separately.

2.6 Teams should unsuit on an item for item basis, i.e., team member $A$ removes hood, team member $B$ removes hood, etc.

2.7 When ready to exit containment building, remove one pair of nonskid boots and gloves external to RWP yellow gloves at step off pad (SOP) \#1. Deposit in drum near inner drum ramp. Work gloves may be placed in tool box. 
2.8 Proceed into airlock; remove I pair non-skids at SOP \#2 and deposit in bag in airlock.

\subsection{DETAILED INSTRUCTION - NORMAL EXIT}

\subsection{Entering Corridor}

NOTE: If you have a question about unsuiting ask an attendant or come to a CCC window.

3.1.1 Place equipment coming out in transfer box in the door of the cCC. All items except trash should be identified, marked and bagged. Place trash in large portal just inside outer CCC door.

3.1.2 Enter enclosure to your right. Remove plastic shoe covers down to rubber boots and place in plastic and trash portal. First person go to station \#2; second person go to station \#1. Identify yourself to the area one attendant. He will tell you to unsuit as "A", "B", "C", or "D" and will inform HP.

\subsection{Dosimeters/BZA's}

3.2.1 Remove digital dosimeter from pouch and $\mathrm{place}$ in your dosimetry/BZA bag.

3.2.2 Remove self reading dosimeter - Pocket Dosimeter - (SRPD) from arm and $\mathrm{place}$ in your dosimetry/BZA bag with your digital dosimeter. Be careful not to jar the dosimeters.

3.2.3 Permit assistant in corridor to remove and bag the sample head from your BZ air sampler. Cut tube 4 inches below head. Ensure that it is placed in your dosimetry/BZA bag. Place Dosimetry/BZA bag in transfer box. 


\subsection{External Equipment}

3.3.1 Remove respirator belt, being careful not to drop any gear or pull on respirator face piece.

3.3.2 Disconnect Motorola Radio from microphone, if worn, and remove from the pouch and gently place in radio portal with antenna going into portal last. Hand radio to teammate carefully, if portal is not in your location. Assistant may ask to hold your radio in area one for re-use.

3.3.3 Remove the BZ air sampler motor from your equipment belt being careful not to pull on respirator face piece and place in designated portal. Hand BZA motor to team member for disposal.

NOTE: Individual working in glove portals or assistant within CCC, may assist in any or all of the unsuiting steps.

3.3.4 Remove safety harness, if worn, and hang on hook in area one.

\subsection{Protective Clothing - Outer Layer}

3.4.1 Assist your teammate in removing plastic hood if worn, then allow teammate to assist you. Repeat for first cloth hood.

3.4.2 Insert plastic hoods in trash and plastic portal at your position. Insert cloth hoods in portal for PC's.

NOTE: Cut plastic down back or sides with safety scissors.

3.4.3 Roll rainsuits carefully back upon themselves and place into trash and plastic portal at your station when removed.

3.4.4 Carefully remove rubber boots, obtaining assistance as required. Insert rubber boots into labeled portal. If rubber boot portal is at teammates location, carefully hand rubber boots to teammate for disposal. 
3.4.5 Remove outer (yellow rubber) gloves and place in rubber boot portal. If portal is not at your location hand gloves to teammate for disposal. Obtain clean rubber goves from wall holder and put on to avoid ripping of neoprene gloves.

3.4.6 Assist as required to remove outer Anti-C's from your teammate. Obtain assistance as required to remove your remaining outer Anti-C's. Place cloth Anti-C's in cloth Anti-C portal. NOTE: Unsuit down to single coveralls, respirator and hood. It is important to keep respirator and one complete set of Anti-C's on in first chamber.

\subsection{Proceed into Area Two}

3.5.l Proceed to door at step off pad \#3 with power purifier and motor assembly belt.

3.5.2 Check that other doors are closed, then open door and sit on chair with feet on contamination side of step off pad.

3.5.3 Hand power purifier motor assemble to assistant, remove outer shoe covers, place feet on the step off pad and hand shoe covers to assistant for disposal.

NOTE: The door must be closed while undressing in area two.

3.5.4 Move to appropriate location by team member. A\&C go to station \#4, B\&D go to station \#3.

3.5.5 Place respirator motor on chair.

3.5.6 Remove outer gloves and place in rubber glove portal.

3.5.7 Obtain clean rubber gloves from holder on wall and put on.

\subsection{Dosimetry}

3.6.1 Remove self reading dosimeters and place in your Dosimetry/TLD Bag. 
3.7 Cloth Hood

3.7.1 Remove cloth hood, providing/receiving assistance as required.

3.8 Respirator

3.8.1 Remove respirator face piece, being careful not to rub face piece or. hose against PC's or skin.

3.8.2 Turn power off on motor assembly.

3.8.3 Remove miçrophone from face piece by plug end. Insert micrọphone into designated portal for motorola radio microphones.

3.8.4 Change gloves and remove respirator glasses, if worn, and place in proper portal.

3.8.5 Obtain respirator. face piece bag from wall opposite portal and insert respirator face piece into it.

NOTE: Do not remove hose from purifier unit.

3.8.6 Close bag (over hose) with tape.

3.8.7 Obtain respirator assembly bag from wall opposite portals and place motor assembly in bag. Place respirator face piece ị separate bag, directiv on top of motor assembly and seal bag with tape.

3.8.8 Insert respirator gently into designated portal. Place station \#3 chair back by SOP \#3.

3.9 Protective Clothing - Inner Layer and TLD's

3.9.1 Remove tape from cloth Anti-c's

3.9.2 Dispose of tape in trash porțal.

3.9.3 Remove rubber goves and place in portal labeled rubber gloves.

3.9.4 Remove cloth Anti-C's, turning uutside out, and place on wall hook. 
3.9.5 Put on clean gloves, and remove TLD's in their holders, from coveralls and place in your Dosimetry/TLD bag and then place bag into transfer box.

3.9.6 Place Anti-C's in cloth Anti-C portal.

3.10 Special Equipment

3.10.1 If wearing Earmark radios, ice vests, etc., under PC's, Do Not remove unless directed to do so. Remove each item and place in bag if required to do so. NOTE: Bags are on wall opposite portals.

3.10.2 Seal each "spceialty equipment" bag and carefully insert into the portal labeled specialty equipment.

3.11 Exiting C.C.C.

3.11.1 Verify that other doors and portals are closed, then open CCC exit door.

3.11.2 Exit across SOP \#4 by removing one pair of booties and place in trash portal. You should also discard any additional gloves put on in area two. You should still be wearing one pair of booties and gloves.

3.11.3 Close and latch door and proceed to SOP \#5. Exit across SOP \#5.

4.0 EMERGENCY EXIT DUE TO ILLNESS, FATIGUE, INJURY OR AT THE COMMAND CENTER

4.1 In the event of an emergency situation, notify the Command Center and teammates, if possible, immediately of the nature and severity of the emergency. Respond to Command Center instructions.

4.2 Follow the instructions of the HP Tech and Lead Ante Room Attendant upon exiting the airlock.

4.3 Upon exit from the Ante Room, follow Shift Supervisor, Safety Department or HP Foreman's instructions, as appropriate. 


\section{A. HEAT STRESS EXPOSURE}

These requirements establish work time guidelines for workers exposed to hot environments before a rest period is given for recovery from heat stress.

Work time guidelines reflect the actual time protective clothing and/or respiratory protection are worn while performing work assignments and does not include suiting up, unsuiting or going to and/or from the work location. Breaks should follow exposure to heat stress. Duration of breaks, extent of clothing removal, and the area where breaks are taken, shall be at the discretion of supervisory personnel.

The following definitions apply:

Anti-C's

Impermeable clothing

Respiratory Protection

Supplied Pir Hood or Suits

Temperature
Paper or cotton coveralls, cotton hood, rutber boots, and gloves.

Rain suits; water resistant olothing.

Negative pressure full-facepiece respirator, SCBA or supplied-air respirator.

Hood or suit with at least 6 cubic feet per minute continuous air flow.

Ambient temperatures at a relative humidity 758 at the work location.

If an extension of the work time guidelines identified herein is required, due to the nature or criticality of the task being performed, permission must be obtained from the supervisor in charge of the job.

Employee heat stress briefing, when required, should be arranged through and provided by the site Safety and Health Department.

When work is planned in hot environments where relative humidities are known to be greater than 908 , the schedule for AntiC's under Impermeable Clothing with Respiratory Protecticn

shall be utilized.

When temperatures exceed $120^{\circ} \mathrm{F}$ or where hot radiant heat sur-

-I faces are encountered, direction shall be provided by the supervisor - Safety and Health for personal protective equipment.

When an individual feels discomfort from heat stress, he/she must immediately notify the person in charge and leave the area. 


\section{HEAT STRESS - TEMPERATURE AND PERMISSABLE LIMITS}

Protective Equipment

Conventional

Work Clothing

Anti-C's (only)

Anti-c's under

Impermeable Clothing

Anti-C's (On1y) With

Respiratory Protection

Anti-C's Under

Impermeable Clothing

With Respiratory

protection

Anti-C's with or Under Supplied Air Hood/Suit

$\begin{array}{lc}\text { Guidelines } \\ \text { Temperature } & \text { For Work Time }\end{array}$

Less than $100^{\circ} \mathrm{F} \quad$ None

$100-100^{\circ} \mathrm{F}$

$110-120^{\circ} \mathrm{F}$

2 Hrs.

45 Min.

$\begin{array}{rl}80-90^{\circ} F & 3 \text { Hrs. } \\ 90=100^{\circ} F & 2 \text { Hrs. } \\ 100-110^{\circ} F & 1 \text { Hr. } \\ 110-120^{\circ} F & 30 \text { Min. }\end{array}$

$\begin{array}{rl}80-90^{\circ} \mathrm{F} & 1.5 \mathrm{Hrs} . \\ 90-100^{\circ} \mathrm{F} & 1 \mathrm{Hr} . \\ 100-110^{\circ} \mathrm{F} & 30 \mathrm{Min} . \\ 110-120^{\circ} \mathrm{F} & 15 \mathrm{Min} .\end{array}$

Less than $80^{\circ} \mathrm{F} \quad 4$ Hrs.

$80-90^{\circ} \mathrm{F} 2 \mathrm{HrS}$.

$90-100^{\circ} \mathrm{F} \quad 1.5 \mathrm{Hrs}$.

$100-110^{\circ} \mathrm{F} \quad \mathrm{I} \mathrm{Hr}$.

$110-120^{\circ} \mathrm{F} \quad 30 \mathrm{Min}$.

$70-80^{\circ} \mathrm{F} \quad 1 \mathrm{Hr}$.

$80-90^{\circ} \mathrm{F} \quad 45 \mathrm{Min}$.

$90-100^{\circ} \mathrm{F}$

$100-120^{\circ} \mathrm{F}$

30 Min.

15 Min.

$\begin{array}{rl}80-100^{\circ} \mathrm{F} & 4 \mathrm{HrS.} \\ 100-110^{\circ} \mathrm{F} & 2 \mathrm{HrS.} \\ 110-120^{\circ} \mathrm{F} & 1 \mathrm{Hr} .\end{array}$

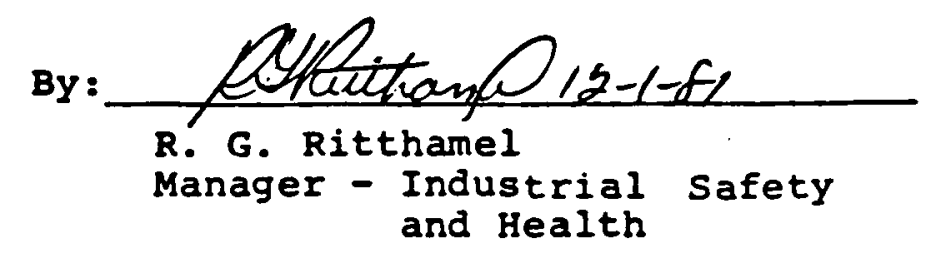


LORKIRE IN HOT ENVIROMIENTS

Keat is a naturally occurring stress under which human beinos have evolved over the ages and to which each of us is exposed at least perfodically during our itives. Industrial heat exposure, however. Frequentiy is much greater than that encountered in the natural eayironment. Hot industries aiso Involve hard physical work which adds to the total heat stress. The effect or consequences of heat stress in the work environment can be seen in decreased worker productivity. increased accident rates, llinesses, and fatallties. The primary concern of this discussion is the control of heat stress, the prevention of heat-related fliness and death.

The body is continually producing heat every seeond that it ifves. This heat comes fron the breakdown of food that the body uses to supply the eneray It needs to support its life processes. About 75: of the energy consuned by the body ends up in. the form of heat which in turn heats up the body. Increased physicel ectivity produces even more body heat. To maintain a nomal acceptable body temperature, this heat must be brought to the skin surface and exchanged with the afr surrounding the body. The physlological process which maintains the balance between heat production and heat removal is a complex one involving the central nervous system, the eirculatory system, the skin, and the museles.: The situation is simfiar to the rorking system for the automobile engine. In the engine, energy and heat are produced in the block. Hater is pumped through the block where it absorbs heat, then through the radiator. where the heat is exchanged with the atmosphere. The rate of circulation is controlled by a thermostat, which opens when the engine is hot. Similarly. In the body the blood carries heat from the core of the body to the skin. The amount of blood flowing to the skin can be increased or decreased. The rate of heat loss can be increased if necessary by wetting the skin with sweat. When waler evaporates. the water molecules absorb a large quantity of heat. The heat gained by the water molecuies as they evaporate is. lost from the wetted skin surface. Under conditions of excessive heat stress. this eveporative cooling becomes the major aveniee for achieving heat balance. The body's cooling system is remarkabiy efficien: and can adjust to steady work in hot environnents. This adjusiment is called acclimatization and is usually completed in a week. Despite the adaptability of the body's cooling system, it can be overloaded by certain extremes in environmentai conditions and physical activity.

Heat stress probiems arise when the body produces more heat than it can get rid of. When this happens; a varfety of flinesses can occur depending on the duration and severity of stress and the effectiveness of steps taken to relieve the stress. These include:

Keat Exhaustion

Heat exhaustion is caused by an insufficient biood fow to the brain because too much blood has been diverted to the skin in an effort to cool the body. Durine heat exhaustion, body tenperature is usually nomal and the skin is cool. we:. and pale. The major symptars are giddiness, headache, heakness, fainting, vomitino, and rapld, weak puise. Rest in b cooi environment and fiuid replacement will result in full recovery. This type of heat liliness is usually caused by inadenuate fluid intake to make up for the body water lost in the sweat.

$$
D-A 3-56
$$


(Continued)

Horking in Hot Environments

\section{Dehydration}

The water lost from the body as sweat must be replaced by drinking water If dehydration is to be prevented. Dehydration rapidiy leads to decreases in performance and work capacity and to heat exhaustion. Sweat production of 8 to 10 quarts each working day is not uncommon in hot industries. This means that water must be replaced at the rate of at least 1 quart each hour. When sweating is heavy, a better practice is to drink about a cup of cool (not cold) water every 10-20 minutes throughout the work day.

\section{Heat Stroke}

Heat stroke results from a high body temperature that is caused by a fallure of the body's cooling system. The high body temperatures accompanying heat stroke can be fatal if they are not lowered. Usually. collapse and coma with high body temperature are the first symptons, and the victims skin may be red, hot, and dry. Treatment consists of rapid reduction of the body temperature by fmersion in ice bath, aicohol spray, or fans and wet sheets. Age, obesity, lack of physical fitness, and hard physical work are factors that increase the chances of heat stroke. Heat stroke is a serious medical emergency and requires speedy medical attention to save the victims life.

\section{Heat Cramps}

Heat cramps result from excessive loss of salt in the sweat without adequate replacement. Heat cramps involve mainly the hand, arm. leg, and abdominal muscles. Heat cramps are not very comon and occur mostly when sweating is heavy, water replacement is adequate, but salt intake is low. A little sait added to the drinking water or the food is an effective treatment and prevention of heat cramps. For heat adjusted (acclimatized) workers the usual diet contains enough salt because their sweat is low in salt. Moderation is needed when increasing salt intake because too much salt actually reduces heat tolerance, and for persons with high blood pressure. Increased salt intake can actually aggravate the condition to a dangerous level. Drinking Gatoraid is the best and safest way to maintain fluid and salt balance at the same time.

The conditions found at MI are normally within the range that your body's heating/cooling system can handle. The range limits may be exceeded when doing hard rork during hot weather or when wearing protective clothing in hot contaminated areas. When necessary, the safety department will measure the environmental conditions in a hot area to see if control measures must be instituted. The early symptoms of heat stress are:

$$
\begin{aligned}
& \text { Heakness } \\
& \text { Extreme Fatigue } \\
& \text { Dizziness }
\end{aligned}
$$

Hore advanced symptons are:

Arm, Ieg, and stomach muscle spasms Irregular or increased heartbeat
Nausea

Headache

Thirst

$$
D-A 3-57
$$

Extreme Thirst

Fainting 
If you note early signs of heat stress, notify your supervisor. The imediate treatment is to:

Rest in a cool place

Drink small amounts of cool water frequently

If symptoms continue, get medical help from First Aid

Don't expect to work at your normal pace for the first few days in a hot orea. If your body is allowed to occustom itself to heat stress a reas gradualiy (acclimatization), within week or so you will be able to stand a full shift of hard work in a hot area with few $\{11$ effects. If you have any further questions about heat stress, contact the First Aid office. 
1.1 The purpose of this procedure is to establish guidelines to insure the protection and health of personnel who work in, about, and'in connection with, confined spaces.

1,2 It is further intended to make employees aware of hazards Involved and give essential training in the use of test methods and piotection equipment necessary in hazardous or toxic environments.

1.3 These requirements are applicable to all areas at a GPU Nuclear facility that meet the definition of a confined space.

1.4 These requirements do not specify radiological work requirements or precautions, as they are the responsibility of the Radiological Controls Department and have separate procedures.

\subsection{RESPONSIBILITIES:}

2.1 Supervisors are responsible for:

2.1.1 Identification of any work area that meets the definition of a confined space.

2.1.2 Discusing questionable areas with the Safety \& Health Department to confirm if a work area meets the definition of a confined space.

2.1.3 Ensuring that employees are informed of the hazards and/or rescue requirements specified on the Confined Space Permit.

2.1.4 Familiarizing all workers who will enter the space with the hazards of the same and assure that all personnel are trained and able to use respiratory protection and other personal protective equipment as specifiel on the permit.

2.1.5 Discuss1r.g a suitable plan for the emergency rescue of disabled personnel with the workers prior to entry.

2.2 Safety Health Department is responsible for:

2.2.1 Deciding what precautions are necessary to safeguard workers entering confined spaces.

2.2.2 Performing air sampling of confined spaces for oxygen and combustible gas concentrations and, when necessary, for toxic materials prior to entry. 


\subsubsection{Authorizing the Confined Space Permit. ... -2.4 Providing all alr sampling instruments required to \\ 2.2.5 Instructing the supervisor regarding what conditions and precautions are covered in the confined space Permit. \\ 2.2.6 Monstoring the work practice to be sure that it is effective. \\ 2.2.7 Posting the Confined Space Permit at the entrance to the conflined space prior to entry.}

\subsection{DEFINITIONS:}

3.1 "Confloed space" means any space having a limited means of access which is subject to the accumulation of toxic or flammable contaminants or nas an oxygen deficlent atmosphere.

3.2 Confined or enclosed spaces include, but are not limited to, excavations, storage tanks, process vessels, blos, bollers, vent1lation ducts, sewers, manholes, underground vaults, pipeline tunnels and open top spaces more than four feet in depth.

\subsection{PRECAUTIONS:}

4.1 Entry of personnel into oxygen deficlent atmospheres, atmospheres with explosive gas mixtures or toxic atmospheres shall not be permitted without the appropriate respiratory protection.

\subsection{PROCEDURES FOR ENTRY AND WORK IN CONFINED SPACES:}

\subsection{Conflned Space Permit}

5.1.1 The Safety \& Health Department shall Issue the Confined Space Permit.

5.1.2 Personnel may enter the confined spaces under the following conditions:

5.1.2.1 When a Confined Space Permit issued by the Safety \& Realth Department has been posted at the entrance to the confined space.

5.1.2.2 When the conditions and requirements of this Safe Work Practice, as specifled in Section 5.5 (Emergency Entry Into Confined Spaces), are met.

$$
D-A 3-60
$$


5.1.3 Permits shall be valid for the time specified on the permit.

5.1.4 With monitoring devices installed, operations shall bi: discontinued $1 f$ oxygen level drops below $19.5 \%$ or combustible gases exceed $20 \%$ of their lower explosive limit. Thls condition shall terminate the permit.

5.1.5 Upon completion of work, the supervisor shall $81 \mathrm{gn}$ off the permit, and return it to the Safety \& Health Dispartment.

\subsection{Procedure for Obraining a Permlt}

5.2.1 Supervisors shall consult with the Safety \& Health Iepartment if there is any question as to whether a work area is a confined space; the decision of the Sufety Bealth Department shall be final.

5.2.2 The Safety Health Department shall, when notified, perform the following:

5.2.2.1 Review the past Confined Space Permits 1soued to determine if toxic materials may be present in the atmosphere.

5.2.2.2 Sample the confined space atmosphere for oxygen and combustible gas, and if necesoary, for toxic materials.

5.2.2.3 Specify on the Confined Space Permit when ventilation, alr monitoring, emergency equipment, and/or a stand-by person are required.

5.3 Requirement for Entry and Work in Confined Spaces

5.3.1 Alr samples shall be taken by the Safety \& Health Dupartment prior to entry into a confined space.

5.3.2 Employees shall not enter a confined space unt1l air sampling results establish that the oxygen concentration 18 between 19.57 and $21 \%$ and the combustible gas concentration 18 between $0 \%$ and $20 \%$ of the lower explosive level (LEL).

5.3.3 When inftial afr sampling results indicate that the oxygen concentration is below $21 \%$ or combustible gases are present, mechanical ventilation shall be ut:.l1zed and retesting shall be performed by the Safety \& Bealth Department. 
5.3.4 The Safety \& Health Department shall specify when continuous ventilation and/or monitoring are required when retesting indicates oxygen concentrations are above $19.5 \%$ but be?.ow $21 \%$ and combustible gases below $20 \%$ but above $0 \%$ of the LEL.

5.3.5 The Safety \& Health Department shall specify when a stand-by rescue person, mechanical ventilation and/or continuous monitoring is required for the confined space.

5.3.6 Whein rescue equipment' is required it shall be located outside the confined space and be Immediately available for use in case of an emergency. This equipment may Include safety belt(s), lifeline(s) and emergency selfcontained breathing equipment.

5.3.7 When a stand-by rescue person is required this person sha:.l be capable of communicating with all workers in the confined space during the entire entry.

5.4 Emergency entry into a confined space without a permit may be authorized by the shift foreman under the following conditions:

5.4.1 An attempt has been made to contact the Safety Health Depurtient.

5.4.2 The job supervisor was not able to contact the-Safety \& Health Department.

5.4.3. When in the case of an extreme emergency, entry is required in a confined space containing flammable gas or vapnr without an atmospheric test, precautions shall be taken to ensure 1gnition does not occur.

5.4.4 When an emergency situation arises, only workmen equipped with a supplied-alr respirator with an auxiliary selfcontained breathing apparatus or SCBA, safety harness, cafaty line, other noosocary protact fvo oquipment, and in communication with the rescue person may enter a confined space without prior testing.

5.4.5 A stand-by person shall be stationed outside the confined space for rescue purposes and shall have the same equipment specified in Section 5.5.4.

5.4.6 The Safety \& Health Department shall be notifled the next regular working day following the emergency entry of the details of the entry. 


\subsection{AIR MONITORING LQUUIPIINT:}

b.l All air montoring instruments used shall have audio and visual alarms which are set at $19.5 \%$ for oxygen and $20 \%$ (LEL) for combustible gases as methane.

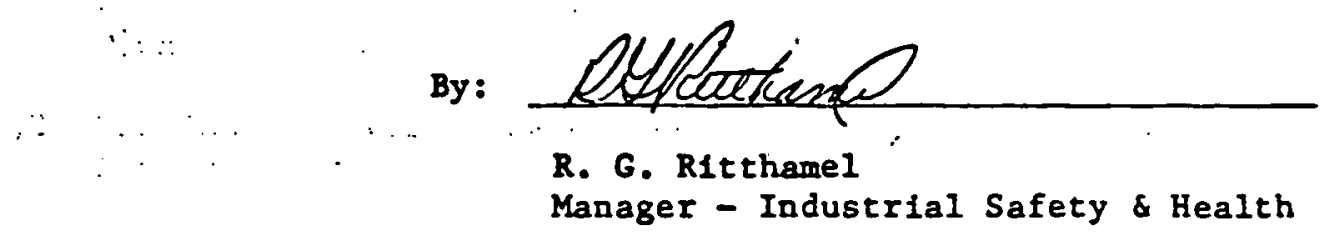




\section{CASUALTY PROCEDURE}

FóR

HIGH RADIATION CONDITION IN CONTAINMENT

This procedure supplements procedure

\section{2-1.7}


MIGH RADIATION CONDITION IN CONTAINMENT

HIGH RADIATION CONDITION DETECTED BY ENTRY PERSONNEL

(Entry in Progress)

mTE: For purposes of this document, the following shall be considered high radiation conditions:

1. An unanticipated increase in the general area background, detected by hand-carried instruments, by a factor of five from the most recently recorded prevfous survey information.

2. An unanticipated increase in the general area background, detected by hand-carried instruments, by a factor of five during the entry.

\section{Entry Personnel shall:}

1. Report readings to Command Center.

2. Hove to a lower radiation area if any.

3. Proceed to personnel airlock as directed by Command Center.

4. Entry team leader report status and location of all team nembers.

Command Center shall:

1. Notify all personnel in containment of high radiation.

2. Order all personnel to exit buifding, unless it is determined that high radiation conditfons were caused by ongoing activities and an evaluation is made by Radiological Controls which coneludes that an evacuation is not necessary.

3. Notify the Control Room.

4. Notify the HP Foreman.

5. Notify the Ante Room.

Control Room shell:

1. Respond in accordance with Unit II Energency Procedure 2202-1.7 us ing procedure requirements applicabie to readings reported by the Comand Center which would be appropriate, if contalnment buliding radiation monitor HP-R-2i3 had detected the reported radiation ievels. .

Ante Room shail (if so directed by the Command Center):

1. Record and report all exiting personnel.

2. Secure any entry preps and clear Ante Room to recefve exiting personnel. 
HIGH RADIATION CONDITION DETECTED BY THE CONTROL ROOM

(Entry In Progress)

MOTE: HP-R-213 is the only area radiation monitor currently operational in contatnment. MP-R-211, 212 and 214 are not operat lonal.

Control Room shall:

1. Respond in accordance with Unit II Emergency Procedure 2202-1.7.

2. Notlfy Command Center of readings and location.

3. Direct Command Center to evacuate containment if required.

Command Center shall:

1. Notify all entry personnel.

2. Order all personnel to exit the butlding if so directed by the Control Room.

3. Notify HP Foreman.

4. Motify Ante Room.

Entry Personnel shall (if so directed by the command Center):

1. Secure work - de-energize equipment.

2. Team leaders report status and location of team members.

3. Exit the bullding.

Ante Room shall (if so directed by Command Center):

1. Record and report all exiting personnel.

2. Secure any entry preps and clear Ante Room to receive exiting personnet. 


\section{CASUALTY PROCEDURE \\ FOR}

FIRE IN CONTAINMENT

This procedure supplements procedure

2202-3.1 


\section{FIRE IM CONTAIMMENT}

When Fire is detected by Entry Personnel:

Entry Personnel shall:

1. Notify Command Center - Fire Elevation (Fili in blanks with approprlate elevation). Fire Elevation

Followed by location, type, size Example:

Location - 5' from In-Core Instrumentation Chase.

Type - Electrical. Trash, Chemfcal

size - Smali (can be extinquished with fire extinguisher) Large (Cannot)

2. If In your judgement you can put the fire out and have the equipment to do so, then put it out. Otherwise, leave and assemble to the Personnei Airlock - (Airlock unaffected by fire)

3. Prior to leaving check to make sure no one is left in area. Entry team leaders are to report location and status of team members to Cormand Center.

4. Secure your equipment.

5. Do not, at anyt ime, endanger yourself except to prevent injury to another team nember.

Command Center shall:

1. Motify all personnel in containment.

2. Notify the Control Room.

3. Notify HP Foreman.

4... Notify Ante Room.

5. Order all personnel not in vicinity of fire to procieed to Alrlock via stairwell and stand by to assist.

TFIII in blanks wth atrlock and stairwell unaffected by fire)

6. Direct entry personnel as required.

7. Maintain visible contact, If possible, via ccTV.

B. Maintain radio contact. 
Command Center shall : (con't)

9. Monitor fire with CCTV if possible.

Note: In the event of fire, the Control Room shall assume control. The Command Center responsfbility is limited to evacuation of personnel and proviston of support as requested by the

: Control Room.

\section{Control Room shell:}

1. Initiate action in accordance with Unit II Emergency Procedure 2202-3.1, Fire.

2. Establish direct communications with Command Center (Main intercom/ console when avallable).

3. If electrical, de-energize nearest breaker feeder.

4. Pressurize fire main in containment.

5. Secure purge.

6. Make arrangements to have plant fire extinguishers staged to the Ante Room to provide extinguishers to fight the fire for 45 minutes.

Ante Room shall:

1. Stage fire ext inguishers to Airlock.

2. If personnel are in process of undress - expedite.

3. If personnel are in process of entry, secure entry (Entry personne? remove one set of booties and leave ante Room. Muster in corridor).

4. Station man near intercom.

5. Station man in Airlock - Man Page Channel 1.

6. Remove excess equipment from Ante Room.

7. Prepare to ald fire brigade.

8. Provide two (2) two-way radios for fire brigade use (no setcoms).

-9. Log and report all personnel exiting and entering the bullding.

Mp Foreman shall:

1. Take charge in Ante Room/staging area for HP matters only.

2. Direct HP Support to II Airlock and Man Page Channel 1. 


\section{Sufety/First Aid shall:}

1. Standby to assist - If personnel are injured.

2. Notify First Aid.

Fire Brigrade shall:

1. Assembie as directed by Control Room.

2. Fire Brigade will enter the containment at the direction of the Control Room.

3. Command center will assist as requested. 


\section{FIRE IN CONTAIMRENT}

When Fire is detected by the Commend Center:

Entry Personnel shall:

1. Secure work and de-energize electrical equipment. Assemble at Airlock as directed by Command Center. Exit when directed. Team leaders report status and location of all team members.

2. Do not, at anytime, endanger yourself except to prevent infury to another tean member.

3. If In the area, and fire extinguishers are avallable and in your judgement you can put out the fire, do so; otherwise leave area via route specified and exit as directed by the command Center.

Commend Center shall:

1. Motify all personnel in containment.

2. Notify the Control Room.

3. Notify HP Foreman.

4. Notify Ante Room.

5. Order all personnel not in vicinity of fire to proceed to Airlock via stafrwell and stand by to assist. (Fill in blanks with afrlock and stairwell unaffected by fire)

6. Direct entry personnel as required.

7. Maintain visible contact, if possible, via ccTV.

8. Maintain radio contact.

9. Monitor fire with CCTV, if possibie.

MOTE: In the event of fire, the Control Room will assume control. The Command Center responsibility is 1 imited to evacuation of personnel and provision of support as requested by the Control Room.

Control Room shall:

1. Initiate action in accordance with Emergency Procedure 2202-3.1, Fire.

2. Establish direct communications with Command Center (Ma in intercom/console when avallable.)

3. If electrical; de-energize nearest feeder breaker.

4. Pressurfze fire main in containment. 


\section{Control Room shall: (con't)}

5. Secure purge.

6. Make arrangements to have plant fire extinguishers staged to the Ante Room to provide extinguishers to fight the fire for 45 ainutes.

Ante Room shall:

1. Stage fire extinguishers to Airlock.

2. If personnel are in process of undress - expedite.

3. If personnel are in process of entry, secure entry (Entry. personnel remove one set of bootfes and leave Ante Room. Muster in corridor).

4. Station man near intercom.

5. Station man In Airiock - Man Page Channel 1.

6. Remove excess equipment from Ante Room.

7. Prepare to ald fire brigade.

8. Provide two (2) two-way radios for fire brigade use (no setcoms).

9. Log and report all personnel exiting and entering the bullding.

HP Foreman shall:

1. Take charge in Ante Room/staging area for HP matters only.

2. Direet HP Support to 1 Airlock and Man Page Channel 1.

Safety/First Ald shall:

1. Standby to assfet - if personnel are injured.

2. Notify First Aid.

Fire Brigade shall:

1. Assemble as directed by Control Room.

2. Fire Brfgade will enter the containment at the direction of the Control Room.

3. Command Center will assist as requested. 


\section{- FIRE IN CONTAIMAENT}

When fire is detected by the Control Room:

\section{Entry Personnel shall:}

1. Secure work and de-energfze electrical equipment. Assemble at Alrlock

: es directed by commant Center. Exit when directed. Team leaders report status and location of all team nembers.

2. Do not, at anytime, endanger yourself except to prevent injury to another tean nember.

3. If In the area, and fire extinguishers are avallable and in your judgement you can put out the fire. do so, otherwise leave area via route speciffed and exit as directed by the command center.

Command Center shall:

1. Notify all personnel in containment.

2. Notify HP Foreman.

3. Notify Ante Boom.

4. Order all personnel not in vicinity of fire to proceed to Airlock via stafrwell and stand by to assist. (Fill in blanks with airlock and stainwell unaffected by the fire.)

5. Direct entry personnel as required.

6. Maintain visible contact, if possible, via CCTV.

7. Maintain radio contact.

8. Honftor the fire via CCTV if possible.

NOTE: In the event of fire, the Control Room will assume control. The Command Center responsiblitty is 11 mited to evacuation of personnel and provision of support as requested by the Control Room.

Control Room shall:

1. Notify Comand Center, fire in containment.

2. Initlate action in accordance with Emergency Procedure 2202-3.1, Fire.

3. Establish direct communications with Comand Center (main intercom/ console if avaliable). 
Control Room shall: (con't).

4. If electrical, de-energlze nearest feeder breaker.

5. Pressurize fire ain in containment.

6. Secure purge.

7. Make arrangements to have plant fire extinguishers staged to the Ante Room to provide extinguisher to fight the fire for 45 alinutes.

\section{Ante Room shall:}

1. Stage fire extinguishers to Airlock.

2. If personnel are in process of undress - expedite.

3. If personnel are in process of entry, secure entry (Entry personnel remove one set of bootles and leave Ante Room. Muster. in corridor.)

4. Station wan near intercom.

5. Station man in Airlock - Man Page Channal 1.

6. Remove excess equipment from Ante Room.

7. Prepare to ald fire brigade.

8. Provide two (2) two-way radios for fire brigade use (no setcoms):

9. Log and report all personnel exiting and entering the buflding. HP Foreman shall:

1. Take charge in Ante Room/staging orea for HP matters only.

2. Direct HP Support to 11 Alrlock and Man Page thannel 1:

\section{Safety/First Aid shall:}

1. Standby to assist - if personnel are injured.

2. Notffy First Aid.

\section{Fire Brigade shall:}

1. Assemble as directed by Control Room.

2. Fire Brigade will enter the containment at the direction of the Control Room.

3. Command Center will assist as required. 


\section{CASUALTY PROCEDURE}

FOR

Personnel Injury or Sickness

In Containment

Th1s procedure supplements procedure 1054.16 
PERSONNEL INUURY OR SICMAESS

When an injured or sick individual is found by entry personnel, the Command

Center or the Control Room,

HP Foreman shall:

1. Take charge in the Ante Room/staging area for HP matters only.

2. Send an additfonal HP for duty in the Ante Room. .

3. Provide recomendation for best use of avallable personnel from a radiological viewpoint.

4. Make preparations to receive and monitor contaminated personnel.

5. Log and report all exiting personnel.

Safety/First Ald shall:

1. Maintain representation in the Command Center.

2. Provide rescue team as soon as practicable.

3. Make recomimendations on rescue action, evacuation, respirator renoval when information is avaflable.

Control Room shail:

1. Initiate action in accordance with procedure 1054.16, Contaminated Injuries/ Radiation Overexposure.

2. Estabilsh direct comunications with the Coimand Center.

3. Muster the rescue and assistance team and stand by to assist. Command Center shall:

1. Request information on the condition of the individual concerned.

2. Wotify other personnel in containment, the Ante Room, Control Room, the HP Foreman and Safety/First Aid.

3. Secure all non essential work including entrance into containment by teams for purposes other than rescue or assistance.

4. Verify locations and stations of ALL entry personnel. 


\section{Command Center continued:}

5. Direct Ante Room ass istance tean to enter. If required.

6. Insure combunfcations have been estabitished in key locations (containment, Ante Room, Control Room, HP Foreman)

7. Based on Safety recommendations, render assistance with Ante Room team. Ante Room shall:

1. Quickly undress any team members exiting.

2. Station one man at the intercom.

3. Assistance team prepare to enter and stand by for instructions in Airlock. Man page, channel 1.

4. Secure any rout ine work.

5. Hold any team ready for entry in stand by.

6. Remove excess equipment from Ante Room.

\section{Entry Personnel shall:}

1. Determine the condition of the individual and nature of injurfes; question him if he is consclous.

2. Inform the command Center of these facts by fastest avallable means, have one man in sight of CCTV camera, If possfble. A status report should Include:

Name of Individual. location. description of injury and condition (conscfous, unconsclous, bleeding, breathing problens, electric shock, heat stress, able to walk, etc.)

3. Entry team leaders report status and location of team members.

4. Awalt further instructions.

5. Do not wove the individual without perwission of the Comand Center. 


\section{Entry Personnel shall: (Continued)}

6. If the Individual is having difficulty in breathing, the respiraotr may be removed. Caution must be exerclsed in removing the respirator In order to avoid additional injury to the Individual. If breathing difficulty is not evident, do not remove the resplrator without permission from the Command Center. 


\section{Fire Protection}

Fire Protection standards have been upgraded in the containment. This includes the following measures:

(1) Replacement and test of fire hoses on El. 305' and El. $367^{\prime}$ (See p. 6, 7 for location).

(2) Installation of portable fire extinguishers in the ante room, E1. 305' and El. $347^{\prime}$ (See p 7, 8 for locations)

(3) Log of transient combustibles maintained by Command Center; use of fire resistant materials where possible.

(4) Monitoring containment following entry with CCTV.

(5) Training of entry personnel on Casualty Procedures and use of Fire Extinguishers.

(6) Training of Fire Brigades on Contalnment conditions.

(7) Welding, cutting, burning, soldering shall be controlled per 1410-Y-26 with fire watches in radio contact with the Command Center.

\section{Use of Fire Extinguisher:}

(1) Transport extinguisher to area needed

(2) Break seal holding hose in place

(3) Charge extinguisher by pressing down where indicated

(4) Red plunger will pop up when ready for use.

(5) Squeeze applicator nozzle to direct chemicals on fire. 
Protection for lamily, workers, and/or posses. sions was your goal in purchasing an Ansul extinguisher. To reach the goal, two more things are needed. First, everyone must be educated. They must know where to find the extinguisher, what fires it can and cannot put out, and they must know how to use it. Second, the extinguisher must be properly maintained in the right place, ready to use when needed. The Nalional Fire Protection Association produces a pamphlet which contains vital information for extin. gulsher owners. The pamphlet is N.F.P.A. No. 10. "Standard For Portable Extingulshers." and may be purchased from National Fire Protection Association, 410 Allantic Avenue, Boston. Massachusetts 02110.

The extinguisher is a container of fire extinguishing agent. It uses a source of energy (0.g. pressure stored in the container) to expel the agent and combat the fire. Every extinguisher has symbols and numbers to indicate the type and size fire the extinguisher should be used on. To interpret that information, refer to appropriate portion of this brochure.

Installation begins with a check to see that your oxtinguisher is properly charged, with the salety seals inlact. If anything indicates possible discharge, have your unit serviced immediately. If, in unpacking and checking your extinguisher, you accidently discharge even the slightest amount of agent, have your unit serviced: partial discharge can cause the oxtingulsher. to slowly lose all of its pressure.

Choose the location of your extinguisher carefully. The extinguisher should be near the type of fire hazard indicated on the nameplate, and should be ciearly visible from the hazard area. Locate your exlinguisher so that the lire will not keep you from reaching it. When reviewing the nameplate information, note any temperature limits and choose your tochon, noto any termperalure limils and choose your location accordingly. Also place the extinguisher near fighter.

The mounting bracket height should allow easy removal of the exlinguisher. Remember also that rust can be your worst enemy; be sure the bracket holds the extinguisher, especially the base, away from mois. ture. Remember that the extinguisher is a heavy device that requires solid support to be safe.
Instruction and training are vital for elfective use of an extinguisher. In the excitement of a fire siluation, the uninitialed layman is much tess likely to perform effectively than is an instiucted person.

In case of a fire, evacuate the occupants of the hazard area and call the fire department. Then use your training and nameplate inlormation to help ascertain if you can effectively deal with the type and size of fire you have.

If you decide to light the fire:

1. Maintain the proper distance (6 to B feet lor most dry chemical hand portable extingt ishers).

2. Try to position yourself so that the wind blaws the fire away from you.

3. Pull the safety pin, or release any salety locks on the unit.

4. Hold your extinguisher firmly and begin spraying the agent at the near edge of the fire. (Most Ansul devices have a "trigger" to squeeze at the handto or the nozzle. Refer to nameplate on your extinguisher. and know how to aclirate your unil BEFORE the need arises.)*

5. Move the stream rapidly side to side covering the entire width of the fire.

6. Advance slowly as your extinguisher pushes the fire back. Try to maintain the optimum distance from the front edge of the fire.

7. After the lire is out, step back and watch for pos. sible reignilion.

-Drawings, elsewhere on this brochure, illusirale basic types of fires and methods of lighting them. In fighting a fire or cleaning up after, try to avoid prolonged close contact with dry chemical extinguishing agent. The agent is not toxic, but pralonged contact may result in temporary eye or cesplieatory irrilation.

Following a fire, there are three things to do immediately. The first is 10 secure the area so the fire won't start again.

Then clean up the debris. Avoid darnage to the surrounding area and equipment by sweeping or yacu. uming dry chemical and lire debris promptly. Finally. regardless of how much extinguishing agent was used, a recharge is required immediately. Refill should be done only by an authorized Ansul distributor. The refill agent must be the same as originally used. Improper filling can result in inoperable/dangerous units.
NOTE: Never incinerafe an exlinguisher. When discarding an extinguisher, remember it is a pressure ves. sel that could explode if incinerated. Discharge fully: remove caps, valves, etc.; dispose of safely.

Inspection is a check that should be performed at least monithly. Where conditions indicale the need 10 for more detalled information. Inspect/Correct List

1. Extinguisher

$$
\begin{aligned}
& \text { D Proper Place } \\
& \text { D Visible } \\
& \text { D Accessible } \\
& \text { D Clean } \\
& \text { D Physical Damage } \\
& \text { D Corrosion/Rust } \\
& \text { D Proper Pressuro } \\
& \text { a Proper Amount ol Agenl (Weight/Huft) }
\end{aligned}
$$

2. Nameplate

$$
\text { C Legible }
$$

3. Sofely Seals/Indicators

- Inlact/Proper Position

4. Hose

$$
\text { o Cracked/Cut/Worn }
$$

5. Mozzle

a Clear of Obstructions

- Trigger Operales Smoothly

6. Mounting Bracket

o Firmly Allached

7. Inspection Record

$\checkmark$ Dated and Initlaled

Maintenance is required periodically (see nameplate) jusl as it is with any important mechanical device. Refer to N.F.P.A. No. 10 for instructions. The following should be included in any maintenance procedure.

Clean and examine the surface thoroughty. Avold dust and corrosion by cleaning and repainting wherever paint chips or imperfections are found. If rust or corrosion is found to have attacked any extinguisher part, see your Ansul distributor immediately.

Protect your investment in fire salety with proper training. proper placement, and proper maintenance. 
Coast Guard Approvals

For extinguishers with U.S. Coast Guard approval, the approval is valid only with the bracket specilied on the extinguisher nameplate.

\section{Basic Dry Chemical Extinguisher Technique}
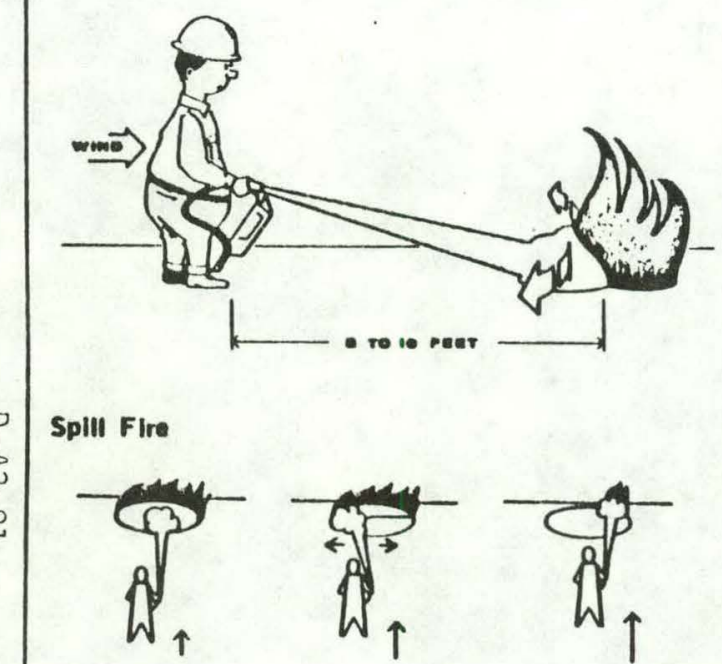

Gravity Fod Fire

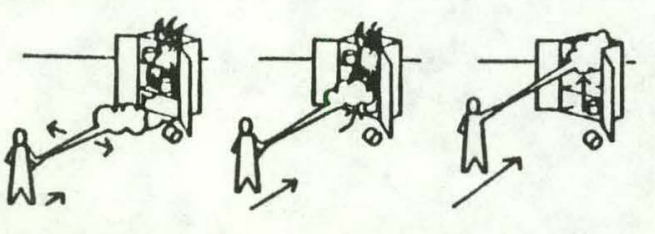

Symbols

Every Ansul extinguisher displays one or more of the Underwriters Laboratories and National Fire Protection Association symbols on its nameplate. Each symbol indicates the type of fire (fuel) on which the extinguisher may be safely and effectively used.

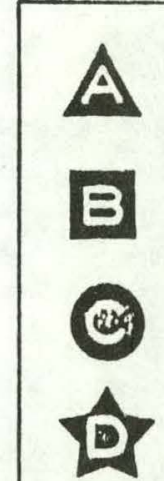

Use " $A$ " rated extinguishers on ordinary fires: wood, paper, cloth, rubber, many plastics, etc. CAUTION: Burning plastics may release toxic fumes.

Use " $B$ " rated extinguishers on flam-

- mable liquids, gases and greases: motor oil, paint thinner, dry cleaning agents, gasoline, propane, natural gas, etc.

Use " $\mathrm{C}$ " rated extinguishers when live electrical equipment is involved, to prevent possible shock or electrocution.

"D" rated extinguishers are for use on

Detal fires such as sodium and magnesi. um. More specific information will be found on the nameplate.

NOTE: Use these extinguishers only as indicated by the symbols. Improper application can be hazardous. Example: Water (Class A) applied to an electrical (Class C) fire could shock or kill the fire fighter.

Each extinguisher nameplate shows the Underwriters Laboratories rating granted for that extinguisher. The rating system includes letters (discussed in the "Symbols" section) and numbers.

\section{Ratings}

Ordinary Class A Ratings: The number preceding the "A" indicates the number of 14.4 galion containers (of water, soda acid, or foam) that the extinguisher is equivalent to in fire fighting capacity.

- Class B Ratings: The number preceding the "B" indlcates the relative fire extinguishing potential of the extinguisher when used on a flammable liquid fire. For details regarding extinguisher placement consult NFPA-10, "Standard for Portable Extinguisher."

Class C and D Ratings: Neither " $C$ " nor "D" ratings have numbers with them. The agent is only classified as acceptable for " $\mathrm{C}$ " or "D" applications. Addition. al information may be available on the extinguisher nameplate.

E Example: An extinguisher rated 4-A:20-B:C - is

roughly equal to four $14 \mathrm{tg}$ gallon containers of Class $A$ agent (or five gallons); is rated for a 20 square foot

Class B fire when used by a non-expert; the agent is safe for use in electrical fires; and the agent should not be used on burning metal (no " $D$ " rating is indicated).

ANSUL. THE ANSUK COMPANY, MARINETIE, MI SA143

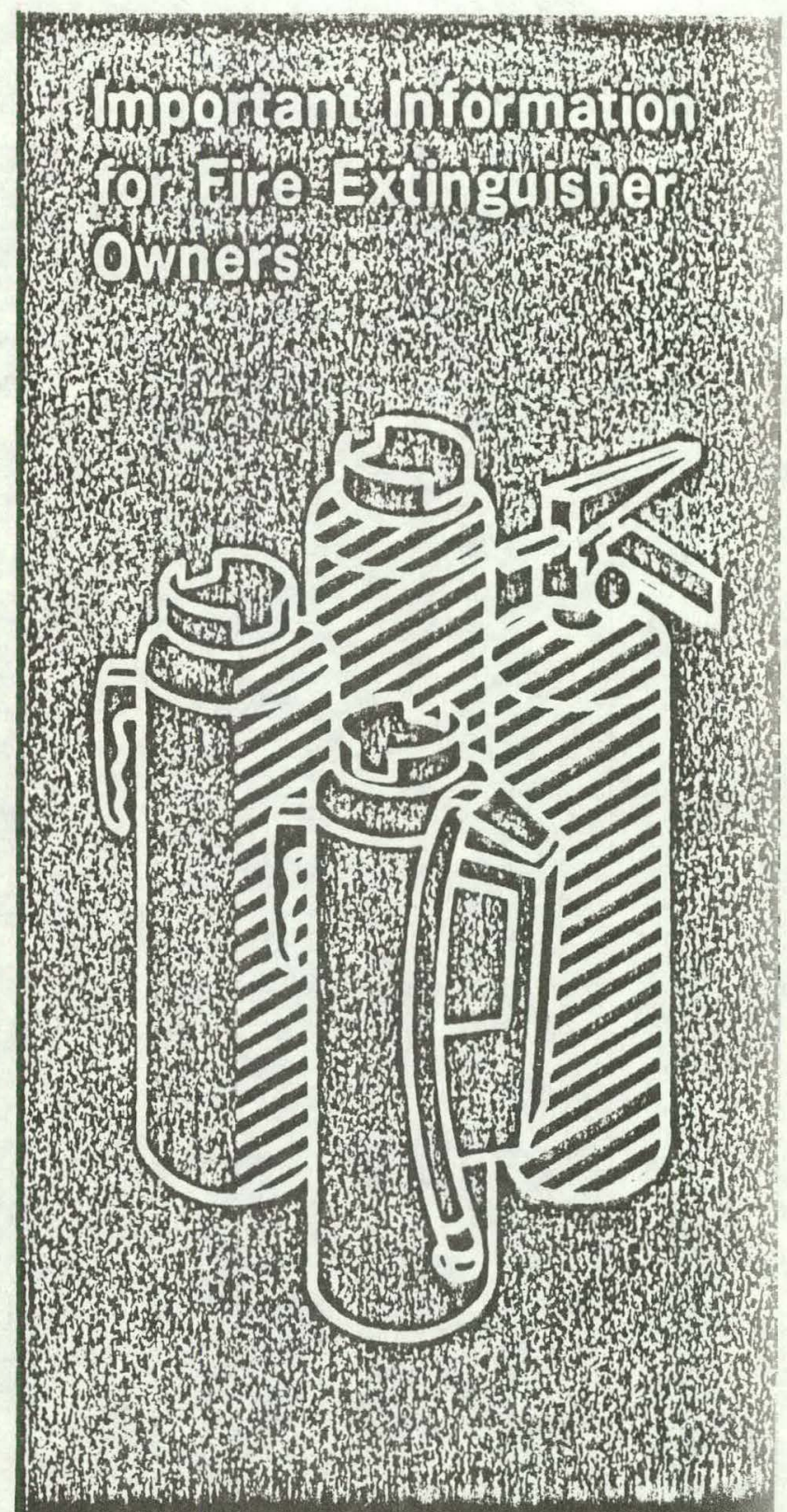




\section{DEBRIEFING}

Each individual debriefed should be prepared to answer the following questions at a minimum:

(1) What was accomplished on work as compared to the plan?

(Answer should allow mockup of work package and note any additional tasks performed).

(2) Did you notice any differences between plant configuration and the documentation you used to prepared for the work?

(3) Was your training adequate?

(4) Were equipment and manning satisfactory for the job?

(5) Did you notice any safety problems?

Any additional comments should be referred to your Task Coordinator or Job Foreman. 


\section{TYPICAL ENTRY DAY SUMMARY}

1. Report to assembly area.

2. Review schedule for the day, noting your scheduled time for dressing and dose pull point.

3. Attend pre-job briefing for your work package and the RWP briefing; record name on attendance sheets.

4. Stand by until you are notified to dress; if you leave for any reason obtain permission from Bechtel or designated coordinator for logistics.

5. Dress when called; an assistant w1ll complete the dressing checklist.

6. Check In at control point with dressing checklist; read RWP and note requirements, sign on RWP (RWP's if applicable; each time you switch RWP's in contalnment you must give a final dosimeter readings).

7. Test radio and enter ante room when directed.

8. Inventory equipment and notify Command Center when ready to enter airlock.

9. Enter afrlock when directed.

10. Notify Command Center when ready for entry.

11. Enter reactor bullding when directed and perform work. DO NOT OPEN INNER DOOR UNLESS DIRECTED BY COMMAND CENTER.

12. Exit when work is complete or other exit criteria are established. You do not need permission to open airlock doors unless door interlock is defeated.

13. Undress in ante room and frisk out. If you become contaminated inform the Command Center.

14. Sign off RWP.

15. Take schedule break, lunch, etc. ; replace body fluids.

16. Attend scheduled debrief; if in doubt as to time or place call individual concerned on the dally schedule.

17. Satisfy any bloassay or whole body count requirements.

18. HP's document surveys at next avallable opportunity and submit to HP Foreman.

19. All personnel Insure bioassay bottles are returned to Admin Building Room 133 (Ext. 8473). 


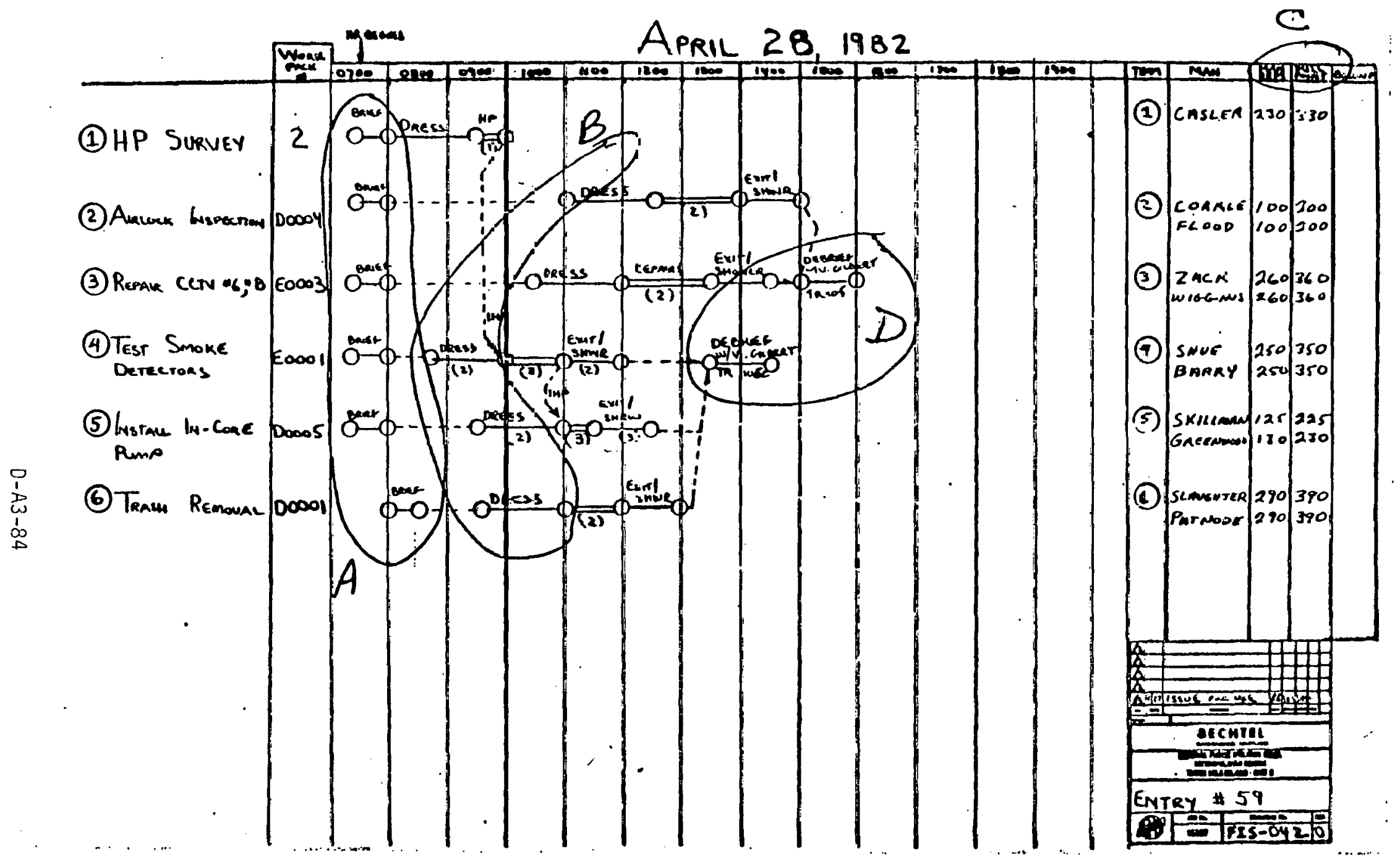

Note on TH AS SCHEdULE:

A) Briefing Time

B) Dress Ont Start Time

C) Dose Estimate \& Pull Point-

D) Debugs Timo/Lochtion/s exriofox 
A'I"I'ACHMENT D-4

PRE-JOB BRIEFING OUTLINE 
A pre-job briefing shall be conducted prior is initiating work per this Work Package. This briefing shall be scheduled to occur within two hours of crew entry into the Containment Building. The purpose of the pre-job briefing is to reinforce important aspects of the formal training program and it should not be construed to be a substitute for formal training. The following items shall be discussed with personnel preparing to enter the Containment Building to perform work per this Work Package:

(1) Administrative control of the work

(2) Scope and purpose of this entry

(3) Conditions which dictate en exit from the Containment Building

(4) Emergency Procedures

(5) Communications

(6) ALARA considerations

(7) Contamination control

(8) Individual and team responsibilities

(9) Reinforcement of techniques for specific, difficult operations as determined in Training Program.

(10) A review of the type questions which will be asked during debriefing. . 


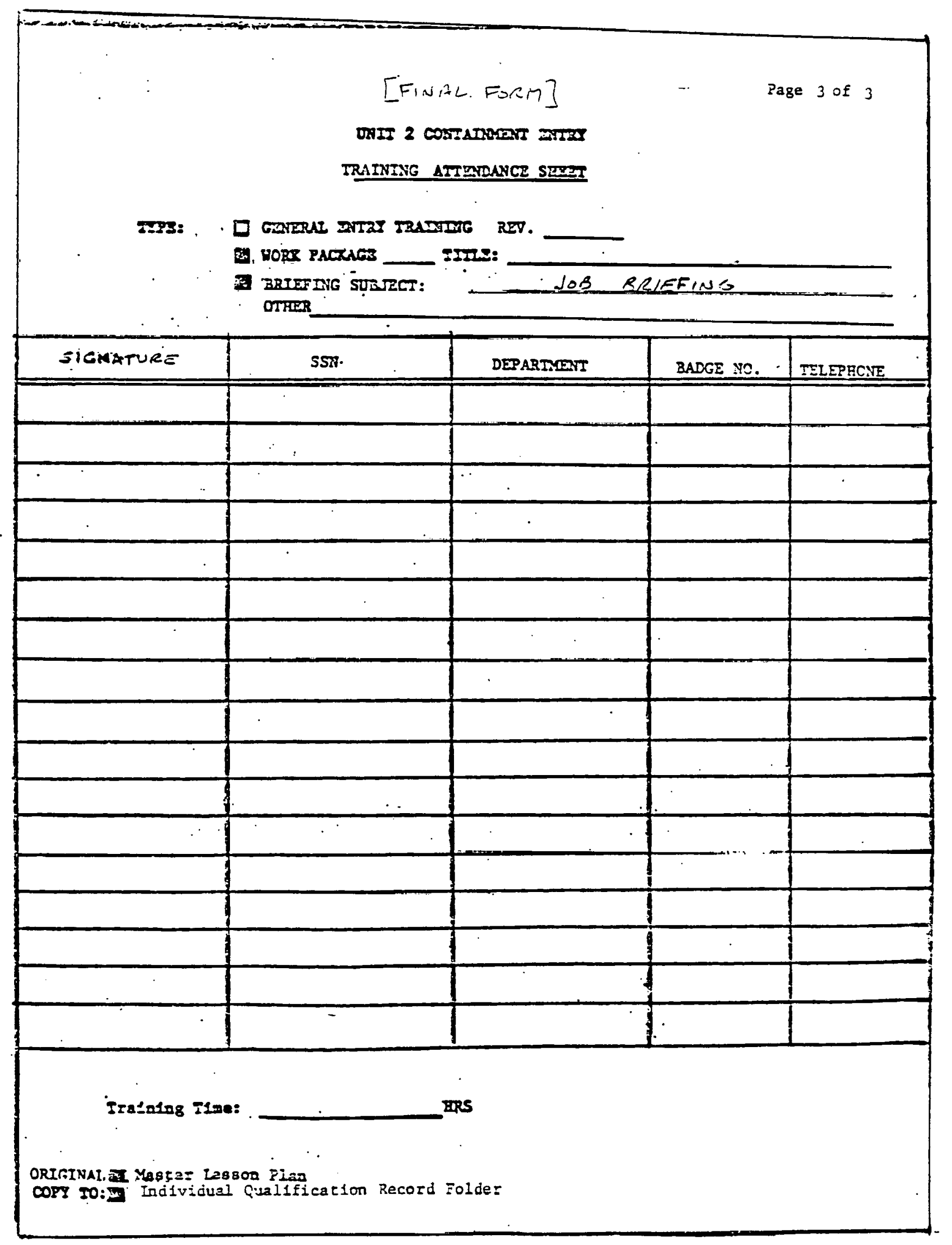


EXHIBIT 2

JOB BRIEFING CHECKLIST

$\frac{\checkmark}{\bigcirc}$ 1. Reason for job brief (10 CFR 19).

2. Discuss exact work location, including access and egress routes.

$($ 3. Review work to be accomplished, ensurling workers are familiar with and capable of periorming the intended operation and expected results.

- 4. Ensure the avallability of necessary tools and equipment prior to entry into work area.

( 5) Emphasize the perfornance of as much work as possible outside the radiologically controlled areas.

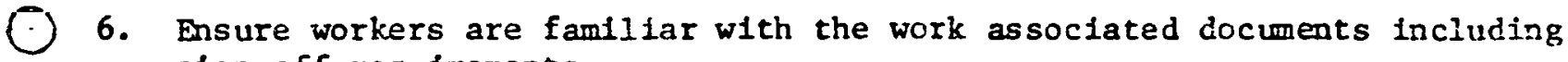
slgn off requiremenis.

( 7. Review methods of disposition of contaminared waste and equipment:

- 8. Discuss emergency actions to be taken if contingencies arise, including exit routes.

9. Review exit criteria.

10. Discuss communications required.

(-) 11. Emphasize workers shouid contact comand center for unusual conditions.

O 12. Discuss authorizations for entry of Reactor Bullding.

(C) 13. Review workers dose pull points and Dafly Entry Schedule.

(.) 14. Review radiological conditions of work area.

2 15. DIscuss Iimits and precautions.

(-) 16. Status of closed circuit television system.

(.) 17. List any specific items requiring discussion not described above: 
WHIST 2

CONTAINMENT ENTRY JOB BRTEFING

1. Work Package , IVP NO.

2. Task Supervisor:

3. Task Supervisor complete Work Package Briafirig using page 2 as a guide; check applicable items discussed.

Comments :

4. Radiological Controls complete any required radiolozical briefing; check applicable item discussed on page 2.

Comments :

5. Autiorized additional work itcms not covered in Work Package:

6. Task Supervisor complete page 3; attendees sigin

7. Completed

$\begin{array}{lll}\overline{\text { Task Supervisor }} & \overline{\text { Time }} \\ \overline{\text { Radiological Control }} & \overline{\text { Date }} & \text { Time }\end{array}$

8. Task Supervisor forward to Entry Supervisor

9. Reviewed/Approved:

$\overline{\text { Entry Supervisor }} \overline{\text { Date }} \overline{\text { Time }}$


ATTACHMENT D-5

POST-.TOB DEBRIEFING OUTLINE 
POST-JOB DEBRIEFING OUTLINE

The post-job debriefing is intended to assimilate, as quickly as possible after performance, descriptive information of conditions as they exist within the containment Building, adequacy of planning, adequacy of equipment, and other information which might be useful to improve future operations. Questions asked during the debriefing shall include, but not be limited to the following:

(1) Was the hands on training adequate?

(2) Did you feel sick at any time during the entry?

(3) Did you feei fatigued at any time during the entry?

(4) Did you have any difficulty in communicating with the Command Center or each other?

(5) Did you notice any tripping hazards not properly identified?

(6) Did you notice any overhead hazards not properly identified?

(7) Were the hot spots properly marked?

(8) Was the lighting adequate?

(9) Did you find the floors or stairs slippery?

(10) Did you notice any rips in your PC's?

(11) Did you experience heat stress?

(12) Did the cooling vest help?

(13) Kere there any obstructions which prevented you from following the prescribed path?

(14) Did you experience any breathing difficulties?

(15) Do you feel a safety harness would be desirable?

(16) Were any of the drains plugged?

(17) Did you experience any difficulty in seeing because of fogging?

(18) Did the shut-off valve work properly?

(19) Did you notice any wearing out of the nozzle? 
(20) Did you experience any clogging of the nozzle?

(21) Did you feel that you were burned or otherwise made uncomfortable by the hot water?

(22) Did you experience excessive splashing?

(23) Qualitatively, which pressure and flow rate do you feel did the best job?

(24) Was the spray wand of adequate length?

(25) Was the spray nozzle hard to handle at the high pressure and high flow rate?

(26) Would a shoulder rest be helpful for the gun?

(27) Did any of the hoses kink or become unwieldly?

(28) Did you experience any inadvertent uncoupling of the hoses or nozzles?

(29) Did you have difficulty in operating the wet vacuum?

(30) Was the water floor scrubber difficult to handle?

In addition to the above questions, a critique of individual performance should he conducted utilizing the videotapes where possible. Particular attention should be directed to adequacy of techniques used. 


\section{DEBRIEFING QUESTIONS*}

(NEW GENERALIZED FORMAT)

1. What was accomplished on the work package (WP) as compared to the plan?

2. Did you perform additional work not related to your work package? (Procedure should allow markup of work package and notes on any additional tasks performed.)

3. Did you notice any differences between plant configuration and the documentation you used to prepare for the work (drawings, WP, etc.)?

4. Were there any abnormal occurrences?

5. Was your training adequate?

6. Were equipment and personnel satisfactory for the job?

7. Did you notice any safety problems?

8. Do you have any other comments?

9. Do you have any recommendations which will improve the Containment Entry Program?

*Each entry team number should be asked debriefing questions. 
ATTACHMENT D-6

HEAT STRESS PROGRAM 
Heat Stress Control Program

Three Mile Island Nuclear Station

GPU Nuclear Corporation

Prepared By:

B. A. Parfitt

J. S. Schork 


\section{Int roduction}

Individuals who work' in the nuclear power plants are exposed to a varlety of chemical and physical stresses. One of the most significant physical stresses to which workers are exposed is a result of working in hot environments. The most obvious sources of heat stress are high air temperatures and radiant heat sources inherent to an operating power plant. Another more subtle, and less easily defined, source of heat stress results from the use of heavy protective clothing required to protect workers from radioactive contamination. Even at relatively low ambient temperatures, heavy protective clothing reduces heat losses through the normal mechanisms of radiation, convection, and sweat evaporation. Impermeable clothing, frequently used to protect workers from the high level contamination resulting from the Unit II accident, is particularly effective in reducing heat loss since it eliminates the evaporative cooling normally provided by the sweat process. Individuals who must work for extended time periods in this type of clothing tend to store heat generated during work activities, resulting in an increase in body temperature and an increased risk of developing a heat related illness. Recognizing this problem, the GPU Nuclear Safety and Health Department has implemented a comprehensive program designed to reduce the occurrence of heat related illnessses through the use of worker training, physiological testing, administrative controls, and personal cooling garments. The following is a brief description of the current program and some potential modifications to the program which are currently under study.

\section{Training}

A fundamental part of any program aimed at controlling exposure to chemical and physical stresses is employee training. This is particularly important with regard to heat stress. Individual response to heat is so highly variable that even the most sophisticated heat stress index cannot eliminate the possibility that a heat related illness will occur. Because of this individual variability, the ultimate decision as to when work can no longer he performed safely in a hot environment rests with the worker's evaluation of his own condition. It has always been the policy of GPU Nuclear that when a worker begins to feel ill while working in a hot environment, the individual is to immediately remove himself from that environment and notify his sunervisar. However, in order for an individual to properly assess his condition, he must have a fundamental understanding of how the body regulates heat, the early symptoms of heat related illnesses, the potential consecuences of those illnesses, first aid procedures used to treat heat related illness, and preventive measures which can be taken to reduce the possibility of . developing a heat related illness. Providing the worker with this information is the major goal of our training program.

Attachment 1 is a copy of our employee training handout on heat stress. It has been distributed and verbally presented at plant and contractor safety meetings. In addition, it has been incorporated into the training program which all personnel are required to receive prior to making a Unit II Reactor Building entry. Worker feedback from this training has been excellent. There have been several instances where personnel have been able to note early symptoms of heat related illness and were able to terminate their entry prior to the onset of any debilatating effects from the heat. 
Because working in a hot environment places a qreat deal of stress on a worker and reaction to this stress can be significantly affected by a number of health problems, it is essential that some type of screening process occur prior to placing personnel in positions which involve exposure to heat stress. By eliminating exposures to individuals who have a higher risk of developing a heat related illness because of other health problems, the risk of injury or illness due to work in hot environments is reduced for the general workforce as well as the individual.

All workers at Three Mile Island, whose job duties require the use of respiratory protection devices, must pass a physical examination administered by a physician at the Site Medical Department. Although this examination is intended primarily to ensure that individuals are physically capable of wearing respiratory protection it does provide us with a basic overview of the individual's general health. In addition, since heavy and impermeable protective clothing is almost exclusively used in conjunction with respiratory protection, this physical examination provides us with a mechanism of evaluating those individuals most severely exposed to heat stress. The examination consists of the gathering of a brief health history, pulmonary function and cardiovascular measurements, and a hands on examination by a physician. Particular emphasis is placed on detecting pulmonary and cardiovascular abnormalities which may affect the individual's ability to safely wear respiratory protection. Such abnomalities would, of course, also increase the risk of ill effects during exposure to heat. The format and criteria utilized in this physical can be found in Attachment 2 .

Impermeable clothing is used most extensively to protect personnel entering the Unit II Reactor Building from high levels of radioactive contamination. Que to the large heat stress placed on individuals who must wear this type of clothing and the potential delays and complications in providing treatment to individuals who may become 111 in this environment, it was felt that additional testing to screen individuals who may be unusually susceptible to heat stress would be advantageous. Although no definitve test for doing this currently exists, research of literature pertaining to the subject indicates that two parameters which would be indicative of heat storage within the body which can be measured are body core temperature and heart rate recovery. $(1,4)$

Rectal temperature is the most effective means of determining body core temperature. However, rectal temperatures are difficult to obtain at an industrial site. For this reason many investigators use oral temperature as an indication of deep body heat storage, using an oral temperature of $37.6^{\circ} \mathrm{C}$ $\left(99.6^{\circ} \mathrm{F}\right)$ to correspond with a deep body temperature of $38^{\circ} \mathrm{C}\left(100.4^{\circ} \mathrm{F}\right) .(1,4)$ This is the criteria we have utilized in our program. The procedure utilized in performing heat stress susceptibility testing is found in Attachment 3.

The pulse rate of a worker reflects the combined demands of environmental heat, work level, elevation of body temperature and cardiovascular fitness. Initially high heart rates which recover quickly during rest are indicative of a high metabolic rate but little heat storage. High heart rates which fall to recover during the rest period indicate that in 
addition to demands created by the work output, an additional stress is placed on the cardiovascular system in trying to shed stored heat. Therefore the amount of heart rate recovery is a good indication of how much heat storage occurred during a given work period.

The test consists of having a worker walk at a comfortable pace for one hnur while wearing impermeable clothing similar to that worn in the actual containnent entry. The individual then perfoins a moderate walking and step climbing exercise for one hour, simulating a $150 \mathrm{kcal} / \mathrm{hr}$ metabolic rate. With average winter temperatures of $65^{\circ} \mathrm{F}$ in the exercise area, calculation of the heat stress incurred using the method developed by Kamon et. al. (3) shows that $58.17 \mathrm{kcal}$ of heat would be stored resulting in an expected oral temperature rise of $l$ of for an average person. After the exercise, the individual is instructed to remove the protective clothing and oral temperature and rerovery heart rates are measured. An oral temperature exceeding $100.4^{\circ} \mathrm{F}$ and a heart rate which does not recover by 10 beats per minute during the three minute recovery period indicates that abnomally high heat storage occurred, and the individual's thermoregulatury mechanisms are substandard. Such individuals have an increased risk of incurring a heat related illness and are disqualified from performing work in the containment building while wearing impermeable clothing. Additionally, an irregular pulse rate is also a disqualifying criteria as it indicates that the combination of work load and heat load placed too much stress on the circulatory system. Disqualification resulting from this test only excludes the individual from wearing impermeable clothing in the containment building. He may perform tasks in the building which do not require the use of impermeable clothing.

This testing program provides a reliable method of screening individuals with high susceptioility to heat stress, however, its major drawack is the length of time required to perform it. This time factor limits the use of this screening test to the containment entry program.

A much more convenient test would be one of short duration which could be administered at the site medical facility. We are currently working with Dr. Elizier Kamon of Penn State University to develop such a test, and to use data collected in our current program to evaluate its effectiveness. The avallability of a quick, simple test will allow us to expand the program to other projects requiring significant exposures to heat stress.

Administrative Controls

The most common method of regulating exposure to heat stress is through the utilization of administrative controls. This is particularly true in nuclear power plants where work locations change on a daily basis. In addition, manipulating environmental conditions to promote greater body heat loss is of limited benefit since massive changes would be required before heat exchanges through protective clothing would be significantly affected.

Although no definitive heat stress guideline currently exists, particularly with regard to protective clothing, we have developed guidelines to assist supervisors and workers in judging how long work can safely be peformed in hot envi ronnents. 
The guidelines currently being utilized are contained within the GPU Nuclear-Heat Stress Exposure Safe Work Practice (Attachment 6). The guidelines are based on operational experience with protective clothing coupled with theoretical considerations adapted from the Heat Stress Index developed by Belding and Hatch. Although the guidelines are not a rigorous mathematical model of the heat transfer which occurs during the use of protective clothing they have been berieficial in that the few heat related 11lnesses which have occurred have been isolated and usually traceable to a pre-existing medical condition. As new guidelines and methods of evaluating heat stress become available our guidelines will be reevaluated and modified as necessary.

One of the newest and most promising methods of evaluating heat stress has been recently developed by Dr. Elizier Kamon of Penn State University. (3) Or. Kamon uses mathematical equations to describe the different types of heat transfer which occur. between an individual and the surrounding environment. What makes this method particularly useful in our application is the inclusion of factors which describe the effect of protective clothing on this heat transfer. Initial comparison of our guidelines with Dr. Kamon's method is favorable; for the most part our guidelines are more conservative. However, there are some instances where significant discrepancies exist. This is to be expected since our guidelines must be simple and general to find practical field use. There are also some problems with Dr. Kamon's method in regard to accurately choosing the insulating val es for different types of protective clothing and incorporating the additional stress placed on a worker utilizing respiratory protection. We are continuing to work with Dr. Kamon to resolve these problems and to incorporate his method into a more comprehensive yet field-usable set of guidelines.

\section{Personal Cooling Systems}

Early Into the TMI Recovery Program for the Unit II Reactor Building it was realized that the high levels of loose radioactive contamination would require the use of extensive protective clothing by entry personnel. While there was no doubt that layered protective clothing would protect workers from becoming contaminated, it was recognized that these same layers of clothing' would impose a potentially serious heat stress burden.

Initial methods used to prevent workers from becoming ill as a result of heat stress incurred while wearing protective clothing concentrated on three basic techniques:

1. Medical screening of personnel prior to Reactor Building entries

2. Education of workers in the recognition of the hazards and symptoms of heat related illness.

3. Imposition of work time limits 
While these methods did provide protection for the workers, they were less than completely successful. Some members of early entry teams terminated their tasks prematurely due to heat stress. Some personnel completed their assigned tașks but became slightly ill upon exiting the Reactor Building. One person suffered extensive dehydration and required short term hospitalization (one day).

After each heat stress incident, action was taken to further protect workers. Some protective clothing requirements were reduced, work time limits were shortened, and attempts were made to acclimate workers to heat stress by conducting pre-entry mock-up simulations of assigned tasks. Each of these actions did provide a better margin of safety for workers exposed to heat stress, however, problems still remained.

The loosening of protective clothing requirements created an increased risk of having personnel contaminated with radioactive material. Work time limits were reduced to the point that they severely hindered productivity and ALARA objectives. Task simulations became so extensive that the tine spent preparing for an entry required a 3-4 week lead time. The methods in use had reached the limits of their ability to protect workers from heat stress.

Clearly, the problem was: How can we protect a heavily clothed worker who must perform work in an expeditious manner from becoming overheated. After a review of current technology, it was determined that the utilization of body cooling systems was the most effective means of controlling heat stress imposed by protective clothing.

Body cooling systems can be divided into two basic categories:

Body Cooling Devices

Body Cooling Garments

Body cooling devices produce a flow of cool air which is introduced close to the skin to remove body heat through convection and increased sweat evaporation. The most common body cooling device is the vortex tube.

Vortex body cooling devices have been utilized in several industries' where protective clothing is utilized in hot environments. In an effort to determine the reasibility of using liese Jevices at TMI, they worc tcotad in the small srale dernntamination experiment conducted in May, 1981 . The cooling effect produced by the vortex tube successfully protected the workers from heat stress, however, there were several logistical and operational problems which hindered extensive use of these devices. The part of the Vortex tube located outside the protective clothing became contaminated with radioactive material and was not able to be decontaminated. In addition, the volume of service air required to operate the vortex tubes is very large. The plant service air system is not large enough to supply compressed air to several workers utilizing these tubes at one time. Finally, the umbilical nature of the hoses supplying air to these systems restricted mobility and location of workers. 
The sum of the logistical and operationai problems associated with Vortex tubes directed our attention to body cooiing garments. Tirree types of body cooling garments were examined. Two garments, the "Cool vest" manufactured by ILC Dover Inc., and the "Cool head" manufactured by Life Support Systems, act on the same basic principal. They consist of close fitting garments through which water is pumped, dumping body heat into frozen ice or chemical packs. The major disadvantages of these systems are their cost, inability to decontaminate the garments and pumps, and the need for regular pump maintenance.

The last type of body cooling garment examined is an ice vest-type garment that has $50-80$ pockets into which small packets of ice are placed. As the skin temperature increases, heat flows into the ice packets, eventually melting the ice. The amount of heat consumed in this process is equal to the heat of fusion of the weight of ice utilized. This garmet, developed under an EPRI grant, is manufactured by Ergocon. Ergocon is headed by Dr. Elizier Kamon, Penn State University, the developer of the ice vest and author of numerous articles and publications concerning the evaluation and control of heat stress. The ice vest was found to be the most useful of the three body cooling garments. It is cheaper, simpler to maintain, and easier to use on a continuing basis.

Six prototype ice vests were ordered and placed into use during the summer of 1981. They have proved to be very useful in diminishing our heat stress problems. While the heat sink provided by the ice packets is limited, it is large enough to allow most tasks to be comoleted with as many layers of protective clothing as is necessary. Recently, Dr. Kamon visited TMI to perform a field evaluation of the ice vest. Heart rates and rectal temperatures were measured during a pre-entry mock-up without the vest and during an actual entry with the vest. The results of this testing can be found in Attachments 4 and 5 . Rectal temperature stayed consistently lower during use of the ice vest while heart rate fluctuated due to differences in work load. Subjective comments provided by workers utilizing the vest also indicate they have been successful.

We are still working on the logistical and operational problems of using the ice vests throughout TMI. The plastic packets of ice tend to crack and leak. The rip stop nylon vests have become unraveled after several washings. The cleaning of the vests on a regular basis is somewhat of a problem since there is no clean non-contaminated laundry at TMI at this time. We are continuing attempts at solving these problems and hope to extend the use of ice vests to other projects at our facilities.

\section{Conclusions}

The program we have established for controlling heat stress is based on the best knowledge currently available. We are constantly studying new evaluation and control techniques and expect to modify the program as new information becomes available. Although it has been an effective program, there is always room for Improvement. The more effective the program becomes, the more expeditiously and safely workers can perform the clean up of TMI Unit II and other maintenance tasks at our facilities. 


\section{References}

1) Fuller, Frank $H$. and Smith, Paul E. Jr., "Evaluation of heat stress in a hot workshop by physiological measurements," American industrial Hygiene Association Journal, Vol. 42, No. 1, pp. 32-37. 1981

2) The Industrial Environment, It's Evaluation and control, National Institute for Dccupationa! Health and Safety, U.S. Department of riealth, Education, and Welfare. 1973

3) Kamon, E. and Ryan, C., "Effective heat strain index using pocket computer," American Industrial Hygiene Association Journal, Vol. - 42, No. 8, pp. 661-615. 1981

4) Minal, C. P. Jr., "Effects of heat stress on physiological factors for industrial workers performing routine work and wearing impermeable vapor - barrier clothing," Anerican Industrial Hygiene Association Journal, Vol 42, No. 2, pp. 97-103. 1981 
Heat is a naturally occurring stress under which human beings have evolved over the ages and to which each of us is exposed at least periodically during our lives. Industrial heat exposure, however, frequentiy is much greater than that encountered in the natural environment. Hot industries also involve hard physical work which adds to the total heat stress. The effect or consequences of heat stress in the work environment can be seen in decreased worker productivity, increased accident rates, illnesses, and fatalities. The primary concern of this discussion is the control of heat stress, the prevention of heat-related illness and death.

The body is continually producing heat every second that it lives. This heat comes from the breakdown of food that the body uses to. supply the energy it needs to support its life processes. About $75^{\circ}$ of the energy consumed by the body ends up in the form of heat which in turn heats up the body. Increased physical activity produces even more body heat. To maintain a normal acceptable body temperature, this heat must be brought to the skin surface and exchanged with the air surrounding the body. The physiologica? process which maintains the balance between heat production and heat removal is a complex one involving the central nervous system, the circulatory system, the skin, and the muscles. The situation is similar to the working system for. the automobile engine. In the engine, energy and heat are produced in the block. Water is pumped through the block where it absorbs heat, then through the radiator, where the heat is exchanged with the atmosphere. The rate of circulation is controlled by a thermostat, which opens when the engine is hot. Similarly, in the body the blood carries heat from the core of the body to the skin. The amount of blood flowing to the skin can be increased or decreased. The rate of heat loss can be increased if necessary by wetting the skin with sweat. When water evaporates, the water molecules absorb a large quantity of heat. The heat gained by the water molecules as they evaporate is lost from the wetted skin surface. Under conditions of excessive heat stress, this evaporative cooling beccmes the major avenue for achieving heat balance. The body's cooling system is remarkably efficient and can adjust to steady work in hot environments. This adjustment is called acclimatization and is usually completed in a week. Despite the adaptability of the body's cooling system, it can be overloaded by certain extremes in environmental conditions and physical activity.

Heat stress problems arise when the body produces more heat than it can get rid of. When this happens, a variety of illnesses can occur depending on the duration and severity of stress and the effectiveness of steps taken to relieve the stress. These include:

\section{Heat Exhaustion}

Heat exhaustion is caused by an insufficient blood flow to the brain because too much blood has been diverted to the skin in an effort to cool the body. During heat exhaustion, body temperature is usually norma! and the skin is cool, wet, and pale. The major symptoms are giddiness, headache, veakness, faintina, vomitina, and a rapid, weak pulse. Rest in a cool environment and fiuid replacement will result in full recovery. This type of heat illness is usually caused by inadequate fluid intake to make up for the body water lost in the sweat. 
Page 2

Working in. Hot Environments

\section{Dehydration}

The vater lost from the body as sweat must be replaced by drinking water if denydration is to be prevented. Dehydration rapidly leads to decreases in perfoimance and work capacity and to heat exhaustion. Sweat production of 8 to 10 quarts each working day is not uncommon in hot industries. This means that water must be replaced at the rate of at least 1 quart each hour. When sweating is heavy, a better practice is to drink about a cup of cool (not cold) water every 10-20 minutes throughout the work day.

\section{Heat Stroke}

Heat stroke results from a high body temperature that is caused by a failure of the body's cooling system. The high body temperatures accompanying heat stroke can be fatal if they are not lowered. Usually, collapse and coma with high body temperature are the first symptons, and the victims skin may be red, hot, and dry. Treatment consists of rapid reduction of the body temperature by immersion in ice bath, alcohol spray, or fans and wet sheets. Age, obesity, lack of physical fitness, and hard physical work are factors that increase the chances of heat stroke. Heat stroke is a serious medical emergency and requires speedy medical attention to save the victims, life.

\section{Heat Cramps}

Heat cramps result from excessive loss of salt in the sweat without adequate replacement. Heat cramps involve mainly the hand, arm, leg, and abdominal muscles. Heat cramps are not very common and occur mostly when sweating is heavy, water replacement is adequate, but salt intake is low. A little salt added to the drinking water or the food is an effective treatment and prevention of heat cramps. For heat adjusted (acclimatized) workers the usual diet contains enough salt because their sweat is low in salt. Moderation is needed when increasing sait intake because too much salt actually reduces heat tolerance, and for persons with high blood pressure, increased salt intake can actually aggravate the condition to a dangerous level. Drinking Gatorade is the best and safest way to maintain fluid and salt baldnce at the same time.

The conditions found at TMI are normally within the range that your body's heating/ccoling system can handle. The range 7 imits may be exceeded when doing hard work during hot weather or when wearing protective clothing in hot contaminated areas. When necessary, the safety department will measure the environmental conditions in a hot area to see if control measures must be instituted. The early symptoms of heat stress are:

\section{Weakness \\ Extreme fatig̣ue. \\ Dizziness}

More advanced symptoms are:

Arm, leg, and stomach muscle spasms Irregular or increased heartbeat
Nausea

Headache

Thirst
Extreme Thirst

Fainting 


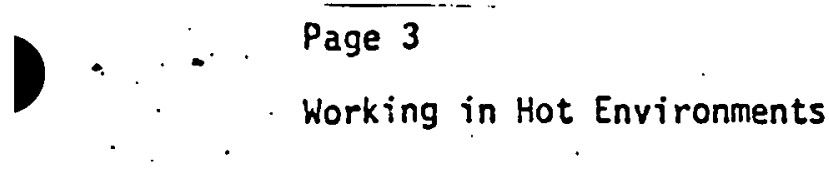

If you note early signs of heat stress, notify your supervisor. The immediate treatment is to:

Rest in a cool place

Drink small amounts of cool water frequently

If symptoms continue, get medical help from First Aid

Don't expect to work at your normal pace for the first few days in a hot area. If your body is allowed to accustom itself to heat stress areas gradually (acclimatization), within a week or so you will be able to stand a full shift of hard work in a hot area with few ill effects. If you have any further questions about heat stress, contact the First Aid office.

$D-A 6-11$ 


\section{Fed Muciear Medical Program}

\section{Safety \& Health Department}

Medical Examination: $\quad$ RESPIRATORY CLEARANCE REPORT

Effective Date:

Page 1 of 2

\section{PURPOSE}

To annualiy physiologicaliy qualify an individual to wear respiratory protection.

\section{APPLICABILITY}

All personnel, including non-GPU Nuclear personnel, required to wear respiratory protection.

\section{SCHEDULING AND NOTIFICATION}

The Safety \& Health Department shall schedule upon receipt of notification

from supervision that such examinations are due.

\section{EXAMINATION CRITERION}

Examination performed to meet the requirements of NUREG 0041 and 29 CFR 1910.134 .

\section{DISQUALIFYING CRITERIA}

EARS :

\section{Ruptured Eardrum}

Otitis Media

Any infection noted on

Ear carials.

Eardrums cannot be visualized

due to excessive wax.

THYROID: Enlargement

History of thyroid disorder

HEART: Abnormal rhythm

Tachycardia $>100$ at rest

Murmurs

Blood Pressure $>140 / 90$

LUNGS: $\quad$ FVC $<75 \%$ of predicted value

FEV $1<75 \%$ of predicted value History of chromic lung disease, emphysema, $T B$, as thma and under no physician's care at this time.
QUALIFYING CRITERIA

Eardrum Intact

No present infection noted

Normal size

Normal rate $\leq 100$

Asymptomatic

Blood Pressure $\leq 140 / 90$

FVC $\geq 75 \%$

FEV $_{1} \geq 75 \%$ 


\section{FedPuclear Medical Program}

\section{Safety \& Health Department}

Medical Examination: RESPIRATORY CLEARANCE REPORT

Effective Date:

Page 2 of 2

\section{MEDICAL OPINION AND DETERMINATION}

Shall be determined by the examining physician in accordance with established company criteria.

FORMS AND TESTS TO BE COMPLETED

GPUN A0000878 (initial)

GPUN A0001173 (annual update)

GPUN A0000882

Spirometry Graph

\section{RECORDS}

Maintained by the Safety \& Heal th Department for thirty years post termination of employee. Hard copy for one year and microfiche thereafter.

Concurred:

Physician's signature 
Name

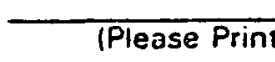
Height in. cm. Weight ibs.

A. itistery: Pulse $B / P$ Sex Race Age

1. Have you ever been told you have or had a lung disease?

2. Do you usually cough first thing in the morning?

3. Do you usulally ronugh dusing the day or at night?

4. Do you usually bring up any phlegm first thing in the morning?

5. Do you usually bring up any phlegm during the duy or at night?

6. Are you ever short of breath? When?

a. Hurrying on level ground?

b. Walking up a slight hill?

c. Walking up your own pace on level ground?

7. Do you ever get wheezing or whistling sounds in your chest?

8. Do you currently smoke tobacco?

a. If yes, how much? packages a day, etc.

b. If no, have you ever previously smoked tobacco?

3. Past Medical History:

1. Did you ever have any serious illnesses? If yes, What and When

2. Did you ever have any operations? If yes, What and When

3. Are you allergic to any foods, medications, or substances? If yes. What

4. Do you take any medications at this time? If so, What

C. Occupational History:

1. Have you ever worked in any of the following:

a. Foundry?

b. Stone quarry or mineral mining?

c. Asbestos mill, processing or handling asbestos?

d. Corton Flex or Hemp mill?

e. In close proximity to other dusts or chemical fumes?

D. Vision:

1. Do you need corrective lenses to see?

2. Are they needed for reading?

3. Do you have bifocal lenses?

4. Was your last eye examination within two years?

E. Cardiac History:

1. Have you ever had high blood pressure?

2. Have you ever been told you had heart disease?

3. Have you ever had a heart attack?

If so, When

F. Hesat H. Heart

G. Thyroid and Neck I. Lungs

Employee's Signature 
Name_- SS\#

A. Has there been any significant change in your health since the last exam? If so. what type of change?

B. Have you ever had any tests involving radioisotopes?

C. Have you ever been or had a tendency to be claustrophobic?

D. Are you taking any medication at present? If so, what?

E. Are you a smoker?

Were you a smoker?

If you stopped smoking, when did you stop?

F. Is there any reason you should not be qualified to wear a respirator? If so, what?

G. Have you seen a physician for any ailments, illnesses, or injuries in the past year?$$
\text { year? }
$$

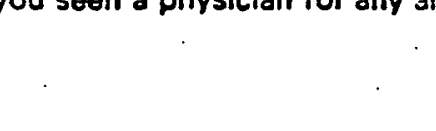


Subject: Physician Respiratory Examination Report

To:

J. K. Venet, R. N.

$\square$ Based on the evidence obtained in this screening, in the examiner's opinion, the following person can wear a respirator or other breathing device while exercising duties, subject to successful completion of a respirator training program.

Name:

6. 6. No.

Date:

Company:

$\cdot$

$\square$ The above named individual is disqualified from wearing a respirator at this time due to the following reason(s).

Doctor:

Date: 
The following procedure is to be utilized during heat stress susceptibility tesing conducted prlor to contalnment entries. By ensuring that all personnel use the same technique, our results should remain consistent.

1. Only workers wearlng complete wetsults (full tops and bottoms) should be monitored for heat stress.

2. The worker should be instructed to walk through the TMI Unit II Turbine Bullding at a comfortable pace for one hour while wearing the following protective clothing:

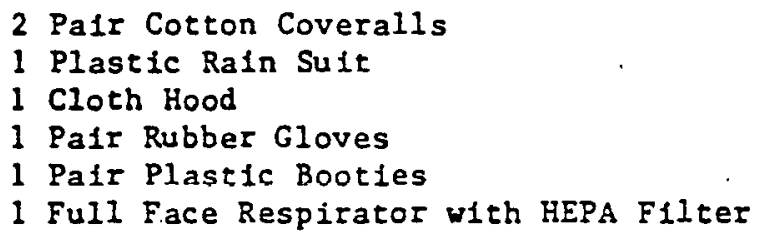

3. Upon completion of the exercise, the worker should be instructed to remove all protective clothing down to the first set of coveralls. The first set of P.C.'s should be unzipped to allow heat to escape. Removal of boots is not necessary.

4. When the worker has finfshed the desulting phase outlined in Item 3 , he should then be instructed to sit down and the oral thermometer should be inserted. This starts the three-minute clock.

5. The pulse rate should then be taken during the last 30-second period of each of the three minutes. These readings will be labeled $P_{1}, P_{2}, P_{3}$.

6. At the end of the three-minute perlod, the oral thermometer should be read.

7. The following criteria shall be utilized in determining if the worker has adequately recovered from the heat stress incurred.

\begin{tabular}{r|r|r} 
ORAL TEMPERATURE & $\mathrm{P}_{1}-\mathrm{P}_{3}$ & ACIION REQUIRED \\
\hline Less than 100.4 & Greater than or equal to 10 beats/min & Qualifies - :in1mal Strain Incurrei \\
Less than 100.4 & Less than 10 beats/min & Qualifies - No Time Extensions \\
Greater than 100.4. & Greater than or equal to 10 beats/min & Qualifies - :o Time Extensions \\
Greater than 100.4 & Less than 10 beats/min & Disqualified from Task
\end{tabular}


8. Heart rate recovery criteria of 10 BPM assumes a $P_{3}$ greater than 90 BPM. $\mathrm{A} \mathrm{P}_{3}$ of less than $90 \mathrm{BPM}$ indicates no significant strain and a $10 \mathrm{BPM}$ recovery would not be expected.

9. When a worker's oral temperature exceeds $100.4^{\circ} \mathrm{F}$ and the pulse does not recover by $10 \mathrm{BPM}$ during the three-minute perlod, it means that he is not qualified to perform work in the Containment Bullding while wearing a wet sult.

10. Extremely abnormal conditions, 1.e, temperature greater than $101.5^{\circ} \mathrm{F}$ or a heart rate above 120 BPM 10 minutes after being undressed, shall be brought to the attention of the Health Services Administrator.

11. When warm weather arrives the duration of the exercise w11l be adjusted, based on temperatures in the Turbine Building. 
ATTACHMENT 4

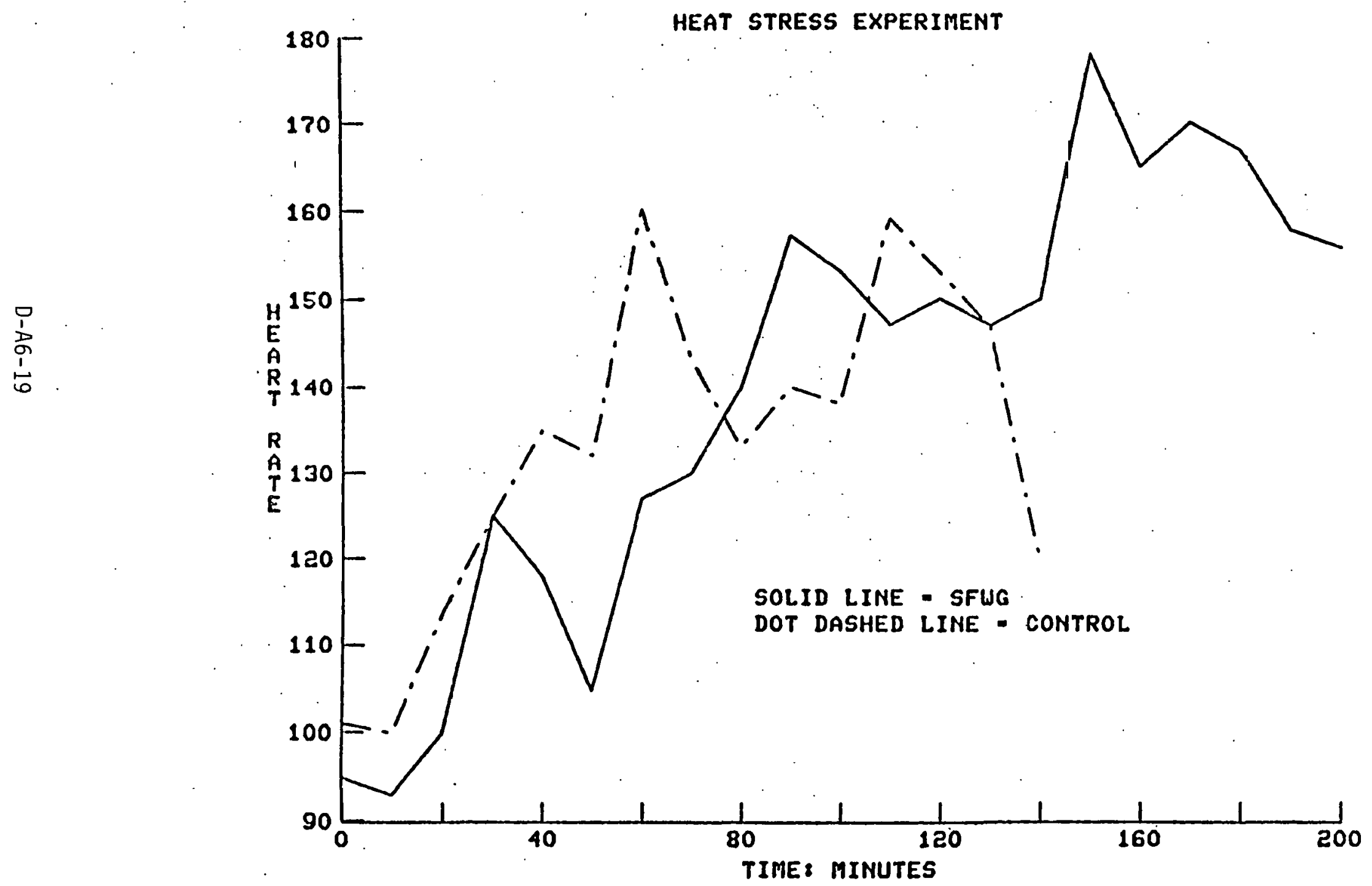




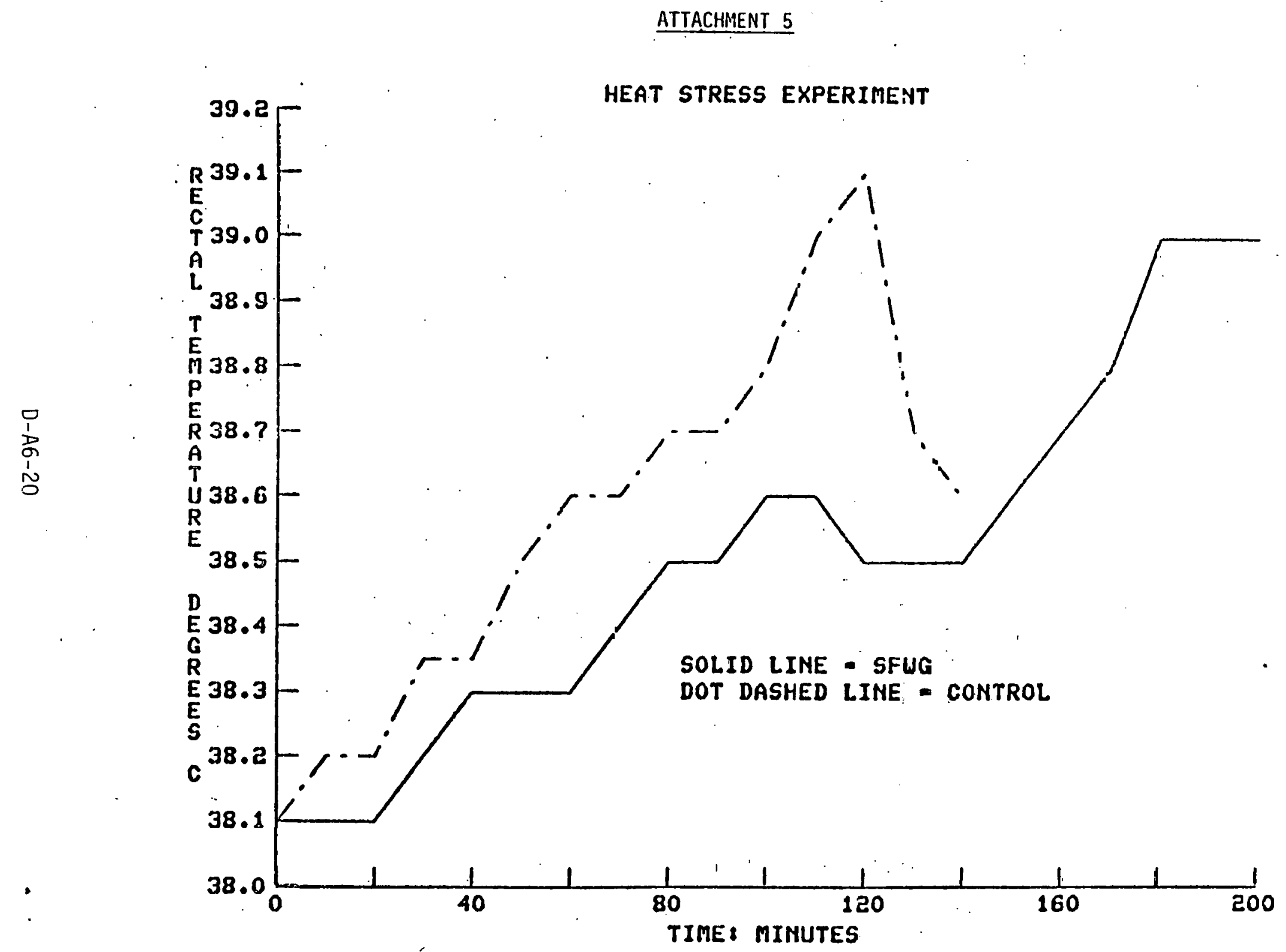


$\because:=$

ATTACHNENT 6

HEAT STRES: EXPOSURE

These requirements estabilish work tine guidelines for workers exposed to hot enviroments before a rest period is given for rccovery from heat stress.

Work time guidelines reflect the actual tirie protective clothing and/or respiratory protection are worn while performing work assignments and does not include suiting up, unsuiting or going to and/or from the work loration. Breaks should follow exposure to heat stress. Duration of breaks, extent of clothing removal, and the area where breaks are taken, shall be at the discretion of supervisory personnel.

The following definitions apply:

ANTI-C'S

IMPERMEABLE CLOTHING

RESPIRATORY PROTECTION

SUFPLIED AIR HOOD OR SUITS

TEMPERATURE
Papei or cotton coverails, cotton liood,. rubber boots, and gloves.

Rain, suits, water resistant clothing. Negative pressure full-facepiece respirator, SCBA or supplied-air reciirator.

Hood or suit with at least 6 cubic feet per minute continuolis ajr flow.

Ambient temperature at a relative humicity of $75 \%$ at the work location.

If an extension of the work time guidelines identified herein is reiuired, due to the nature or criticality of the task being peiformed, permission must be obtained from the supervisor in charge of the job.

Employee heat stress triefing, when required; should be arranged through and provided by the Site Safety \& Health Department.

When work is planned in hot environments where relative humidities are known to be greater than $90 \%$, the schedule for Anti-C's under Imperineabie Clothing with Respiratory Protection shail be ut1lized.

When temperatures exceed $120^{\circ} \mathrm{F}$ or where hot radiant heat surfaces are entcountered, direction shall be provlded by the Supervisor - Safety \& Hedlth for personal protective equipment.

When an individual feels discomfort from heat stress, he/she must immediately notify the person in charge and leave the area. 


\section{PROTECTIVE EQUIPMENT}

Conventional Work

Clothing

Anti-C's (only)

$A-i=C$ - $s$ under

Impermeable Clothing

Anti-C's (only) with

Respiratory Protection

Anti-C'E under Impormaablo

Clothing with Respiratory

Protection

Anti-C's with or under

Supplied. Alr Hood/Sult
TEMIIIRATURE

Less than $100^{\circ} \mathrm{F}$

$100=110^{\circ} \mathrm{F}$

$110-120^{\circ} \mathrm{F}$

$$
\begin{gathered}
80-90^{\circ} \mathrm{F} \\
90-.100^{\circ} \mathrm{F} \\
100-110^{\circ} \mathrm{F} \\
110-120^{\circ} \mathrm{F} \\
\therefore \because
\end{gathered}
$$

$$
\begin{array}{r}
80-.90^{\circ} \mathrm{F} \\
90-100^{\circ} \mathrm{F} \\
100-110^{\circ} \mathrm{F} \\
110-120^{\circ} \mathrm{F}
\end{array}
$$

$$
\begin{aligned}
& \text { Less than } 80^{\circ} \mathrm{F} \\
& 80^{\circ}-90^{\circ} \mathrm{F} \\
& 90-100^{\circ} \mathrm{F} \\
& 100-110^{\circ} \mathrm{F} \\
& 110-120^{\circ} \mathrm{F}
\end{aligned}
$$

$$
\begin{array}{r}
70=80 \% \mathrm{~F} \\
80-90 \% \mathrm{~F} \\
90-100^{\circ} \mathrm{F} \\
100-120^{\circ} \mathrm{F}
\end{array}
$$

GUIDELINES

FOR W'ORK T'J:AlES

None

2 hours

45 minutes

3 nours

2 hours

1 hour

30 minutes

1.5 hours

1 nour

30 minutes

15 minute!;

4 hours

2 hours

1.5 hours

1 hour

30 minuten
1 hour

45 minutes

30 minutes
15 minutes
$80-100^{\circ} \mathrm{F}$
4 hours
$100-110^{\circ} \mathrm{F}$
$110-120^{\circ} \%$
2 hourt:
1 hour

$\div$

By:

R. G. Rit thame1

Manager - Industrial Safety \& health 
ATTACHMENT D-7

TRAINING PROGRAM EFFECTIVENESS EVALUATION 
1. Is the objective being accomplished in a reasonable amount of time?

2. Is any work being repeated beçause workers do not understand nr lack ability to perform a task? Do observations of workers from the command center also indicate this?

3. Is feedback on all problems being provided by workers?

4. Are problems a result of poor training?

5. Is a follow-up system used to correct known deficiencies? It is responsive to needs?

6. Is all training conducted against a prescribed standard?

7. Are standards maintained by:

- Control of lesson plan content?

o Use of qualified instructors?

o Periodic monitoring by training administrator?

o Revisions to lesson plans when required?

8. Are periodic audits conducted to evaluate the training system?

9. Is time set aside to develop and improve training standards? 
ATTACIMENT D-8

TRAINING HOURS ESTIMATE BY MANPOWFR SOIRC.F. - 
TRAINING IIOURS ESTJMATE BY MANPOWER SOURCE

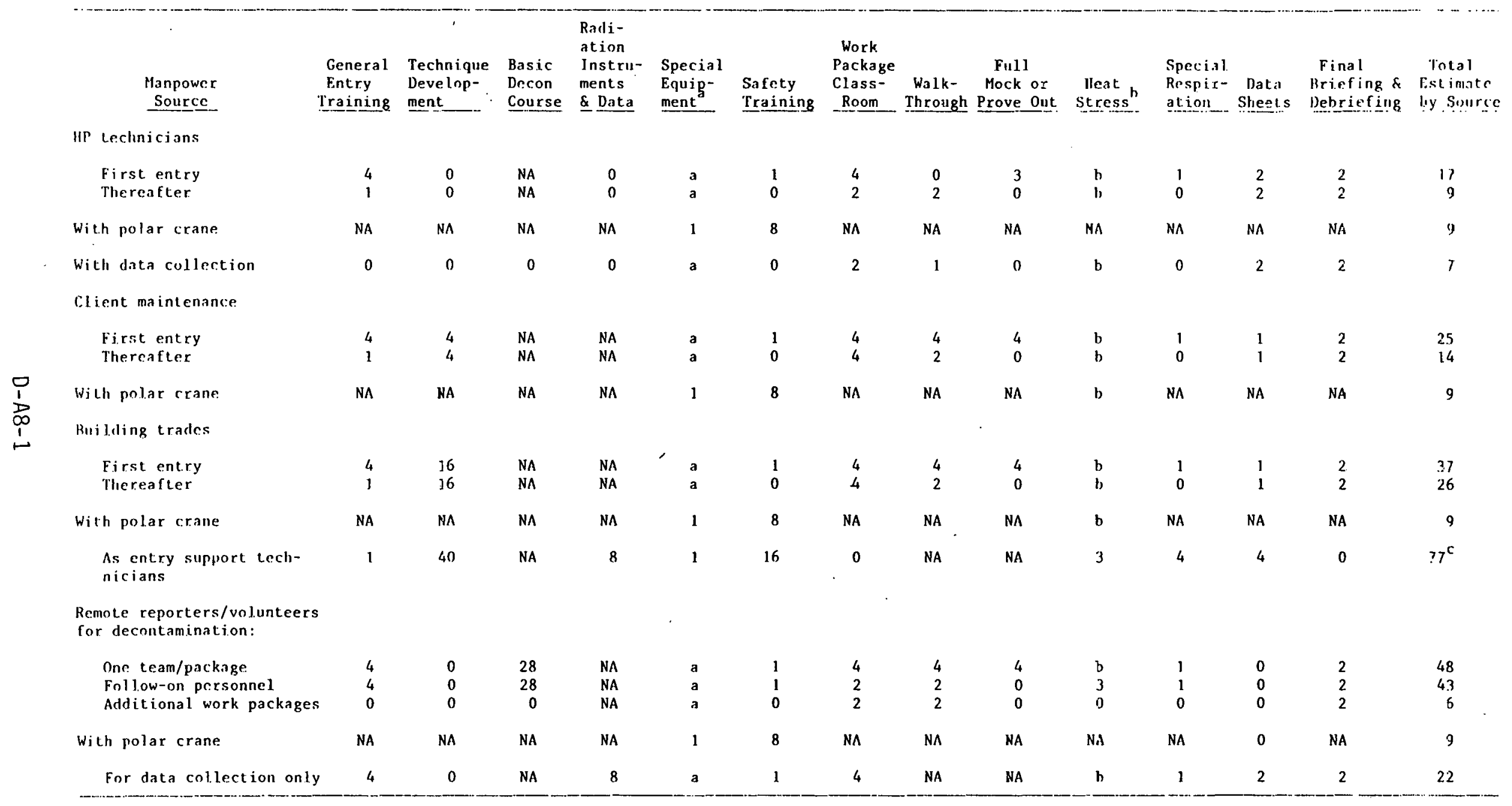


TRATNING hOURS ESTIMATE RY MANPOWER SOURJE (Continued)

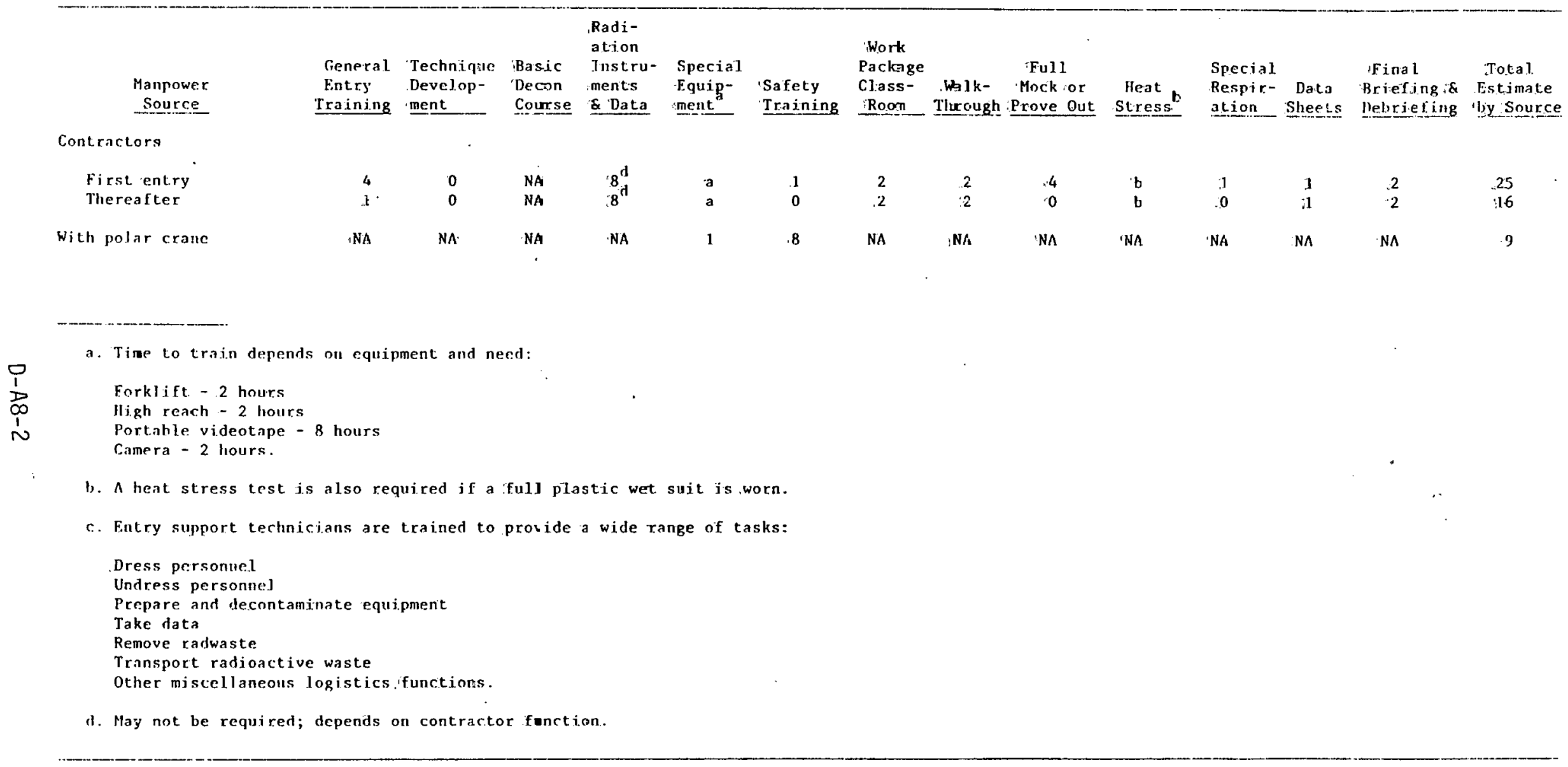




\section{DO NOT MICROFILM \\ b. THIS PAGE}




\section{APPENDIX E}

ORGANIZATION AND SUPPORT 
CONTENTS

ORGANIZATIONAL RESPONSIBILITIES

$E-1$

APPROVAL, PLANNING, AND EXECUTION OF THE

DECONTAMINATION EXPERIMENT

$E-3$

PROCEDURES AND OPERATING INSTRUCTIONS WRITTEN

TO SUPPORT DECONTAMINATION

$E-5$

ENGINEERING CHANGES TO SUPPORT DECONTAMINATION

$\mathrm{E}-8$

SPECIAL SUPPORT EQUIPMENT

E-9

RADIOLOGICAL CONTROLS DEPARTMENT SUPPORT

$\mathrm{E}-12$

UNIT 2 OPERATIONS AND MAINTENANCE DEPARTMENT SUPPORT

E-16

INDUSTRIAL SAFETY AND HEALTH DEPARTMENT SUPPORT

$\mathrm{E}-17$

BUILDING TRADES

E-19

ATTACHMENTS

E-1 ORGANIZATIONAL INTERFACE FOR OVERALL DECONTAMINATION EXPERIMENT

E-2 ORGANIZATIONAL INTERFACE FOR DECONTAMINATION TASKS

E-3 BNOC PROJECT CONSTRUCTION ORGANIZATION

E-4 WORK PACKAGE PLANNING AND EXECUTION SEQUENCE BY BNOC CONSTRUCTION

E-5 ACCESS TO AND WORK PERFORMED IN THE CONTAINMENT BUILDING

E-6 CASUALTY PROCEDURE FOR HIGH RADIATION CONDITION IN-CONTAINMENT

E-7 CASUALTY PROCEDURE FOR FIRE IN-CONTAINMENT

E-8 CASUALTY PROCEDURE FOR PERSONNEL INJURY OR SICKNESS IN-CONTAINMENT 
APPENDIX E - ORGANIZATION AND SUPPORT

ORGANIZATIONAL RESPONSIBILITIES

An outline of the various organization responsibilities follows.

Client (GPU)

o Review and approve all work scope, finding, and milestone schedules

- Maintain license regulatory responsibilities for radiological protection and technical specification compliance to include:

- Radiological controls

- Radiological engineer

- Dosimetry

- Respiratory protection

- Site sample analysis

- Approval of procedures

- Operations Department assistance and interface

- Maintenance Department assistance and interface

- Radwaste handling and shipping

- Industrial safety and health 
- Propose research tasks

- Fund those tasks approved

- Supply contracted equipment and services

\section{Technical Planning and Guidance (BNI)}

- Define data acquisition program tasks

- Issue decontamination tasks and sequence plan through GPU

\section{Prime Contractors for Recovery}

\section{Engineering (BNoC)}

- Provide engineering required for support system

- Procure material

- Provide technical guidance to Project Construction Group 


\section{Project Construction}

- Execute the decontamination plan

- Ensure safe operations

- Install services and support systems

- Coordinate and schedule entries

APPROVAL, PLANNING, AND EXECUTION OF THE DECONTAMINATION EXPERIMENT

Approval and Funding for Scope of Work

After a scope of work was negotiated, review, approval, and funding of the Decontamination Experiment proceeded as illustrated by Attachment E- 1 .

\section{$\underline{\text { Planning }}$}

Individual decontamination and data acquistion tasks were planned through the preparation and approval of data acquisition sample packages. The overall plan required testing of several decontamination methods and equipment. Plans took into account the lessons learned from the previous decontamination experiments of containment entries 4,5 , and 10 .

The organizational interface and sequence for these tasks are represented in Attachment E-2. Following receipt of the sample packages, Engineering 
Change Memorandums (ECMs), or other forms of technical direction, BNoC Construction drafted work packages for execution.

\section{$\underline{\text { Execution }}$}

The BNoC Project Construction Urganization is illustrated by Attachment E-3. The responsibilities of the various groups within the organization, under the direction of the Ficld Construction Manager, were outlined as follows :

- Field Engineering was responsible for work packages and procurement associated with the installation of special equipment and related services.

- Cost and Schedule tracked all funding-related information and issued the following schedules:

- Milestone schedule

- Two-week look-ahead cchedulc

- Daily entry schedule

- The Containment Access Group was responsible for the overall conduct of entries. It provided review, training, processing, and approval functions for each work package.

- The Decontamination Group was responsible for writing and carrying out all Decontamination Experiment work packages not otherwise assigned to Field Engineering.

$$
E-4
$$


- The Contracts Coordinator was responsible for coordination of building trades personnel. This included review of all affected work packages and related techniques.

\section{Work Package}

The work package planning and execution sequence is illustrated by Attachment E-4. In the course of the experiment, about 62 work packages were executed using this process between entries 17 through 56.

PROCEDURES AND OPERATING INSTRUCTIONS WRITTEN TO SUPPORT DECONTAMINATION

Several procedures were required to support the decontamination experiment.

These procedures include the following:

o Containment Access Procedure

- Containment casualty procedures for high radiation exposure, fire, and personal injury or sicknese

- Radiological and safety evaluation

- Special operating procedures for the decontamination service systems and testing of the fire water system

- Test procedure for decontamination service penetration R-561

o Operating instructions for decontamination systems 
All procedures had to be approved prior to commencement of the affected entry.

\section{Containment Access Procedure}

The Containment Áccess Procedure is included in Attachment E-5. This procedure provided all administrative controls for entry implementation, including:

- Entry schedules and approvals

- Limitations and precautions

- Upgraded fire protection requiremente

- Command center organization and responsibilities

- Requirements for casualty procedures

- Control room interface

\section{Casualty Procedures}

Casualty procedures are included as Attachments E-6 through E-8. These procedures supplemented existing site procedures for the three casualties covered. Responsibilities for a projected casualty were assigned to:

- Command center

- Anteroom 
o Entry teams

- Control room

o Other support personnel

\section{Radiological and Safety Evaluation}

This document was prepared by BNoC Project Engineering. It evaluated the planned activities of the Decontamination Experiment for impact in the following areas:

o Effluents released to the environment

o Occupational exposure (man-rem estimate)

- Radioactive waste management

- Industrial safety

- Nuclear safety evaluation in accordance with 10 CFR 50.59 


\section{Other Procedures and Instructions}

Special operating procedures were temporary in nature and were written whenever a temporary rather than permanent procedure was required. Examples include:

o Operating plant system interface valves in a temporary system, such as decontamination water and its connection to penetration $R-561$

- Post-installation test procedures for new systems

- One-time tests on permanent plant systems, such as the post-acicident operability test performed on the containment fire water system

Operating instructions were prepared by BNoC Construction with technical direction from $B N o C$ Engineering. They describe the methods for operation of temporary systems outside the plant system interfacing valves.

\section{ENGINEERING CHANGËS TO SUPPORT DECONTAMINATION}

Several ECMs were written by BNoC Project Engineering and approved for installation. They include:

- ECM $950 \quad 120 \mathrm{~V}$ service at elevations $305^{\prime}$ and $347^{\prime}-6^{\prime \prime}$

- ECM 951 Support structure for aerial work platform

- ECM 952 Electrical supply for aerial work platform 
- ECM 958 Electrical supply to hot water heater

- ECM 960 Containment penetration for radio equipment

- ECM 963 Containment penetration for high pressure water supply

- ECM 964 Electrical supply to high pressure pump

- ECM 975 Alternate to electric supply for hot water heater

Installation of these ECMs was required prior to the commencement of flushing operations.

\section{SPECIAL SUPPORT EQUIPMENT}

Several types of special equipment were brought into the containment or installed as part of the experiment. These items include:

- Spider work platform

- New radio system

- High reach scissors lift work platform

- Forklifts

- Elevation 347-6" lifting service 


\section{$\underline{\text { Spider Work Platform }}$}

This is an clectrohydraulic device capable of lifting two to four personnel or 1100 pounds of equipment from elevation 347'-6" to the polar crane walkway at elevation 426'. The installation of this device was necessary to provide rapid ascent and descent of workers and to allow for safe decontaminaLiun of the polar crane. Plans to expand the lifting capability to include elevation 305' were not completed. Ascent time to the crane from elevation 347-6" was about 4 minutes; climbing took about 20 minutes. Skin contaminations resulting from use of the climbing technique were significantly reduced after the lifting device was installed. In addition, crane working time was extended about 1 hour per man as a result of time and endurance savings.

\section{New Radio Systems}

During the experiment an attempt was made to install an improved radio system. The proposed system offered several functional improvements and greater reliability, and prnvided rlear rereption in preliminary tests. It operated at a lower power level and could be worn inside protective clothing. Installation in the containment required additional antennas to be installed at penetration R-bU/, with the remaining equipment being placed uulside lle containment. After the antenna installation was complete, several tests were conducted with the following general results:

- Reception in the containment was satisfactory in all areas tested:

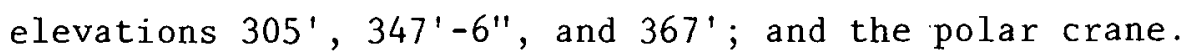

o Reception in the command center varied from satisfactory to unacceptable, depending on the location of the individual. Areas near R-507 
( 40 percent of elevation $305^{\prime}$ and 25 percent of elevation $347^{\prime}-6^{\prime \prime}$ ) were satisfactory; the remaining areas appeared as "dead spots" with no reception at all.

- In-containment reception was improved with linear amplification of the command center signal; returning signals were unamplified and attenuated by the containment structure.

o Subsequent operations during the experiment were performed using the existing radio system.

- Decontamination operations were impacted by use of the existing radio system. The radio problems increased the number of man-hours by approximately 5 percent. In addition, a loss of decontamination coverage or "holidays" occurred in the surface decontamination because of the frequent and inaudible radio transmissions, which resulted in interrupted work.

\section{High Reach Scissors Lift Work Platform}

This is a self-propelled, battery-operated access platform with a maximum platform height of 15 feet which was placed in the containment for use during the decontamination test. The platform had an integral battery charger and a battery capacity of 250 amp-hours. The platform moved at 5 miles per hour when lowered below 10 feet and at 2.5 miles per hour when fully extended. The platform was controlled either by an operator on the platform or from the ground, and when fully lowered, it was 41 inches above floor level. The platform had a lifting capacity of 750 pounds and an overreach length of 2.5 feet.

The platform was used on several occasions to work on or to inspect areas where scaffolding would normally have had to be installed. 


\section{Forklifts}

Two forklifts were purchased for use in the experiment. They are batterypowered and self-propelled with a 4000-pound lifting capacity. One unit was placed in the containmenl. The other unit was used in the anteroom and for training. The forklifts were used successfully to move lead and other heavy ob.jects into the cont.ainment.

\section{Elevation $347^{\prime}$ Lift Device}

I'his unit was designed and fabricated on site by BNoC Construction. It is a multipurpose frame device capable of lifting dcck plates, grating, or other objects that weigh up to 1500 pounds. A lead counterweight provides stability, and the device is mounted on wheels for greater mobility. Less human effort is required to lift loads as a result of the installation of a "tugger" electric winch which raises loads slowly by electric power. Lifting speed is about 15 feet per minutc. The lift device was carried into the containment in subassemblies and put together on elevation $347^{\prime}-6^{\prime \prime}$.

BADIOLOGICAL GONTROLE DETARTRENT SUPPORT

The Radiological Controls Department was responsible for compliance with regulations affecting radiation protection. The following sections describe interfaces and responsibilities within the department related to the Decontamination Experiment. 


\section{$\underline{\text { Radiological Engineering }}$}

Radiological Engineering was responsible for ensuring that when work was done in radiation areas the resulting exposure is as low as reasonably achievable (ALARA). For containment entries, the following tasks were required:

o Conduct ALARA review of each Radiation Work Permit (RWP)

- Specify and coordinate required dosimetry

- Specify when radiological hold points, measurements, or samples were required

- Track entry radiological data for trends

- Specify follow-up action for radiological problems

- Write radiological procedures

- Track radiological exposure by assignment of ALARA review number and use of computer system

\section{Radiological Field Operations}

Radiological Field Operations, through the use of health physics (HP) technicians, was responsible for identifying radiological conditions throughout the plant and for providing radiological coverage when required by the RWP. The following tasks were required:

- Administer RWPs, including screening individuals for the necessary qualification prerequisites 
- Provide entry HP technicans for initial air sample analyses of particulate matter and tritium, as well as general surveys of all containment areas when radiological conditions were not known or were expected to change; provide HP technicians to obtain tritium samples during flushing operations

- Support HP technicans to conduct briefings and monitor RWP control point and anteroom

- Support HP technicians to inspect, issue, and decontaminate the following radiological support equipment:

- Radiological eurvey inctrumente

- Air sampling devices

- Dosimeters

- Breathing zone air sampler

- Other miscellaneous support items

- Control issue of keys to high radiation areas

- Perform requested radiological surveys to support movement of trash, equipment, and samples

- Escort radioactive material when required

o Perform routine radiological surveys of anteroom, decontamination room, dressing area, and training area 


\section{Dosimetry}

Dosimetry was responsible for the following tasks:

- Issue and read thermoluminescent dosimeters

- Track exposure histories

- Record bioassay results

- Record whole body count results

\section{$\underline{\text { Respiratory Protection }}$}

Respiratory Protection was responsible for the following tasks:

- Issue respiratory training standards

- Supply and decontaminate respiratory devices

o Issue and monitor radiological procedures related to respiratory protection.

\section{Command Center}

Command center representation was maintained by the Containment Access Procedure, Attachment E-5, Section 4.4.5.3. 
UNIT 2 OPERATIONS AND MAINTENANCE DEPARTMENT SUPPORT

For the Decontamination Experiment, operations or maintenance technicians or supervisors were provided through a group coordinator on an individual task basis.

\section{Operations}

The related duties for Operations include:

- Chair and publish the Plan of the Day, which scheduled and set priorities for all site activities

- Carry out required containment plant surveillance activities through BNoC Project Construction

- Provide plant operator for decontamination water and service air (special operating procedure)

- Provide plant operators to complete protection of plant equipment

- Operate plant systems

- Control issue of plant keys through the shift supervisor/foreman

- Perform air lock leak tests, as required

o Comply with other Technical Specifications, as appropriate

- Direct emergency actions 
- Provide an Operations supervisor for entries, as required by Attachment E-5, Section 4.4.5.4

\title{
lainlenance
}

The related duties for Maintenance include:

- Repair or replace plant system components

- Provide maintenance and improvement program for closed-circuit television system (CCTV)

o Provide instrumentation and controls shop support for command center electrical equipment, radios, and portable CCTV hardware

- Provide temporary services system for plant tie-in installation

- Provide services to the Decontamination Group for decontamination of tools and equipment; provide radwaste disposal and interim radwaste storage support

\author{
INDUSTRIAL SAFETY AND HEALTH DEPARTMENT SUPPORT
}

The Safety Department was responsible for or assumed the duties for the following during the Decontamination Experiment:

- Screen incoming personnel for respiratory qualifications

- Specify safety requirements necessary to support work packages 
- Administer the heat stress test in accordance with the published requirements contained in Attachment D-6 (Heat Stress Control Program) of Appendix D, Training and Safety

- Publish training standards and lesson plans for safety issues; provide or qualify instructors to teach safety procedures

- Herfórm salety inspeclions

o Write safety procedures

- Supply safety equaipineint

- Conduct body-cooling experiments and other development programs to improve entry performance

- Supply industrial hygiene equipment, such as oxygen/combustible gas monitors

- Provide paramedis when needed

The command center was manned by a Safety Representative as required by Attachment E-5, Section 4.4.5.6.

During entry 53, the Safety Department supplied three personnel to perform the mechanical floor scrubber test. Their participation was part of a controlled experiment to measure the benefits of the ice jacket for body cooling. In several other entries, the Safety Department supplied inspectors or safety escorts for installation of the spider work platform. 


\section{BUILDING TRADES}

The building trades provided manpower for technique development and work package execution for installation and repair services. The following sections outline the experiment contributions by trade.

\section{Laborer}

The laborer trade supplied in-containment manpower for trash removal, data taking, equipment movement, and other miscellaneous tasks.

Out of containment, the laborers served as'support technicians for a variety of tasks, including:

- Maintain training area and dressing area cleanliness

- Stock consumable materials

- Stage and move equipment

o Support training

- Dress personnel

- Unsuit personnel in anteroom

- Prepare equipment for entry into containment

- Decontaminate equipment and anteroom 


\section{Ironworker}

The ironworker trade supplied manpower for the following:

o Spider work platform installation and maintenance

- Rigging services

- Fabrication of equipment

\section{Carpenter}

The carpenter trade supplied manpower for the following:

o Installation of high reach work platform and forklift

- Rigging services

- Trash removal

- Scafffolding

- Out-of-containment fabrication and construction, including contamination control corridor, air lock mock-up, and other support facilities 


\section{Electrician}

The electrician trade supplied manpower for the following:

- Spider work platform electrical installation and maintenance

- Electrical component replacement

- Polar crane inspection 
ATTACHMENT E-1

ORGANIZATIONAL INTERFACE

FOR

OVERALL DECONTAMINATION EXPERIMENT 
ATTACHMENT E-1

ORGANIZATION INTERFACE

FOR OVERALL DECONTAMINATION EXPERIMENT

APPROVAL, FUNDING, AND MILESTONE SCHEDULE

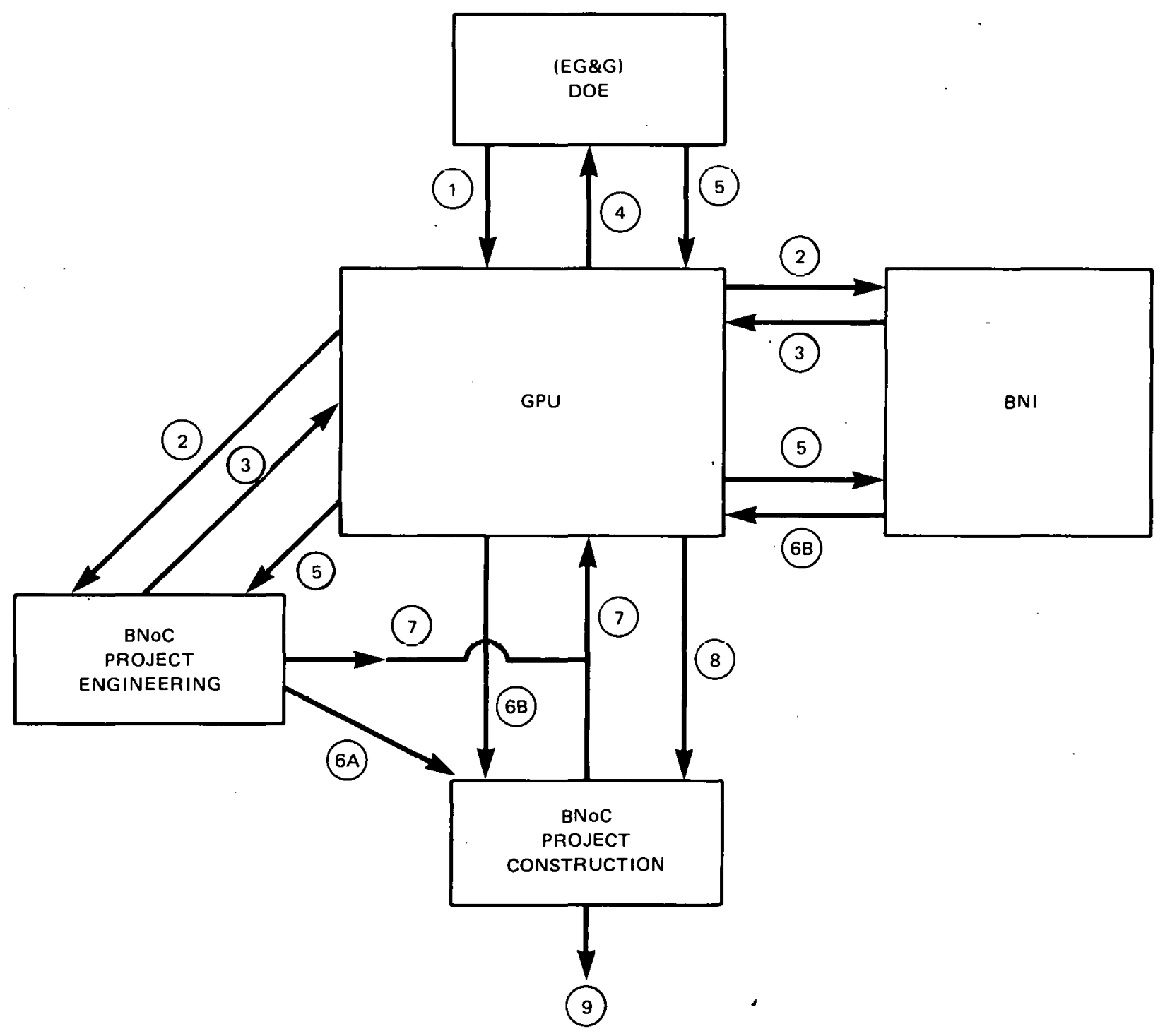
(1) PROPOSAL
(2) REVIEW FOR IMPACT/FEASIBILITY/TECHNICAL CONTENT
(3) RESPONSE TO PROPOSAL BY BNOC/BNI
(4) RESPONSE TO DOE BY GPU
(5) FUNDING AUTHORIZATION AND SCOPE DEFINITION
(6A) TECHNICAL ENGINEERING DIRECTION
6B) SEQUENCE RESTRAINTS FOR DECONTAMINATION PLAN
(7) PROPOSED MILESTONE SCHEDULE
(8) APPROVE MILESTONE SCHEDULE
(9) BEGIN IMPLEMENTATION 
ATTACHMENT E-2

ORGANIZATIONAL - INTERFACE

FOR

DECONTAMINATION TASKS 


\section{ATTACHMENT E-2}

ORGANIZATION INTERFACE

FOR DECONTAMINATION TASKS

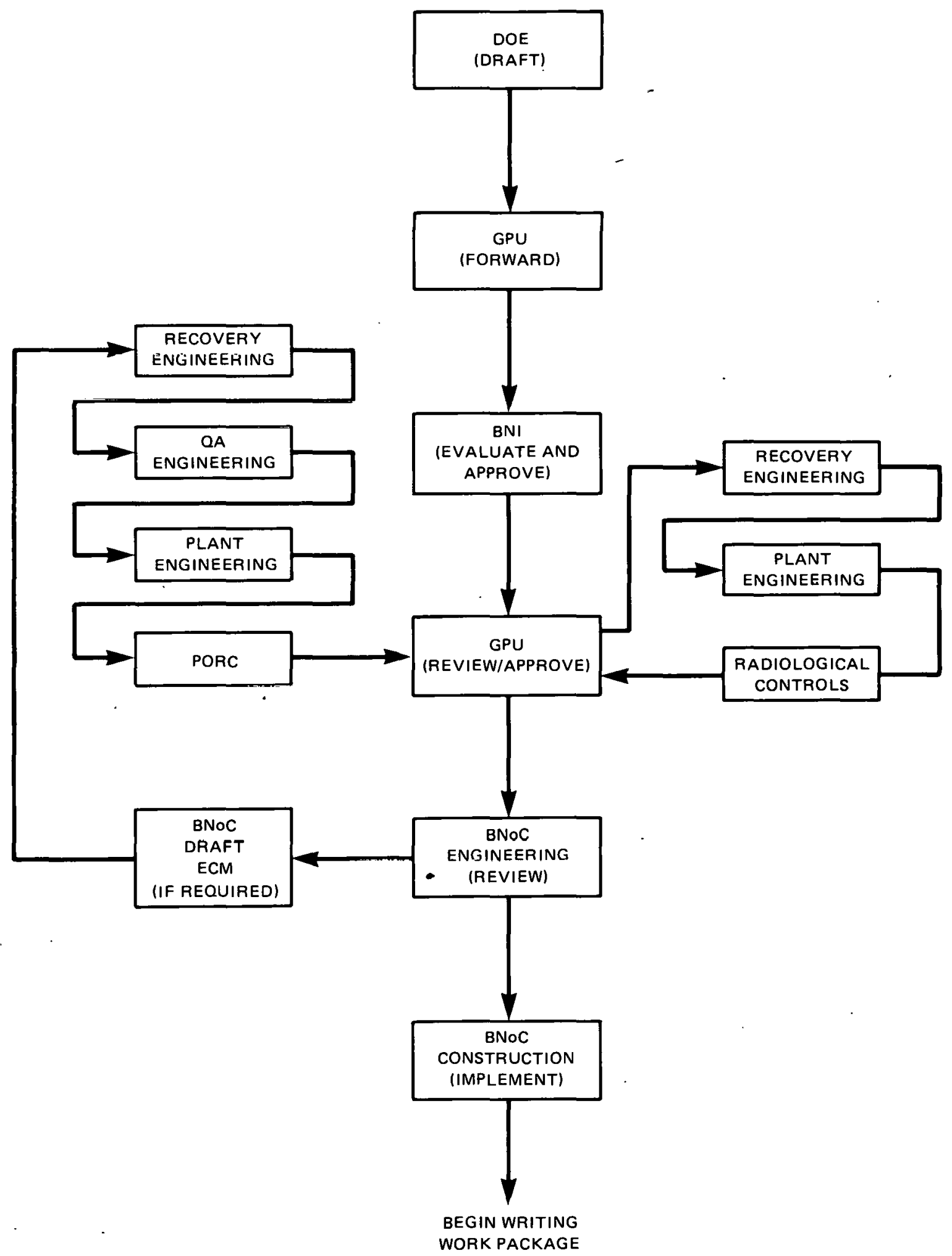


ATTACHMENT E-3

BNOC PROJECT CONSTRUCTION ORGANIZATION

$\checkmark$ 


\section{ATTACHMENT E-3}

\section{BNOC PROJECT CONSTRUCTION ORGANIZATION}

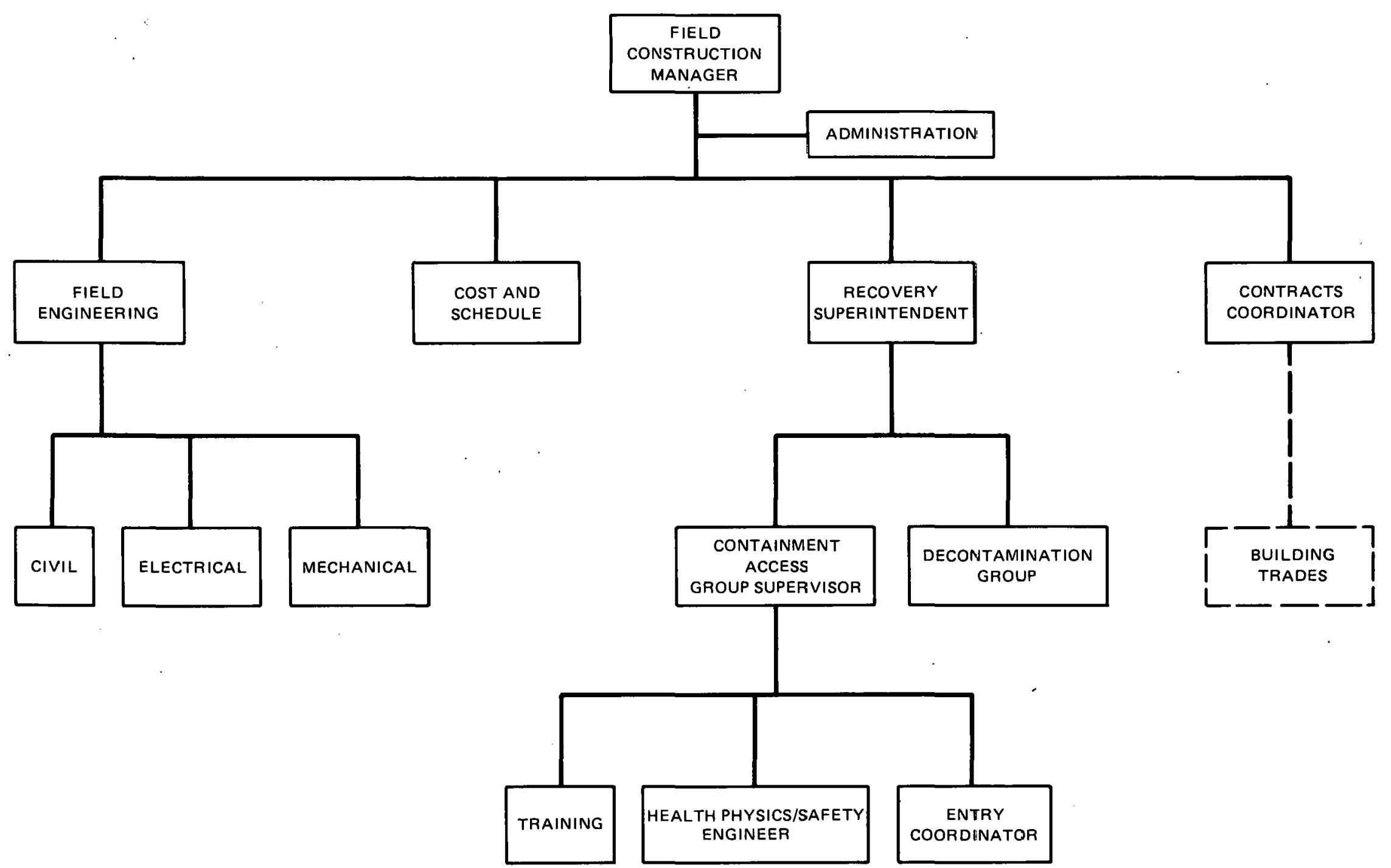


AT'TACHMENT' E-4

WORK PACKAGE PLANNING AND EXECUTION SEQUENCE

BY

BNOC CONSTRUCTION 


\section{ATTACHMENT E-4}

WORK PACKAGE PLANNING AND EXECUTION SEQUENCE BY BNOC CONSTRUCTION

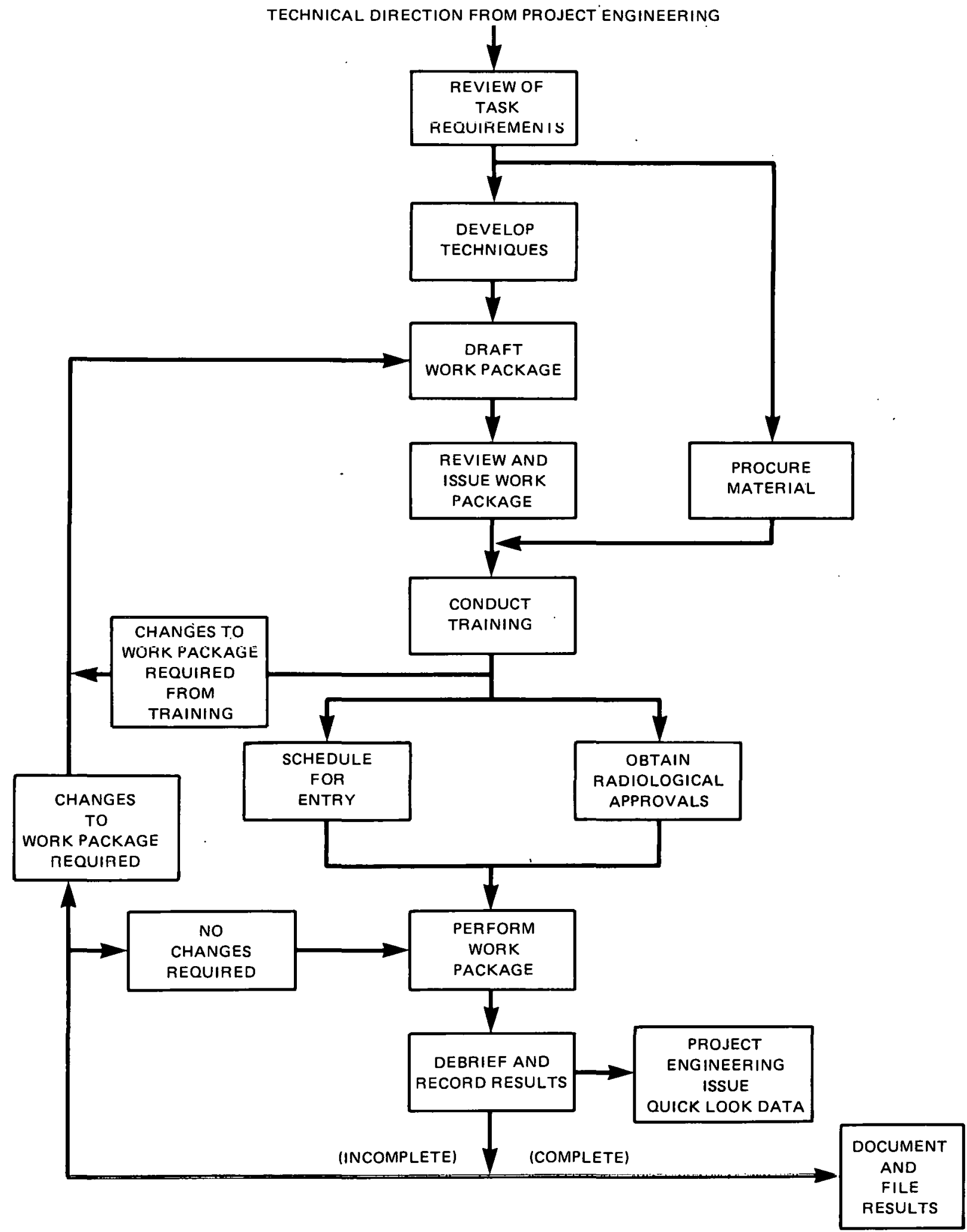


ATTACHMENT E-5

ACCESS TO AND WORK PERFORMED IN THE CONTAINMENT BUILDING 


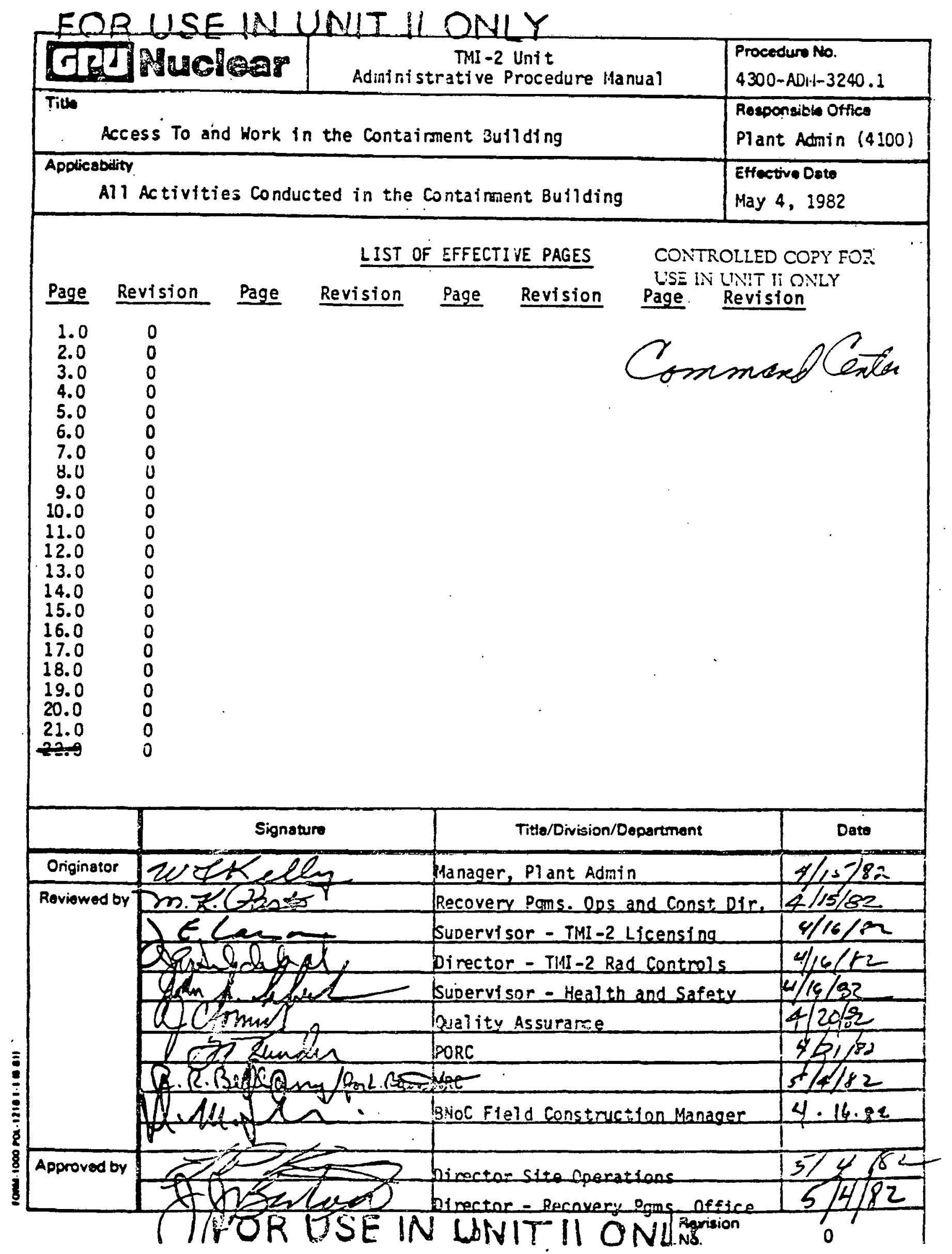

E..A5-1 
Access To and Work in the Contaiment Building

SECTION

TITLE

PAGE

1.0 PURPOSE

4.0 .

2.0 APPLICABILITY/SCOPE

4.0

3.0 DEF INITIONS

4.0

4.0 PROCEDURE

4.0

4.1 Documents and Approvals

4.0

4.1.1 Schędules

4.1.2 GPU Approvals

4.0

4.1.3. In Contairment Activities

5.0

4.1 .4

Unscheduled Entries

5.0

5.0

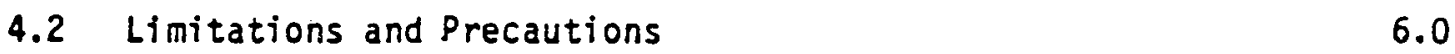

4.2.1 Exposure Rates 6.0

4.2.2 Emergency Lighting 6.0

4.2.3 Minimum Number of Personnel (Polar Crane) , 6.0

4.2.4 Minimum Number of Personnel (Out of Contact) 7.0

4.2.5 Activity Review 7.0

4.2.6 Water for Uecontamination Uses $\quad * \quad 7.0$

4.2.7 Tools and Equipment 8.0

4.2.8 Worker Training 8.0

4.2.9 Digital Dosimeters 8.0

4.2.10 Radiological Controls $\quad 8.0$

4.2.11 Ante - Room Personel 10.0

4.2.12 Containment Building Purging. 10.0

4.2.13 Purge and Stack Effiluent Monttors 10.0

4.2.14 Air Lock Door 11.0

$\begin{array}{lll}4.3 & \text { Fire Protection } & 11.0\end{array}$

$\begin{array}{lll}\text { 4.3.1 Precautions } & 11.0\end{array}$

$\begin{array}{ll}\text { 4.3.2 Requirements } & 11.0\end{array}$

4.4 Pl anning and Implementation 11.0

4.4.1 Scheduling 11.0

4.4.2 Training 13.0

4.4.3 Notification 14.0

4.4.4 Execution 14.0

4.4.5 Conmand Center Organization 15.0

4.4.6 Casuaity Proredires 20.0

4.5 Control Room Interface 20.0 


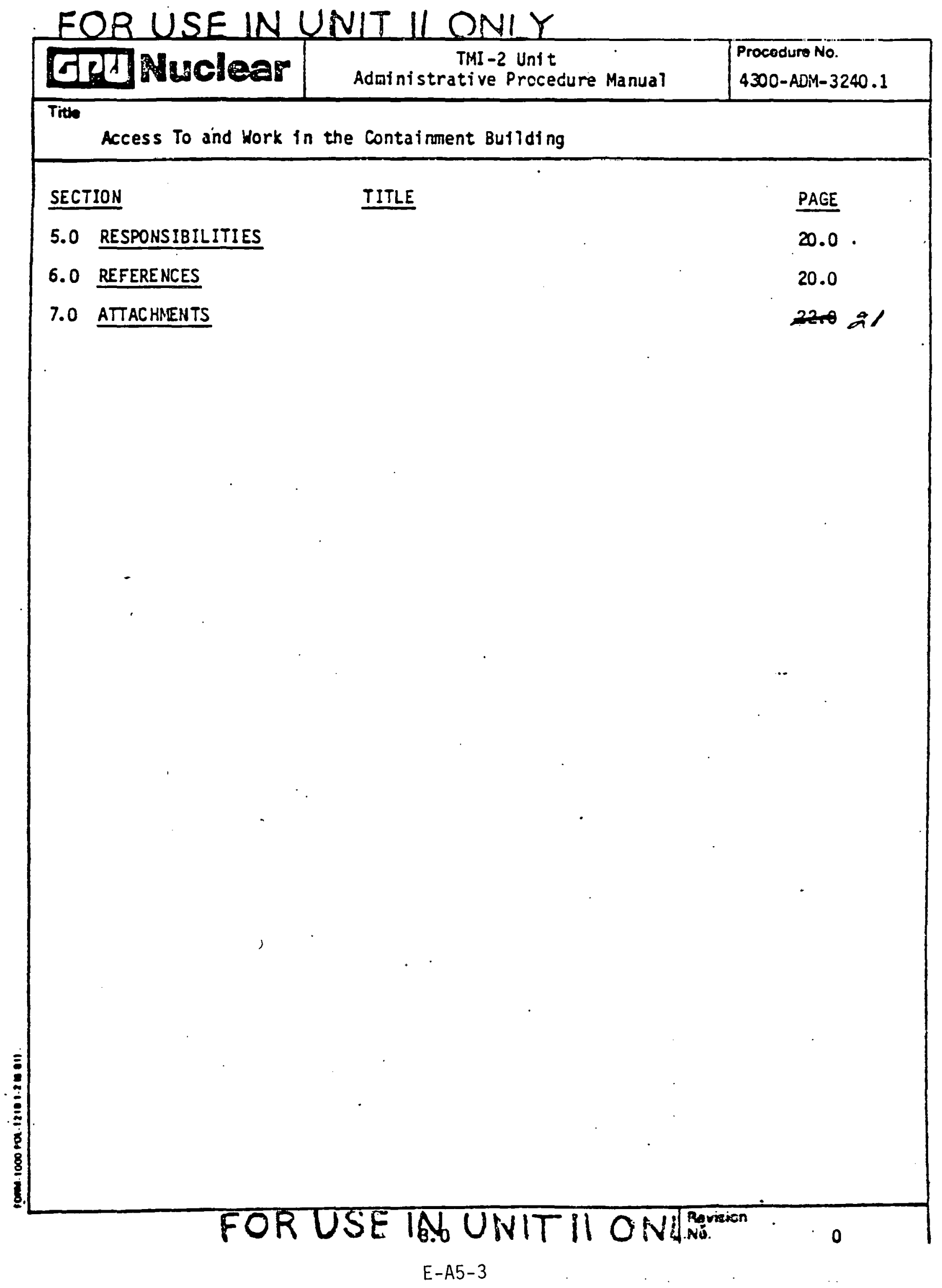




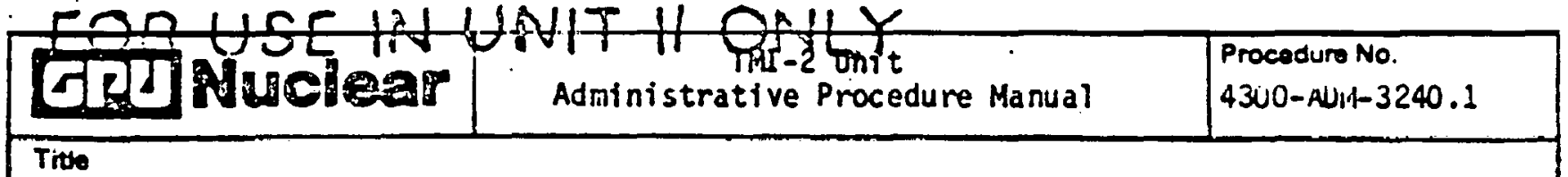

Access To and Hork in the Containment Bufiding

\subsection{PURPOSE}

To describe the procedural requirements which govern access to containnent and work inside contaiment.

\subsection{APPLICABILITY/SCOPE}

2.1 Applicability - This procedure is applicable to all activities conducted in the containment.

2.2 Scope - Activities that fall within the scope of this procedure are:

a. Any activity scheduled in the containment for preparation for or performance of authorized Recovery tasks.

b. Data Acquisition activities.

c. Normal Plant lialntenance, Operations, and Survefllance.

d. Routine Corrective or Preventive Maintenance on specialty equipment in containinent for Recovery or Data Acquisition Tasks.

e. Housekeeping activities in containment.

f. Unscheduled Containment Building entries.

\subsection{DEFINITIONS}

None

4.0 PROCEDURE.

4.1 Documents and Approvals

4.1.1 Schedules

All scheduled activities to be conducted in the Containnent Building shall be incorporated into a Field Sumary schedule (revised monthly) prepared by Bechtel Northern Corporation (BNOC) and approved by the GPU Recuvery Programs Operations and Construction Uirector. GPU approval of the schedule signifies approval to implement the scheduled activities subject to availability of the following properly approved documents where required:

4.1.1.1 Engineering Change Memorandum/Au thorization (ECH/ECA).

4.1.1.2 Haintenance Job Ticket or Preventive Maintenarce Cherk Sheet.

4.1.1.3 Procedure or Work Package.

4.1.1.4 Radiological Enginearing Reviey.

4.1.1.5 Radiation Work Permit (RMP).

\section{FOR USE IAD UNITII ONU}

$$
E-A 5-4
$$




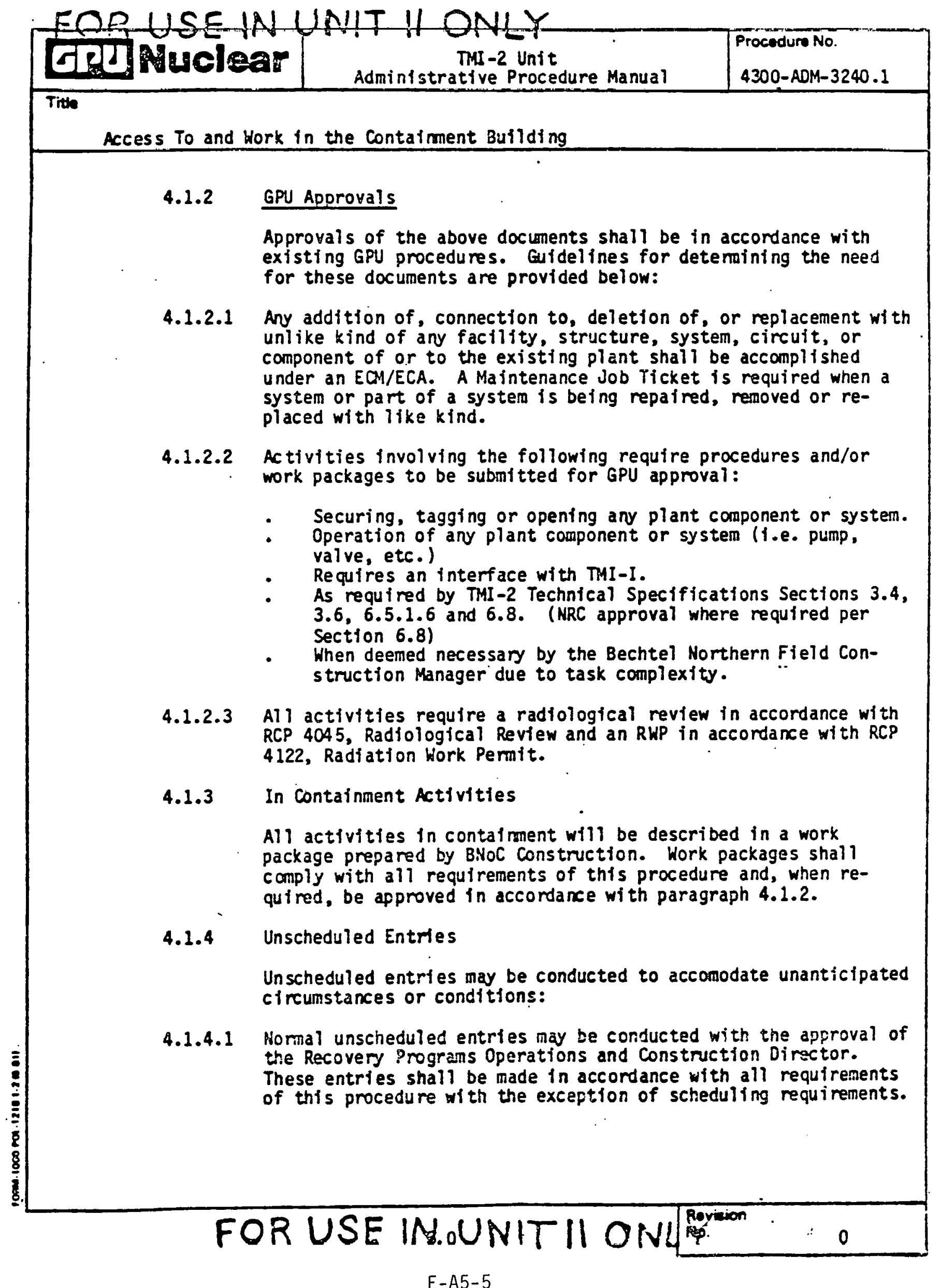




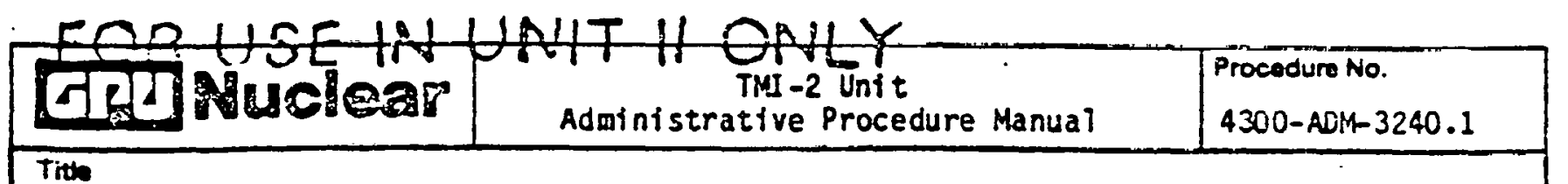

Access To and Nork in the Contaiment Building

4.1.4.2 Expedited entries may be made to obtain data on plant status or to correct plant conditions where there is no immediate jeopardy to personnel or plant safety. The purpose of performing an expedited entry is to reduce the time required to enter containment. The primary concern is personnel safety. Precautions nomally taken to protect personnel and equipment from radioactive contamination and for controlling the spread of radioactive contamination may be reduced with the concurrence of the Radiological Controls Shift Foreman and Radiological Engineering. The description of the activities to be conducted may be included in the RWP instead of in a work package or procedure. All other requirements of this procedure apply except schedu 1ing. Expedited entries require the approval of the Director, TMI -2.

4.1.4.3 Emergency entries may be conducted when there is or appears to be immediate jeopardy to personnel or plant safety. The approva) of the Manager, Plant Operations or the Operations Shift Foreman is required for an emergency entry. All requirements of this procedure are waived for emergency entries. The entry shall be under the direction and control of the Operations Shift Foreman or his designated representative. RCP 4122, Radiation Hork Pemit, requiring Radiological Controls escort applies. At the option of the Operations Shift Foreman, all or a fortion of the Command Center Organization (See Para-graph 4.4.5) may be mobilized to assist in control of the entry. The Operations Shift Foreman is responsible for notifi-cation to the NRC that an emergency entry is being initiated.

Fire emergency entries shall be conducted per 2202-3.1 - Fire.

\subsection{Limitations and Precautions}

In addition to the limitations and specifications included via the formal document review process requlred for each document (See section 4.1), the following shall be applied to all work in contafnent as appropriate:

4.2.1 All personnel will work in an area with the exposure rate set by a qualified Radiological controls technician.

4.2.2 All personnel will be equipped with emergency flashifghts unless emergency ? ighting is ayallable in containgent.

4.2.3 A minimum of three (3) personnel will be on tha polar crane when work is being performed on the crane and the Splder Shafter is not avaliable. Tyo people are regulred with the Spider Shafter ovaliabie. If the Splder Shafter becomes iroperabie while only two persons are on the crane, they snall either descend immediately in accordance with procadure $210 \$-9.2$ or a third persen shall immediately ascend to the crane.

FOR IJSF IAh IINITII TNMThavision 


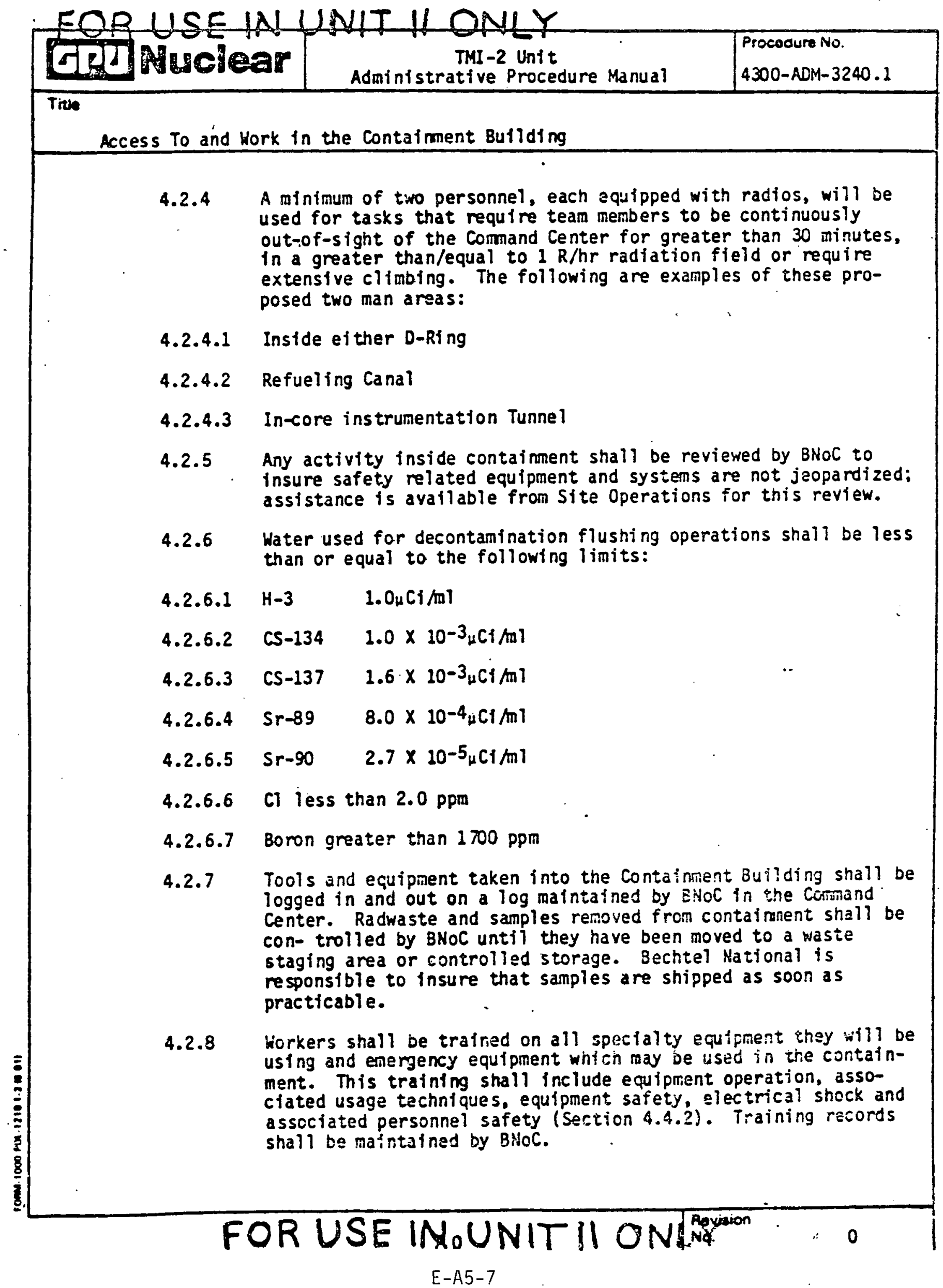


Access To and Work in the Contaiment Butiding

4.2.9 Digital dostmeters will be required for all personnel in containnent under any of the following conditions:

4.2.9.1 Any individual entering containment whose exposure upon entering is greater than 2 rem for the qua rter.

4.2.9.2 Any individual entering containment whose exposure upon entering is greater than 4 rem for the year.

4.2.9.3 Any individual working in an area where dose rates are greater than $1 R /$ hour.

4.2.9.4 Any Individual entering a High Radiation Area shall (a) use a continuousiy indicating dose rate device or (b) use a dose rate integrating device which alarms at a preset dose level or $(c)$ assure that a radiological control technician provides periodic radiation survelllance with a dose rate monitoring instrument. The NRC shall be notified by Radiological Controls if any individual enters the Reactor Building without a dose integrating device which alams at a preset dose level.

In addition, self reading dosimeters will be worn by all individuals entering the containment building.

4.2.10 The radiological controls applied for containment entry shall be in accordance with approved procedures. The applicable procedures include but are not 1 imited to the following:

\subsubsection{Use of Digitals}

RCP 4122 Radiation Hork Pernit

RCP 4123 Self Reader Dosimeter.Usage and Record Keeping

4.2.10.2 Bioassay and Whole Body Count

RCP 4238 Bloassay Program

SOM No.7 Minimum Protective Clothing and Dosimetry

SOM No. 11 Tritium Exposure control

\subsubsection{BZA's}

RCP 4101 Afr Sample Counting, Handling, and Actions

RCP 4104 Air Sampling Procedure

SOH No.7 Minimum Protective Clothing and Dosimetry

Required for Entries into the Reactor Building

\section{FOR USE IN.OUNITII ONL}




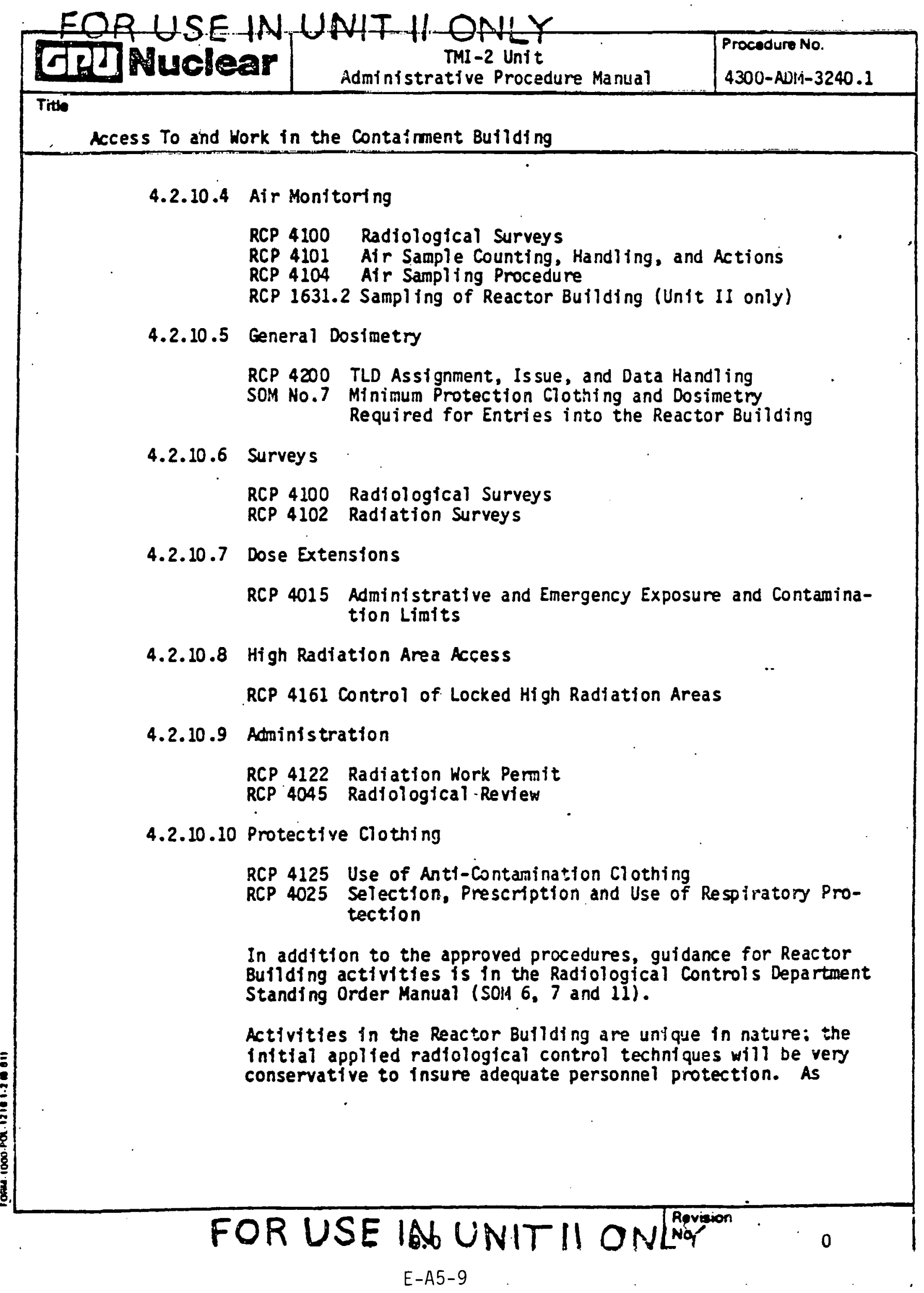


Access To and Kork in the Contairment Building

experience is gained and radiological conditions are changed the Radiological Control techniques will be modified, always insuring the adequate protection of personnel. Because of these changing conditions, a qualified Radiological Controls representative shall be constantly present in the comnand Center monftoring and evaluating the activities in the Reactor Building.

Additionaliy, these changing conditions preclude a comitment to a spectfic radiological control methodology to be applied. Radiological Controls personnel shall appiy the most appropriate techniques in accordance with good radiological control practices. NRC shall be briefed on proposed changes to radiation protection measures in the Reactor Building.

4.2.11 Ante-Room personnel shall be trained for in-containnent personnel assistance activities and will be utilized for personnel assistance where required by personnel in containment. These Ante-Room personnel are imediately avallable for entry when persontel assistance is required. Certain activities may require trained backup teams to be trained, fully dressed and avallable for irmediate entry during in-containment operations. The need for these backup teams will be determined by BNoC on a case by case basis.

4.2.12 Contaiment Bullding purging shall be in accordance with Procedure 2104-4.91, Reactor Building Purge using the Modified Purge System. Engineered features will be used to the maximum extent practicable to minimize airborne concentrations. In the event that the purge system is not available prior to an entry or becomes unavailable during an entry, an evaluation shalt be made by GPUN Radiological controls. If it is decided to continue without punging, the NRC shall be notified by GPUN Radiological Controls. This notification shall be made prior to an entry if an entry is not in progress.

4.2.13 If purging is in progress, Purge and Stack effluent monitors will be operable and monitored during entries with any alanm conditions imediately relayed to the Command Center.

4.2.14 THE OUTER AIRLOCX DOOR CAN BE OPENED ONLY IF THE INHER DOOR IS CLOSED, UNLESS THE INTERLOCK HAS BEEH DEFEATED. Comand Center personnel should be aware of this and provide special attention when only one individual is entering contalnment so that prompt action can be taken in the event of injury. The length of time that the inner door is open should be minimized. 


\begin{tabular}{|c|c|c|}
\hline & $\begin{array}{l}\text { IT IT } \\
\text { Administrative Procedure Manual }\end{array}$ & $\begin{array}{l}\text { Procodure No. } \\
4300-A D H-3240.1\end{array}$ \\
\hline Trite & Contaiment Bullding & \\
\hline
\end{tabular}

4.2.15 When containment a tmosphere is known or suspected to be immediately dangerous to life or health (IDLH atmosphere is any atmosphere that has less than 16 percent oxygen by yolume or any atmosphere that is conbustible or toxic), personnel entering containment shall wear self contained breathing apparatus. If no emergency or casualty is in progress, microphones and earpieces shall be worn for radio comunications. In the case of emergency or casualty, communication equipment requirements shall be based on the available time, available equipment and the task involved; however, some form of communications is required.

\subsection{Fire Protection}

4.3.1. Precautions

4.3.1.1 Transient combustibles shall be minimized and shall be controlled per PIant Procadure AP 1034. Transient combustibles shall be logged into and out of contaiment in the log kept by BNOC in the command Center.

4.3.1.2 Welding, cutting, burning, soldering, etc., shall be controlled per Plant Procedure MP 1410-Y-26. In addition, fire watches will be equipped with radios and in contact with the comand Center.

4.3.1.3 Wood used in contaiment shall be fire retardant treated, preferably the pressure treated type fire retardant. If possible, non-combustible materlals should be used in place of wood.

4.3.1.4. Personnel should be alert for fires and stgns of fire during entries. All fires and signs of fire shall be reported to the command Canter and investigated as soon as possibie.

\subsubsection{Equipment Requirements}

4.3.2.1 Fire extingulshers (4) with an A:B:C rating will be on lightweight, portable racks, two extinguishers to a rack. One rack on $305^{\circ}$ elevation and one on $347^{\circ}$ elevation. There will be additional extinguishers in the Ante-Room and piant extinguishers will also be avallable.

4.3.2.2 If the Contairment Ruilding Fire Detection System is inoperatie, the Reactor Bullding shall be monitored by plant Operations via the CCTV system, for fires or signs of fire, hourly for four hours after an entry plus at least twice in the ensuing 20 hour 
period. Examinations shall be timed so that they occur at least once each shift. Any indication of fire shall be reported to the Control Room imnediately for proper action. Time of monitoring and results shall be reconded and the record retained in the Control Room.

4.3.2.3 Hose reels on $305^{\prime}$ and $347^{\prime}$ elevations shall be in service. Nozzles and hose reel valves will be shut, outside containment: isolation valve, FS-V639, will be shut and inside containment isolation valve, FS-V640, will be left open. FS-Y639 shall be opened during entries requiring:

4.3.2.3.1 Qutting, welding, burning, soldering, etc.

4.3 2.3.2 Water spraying.

4.3.2.3.3 Use of flammable liquids.

4.3.2.3.4 The use of or generation of large quantitfes of combustibles.

4.3.2.3.5 Any condition for which Plant Operations detemines the hose reels should be in service.

4.4 Planning and Implementation

4.4.1 Scheduling - Prior to scheduling an activity, a review by Bechtel Construction will be made to determine the following to the maximum extent possible:

4.4.1.1 When services (if required) will be available.

4.4.1.2 If the in containment time to do the task is available.

4.4.1.3 The task does not conflict with any other task currentiy scheduled.

4.4.1.4 Personnel are avallable to do the task, $i . e .$, the proper mix of trades, etc.

4.4.1.5 The equipment recessary to do the task is or will be avaflable.

4.4.1.6 The extent of training requifrements.

4.4.1.7 Regulatory requirenents are properly addressed and satisfied. Upon satisfactory review of these items, the activity will be placed on the Fieid Sumary Schedule and tracked untll completion. When scheduled. BNoC wtll assign a responsible field engineer to the task. 


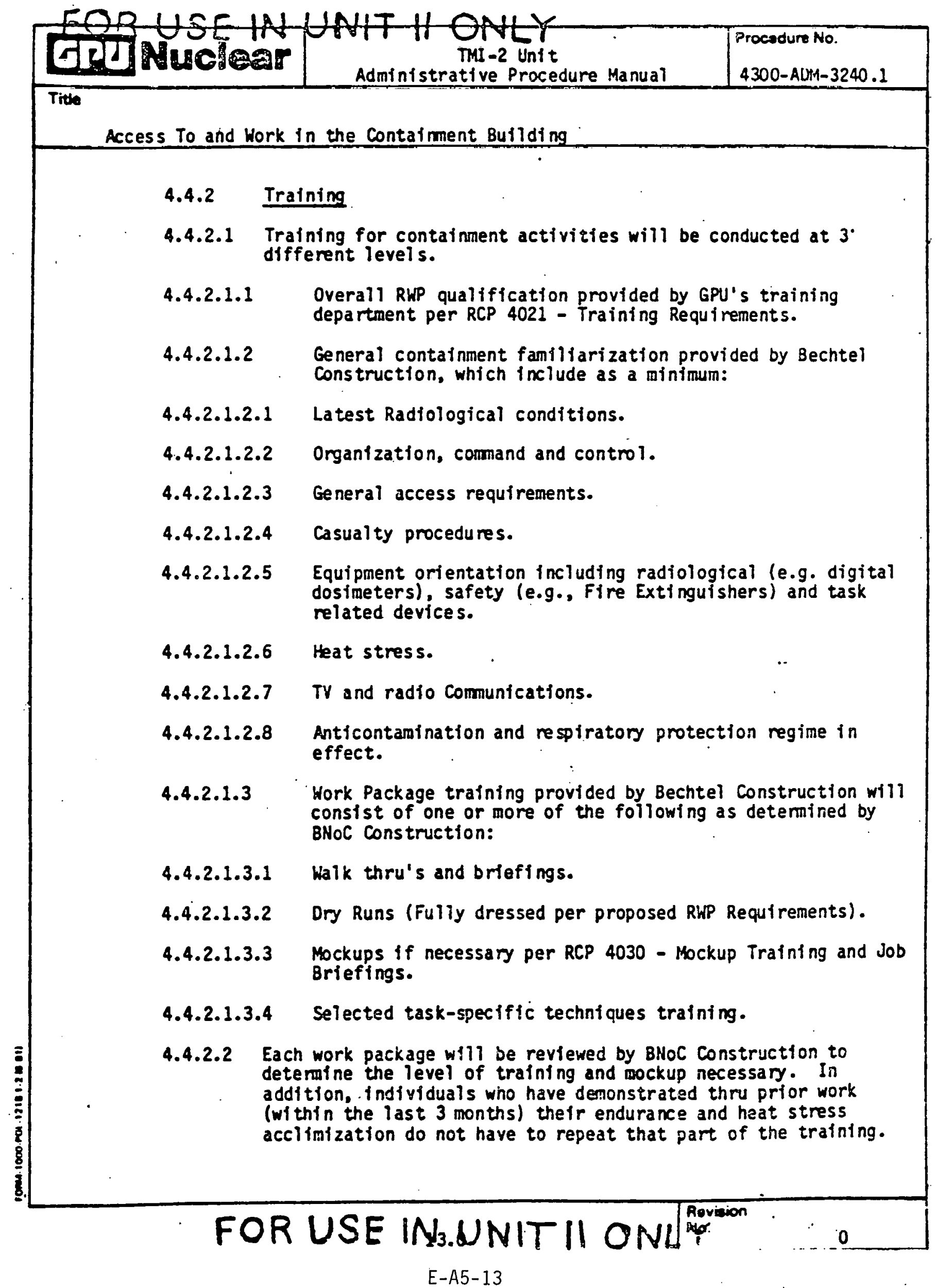




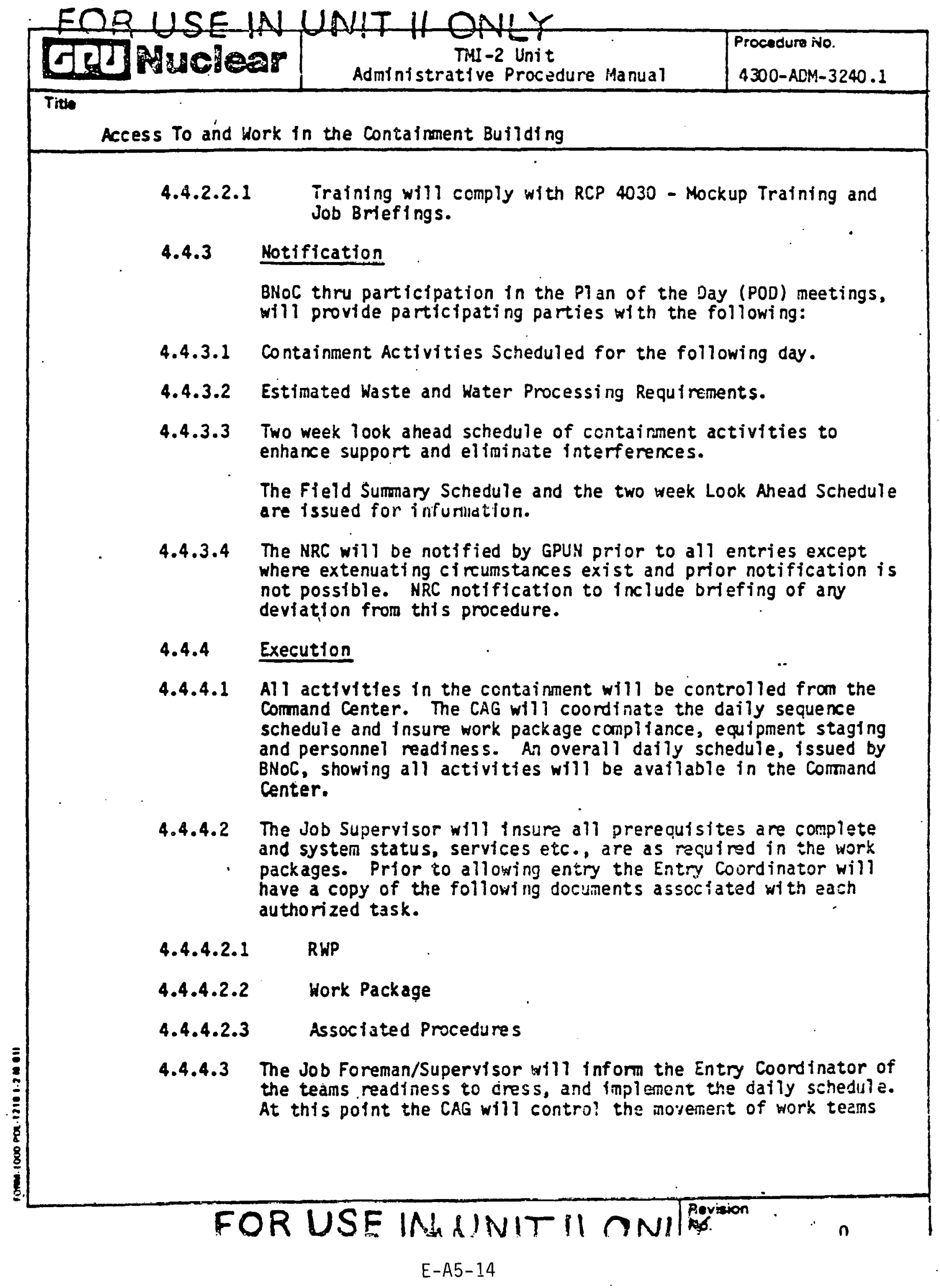


Access To and Work in the Containment Buflding

until they exit the Unit 2 Contalnuent. Performance of work will be supervised by the task supervisor. Containment entries will be conducted in accordance with Unit 2 Operation Procedures 2104-4.55, Reactor Building Entry.

\subsubsection{Command Center Organization}

The CAG Entry Supervisor is in overall charge of an entry. An Entry Coordinator will direct the details of the entry i.e., when to dress, sign-off prerequisites, etc.

Only the CAG Entry Supervisor may change the scope of work or otherwise modify the entry as long as it is consistant with the RWP and the Radiological Review (4045).

The Operations, Safety, and Radiological Control representatives have the authority to stop activities in the containment if conditions affecting their scope of responsibility warrant.

The following are the responsibilities and authorities of the Command Center Personnel:

\subsubsection{CAG Entry Supervisor (ES)}

4.4.5.1.1 Insure proper control is exercised in the Command Center (1.e., procedures are being followed, extraneous conversation or excess people are not allowed).

4.4.5.1.2 Act on recommendation and observation of the Operations, Safety and Radiological Control representatives. In the event of a conflict between Safety, Radcon or Operations considerations, the Entry Supervisor will determine the course of action to be followed. Stop work authority of Safety, Radcon or Operations overrides this determination.

4.4.5.1.3 Direct changes in the entry scenario, for example:

4.4.5.1.3.1 Deletion of planned activity.

4.4.5.1.3.2 Changes in sequence of events.

4.4.5.1.3.3 Authorizes the conduct of optional activities covered by the scenario or work package so long as time, dose, and personal stamina permit.

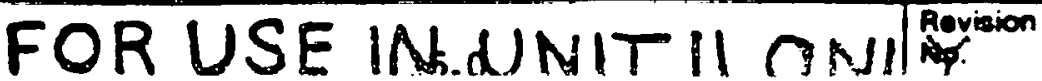




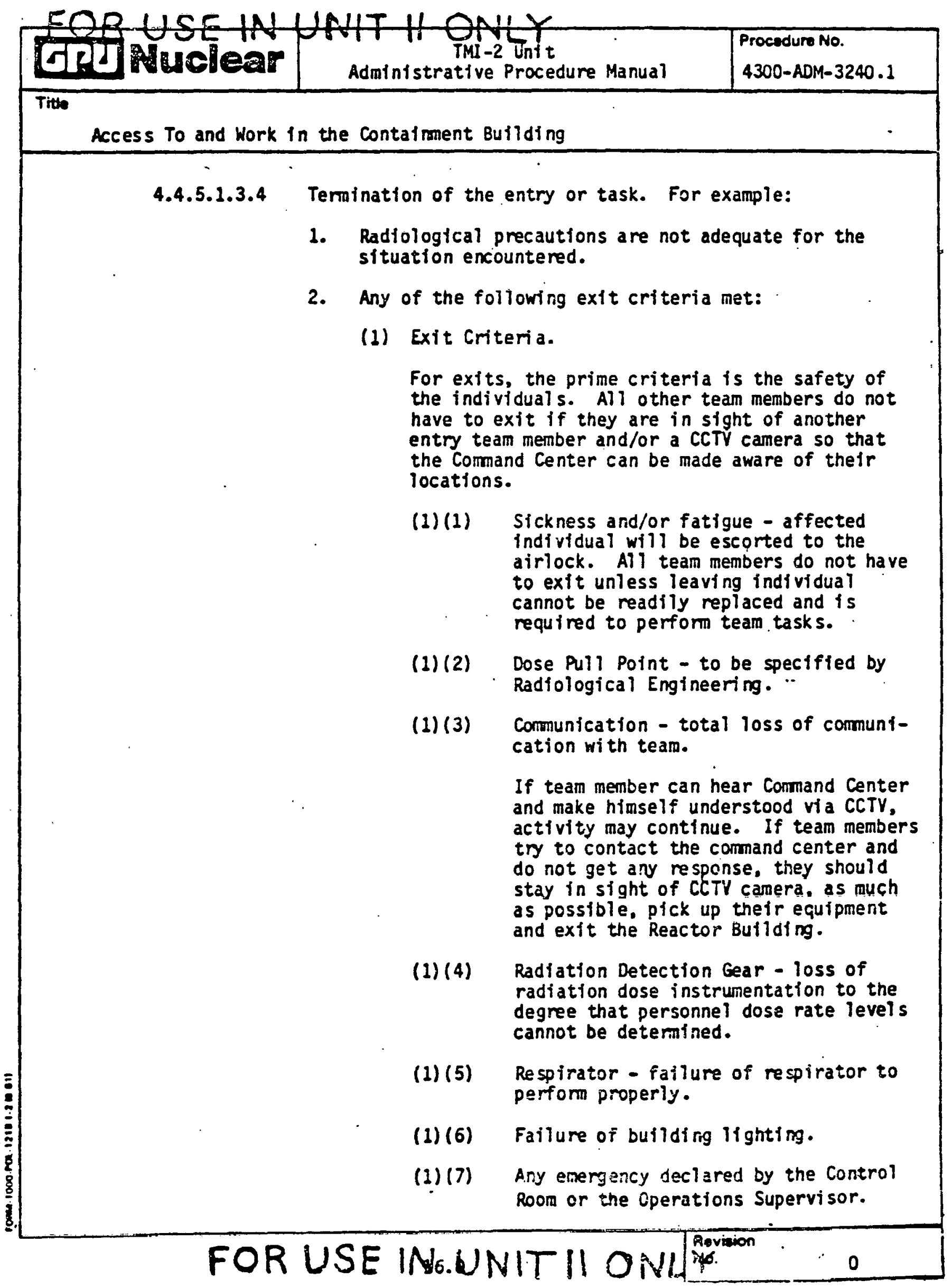




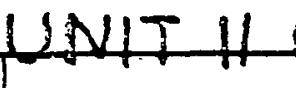

Access To and Work in the Contairment Building

3. Physical configuration not in accordance with drawing to such an extent it invalidates the procedure and the training.

$4.4 .5 \cdot 1.3 .5$

$4.4 .5 \cdot 1.3 .6$

Changes to tasks within the scope of approved proceduras as recommended by Task Supervisor.

Add minor tasks to team activities such as reconnecting CCTY cables that do not require a procedure or add significantly to the stay time (Not to exceed 10 minutes), with the concurrence of the Operations. Safety and Radiological Controls representatives.

4.4.5.1.4 Report containment building entrance and exit to the Control Room Operator and keep the Control Room informed on activities in contaiment.

\subsubsection{Entry Coordinator and/or Entry Supervisor}

4.4.5.2.1 Insure all preparations and prerequisites are completed prior to executing the entry. This includes but is not iimited to:

4.4.5.2.1.1 RWP's processed including radiological reviews.

4.4.5.2.1.2 Containment Entry Procedure prerequisites.

4.4.5.2.1.3 Command Center manned.

4.4.5.2.2 Console operator (The entry coordinator nomally functions as the console operator).

4.4.5.2.2.1 Maintain comunications with designated personnel.

4.4.5.2.2.2 Log significant reports. Make verbal reports to Entry Supervisor.

4.4.5.2.2.3 Track actual vs. planned team progress. Make verbal reports to Entry Supervisor on significant variations.

4.4.5.2.2.4 Inform entry team of scenarlo changes as directed by the Entry Supervisor.

4.4.5.2.2.5 yideo tape entry team activities.

\section{FOR USE INh.WNNT}


Access To and Hork in the Contalment Buflding

\subsubsection{Radfological Controls Representative}

NOTE: The Radiological Controls Representative shall be a Radiological Englneering Supervisor, a Radiological Engineer or a Radiological controls Foreman.

\subsection{Monitor entry progress.}

4.4.5.3.2 Advise Entry Supervisor of potential radiological problems.

4.4.5.3.3 Recommend to Entry Supervisor suitable actions relevant to radiological controls.

4.4.5.3.4 If in the opinion of the radiological controls representative proper radiological controls are not being exercisad, he is to provide specific directions with respect to radiological controls to the Entry Supervisor to remedy the situation including temination of that part of the entry.

\section{$4.4 \cdot 5 \cdot 3 \cdot 5$ \\ Track exposure and advise Entry Supervisor of reinaining} stay time(s).

\subsubsection{Operations Supervisor}

For each entry, an operations supervisor will be in the Comand Center to consult with the Entry Supervisor as follows:

4.4.5.4.1 Based on the information provided, advise or recomend actions to the Entry Supervisor.

4.4.5.4.2 Provide directions for the technician in containment when it involves Plant Safety.

4.4.5.4.3 If in the opinion of the operatiuls supervisor proper controls over plant operations a re not being exercised. te is to provide the entry supervisor with specific directions to remedy the situation including temination of that part of the entry.

4.4.5.4.4 In any type of emergency involving plant systems or safety of the plant, the Operations Superyisor in the Cormand Center will take charge with directions fron the Control Room Duty Supervisor.

\subsubsection{Task Supervisor}

The Task Supervisor will be present in the Comand Center during the task execution to supervise his assigned task(s). If 


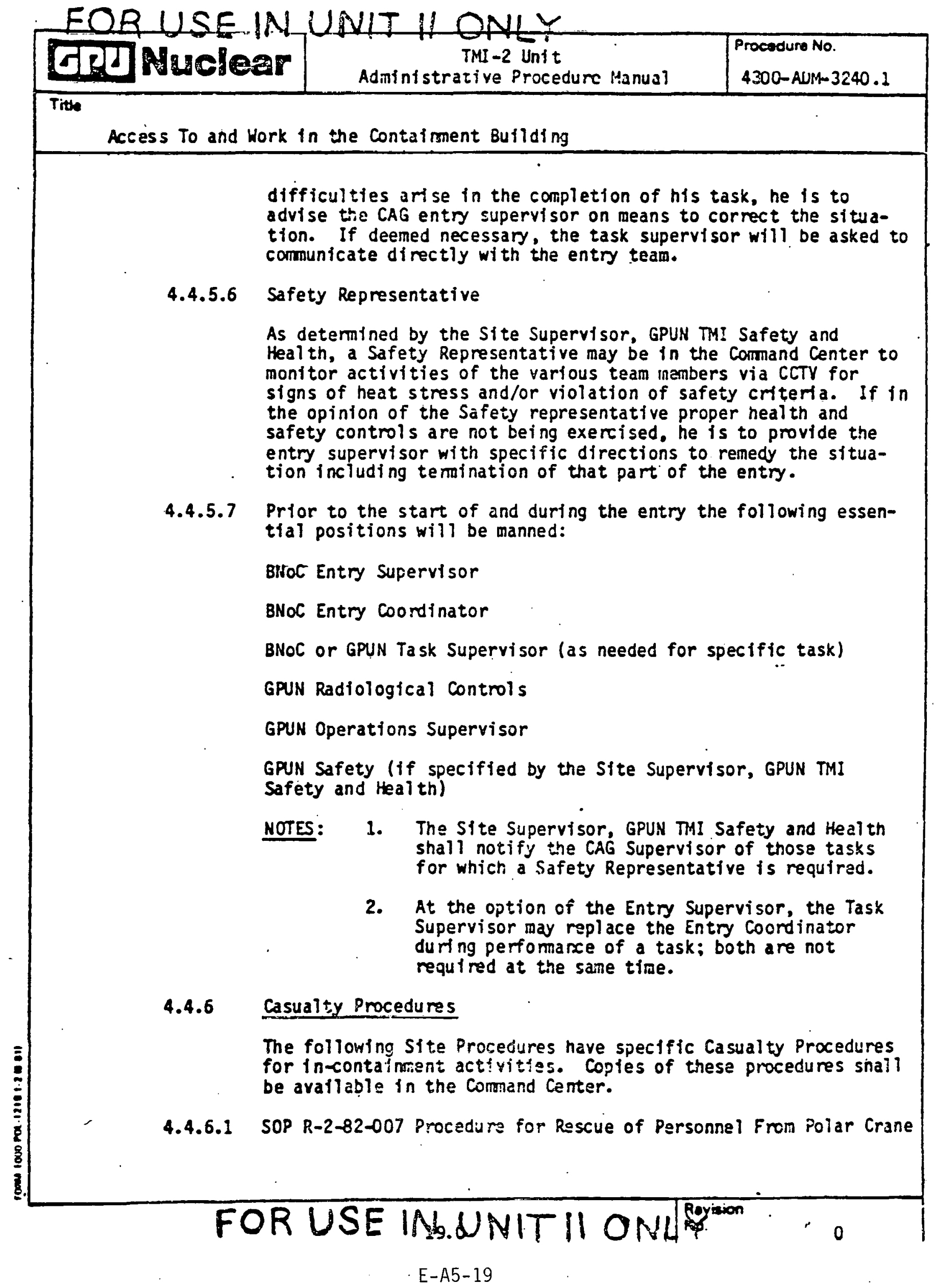


Access To and Hork in the Contaiment Buliding

\subsubsection{Procedure 2202-3.1 Fire \\ 4.4.6.3 Procedure 1054.16 Contaminated Injuries/Radfation Overexposure \\ 4.4.6.4 Procedure 202-1.7 Excessive Radiation Levels}

\subsection{Control Room Interface}

A CCTV eonsole and intercem is to be installed in the control room for monitoring contaiment entry activities. The Command Center will be in charge of all entry activities and an operations supervisor will nomally be present in the command center. The control room is not expected to participate in the conduct of the entries and will use the console to monitor in-containment activities; however if any control Room indications show a situation that could potentially upset Reactor Building conditions, this infomation shall be communicated to the Command Center immediately.

Installation or operation of the CCTV and intercom in the control room is not a prerequisite for containment building entry.

In the event of an emergency in the contaiment which involves plant equipment and could the refore impact plant status, all activities in the containment will be secured. The operations supervisor in the comand Center will assume control of Reactor Building activities, with directions from the Control Room Duty Supervisor, to return plant status to nomal. Command Center personnel will assist as necessary to control the emergency. Non-qualiffed personnel will not be used to control emergencies.

If qualified personnel are in the containment building as part of the day's activities, they may be utilized to recover from any emergency. other personnel in containment will be directed to exit the building.

\subsection{RESPONSIBILITIES}

Responsibilitfes are as presented within Section 4.0 of this procedure.

\subsection{REFEREENCES}

6.1 Procedure 4000-ACM-3040.3, "Englneering Change Authorization"

6.2 Procedure RCP 4045, "Radiological Review of Hork Instructions"

6.3 Procedure RCP 4122, "Padiation Horx Pemit"

6.4 Procedure RCP 4123, "Self Readar Dosimeter Usage and Record Keeping"

6.5 Procedure RCP 4238, "B101550̈y Prcgran"

\section{FOR USE IN.UNITII ONIL, ?}


Access To and Hork in the Contafrment Buflding

6.6 Procedure RCP 4101, "Air Sample Counting, Handling and Actions"

6.7 Procedure RCP 4104, "Air Sampling Procedures"

6.8 Procedure RCP 4100, "Radiological Surveys"

6.9 Procedure RCP 4200, "TLD Assigment, Issue and Data Handiing"

5.10 Procedure RCP 4015, "Administrative and Emergency Exposure and Contamination Linits"

6.11 Procedure 2104-4.91, "Reactor Building Purge Using the Modified Purge System"

6.12 Procedure AP 1034, "Control of Combustible Material s"

6.13 Procedure MP 1410-Y-26, "Welding, Cutting, Grinding and Open Flamework Procedure for Fire Safety" 6.14 Procedure RCP 4052, "Selection, Prescription and Use of Respiratory
Protection"

6.15 Procedure RCP 4125, "Use of Anti-Contamination Clothing"

6.16 Procedure 1631.2, "Sampling of Reactor Butlding"

6.17 Procedure RCP 4021, "Training Requirements"

6.18 Procedure RCP 4030, "Mock Up Training and Job Briefings"

6.19 Operations Procedure 2104-4.55, "Reactor Buflding Entry"

6.20 Special Operating Procedure R-2-82-007, "Procedure for Rescue of Personnel from Polar Crane.

6.21 Procedure 2202-3.1, "FIre"

6.22 Procedure 1054.16, "Contaminated Injuries/Radiation Overexposure"

6.23 Procedure 2202-1.7. "Excessive Radiation Level s"

6.24 Procedure 1407-1, Unit 2 Corrective llaintenance Procedure

7.0 ATTACHMENTS

None 
ATTACHMENT E-6

CASUALTY PROCEDURE

FOR

HIGH RADIATION CONDITION IN-CONTAINMENT

This procedure supplements Procedure 2202-1.7 
HIGH RADIATION COHDITION IN CONTAIKMENT

HIGH RADIATION CONDITION DETECTED BY ENTRY PERSONHEL (Entry in Progress)

MTE: For purposes of this document. the following shall be considered high radiation conditions:

1. An unanificipated increase in the general area background, detected by hand-carried instruments, by a factor of five from the most recentiy recorded prevfous survey informetion.

2. An unanticipated increase in the general area background, detected by hand-carrfed instruments, by a factor of flve during the entry.

Entry Personnel shall:

i. Report readings to Command Center.

2. Hove to a lower radiation area if eny.

3. Proceed to personnel airlock as directed by Command Center.

4. Entry team leader report status and location of all team nembers.

Command Center shall:

8. Hotify all personnel in containment of high radiation.

2. Order all personnel to exit bullding, uniess it is determined that high radiation conditions were caused by ongoing activitfes and an evaluation is made by Radiological Controls whtch concludes that an evacuation is not necessary.

3. Notify the Control Roow.

4. Notify the HP Foreman.

5. Notify the Ante Room.

Control Room shall:

1. Respond in accordance with Unit II Energency Procedure 2202-1.7 us ing procedure requirements applicable to readings reported by the Comand Center which yould be epproprlate, if contoinment bullding radiation monitor HP-R-213 had detected the reported radiation levels.

Ante Room shali (if so directed by the Command Center):

1. Record and report all exiting personnei.

2. Secure any entry preps and clear Ante Room to recefve exiting personnel. 
MIGH GADIATION CONDIYION WE LOTEO BY THE CONTROL ROON Teñtry की Frogress)

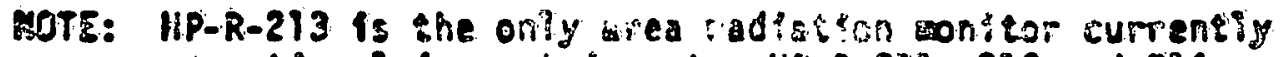

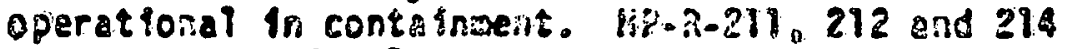
are no: oparotionel.

\section{Control foom shail:}

8. Respond in accoidance with this II Emergency Procedure 2202-1.7.

8. Wotify Conitiand Center of readings and location.

3. Direst Comand Center so suscuste contatnasis if required. Comend center shail:

1. Hotfiy all entry persomes?

2. Order all personnel to exis the bufluing if so directed by the Control Room.

3. Not1fy HP Forenan.

4. Motify Ante Boom.

Entry Persomel shall (18 so dprecsed by she Comand Center):

1. Secure pork o. Ge-energfze equigment.

2. Team Teaders report siatus and rocation of geam nembers.

3. Exit the bullding.

Ante Roos shall (If so directed by woitiend center):

7. Record and report all exiting personnet.

2. Secure any entry preps and ciaar Ante Roon to recelve exiting personnel. 


\section{ATTACHMENT E-7 \\ CASUALTY PROCEDURE \\ FOR \\ FIRE IN-CONTAINMENT}

This procedure supplements Procedure 2202-3.1 


\section{FIRE IN CONTAIMMENT}

When Fire is detected by Entry Personnel:

Entry Personnel shall:

8. Motify Commend Center - Fira Elevation

(Fill in blanks with approprlate elevition).

Fire Elevation

Followed by location, sype, size

Exampie:

location - $5^{\circ}$ from In-Core. Instrumentation Chase.

Type - Elecirical, Trash, Chentcal

size - Small (can be extinguished with fire extinguisher) Large (Cannog)

2. If In your judgement you can put the fire out and have the equipment so do so, then put it out, otherwise, Teave and assemble to the Personnel Alrlock: - (Airlock unaffected by fire)

3. Prior to leaving check to aake sure no one is left in area. Entry team leaders are to report location and status of team members to Command Center.

4. Secure your equipnent.

5. Do not, at anyt ime, endanger yourself except to prevent injury to another team member.

Command Center shail:

1. Notify all personnei in containment.

2. Motify the Control Boom.

3. Notify HP Forenan.

4.- Notify Ante Roow.

5. Order all personnel not in vicinity of fire to proceed to Afrlock via stafrwell and stand by to essist. (FII in bianks atth airiock and stainwell unaffected by fire)

6. Direct entry personnel as regulfed.

7. Muintain visfbie contact, If poss fble. vie CTTV.

8. Haintaín radio contact. 


\section{Commend Center shall : (con't)}

\section{Ponftor fire with CCTY if possibie.}

Hota: In the event of fire, the Control Room shall assume control. The Command Center responsibility is limited to evacuation of personnel and provision of support as requested by the control Room.

\section{Control Room shall:}

1. Inftiate action in accordance with Unit II Emergency Procedure 2202-3.1. Fire.

2. Estabitsh direct communications with Comand Center (Main intercom) console when avallable).

3. If elactrical, de-energize nearest breaker feeder.

4. Pressurize fire in in containment.

5. Secure purge.

6. Make arrangements to have plant fire extinguishers staged to the Ante Room to provide extinguishers to fight the fire for 45 minutes.

Ante Room shall:

1. Stage PIre extinguishers to Airlock.

2. If personnel are in process of undress - expedite.

3. If personnel are in process of entry. secure entry (Entry personnel remove one set of booties and leave Ante Roon. Huster in corridor).

4. Station man near intercom.

5. Station wan in Airlock - Man Page Channet 1.

6. Remove excess equipment from Ante Room.

7. Prepare to aid fire brigade.

8. Provide two (2) two-way radios for fire brigade use (no setcons).

- . Log and report ali personnet exiting and entering the bullding.

HP Foreman shall:

1. Take charge in Ante Room/staging area for HP natters only.

2. Direct MP Support to 11 Airlock and Man Page Channel I. 
Safety/First Ald shall:

B. Standby to assist - if personnel are injured.

2. Notify First Aid.

\section{Fire Brigrade shall:}

1. Assemble as directed by Control Poom.

2. Fire Brigade w111 enter the containment at the direction of the Control Room.

3. Comand canter wili assist as requested. 


\section{FIRE IN CONTAIMAEMT}

\section{When Fire is detected by the command Center:}

\section{Entry Personnel small:}

7. Secure work and de-energizo electrical equipment. Assemble at Airlock as directed by Command Center. Exit then directed. Tean leaders report status and gocation of all team wembers.

2. Do not, at anytime, endanger yourself except to prevent injury to another team member.

3. If In the area, and fire extinquishers are avaliabie and in your judgeaent you can put out the fire, do so; otherwise leave area via route speciffed and exit as directed by the comand Center.

Command Center shail:

1. Hotify all personnel in congainment.

2. Notify the Control Room.

3. Hotify HP Foreman.

4. Hotify Ante Room.

5. Order all personnel not in vicinity of ffre to proceed to Airlock via stairwell and stand by to ossist. (Fill in bianks with afriock and stafrwell unaffected by fire)

6. Direct entry personnel as required.

7. Maintain visibie contact. If possible. 'vin crity.

8. Maintain radio contact.

9. Fonitor fire with CCTY, if possible.

MOTE: In the event of fire, the Control Room will assume control. The command Center responsiblitity is ifmited to evacuation of personnel and provision of support as requested by the Control Roow.

Control Room shail:

1. Intilate action in accordance with Energency Procedure 2202-3.1. Fire.

2. Establish direct communications with Command Center (Ma in intercom/console when avallable.)

3. If electrical; de-energize nearest feeder breaker.

4. Pressurize fire moin in containment. 
Control Room shall: (con't)

3. Secure purge.

6. Make arrangements to have piant fire extinguishers staged to the Ante Roon to provlde extinguishers to fight the fire for 45 sinutes.

Ante Room shall:

8. Stage fire extinguishers to Alriock.

2. If personnel are in process of undress - expedste.

3. If personnel are in process of entry, secure entry (Entry personnel remove one set of booties and ieave Ante poom. Ruster in corridor).

4. Station man near intercom.

5. Station man In Afriock - Man Page Channel 3.

6. Renove excess equipment from Ante Room.

7. Prepare to afd fire brigade.

8. Provide two (2) two-kay radios for fire brigade use (no setcoms).

9. Log and report all personnel exiting and entering the bullding.

HP Foreman shall:

1. Take charge in ante Room/staging area for HP matters only.

2. Direct HP Support to $n$ Alrlock and Man Page Channe? 1.

Safety/First Aid shall:

1. Standby to assist - if personnel are injured.

2. Notify First Aid.

Fire Brigade shall:

1. Assemble as ofrected by Control Roow.

2. Fire Brigade will enter the containment at the direction of the Control Room.

3. Comand center will assist as requested. 


$$
\text { -6 }
$$

\section{FIRE IN COATAIKAENT}

When fire is detected by the Control Room:

\section{Entry Personnel shail:}

1. Secure work and de-energize electrical equipment. Assemble at Airlock as directed by Coimant Center. Exit when directed. Team ieaders report status and location of all team nembers.

2. Do not, at anyt ime, endanger yourself except to prevent injury to another team nember.

3. If in the area, and fire extinguishers are avallable and in your judgement you can put out the fire, do so, otherwise leave area via route specfified and exit as directed by the Comand center.

\section{Command Center shall:}

8. Notify all persoanel in containment.

2. Notify HP Foreman.

3. Notify Ante 200m.

4. Order all personnel not in vicinity of fire to proceed to Airlock via stafrwell and stand by to ass ist. (Ffll in blanks atth afriogk and stainfell unaffected by the fire.)

5. Direct entry personnei as required.

6. Maintain uisibie contact. If posstbie, via CCTY.

7. Maintain radto contact.

8. Fonteor the fire via cCTy if possible.

MOTE; In the event of fire, the Contrat Ronm 111 assume control. The Command Center responsibllity is 1 im!ted to evacuation of personnel and provision of support as requested by the Control Roow.

Control Room shall:

1. Notify Comand Center. fire in containment.

2. Initiate action in accordance with Emergency Procedure 2202-3.1. Fire.

3. Estabiish direct communications with Comand center (win intercom/ console if avaliable). 
Control Room shall: (con't)

4. If electrical, de-energize nearest fceder breaker.

5. Pressurize fire ain in containment.

c. Secure purge.

7. Make arrangements so have plant pire extinguishers staged to the Ante Roow to provide extinguisher to fight the fire for 45 ainutes.

Ante Room shall:

1. Stage fire extinguishers to Airlock.

2. If personnel are in process of undress - expedite.

3. If personnel are in process of entry, secure entry (Entry personnel remove one set of booties and leave Ante Room. Auster in corridor.)

4. Station near iniercom.

5. Station man In Airiosk - Man Page Cirannel 1.

6. Remove excess equipment from Ante Room.

7. Prepare to ald fire brigade.

8. Provide two (2) two-way radios for fire orfgade use (no setcoms).

9. Log and report all personnel exiting and entering the buliding.

MP Foreman shall:

1. Take charge in Ante Room/staging area for HP matters oniy.

2. Oirect MP Support to II Airlock and Man Page Chennel 1.

Safety/first Rid shall:

1. Standby to assist - If personnel are ingured.

2. Motify First Aid.

Fire Brigade shall:

i. Assemble as directed by Control Room.

2. Fire Brigade will enter the contalnment at the direction of the Control Room.

3. Command Center will assist as required. 


\section{ATTACHMENT E-8 \\ CASUALTY PROCEDURE \\ FOR}

PERSONNEL INJURY OR SICKNESS IN-CONTAINMENT

This procedure supplements Procedure 1054.16 


\section{PERSONNEL INJURY OR SICKAESS}

When an injured or sict individual is found by entry personnet. the Command Center or the Control Roow.

HP Foreman sha11:

7. Take charge in the Ante froom/staging area for HP matters only.

2. Send an additional HP for duty in the ante Room. .

3. Provide recomendation for best use of avallable personnel from a radiological vievpoint.

4. Hake preparations to receive and monitor contaminated personnel.

5. Log and report all exiting personnel.

Safety/first Ald shall:

1. Paintain representation in the comand Center.

2. Provide rescue team as soon as practicable.

3. Hake recomendations on rescue action, evacustion, respirator removal then information is avaligble.

Control Room shall:

1. Initiate action in eccordanee aith procedure 1054.16, Contaminated Injuries/ Radiation Overexposure.

2. Estabifsh direct communicatiens with the Commend Center.

3. Muster the rescue and assistance team and stand by to assist.

Command Cencer shall:

1. Request information on the condition of the individual concerned.

2. Wotify other personnel in conteinment, the Ante Room, Control Room, the MP Foreman and Sufety/firsi Ald.

3. Secure all non essentfal work including entrance into containment by teams for purposes other then rescue or assistance.

4. Verlfy locations and stations of ALL entry personner. 
Commend Center continued:

5. Direct Ante Room assistance tean to enter. If required.

6. Insure communications have been established in key locations

(çontainnent, Ante Room, Control Room, MP Foreman)

7. Besed on Safety reconmendations, render assistance with Ante Room team. Ante Room sharr:

1. Quickly undress any team nembers exiting.

2. Station one wan at the intercom.

3. Assibtance qeam propare to enter and stand by for instructions in Miriock. Man page, channzi i.

4. Secure any rout ine tork.

5. Hold any team ready for entry in stand by.

6. Remove excess equipment from Ante Room.

Entry Personnel shall:

1. Determine the condition of the Individual and nature of injuries: question him if he is consefous.

2. Inform the comand Center of these facts by fastest avallable means. haye one man in sight of CCTV camera. if posstbie. A status report should inciude:

Narie of Individual. Iocation, description of injury and condition (conscious, unconse feus, bleeding. breathing problems, electric shock, heat stress, able to waik, etc.)

3. Entry qean leaders report status and location of team nembers.

4. Awatt further instructions.

5. Do not move the individual without perwission of the commend center. 
Entry Personnel shall: (Continued)

6. If the Individual is having difficulty in breathing, the respiraotr may be removed. Caution must be exercised in removing the respirator in order to avold additional injury to the individual. If breathing difficulty is not evident, do not remove the respirator whout permisision from the Command Center. 


\section{DO NOT MCROFILM THIS PAGE}


APPENDIX F

PHOTOGRAPHS AND VIDEOTAPE RECORDINGS

OF THE DECONTAMINATION EXPERIMENT 


\section{CONTENTS}

PHOTOGRAPHS

VIDEOTAPING
F-1

F-4

ATTACHMENT F-1 GENERAL PHOTOGRAPHS AND DESCRIPTIONS (Photographs F-1 Through F-20) 


\section{APPENDIX F - PIIOTOGRAPHS AND VIDEOTAPE RECORDINGS \\ OF THE DECONTAMINATION EXPERIMENT}

\section{PHOTOGRAPIIS}

The successful use of still cameras to document the conditions of specific areas and items is a major accomplishment of the entry program. Photographs were used to characterize the general condition of the reactor building as well as to identify specific problem areas. (see Attachment F-1). The photographs. proved a valuable planning and training aid to task planners and entry personnel,

\section{$\underline{\text { Equipment }}$}

The equipment used to photograph the inside of the reactor building consisted of $35 \mathrm{~mm}$ SLR cameras (Nikon FE, Pentax LX, and Nikonas III), each equipped with an autowinder and standard lens $(28,35$, or $50 \mathrm{~mm}$ or telephoto/ zoom lens). The flash units (Vivitar 285 or Metz $60 \mathrm{cT}-1$ ) had Nikad rechargeable batteries in an internal or belt-type pack. Kodacolor film (ASA 100 or ASA 400) was used most of the time. Ultraviolet haze type filters were used to protect the lens and the eyepieces for the viewfinder from contamination. The cameras and flash units were completely covered, except for the lens and viewfinder, in a handmade, tight-fitting plastic bag which allowed the user to focus and operate the shutter freely. All other settings were preset and locked down in accordance with the requirements of lighting, distance, and film speed for the task. Only one case of severe radiation fogging occurred.

The process of bagging the camera and flash units to prevent contamination took approximately 2 man-hours per camera. Some manufactured camera containments were tested but without the success of the handmade type. Unbagging the camera after use required more time and careful handling to prevent contamination of the camera and film. 


\section{Development and Distribution of Photos}

The film was developed and $8-\mathrm{x} 10$-inch prints were made by the Bechtel Photo Lab and EG\&G. The photographs were assigned numbers prior to reproduction through use of the proof sheet. These numbers were made a permanent part of each negative and print.

The numbers were assigned by two methods. The first method was to number the photographs by entry number, camera number (arbitrarily assigned), and negative number (i.e., Entry 36, 1-29). This provided easy documentation of the photographs; in addition, a map could be drawn to show the location and angle of the photographs. The second method was used in a reactor building characterization task with a camera and a 250-shot film pack. The rcactor building was broken down into areas, and the areas were photographed from designated locations. The photographs were then numbered by entry number, area, location number, and photograph number taken at the position (i.e., Entry 26, Area 12A, 7.4). Documentation for the second method was more confusing tian for the first method since it was difficult to keep track of the cotal number of protograns, but the advantage of the second method was that the location and angle were speciried.

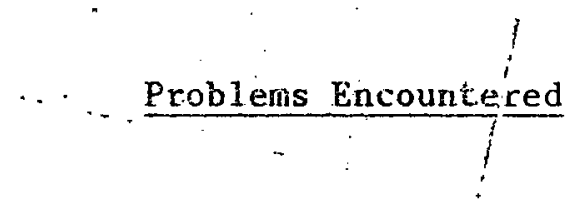

Diverse problems were encountered in obtaining good quality phutographs. The source of the problems ranged from the photographers themselves to the development of the film. One of the major difficulties arose from the fact that personnel taking the photographs were unfamiliar with $35 \mathrm{~mm}$ cameras and their operation. Training for these people was usually limited to showing them (a) the camera's settings, (b) how to focus the camera and operate the shutter, (c) how to determine when the flash was ready, and (d) how to tell if the camera was jammed. A short time was spent on practicing how to focus the camera while wearing a respirator, a problem which varied among individuals and was almost impossible to correct. A couple of practice photographs were also 
taken. Any training beyond this point was limited by the inability of the photographer to manipulate the other settings or effect minor repairs because of the anticontamination bag surrounding the camera.

Another major problem involved equipment malfunction or breakage. The task would have to be scrubbed whenever the camera jammed, flash stopped functioning, settings were bumped off from the proper location, or any part of the camera ur flash was broken. The camera and/or flash would then have to be unbagged, decontaminated, repaired, and then rebagged prior to reuse. The problem of breakage was most frcquently encountered, especially breakage of the flash units - it was difficult to impress upon "non-photographers" that carefu $\perp$ handling of $35 \mathrm{~mm}$ cameras is required.

It was also difficult to impress upon inexperienced photographers the type of photographs the camera was set up to take and the fact that almost any other type of photograph would not turn out. Adding to these problems was the fact that the photographic assignment was, for the most part, an add-on task to an individual's main body of work rather than a primary concern. This circumstance only emphasized the weak areas in training and execution.

Development and distribution of the photographs proved to be yet another major problem, primarily because of the amount of time required to make prints and slides, to copy negatives (ensuring that they were numbered and oriented correctly), to collate the copies, and to make distribution. Each set of photographs had its own special requirements: some needed date and number of required copies; others could be handled without regard for numbering or making the required distribution.

\section{Lessons Learned}

The lessons learned from the work accomplished to date are important to note so that future performance can be improved. Although the photographic equipment used was excellent, cameras employing a fixed focus would probably be 
easier to use, in some cases provide better photographs, and make preparations easier. All photographic documentation, processing, and distribution should be handled by one group to eliminate confusion. The same group should also be responsible for obtaining extra copies or reprints. All negatives should be kept in a central location where they can be protected from loss or damage. The Bechtel Photo Lab is the most logical choice for this storage location. A log in/out system should be instituted to prevent loss of photographs or sets of photographs that are available tor use by more chan unt gruup.

When quick turnaround of photographs was required, the hest method proved to be making up the required sets without numbering them and making the standard distribution of the numbered prints later. This method got the photographs out as quickly as possible and still allowed control of the distribution. When the photographs are not required immediately, distribution could be held up and all prints numbered tor documeñation.

More time spent on selection and training of personnel would have been well worth the costs involved and would have helped minimize problems. Training should include actual taking of photographs under varied conditions with subsequent discussion of the results and suggestions for improvement. It should be noted that while a general photographic survey is very useful, it does not provide details or show orientation of specific objects. Several photographs from various angles need to be taken to document these items.

\section{VIDEOTAPING}

The installation of the CCTV camera system prior to the start of the Decontamination Experiment provided the ability to characterize the reactor building and allowed documentation of the decontamination work performed. In addition to the black-and-white videotapes obtained through the CCTV system, color videotapes were made of specific work tasks with a portable video camera and recorder. The videotapes will facilitate training and orientation of personnel for future reactor building entries. 


\section{$\underline{\text { Equipment }}$}

Equipment used in the videotaping operations is comprised of a permanently installed CCTV system: a black-and-white, low-light, Sony hand-held camera tied into the main CCTV system, and a color Hitachi hand-held camera connected to a portable Sony videotape recorder (VTR).

The main CCTV system consists of eight cameras which can be panned, tilted, zoomed in and out, and focused from a remote control panel: Images from two cameras at a time, can be recorded on Sony VTRs. The cameras themselves are black and white with low-light requirements; therefore, no additional lighting outside normal building lighting is needed. The VTRs can use either a Sony XCA 60-minute tape or a 20-minute tape. The Sony camera was used to cover areas outside the view area of the main CCTV system. The Hitachi camera was used to film specific work tasks in color. Because it was not low-light sensitive, the Hitachi camera required additional lighting to obtain the desired results. The preparation of the hand-held equipment used in the reactor building was similar to the preparation of $35 \mathrm{~mm}$ cameras. The cameras and tape decks were completely bagged (except for the lenses) to prevent contamination of the components and tapes.

\section{Distribution}

A distribution system for videotapes was never developed prior to the Decontamination Experiment. As a consequence, the tapes were simply numbered by entry and sequence and stored for later distribution. Similarly, the tapes obtained in the characterization and in the decontamination work were held for later editing and distribution. If any tape was requested for special use, it was loaned without hesitation. 


\section{Problcms Encountered}

Problems with the video equipment during the Decontamination Experiment caused the loss of documentation of the work mostly bccausc of breakdowns in the main CCTV cameras. Since there was no overlap of coverage areas between cameras, the loss of a camera meant. the loss of coverage in the area around that camera. Repairs of the cameras were dictated by the availability of spare parts.

Other problems included the requirement for additional lighting and the bulky VTR that were necessary when the Hitachi camera was in use, and problems with the cabling required to transmit the signal out of the reactor building

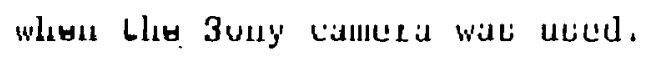

\section{Lessons Learned}

The lessons learned from the use of the video equipment and taping done remotely and locally cover the entire scope of the task. The equipment used both inside and outside the reactor building should be as simple and easily repairable as possible without loss of quality. The simplicity of the equipment will also facilitate its preparation for use in the reactor building. In addition, sufficient equipment must be on hand to use for training and repairs to avoid loss of coverage of tasks.

Another lesson learned is that general coverage by videotaping is not sufficient to show details of most equipment because taping angles do not provide the best view.

Improvements can be made in the handling of videotapes. The tapes should be labeled with the tasks covered so that the tapes do not have to be reviewed and labeled later. This will also expedite the editing process in the future. Duplicates of the tapes should be made as soon as possible and stored separately from the originals to minimize chances of loss or damage. $\Lambda$ sign in/out log should also be maintained to prevent loss of the tapes. 
ATTACHMENT $\mathrm{F}-1$

GENERAL PHOTOGRAPHS ANT DESCRIPTIONS 
$\underline{\text { Photographs } F-1 \text { to } F-8}$

These are examples of the areas that could not be cleaned with the spin jet because of the lack of operating room. Residual debris in these areas contributed to area radiation levels.

Photograph F-9

This is an area on elevation 305' where a $2000 \mathrm{psi}$ and low flow rate technique was used. As the photograph shows, the cleaning was not effective where the pressure and flow rate were below the optimum for effective decontamination results.

$\underline{\text { Photograph } \mathrm{F}-10}$

The equipment hatch and floor arnund it on elevation $305^{\prime}$ were cleaned with $6000 \mathrm{psi}$ and $24 \mathrm{gpm}$ water pressure and flow rate. Note the difference in effectiveness between this combination and the one illustrated by Photograph F-9.

\section{Photograph $F-11$}

In this area the outline of where the spin jet operated is visible, as are the portions not adequately cleaned. If the pressure used here had been increased and the worker rate slowed, the floor would be cleaner. In training on similar surfaces in the auxiliary building, there was a very fine line between the pressure that adequately cleaned and the pressure that stripped the paint. 
This area in front of the open stairwell on elevation $305^{\prime}$ was a major source of recontamination duc to the heavy trafic.

Photograph Fi-13

This photograph shows that the diamond plate has some oxidation but is fairly clean overall. There are some floor areas not effectively cleaned where wheel marks are visible in the debris, Also, the primer is exposed in spots die to traffic and wear.

\section{Photograph F-14}

The steel grating on elevation $347^{\prime}-6^{\prime \prime}$ was cleaned fairly well. Ilowever, during the flushing, water and debris went through the grating onto elevation $305^{\prime}$.

Photograph F-15

This is an example of surface deposition sample points for pre- and postdecontamination. Note that the borings have been painted.

Photographs $\mathrm{F}-16$ and $\mathrm{F}-17$

During the flushing activities, junction boxes and critical components of the reactor head service structure were protected with yellow herculite.

Photograph F-18

Pump and heater equipment set up for Lraining is shown, 
Photograph F-19

Air lock No. 2 and contamination control corridor for mock-up are shown.

Photograph F-20

Command center monitors during decontamination operations are shown. 

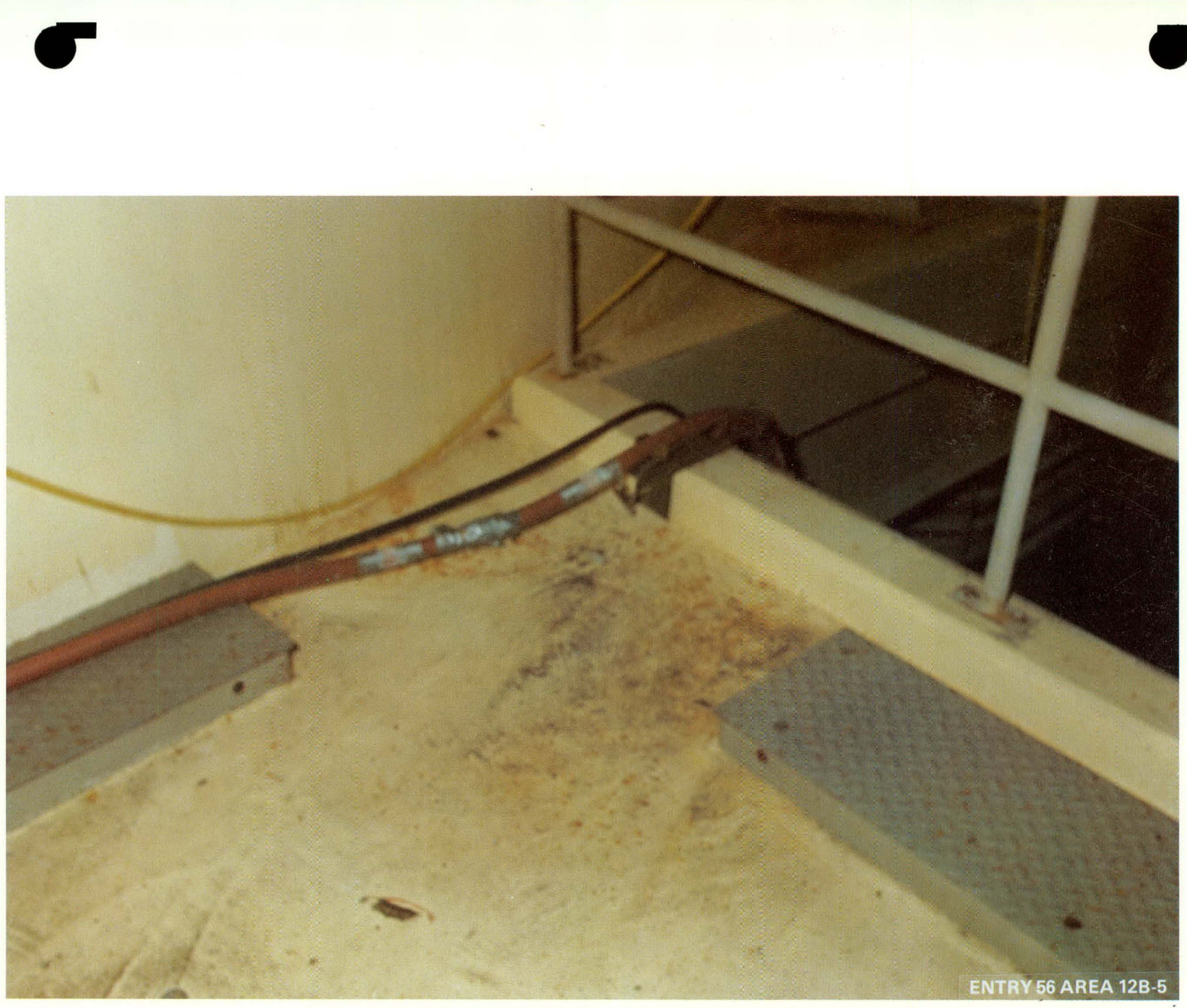

PHOTOGRAPH F-1 


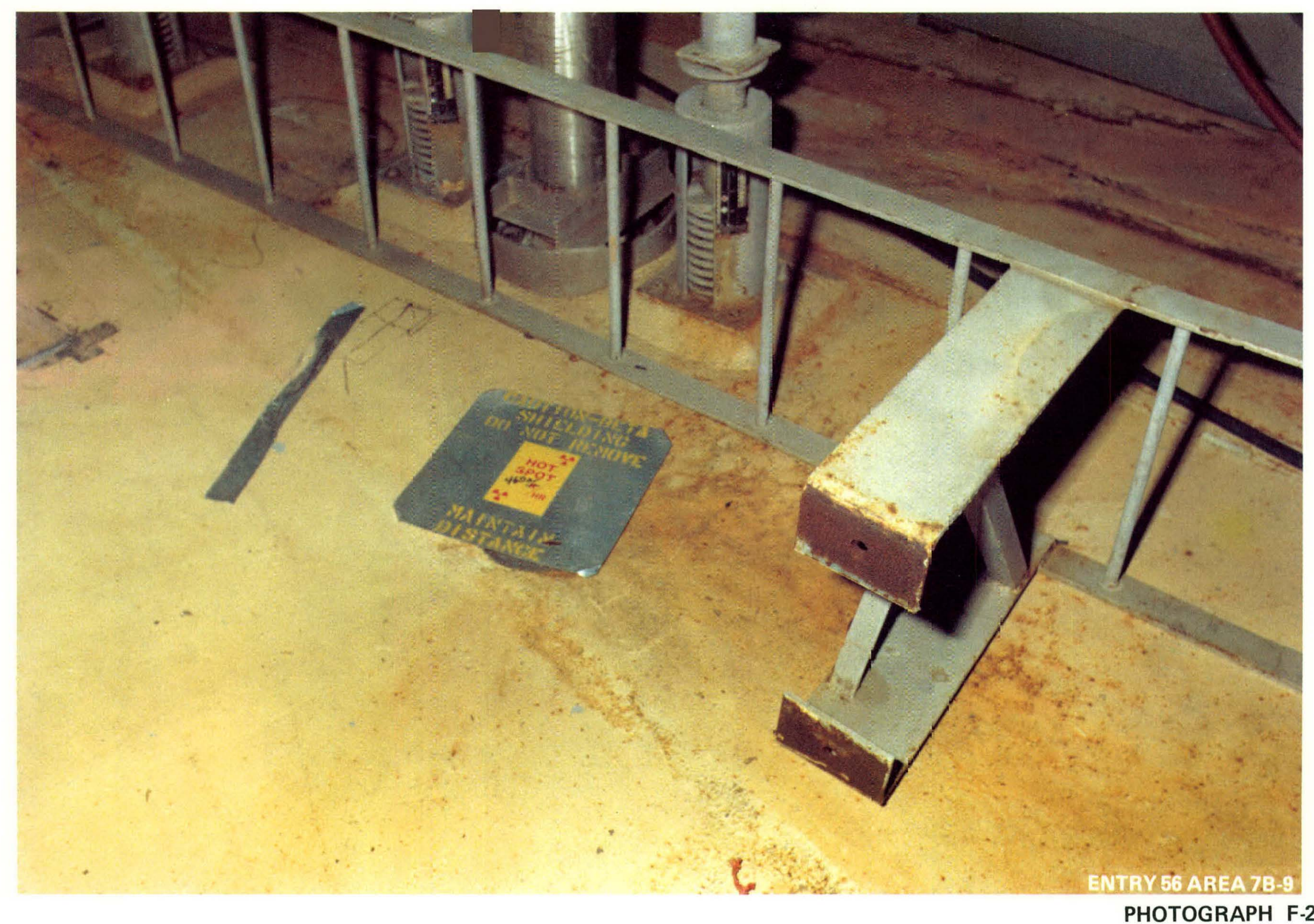

PHOTOGRAPH F-2 


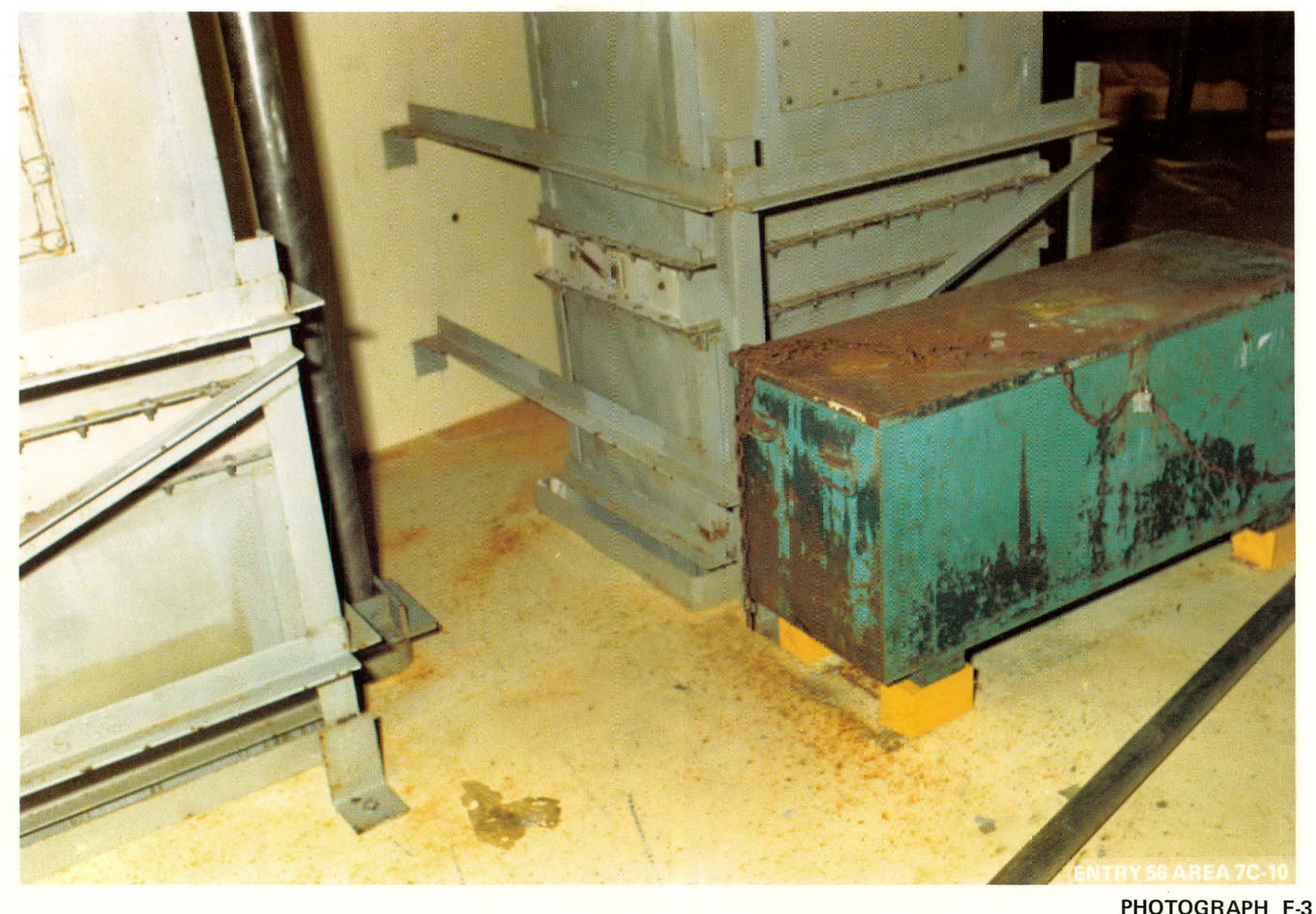




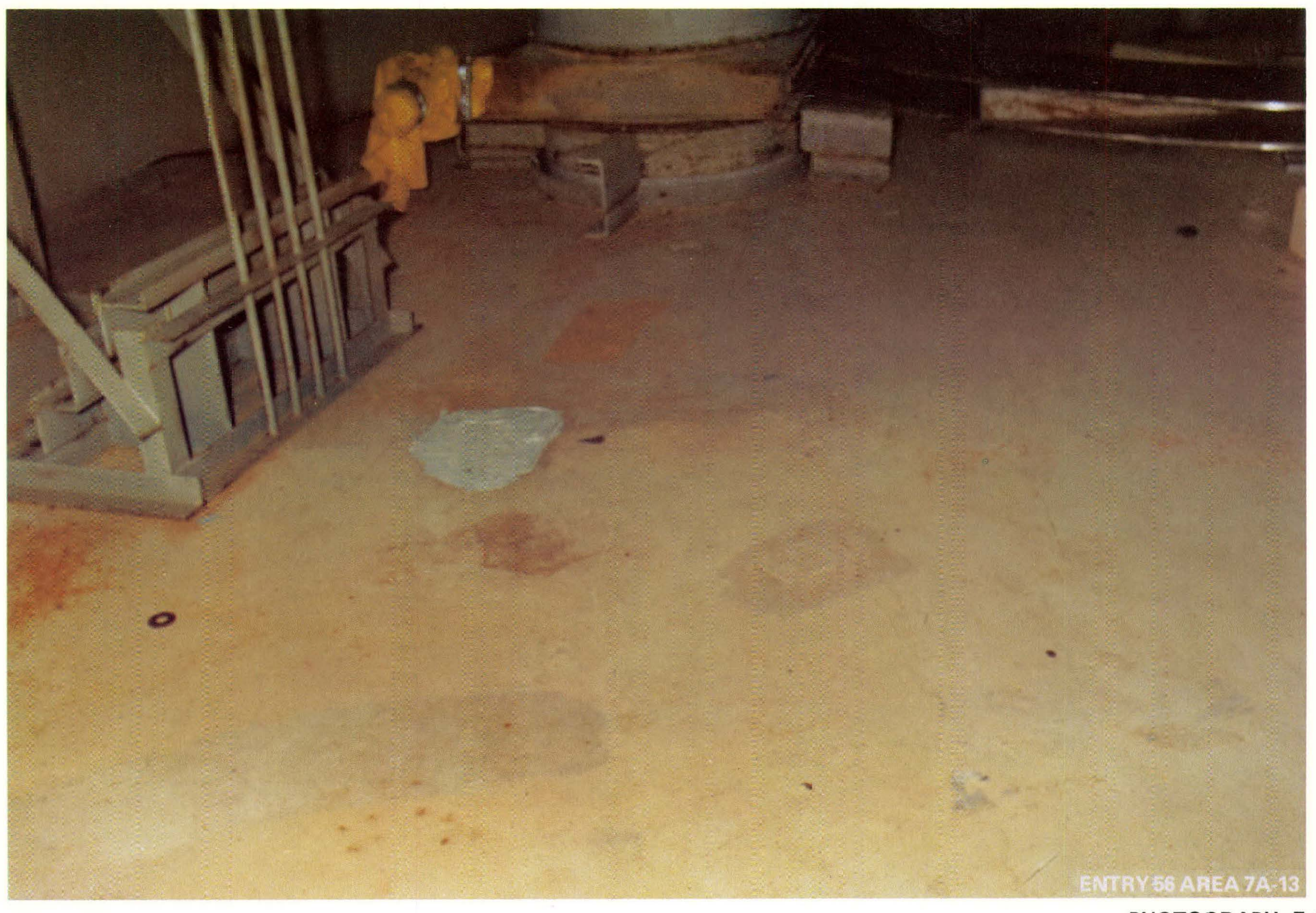

PHOTOGRAPH F-4 


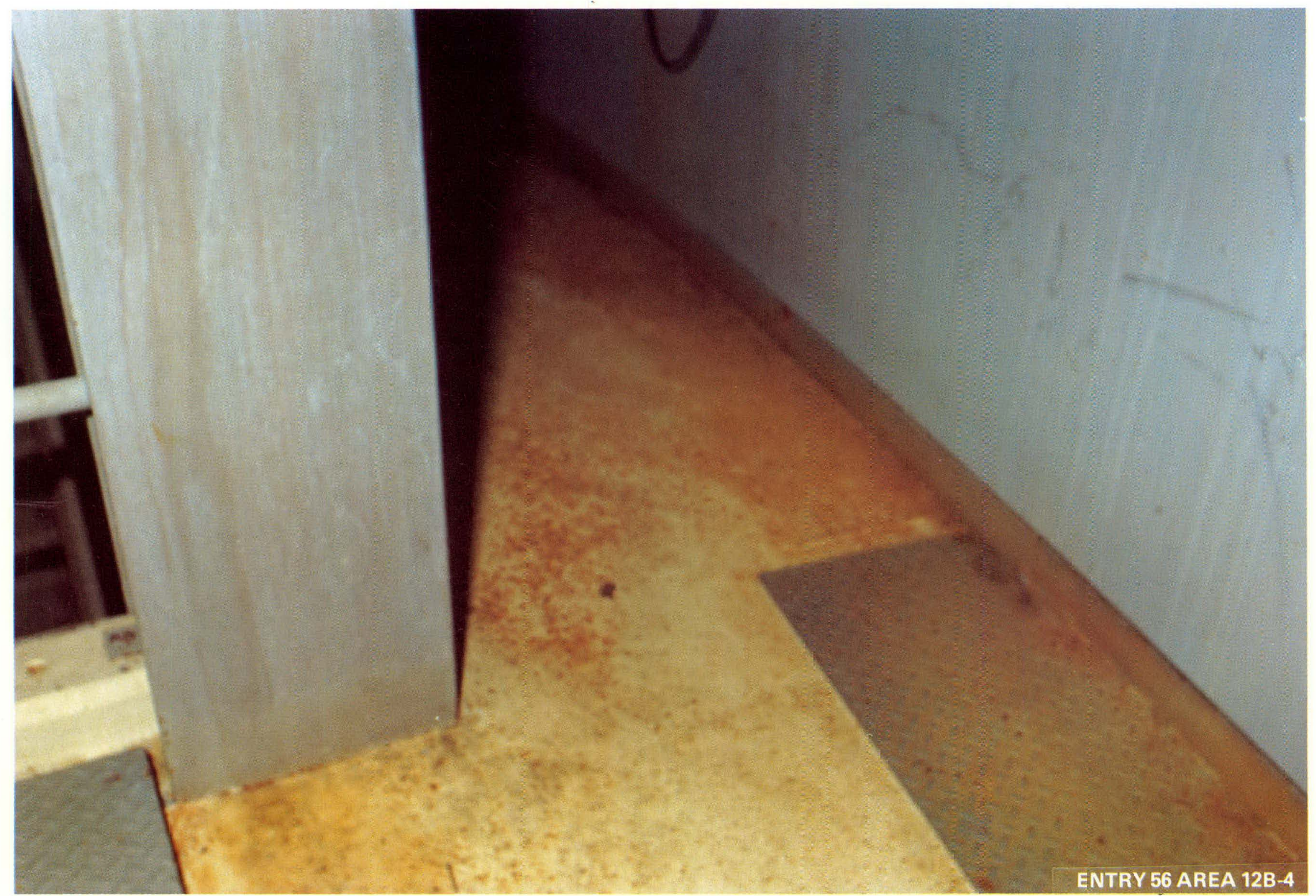

PHOTOGRAPH F-5 


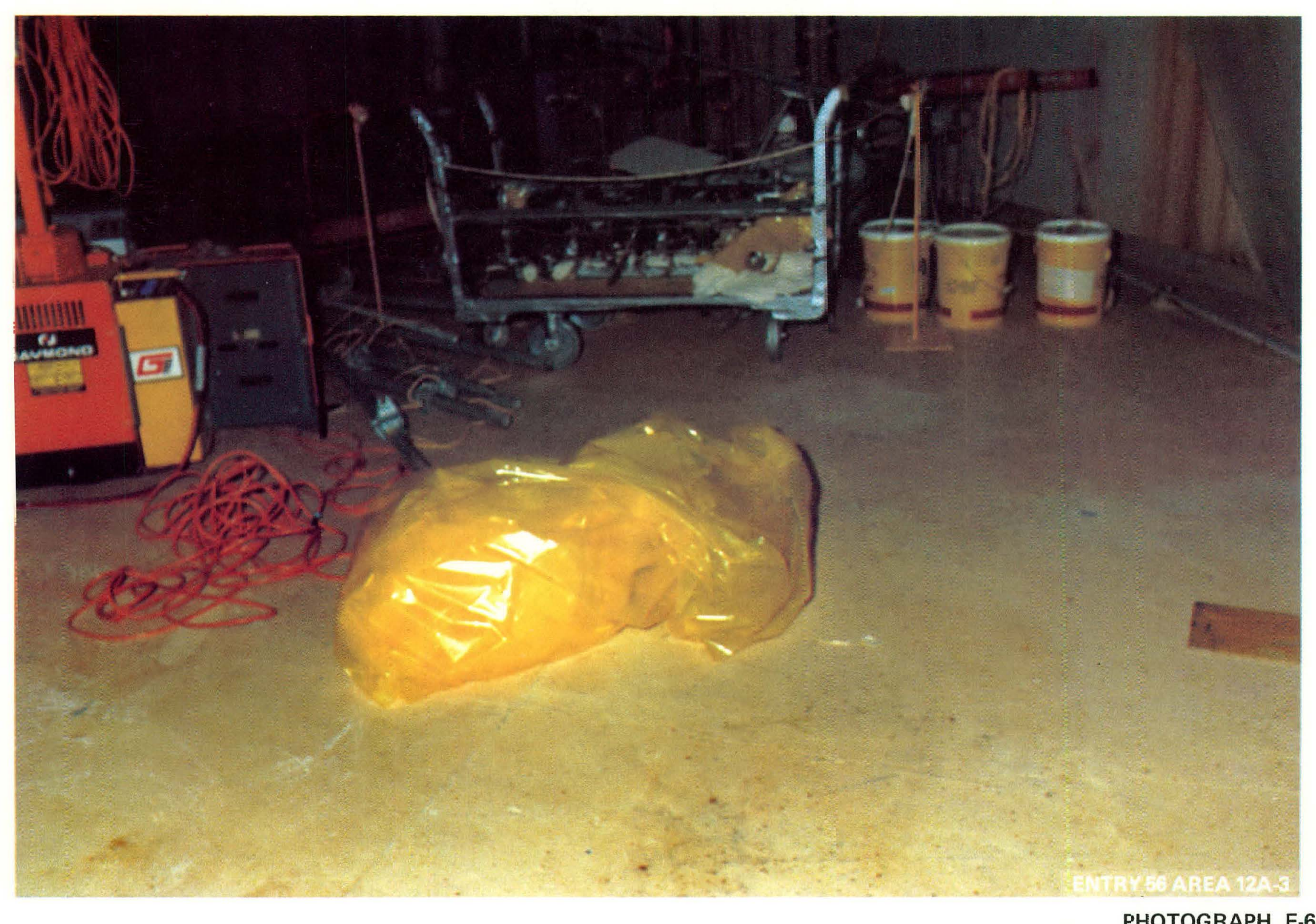

PHOTOGRAPH F-6 


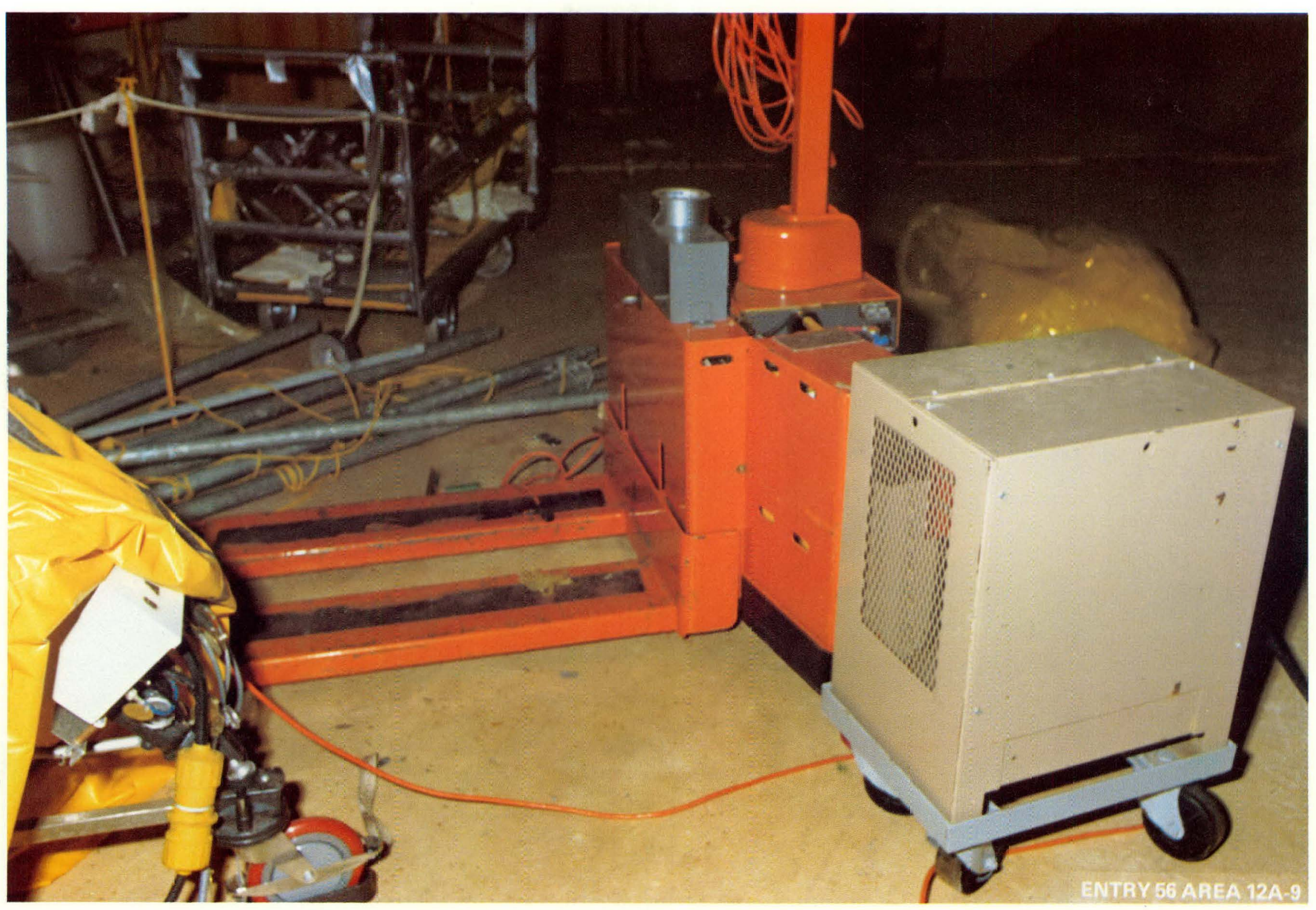

PHOTOGRAPH F-7 


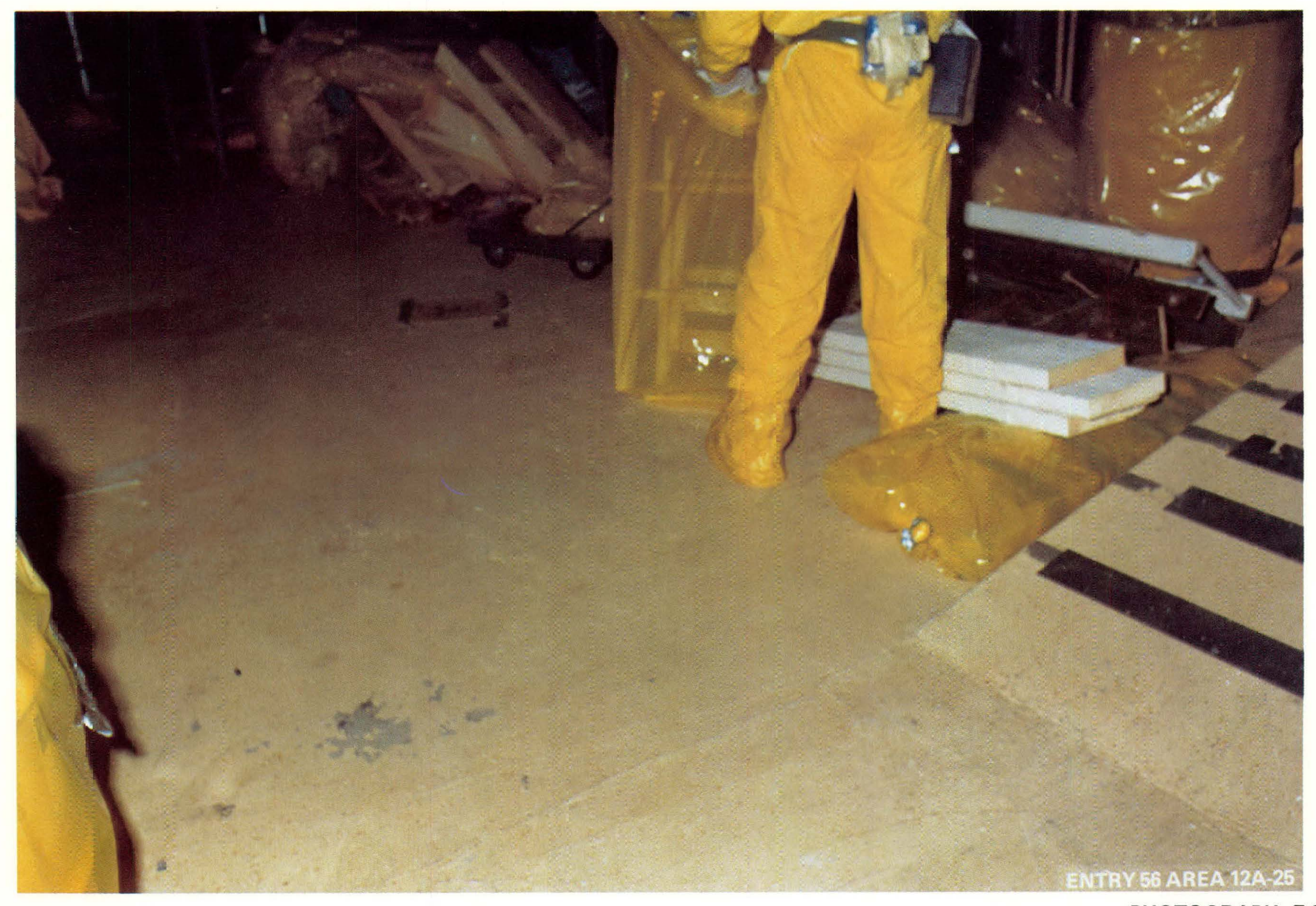

PHOTOGRAPH F-8 


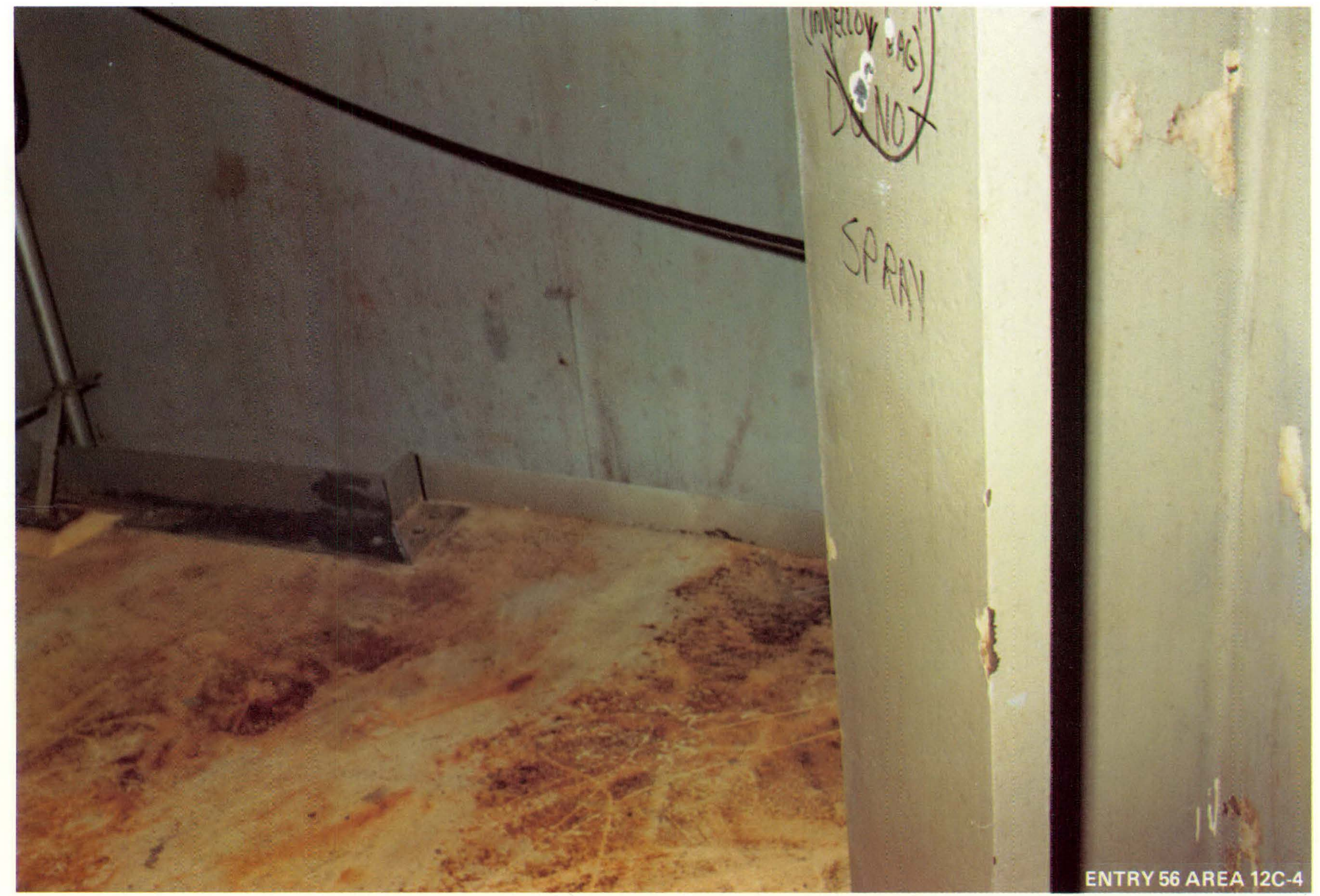

PHOTOGRAPH F-9 


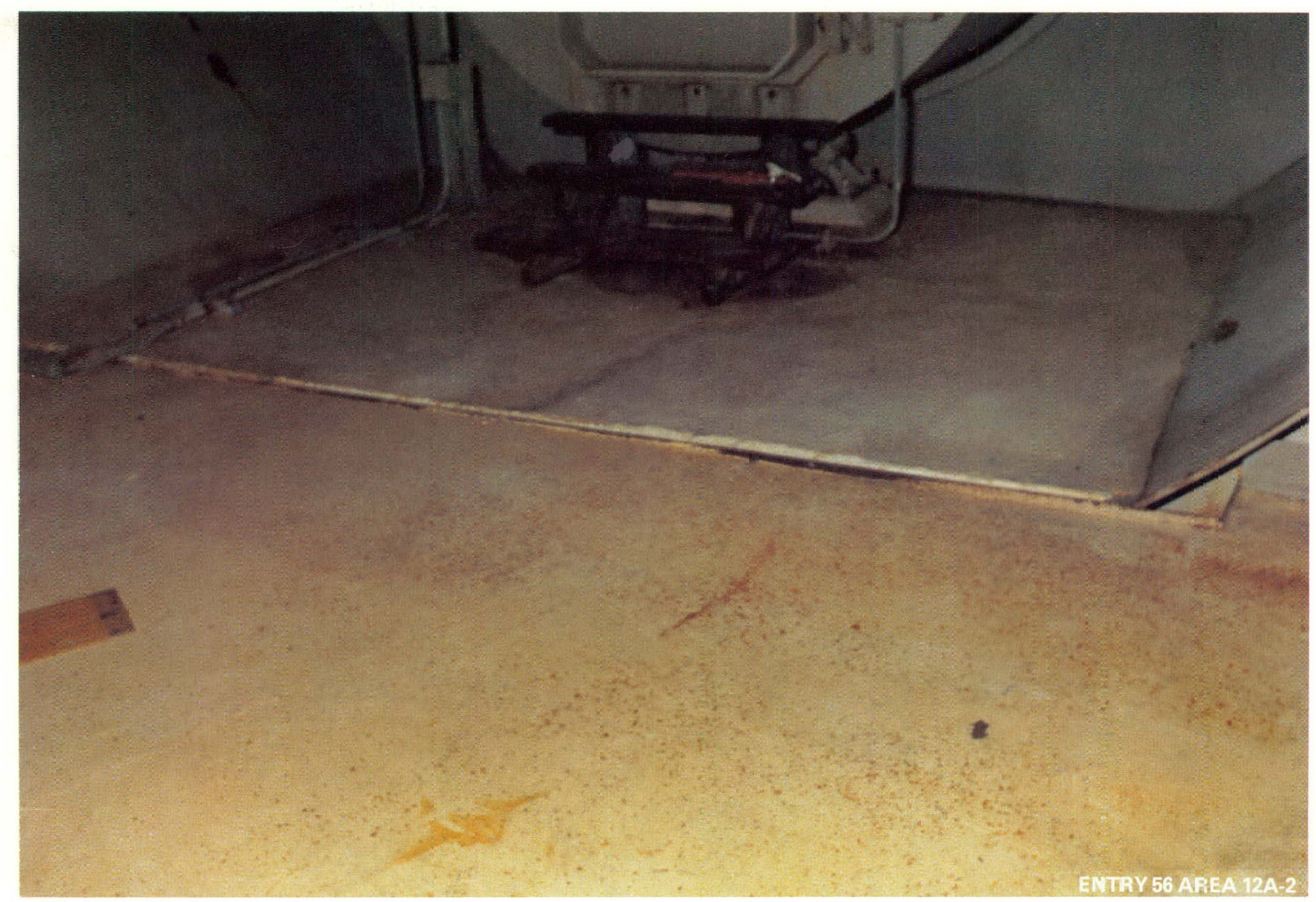

PHOTO:RAPH F-10 


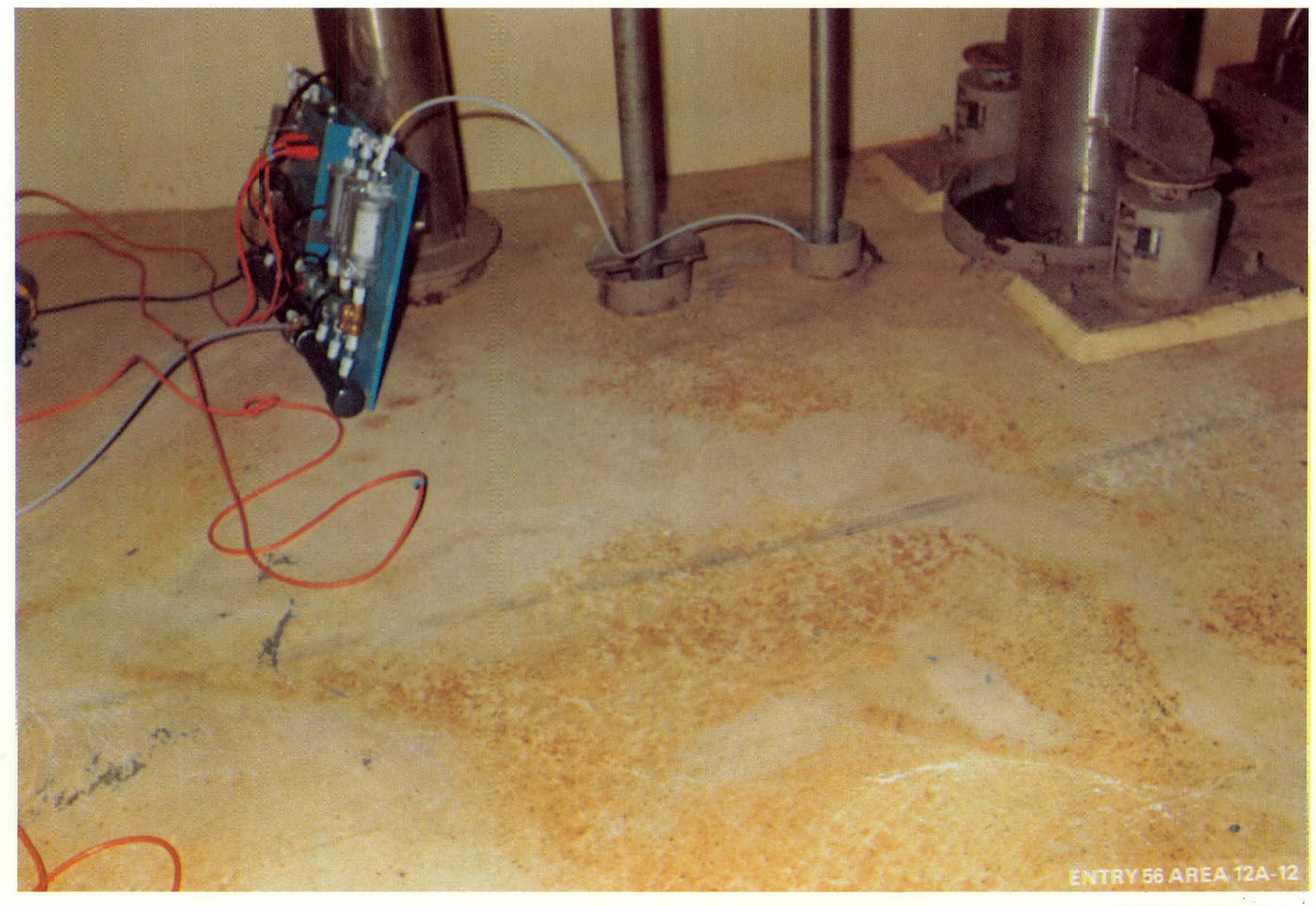




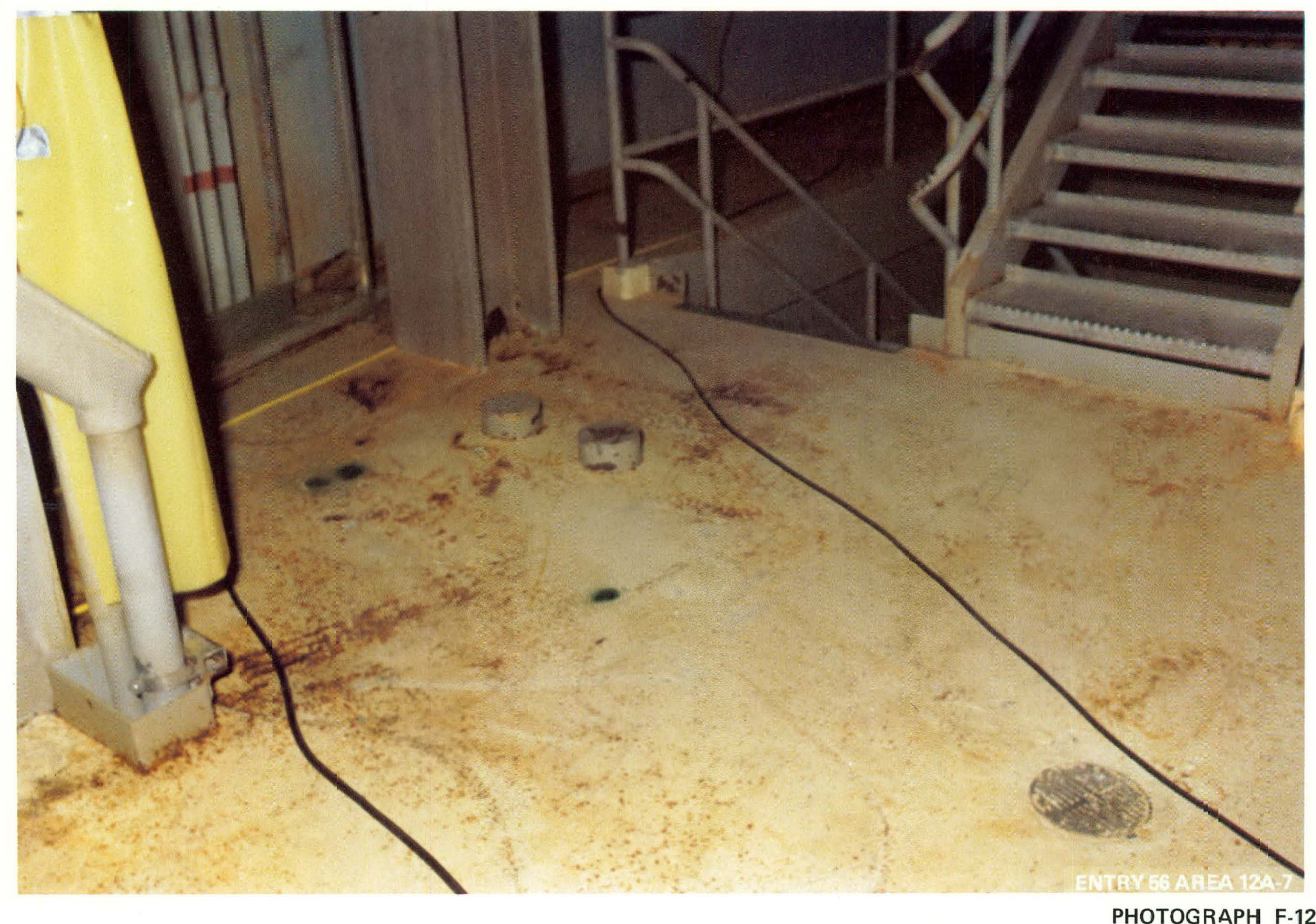




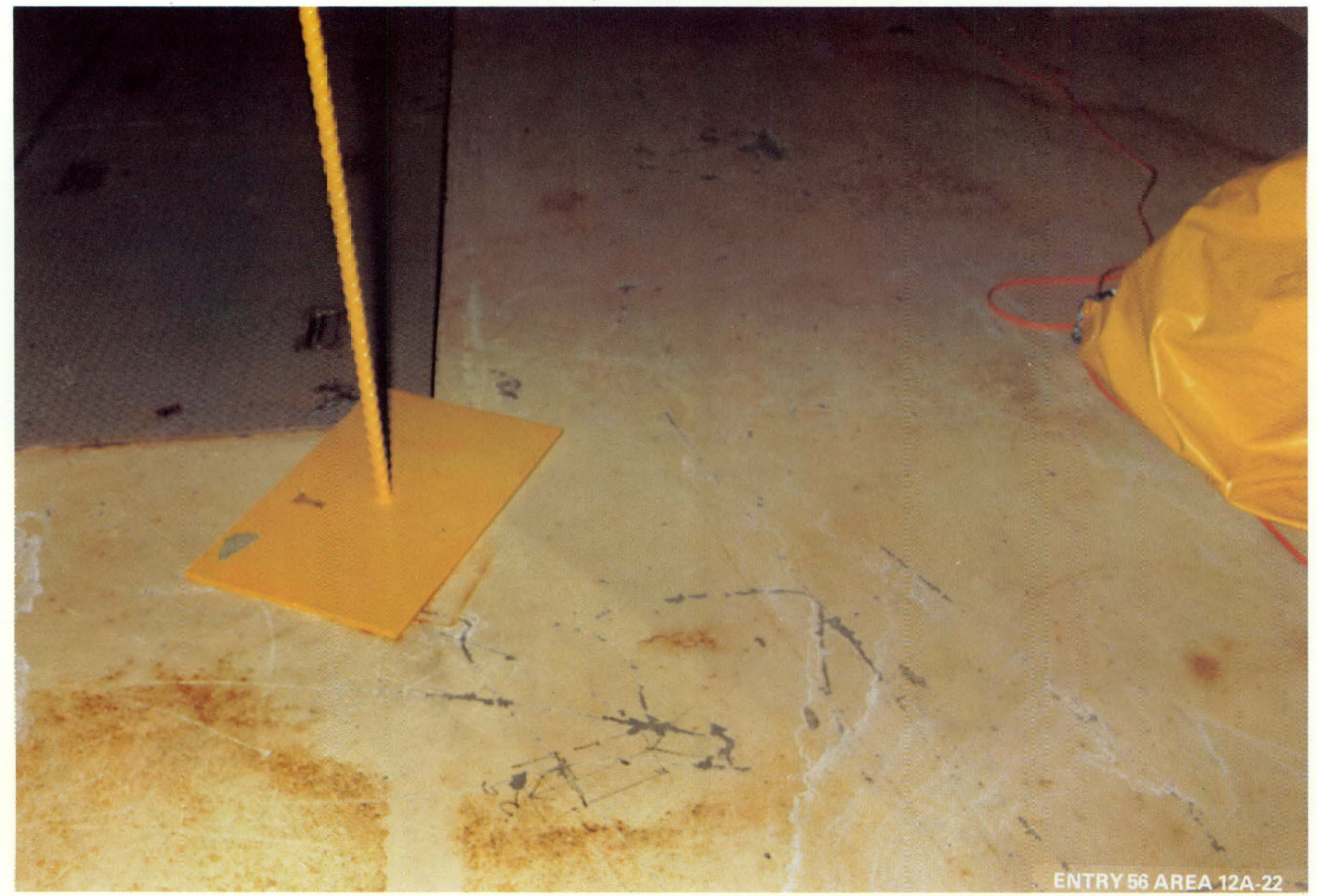




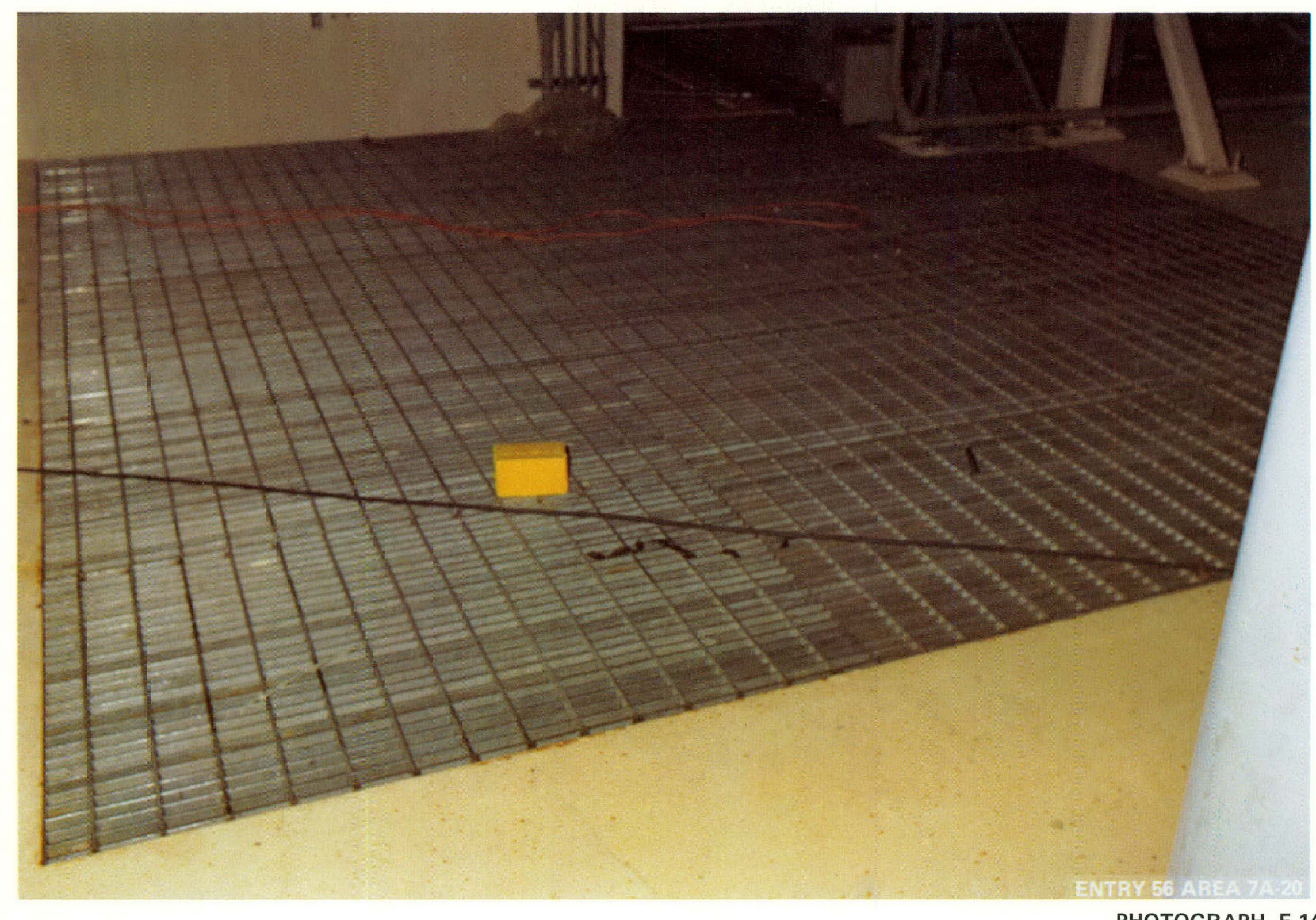

PHOTOGRAPH F-14 


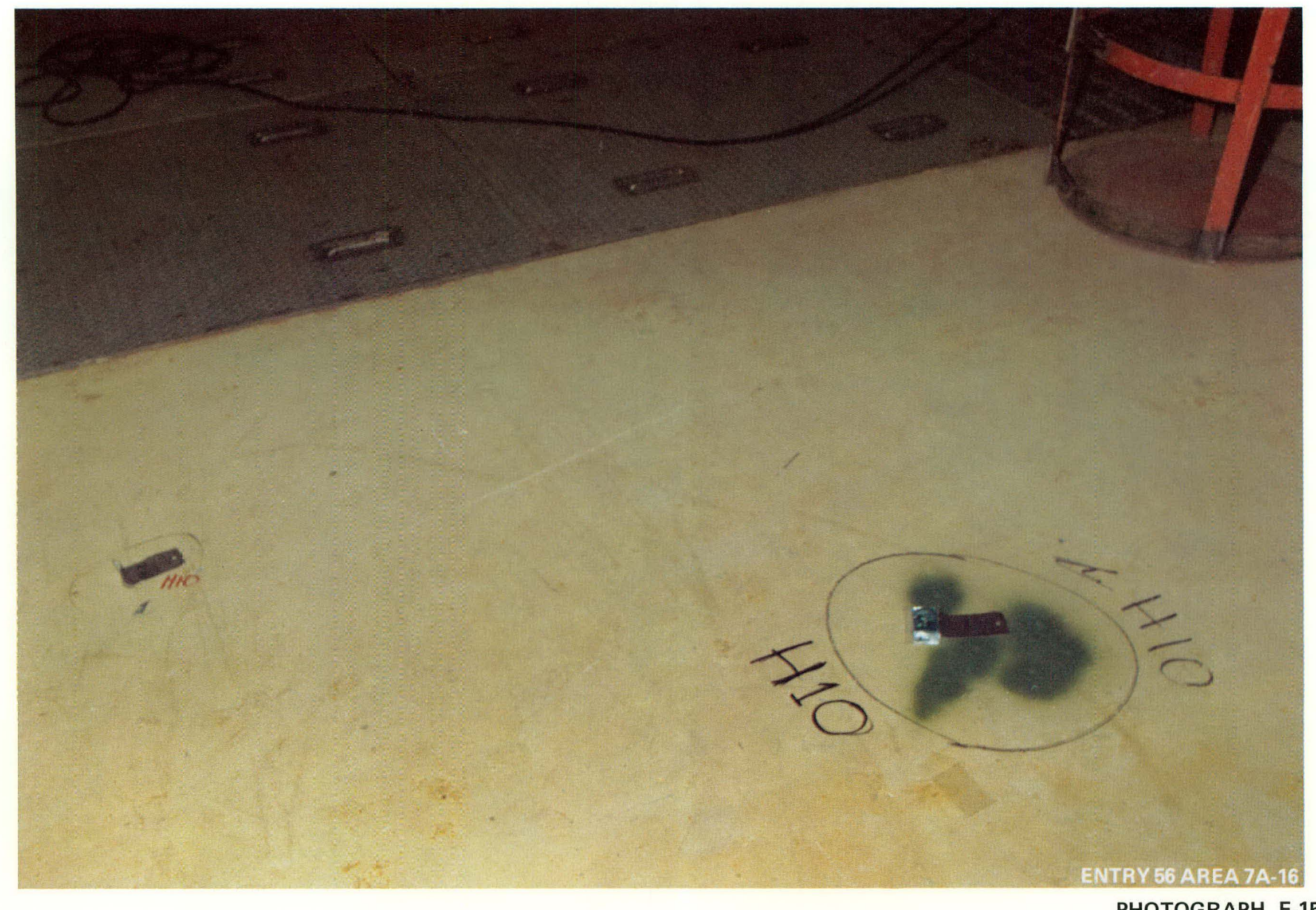

PHOTOGRAPH F-15 


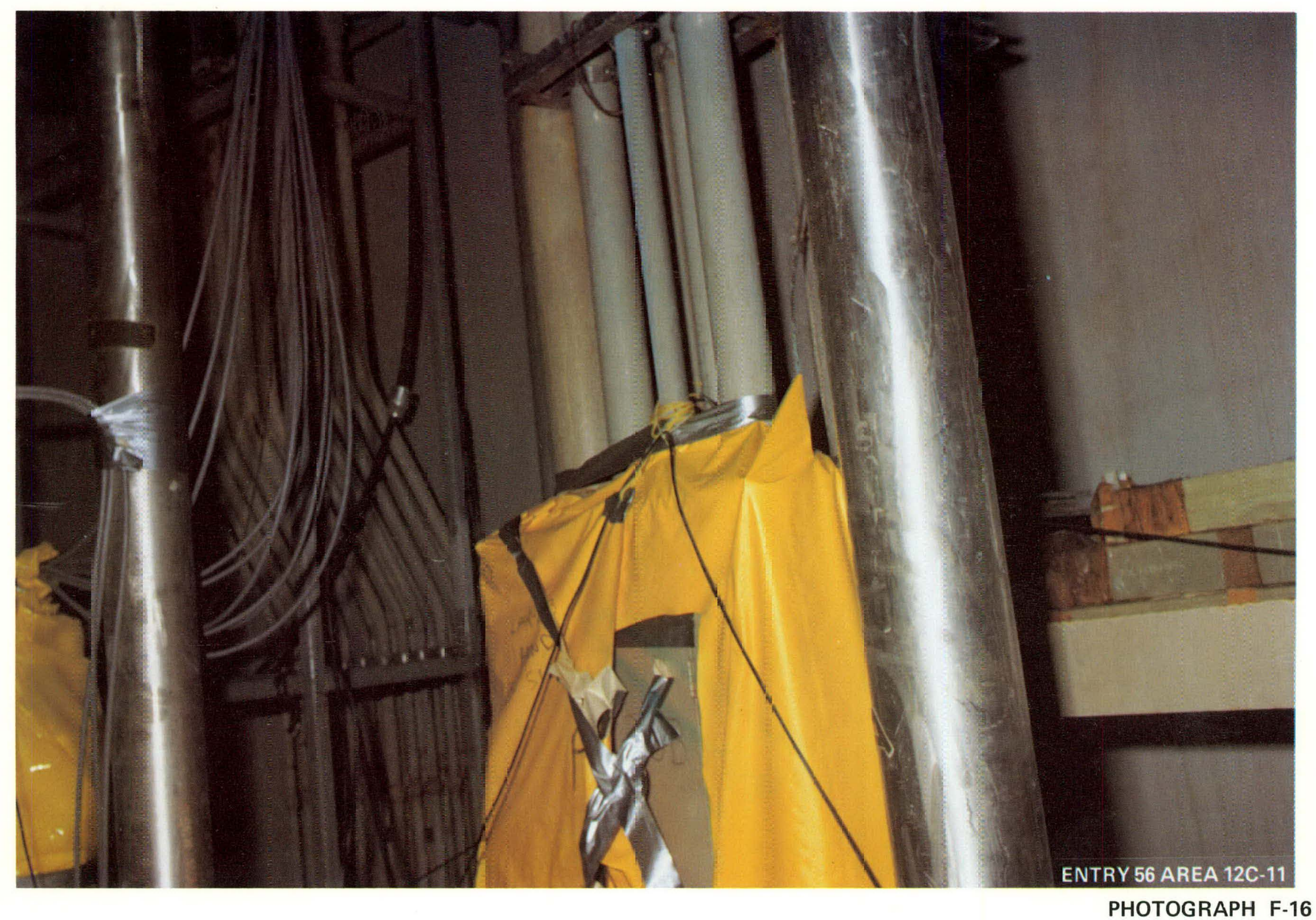




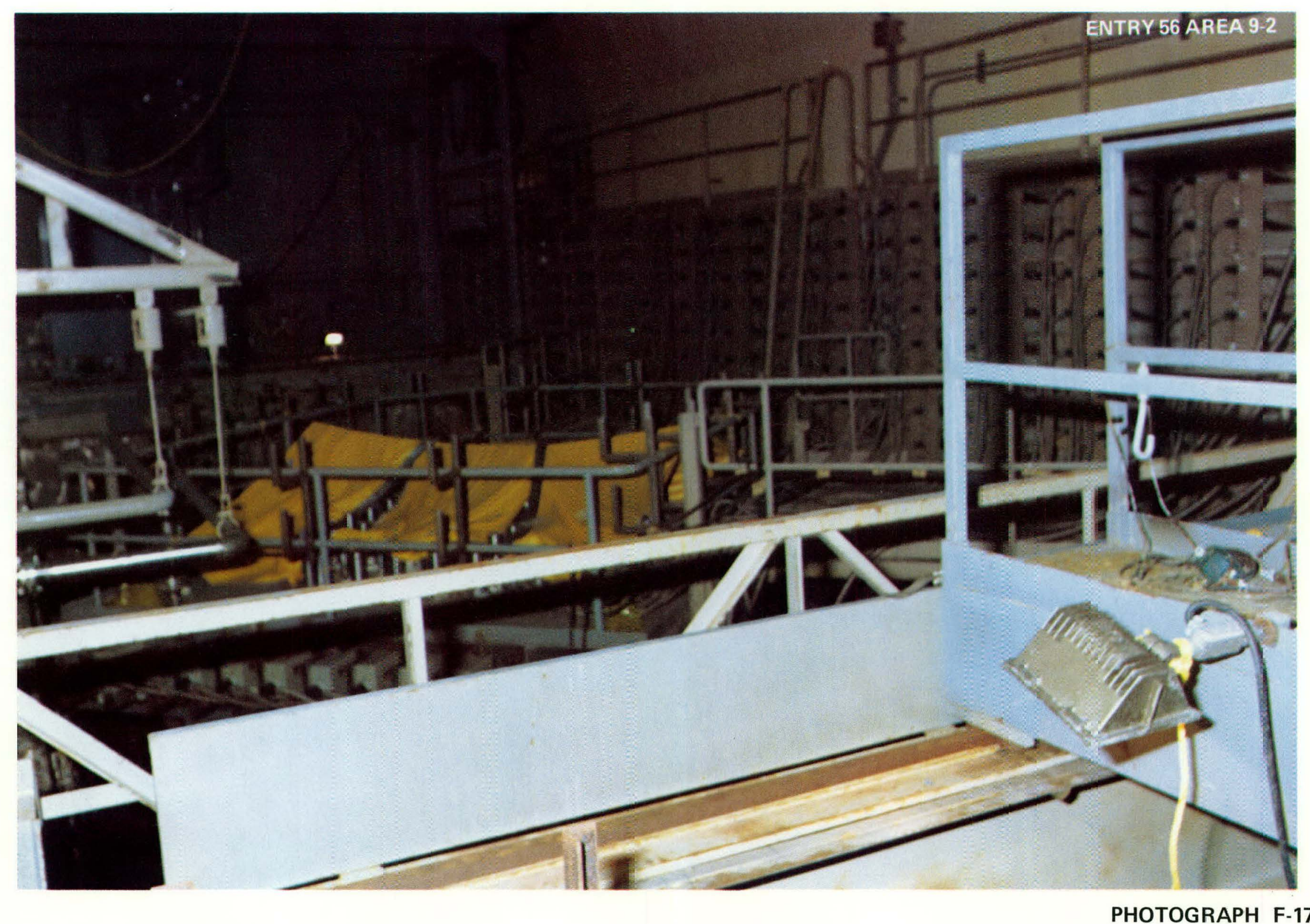




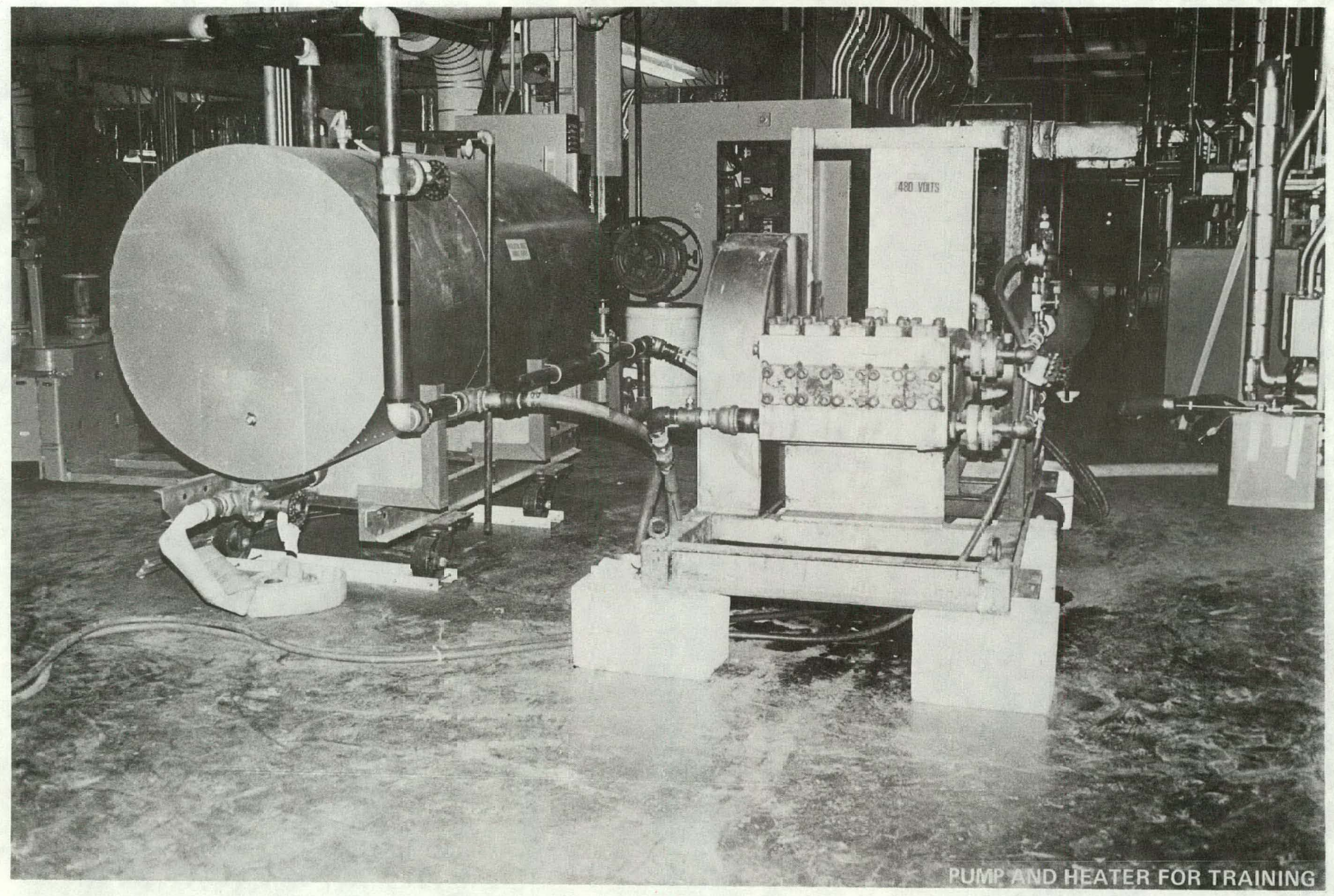




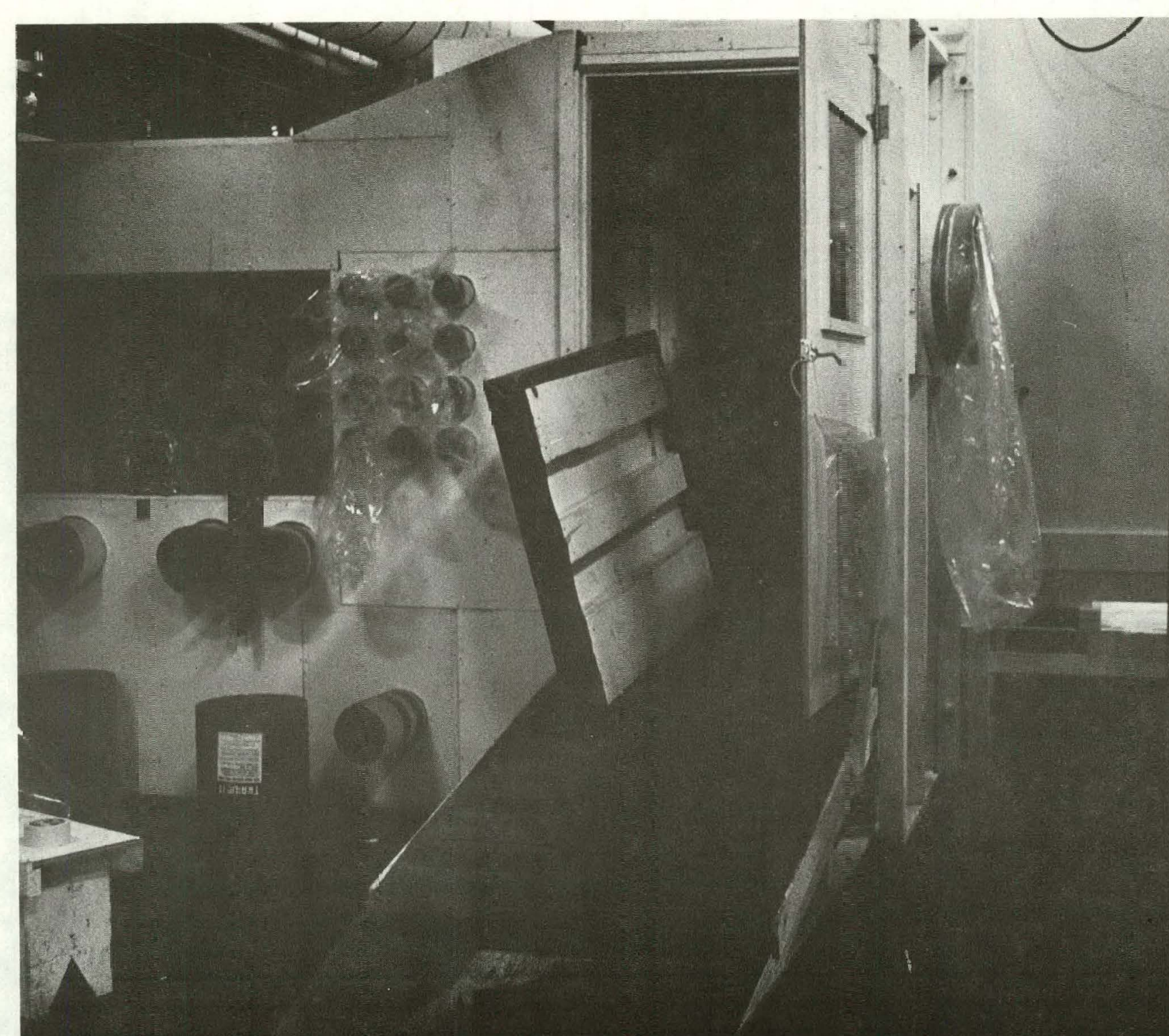

AIRLOCK NO. 2 MOCKUP

PHOTOGRAPH F-19 


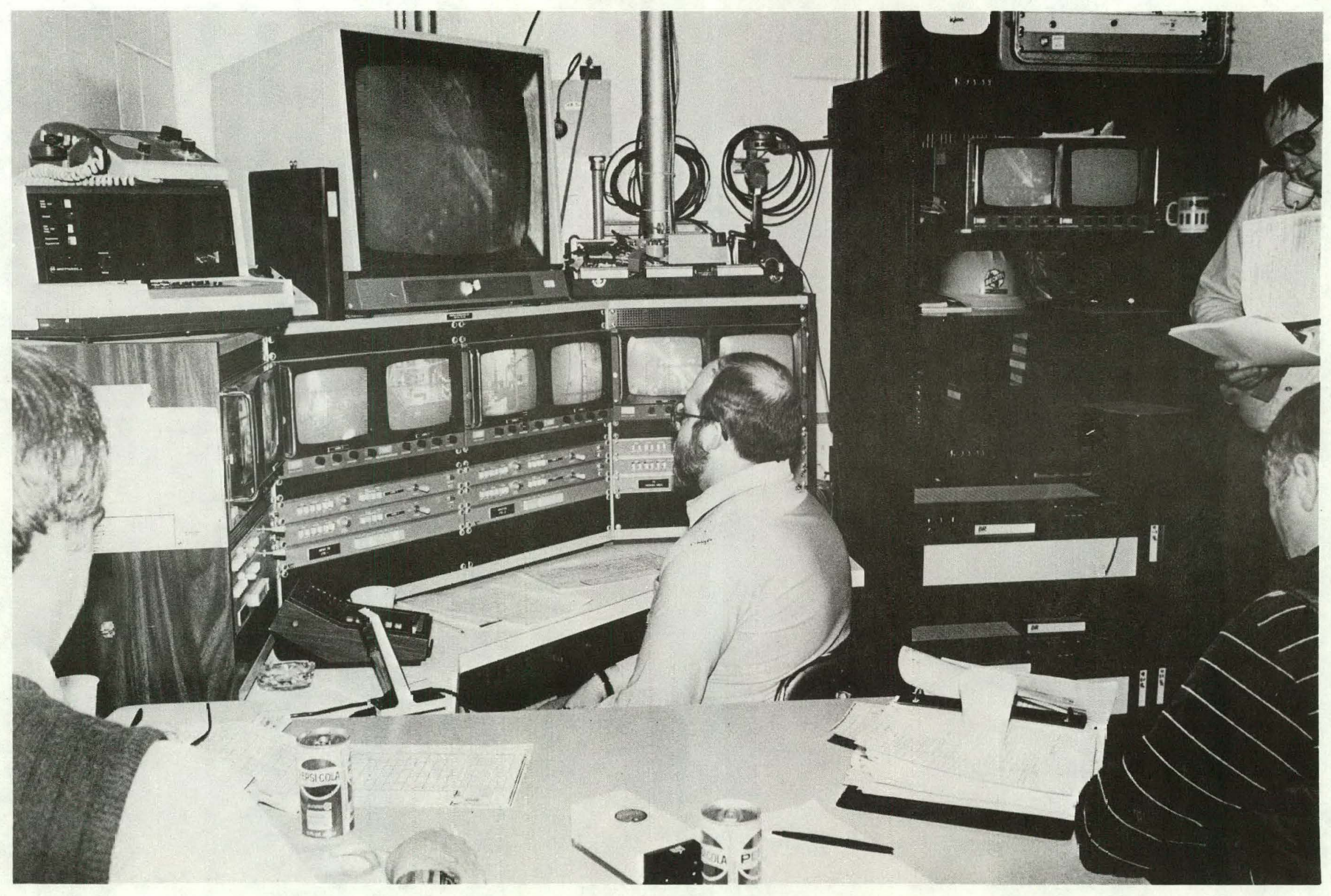


APPENDIX G

VIDEOTAPE AND WORK PACKAGE LISTING 


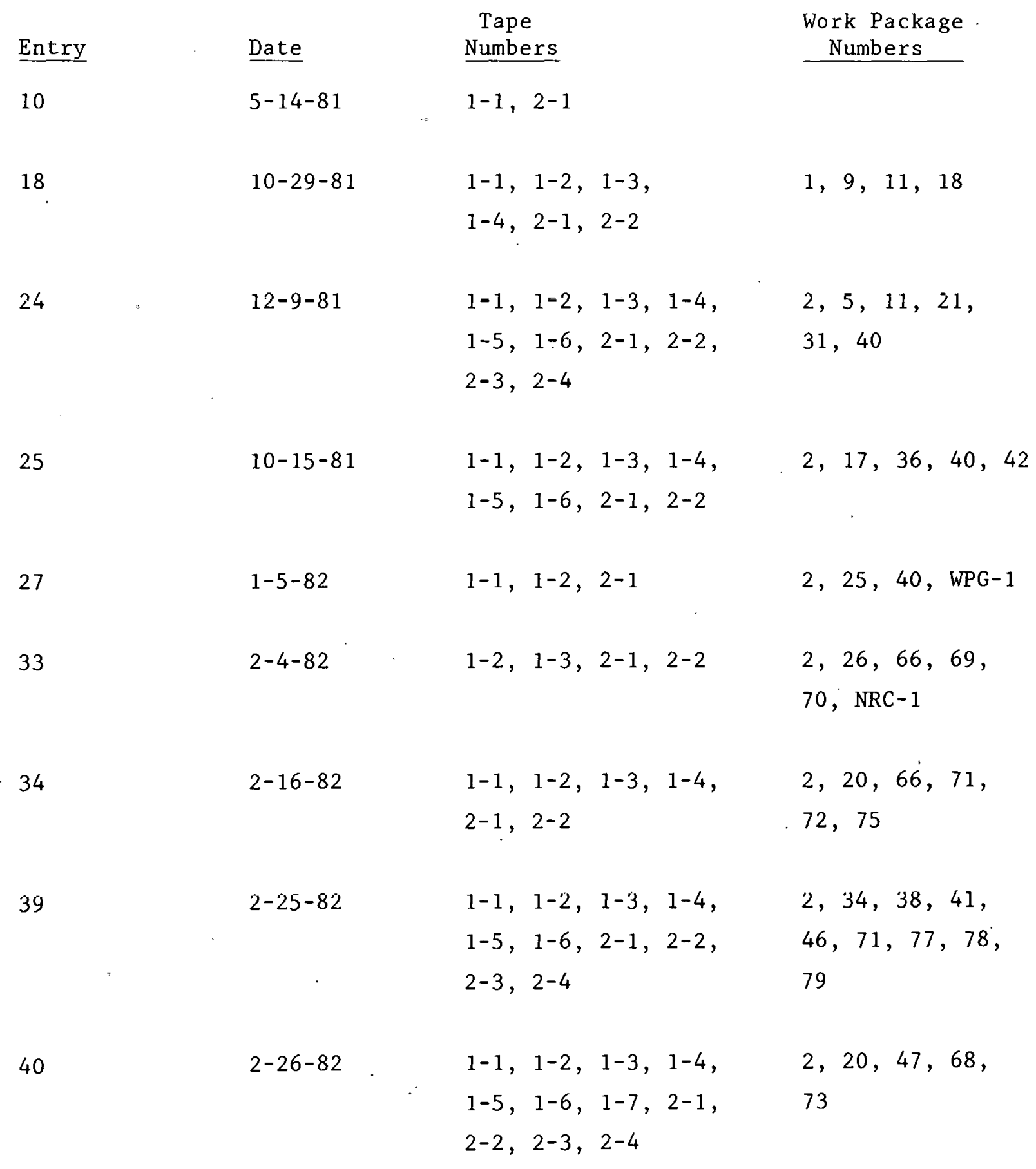


VIIDEOTAPE AND WÖRK PACKAGE LISTING

(Continued)

\begin{tabular}{|c|c|c|c|}
\hline Entry & Date & $\begin{array}{c}\text { Tàpe } \\
\text { Numbers }\end{array}$ & $\begin{array}{l}\text { Work Package } \\
\text { Numbers }\end{array}$ \\
\hline 41 & $3-2-82$ & $\begin{array}{l}1-1, \quad 1-2, \quad 1-3, \quad 2-1, \\
2-2\end{array}$ & $2,47,66$ \\
\hline 42 & $3-3-82$ & $1-1,1-2$ & 2,31 \\
\hline 43 & $3-4-82$ & $\begin{array}{ll}1-1, & 1-2,1-3,1-4, \\
1-5, & 1-6,2-2\end{array}$ & $2,47,53$ \\
\hline 44 & $3-5-82$ & $1-1,2-1$ & 2,53 \\
\hline 45 & $3-8-82$ & $1-1,1-2,1-3,2-1$ & $2,49,53$ \\
\hline 46 & $3-10-82$ & $\begin{array}{ll}1-1, & 1-2,1-3,1-4, \\
1-5, & 2-1,2-2\end{array}$ & $2,49,50$ \\
\hline 47 & $3-11-82$ & $\begin{array}{ll}1-1, & 1-2,1-3,1-4, \\
1-5, & 2-1\end{array}$ & $2,49,51$ \\
\hline 48 & $3=12-82$ & $\begin{array}{l}1-1,1-2,1-3,1-4, \\
1-5,1-6,2-1\end{array}$ & 2,51 \\
\hline 49 & $3-15-82$ & $\begin{array}{ll}1-1, & 1-2,1-3,1-4, \\
2-1, & 2-2\end{array}$ & $\begin{array}{l}2,47,51, \\
90\end{array}$ \\
\hline 50 & $3-17-82$ & $\begin{array}{ll}1-1, & 1-2,1-3,1-5 \\
2-1, & 2-2,2-3\end{array}$ & $\begin{array}{l}2,47,51, \\
52\end{array}$ \\
\hline
\end{tabular}


VIDEOTAPE AND WORK PACKAGE LISTING

(Continued)

\begin{tabular}{|c|c|c|c|}
\hline Entry & $\underline{\text { Date }}$ & $\begin{array}{l}\text { Tape } \\
\text { Numbers } \\
\end{array}$ & $\begin{array}{l}\text { Work Package } \\
\text { Numbers }\end{array}$ \\
\hline 51 & $3-18-82$ & $1-1, \quad 1-2, \quad 2-1$ & 2,93 \\
\hline 52 & $3-19-82$ & $1-1,1-2,2-1$ & 2,47 \\
\hline 53 & $3-24-82$ & 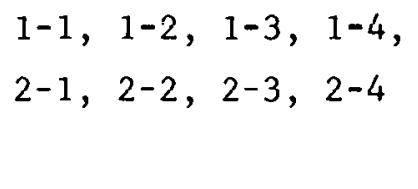 & $\begin{array}{l}2, \mathrm{C} 0001, \\
\mathrm{D} 100, \mathrm{M} 0001 \\
54,80,81\end{array}$ \\
\hline 54 & $3-25-82$ & $\begin{array}{ll}1-1, & 2-1 ; 2-2 \\
2-3, & 2-4,2-5\end{array}$ & $\begin{array}{l}2,85,86, \\
92, \mathrm{D} 101\end{array}$ \\
\hline 55 & $3-26-82$ & $\begin{array}{ll}2-1, & 2-2,2-3, \\
2-4, & 2-5,2-6,2-7\end{array}$ & $\begin{array}{l}2,54,81, \\
85,86, \mathrm{C} 0001, \\
\mathrm{E} 0002, \mathrm{D} 101\end{array}$ \\
\hline 56 & $3-31-82$ & $\begin{array}{l}2-1,2-2,2-3 \\
2-4\end{array}$ & $\begin{array}{l}2,53, \mathrm{D} 0001, \\
\mathrm{D} 100, \mathrm{E} 0002\end{array}$ \\
\hline
\end{tabular}




\section{WORK PACKAGES}

Work Package

Number

1

2.

3

4

5

6

7

8

$9 ;$

10

11

12

13

14
Title

Area Cleanup

HP Survey

Electrical Power Walkdown

Pull: Small Grating

Equipment Frotections

Decuntaminaliun Ploulus

Insulation Removal

Snubber Inspection

Videntapipe

Reinstall 56:1 Blank

H.PR -212

AHV -74

AlHV -6

Biological Samples
Gross Decontamination Experiment

Data Acquisition.

Task Number 
WORK PACKAGES (Continued)

Work Package

Number

15

16

17

18

19

20

21

22

23

24

25

26

\section{Gross Decontamination Experiment \\ Data Acquisition \\ Task Number}

Title

Liquid Sample at Polar Crane

Sump Refill Line

Surface Deposition

Gamma Spectrometer

Radio System

120-Volt Service (ECM 950)

Transient Combustible Control Inventory

Install Portable CCTV Cameras

Polar Crane Walkdown

Polar Crane Inspection

Supports for Spider at Polar Crane

and Install Lift Rig

Power to Spider/Operational Test 
WORK PACKAGES (Continued)

Work: Package

Number

2.7

28

29

30

31

32

33

3.4

35

36

37.
Title

Pull Hatch

Stage Spider

Operation of High Reach

Move Beams.

CCTV Work

Ramp:

Stage High Reach

Load: Test Spider Supports in

Containment

CAG Inspecliun aud Radiu Tesl

Hydrogen Bụrn Samples

Provide Access Platform at

Ellevation $3477^{\prime}-6 "$ "
Gross Decontamination Experiment

Data Acquisition Task Number 


\section{WORK PACKAGES (Continued)}

Work Package

Number

\section{Title}

Safety Equipment for Spider

41

43

44

45

46

47

48

49

50

Constant Air Monitors

Characterization Survey

Install Hoses and Test

Shut Ventilation Dampers to

Elevation 282'

HPR-214. Inspection

Snubber Removal

Cable Samples

Decontaminate Water (ECM 963)

LP Elevation 305'

Decontaminate Stairwell

LP Elevation Missile Shields, D-Rings

LP Elevation 347'-6"
Gross Decontamination

Expcriment Data Acquisition Task Number 
WORK PACKAGES (Continued)

, .

Work Package

Number

51

52

53

54

55

56

57

59

60

61

62

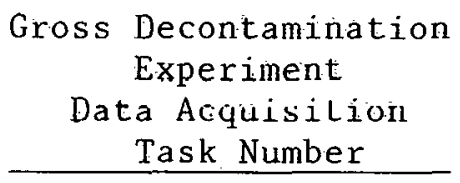

4

6

4

(Elevation 347'-6"')

Spider Lifl Electrical Inspection

Load Test and Welding Inspections

for Spider Supports (Out of

Containment)

Tnstal1 ronosenerks

Move Resin Column

New Temperature Lights on

Elevation $305^{\prime}$

Emergency Lights

Electrical Status $480 \mathrm{~V}$ Systems 
WORK PACKAGES (Continued)

\section{Work Package \\ Number}

63

64

65

66

NRC -1

68

69

70

71

72

73

74 $\underline{\text { Title }}$

Refueling Canal Lights

Remove HPR-214

Pre-head Lift Exam No. 1 (Tool

Inventory)

Replace Fire Hoses

NRC Inspection

Equipment Protection on Polar Crane

Remove RM-16 (Radiation Detectors)

Identify Contents of 55-Gallon

Drums on Elevation 347'-6"

Gamma Spectrometer Rigging

Gamma Spectrometer on Elevation 347'-6"

Relocate CCTV Camera and Additional

Lighting at Refueling Canal

Fire Detection System
Gross Decontamination Experiment Data Âcquisition Task Number 
WORK PACKAGES (Continued)

Work Package

Number

75

76

77

18

79

80

81

หั.

83

84

85
Gross Decontamination

Experiment

Title

Data Acquisilion

Task Number

Contairuilent Physical Characteristics;

Supply Photos

Remove Pendant From P.C.

Decontamination Safety Inspection

All

Quarterly Inspection of P. $\dot{C}$.

Equipment

Replace and Protect Lifling

Equipment for ALARA Considerations

Mechanical Floor Scrubber

4.

Strippable Coating on Elevation 30.5'

5

Sperial $\mathrm{O}_{2}$ and $\mathrm{H}_{2}$ Gas Monitoring

Combustible Gas Monitoring

Install Landing Platform

on Elevation 305'

Post-Decontamination Surface

Deposition 
WORK PACKAGES (Continued)

Work Package
Number

86

87

88

89

90

91

92

93

D-100

D-101
Title

Post-Decontamination Containment

Characterization

Load Test Second Lift Rig

Hydro "Orange Duck" NLB Pump

Without Pulsation Damper

Videotaping of Decontamination

Operations

Move Items from Elevation 347'-6"

Storage Area

Relucate Cameras to Elevation $347^{\prime}-6^{\prime \prime}$

Incore Photographs

Trash Removal

Post-Test Photographs - Work

Packages 49, 51, 52

4,6 
DO NOT MOROFLLM THIS PAGE 
APPENDIX H

EXPERIMENTAL DESIGN AND METHODOLOGY 


\section{CONTENTS}

EXPERIMENTAL DESIGN H-

EXPERIMENTAL MEASUREMENT METHODOLOGIES $\mathrm{H}-7$

RECOMMENDATIONS H-8

TABLE H-1 Data Acquisition Specified in Sample Packages for Gross Decontamination Experiment

ATTACHMENTS

H-1 TECHNIQUE SHEET - RO-2 AND RO-2A USE

H-2 TECHNIQUE SHEET - SWIPE SURVEY

$\mathrm{H}-3 \quad$ DATA ANALYSIS 


\section{APPENDIX H - EXPERIMENTAL DESIGN AND METHODOLOGY}

The purpose of this appendix is to detail the experimental design and methodology used to evaluate the efficacy of the decontamination techniques that were the subject of this experiment. The appendix is divided into separate sections addressing the experimental design and the experimental measurement methodologies.

\section{EXPERIMENTAL DESIGN}

In order to evaluate those techniques used to perform gross decontamination of the reactor building, a design was necessary to collect the needed data. Designs available for characterization studies give some guidance as to the necessary number and types of measurements. Any design applied for the specific purposes within the reactor building has to be tempered by the heterogeneity of the contamination and surface types, and by the time and dose constraints on workers in the containment.

The discussion on experimental design is divided into five sections: scope and purpose, relationship to the entry program and the large-scale decontamination experiment, design, implementation, and evaluation of design and its implementation.

\section{$\underline{\text { Scope and Purpose }}$}

The scope of the data acquisition design included all flushing, scrubber, and strippable coating decontamination techniques as they were tested on the several reactor building surfaces, including special equipment items. The purpose of the data acquisition design was to allow comparison of the decon- . tamination techniques used, in terms of removed contamination. The optimal techniques were to be identified by reactor building surface. 


\section{Relationship to Entry Program and to Large-Scale}

\section{Derontamination Test}

The design for data acquisition was based in part on the data acquisition results from the reactor building entry program and from the large-scale decontaninalion test. The objective of data acquisition during the initial reactor building entry program was to evaluate the probable mechanism of contamination and to characterize the radiological conditions of the reactor building surfaces,

Data and sample locations, which might elucidate the array of radiological conditions on the different reactor building surfaces, werc idcntified. Many of these sample locations were repeatedly measured/sampled in order to determine changes in radiological conditions with time.

Data/sample locations designated for use in the large-scale decontamination test were marked so that they could be reevaluated after the test. The dala/sample collection methods were used to define exact procedures for further characterization of the building, and for data acquisition tasks within the Gross Decontamination Experiment. For example, repeated measurements could be reproducible only if the orientation of the data acquisition technician was repeatedly the same with respect to walls, equipment, etc.

\section{Experinental Desigit}

The design used for data/sample collection was a simple extension of those points designated for reactor building characterization. The points designated were chosen to represent the array of surface/equipment types in the building. The design was minimal because of the constraints discussed below.

Intent of the Design

The sample/data points chosen were scattered over vertical and horizontal diamond plate and concrete surfaces, and on exposed surfaces of equipment 
items. The points were scattered in areas known to be in the contamination pathway and areas only contaminated by secondary deposition.

'l'he intent of the design was to furnish a before-versus after-decontamination technique comparison of removable and fixed contamination at the sample/ data collection points. These data would then allow technique efficiencies to be compared by surface/equipment type.

\section{Constraints}

In order to rigorously evaluate the decontamination techniques used, a large data base was required. The problems in establishing a rigorous data base included:

- Heterogeneity of reactor building surfaces and coatings

- Irregular geometry of equipment surfaces

- Heterogeneity of the contamination pathway and resulting deposition patterns

- Difficulty in measurements made in an environment of multiple sources, changing patterns of resuspension and deposition, and high relative humidity

There were several constraints in obtaining data required to assess the efficiency of decontamination techniques. Consequently, the minimal data base to compare techniques was obtained. Constraints on the data acquisition tasks for the gross decontamination experiment included:

- Number of worker man-hours available to support the data acquisition tasks

- Man-rem available to support the data acquisition tasks 
- Cost of radiological analysis

- Cost of data synthesis and interpretation

The impact of these constraints on the ability to statistically compare decontaminalion lechniques should not be underestimated. In order to satisfy statistical criteria, it would be necessary to obtain many more data than were able to he designated for the gross decontamination experiment.

\section{Sample/Data Point Designations}

Sample/data points were designated within each treatment area. For the most part, these points were designated by the sample packages and were those used in the reactor building characterization. Detailed maps of sample/data point locations for specific treatment areas are shown in the next section. Table H-1 shows the types of data/samples requested for the two principal elevations. This table does not discriminate between surfaces of different materials or coatings, however. While designated points were dominately on concrete surfaces, the number of points certainly represents a minimum data base, even for these surfaces.

When work packages were prepared, some sample/data points were designated for more intensive evaluation. The rationale for these additions was the néčés̄íty to compare statıstıcally betore/atter treatment measurements on at least one reactor building surface. Since it was unclear whether surfaces other than floors would be treated, additional data points were designated on floor surfaces as the work packages were prepared. The designation was made of at least one location in each treatment area near the middle of the area. At this location, not only would area and contact readings be made at the point, but at the ends of 1 -meter intervals in a metric cross pattern. This resulted in five sets of measurements at these locations, rather than one set. 
TABLE H-1. DATA ACQUISITION SPECIFIED IN SAMPLE PACKAGES FOR GROSS DECONTAMTNATTON F.XPERTMENT

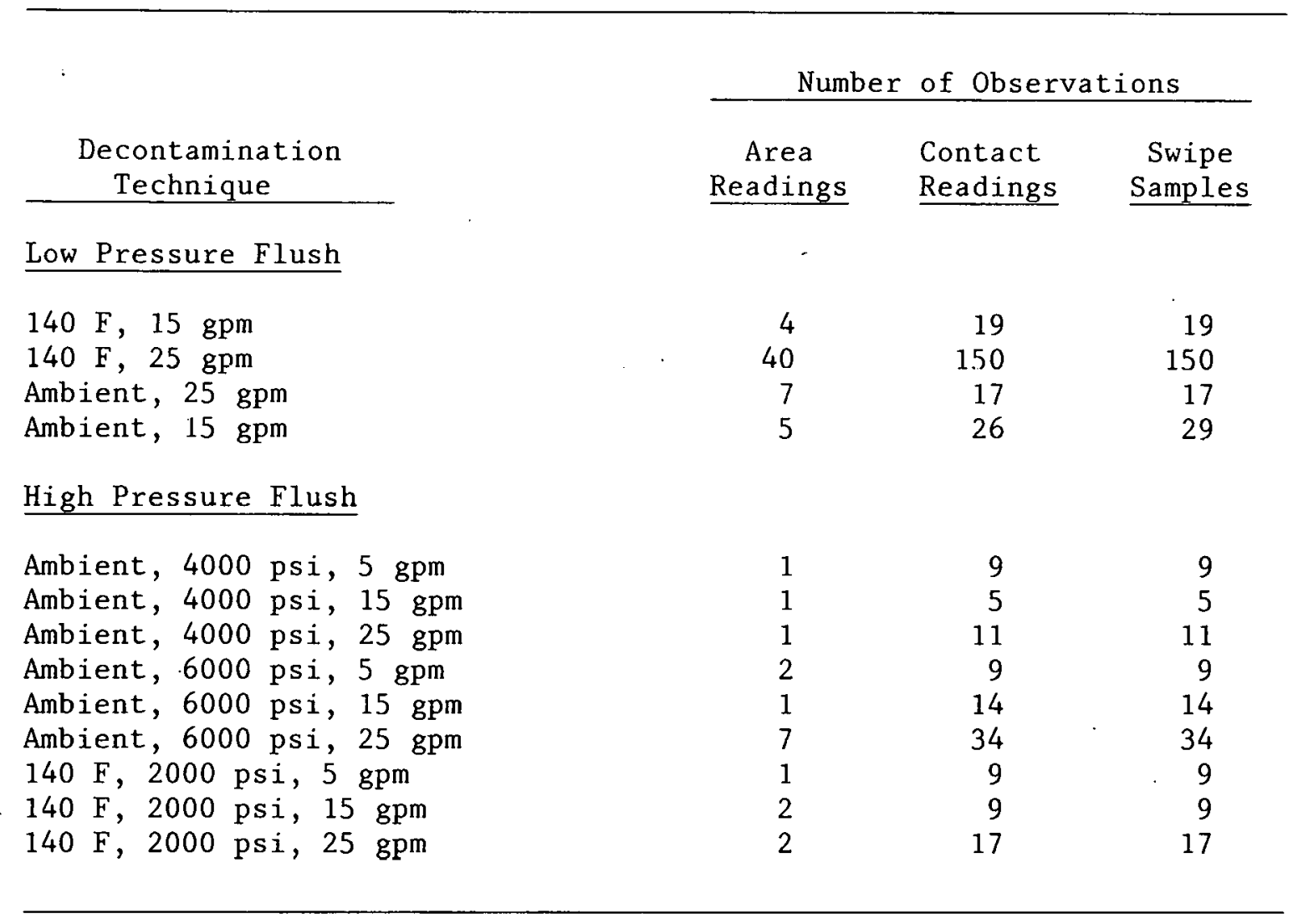

While the number of data points was thus increased appreciably, allowing more rigorous statistical treatment, the impact on man-hour and dose expenditure was minimal due to the proximity of the measurements.

$\underline{\text { Problems and Limitations in the Design }}$

The problems in interpretation due to omission of data have been discussed in other sections and will not be treated here. However, there were certain 
problems inherent in the data acquisition design that limit interpretations. These problems include:

- The random pattern of sample points made representative area characterization difficult.

- Too few data/sample points were designated on specific reactor building/equipmenl surfaces lo allow adequate statıstical evaluation.

o The design did not address combination treatment effects, and these cannot be statistically differentiated.

\section{Implementation of Experimental Design}

The data acquisition tasks were implemented fairly successfully. Data/ sample points were permanently marked and procedures dictated instrument orientation in order to allow reproducible measurements to be made.

Approximately 90 percent of the data specified for acquisition during operations were successfully obtained. This value does not include data omitted from work during operations by decisions made to expedite decontamination.

The grealest difflculiy in implementâtion was in obtaining air samples. Equipment failures led to use of only the GPU radiological engineering air radioactivity data base. Another difficulty was in obtaining reproducible swipes because of the vastly changing surface moisture conditions during different operations of the experiment. 
EXPERIMENTAL MEASUREMENT METHODOLOGIES

Instrumental Measurements

Area and contact radiation measurements were primarily made using the Eberline RO-2A. This instrument is tolerant of variable enviromental conditions, can measure gamma and beta-gamma radiation, and is accurate in the range of values observed in the TMI reactor building. Several instruments were evaluated before the RO-2A was chosen for routine use (Walker et al, 1981).

Instrument measurements in-containment were difficult to obtain due to surface geometries and multiple radiation sources. Procedures were developed to minimize these impacts on data quality (see Attachment $\mathrm{H}-1$ ).

\section{Swipe Samples and Analysis}

Swipe samples were taken to determine the relative amount of removable contamination and to determine isotopic composition of this removable fraction.

The procedure for taking swipes is shown in Attachment $\mathrm{H}-2$. Swipes were analayzed on site by GPU staff.

\section{Air Samples and Analysis}

Although other samples were to be taken, due to equipment failures only the GPU air data are available. Particulates and tritium were measured in the morning and periodically during operations. In addition, breathing zone analyzers (BZAs) were used by workers during operations.

\section{Personnel for Data Acquisition}

During training and during the experiment it became apparent that qualified radiological control technicians were more efficient and accurate in data 
acquisition tasks than other personnel. Familiarity with instruments, radiological conditions in-containment, and radio equipment, was necessary to ensure data quality.

Data acquisition tasks were monitored from the command center and points skipped were noted. Usually, full data acquisition tasks were completed. While some problems occurred in tracking data and samples, information integlity was labigely pieserved.

\section{RECOMMENDA'I IONS}

There are several recommendations which can be made as a result of the data acquisition activities supporting the Gross Decontamination Experiment.

- The experimental design used should be based on Regulatory Guide 1.86 and on standard methods developed and available for radiological characterizations of building surfaces.

- Planning should directly address the level of data required to meet the objectives of the experiment. Any confounding of effects due to experimental design or number of data points should be identified early.

o Measurement methodologies should be carefully planned, and equipment should be checked and calibrated frequently.

- Personnel qualified in data acquisition should be dedicated to these tasks. Training should be adequate to ensure implementation consistent with the purpose and goal of the work.

- Data interpretation methods should be specified, and the adequacy of proposed data should be determined prior to the start of the experiment. 
Changes in data acquisition during operations should be minimized. 
ATTACHMENT H-1. TECHNIQUE SHEET - RO-2 AND RO-2A USE

\section{DESCRIPTION}

Radiation reading techniques must be such that a consistent reading will be obtained by various individuals involved in data collection. These techniques provide for a consistent method for placement of both the instrument and the data colleclus lu ceduce lie magnilude of the variables contributed by shielding introduced by the body of the data collector, and to eliminate variables introduced hy instrument location.

\section{GENERAL}

- Instruments will have been calibrated within 90 calendar days of use.

- Beta factors greater than 4.1 or less than 3.8 will not be acceptable for use in data collection.

- Immediately prior to use, the instrument batteries will be checked and must be good for the instrument to be used.

- Prior to being taken into the containment building, the instrument will be enclosed in a single, clear, poly bag. The bag will bc scaled bui will allow room for the operator to change the scale selector swilch.

o During readings involving contact with horizontal surfaces, the bottom of the instrument will be wiped, as necessary, with maslin cloths to prevent contamination buildup. 


\section{DETAILED INSTRUCTIONS}

\section{General Area Readings}

- Locate each survey point as listed in the data collection sheet.

- Mark the surface at the points indicated with a number and by outlining the instrument while it is pointing directly away from the D-ring (if not previously marked).

- Mark an arrow inside the outline pointing directly away from the D-ring, with the tail forming a 90-degree angle with the base of the RO-2A out 1 ine.

o Mark the right side of the RO-2A with a large dot measured 2 inches from the back of the meter and 2 inches up from the bottom of the meter.

- Stand at the tail of the arrow, centering the body behind the arrow.

o Place the meter stick at the point of the arrow; hold it with the left hand.

- Holding the RO-2A with the window closed and away from the body, place the right side of the RO-2A horizontally across the top of the meter stick with the dot centered over the meter stick.

o The RO-2A meter face should be to the left of the meter stick.

o Record the general area radiation reading on the data collection sheet. 


\section{Contact Surface Readings}

- Locate each survey point as listed on the data collection sheet.

- Mark the surface of the survey point by outlining the instrument while it is pointing directly away from the D-ring wall (if not previously marked).

- Mark an arrow inside the outline with the tail forming a 90-degree angle with the base of the $\mathrm{RO}-2$ or RO-2A outline, with the arrow pointing directly away from the D-ring wall.

- Position the body behind the tail of the arrow, located in the marked survey point, and center the body behind the arrow.

- Open the window on the R0-2 or RO-2A and position the instrument within the marked outline, with the instrument meter scale aligned with the head of the arrow.

- Obtain a rcading for window open and record on the data collection sheet for the survey point.

o Close the window on the RO-2 or RO-2A.

- Position the instrument on the same survey point as described in item 3.2 .6 with the window closed.

o Obtain the closed window reading and record the data on the data collection sheet.

NOTE: Allow adequate time for the instrument reading to stabilize before recording the reading. ( 10 seconds $)$. 
NOTE: If the meter reading is at the extreme low end of the scale, select the next lower multiplier on the range selector switch. 


\section{ATTACHMENT H-2. TECHNIQUE SHEET - SWIPE SURVEY}

\section{DESCRIPTION}

This technique describes how to conduct a swipe survey for data collection during the Decontamination Experiment.

\section{GLINLERAL}

o Swipe survey locations will be numbered and marked using a template and a black indelible marker on all painted surfaces.

- Swipe survey locations will be numbered and marked using a low- or no-chloride marker and a template on stainless steel surfaces.

- Swipes will be individually numbered and will have numbered plastic bags .

- Swipes will be taken within a marked $100 \mathrm{~cm}^{2}$ area.

$$
\text { SMF.AR COOTITSCTION }
$$

- Package smears and label both the smear and package by data acquisition survey point number and conlalmulnl eulıy number (i.c., 32-1, etc.).

o Mount packaged smears on a ring holder in sequential order.

o During movement into the containment and while in the containment, be careful not to contaminate the smears by touching, brushing, dropping, etc. 
- When ready to use a smear, remove the smear and package from the ring holder.

- Carefully hold the smear package without touching the smear surface or internal packaging surfaces.

- Holding the packaging in one hand, apply the face of the smear to the marked area where data are being collected and firmly swipe the entire $100 \mathrm{~cm}^{2}$ surface using only one hand.

o Close the smear folder which was held open, and insert the folder with the smear into the plastic bag.

- Fold the plastic bag over the smear. folder until all excess plastic has been wrapped around the smear folder.

- Placing the loose end of the package down, insert the used smear into the used smear holder.

o Repeat the above steps until all smear data collection is completed.

- Upon exit from the containment, take the entire used smear container, with smears bagged, and label the bag with the entry number and area surveyed. Then carefully place the bagged smears into the shielded sample drum in the anteroom.

NOTE: Take caution not to contaminate with your gloves.

NOTE: Notify the command center if you loose a swipe.

NOTE: During debriefing, make known any swipes you feel may be cross contaminated. 
In order to evaluate the techniques tested, several decontamination reduction factors were calculated for each data point. The different DFs were bascd on area gamma, contact gainuil and beta, and smearable pre- and post-test readings (see sample calculation below). Due to location (confined spaces, for example) or observed procedures, certain data points on the floor surfaces were not felt to be representative of the techniques used. Therefore, these points were elimlnaced from final analysis. Higures $H-1$ and $H-2$ identify and locate the points considered representative of the techniques for elevations $305^{\prime}$ and 347'-6", respectively. The following sample calculation shows how the pre- and post-test readings were evaluated and DFs computed.

\section{Sample Calculation}

Area 1 LY Flush - Ellevation 305' (from test data - Reference 1)

\begin{tabular}{|c|c|c|c|c|}
\hline $\begin{array}{l}\text { Pre-Lesl } \\
\text { Location }\end{array}$ & $\begin{array}{l}\text { Area } \\
\text { Gamma } \\
\text { (mrem) }\end{array}$ & $\begin{array}{c}\text { Contact } \\
\text { Gamma } \\
\text { (mrem) }\end{array}$ & $\begin{array}{c}\text { Contact } \\
\text { Beta } \\
\text { (mrem) }\end{array}$ & $\begin{array}{c}\text { Cs }-137+C s-134 \\
\text { Swipes } \\
\left(\mathrm{dpm} / 100 \mathrm{~cm}^{2}\right) \\
\end{array}$ \\
\hline 1 (Floor) & 240 & 320 & 1060 & $5.13 \times 10^{6}$ \\
\hline 12 (Floor) & 170 & 286 & 2026 & $5.10 \times 10^{6}$ \\
\hline 15 (Pipc) & 200 & 200 & 380 & $-\quad-$ \\
\hline
\end{tabular}

\begin{tabular}{|c|c|c|c|c|}
\hline $\begin{array}{l}\text { Poot-teot } \\
\text { Location }\end{array}$ & $\begin{array}{l}\text { Area } \\
\text { Camma } \\
\text { (mrem) }\end{array}$ & $\begin{array}{c}\text { Contact } \\
\text { Gamma } \\
\text { (imrent) } \\
\end{array}$ & $\begin{array}{l}\text { Contact } \\
\text { Beta } \\
\text { (mrem) }\end{array}$ & $\begin{array}{c}\text { Cs-137+Cs-134 } \\
\text { Swipes } \\
\left(\mathrm{dpm} / 100 \mathrm{~cm}^{2}\right) \\
\end{array}$ \\
\hline 1 & 220 & 290 & 1930 & $\times 10^{6}$ \\
\hline 12 & 107.6 & 146 & 539.6 & $4.62 \times 10^{6}$ \\
\hline 15 & - & 100 & 228 & $0.417 \times 10^{6}$ \\
\hline
\end{tabular}

Activity Removed (difference in contact gamma). The gamma measurements can be correlated to estimate the activity removed using the conversion factor $28 \mathrm{mrem} / \mathrm{hr} / \mu \mathrm{Ci} / \mathrm{cm}^{2}$ (Reference 2). Remaining activity is estimated using the final contact beta measurements and the conversion factor $7.99 \mathrm{rem} / \mathrm{hr} / \mathrm{\mu Ci} / \mathrm{cm}^{2}$ (Reference 2). 


$$
\begin{aligned}
& \text { For Location 1, } \Delta \text { gamma }=320-290=30 \mathrm{mrem} / \mathrm{hr} \\
& \frac{30 \mathrm{mrem} / \mathrm{hr}}{28 \mathrm{mrem} / \mathrm{hr} / \mu \mathrm{Ci} / \mathrm{cm}^{2}}=1.07 \mu \mathrm{Ci} / \mathrm{cm}^{2} \\
& \text { Final beta }=\frac{1.930 \mathrm{rcm} / \mathrm{hr}}{7.99 \mathrm{rem} / \mathrm{hr} / \mu \mathrm{Ci} / \mathrm{cm}^{2}}=0.241 \mathrm{\mu Ci} / \mathrm{cm}^{2}
\end{aligned}
$$

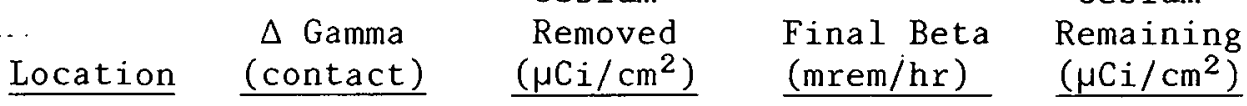

$\begin{array}{rrlll}1 & 30 & 1.07 & 1930 & 0.241 \\ 12 & 140 & 5 & 539.6 & 0.067 \\ 15 & 100 & 3.57 & 228 & 0.029\end{array}$

A Relative Decontamination Factor (RDF) is calculated by dividing total cesium (cesium removed + cesium remaining) by cesium remaining.

\section{Location}

1

12

15
$\mathrm{RDF}$

10.8

75.6

$$
\frac{3.57+0.029}{0.029}
$$

124

By swipes: $\frac{\text { Average floor pre-test }}{\text { Average floor post-test }}=$ Decontamination Factor

$\mathrm{DF}=\frac{5.115 \times 10^{6}}{4.995 \times 10^{6}}=1.02$

Area dose reduction:

$\frac{\text { pre-average area gamma - post-average area gamma }}{\text { pre-average area gamma }}=\frac{205-163.8}{205}=20 \%$ 
Area Exposure Reduction Factor (ERH):

$\begin{aligned} & \text { pre-average area gamma } \\ & \text { post-avcragc area gamma }\end{aligned}=\frac{205}{163.8}=1.25$

From operational parameter data (Reference 1):

229 gallons used

19 minutes total flush time
$229 / 989 \mathrm{ft}^{2}=0.24 \mathrm{gal} / \mathrm{ft}^{2 *}$

$19 / 939 \mathrm{ft}^{2}=0.02 \mathrm{~min} / \mathrm{ft}^{2} \%$

Dosimeter Readings:

$\begin{aligned} & \text { Worker 非 } \\ & \text { Worker 非 } \\ & \text { Worker 非 }\end{aligned}$
$\begin{aligned} \frac{171.7}{19 \mathrm{~min}} \times \frac{\mathrm{mrem}}{172 \mathrm{mrem}} \\ \frac{60 \mathrm{~min}}{1 \mathrm{hr}}\end{aligned}$
$\begin{aligned} \frac{171.7}{939} & =542 \mathrm{mrem} / \mathrm{hr} \\ & =0.183 \mathrm{mrem} / \mathrm{ft}^{2}\end{aligned}$

Sample Work Sheet

Table H-2 shows the sample work sheet that was developed for each test and what items were used to distinguish between the tests. The $\mu \mathrm{Ci} / \mathrm{cm}^{2}$ of average activity removed and remaining were not used as absolute values, but as separators between the various tests. The RDFs calculated from these numbers, however; did correlate with the surface deposition DFs.

Dernntamination Fartor

The DF used in the report is a measure of the efficiency for:

- A particular process (e.g.; low pressure flushing)

*Floor area for Area I is 939 square fect (from area calculations, Reference 3). 
- A particular application (e.g., particulate radioactive material as measured by swipe testing)

- A particular iteration of that process (e.g., third flush).

in decontaminating or removing a contaminant from a given matrix. The contaminant is defined both in terms of the nature of the contaminant and the method by which it was measured before and after the process. To be directly compared, all facets of the DF determination were the same.

Methods. DF is expressed as:

- Amount of activity removed

- Amount of residual activity

- Fraction of activity removed.

Where the RDF was determined by a direct measurement, care was used in evaluating the possible interference of ambient radiation fields.

Where DFs for a given situation can vary from segment to segment on the same material or situation due to a large number of variables, such as a wall or other large surface area, an average DF and the range of DF values were calculated. In complex systems, or areas of the "metric star," individual local DFs were used as appropriate.

Note: "Exposure Reduction Factor" is the ratio of the original exposure rate at a location to the final exposure rate after attempts at decontamination. The term ERF must not be confused with DF. They can differ for at least two reasons:

1. ERF is based on the item decontaminated, and there may be other uncleaned areas or sources nearby that contribute to the exposure rate. One could conceivably have a real DF of 100 or 1000 in an area, and the ERF could be 4 due to shine. 
2. The source may consist of mixed heta and gamma emittcrs. The first. decontamination may decrease the dirt covering the fixed activity, resulting in high beta fields. It may also preferentially remove one of the contaminants, changing the character of the field. 'The choice of selecting the method for RDFs was made based on these considerations.

\section{Calculation References}

1. Raw data from Decontamination Experiment (see Appendix C).

2. TDR 068, GPU Document, 1980.

3. Floor area calculations. 


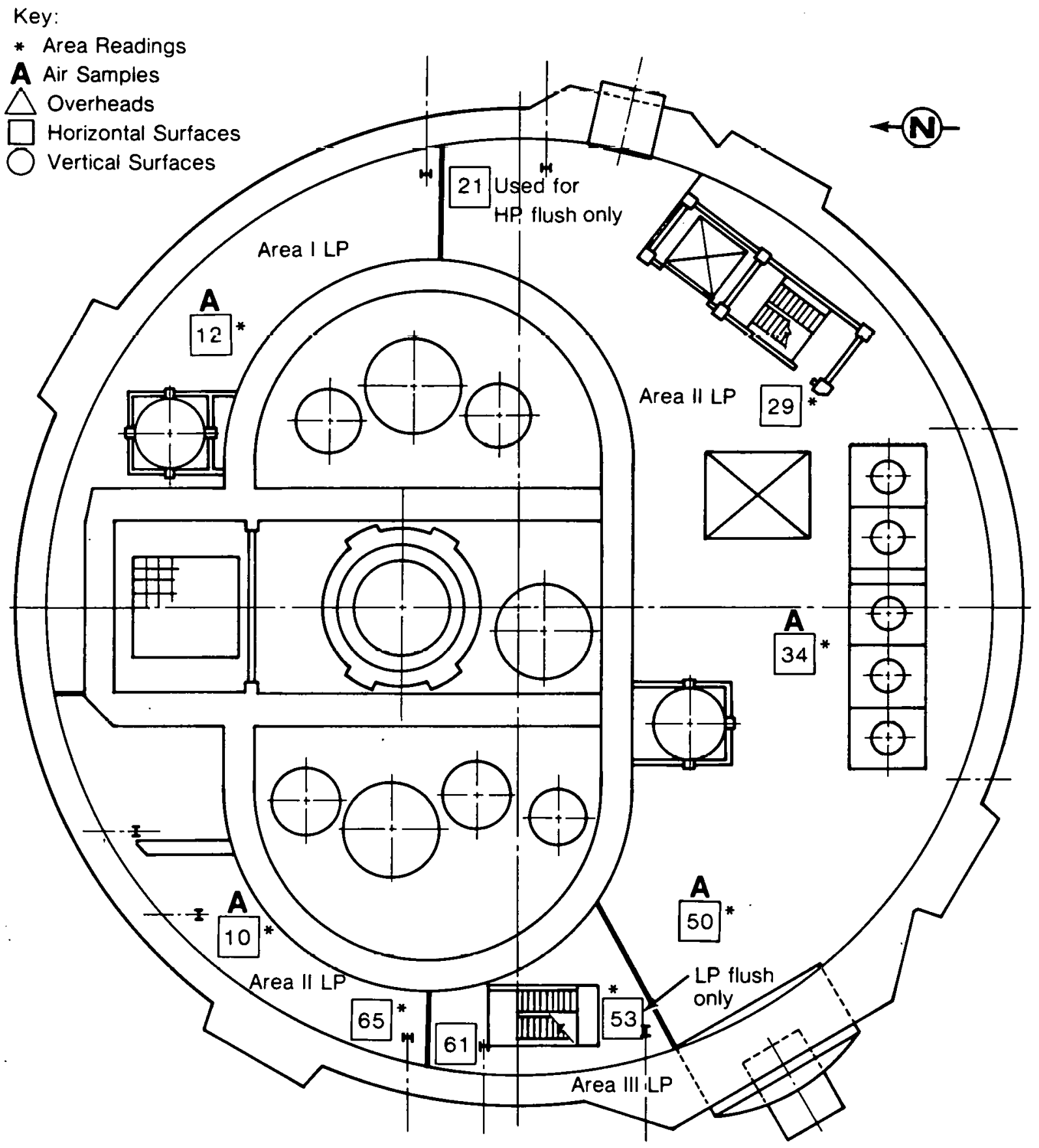

Plan El. 305'-0',

Figure H-1. Elevation 305' representative data points. 
Key:

* Area Readings

Horizontal Surfaces

Vertical Surfaces

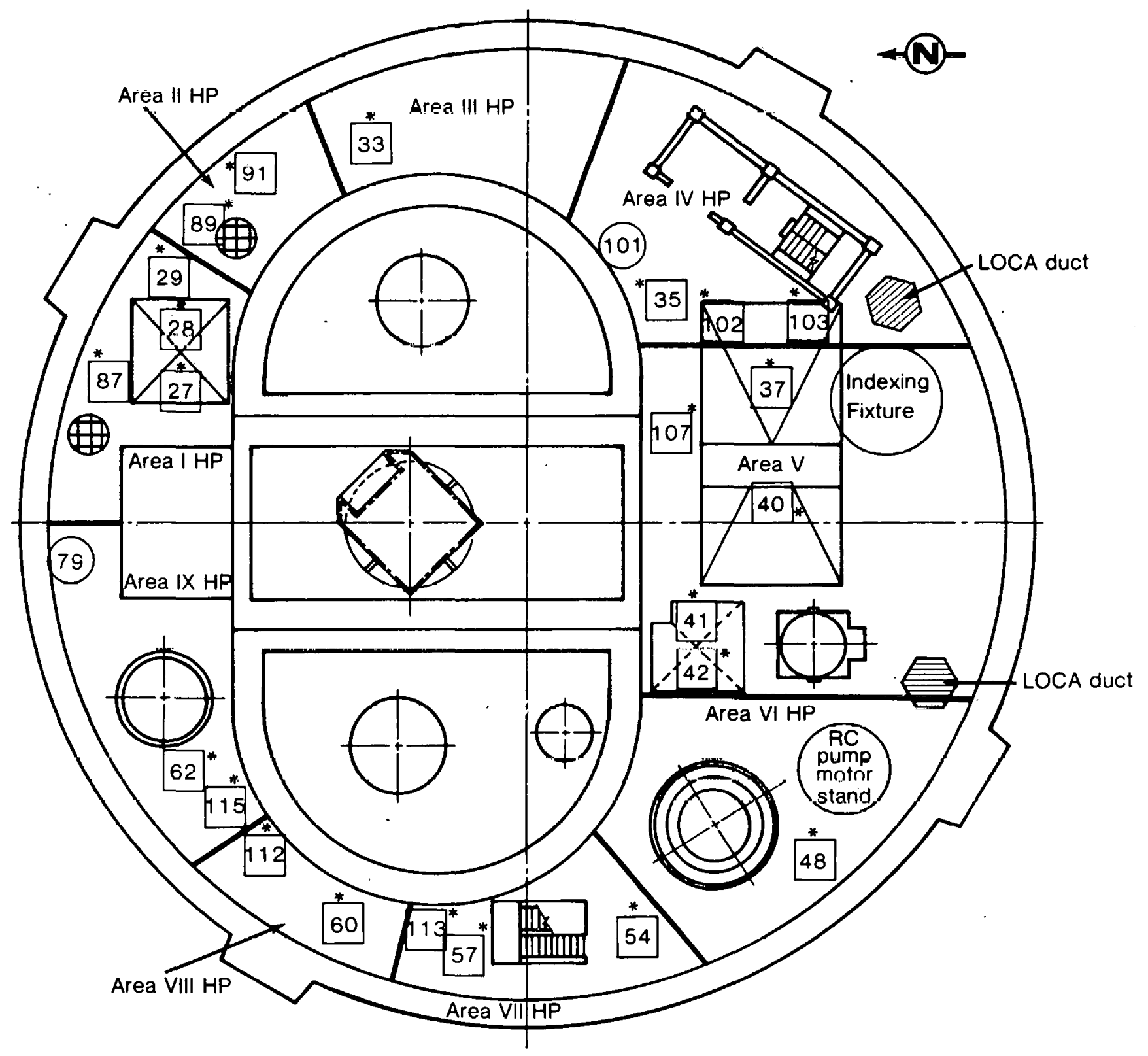

Plan El. 347'-6'"

Figure H-2. Elevation 347 ' -6 '' representative data points. 
TABIE H-2. SAMPLE WORK SHEET. (SUMMARY - ELEVATION 305')

\begin{tabular}{|c|c|c|c|c|c|c|c|c|c|c|c|}
\hline \multirow[b]{2}{*}{ Area } & \multirow[b]{2}{*}{ Surface } & \multirow{2}{*}{$\begin{array}{l}\text { Area Dose } \\
\text { Reduction } \\
\text { (ERF) }^{2}\end{array}$} & \multicolumn{2}{|c|}{$\begin{array}{c}\text { Average Cesium } \\
\text { Activity }\left(\mu \mathrm{Ci} / \mathrm{cm}^{2}\right)\end{array}$} & \multirow[b]{2}{*}{$\mathrm{RDF}$} & \multicolumn{2}{|c|}{$\begin{array}{l}\text { Swipes - Cesium } \\
\left(\mathrm{dpm} / 100 \mathrm{~cm}^{2}\right)\end{array}$} & \multirow{2}{*}{$\begin{array}{l}\text { Water Use } \\
\left(\text { gal } 1 / \mathrm{ft}^{2}\right)\end{array}$} & \multirow{2}{*}{$\begin{array}{l}\text { Worker Rate } \\
\left(\mathrm{min} / \mathrm{ft}^{2}\right) \\
\end{array}$} & \multicolumn{2}{|c|}{$\begin{array}{c}\text { Worker } \\
\text { Exjosure Rates }\end{array}$} \\
\hline & & & Removed & Remaining & & Final $\times 10^{6}$ & $\overline{\mathrm{DF}}$ & & & mrem/hr & mrem/ft ${ }^{2}$ \\
\hline $\begin{array}{l}\text { I LP } \\
20 \mathrm{gpm}\end{array}$ & Floor & $1.25 / 20 \%$ & 3.03 & 0.154 & 20.7 & 4.995 & 1.02 & 0.24 & 0.02 & 542 & 0.183 \\
\hline Ambient & $\begin{array}{l}\text { Stainless } \\
\text { Steel }\end{array}$ & - & 3.57 & 0.029 & 124 & 0.417 & - & - & - & - & - \\
\hline $\begin{array}{ll}\text { II } & \text { LP } \\
23 & 8 \mathrm{pm}\end{array}$ & Floor & $1.14 / 12 \%$ & 2.29 & 0.466 & 5.91 & 1.058 & 13.3 & 0.144 & 0.012 & $81 ?$ & 0.16 \\
\hline $118 \mathrm{~F}$ & Stainless & Stee $\overline{1}$ & - & 0.143 & - & 0.335 & 18.9 & - & - & - & - \\
\hline $\begin{array}{l}\text { I I I LP } \\
23 \mathrm{gpm} \\
96 \mathrm{~F}\end{array}$ & Floor & $1.50 / 33 \%$ & 44.6 & 0.691 & 65.5 & 6.09 & 0.89 & 0.22 & 0.019 & $15 L$ & 0.048 \\
\hline $\begin{array}{l}\text { IV I.P } \\
17 \mathrm{gpm} \\
110 \mathrm{~F}\end{array}$ & Floor & $1.37 / 27 \%$ & 6.21 & 0.23 & 28.0 . & 8.19 & 2.38 & 0.205 & 0.017 & 515 & 0.146 \\
\hline $\begin{array}{l}X \text { HP } \\
14 \mathrm{gpm}\end{array}$ & Floor & $0.9 / 0 \%$ & 0.71 & 0.024 & 30.6 & 0.189 & 24.4 & 0.39 & 0.040 & 211 & 0.014 \\
\hline 2000 psi. & $\begin{array}{l}\text { Stainless } \\
\text { Ambient }\end{array}$ & Steel & 0 & 0.019 & 1 & 0.460 & 0.91 & - & - & - & - \\
\hline
\end{tabular}

a. Area dose reduction $=$ average pre-test area gamma - average post-test area gamma 


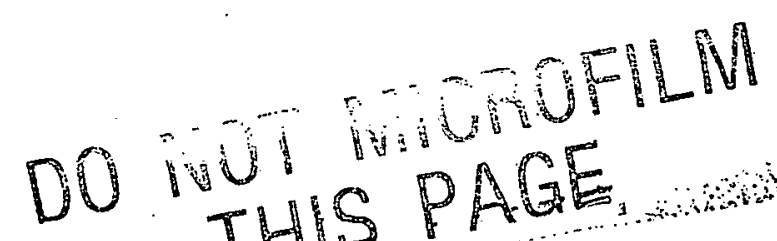
THIS PAGE 
1

APPENDIX I

GAMMA SPECTROMETER RESULTS 
PRE-AND-POST DECONTAMINATION GAMMA-RAY SCANS OF TMI-2 CONTAINMENT SURFACES, ELEVATIONS 305 AND 347 FEET

E. D. Barefoot

J. E. Cline

J. A. Daniel

D. G. Keefer

T. L. McVey

E. A. Schlomer

C. D. Thomas, Jr.

April 22, 1982

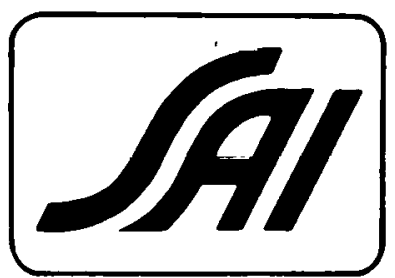

\section{SCIENCE APPLICATIONS, INC.}

NUCLEAR ENVIRONMENTAL SERVICES

3 Choke Cherry Road, Rockville, Maryland 20850, (301) 977-4480 
SUMMARY. . . . . . . . . . . . . . . . . . . . . . . . 1 MEASUREMENT TECHNIQUES AND DETECTOR CALLIBRATION. . . . . . . . . . . 2 MFASUREMENTS AND RESULTS . . . . . . . . . . . . . . . . . . 7 REFERENCES . . . . . . . . . . . . . . . . . . . . . 16 APPENDICES . . . . . . . . . . . . . . . . . . . . 18 Appendix A - Model of Detector Calibration for Extended Sources . . . . . . . . . . . . . . . . . . . 18 
1. Gama-Ray Energies and Source Intensities for Detector Calibration standard . . . . . . . . . . . . . . . . . . . . . 5

2. On-Axis and off-Axis Distances at which Calibration Measurements

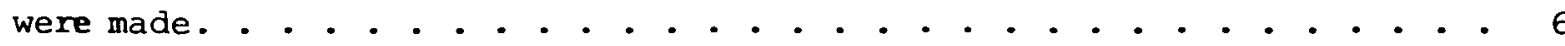

3. Listing of Areas of TMI-2 Containment, Elevations 305- and 347foot for which Measurements were made of the Surface contamination

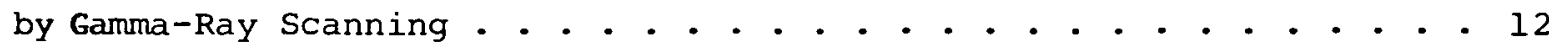

4. Net ${ }^{137} \mathrm{Cs}$ Counting Rates and Surface Contamination Levels for the

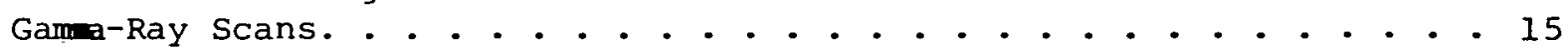


FIGURES

1. Mark I SAI Gamma Scanner..................... 3

2. Sketch of Collimator shielding . . . . . . . . . . . . 4

3. Gamma-Ray Detection Efficiency Curves For Floor Scans. . . . . . 9

4. Floor Plan of TMI-2 Reactor Building 305' Elevation Showing

Measurement Locations. . . . . . . . . . . . . . . 10

5. Floor Plan of TMI-2 Reactor Building 347' Elevation Showing

Medsurement Locations, . . . . . . . . . . . . . . . . 11

6. Portion of Gamma-Ray Pulse-Height Spectrum . . . . . . . . . 13

7. Portion of Pulse-Height Spectrum Showing Gamma-Ray Peaks . . . . . 14

Al. Schematic Drawing of Detecțor Model. . . . . . . . . . . 19

A2. Two Dimensional Sketch of Oblique Scan Geometry. . . . . . . . . . 22

A3. Two Dimensional Sketch Showing Definition of Integration

Variables. . . . . . . . . . . . . . . . . . . . 24 
PRE-AND-POST DECONTAMINATION GAMMA-RAY SCANS OF TMI-2

CONTAINMENT SURFACES, ELEVATIONS 305 AND 347 FOOT

\section{SUMMARY}

The SAI collimated gamma-ray detector scanned surfaces of the TMI-2 Containment Building floors and walls both before and after the decontamination experiments in mid March 1982. The surface contamination at five locations each on the 305-foot and 347-foot elevations were measured in the scans. The pre-decontamination measurements were made on December 16, 1981 and February 16, 1982, respectively, for the 305- and 347-foot elevations; the post-decontamination measurements were made on March 25 and March 26 , 1982. Most of the measurements showed contamination levels for ${ }^{137} \mathrm{Cs}$ that were less than $1 \mu \mathrm{Ci} / \mathrm{cm}^{2}$. A few areas showed levels that were below the minimum detectable limits. In some cases, the level of activity after decontamination was above that measured before decontamination. 


\section{MEASUREMENT TECHNIQUES AND DETECTOR CALIBRATION}

The SAI collimated gamma-ray spectrometer ("gamma-ray camera") was designed specifically for scanning reactor piping and components to determine the concentration of each radionuclide in these items. It is used with a method of analysis and calibration developed ${ }^{1,2}$ by SAI for use with sources of abnormal or extended geometry. This or similar collimators have been used ${ }^{3-14}$ in previous scans of reactor system components.

A photograph of the detector and collimator assembly is shown in Figure 1. Removable stepped plugs are inserted into the open end of the collimator. Used in the present measurements are a plug with a 1-cm diameter hole and a solid plug used for background measurements. Figure 2 shows a cross-sectional view of the collimator shielding. The assembly can be rotated to aim at any angle from $0^{\circ}$ to $180^{\circ}$ with respect to a perpendicular to the floor. The frame is mounted on eight-inch diameter wheels for easy movement. An $8 \%$ efficient (relative to 3"x3" NaI(T1)) hyperpure germanium detector was used in the assembly. The nitrogen retention time of the detector dewar is about eight hours. The detector preamplifier is a portion of the detector assembly. Detector bias supply, amplifier, and system low-voltage power supply are mounted on the collimator cart. Multichannel analyzer (MCA) and input-output devices (printer and magnetic tape unit) are placed separately from the cart; as much as 500 feet of signal cable can connect the MCA with the amplifiex.

Calibration of the detector-collimator system used the techniques discussed in References 1 and 2. A certified mixed-isotope point-source standard was used to measure both on-axis and off-axis detector response. Energies and intensities of the gamma-rays emitted by this standard are listed in Table 1. Measurements wère made at several distances dluny lise symmetry axio of the detector and at several distances off axis at a fixed distance along the detector. The values of these distances are given in Table. 2 .

Distances along the detector symmetry axis are measured from the cap of the detector cryostat. The distance of $12.76-\mathrm{cm}$ is the distance to the outside of the collimator. The diameter of the hole in the collimator is $1-\mathrm{cm}$ and measurements were made to angles off-axis that were equivalent to twice that subtended by the collimator hole. Data from the calibration measurements were fit to obtain the values for the parameters describing the detector response (as in the detector model of Reference 2). We used these values to 


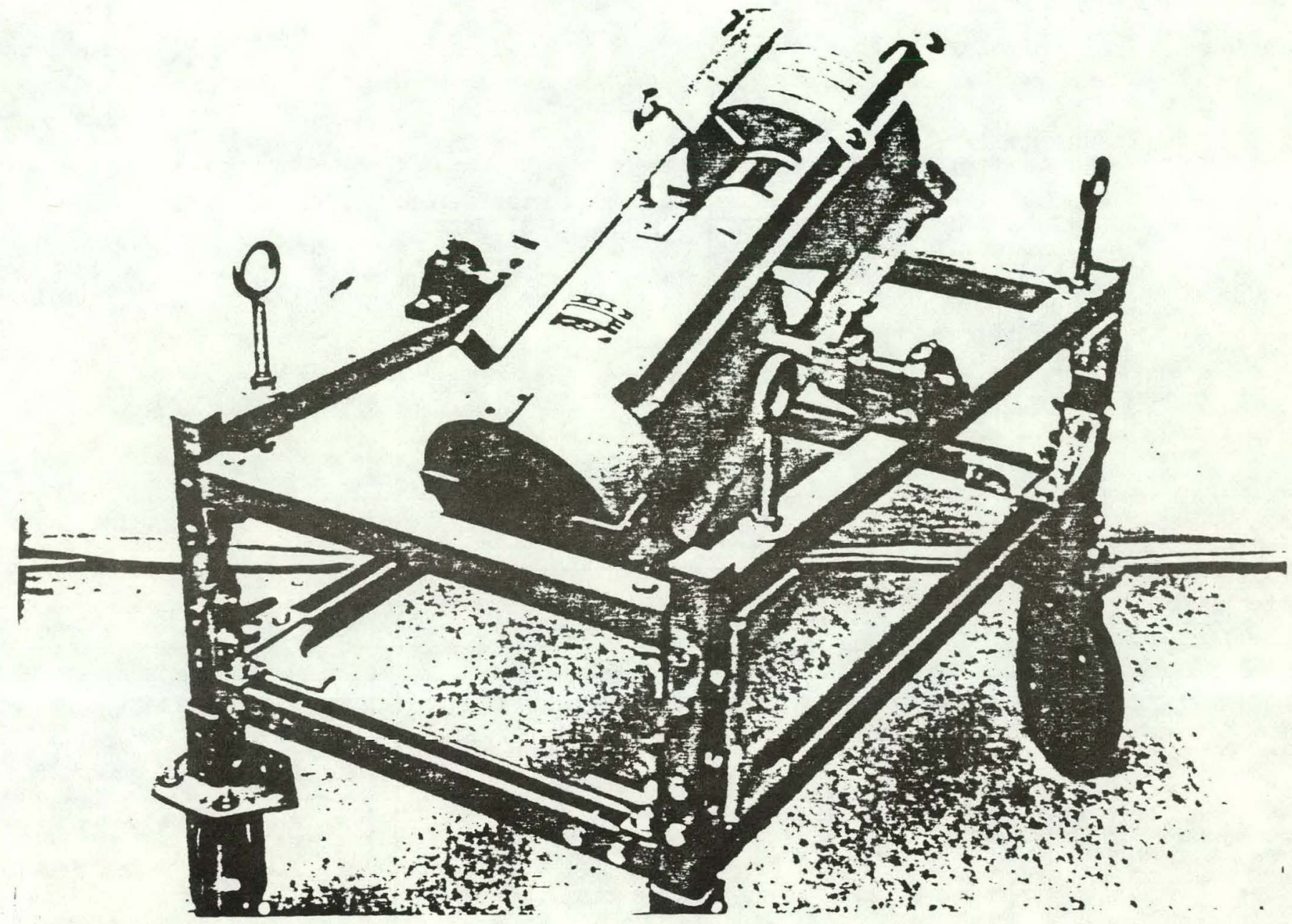

Figure 1. MARK I SAI GAMMA SCANNER 


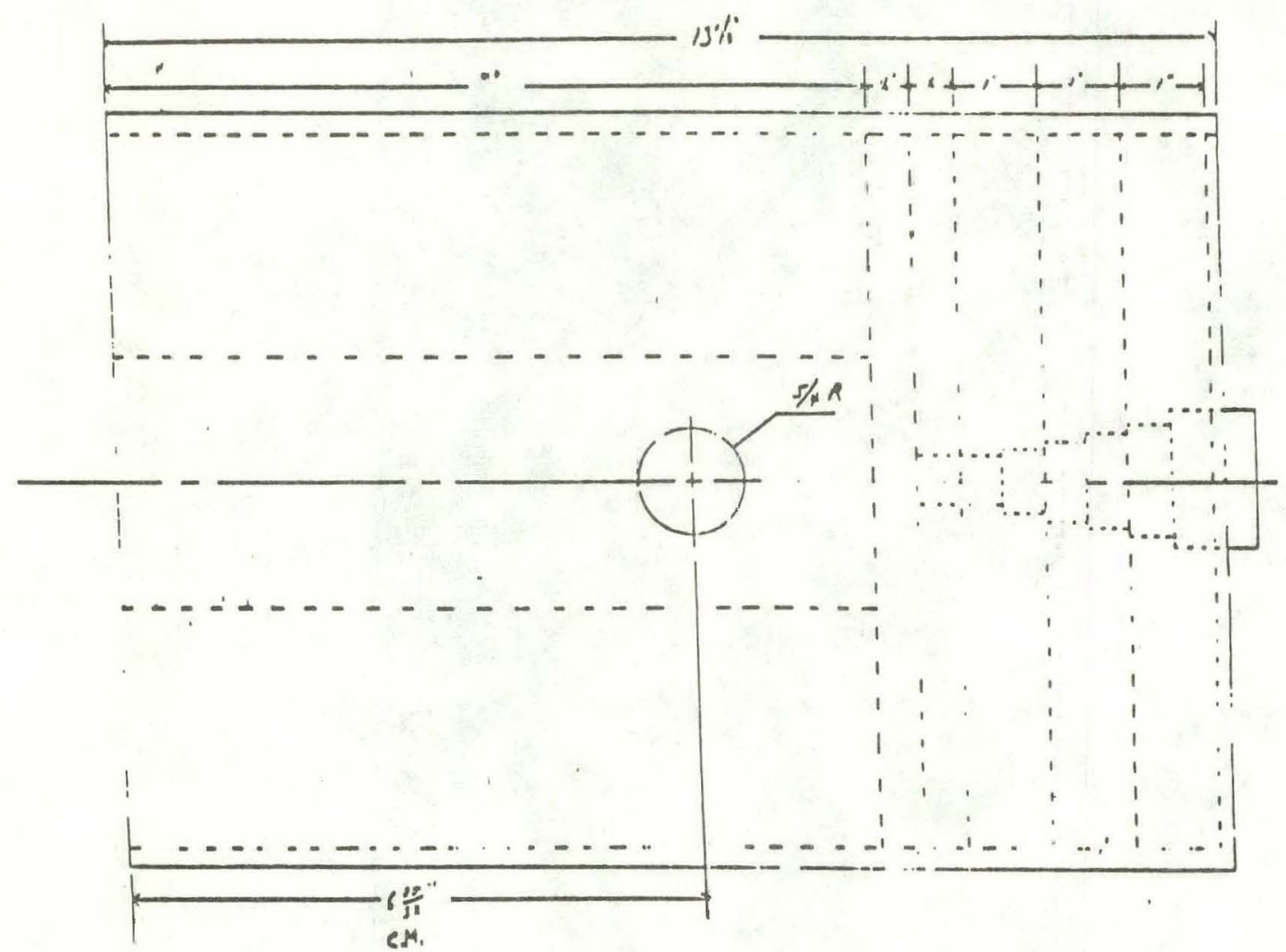

Figure 2. Sketch of Collimator Shielding 
TABLE 1. GAMMA-RAY ENERGIES AND SOURCE INTENSITIES FOR DETECTOR CALIBRATION STANDARD

\begin{tabular}{cc}
\hline $\begin{array}{c}\text { Gamma-Ray } \\
\text { Energy (keV) }\end{array}$ & $\begin{array}{c}\text { Intensity } \\
\text { Gamma-Rays per Second }\end{array}$ \\
\hline 88 & 1345 \\
122 & 1034 \\
166 & 1001 \\
279 & 2453 \\
392 & 2919 \\
514 & 5146 \\
662 & 7817 \\
898 & 8597 \\
1173 & 9547 \\
1332 & 9559 \\
1836 & 9165 \\
\hline
\end{tabular}


TABLE 2. ON-AXIS AND OFF-AXIS DISTANCES AT WHICH CALIBRATION MEASUREMENTS WERE MADE

\begin{tabular}{cc}
\hline $\begin{array}{c}\text { Distance Along } \\
\text { Detector Symmetry } \\
\text { Axis (cm) }\end{array}$ & $\begin{array}{c}\text { Distance Off } \\
\text { Detector Symmetry } \\
\text { Axis (cm) }\end{array}$ \\
\hline 12.76 & 0 \\
12.76 & 0.1 \\
12.76 & 0.2 \\
12.76 & 0.3 \\
12.76 & 0.4 \\
12.76 & 0.6 \\
12.76 & 0.7 \\
12.76 & 0.8 \\
12.76 & 1.0 \\
17.26 & 0 \\
22.76 & 0 \\
30.96 & 0 \\
\hline
\end{tabular}


calculate detection efficiencies for the geometries of the experiment. Figure 3 shows the calculated detection efficiencies for the configuration as a function of collimator angle and of gamma-ray energy.

\section{MEASUREMENTS AND RESULTS}

The measurements were of five areas of the TMI-2 Reactor Containment Building 305-foot and five areas of the 347-foot elevations. They included both wall and floor measurements. Figure 4 shows a floor plan of the 305foot elevation and Figure 5 shows a similar plan of the 347-foot elevation. Figures 4 and 5 also show the locations of where gamma-ray measurements were made. Table 3 gives descriptions of these locations.

Pre-decontamination measurements on the 305-foot elevation were made in an entry December 16, 1981 and those on the 347-foot elevation were made February 16, 1982. Post decontamination measurements were made on March 25 and March 26, 1982, respectively for the 305-foot and 347-foot elevations. Entries into containment were through the personnel air lock on the 305-foot elevation. Access to the 347-foot level was by a hoist through the equipment hatch. The cart was rolled into position and the collimator aimed at the surface to be scanned. The collimator was aligned to an angle of $45^{\circ}$ for the floor scans so as to eliminate any effects from the intense radiation on the 281 -foot level that passes through the concrete floors. The multichannel analyzer (MCA) was located in a clean area in the service building. Amplified signals from the detector were transmitted to the MCA through a containment penetration cable and approximately two-hundred feet of RG 59/U coaxial cable.

Two spectra were collected at each location, one with the $1-\mathrm{cm}$ diameter collimator hole and one with the solid plug for background determinations. Figures 6 and 7 show typical spectra taken with these two configurations. These spectra were taken during a previous entry. The peaks shown are from the nuclides ${ }^{134} \mathrm{Cs}$ and ${ }^{137} \mathrm{Cs}$. In all of the scans of the TMI-2 containment, these were the only nuclides whose presence was observed. There was no evidence for the presence of either ${ }^{60} \mathrm{Co}$ or ${ }^{144} \mathrm{Ce}$ in any of the spectra. Lower estimates for the concentration of these nuclides are a factor of $10^{-5}$ below that for ${ }^{137} \mathrm{Cs}$ at the positions measured.

Table 4 shows the results of the pre- and post-decontamination scans for both the 305-foot and the 347-foot elevation. The table gives the net counting 
rate for the $662-\mathrm{keV}$ peak from ${ }^{137} \mathrm{Cs}$. The net counting rate is determined by subtracting the integral of the counting rate in the peak from this gammaray in the spectrum taken with the solid plug from that taken with the 1-cm collimator. The results expressed in terms of $\mu \mathrm{Ci} / \mathrm{cm}^{2}$ are also shown in the table. The uncertainties in the values are the propagated statistical uncertainties. 
$1 E_{-}-3$

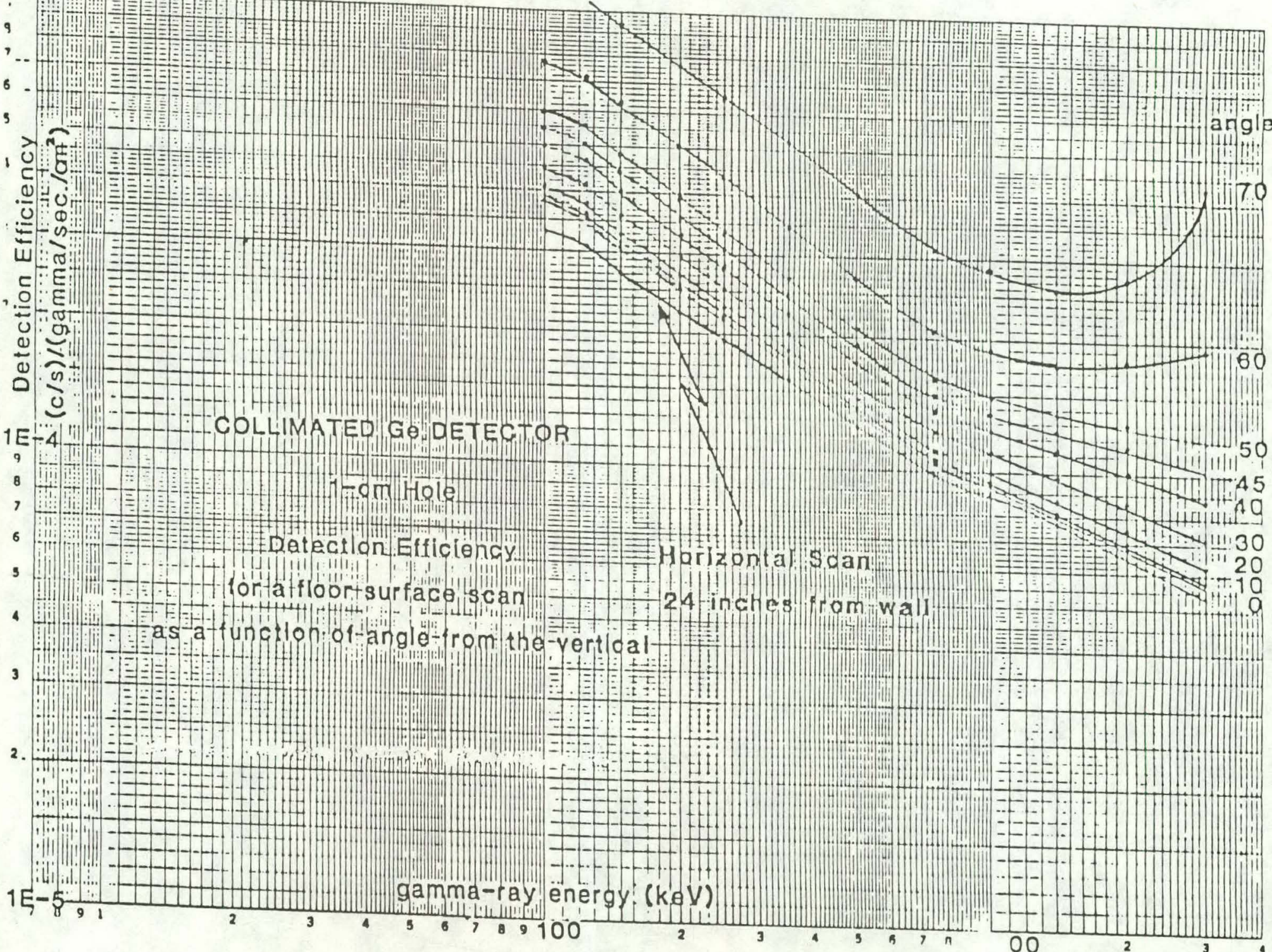

Figure 3. Gamma-Ray Detection Efficiency Curves 


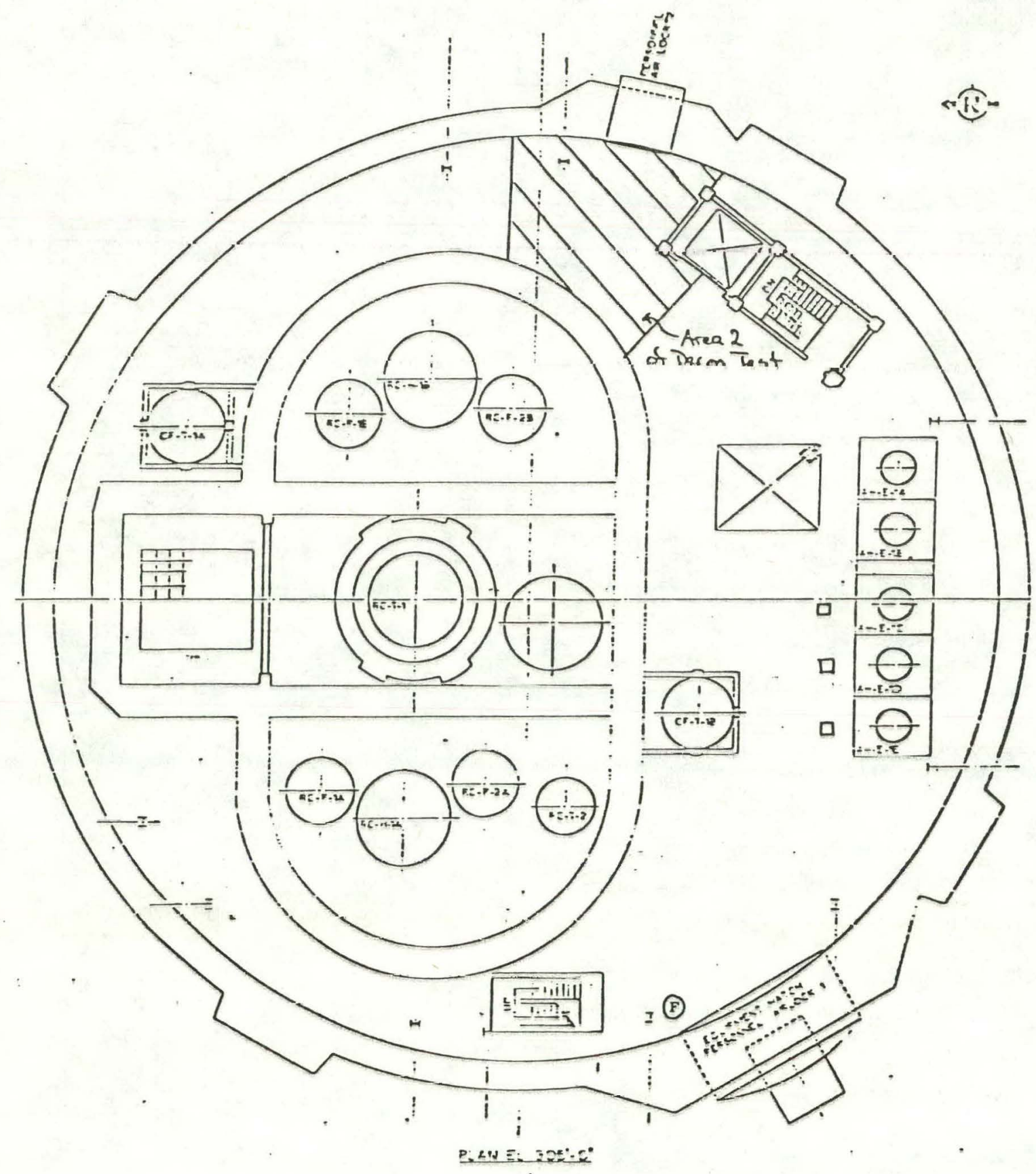

Figure 4. Floor Plan of TMI-2 Reactor Building 305' Elevation Showing Measurement Locations 


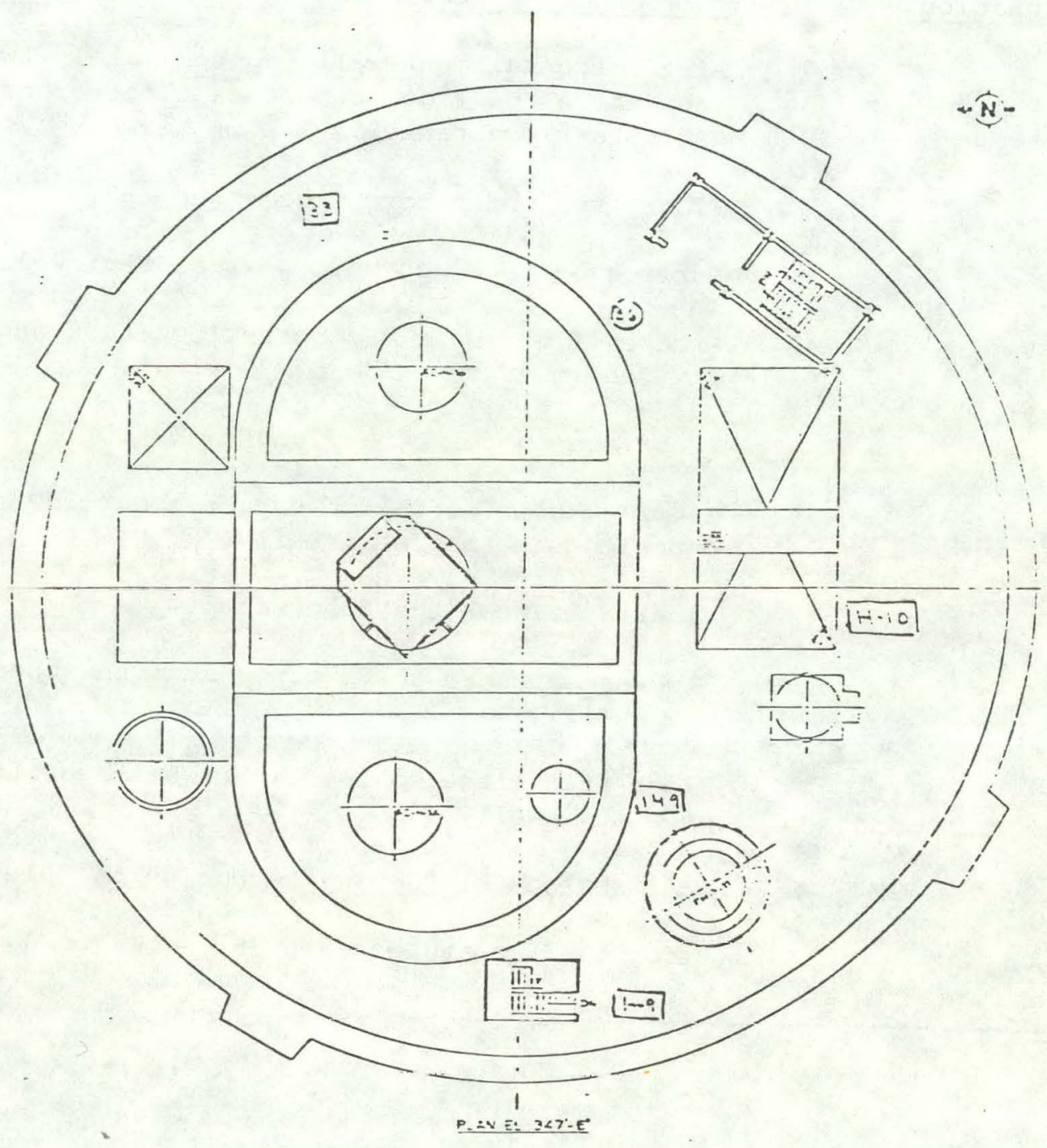

Figure 5. Floor Plan of TMI-2 Reactor Building 347' Elevation Showing Measurement Locations 
TABLE 3. LISTING OF AREAS OF TMI-2 CONTAINMENT, ELEVATIONS 305'

347' FOR WHICH MEASUREMENTS WERE MADE BY GAMMA-RAY SCANNING OF THE SURFACE CONTAMINATION BEFORE AND AFTER SPRAY DECONTAMINATION

Area Designation

13

H7

V9

34

H5

33

$\mathrm{H} 1 \mathrm{O}$

149

H9

36

$36-A$

\section{Description of Area}

Area of containment wall, approximately two feet above the floor. Northeast corner near "A" core-flood-tank.

Floor area under core-flood-tank "A".

Surface of "D-ring" wall near \#2 stairwell.

Area of floor near " $R$ " core-flood-tank and six feet out from cdge of "D-ring".

Floor area under core-flood-tank "B".

Fluus asea in northeast corncr about $180^{\circ}$ opposite the open stairwell.

Floor area near the open hatch.

Floor area close to "D-ring" near the open stairwell.

Floor area close to the liner wall near the open stairwell.

Wall surface of "D-rinq" opposite the elevator.

Floor surface at location 36. 


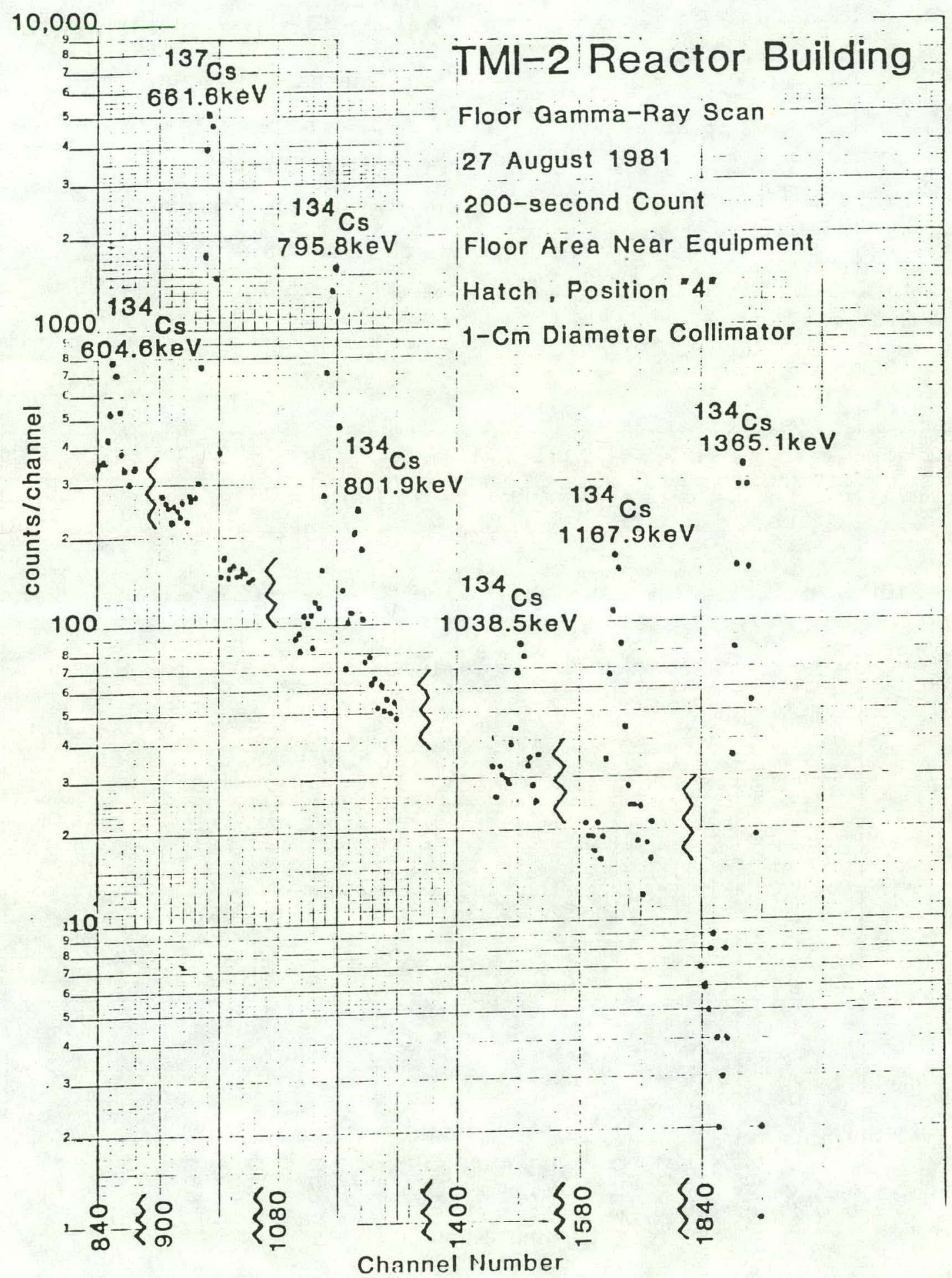

Figure 6. PORTION OF GAMMA-RAY PULSE-HEIGHT SPECTRUM 


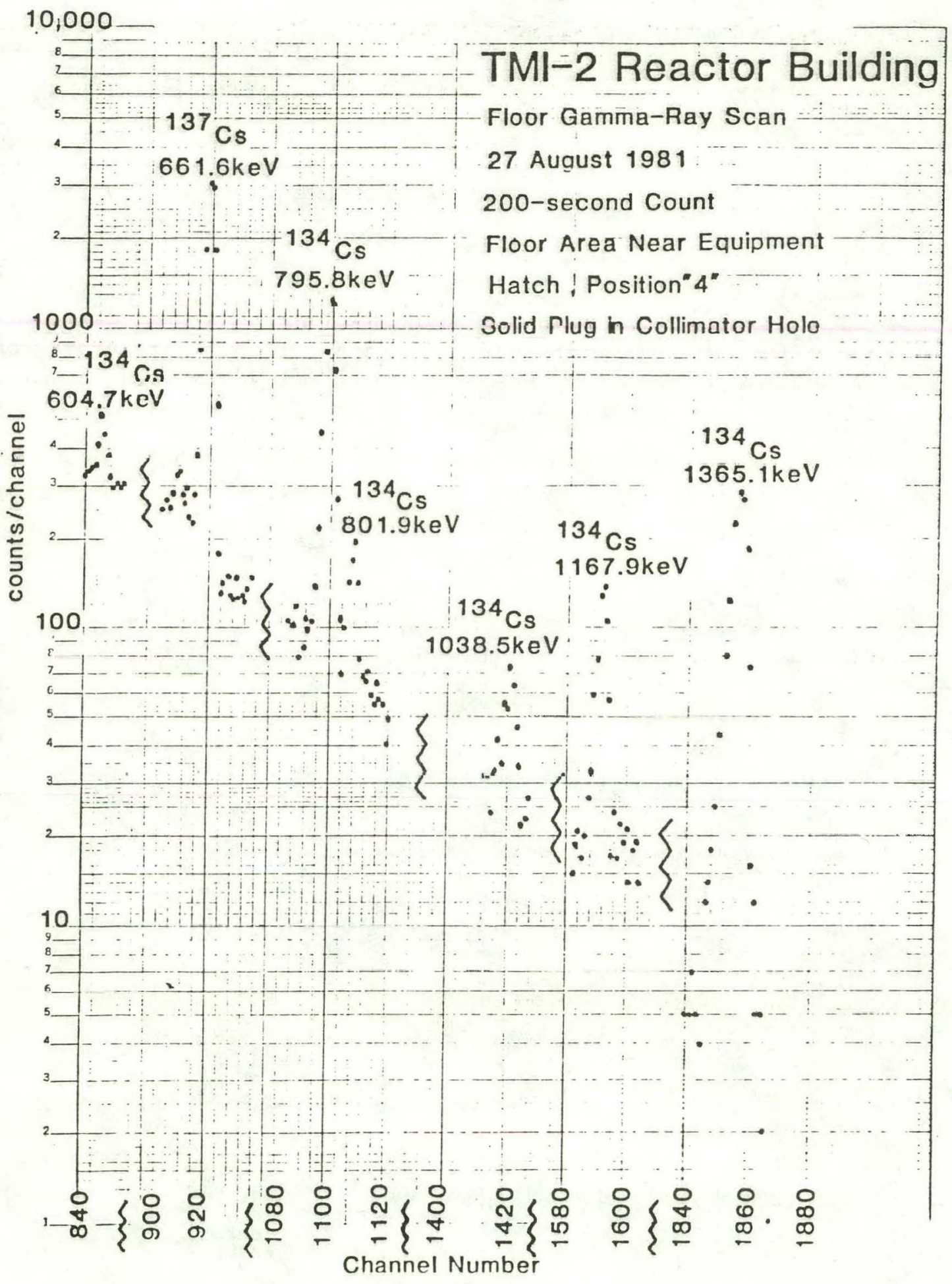

Figure 7. PORTION OF PULSE-HEIGHT SPECTRUM SHOWING GAMMA-RAY PEAKS 
TABLE 4. NET ${ }^{137}$ CS COUNTING RATES AND SURFACE CONTAMINATION LEVELS ON 305- AND 347-FOOT ELEVATIONS IN THE TMI REACTOR CONTAINMENT BUILDING BEFORE AND AFTER SPRAYING

\begin{tabular}{|c|c|c|c|c|}
\hline \multirow[b]{3}{*}{$\begin{array}{c}\text { Area } \\
\text { Designation } \\
\end{array}$} & \multicolumn{2}{|c|}{ 305-Foot Elevation } & \multirow{2}{*}{\multicolumn{2}{|c|}{$\begin{array}{c}137_{\text {Cs Surface }} \\
\text { Contamination } \\
\left(\mu \mathrm{Ci} / \mathrm{cm}^{2}\right)\end{array}$}} \\
\hline & \multicolumn{2}{|c|}{$\begin{aligned} \text { Net } & 137 \mathrm{Cs} \\
\text { Counting } & \text { Rate }(\mathrm{c} / \mathrm{s})\end{aligned}$} & & \\
\hline & $\begin{array}{c}12 / 16 / 81 \\
\text { Before } \\
\text { Spraying }\end{array}$ & $\begin{array}{l}3 / 25 / 82 \\
\text { After } \\
\text { Spraying } \\
\end{array}$ & $\begin{array}{c}12 / 16 / 81 \\
\text { Before } \\
\text { Spraying } \\
\end{array}$ & $\begin{array}{l}3 / 25 / 82 \\
\text { After } \\
\text { Spraying } \\
\end{array}$ \\
\hline 13 & $<0.6$ & $1.5 \pm 0.4$ & $<0.2$ & $0.5 \pm 0.2$ \\
\hline $\mathrm{H} 7$ & $4.5 \pm 0.5$ & $1.7 \pm 0.5$ & $0.96 \pm 0.10$ & $0.4 \pm 0.2$ \\
\hline V9 & $1.7 \pm 0.9$ & $<1.6$ & $0.5 \pm 0.3$ & $<0.6$ \\
\hline 34 & $4.1 \pm 0.8$ & $25 \pm 1$ & $0.9 \pm 0.2$ & $5.3 \pm 0.4$ \\
\hline H5 & $<1.5$ & Not Measured & $<0.3$ & Not Measured \\
\hline \multicolumn{5}{|c|}{ 347-Foot Elevation } \\
\hline & $\begin{array}{r}\text { Net } \\
\text { Counting } \\
\end{array}$ & $\begin{array}{l}37 \mathrm{Cs} \\
\text { ate }(\mathrm{c} / \mathrm{s})\end{array}$ & \multicolumn{2}{|c|}{$\begin{array}{c}137 \mathrm{Cs} \text { Surface } \\
\text { Contamination } \\
\left(\mu \mathrm{Ci} / \mathrm{cm}^{2}\right)\end{array}$} \\
\hline $\begin{array}{c}\text { Area } \\
\text { Designation } \\
\end{array}$ & $\begin{array}{l}2 / 16 / 82 \\
\text { Before } \\
\text { Spraying } \\
\end{array}$ & $\begin{array}{c}3 / 26 / 82 \\
\text { Before } \\
\text { Spraying } \\
\end{array}$ & $\begin{array}{l}2 / 16 / 82 \\
\text { Before } \\
\text { Spraying } \\
\end{array}$ & $\begin{array}{c}3 / 26 / 82 \\
\text { After } \\
\text { Spraying } \\
\end{array}$ \\
\hline 33 & $0.69 \pm 0.33$ & $5.1 \pm 0.4$ & $<0.14$ & $1.1 \pm 0.2$ \\
\hline $\mathrm{HlO}$ & $2.40 \pm 0.38$ & $3.8 \pm 0.5$ & $0.5 \pm 0.16$ & $0.8 \pm 0.2$ \\
\hline 1.49 & $4.69 \pm 0.40$ & $9.6 \pm 0.3$ & $0.97 \cdot 0.17$ & $2.0 \pm 0.1$ \\
\hline H9 & $4.10 \pm 0.40$ & Not Measured & $0.85 \pm 0.17$ & Not Measured \\
\hline 36 & $0.59 \pm 0.34$ & $<1.0$ & $<0.20$ & $<0.3$ \\
\hline $36-A$ & $4.64 \pm 0.37$ & Not Measured & $0.96 \pm 0.15$ & Not Measured \\
\hline
\end{tabular}


REFERENCES

1. J. E. Cline, A Technique of Gamma-Ray Detector Absolute Efficiency Calibration For Extended Sources, Computers in Activation Analysis and Gamma-Ray Spectroscopy, DOE Symposium Series 49, CONF-780421, 1979.

2. J. E. Cline and P. G. Voilleque, Germanium Spectrometer Calibration Procedures, Volume 2, ISPO-80, SAI-139-79-501-RV, Program For Technical Assistance to IAEA Safeguards, November 1979.

3. C. D. Thomas, Jr., J. E. Cline, P. Roy, Radiation Measurements in Steam Generator "B" at the Palisades Nuclear Station, March 1980.

4.' J. E. Cline, P. G. Voilleque, C. D. Thomas, Jr., Gamma-Ray Measurements of the TMI-2 Containment Surfaces by Scans Through the Equipment Hatch, June 1979.

5. J. E. Cline, C. D. Thomas, Jr., P. G. Voilleque, E. Walker, T. Menzel, Gamma-Ray Measurements in Containment Penetration R-605 at TMI-2, August 1979.

6. J. E. Cline, C. D. Thomas, Jr., E. Walker, Gamma-Ray Measurements in Containment Penetration R-626 at TMI-2, September 1979 .

7. C. D. Thomas, Jr., J. E. Cline, T. Fritz, J. Tate, Gamma-Ray Measurements Through the Inner Door of the Personnel Airlock at TMI-2, March 1980.

8. J. E. Cline, D. S. Cameron, D. A. Keefer, Gamma-Ray Measurements in the Reactor Building at the J. A. Fitzpatrick Power Plant, February 1981.

9. J. E. Cline, C. D. Thomas, Jr., J. A. Daniel, E. A. Schlomer, D. Keefer, M. Pavelek, Measurements of Activities in the keactor Cuolanl Bleed Tanks at TMI-2, Nugust 1981 .

10. J. E. Cline, C. D. Thomas, Jr., D. S. Cameron, John R. Cooper, J. E. Tarpinian, Measurement of Surface Contamination T.evels on Designated Floor Areas on Elevation 305', TMI-2 Reactor Building, SAI-139-81-01-RV, September 1981.

11. D. S. Cameron, E. D. Barefoot, C. D. Thomas, Jr., J. E. Cline, Measurements of Contamination on containment Coolers C, D, and E and Surface Contamination on a Designated Floor Area on Elevation 305', TMI-2 Reactor Building, SAI-139-81-06-RV, November 1981.

12. J. E. Cline and D. S. Cameron, Gamma-Ray Scans of Selected Control-Rod Blades and Fuel Flow Channels in Oyster Creek Fuel Pool, SAI-139-81-09-RV, December 21, 1981. 
13. E. D. Barefoot, D. S. Cameron, J. E. Cline, J. A. Daniel, D. G. Keefer, E. A. Schlomer, C. D. Thomas, Jx., Pre-Decontamination Gamma-Ray Surface Scans in TMI-2 Containment Building 305' Elevation, SAI-139-81-10-RV, December 21, 1981 .

14. E. D. Barefoot, J. E. Cline, J. A. Daniel, D. G. Keefer, E. A. Schlomer, C. D. Thomas, Jr., Pre-Decontamination Gamma-Ray Surface Scans in TMI-2 Containment Building 347' Elevation, SAI-139-82-02-RV, March 1982. 
APPENDIX A

MODEL OF DETECTOR CALIBRATION FOR EXTENDED SOURCES

A semi-empirical model can mathematically describe the response of a Ge detector. The model can then be used to calculate detection efficiencies for this detector. The principal difficulty is describing the detector response to sources located away from the symmetry axis of the normally cylindrical detector. The model describes the detector as a point located along the symmetry axis within the volume of the detector. The location of this point relates to the average depth of interaction of the gamma ray within the detector material (penetration depth) and therefore varies with gamma-ray energy. The detector response is a function of both source-decectur dlslance along the detector axis and of the anyle subtended by this axis and a direct path from the source to the detector. The function of angle takes into account the collimator used with the detector; values of the function parameters are empirically determined. Using the response function, the respunse of the detector can be described for a specific sample volume element. Gamma-ray detection efficiency of the entire sample is then obtained by integrating this response function over the sample volume. The integration includes gamma-ray self attenuation within the sample.

Figure Al schematicalily represents the geumetry of the calculations for a cylindrical or spherical sample. A two-dimensional slice through the sample is shown. The equation describing the ettıcıency, $c$, for the deleclim of a gamma-ray of energy, $E$, emitted from the vulume element, $\Delta V$, inside the source, is :

$\varepsilon(E)=\frac{\varepsilon_{I}(E) \times\left(H(D) \times e^{-\left(\mu_{C}(E) t+\mu_{S}(E) d\right)}\right.}{4 \pi[(P(E)+D+T+R-r \cos \theta) / \cos (G(\phi, E))]^{2}}$

where

$$
\begin{aligned}
E(E)= & \text { a detector and an energy depcndent normalization parameter } \\
& \text { called the intrinsic efficiency } \\
P(E)= & \text { the effective penetration depth (location of 'point' detector) } \\
& \text { inside the deteclor cryostat } \\
\phi= & \text { the angle subtended by a line between the source element and } \\
& \text { the detector symmetry axis }
\end{aligned}
$$




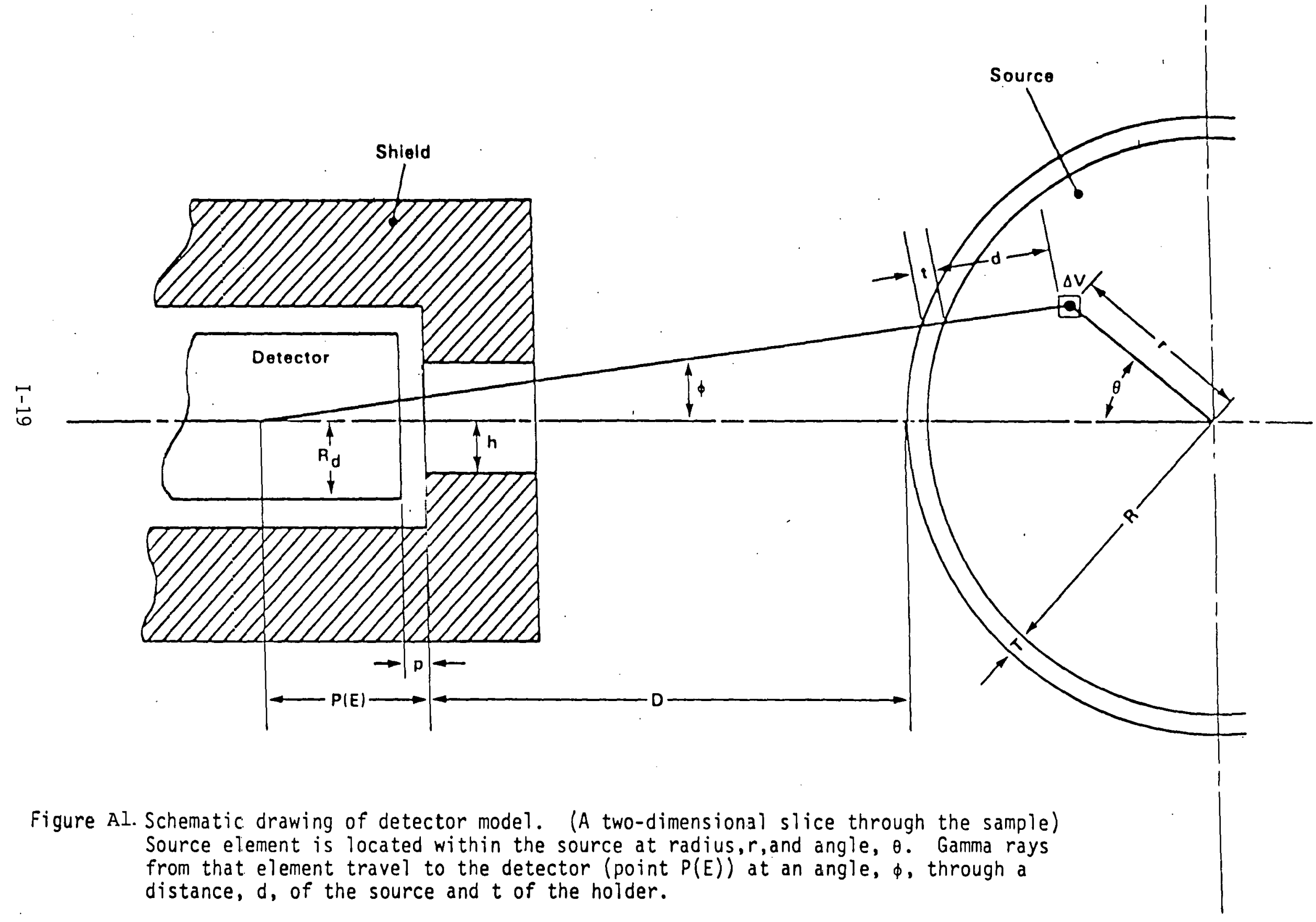




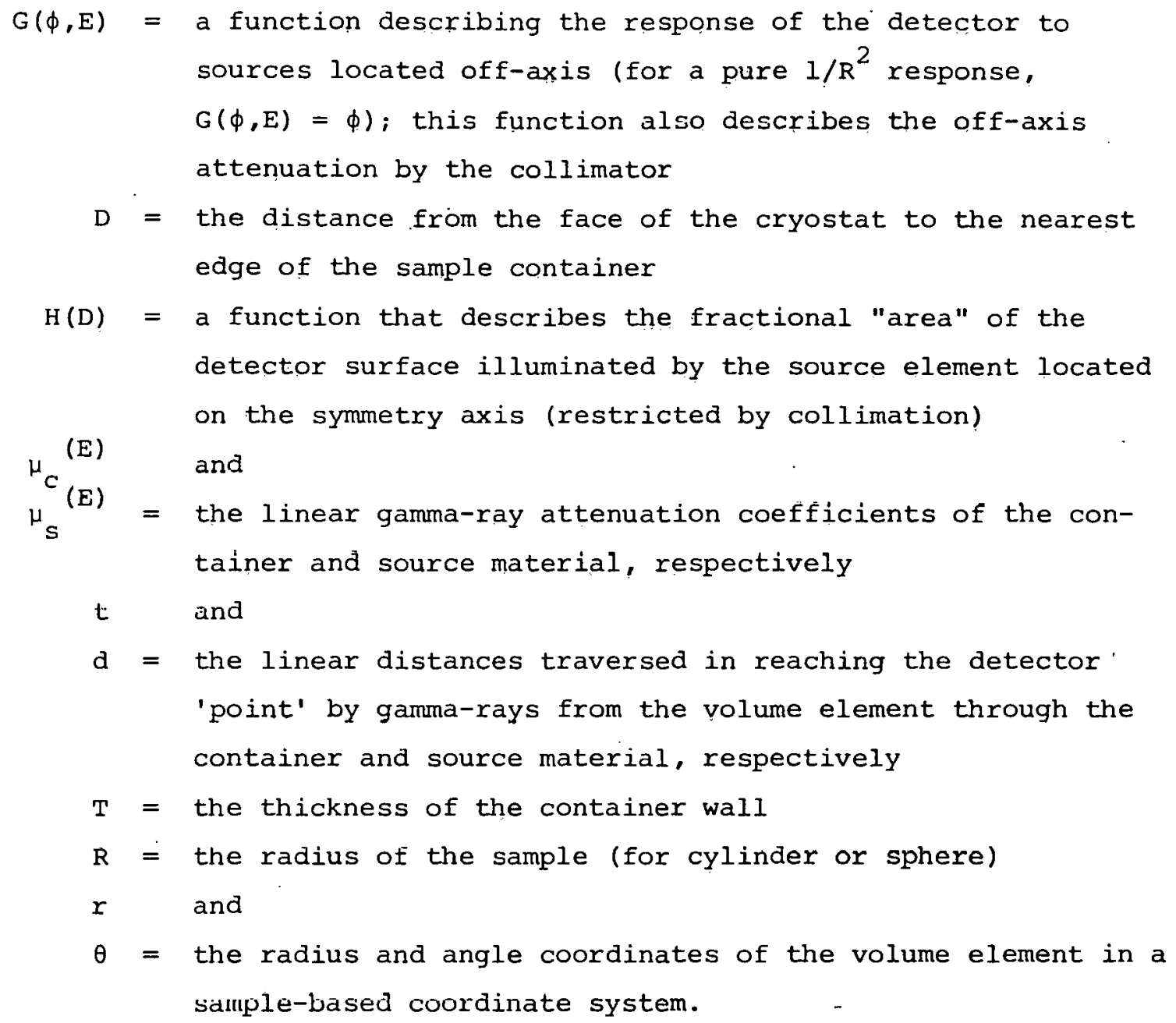

Sample height (perpendicular to the plane of the figure) enters by quadrature in the calculation of $\phi, t$, and $d$. An integral is taken over the volume of the source to obtain the detection efficiency for the entire source.

The functional form used to describe $G(\phi, E)$ is a power series in $\phi$ :

$G(\phi, E)=G_{0}(E)+G_{1}(E) \phi+G_{2}(E) \phi^{2}$

The coefficients $G_{0}(E), G_{l}(E)$, and $G_{2}(E)$, and the penetration factor $P(E)$ are second-order power series in the log of the energy, of the form:

$Y(E)=Y_{0}+Y_{1}(\ln E)+Y_{2}(\ln E)^{2}$

The form of the absorption coefficients, $\mu$, is:

$(\ln \mu)=A+B(\ln E)+C(\ln E)^{2}$. 
$H(D)=\left(\frac{h(D+p)}{R_{D} D}\right)^{2}, h<\frac{D R_{D}}{D+p}$

and

$H(D)=1, h \geq \frac{D R_{D}}{D+p}$,

where

$$
\begin{aligned}
\mathrm{p} & =\text { distance from face of the cryostat to face of the detector ingot } \\
\mathrm{h} & =\text { radius of collimator hole, and } \\
\mathrm{R}_{\mathrm{D}} & =\text { radius of the detector. }
\end{aligned}
$$

DETECTOR EFFICIENCY CALCULATION FOR OBLIQUE INCIDENCE

ON SURFACES OF UNIFORM SOURCE STRENGTH

Fiyure A2 shows the geometry of a horizontal surface being scanned obliquely by a collimated detector. The area scanned is an oblique crosssection of a cone, i.e., an ellipse on the surface. Referring to Figure A2, the major and minor radii of the ellipse are given by:

$$
r_{\text {major }}=\mathrm{H}_{\mathrm{v}}\left[\tan \alpha\left(1+\tan ^{2} \theta\right)\left(\frac{1}{1-\tan ^{2} \theta \tan ^{2} \alpha}\right)\right]
$$

and

$$
\mathrm{r}_{\text {minor }}=\mathrm{H}_{\mathrm{v}} \frac{\tan \alpha}{\cos \theta}
$$

where

$$
\begin{aligned}
\text { Lan } u & =\frac{2 d}{t} \\
d & =\text { diameter of collimator, and } \\
t & =\text { thickness of collimator. }
\end{aligned}
$$




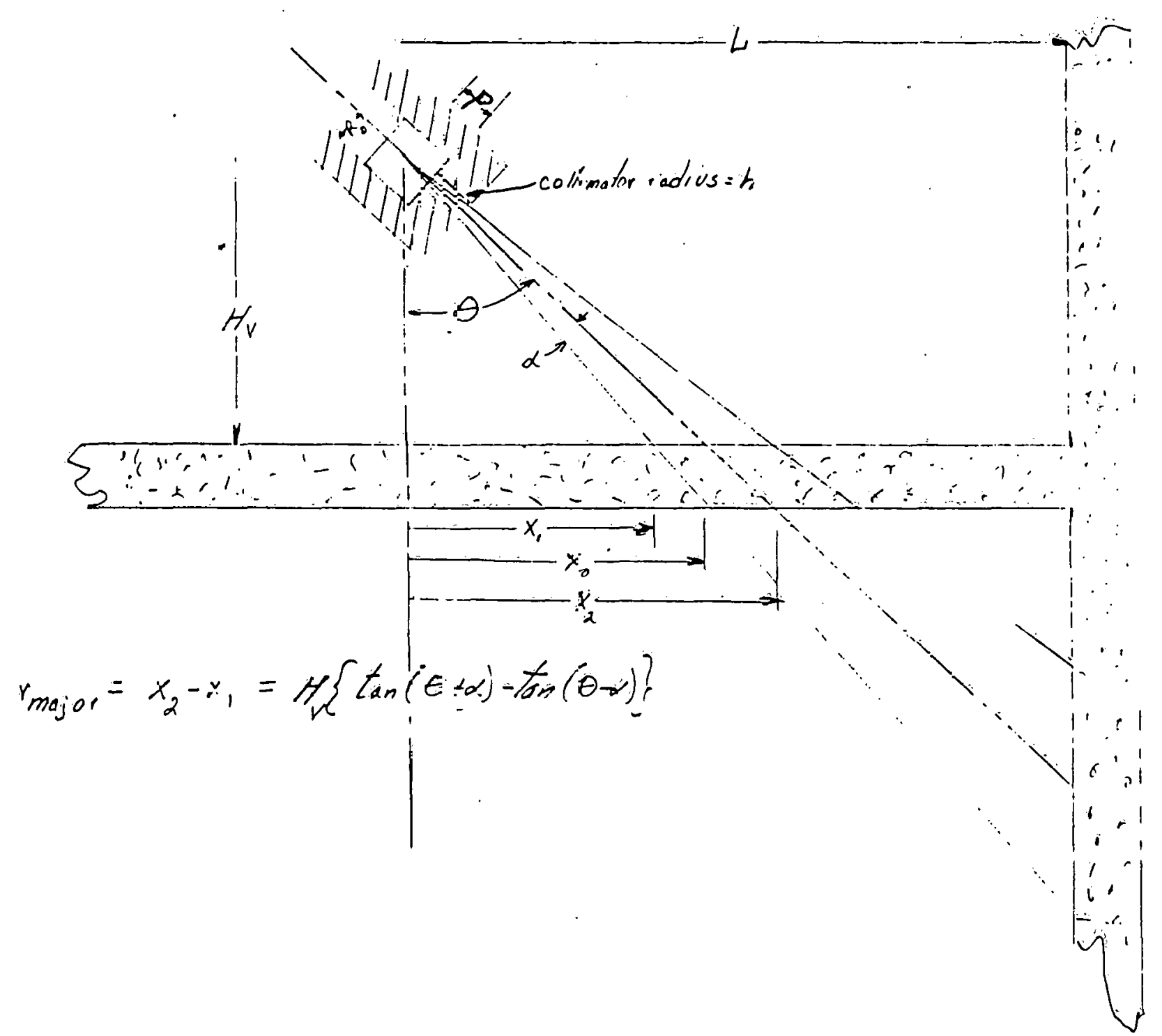

Figure A2. Two Eimensional Sketch of oblique Scan Geometry 
Using the formalism of the calibration technique, the proper concentration of activity on the surface can be determined through an efficiency based on an integration of a point kernal over the entire surface being scanned. Since the detector response function falls very rapidly as the area falls outside the collimator aperture, it is necessary only to integrate over an area beyond wich the detector response falls to a negligible amount. Let us arbitrarily (and conservatively) choose this to be a square area whose sides have a length of :

$\boldsymbol{W}=2.0 r_{\text {major }}$

Using Equations 1, 2 and 4 and Figures $A 2$ and $A 3$, the efficiency for the detection of gamma rays emitted from a surface element,

$d s=d w d w_{1}$

at $x_{0} ; w$ and $w_{1}$ can be given by:

$(E)=\frac{\varepsilon_{I}(E) \times H(D) d s}{4 \pi\left[\left(P(E)+x_{o} / \sin \theta-\left(\frac{W}{2}-w\right) \sin \theta\right) / \cos (G(\phi, E))\right]^{2}}$

where

$$
\begin{aligned}
\tan \phi= & \frac{\left.\{(w / 2-2) \cos )^{2}+w_{1}\right\}^{\frac{1}{2}}}{\mathrm{H}_{\mathrm{v}} / \cos \theta+(\mathrm{w} / 2-\mathrm{w}) \sin \theta} \\
\varepsilon(I)= & \text { intrinsic efflciency } \\
P(E)= & \text { penetration depth } \\
\phi= & \text { angle between the surface element and the detector } \\
& \text { symmetry axis extended } \\
G(\phi)= & \text { function describing "effective angle" to axis } \\
\mathrm{X}_{\mathrm{O}}= & \text { distance along surface from vertical projection of } \\
& \text { delectur axis to intersection of symmetry axis with } \\
& \text { the surface: } \\
& \mathrm{x}_{\mathrm{O}}=\mathrm{H}_{\mathrm{v}} \text { tan } \theta \\
\mathrm{W}= & \text { width of surface area being computed }
\end{aligned}
$$




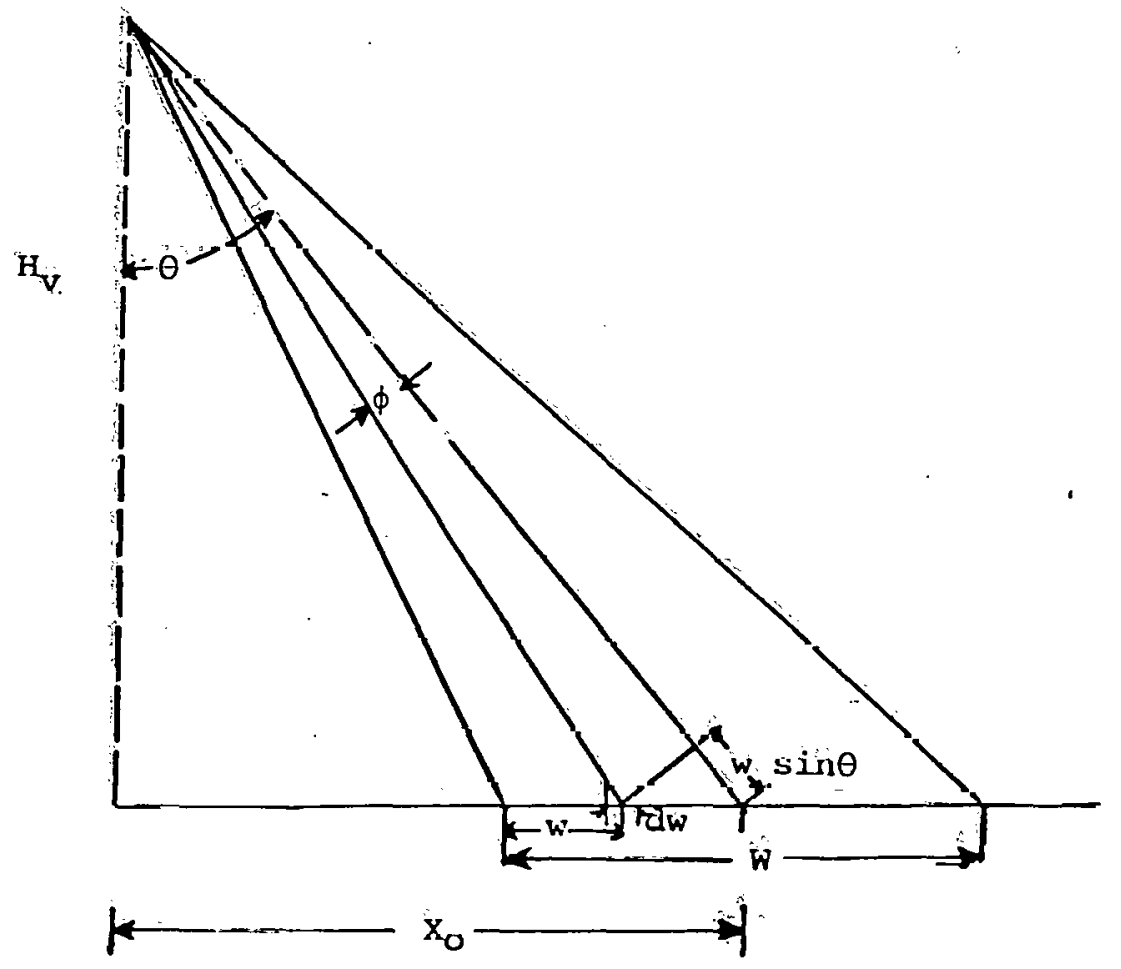

Figure A3. TWO DIMENSIONAL SKETCH SHOWING DEFINITION OF
INTEGRATION VARIABLES 


$$
\mathrm{W}=2.0 \mathrm{H} v\left[\frac{\tan \alpha\left(1+\tan ^{2} \theta\right)}{1-\tan ^{2} \theta \tan ^{2} \alpha}\right]
$$

$\mathrm{H}(D)=$ collimator factor or fraction of detector surface exposed

$$
H(D)=\left(\frac{h(D+P)}{R_{d} D}\right)
$$

where

$$
\begin{aligned}
\mathrm{h}= & \text { radius of collimator } \\
\mathrm{P}= & \text { distance from end of collimator to end of germanium } \\
& \text { ingot } \\
\mathrm{R}_{\mathrm{d}=} & \text { radius of germanium ingot } \\
\mathrm{D}= & \text { distance from end of cryostat to projection of } \\
& \text { surface element on detector axis } \\
& \mathrm{D}=\mathrm{P}(\mathrm{E}) \times \mathrm{x}_{\mathrm{o}} / \sin \theta-\left(\frac{\mathrm{W}}{2}-\mathrm{w}\right) \sin \theta
\end{aligned}
$$

Integrating the function over the area defined by $w$,

$$
\varepsilon(E)=\frac{\varepsilon_{I}(E)}{2 \pi} \int_{-W / 2}^{W / 2} \frac{H(D) d_{1} d w}{\left[\left(P(E)+x_{0} / \sin \theta-\left(\frac{w}{2}-w\right) \sin \theta\right) / \cos (G(\phi, E))\right]^{2}}
$$

The function is symmetric in $w_{1}$, therefore

$$
E(E)=\frac{E_{I}(E)}{4 \pi} \int_{-W / 2}^{W / 2} \int_{-W / 2}^{W / 2} \frac{H(D) d w d w_{1}}{\left[\left(P(E)+x_{0} / \sin \theta-\left(\frac{W}{2}-w\right) \sin \theta\right) / \cos (G(\phi, E))\right]^{2}}
$$


Substitute a summation for the integrals.

$$
\begin{aligned}
& d w \Rightarrow \Delta w_{1}=\frac{w}{J}, \quad w=\frac{(2 j-1)}{2 J} w \\
& d w_{1} \Rightarrow \Delta w_{1}=\frac{w}{2 K}, \quad w_{1}=\frac{(2 k-l)}{2 K} \frac{w}{2} \\
& \varepsilon(E)=\frac{\varepsilon_{I}(E)}{2 \pi} \sum_{j=1}^{J} \sum_{k=1}^{K} \frac{H(D)\left(\frac{W^{2}}{2 J K}\right)}{\left[\left(E(E)+x_{0} / \sin \theta-\left(\frac{W}{2}-\left(2 j-\frac{i}{2 J} w\right) \sin \theta\right) / \delta n s(G(\phi . E))\right]^{2}\right.} \\
& \phi=\tan ^{-1}\left(\frac{w\left\{\left[\left(\frac{(2 j-1)}{2 J}-1 / 2\right) \cos \theta\right]^{2}+\left(\frac{(2 k-1)}{4 k}\right)^{2}\right\}^{1 / 2}}{H_{v} \tan \theta+w\left(\frac{2 j-1}{2 J}-2 / 2\right)}\right. \\
& W=2.0 \mathrm{H} v\left[\frac{\tan \alpha\left(1+\tan ^{2} \theta\right)}{1-\tan ^{2} \theta \tan ^{2} \alpha}\right]
\end{aligned}
$$

